\title{
Additional Confirmatory LBL Analysis of AGR-5/6/7 Compacts and Overcoated Particles
}

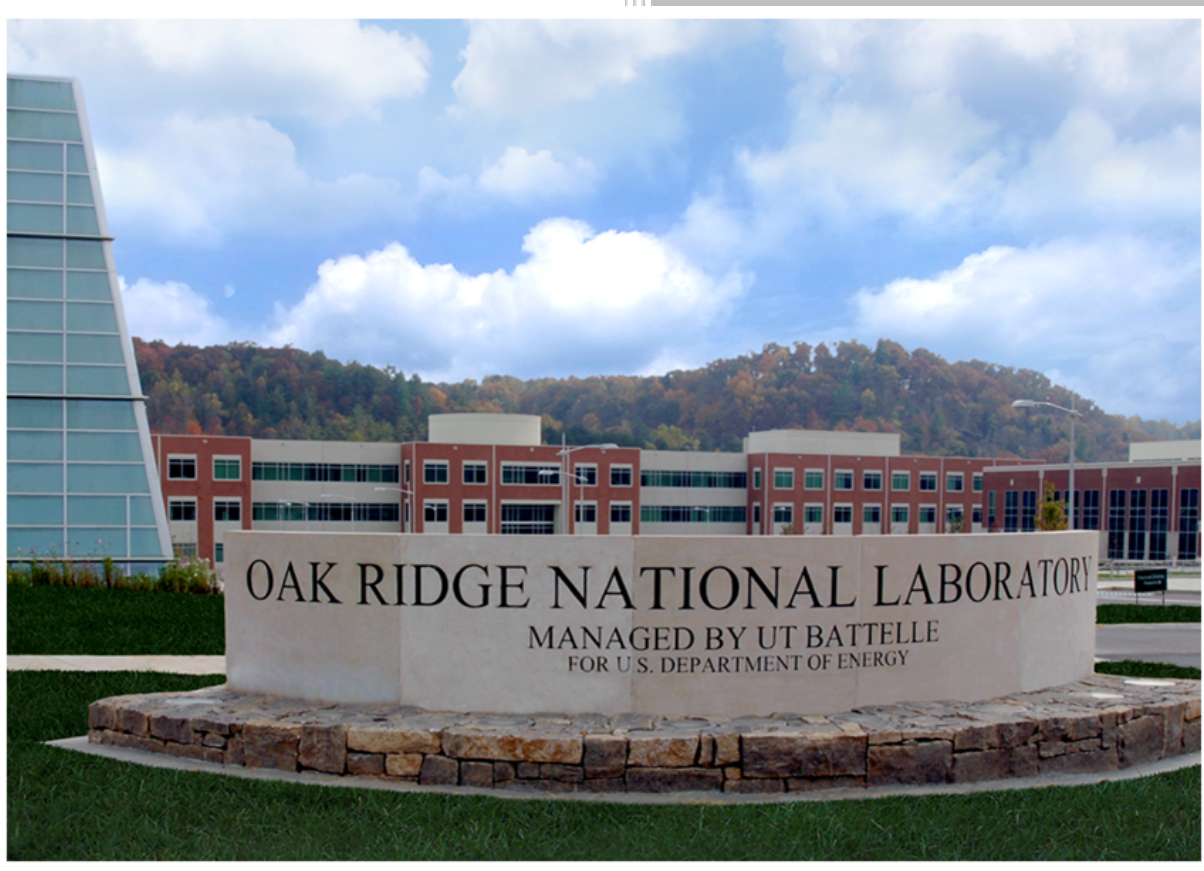

\section{Approved for public release.}

Distribution is unlimited.

John D. Hunn

Fred C. Montgomery

Grant W. Helmreich

Andrew K. Kercher

November 2019 


\title{
DOCUMENT AVAILABILITY
}

Reports produced after January 1, 1996, are generally available free via US Department of Energy (DOE) SciTech Connect.

\section{Website www.osti.gov}

Reports produced before January 1, 1996, may be purchased by members of the public from the following source:

\author{
National Technical Information Service \\ 5285 Port Royal Road \\ Springfield, VA 22161 \\ Telephone 703-605-6000 (1-800-553-6847) \\ TDD 703-487-4639 \\ Fax 703-605-6900 \\ E-mail info@ntis.gov \\ Website http://classic.ntis.gov/
}

Reports are available to DOE employees, DOE contractors, Energy Technology Data Exchange representatives, and International Nuclear Information System representatives from the following source:

Office of Scientific and Technical Information

PO Box 62

Oak Ridge, TN 37831

Telephone 865-576-8401

Fax 865-576-5728

E-mail reports@osti.gov

Website http://www.osti.gov/contact.html

This report was prepared as an account of work sponsored by an
agency of the United States Government. Neither the United States
Government nor any agency thereof, nor any of their employees,
makes any warranty, express or implied, or assumes any legal liability
or responsibility for the accuracy, completeness, or usefulness of any
information, apparatus, product, or process disclosed, or represents
that its use would not infringe privately owned rights. Reference herein
to any specific commercial product, process, or service by trade name,
trademark, manufacturer, or otherwise, does not necessarily constitute
or imply its endorsement, recommendation, or favoring by the United
States Government or any agency thereof. The views and opinions of
authors expressed herein do not necessarily state or reflect those of
the United States Government or any agency thereof.




\title{
ADDITIONAL CONFIRMATORY LBL ANALYSIS OF AGR-5/6/7 COMPACTS AND OVERCOATED PARTICLES
}

\section{BWXT NOG BATCHES 11034, 11035, 14154C\&D, 14155C\&D, AND 14156C\&D}

John D. Hunn

Fred C. Montgomery

Grant W. Helmreich

Andrew K. Kercher

Date Published: November 2019

\author{
Work sponsored by \\ US DEPARTMENT OF ENERGY \\ Office of Nuclear Energy \\ under the
}

Advanced Gas Reactor Fuel Development and Qualification Program

\author{
Prepared by \\ OAK RIDGE NATIONAL LABORATORY \\ Oak Ridge, TN 37831-6283 \\ managed by \\ UT-BATTELLE, LLC \\ for the \\ US DEPARTMENT OF ENERGY \\ under contract DE-AC05-00OR22725
}





\section{CONTENTS}

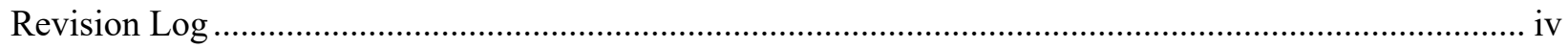

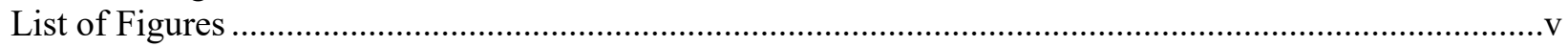

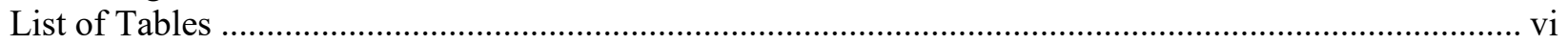

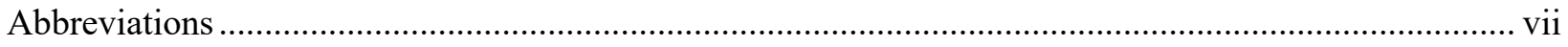

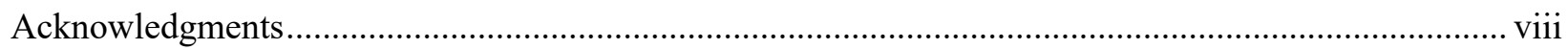

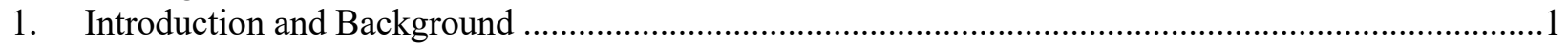

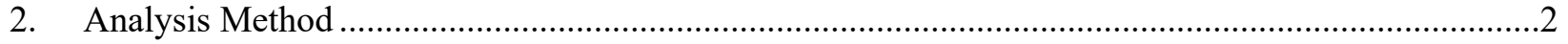

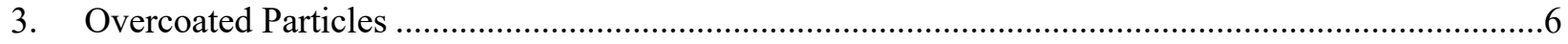

3.1 LBL Analysis for Exposed Uranium in 40\% PF OC TRISO ...............................................

3.2 Comparison to BWXT NOG LBL Analysis of TRISO Particles ............................................10

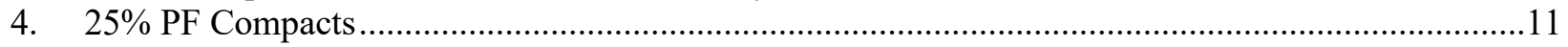

4.1 LBL Analysis for Exposed Uranium in 25\% PF Compacts..................................................11

4.2 Comparison between ORNL and BWXT NOG LBL of 25\% PF Compacts ...........................15

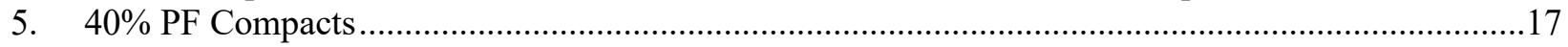

5.1 LBL Analysis for Exposed Uranium in 40\% PF Compacts..................................................17

5.2 Comparison between ORNL and BWXT NOG LBL of 40\% PF Compacts ...........................20

5.3 BL Analysis for Exposed Uranium in 40\% PF Compacts ......................................................21

5.4 X-ray Analysis of Defective Particles in 40\% PF Compacts .................................................23

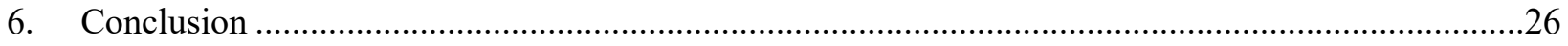

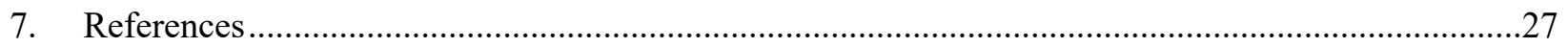

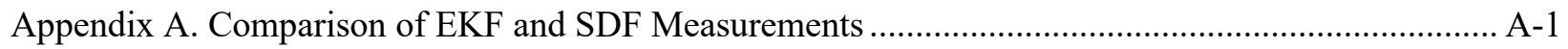

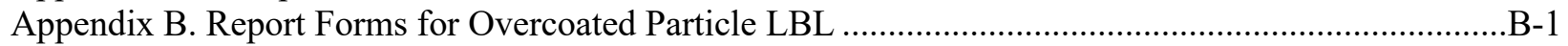

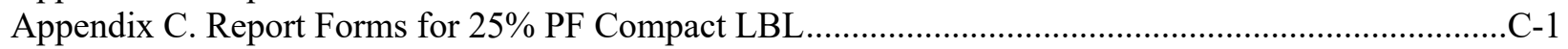

Appendix D. Report Forms for 40\% PF Compact LBL ................................................................ D-1

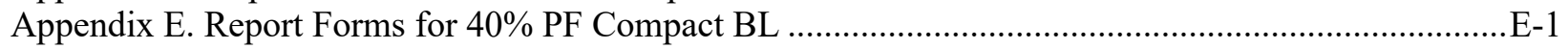




\section{REVISION LOG}

\begin{tabular}{llll}
\hline Revision & Date & Affected Pages & Revision Description \\
\hline 0 & & All & Initial issue
\end{tabular}




\section{LIST OF FIGURES}

Figure 3-1. Tomographic cross section of a particle from Batch 93168 with embedded kernel fragments and uranium dispersion in the buffer layer.

Figure 3-2. Tomographic cross-section of a particle from Batch 93172 with embedded kernel fragments and uranium dispersion in the buffer layer.

Figure 4-1. (a) Low resolution x-ray radiograph and (b) high-resolution x-ray tomogram showing what may be a partially leached particle from Clutch $14156 \mathrm{D}-2$.

Figure 5-1. X-ray tomograms of SiC shells from two particle from Clutch $14155 \mathrm{C}-1$.

Figure 5-2. X-ray tomogram of particle from AGR-5/6/7 TRISO composite with degraded SiC.

Figure 5-3. X-ray tomograms of two particle from Clutch $14155 \mathrm{C}-1$ with defective IPyC but no indication of partial leaching. 


\section{LIST OF TABLES}

Table 1-1. Samples analyzed at ORNL .1

Table 3-1. Uranium leached from 40\% PF OC TRISO before the burn...................................................6

Table 3-2. Uranium leached from 40\% PF OC TRISO after the burn...................................................

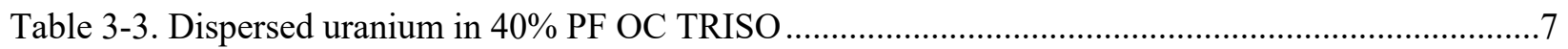

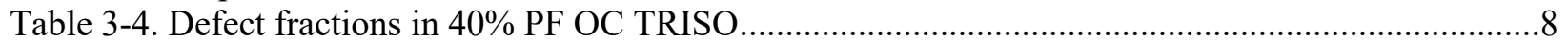

Table 3-5. Defect fractions in TRISO particle Lot 98005 prior to overcoating........................................10

Table 4-1. Uranium leached from 25\% PF compacts before the burn .....................................................11

Table 4-2. Uranium leached from 25\% PF compacts after the burn........................................................12

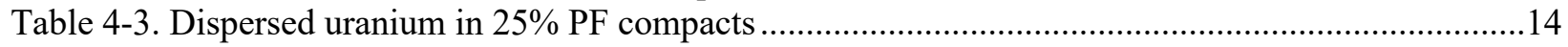

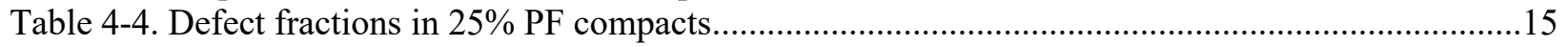

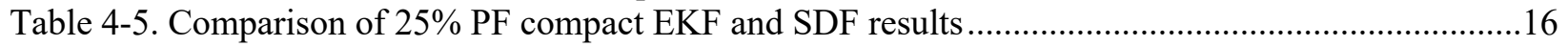

Table 5-1. Uranium leached from 40\% PF compacts before the burn ......................................................17

Table 5-2. Uranium leached from 40\% PF compacts after the burn......................................................18

Table 5-3. Dispersed uranium in 40\% PF compacts .............................................................................18

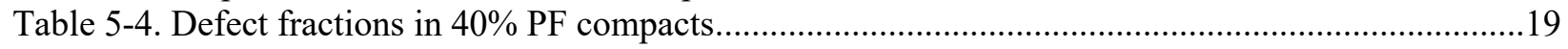

Table 5-5. Comparison of 40\% PF compact LBL results .....................................................................21

Table 5-6. Uranium leached from $40 \%$ PF compacts using burn-leach procedure ....................................22

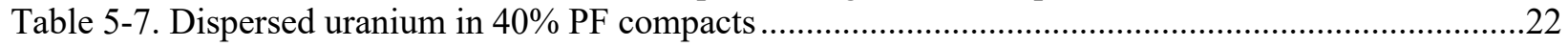

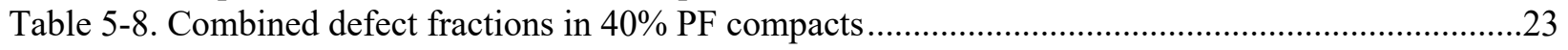




\section{ABBREVIATIONS}

AGR

AGR-5/6/7

ATR

BL

Advanced Gas Reactor Fuel Development and Qualification (Program)

BWXT NOG AGR program irradiation experiments five, six, and seven

CVD

DAM

DOE

DRF

Advanced Test Reactor

DUF

burn-leach

DUF $_{\text {Post }}$

DUF $_{\text {Pre }}$

BWX Technologies Nuclear Operations Group (located in Lynchburg, Virginia)

chemical vapor deposition

data acquisition method

DUF $_{\text {Total }}$

US Department of Energy

data report form

dispersed uranium fraction

postburn leach dispersed uranium fraction

EKF

INL

preburn leach dispersed uranium fraction

total dispersed uranium fraction

IPyC

IRF

LBL

MAD

$\mathrm{OC}$

OPyC

ORNL

exposed kernel fraction

Idaho National Laboratory

inner pyrolytic carbon (TRISO layer)

inspection report form

leach-burn-leach

median absolute deviation

overcoated (TRISO particles)

$\mathrm{PF}$

outer pyrolytic carbon (TRISO layer)

SDF

$\mathrm{SiC}$

TRISO

UCO

$\mathrm{XCT}$

Oak Ridge National Laboratory

packing fraction (TRISO volume fraction in a compact)

$\mathrm{SiC}$ defect fraction

silicon carbide (TRISO layer)

tristructural-isotropic (coated particles)

uranium carbide/uranium oxide mixture (fuel kernels)

$\mathrm{Z}$

$\mathrm{x}$-ray computed tomography

atomic number 


\section{ACKNOWLEDGMENTS}

This work was sponsored by the US Department of Energy's Office of Nuclear Energy-Advanced Reactor Technologies as part of the Advanced Gas Reactor Fuel Development and Qualification Program. Analysis of leach solutions was provided by the Oak Ridge National Laboratory Nuclear Analytical Chemistry \& Isotopics Laboratory. 


\section{INTRODUCTION AND BACKGROUND}

Fuel compacts for the Advanced Gas Reactor Fuel Development and Qualification (AGR) Program's AGR-5/6/7 irradiation test in the Idaho National Laboratory (INL) Advanced Test Reactor (ATR) were fabricated by BWX Technologies Nuclear Operations Group (BWXT NOG) located in Lynchburg, Virginia. Two compact packing fractions (PFs) were produced - nominally, $40 \% \mathrm{PF}$ and $25 \% \mathrm{PF}$ - in which the tristructural-isotropic (TRISO)-coated particle volume was targeted to be approximately $40 \%$ and $25 \%$ of the total compact volume, respectively. The TRISO coatings were deposited using a $150 \mathrm{~mm}$ diameter fluidized-bed chemical vapor deposition (CVD) furnace on spherical kernels that were nominally $425 \mu \mathrm{m}$ in diameter. The kernels were from kernel composite Lot J52R-16-69317, which contained low-enriched uranium $\left(15.5 \%{ }^{235} \mathrm{U}\right)$ in a mixture of uranium carbide and uranium oxide (UCO). Kernels were coated with four concentric CVD layers: a porous carbon buffer layer that was nominally $100 \mu \mathrm{m}$ thick, an inner pyrolytic carbon (IPyC) layer that was nominally $40 \mu \mathrm{m}$ thick, a silicon carbide (SiC) layer that was nominally $35 \mu \mathrm{m}$ thick, and an outer pyrolytic carbon (OPyC) layer that was nominally $40-\mu \mathrm{m}$-thick. Coated particle composite J52R-16-98005 was overcoated (OC) with a graphite/resin blend, and these OC TRISO particles were pressed to form cylindrical compacts that were nominally a half inch in diameter and one inch long.

Compact samples were deconsolidated and analyzed using the leach-burn-leach (LBL) procedure at Oak Ridge National Laboratory (ORNL) to provide additional data for use in evaluating the compact properties previously measured by LBL analysis at BWXT NOG. In addition, samples of OC TRISO particles were analyzed by LBL at ORNL to distinguish possible changes in defect fractions that result from (1) the OC process (by comparison to non-OC TRISO particle LBL) and (2) the compacting process (by comparison to compact LBL). Table 1-1 lists the samples analyzed at ORNL. Results from the first test series were reported in ORNL/TM-2019/744 (Hunn et al. 2018a). Results include the exposed kernel fraction (EKF), the $\mathrm{SiC}$ defect fraction (SDF), and the dispersed uranium fraction (DUF). Select impurities (Fe, Cr, Mn, Co, Ni, Ca, Al, Ti, and V) were also measured on some sub-samples. The definitions of EKF, SDF, and DUF are explained further in Section 2, and the methods for their calculation from the amount of leached $U$ are presented. The combined results from the first and second test series are reported herein to provide better statistical sampling and to answer questions that arose from the first test series. The second test series only included analysis of leached U, because additional measurement of metallic impurities was not required. To address questions regarding possible artifacts from particle damage introduced by the LBL procedure, eighty $40 \% \mathrm{PF}$ compacts were analyzed in the second test series by burn-leach (BL) to avoid the steps most likely to introduce damage.

Table 1-1. Samples analyzed at ORNL

\begin{tabular}{|c|c|c|c|c|}
\hline Test Series & Nominal PF & Batch ID & Description & Analysis \\
\hline 1 & $40 \%$ & J52R-16-14154C & 40 compacts & LBL in 2 groups of 4 clutches of 5 compacts \\
\hline 2 & $40 \%$ & J52R-16-14154C & 20 compacts & LBL in 1 group of 4 clutches of 5 compacts \\
\hline 2 & $40 \%$ & J52R-16-14155C & 40 compacts & LBL in 2 groups of 4 clutches of 5 compacts \\
\hline 2 & $40 \%$ & J52R-16-14154D & 40 compacts & BL in 2 groups of 4 clutches of 5 compacts \\
\hline 2 & $40 \%$ & J52R-16-14155D & 40 compacts & BL in 2 groups of 4 clutches of 5 compacts \\
\hline 1 & $25 \%$ & $\begin{array}{l}\text { J52R-16-14156C } \\
\text { J52R-16-14156D }\end{array}$ & $\begin{array}{l}29 \text { compacts } \\
11 \text { compacts }\end{array}$ & LBL in 2 groups of 4 clutches of 5 compacts ${ }^{a}$ \\
\hline 2 & $25 \%$ & $\mathrm{~J} 52 \mathrm{R}-16-14156 \mathrm{D}$ & 20 compacts & LBL in 1 group of 4 clutches of 5 compacts \\
\hline 1 & $40 \%$ & J52R-16-11034 & OC TRISO & LBL in 2 groups of 4 clutches of OC TRISO $b$ \\
\hline 2 & $40 \%$ & J52R-16-11035 & OC TRISO & LBL in 2 groups of 4 clutches of OC TRISO ${ }^{b}$ \\
\hline
\end{tabular}

Note: Each 5-compact clutch was randomly chosen.

${ }^{a}$ The $25 \%$ PF compacts in the first test series were from production batches $14156 \mathrm{C}$ and $14156 \mathrm{D}$.

${ }^{b}$ OC TRISO clutches were random samples with roughly the same number of particles as a 5-compact clutch. 


\section{ANALYSIS METHOD*}

Deconsolidation and LBL analysis were performed on BWXT NOG compacts according to data acquisition method (DAM) AGR-CHAR-DAM-26 (Hunn and Montgomery 2018a) This DAM provides the instructions for performing deconsolidation and LBL analysis of cylindrical compacts containing coated particles. The LBL method attempts to thoroughly leach uranium (and other metallic impurities) not contained within gas-tight and liquid-tight SiC layers. The AGR-5/6/7 Fuel Specification (Marshall 2017) has specified limits for the amounts of selected metallic impurities (Fe, Cr, Mn, Co, Ni, Ca, Al, Ti, and $\mathrm{V}$ ) in the compact outside of the intact $\mathrm{SiC}$ layers. The specification also includes a series of calculations that use the amount of uranium leached before and after burning off exposed carbon to calculate EKF, SDF, and DUF, as described below, and it specifies limits on these fractions.

Per DAM-26, compacts were electrolytically deconsolidated to separate the coated particles from the surrounding matrix of graphite and carbonized resin. This process involves submerging the tip of a compact in nitric acid and applying a voltage between the compact (the anode) and a platinum cathode in contact with the acid. During electrolytic deconsolidation, intercalation of nitrate anions and nitric acid between the basal planes of the graphite material in the compact matrix dissociates the graphite structure, breaks up the matrix, and releases the coated particles. Compacts were analyzed in randomly selected clutches of five compacts each. All compacts in a given clutch were sequentially deconsolidated into the same vessel by stacking them in a cylindrical-shaped deconsolidation tube with an open mesh bottom and a diameter slightly larger than the compacts. The deconsolidation tube was lowered into a vessel containing nitric acid to wet the tip of the bottom compact and a weighted rod with the anode wire placed on the top compact. As the lowest compact in the stack was deconsolidated, the compacts were gravityfed downward such that the bottom of the lowest compact remained in contact with the acid until all compacts were deconsolidated.

Deconsolidated particles and matrix debris were subjected to two 24-hour preburn leaches in boiling concentrated nitric acid. The deconsolidation acid was used for the first preburn leach because some exposed uranium and metallic impurities can be dissolved in the room temperature acid during the deconsolidation phase. This first preburn leach acid was separated from the particles and matrix debris by centrifuging and decanting, and fresh acid was used for the second leach. Aliquots from the leach solutions were analyzed by mass spectrometry to determine the concentration of uranium and selected impurities dissolved in the acid. Measured concentrations were converted to mass quantities by multiplying by the collected volume of each leach solution. The equivalent number of leached kernels (kernel equivalent) was determined by dividing the total mass of uranium dissolved during the preburn leach by the average uranium content of one kernel.

Per DAM-26, sample clutches are typically leached at least twice; and if the uranium in the second leach is above the minimum detection limit and more than $10-20 \%$ of the amount in the first leach, then this is an indicator that uranium leaching may have been incomplete, so additional leaching is needed for better confidence in the results. Best practice is to postpone the burn phase until the uranium analysis of the first two preburn leaches is completed; this allows for the option of additional leaching in the preburn state if the second leach value indicates incomplete leaching of exposed uranium. However, due to schedule restraints for the confirmatory analysis presented herein, samples were subjected to burn-leach before preburn leach results were available.

To provide additional information on the adequacy of the two 24-hour leaches, an aliquot from the water used after the second leach to rinse the glassware, particles, and matrix debris was also analyzed in most cases. Per DAM-26, the data from the water rinse analysis were only included in the total if they were

\footnotetext{
${ }^{*}$ This section was duplicated with minor modifications and additions from ORNL/TM-2019/744 for the convenience of the reader and definition of terms used herein.
} 
determined to be significant based on criterion that impurity values were $>10 \%$ of the second leach, and for uranium analysis, significance was based on the criterion that values were $>10 \%$ of the second leach and $>1 \%$ of the average uranium per kernel. These criteria were applied so that the small values often dominated by measurement thresholds would not artificially elevate the totals.

After two 24-hour preburn leaches, each sample was heated at $750^{\circ} \mathrm{C}$ in air for 72 hours to oxidize and remove any exposed carbonaceous material, which would include the compact matrix carbon, the OPyC, and any IPyC and buffer coatings that were exposed to air due to a through-layer defect in the SiC layer. Uranium and metallic impurities exposed by the burn or not completely dissolved during the preburn leach phase were also oxidized during the burn phase, making them more soluble in hot nitric acid during the postburn leach phase.

Similar to the preburn leach phase, the "burned-back" particles and any residual ash were subjected to two 24-hour leaches in hot nitric acid to dissolve any exposed uranium and/or impurities. These postburn leaches were performed just below the $120^{\circ} \mathrm{C}$ boiling point of the $\sim 70 \%$ concentrated nitric to minimize the chance of the solutions bumping, which can violently eject particles from the heating flask. Aliquots from the leach solutions and final water rinse were analyzed in the same manner as the preburn leach solutions.

The AGR-5/6/7 Fuel Specification provides a method for determining the EKF, SDF, and DUF based on the following definitions and assumptions. A particle is considered to have an exposed-kernel defect if the coating layers cannot prevent nitric acid from penetrating to the kernel during the preburn leach phase. Such a particle would likely perform poorly in a reactor, releasing an undesirable fraction of the radioactive material it was designed to retain. A particle is considered to have a SiC defect if uranium in the kernel is retained during preburn leaching but can be acid leached after removal of the exposed carbon coating layers by heating in air during the burn step described above. Particles with exposed-kernel defects also have through-layer defects in the $\mathrm{SiC}$, but these particles are not counted again as SiC-defect particles because counting them as exposed-kernel defects already fully accounts for their impact on irradiated particle performance, as particles with exposed-kernel defects are presumed to release more fission products than those with $\mathrm{SiC}$ defects.

The AGR-5/6/7 Fuel Specification applies an assumption that uranium in a particle with an exposedkernel defect or $\mathrm{SiC}$ defect will be almost completely leached during the preburn leach or postburn leach phase, respectively, yielding a uranium content that is close to the average of one kernel. If the total amount of uranium detected in either the preburn or postburn leaching of a clutch is below 0.5 kernel equivalents, then the specification stipulates that this uranium is to be identified as dispersed uranium contamination that is not associated with an individual particle with an exposed-kernel defect or SiC defect. The DUF is this dispersed uranium contamination divided by the amount of uranium in the clutch, which is approximately equal to the kernel equivalent amount of dispersed uranium divided by the average number of particles in a clutch.

Based on the methods prescribed in the AGR-5/6/7 Fuel Specification, a preburn leach dispersed uranium fraction $\left(D U F_{\text {Pre }}\right)$ was determined for each clutch for which the cumulative leached uranium during the preburn leaching was $<0.5$ kernel equivalents. Similarly, a postburn leach dispersed uranium fraction $\left(D_{\text {Post }}\right)$ was determined for each clutch for which the cumulative leached uranium during the postburn leaching was $<0.5$ kernel equivalents. Measured means and standard deviations for DUF Pre $_{\text {and }}$ DUF Post were calculated using all sampled clutches for which a DUF value was determined. The measured mean $D_{U} F_{\text {Total }}$ for each sample was calculated as the sum of the measured mean values for DUF Pre and DUF $F_{\text {Post, }}$ as prescribed in the AGR-5/6/7 Fuel Specification. This implies an assumption that the DUFPre and DUF $_{\text {Post }}$ mean values are measurements of variable properties of the batch, and these properties are independent. 
Student's t-test statistics were applied to the mean $(\mu)$ and standard distribution $(\sigma)$ of the DUF Pre and DUF $_{\text {Post }}$ measurements using the t-test equation and methods described in the AGR-5/6/7 Statistical Sampling Plan (Lybeck and Einerson 2016) to calculate the 95\% confidence limits on the maximum mean

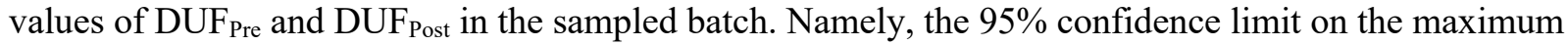
mean value in the batch was calculated to be

$$
\leq \mu+t_{c, n-1}(\sigma / \sqrt{n})
$$

where $n$ is the number of determined DUF values, and $t_{c, n-1}$ is the one-sided Student's t-distribution critical value for $n-1$ degrees of freedom and a cumulative probability or confidence $(c)$ of $95 \%$.

The calculation of the $95 \%$ confidence limit on the maximum mean value of $\mathrm{DUF}_{\text {Total }}$ in the sampled batch could not be directly calculated using the simple Student's t-test equation provided in the sampling plan because DUF ${ }_{\text {Total }}$ was not based on individual measurements of $D \mathrm{~F}_{\text {Total }}$ in each clutch but rather on the combination of independent measurements of DUF ${ }_{\text {Pre }}$ and $D \mathrm{FF}_{\text {Post. }}$ To calculate the limit value for DUF $_{\text {Total, }}$ approximations of the cumulative probability distributions for DUF $F_{\text {Pre }}$ and DUF Post $_{\text {were }}$ constructed using stepwise evaluations of the Student's t-distribution and combined as described below.

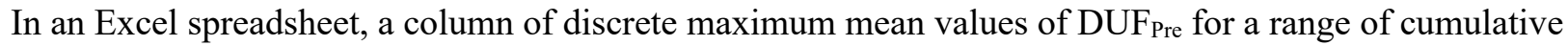
probabilities from 0 to $100 \%$, exclusive, was generated using the t-test equation

$$
\max _{i}\left(\mathrm{DUF}_{\mathrm{Pre}}\right)=\mu+t_{c_{i}, n-1}(\sigma / \sqrt{n}) \text { for } i=1 \text { to }(100 / \Delta)-1 \text { and } c_{i}=i \times \Delta \text {, }
$$

where $\mu, \sigma$, and $n$ are the same values used to calculate the $95 \%$ confidence limit on the maximum mean value of DUF Pre $_{\text {in Eq. }}(2.1), t_{c_{i}, n-1}$ is the one-sided Student's t-distribution critical value for $n$ - 1 degrees of freedom and a cumulative probability $c_{i}$, and $\Delta$ is a constant stepsize. Thus, the series of $\max _{i}$ values defined in Eq. (2.2) made up a stepwise approximation of the Student's t cumulative probability distribution for the maximum mean value of DUF $F_{\text {Pre }}$ in the sampled batch. Each $\max _{i}$ value was a slight overestimate of the possible true mean value of the batch, with a probability equal to the stepsize $\Delta$ of being the maximum value over the cumulative probability interval $\left(c_{i}-\Delta, c_{i}\right)$.

Similarly, an approximation of the cumulative probability distribution for the maximum mean value of

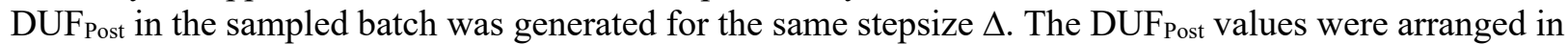
a row in the Excel spreadsheet so that a matrix could be easily generated by summing all possible pairs of values from the two cumulative probability distributions,

$$
\operatorname{sum}_{i j}=\max _{i}\left(\mathrm{DUF}_{\mathrm{Pre}}\right)+\max _{j}\left(\mathrm{DUF}_{\mathrm{Post}}\right) \text { for } i \text { and } j=1 \text { to }(100 / \Delta)-1 \text {. }
$$

The probability associated with each individual $s_{i j}$ combination was the product of the probabilities for the corresponding $\max _{i}$ and $\max _{j}$, namely, $\Delta^{2}$ in every case. To approximate the $95 \%$ confidence limit on the maximum mean value of DUF ${ }_{\text {Total, }}$, the individual $s u m_{i j}$ values were combined as described below.

Starting with the measured mean, $\mu\left(D_{U F} F_{\text {Total }}\right)$, for each sample (i.e., the sum of the measured means for DUF $_{\text {Pre }}$ and $D_{U F} F_{\text {Post }}$ ), a series of discrete possible maximum mean values of $D F_{\text {Total }}$ was generated over a sufficient range,

$$
\max _{k}\left(\mathrm{DUF}_{\mathrm{Total}}\right)=\mu\left(\mathrm{DUF}_{\mathrm{Total}}\right)+k \times \partial \text { for } k=1 \text { to } N \text {, }
$$

where $\partial$ is a constant stepsize, and $\mathrm{N}$ is adjusted to ensure that enough values are generated in the series to reach a $\max _{k}$ value that corresponds to a $95 \%$ cumulative probability. The approximate cumulative probability $\left(c_{k}\right)$ for each possible maximum mean value, $\max _{k}\left(\mathrm{DUF}_{\mathrm{Total}}\right)$, is determined by searching the 
matrix of individual $s u m_{i j}$ values and counting the number of $s u m_{i j}$ values that are less than or equal to the candidate $\max _{k}$ value,

$$
c_{k}=\Delta^{2} \times \operatorname{CountIf}\left(\operatorname{sum}_{i j} \leq \max _{k}\left(\mathrm{DUF}_{\mathrm{Total}}\right)\right) \text { for } k=1 \text { to } N \text {. }
$$

The $\max _{k}$ value corresponding to the $c_{k}$ value closest to and also greater than or equal to $95 \%$ is taken as the best approximation of the $95 \%$ confidence limit on the maximum mean value of DUF $_{\text {Total }}$ in the sampled batch. The approximation was conservative, as it was calculated to be a slight overestimate by using the upper bounds in the stepwise approximations of the Student's t cumulative probability distribution for the maximum mean values of $\mathrm{DUF}_{\text {Pre }}$ and $\mathrm{DUF}_{\text {Post }}$, and it was required to have a confidence of at least $95 \%$. The accuracy of the approximation was dependent on the stepsize $\Delta$ used in the stepwise approximations of the Student's t cumulative probability distribution for the maximum mean

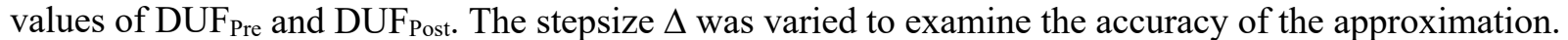
As stepsize $\Delta$ was reduced, the approximation of the $95 \%$ confidence limit on the maximum mean value of $\mathrm{DUF}_{\text {Total }}$ asymptotically approached a minimum value from above. The stepsize was small enough to no longer change the value to three significant figures when the stepwise approximations of the Student's $t$ cumulative probability distribution for the maximum mean values of DUF Pre and DUF Post $_{\text {did not change }}$ by more than $\sim 0.1 \%$ per step. A stepsize around $0.1 \%$ was typically sufficient. The accuracy of the approximation was also dependent on the stepsize $\partial$ used to generate the search list of discrete possible maximum mean values of $\mathrm{DUF}_{\text {Total }}$. The stepsize $\partial$ was also varied to ensure that an accurate approximation was calculated. For $\partial$, it was important that the candidate $\max _{k}$ values in the search series with corresponding $c_{k}$ value immediately above and below $95 \%$ did not vary when rounded up to three significant figures.

In the definition of the EKF and SDF, according to the AGR-5/6/7 Fuel Specification, it is assumed that the equivalent number of leached kernels is dominated by individual defective particles in which the uranium in the kernel is exposed because of abnormal or damaged coatings (when they are present). Therefore, these defects are treated as attribute properties, and defect fractions are determined from the equivalent number of defective particles vs. the number of particles in the measured sample. Binomial distribution statistics are applied to determine with $95 \%$ confidence whether the sampled material is below a specified upper limit for the defect fraction.

Equations for determining EKF and SDF are provided in the AGR-5/6/7 Fuel Specification. The equivalent number of leached kernels detected during preburn leaching of a clutch of compacts is corrected by subtracting the kernel equivalent contribution from the dispersed uranium (assumed to be the mean DUF $F_{\text {Pre }}$ times the average number of particles per clutch). This corrected kernel equivalent value is rounded to the nearest integer to arrive at the preburn exposed kernel count for that clutch. The preburn exposed kernel count for all analyzed clutches is summed and divided by the estimated number of analyzed particles (calculated from the average number of particles per clutch times the number of clutches) to get the measured EKF. The $95 \%$ confidence determination of whether the sampled composite has an EKF below the allowed upper limit applies a binomial distribution calculation using the total preburn exposed kernel count and estimated number of analyzed particles. The SDF values are calculated in the same way, except the equivalent number of leached kernels detected during postburn leaching of a clutch is corrected with the mean DUF Post $_{\text {value. }}$

LBL analysis was performed on BWXT NOG OC particles according to AGR-CHAR-DAM-21 (Hunn and Montgomery 2018b). This procedure is essentially the same as DAM-26, except the compact deconsolidation is not required prior to the preburn acid leaching. The EKF, SDF, and DUF were calculated as they were for the compacts. 


\section{OVERCOATED PARTICLES}

Supplementary LBL analysis was completed on samples from two OC TRISO batches that were used for the $40 \%$ PF compacts (Table 1-1). One large sample of OC TRISO from each batch was shipped from BWXT NOG to ORNL. Random samples (clutches) for LBL analysis were created from each large sample with approximately the same number of particles per clutch as in the five-compact clutches used in the $40 \%$ PF compact LBL analysis (Section 5). Rather than rotary riffling, gentler but less random sampling methods (cone and quartering supplemented by scoop sampling) were used to reduce the possibility of damage to the particles prior to analysis. Ten sub-samples from each batch were also used for measurement of average OC TRISO weight according to the procedure in AGR-CHAR-DAM-22 (Hunn 2017). The particle number in each clutch was determined by weighing the clutches and dividing by the average weight per OC particle in the relevant batch. Clutches were analyzed by LBL in groups of four. All leach solutions were analyzed for uranium content only. Appendix B contains copies of the official preburn leach and postburn leach data report forms (DRFs) for each analyzed clutch and inspection report forms (IRFs) that summarize the data. The data are further presented and discussed in the remainder of this section.

\subsection{LBL ANALYSIS FOR EXPOSED URANIUM IN 40\% PF OC TRISO}

Table 3-1 shows details regarding the uranium (in kernel equivalents) in each solution collected during preburn leaching of the OC TRISO clutches and the total uranium leached from each clutch. According to the procedure in DAM-21, the water rinse data were not included in the total because they were $\leq 10 \%$ of the second leach or $\leq 1 \%$ of the average uranium per kernel. Table 3-1 also shows the individual preburn leach DUF $F_{\text {Pre }}$ values for each clutch without an exposed-kernel defect (i.e., the total leached uranium was $<0.5$ kernel equivalents per the AGR-5/6/7 Fuel Specification). Table 3-2 shows the same type of data for the postburn leach. The DUF Pre and DUF Post values were very consistent in the preburn and postburn clutches, respectively, and the uranium content in each second leach was appropriately lower than the first leach. These observations are good indicators that the LBL process was effective.

Table 3-1. Uranium leached from 40\% PF OC TRISO before the burn

\begin{tabular}{cccccccc}
\hline Series & Clutch & Particles & First leach & Second leach & $\mathrm{H}_{2} \mathrm{O}$ rinse ${ }^{a}$ & Total & DUFPre $^{b}$ \\
\hline \multirow{2}{*}{1} & $11034-1$ & 17,627 & $7.92 \mathrm{E}-2$ & $1.05 \mathrm{E}-2$ & $6.36 \mathrm{E}-4$ & 0.090 & $5.09 \mathrm{E}-6$ \\
& $11034-2$ & 18,614 & $8.03 \mathrm{E}-2$ & $1.61 \mathrm{E}-2$ & $9.27 \mathrm{E}-4$ & 0.096 & $5.18 \mathrm{E}-6$ \\
& $11034-3$ & 17,972 & $8.06 \mathrm{E}-2$ & $1.10 \mathrm{E}-2$ & $7.25 \mathrm{E}-4$ & 0.092 & $5.10 \mathrm{E}-6$ \\
& $11034-4$ & 17,826 & $7.88 \mathrm{E}-2$ & $1.85 \mathrm{E}-2$ & $9.78 \mathrm{E}-4$ & 0.097 & $5.46 \mathrm{E}-6$ \\
\hline & $11035-1$ & 17,409 & $8.33 \mathrm{E}-2$ & $4.66 \mathrm{E}-3$ & $2.84 \mathrm{E}-4$ & 0.088 & $5.05 \mathrm{E}-6$ \\
& $11035-2$ & 17,368 & $8.23 \mathrm{E}-2$ & $3.63 \mathrm{E}-3$ & $1.44 \mathrm{E}-4$ & 0.086 & $4.94 \mathrm{E}-6$ \\
& $11035-3$ & 17,369 & $8.20 \mathrm{E}-2$ & $4.10 \mathrm{E}-3$ & $1.31 \mathrm{E}-4$ & 0.086 & $4.96 \mathrm{E}-6$ \\
& $11035-4$ & 17,378 & $7.95 \mathrm{E}-2$ & $5.84 \mathrm{E}-3$ & $1.82 \mathrm{E}-4$ & 0.085 & $4.91 \mathrm{E}-6$ \\
& $11035-5$ & 17,389 & $8.20 \mathrm{E}-2$ & $7.38 \mathrm{E}-3$ & $2.69 \mathrm{E}-4$ & 0.089 & $5.14 \mathrm{E}-6$ \\
& $11035-6$ & 17,364 & $7.79 \mathrm{E}-2$ & $6.01 \mathrm{E}-3$ & $2.30 \mathrm{E}-4$ & 0.084 & $4.83 \mathrm{E}-6$ \\
& $11035-7$ & 17,395 & $8.77 \mathrm{E}-2$ & $4.14 \mathrm{E}-3$ & $1.05 \mathrm{E}-4$ & 0.092 & $5.28 \mathrm{E}-6$ \\
& $11035-8$ & 17,371 & $8.57 \mathrm{E}-2$ & $4.50 \mathrm{E}-3$ & $1.23 \mathrm{E}-4$ & 0.090 & $5.20 \mathrm{E}-6$ \\
\hline
\end{tabular}

Note: Uranium content in each leach is reported in kernel equivalents.

${ }^{a}$ Gray shading indicates that the water rinse was not added to the total.

${ }^{b}$ Individual DUF $F_{\text {Pre }}$ is the preburn leach fraction of exposed uranium in each clutch with $<0.5$ exposed kernel equivalents. 
Table 3-2. Uranium leached from 40\% PF OC TRISO after the burn

\begin{tabular}{|c|c|c|c|c|c|c|c|}
\hline Series & Clutch & Particles & First leach & Second leach & $\mathrm{H}_{2} \mathrm{O}$ rinse $^{a}$ & Total & DUFPost $^{b}$ \\
\hline \multirow{4}{*}{1} & $11034-1$ & 17,627 & $2.38 \mathrm{E}-3$ & $1.34 \mathrm{E}-3$ & not done & 0.004 & $2.11 \mathrm{E}-7$ \\
\hline & $11034-2$ & 18,614 & $2.58 \mathrm{E}-3$ & $3.56 \mathrm{E}-4$ & not done & 0.003 & $1.58 \mathrm{E}-7$ \\
\hline & $11034-3$ & 17,972 & $3.01 \mathrm{E}-3$ & $5.52 \mathrm{E}-4$ & not done & 0.004 & $1.98 \mathrm{E}-7$ \\
\hline & $11034-4$ & 17,826 & $1.23 \mathrm{E}+0$ & $3.47 \mathrm{E}-3$ & not done & 1.234 & --- \\
\hline \multirow{8}{*}{2} & $11035-1$ & 17,409 & $1.56 \mathrm{E}-3$ & $5.54 \mathrm{E}-4$ & $1.38 \mathrm{E}-5$ & 0.002 & $1.21 \mathrm{E}-7$ \\
\hline & $11035-2$ & 17,368 & $1.66 \mathrm{E}-3$ & $9.69 \mathrm{E}-4$ & $1.58 \mathrm{E}-5$ & 0.003 & $1.51 \mathrm{E}-7$ \\
\hline & $11035-3$ & 17,369 & $1.83 \mathrm{E}-3$ & $4.68 \mathrm{E}-4$ & $2.03 \mathrm{E}-5$ & 0.002 & $1.32 \mathrm{E}-7$ \\
\hline & $11035-4$ & 17,378 & $2.10 \mathrm{E}-3$ & $2.60 \mathrm{E}-4$ & $3.57 \mathrm{E}-5$ & 0.002 & $1.36 \mathrm{E}-7$ \\
\hline & $11035-5$ & 17,389 & $1.72 \mathrm{E}-3$ & $3.75 \mathrm{E}-5$ & $1.02 \mathrm{E}-6$ & 0.002 & $1.01 \mathrm{E}-7$ \\
\hline & $11035-6$ & 17,364 & $3.60 \mathrm{E}-3$ & $9.56 \mathrm{E}-5$ & $1.02 \mathrm{E}-6$ & 0.004 & $2.13 \mathrm{E}-7$ \\
\hline & $11035-7$ & 17,395 & $1.01 \mathrm{E}+0$ & $4.37 \mathrm{E}-3$ & $1.72 \mathrm{E}-5$ & 1.013 & --- \\
\hline & $11035-8$ & 17,371 & 8.06E-3 & $1.75 \mathrm{E}-4$ & $9.80 \mathrm{E}-6$ & 0.008 & $4.74 \mathrm{E}-7$ \\
\hline
\end{tabular}

Note: Uranium content in each leach is reported in kernel equivalents.

${ }^{a}$ Gray shading indicates that the water rinse was not added to the total.

${ }^{b}$ Individual DUF ${ }_{\text {Post }}$ is the postburn leach fraction of exposed uranium in each clutch with $<0.5$ exposed kernel equivalents.

Table 3-3 summarizes the dispersed uranium analysis results for OC TRISO Batch 11034 and Batch 11035 separately and considered as a pooled data set. The mean and standard deviations for DUF Pre

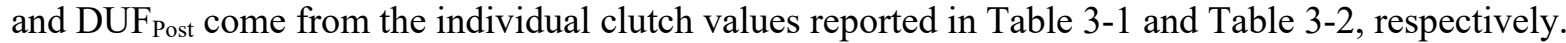
The 95\% confidence limits in Table 3-3 are the upper bounds of the 95\% confidence interval of the mean value for the sampled material based on the measured sample. The DUF Pre $_{\text {and }}$ DUF Post $95 \%$ confidence limits were calculated using the Student's t-test (Equation 2.1). The DUF Total $_{\text {mean value was calculated }}$ by adding the DUF ${ }_{\text {Pre }}$ and DUF Post mean values as stipulated in the AGR-5/6/7 Fuel Specification, and the $95 \%$ confidence limit was determined from approximations of the cumulative probability distributions for

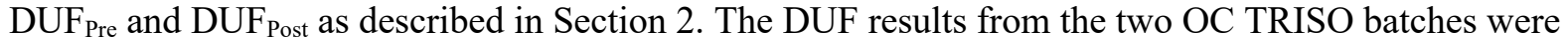
very similar, so pooling the data to provide better statistical sampling appears to be justified. Approximately $96 \%$ of the total dispersed uranium was leached in the preburn leaches.

Table 3-3. Dispersed uranium in $40 \%$ PF OC TRISO

\begin{tabular}{llccc}
\hline Batch & & DUFPre & DUFPost & DUFTotal \\
\hline \multirow{4}{*}{11034} & Measured mean & $5.20 \mathrm{E}-6$ & $1.89 \mathrm{E}-7$ & $5.39 \mathrm{E}-6$ \\
& Standard deviation & $1.73 \mathrm{E}-7$ & $2.78 \mathrm{E}-8$ & --- \\
& $95 \%$ confidence limit & $\leq 5.41 \mathrm{E}-6$ & $\leq 2.37 \mathrm{E}-7$ & $\leq 5.62 \mathrm{E}-6$ \\
\hline \multirow{4}{*}{11035} & Measured mean & $5.04 \mathrm{E}-6$ & $1.90 \mathrm{E}-7$ & $5.23 \mathrm{E}-6$ \\
& Standard deviation & $1.55 \mathrm{E}-7$ & $1.30 \mathrm{E}-7$ & --- \\
& $95 \%$ confidence limit & $\leq 5.15 \mathrm{E}-6$ & $\leq 2.86 \mathrm{E}-7$ & $\leq 5.38 \mathrm{E}-6$ \\
\multirow{2}{*}{ Pooled } & Measured mean & $5.09 \mathrm{E}-6$ & $1.90 \mathrm{E}-7$ & $5.28 \mathrm{E}-6$ \\
& Standard deviation & $1.73 \mathrm{E}-7$ & $1.07 \mathrm{E}-7$ & --- \\
& $95 \%$ confidence limit & $\leq 5.19 \mathrm{E}-6$ & $\leq 2.52 \mathrm{E}-7$ & $\leq 5.40 \mathrm{E}-6$ \\
\hline
\end{tabular}


Table 3-4 presents the EKF and SDF values calculated from the data presented in Table 3-1 and Table 3-2, respectively. Again, results are provided for Batches 11034 and 11035 separately and as a pooled data set. The 95\% confidence limits in Table 3-4 correspond to the true defect fractions in the sampled population that yield a cumulative binomial distribution value of 0.95 for the observed number of defects and sample size. These values are the lowest tolerance limits for which the compact lot would be deemed acceptable at $95 \%$ confidence, based on the sample that was measured. There is no strong evidence for a significant difference in EKF and SDF in Batches 11034 and 11035, and given that they were processed similarly, it is reasonable to assume that pooling the data is justified. There were no exposed kernels detected in the preburn leach solutions. Zero exposed-kernel defects in a pooled sample of 211,082 OC particles satisfies an upper limit on the EKF in the OC TRISO composite of $\leq 1.42 \mathrm{E}-5$ with $95 \%$ confidence. Based on the prescribed data analysis methods in the fuel specification, there were two exposed kernels detected in the postburn leach solutions, which satisfies to a $95 \%$ confidence an upper limit on the SDF in the OC TRISO composite of $\leq 2.99 \mathrm{E}-5$.

Table 3-4. Defect fractions in $40 \%$ PF OC TRISO

\begin{tabular}{clcc}
\hline Batch & & EKF & SDF \\
\hline \multirow{4}{*}{11034} & Number of defects & 0 & 1 \\
& Number of particles & $\sim 72,039$ & $\sim 72,039$ \\
& Measured defect fraction & 0 & $1.39 \mathrm{E}-5$ \\
& $95 \%$ confidence limit & $\leq 4.16 \mathrm{E}-5$ & $\leq 6.59 \mathrm{E}-5$ \\
\hline \multirow{4}{*}{11035} & Number of defects & 0 & 1 \\
& Number of particles & $\sim 139,043$ & $\sim 139,043$ \\
& Measured defect fraction & 0 & $7.19 \mathrm{E}-6$ \\
& $95 \%$ confidence limit & $\leq 2.16 \mathrm{E}-5$ & $\leq 3.42 \mathrm{E}-5$ \\
\hline \multirow{4}{*}{ Pooled } & Number of defects & 0 & 2 \\
& Number of particles & $\sim 211,082$ & $\sim 211,082$ \\
& Measured defect fraction & 0 & $9.47 \mathrm{E}-6$ \\
& $95 \%$ confidence limit & $\leq 1.42 \mathrm{E}-5$ & $\leq 2.99 \mathrm{E}-5$ \\
\hline
\end{tabular}

The amount of uranium leached from Clutch 11035-7 after the burn was 1.013 kernel equivalents, which strongly supports a conclusion that the uranium came from a single particle with an exposed-kernel defect. The amount of uranium leached from Clutch 11034-4 was 1.234 kernel equivalents, which is uncharacteristically high for a typical LBL analysis involving one defective particle. Possible explanations include (1) higher than normal error in the mass spectrometry, (2) the presence of more than one particle with an exposed-kernel defect in conjunction with incomplete leaching, and (3) one particle with an exposed-kernel defect that had abnormally high uranium content. Incomplete leaching is unlikely given the low uranium content in the second postburn leach. The possibility that a single defective particle contained an abnormally high amount of uranium is likely given the observation of particles with additional kernel material in samples from the AGR-5/6/7 TRISO particle composite and from the individual TRISO particle batches that were blended to form the composite (Helmreich et al. 2017a, Helmreich et al. 2017b). In the x-ray analysis of 241,822 particles from the AGR-5/6/7 TRISO particle composite, six particles with additional kernel material were identified. The additional kernel material was related to the inclusion of fragments of fractured kernels that were bonded to the main kernel prior to coating or trapped in the buffer layer during coating. Figure 3-1 and Figure 3-2 show examples. Because the embedded fragments produce abnormal shapes and dispersed uranium in the coating layers, there may be a greater chance that particles of this type will also have coating defects. 


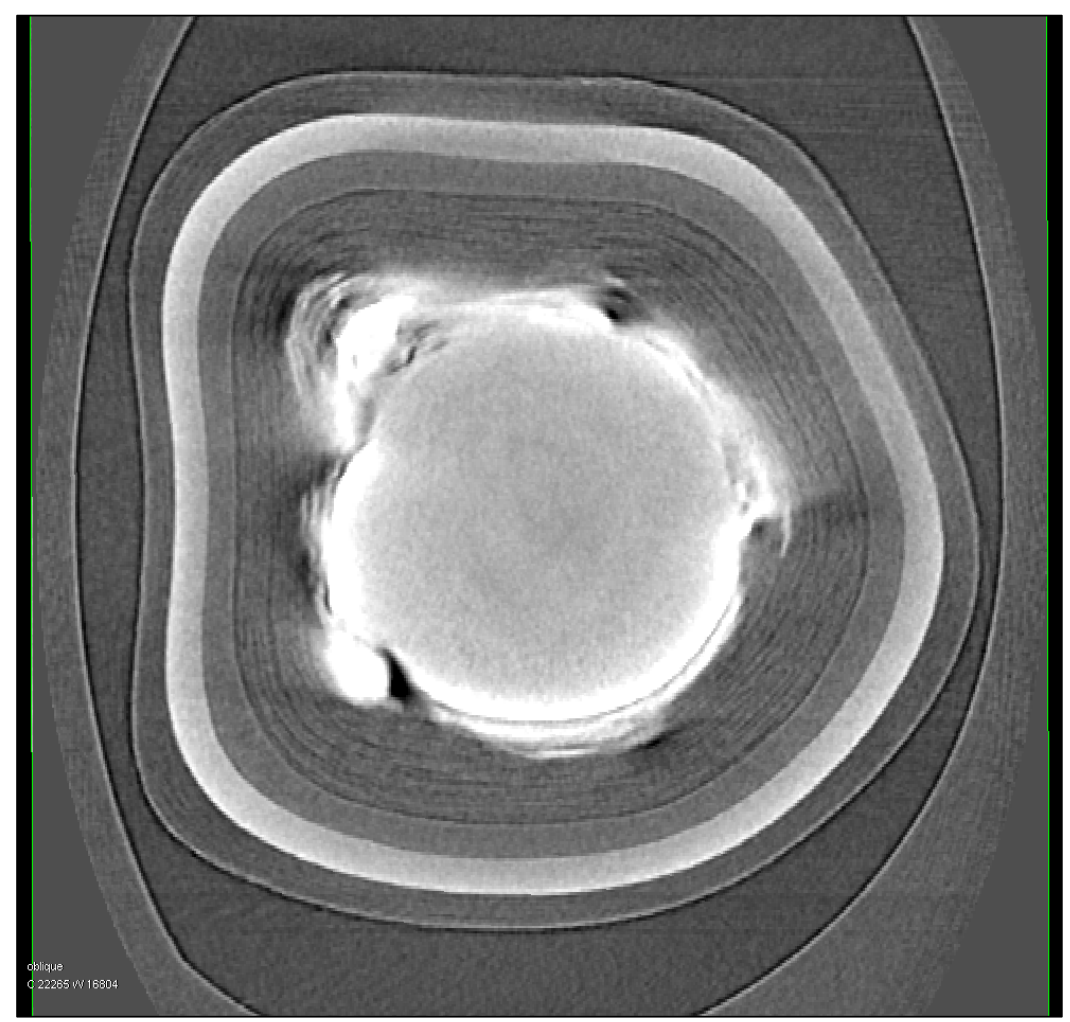

Figure 3-1. Tomographic cross section of a particle from Batch 93168 with embedded kernel fragments and uranium dispersion in the buffer layer (Helmreich et al. 2017b, Figure 2-12).

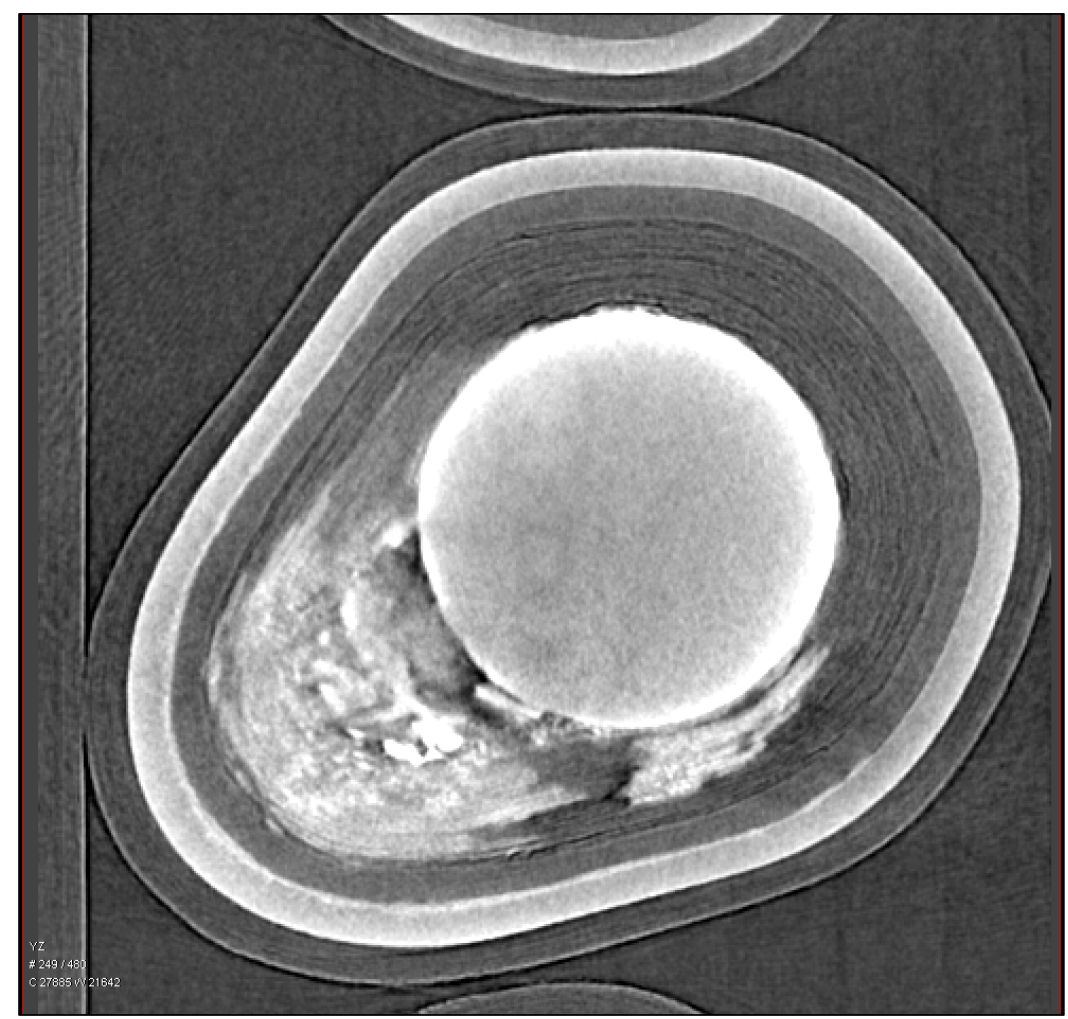

Figure 3-2. Tomographic cross-section of a particle from Batch 93172 with embedded kernel fragments and uranium dispersion in the buffer layer (Helmreich et al. 2017b, Figure 2-11). 
The data presented herein do not include data from the second group of four OC TRISO samples analyzed in the first test series, which included three exposed kernels in the preburn leach of one clutch and four in another. These data were reported and discussed in ORNL/TM-2019/744. The second sample group in the first test series was suspected to contain erroneous data due to (1) the challenge of working with the AGR-5/6/7 graphite/resin overcoating material, which produced a viscous suspension in the leach acid that was difficult to separate from the TRISO particles, combined with (2) the fact that the analysis of the second sample group in the first test series was performed by less experienced personnel. Statistical analysis of the observed preburn leach defect distribution in the eight clutches from Batch 11034 in the first test series determined there was $\leq 1 \%$ probability for the observed distribution. The fact that no exposed kernels were observed in the preburn leaches performed on eight more OC TRISO clutches from Batch 11035 in the second test series reduces the probability to $<0.05 \%$ with the assumption that the two batches should have similar EKFs. Therefore, the data from the suspect group have been discarded from the analysis of the results presented herein.

\subsection{COMPARISON TO BWXT NOG LBL ANALYSIS OF TRISO PARTICLES}

The OC TRISO particles in Batches 11034 and 11035 were made from a composite of four coated particle batches, Composite J52R-16-98005. TRISO particles from Composite 98005 were analyzed with LBL by BWXT NOG, and the DUF, EKF, and SDF results reported in INL/EXT-18-45110 (Marshall 2018) are shown in Table 3-5. The measured values and 95\% confidence upper limits for the TRISO particles prior to overcoating are higher than what was determined for the pooled data from the ORNL LBL analysis of the OC TRISO particles (Table 3-3 and Table 3-4).

Table 3-5. Defect fractions in TRISO particle Lot 98005 prior to overcoating (Marshall 2018)

\begin{tabular}{lccc}
\hline & DUFTotal & EKF & SDF \\
\hline Number of defects & --- & 3 & 3 \\
Number of particles & --- & $\sim 319,000$ & $\sim 159,000$ \\
\hline Measured defect fraction & $1.04 \mathrm{E}-5$ & $9.40 \mathrm{E}-6$ & $1.89 \mathrm{E}-5$ \\
$95 \%$ confidence limit & $a$ & $\leq 2.43 \mathrm{E}-5$ & $\leq 4.88 \mathrm{E}-5$ \\
\hline
\end{tabular}

${ }^{a}$ No $95 \%$ confidence value was available for DUF because only one of the three postburn leach samples had no exposed kernels.

Using the comparison method described in Appendix A and the data in Table 3-4 and Table 3-5, the odds are 29:1 that the OC TRISO EKF is not $>1 \mathrm{E}-5$ higher ${ }^{\dagger}$ than the TRISO EKF, and the odds are $42: 1$ that the OC TRISO SDF is not $>2 \mathrm{E}-5$ higher ${ }^{\dagger}$ than the TRISO SDF. In both cases, it is more likely that the two populations had defect fractions within the chosen margins for comparison. This leads to the reasonable conclusion that the overcoating process did not significantly increase the populations of defective particles already present in the TRISO particle feedstock. The limited available information

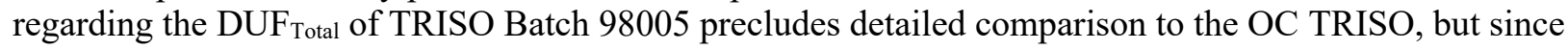

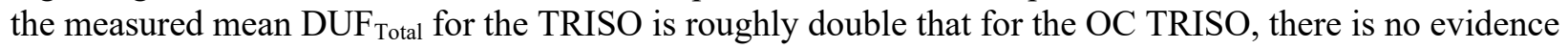
that DUF increased during overcoating.

\footnotetext{
$\dagger$ As discussed in Appendix A, the margins chosen for the statistical comparison between data sets are typically equal to $20 \%$ of the specified limits for EKF $(20 \% \times 5 E-5=1 E-5)$ and SDF $(20 \% \times 1 E-4=2 E-5)$. Differences less than this margin are expected to have insignificant impact on the acceptance testing.
} 


\section{4. $25 \%$ PF COMPACTS}

Confirmatory LBL analysis was completed on 60 AGR-5/6/7 compacts with a nominal 25\% PF (Table 1-1). Compacts were sampled in clutches of five compacts each and analyzed in groups of four clutches at a time. The eight clutches analyzed in the first test series were from two different BWXT NOG furnace tray batches. Each clutch was randomly selected from a composite sample containing 29 compacts from Batch 14156C and 11 compacts from Batch 14156D. These batches were pressed in the same compacting run but were heat treated separately. The 20 compacts measured in the second test series all came from Batch 14156D. All leach solutions were analyzed for uranium content, and the first group in the first test series was also analyzed for other impurities ( $\mathrm{Fe}, \mathrm{Cr}, \mathrm{Mn}, \mathrm{Co}, \mathrm{Ni}, \mathrm{Ca}, \mathrm{Al}, \mathrm{Ti}$, and $\mathrm{V}$ ). The impurity analysis results are reported in ORNL/TM-2019/744. Appendix C contains copies of the preburn leach and postburn leach DRFs for each analyzed clutch, as well as the IRFs that summarize the data. The data are further presented and discussed in the remainder of this section. Only analysis of the pooled data is presented because the results associated with Batches 14156C and 14156D in the first test series cannot be separated. With 29 compacts from Batch 14156C and 31 from Batch 14156D, the two batches are represented equally in the pooled data.

\subsection{LBL ANALYSIS FOR EXPOSED URANIUM IN 25\% PF COMPACTS}

Table 4-1 shows the amounts of uranium (in kernel equivalents) detected in the solutions collected during preburn leaching of the $25 \%$ PF compact clutches, and Table 4-2 shows similar data for the postburn leaching. The values for total uranium leached from each clutch do not include the water rinse data except for the preburn leach total for Clutch $14156 \mathrm{C} / \mathrm{D}-6$, which met the DAM-26 criteria for inclusion because the uranium detected in the water rinse was $>10 \%$ of the second leach and $>1 \%$ of the average uranium per kernel. The elevated uranium content in the preburn water rinse of $1.56 \mathrm{E}-2$ in Clutch $14156 \mathrm{C} / \mathrm{D}-6$ indicates that leaching of exposed uranium may not have been complete. Clutch 14156C/D-6 was also the only clutch in which a preburn leach exposed-kernel defect was detected based on the AGR-5/6/7 Fuel Specification definitions described in Section 2. Table 4-1 shows the individual preburn leach DUF ${ }_{\text {Pre }}$ values for the other clutches in which the preburn leached uranium was $<0.5$ kernel equivalents. Similarly, Table 4-2 shows the DUF Post values for the clutches with $<0.5$ kernel equivalents in the postburn leach solutions.

Table 4-1. Uranium leached from $25 \%$ PF compacts before the burn

\begin{tabular}{|c|c|c|c|c|c|c|c|}
\hline Series & Clutch & Particles $^{a}$ & First leach & Second leach & $\mathrm{H}_{2} \mathrm{O}$ rinse ${ }^{b}$ & Total & DUFPre $^{c}$ \\
\hline \multirow{8}{*}{1} & $14156 \mathrm{C} / \mathrm{D}-1$ & 11,465 & $3.66 \mathrm{E}-2$ & $6.77 \mathrm{E}-3$ & $6.56 \mathrm{E}-4$ & 0.043 & $3.79 \mathrm{E}-6$ \\
\hline & $14156 \mathrm{C} / \mathrm{D}-2$ & 11,465 & $2.90 \mathrm{E}-2$ & $6.01 \mathrm{E}-3$ & $6.18 \mathrm{E}-4$ & 0.035 & $3.05 \mathrm{E}-6$ \\
\hline & $14156 \mathrm{C} / \mathrm{D}-3$ & 11,465 & $1.87 \mathrm{E}-1$ & $2.87 \mathrm{E}-2$ & $2.98 \mathrm{E}-3$ & 0.216 & $1.88 \mathrm{E}-5$ \\
\hline & $14156 \mathrm{C} / \mathrm{D}-4$ & 11,465 & $6.74 \mathrm{E}-2$ & $8.13 \mathrm{E}-3$ & $1.17 \mathrm{E}-3$ & 0.076 & $6.59 \mathrm{E}-6$ \\
\hline & $14156 \mathrm{C} / \mathrm{D}-5$ & 11,465 & $4.12 \mathrm{E}-2$ & $4.75 \mathrm{E}-3$ & 7.66E-4 & 0.046 & $4.00 \mathrm{E}-6$ \\
\hline & $14156 \mathrm{C} / \mathrm{D}-6$ & 11,465 & $8.70 \mathrm{E}-1$ & $6.29 \mathrm{E}-2$ & $1.56 \mathrm{E}-2$ & 0.949 & --- \\
\hline & $14156 \mathrm{C} / \mathrm{D}-7$ & 11,465 & $2.81 \mathrm{E}-2$ & $2.96 \mathrm{E}-3$ & 4.53E-4 & 0.031 & $2.71 \mathrm{E}-6$ \\
\hline & $14156 \mathrm{C} / \mathrm{D}-8$ & 11,465 & $3.15 \mathrm{E}-2$ & $5.78 \mathrm{E}-3$ & $8.55 \mathrm{E}-4$ & 0.037 & $3.26 \mathrm{E}-6$ \\
\hline \multirow{4}{*}{2} & $14156 \mathrm{D}-1$ & 11,465 & $3.75 \mathrm{E}-2$ & $3.91 \mathrm{E}-3$ & $1.88 \mathrm{E}-4$ & 0.041 & $3.61 \mathrm{E}-6$ \\
\hline & $14156 \mathrm{D}-2$ & 11,465 & $3.88 \mathrm{E}-2$ & $5.00 \mathrm{E}-3$ & $2.41 \mathrm{E}-4$ & 0.044 & $3.82 \mathrm{E}-6$ \\
\hline & $14156 \mathrm{D}-3$ & 11,465 & $4.80 \mathrm{E}-2$ & $4.34 \mathrm{E}-3$ & $2.36 \mathrm{E}-4$ & 0.052 & $4.56 \mathrm{E}-6$ \\
\hline & 14156D-4 & 11,465 & $3.07 \mathrm{E}-2$ & $3.13 \mathrm{E}-3$ & $1.65 \mathrm{E}-4$ & 0.034 & $2.95 \mathrm{E}-6$ \\
\hline
\end{tabular}

Note: Uranium content in each leach is reported in kernel equivalents.

${ }^{a}$ The number of particles per clutch was estimated from a determination of the average number of particles per compact, namely 2293 for Batch 14156 (Marshall 2019).

${ }^{b}$ Gray shading indicates that the water rinse was not added to the total.

${ }^{c}$ Individual DUF ${ }_{\text {Pre }}$ is the preburn leach fraction of exposed uranium in each clutch with $<0.5$ exposed kernel equivalents. 
Table 4-2. Uranium leached from $25 \%$ PF compacts after the burn

\begin{tabular}{|c|c|c|c|c|c|c|c|}
\hline Series & Clutch & Particles $^{a}$ & First leach & Second leach & $\mathrm{H}_{2} \mathrm{O}$ rinse $^{b}$ & Total & DUFPost $^{c}$ \\
\hline \multirow{8}{*}{1} & $14156 \mathrm{C} / \mathrm{D}-1$ & 11,465 & $1.25 \mathrm{E}-2$ & $3.59 \mathrm{E}-4$ & $2.04 \mathrm{E}-5$ & 0.013 & $1.13 \mathrm{E}-6$ \\
\hline & $14156 \mathrm{C} / \mathrm{D}-2$ & 11,465 & $1.35 \mathrm{E}-2$ & 2.96E-4 & $2.12 \mathrm{E}-5$ & 0.014 & $1.20 \mathrm{E}-6$ \\
\hline & $14156 \mathrm{C} / \mathrm{D}-3$ & 11,465 & $1.29 \mathrm{E}-1$ & $2.31 \mathrm{E}-4$ & $1.79 \mathrm{E}-5$ & 0.129 & $1.13 \mathrm{E}-5$ \\
\hline & $14156 \mathrm{C} / \mathrm{D}-4$ & 11,465 & $1.25 \mathrm{E}-2$ & $3.94 \mathrm{E}-4$ & $7.68 \mathrm{E}-5$ & 0.013 & $1.13 \mathrm{E}-6$ \\
\hline & $14156 \mathrm{C} / \mathrm{D}-5$ & 11,465 & $1.17 \mathrm{E}+0$ & $5.52 \mathrm{E}-3$ & $5.42 \mathrm{E}-4$ & 1.176 & --- \\
\hline & $14156 \mathrm{C} / \mathrm{D}-6$ & 11,465 & $2.16 \mathrm{E}+0$ & $5.85 \mathrm{E}-3$ & $4.08 \mathrm{E}-4$ & 2.164 & --- \\
\hline & $14156 \mathrm{C} / \mathrm{D}-7$ & 11,465 & $1.45 \mathrm{E}-2$ & $6.71 \mathrm{E}-4$ & $1.01 \mathrm{E}-4$ & 0.015 & $1.32 \mathrm{E}-6$ \\
\hline & $14156 \mathrm{C} / \mathrm{D}-8$ & 11,465 & $1.35 \mathrm{E}-2$ & $2.59 \mathrm{E}-3$ & $1.09 \mathrm{E}-4$ & 0.016 & $1.40 \mathrm{E}-6$ \\
\hline \multirow{4}{*}{2} & $14156 \mathrm{D}-1$ & 11,465 & $1.25 \mathrm{E}-2$ & $4.21 \mathrm{E}-4$ & $1.74 \mathrm{E}-5$ & 0.013 & $1.12 \mathrm{E}-6$ \\
\hline & $14156 \mathrm{D}-2$ & 11,465 & $1.27 \mathrm{E}-1$ & $1.18 \mathrm{E}-1$ & $2.92 \mathrm{E}-4$ & 0.246 & $2.14 \mathrm{E}-5$ \\
\hline & $14156 \mathrm{D}-3$ & 11,465 & $1.21 \mathrm{E}-2$ & $3.05 \mathrm{E}-4$ & $6.00 \mathrm{E}-5$ & 0.012 & $1.08 \mathrm{E}-6$ \\
\hline & $14156 \mathrm{D}-4$ & 11,465 & $1.25 \mathrm{E}-2$ & $3.37 \mathrm{E}-4$ & $3.21 \mathrm{E}-5$ & 0.013 & $1.12 \mathrm{E}-6$ \\
\hline
\end{tabular}

Note: Uranium content in each leach is reported in kernel equivalents.

${ }^{a}$ The number of particles per clutch was estimated from a determination of the average number of particles per compact, namely 2293 for Batch 14156 (Marshall 2019).

${ }^{b}$ Gray shading indicates that the water rinse was not added to the total.

${ }^{c}$ Individual DUF Post $_{1}$ is the postburn leach fraction of exposed uranium in each clutch with $<0.5$ exposed kernel equivalents.

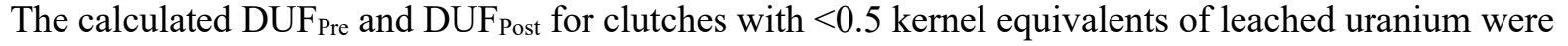
fairly consistent except for four significant outliers. Clutch $14156 \mathrm{C} / \mathrm{D}-3$ had elevated levels of uranium detected in both the preburn and postburn leach series, Clutch $14156 \mathrm{C} / \mathrm{D}-4$ had a slightly elevated level of uranium in the preburn leach series, and Clutch 14156D-2 had elevated levels detected in the postburn leach series. The source of these abnormally high levels of leached uranium can only be conjectured using the existing data. Possible sources may be (1) individual particles with an exposed kernel or SiC defect that were incompletely leached, or (2) the excess uranium could be from inclusion of a kernel fragment or some other localized uranium contamination. Incomplete leaching of the kernel in an individual particle due to restriction of acid infiltration to the kernel is unlikely for the preburn and postburn leaches of Clutch 14156C/D-3 because the successive analysis of the first leach, the second leach, and the water rinse showed significant reduction in the amount of uranium leached at each step, and the second postburn leach was very low, with a total of only 0.345 kernel equivalents leached. A more likely scenario is that an abnormally high amount of uranium was in the OPyC or matrix, and this uranium was in a form that was not easily leached until after the burn. Two observations support this hypothesis: (1) while the amount of uranium detected in each successive preburn leach dropped by approximately an order of magnitude, the amount in each leach was higher than observed in most of the other clutches, and (2) the amount of uranium leached after the burn dropped approximately three orders of magnitude after the first postburn leach to a level less than observed in most of the other clutches. The preburn leach progression in Clutch $14156 \mathrm{C} / \mathrm{D}-4$ also suggests localized uranium contamination in the OPyC or matrix. In contrast, the elevated amount of uranium detected in the postburn leaches of Clutch 14156D-2 appears to be more consistent with incomplete leaching of the kernel from a particle with defective SiC because the second acid leach contained almost as much uranium as the first.

After LBL, all particles in Clutch 14156D-2 were mounted in a single layer on Kapton tape for x-ray radiography. Examination of the x-ray radiographs revealed one particle with unusual x-ray opacity. This particle is shown in Figure 4-1a, where the darker areas in the radiograph indicate lower x-ray attenuation and the brighter areas indicate higher x-ray attenuation. The abnormal particle was removed from the Kapton tape and imaged with x-ray computed tomography (XCT). The x-ray tomogram in Figure 4-1b shows a lining inside the $\mathrm{SiC}$ layer containing material with high atomic number $(\mathrm{Z})$, probably uranium. The interior of the particle could not be imaged because of the x-ray attenuation in this high-Z lining. A region of degraded $\mathrm{SiC}$ can also be seen in Figure $4-1$ b, with high- $\mathrm{Z}$ material in the degraded region. It is 
possible that some of the particle's uranium was leached through the region of degraded $\mathrm{SiC}$ and that this particle is responsible for most of the 0.246 kernel equivalents detected during the postburn leach of Clutch $14156 \mathrm{D}-2$. Confirmation of this hypothesis would require further analysis to determine how much uranium remains in the particle and why the $\mathrm{SiC}$ degradation only resulted in partial leaching.
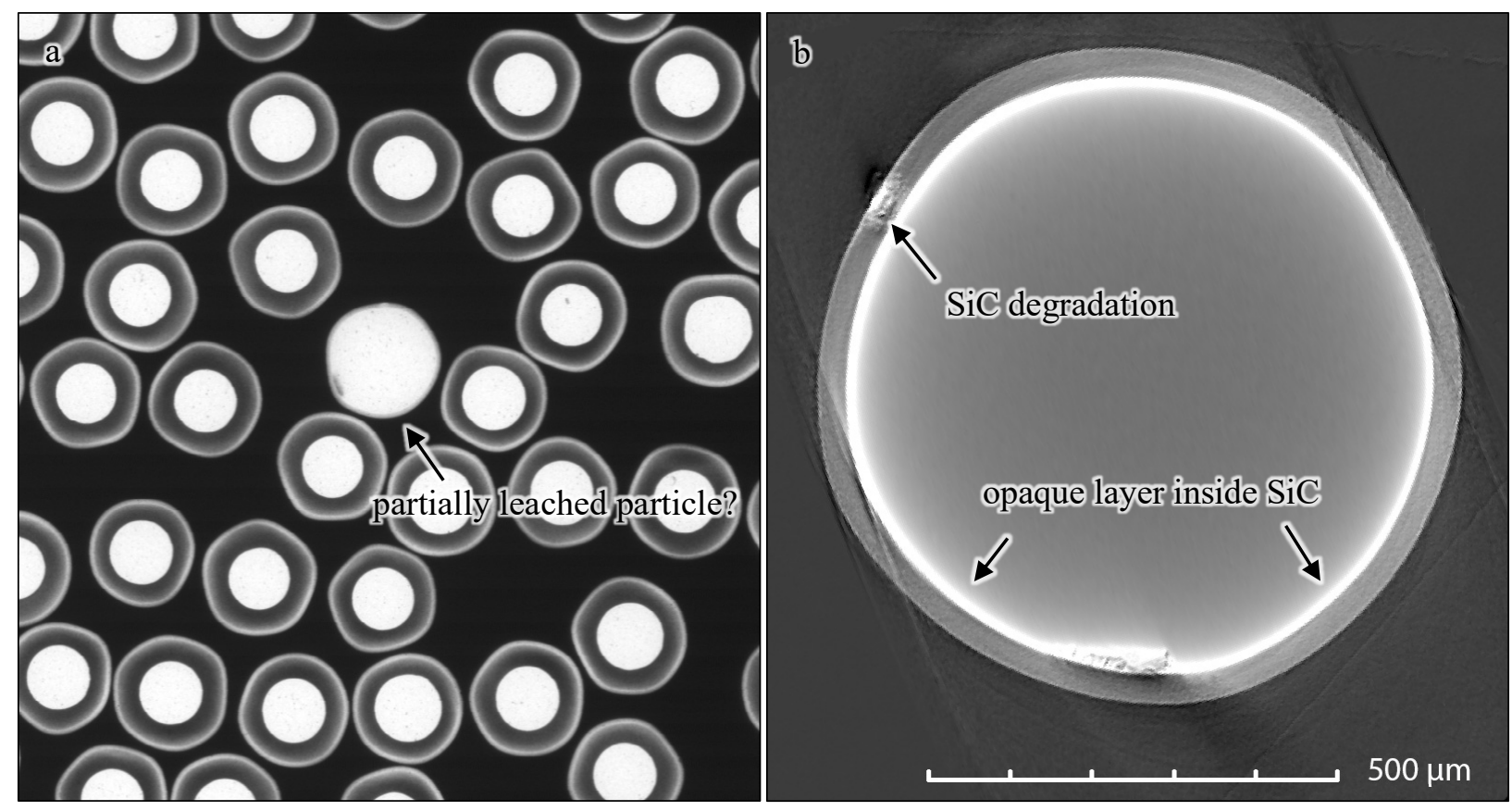

Figure 4-1. (a) Low resolution x-ray radiograph and (b) high-resolution x-ray tomogram showing what may be a partially leached particle from Clutch 14156D-2.

Table 4-3 shows the DUF data for the $25 \%$ PF compacts in terms of mean, standard deviation, and upper bounds of the $95 \%$ confidence interval of the mean value for the sampled material based on the measured samples. The distributions of the DUF values determined by the LBL analysis of the $25 \%$ PF compacts suggest that the measured DUF is comprised of uniformly distributed dispersed uranium plus localized higher concentrations in a few individual compacts. Such outliers do not conform to the definition for dispersed uranium and the assumption that it is a variable property as measured. Table 4-3 shows the calculated DUF using all available data and two alternate calculations using filtered data sets, where outliers were excluded to estimate the uniformly distributed contribution. Filtering was achieved by first calculating the median and median absolute deviation (MAD) from all available DUF Pre and DUF Post $_{\text {P }}$ values, and then excluding values that deviated from the median by more than selected multiples of the MAD. A filter criterion of $<10 \times$ MAD above the median can be considered to be a conservative approach for culling out only the outliers with an extreme deviation, and it resulted in the filtering out of the DUF contributions from the Clutch 14156C/D-3 preburn leach, the Clutch 14156C/D-3 postburn leach, and the Clutch 14156D-2 postburn leach. A filter criterion of $<3 \times$ MAD above the median also filtered out the Clutch 14156C/D-4 preburn leach data. The mean, standard deviation, and 95\% confidence limit for the filtered DUF values shown in Table 4-3 were calculated with the standard methods prescribed in the AGR-5/6/7 Fuel Specification and discussed in Section 2. 
Table 4-3. Dispersed uranium in $25 \%$ PF compacts

\begin{tabular}{|c|c|c|c|c|}
\hline & & DUFPre & DUFPost & DUFTotal \\
\hline \multirow{3}{*}{ All data } & Measured mean & $5.20 \mathrm{E}-6$ & $4.22 \mathrm{E}-6$ & $9.42 \mathrm{E}-6$ \\
\hline & Standard deviation & $4.63 \mathrm{E}-6$ & $6.83 \mathrm{E}-6$ & --- \\
\hline & $95 \%$ confidence limit & $\leq 7.73 \mathrm{E}-6$ & $\leq 8.19 \mathrm{E}-6$ & $\leq 1.42 \mathrm{E}-5$ \\
\hline \multirow{2}{*}{ All data } & Measured median & $3.79 \mathrm{E}-6$ & $1.17 \mathrm{E}-6$ & --- \\
\hline & Median absolute deviation & $7.30 \mathrm{E}-7$ & $6.48 \mathrm{E}-8$ & --- \\
\hline \multirow{3}{*}{$<10 \times$ MAD filtered data $^{a}$} & Measured mean & $3.83 \mathrm{E}-6$ & $1.19 \mathrm{E}-6$ & $5.02 \mathrm{E}-6$ \\
\hline & Standard deviation & $1.12 \mathrm{E}-6$ & $1.14 \mathrm{E}-7$ & --- \\
\hline & $95 \%$ confidence limit & $\leq 4.49 \mathrm{E}-6$ & $\leq 1.27 \mathrm{E}-6$ & $\leq 5.68 \mathrm{E}-6$ \\
\hline \multirow{3}{*}{$<3 \times$ MAD filtered data ${ }^{b}$} & Measured mean & $3.53 \mathrm{E}-6$ & $1.19 \mathrm{E}-6$ & $4.72 \mathrm{E}-6$ \\
\hline & Standard deviation & $5.87 \mathrm{E}-7$ & $1.14 \mathrm{E}-7$ & --- \\
\hline & $95 \%$ confidence limit & $\leq 3.90 \mathrm{E}-6$ & $\leq 1.27 \mathrm{E}-6$ & $\leq 5.10 \mathrm{E}-6$ \\
\hline
\end{tabular}

The $\mathrm{DUF}_{\text {Total }}$ mean and $95 \%$ confidence limit values for the $25 \% \mathrm{PF}$ compact filtered data shown in Table

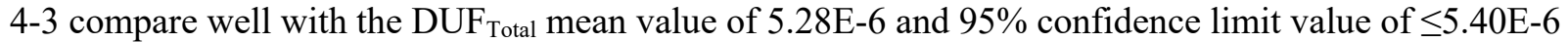
for the pooled OC TRISO data summarized in Table 3-3. This shows that the uranium contamination was generally not any higher in the majority of the $25 \% \mathrm{PF}$ compacts than in the particles. ${ }^{\star}$ However, for cases in which the DUF $F_{\text {Pre }}$ was $\sim 96 \%$ of the DUF ${ }_{\text {Total }}$ in the OC TRISO, the filtered DUF ${ }_{\text {Pre }}$ was $\sim 75-76 \%$ of the DUF $_{\text {Total }}$ in the $25 \% \mathrm{PF}$ compacts. This could indicate that the $1,800^{\circ} \mathrm{C}$ heat treatment was driving reaction of the dispersed uranium with the surrounding carbon, such that the preburn leachability of the uranium was reduced. Such an effect would also explain the slow preburn leaching of what is presumed to be localized uranium contamination in Clutch $14156 \mathrm{C} / \mathrm{D}-3$.

Although the $\mathrm{DUF}_{\text {Total }}$ for the filtered data sets indicates that the uniformly distributed dispersed uranium was below the specified limit of $\leq 1 \mathrm{E}-5$ at $95 \%$ confidence, the impact of the outlier data on the overall amount of exposed uranium cannot be ignored. Without supplemental analyses to show that the excess uranium leached from these outlier samples came from individual particles with exposed-kernel defects or $\mathrm{SiC}$ defects, the most conservative approach is to include the outlier data in the calculation of mean DUF because the specification on maximum DUF is the most stringent $(\leq 1 \mathrm{E}-5$ at $95 \%)$ compared to the limits on EKF $(\leq 5 \mathrm{E}-5$ at $95 \%)$ and SDF $(\leq 1 \mathrm{E}-4$ at $95 \%)$. The upper bounds of the $95 \%$ confidence interval of

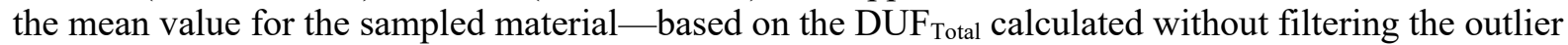
DUF data - are above the AGR-5/6/7 specified limit of $\leq 1 \mathrm{E}-5$ at $95 \%$ confidence. Thus, it appears that the cause of the $25 \% \mathrm{PF}$ compact batches failing to meet the specified criteria for $\mathrm{DUF}_{\text {Total }}$ may be associated with abnormal, localized contamination in individual compacts (most likely in individual particles). In addition, the fact that the outlier DUF values skewed the distribution of measured DUF values suggests that the Student's t-test based on means and standard deviations may not be appropriate for the calculation of the confidence interval.

Table 4-4 shows the calculated EKF and SDF for the 25\% PF compacts. The $95 \%$ confidence limits in the table correspond to the true defect fractions in the sampled population that yield a cumulative binomial distribution value of 0.95 for the observed number of defects and sample size. These values are the lowest tolerance limits for which the compact lot would be deemed acceptable at $95 \%$ confidence based on the

\footnotetext{
\# While the data in Section 3 are from OC TRISO used for the $40 \%$ PF compacts, it is reasonable to presume that the source of the DUF, EKF, and SDF is from the underlying TRISO particles that were used for both AGR-5/6/7 packing fractions. Therefore, comparisons between the $40 \%$ PF OC TRISO and the $25 \%$ PF compacts are valid.
} 
sample measured. The 95\% confidence upper limits for EKF and SDF calculated from the pooled data were below the AGR-5/6/7 specified maximum values for EKF ( $\leq 5 \mathrm{E}-5$ at $95 \%)$ and SDF ( $\leq 1 \mathrm{E}-4$ at $95 \%)$. In the previous analysis of the first test series of $4025 \% \mathrm{PF}$ compacts that was reported in ORNL/TM$2018 / 744$, the $95 \%$ confidence upper limit on EKF ( $\leq 5.18 \mathrm{E}-5$ ) was just above the specified maximum. It was hypothesized in that report that additional sampling of the $25 \%$ PF compacts would likely provide a lower $95 \%$ confidence limit because the measured defect fraction in the 40 -compact sample was only 1.09E-5. This hypothesis has been confirmed via the addition of 20 more compacts to the sample size.

Table 4-4. Defect fractions in $25 \%$ PF compacts

\begin{tabular}{lcc}
\hline & EKF & SDF \\
\hline Number of defects & 1 & 3 \\
Number of particles & $\sim 137,580$ & $\sim 137,580$ \\
\hline Measured defect fraction & $7.27 \mathrm{E}-6$ & $2.18 \mathrm{E}-5$ \\
$95 \%$ confidence limit & $\leq 3.45 \mathrm{E}-5$ & $\leq 5.64 \mathrm{E}-5$ \\
\hline
\end{tabular}

The measured defect fractions for EKF and SDF obtained from the 60 analyzed 25\% PF compacts (Table 4-4) were higher than the measured defect fractions for EKF and SDF obtained from the OC TRISO analysis but were less than the 95\% confidence limits for the OC TRISO EKF and SDF (Table 3-4). Using the comparison method described in Appendix A and the data in Table 3-4 and Table 4-4, the odds are only $0.65: 1$ that the EKF for the $25 \%$ PF compacts was $>1 \mathrm{E}-5$ higher than the OC TRISO EKF, and the odds are only $0.48: 1$ that the SDF was $>2 \mathrm{E}-5$ higher in the $25 \%$ PF compact lot. This comparison suggests that the $25 \% \mathrm{PF}$ compacting may have resulted in a minor increase in the defect fractions, but the statistics do not provide significant certainty for this conclusion. Any increase can be considered essentially insignificant compared to the AGR-5/6/7 fuel specification limits given that the $25 \% \mathrm{PF}$ compacts nevertheless pass the acceptance tests for EKF and SDF based on the data in Table 4-4. As discussed in Section 5.1, there is much stronger evidence that increasing the packing fraction to $40 \%$ resulted in significant particle damage. Therefore, it is possible that some particle damage was also occurring during compacting of the $25 \% \mathrm{PF}$ compacts, but with lower probability due to the lower packing fraction.

\subsection{COMPARISON BETWEEN ORNL AND BWXT NOG LBL OF 25\% PF COMPACTS}

Table 4-5 summarizes the available EKF and SDF data for the 25\% PF compacts obtained from the independent analyses performed at BWXT NOG and ORNL. Using the comparison method described in Appendix A and the data in Table 4-5, the BWXT NOG data for the two sampled batches indicate odds of 1.4:1 that the Batch 14156C EKF was $>1 \mathrm{E}-5$ higher than the Batch $14157 \mathrm{C}$ EKF. This does not provide a high certainty that the variation in the EKF values for the two compacting runs analyzed by BWXT NOG was significant. Comparison of the BWXT NOG Batch 14156C EKF data to the ORNL Batch 14156C/D EKF data gave essentially even odds of 0.90:1 that the two sampled populations were within a comparison margin of 1E-5 and 3:1 odds that they were within 2E-5. Comparison of the BWXT NOG Batch 14157C EKF data to the ORNL Batch 14156C/D EKF data indicates better agreement, with odds of 1.3:1 that the EKF of the sampled populations were within a 1E-5 comparison margin and 4.5:1 that they were within 2E-5. Pooling all the EKF data in Table 4-5 gives a measured defect fraction of 7.35E-6 ( 3 defects in 408,000 particles), and the pooled data indicate that the pooled population would pass an acceptance criteria of $\leq 1.91 \mathrm{E}-5$ at $95 \%$ confidence. Pooling just the BWXT NOG Batch $14157 \mathrm{C}$ EKF data and the ORNL Batch 14156C/D EKF data gives a lower measured defect fraction of 3.70E-6 (1 defect in 270,420 particles), but the pooled data only indicate that the pooled population would pass a slightly lower acceptance criteria of $\leq 1.76 \mathrm{E}-5$ at $95 \%$ confidence. Therefore, even if it is biased high, 
including the BWXT NOG data from Batch $14156 \mathrm{C}$ does not significantly impact the acceptance testing results.

Table 4-5. Comparison of $25 \%$ PF compact EKF and SDF results

\begin{tabular}{clcccc}
\hline & & \multicolumn{3}{c}{${\text { BWXT NOG data }{ }^{a}}$} & ORNL data \\
\cline { 3 - 6 } & & $14156 \mathrm{C}$ & $14157 \mathrm{C}$ & Pooled & $14156 \mathrm{C} / \mathrm{D}$ \\
\hline \multirow{4}{*}{ EKF } & Number of defects & 0 & 2 & 1 \\
& Number of particles & $\sim 137,580$ & $\sim 132,840$ & $\sim 270,420$ & $\sim 137,580$ \\
& Measured defect fraction & $1.45 \mathrm{E}-5$ & 0 & $7.40 \mathrm{E}-6$ & $7.27 \mathrm{E}-6$ \\
& $95 \%$ confidence limit & $\leq 4.58 \mathrm{E}-5$ & $\leq 2.26 \mathrm{E}-5$ & $\leq 2.33 \mathrm{E}-5$ & $\leq 3.45 \mathrm{E}-5$ \\
\hline \multirow{4}{*}{ SDF } & 17 & 8 & 25 & 3 \\
& Number of defects & $\sim 137,580$ & $\sim 132,840$ & $\sim 270,420$ & $\sim 137,580$ \\
& Number of particles & $1.24 \mathrm{E}-4$ & $6.02 \mathrm{E}-5$ & $9.24 \mathrm{E}-5$ & $2.18 \mathrm{E}-5$ \\
& Measured defect fraction & $\leq 1.86 \mathrm{E}-4$ & $\leq 1.09 \mathrm{E}-4$ & $\leq 1.30 \mathrm{E}-4$ & $\leq 5.64 \mathrm{E}-5$ \\
\hline
\end{tabular}

${ }^{a}$ The BWXT NOG pooled data was extracted from INL/EXT-18-45110 (Marshall 2018), and the BWXT NOG batch data was extracted from the spreadsheet used for that report (Marshall 2019).

Using the comparison method described in Appendix A to examine the SDF data in Table 4-5 indicates significant discrepancies between the ORNL and BWXT NOG data. Comparison of the BWXT NOG Batch 14156C SDF data to the ORNL Batch 14156C/D SDF data gives odds of 137:1 that the population sampled by BWXT NOG had an SDF that was more than 2E-5 higher than the population sampled by ORNL. Since both these measured samples came from the same compacting run, this disagreement shows strong inconsistency in the analysis results. Comparison of the BWXT NOG Batch 14157C SDF data to the ORNL Batch 14156C/D SDF data indicates that the odds are 3.2:1 that the population sampled by BWXT NOG had an SDF $>2 \mathrm{E}-5$ higher than the population sampled by ORNL. Comparison between the BWXT NOG analyses of the SDF in Batches 14156C and 14157C is also unfavorable, with indication of 7.0:1 odds that the SDF in the Batch $14156 \mathrm{C}$ sampled population was $>2 \mathrm{E}-5$ higher than in the Batch $14157 \mathrm{C}$ sampled population.

It is most likely that the high SDF values observed in the BWXT NOG analyses were an artifact of the analyses. Otherwise, the comparison of the BWXT NOG TRISO particle data to the BWXT NOG data for the $25 \%$ PF compacts indicates there was a significantly higher SDF after compacting, especially for the Batch 14156C population, where the BWXT NOG analysis data indicates odds of 289:1 that the SDF was $>2 \mathrm{E}-5$ higher than the TRISO and 59:1 odds that it was $>4 \mathrm{E}-5$ higher. It is not reasonable that the SDF would increase this much without the EKF also increasing significantly. In contrast, comparing the ORNL 25\% PF compact data for SDF to the BWXT NOG TRISO particle SDF data does not show a significant change in the SDF after compacting, with odds of 0.23:1 for the compact SDF being $>2 \mathrm{E}-5$ higher than the TRISO SDF, 0.11:1 for the TRISO SDF being $>2 \mathrm{E}-5$ higher than the compact SDF, and 2.5:1 for the compacts and TRISO having SDF values within the 2E-5 margin of comparison.

The ORNL DUF results are not compared herein to the BWXT NOG DUF results because of discrepancies in the available BWXT NOG data that would require additional information and analysis for meaningful comparison. The primary issue was the existence of non-physical zero values in the BWXT data for many of the clutches that skew the cumulative results. There are indications from a survey of the non-zero BWXT clutch data that some of the BWXT DUF results may be consistent with the ORNL DUF values and with observations made regarding contributions from general dispersed uranium and from localized higher concentrations of uranium contamination. 


\section{5. $40 \%$ PF COMPACTS}

Confirmatory LBL analysis was completed on 100 AGR-5/6/7 compacts with a nominal 40\% PF (Table 1-1). Compacts were randomly sampled in clutches of five compacts each and analyzed in groups of four clutches at a time. The first two groups were measured in the first test series and were obtained from Batch 14154C. The second test series included another group of 20 compacts from Batch $14154 \mathrm{C}$ and 40 compacts from Batch 14155C. All leach solutions were analyzed for uranium, and leachates from the second group in the first test series were also analyzed for other impurities $(\mathrm{Fe}, \mathrm{Cr}, \mathrm{Mn}, \mathrm{Co}, \mathrm{Ni}, \mathrm{Ca}, \mathrm{Al}$, $\mathrm{Ti}$, and V). Impurity analysis results are reported in ORNL/TM-2019/744. Appendix D contains copies of the preburn leach and postburn leach DRFs for each analyzed clutch, as well as the IRFs that summarize the data. The data are presented and discussed further in the remainder of this section.

\subsection{LBL ANALYSIS FOR EXPOSED URANIUM IN 40\% PF COMPACTS}

Table 5-1 shows the amounts of uranium (in kernel equivalents) detected in the solutions collected during preburn leaching of the 40\% PF compact clutches, and Table 5-2 shows similar data for the postburn leaching. Individual preburn leach DUF Pre $_{\text {values and postburn leach DUF }}$ Post values are shown for cases in which the total uranium leached before or after the burn was $<0.5$ kernel equivalents, respectively. There was a significant amount of uranium in each of the preburn leach water rinse solutions for the first four samples in the first test series $(>10 \%$ of the second leach and $>1 \%$ of the average uranium per kernel), so these data were included in the total leached uranium values. The water rinses were not analyzed for the other samples in the first test series.

Table 5-1. Uranium leached from $40 \%$ PF compacts before the burn

\begin{tabular}{cccccccc}
\hline Series & Clutch & Particles $^{a}$ & First leach & Second leach & $\mathrm{H}_{2} \mathrm{O}$ rinse ${ }^{b}$ & Total & DUFPre $^{c}$ \\
\hline & $14154 \mathrm{C}-1$ & $\sim 17,395$ & $1.95 \mathrm{E}+0$ & $1.38 \mathrm{E}-1$ & $3.03 \mathrm{E}-2$ & 2.12 & --- \\
& $14154 \mathrm{C}-2$ & $\sim 17,395$ & $8.55 \mathrm{E}-1$ & $1.89 \mathrm{E}+0$ & $3.22 \mathrm{E}-1$ & 3.07 & --- \\
& $14154 \mathrm{C}-3$ & $\sim 17,395$ & $1.82 \mathrm{E}+0$ & $1.86 \mathrm{E}-1$ & $3.79 \mathrm{E}-2$ & 2.04 & --- \\
1 & $14154 \mathrm{C}-4$ & $\sim 17,395$ & $2.47 \mathrm{E}+0$ & $2.43 \mathrm{E}-1$ & $2.79 \mathrm{E}-2$ & 2.75 & --- \\
& $14154 \mathrm{C}-5$ & $\sim 17,395$ & $2.76 \mathrm{E}-2$ & $5.73 \mathrm{E}-3$ & & 0.03 & $1.91 \mathrm{E}-6$ \\
& $14154 \mathrm{C}-6$ & $\sim 17,395$ & $3.87 \mathrm{E}-2$ & $6.84 \mathrm{E}-3$ & & 0.05 & $2.62 \mathrm{E}-6$ \\
& $14154 \mathrm{C}-7$ & $\sim 17,395$ & $9.33 \mathrm{E}-1$ & $1.52 \mathrm{E}-1$ & & 1.09 & --- \\
& $14154 \mathrm{C}-8$ & $\sim 17,395$ & $2.60 \mathrm{E}-2$ & $6.36 \mathrm{E}-3$ & & 0.03 & $1.86 \mathrm{E}-6$ \\
\hline & $14154 \mathrm{C}-1$ & $\sim 17,395$ & $1.03 \mathrm{E}+0$ & $3.71 \mathrm{E}-3$ & $1.22 \mathrm{E}-4$ & 1.03 & --- \\
& $14154 \mathrm{C}-2$ & $\sim 17,395$ & $9.75 \mathrm{E}-1$ & $4.78 \mathrm{E}-2$ & $8.33 \mathrm{E}-4$ & 1.02 & --- \\
& $14154 \mathrm{C}-3$ & $\sim 17,395$ & $1.02 \mathrm{E}+0$ & $4.72 \mathrm{E}-2$ & $1.38 \mathrm{E}-3$ & 1.07 & --- \\
& $14154 \mathrm{C}-4$ & $\sim 17,395$ & $3.11 \mathrm{E}-2$ & $5.01 \mathrm{E}-3$ & $1.68 \mathrm{E}-4$ & 0.04 & $2.08 \mathrm{E}-6$ \\
& $14155 \mathrm{C}-1$ & $\sim 17,100$ & $4.23 \mathrm{E}+0$ & $2.34 \mathrm{E}-1$ & $7.36 \mathrm{E}-3$ & 4.46 & --- \\
& $14155 \mathrm{C}-2$ & $\sim 17,100$ & $2.02 \mathrm{E}-1$ & $2.65 \mathrm{E}-2$ & $1.07 \mathrm{E}-3$ & 0.23 & $1.33 \mathrm{E}-5$ \\
& $14155 \mathrm{C}-3$ & $\sim 17,100$ & $4.14 \mathrm{E}-2$ & $5.03 \mathrm{E}-3$ & $2.78 \mathrm{E}-4$ & 0.05 & $2.71 \mathrm{E}-6$ \\
& $14155 \mathrm{C}-4$ & $\sim 17,100$ & $1.97 \mathrm{E}+0$ & $1.01 \mathrm{E}-1$ & $3.60 \mathrm{E}-3$ & 2.08 & --- \\
& $14155 \mathrm{C}-5$ & $\sim 17,100$ & $1.91 \mathrm{E}+0$ & $8.33 \mathrm{E}-2$ & $2.50 \mathrm{E}-3$ & 1.99 & -- \\
& $14155 \mathrm{C}-6$ & $\sim 17,100$ & $3.90 \mathrm{E}-2$ & $3.92 \mathrm{E}-3$ & $2.80 \mathrm{E}-4$ & 0.04 & $2.51 \mathrm{E}-6$ \\
& $14155 \mathrm{C}-7$ & $\sim 17,100$ & $1.98 \mathrm{E}+0$ & $1.35 \mathrm{E}-1$ & $5.23 \mathrm{E}-3$ & 2.12 & --- \\
& $14155 \mathrm{C}-8$ & $\sim 17,100$ & $9.98 \mathrm{E}-1$ & $5.82 \mathrm{E}-2$ & $2.60 \mathrm{E}-3$ & 1.06 & --- \\
\hline
\end{tabular}

Note: Uranium content in each leach is reported in kernel equivalents.

${ }^{a}$ The number of particles per clutch was estimated from a determination of the average number of particles per compact, namely 3479 for Batch 14154 and 3420 for Batch 14155 (Marshall 2019).

${ }^{b}$ Gray shading indicates that the water rinse was not added to the total; blanks indicate that no measurement was taken.

${ }^{c}$ Individual DUF ${ }_{\text {Pre }}$ is the preburn leach fraction of exposed uranium in each clutch with $<0.5$ exposed kernel equivalents. 
Table 5-2. Uranium leached from $40 \%$ PF compacts after the burn

\begin{tabular}{|c|c|c|c|c|c|c|c|}
\hline Series & Clutch & Particles $^{a}$ & First leach & Second leach & $\mathrm{H}_{2} \mathrm{O}$ rinse ${ }^{b}$ & Total & DUFPost $^{c}$ \\
\hline \multirow{8}{*}{1} & $14154 \mathrm{C}-1$ & $\sim 17,395$ & $1.03 \mathrm{E}+0$ & $8.35 \mathrm{E}-3$ & $1.38 \mathrm{E}-4$ & 1.04 & --- \\
\hline & $14154 \mathrm{C}-2$ & $\sim 17,395$ & $8.10 \mathrm{E}-2$ & $5.14 \mathrm{E}-3$ & $2.10 \mathrm{E}-4$ & 0.09 & $4.95 \mathrm{E}-6$ \\
\hline & $14154 \mathrm{C}-3$ & $\sim 17,395$ & $8.27 \mathrm{E}-1$ & $1.23 \mathrm{E}-2$ & 2.44E-4 & 0.84 & --- \\
\hline & $14154 \mathrm{C}-4$ & $\sim 17,395$ & 7.23E-1 & $3.17 \mathrm{E}-1$ & $3.70 \mathrm{E}-3$ & 1.04 & --- \\
\hline & $14154 C-5$ & $\sim 17,395$ & $3.70 \mathrm{E}-2$ & 7.26E-4 & $8.88 \mathrm{E}-5$ & 0.04 & $2.17 \mathrm{E}-6$ \\
\hline & $14154 C-6$ & $\sim 17,395$ & $3.14 \mathrm{E}-2$ & $7.58 \mathrm{E}-4$ & $1.50 \mathrm{E}-4$ & 0.03 & $1.85 \mathrm{E}-6$ \\
\hline & $14154 \mathrm{C}-7$ & $\sim 17,395$ & $1.06 \mathrm{E}+0$ & $8.41 \mathrm{E}-3$ & $1.60 \mathrm{E}-4$ & 1.07 & --- \\
\hline & $14154 \mathrm{C}-8$ & $\sim 17,395$ & $3.47 \mathrm{E}-2$ & $6.62 \mathrm{E}-4$ & $2.03 \mathrm{E}-4$ & 0.04 & $2.03 \mathrm{E}-6$ \\
\hline \multirow{12}{*}{2} & $14154 \mathrm{C}-1$ & $\sim 17,395$ & $4.09 \mathrm{E}-2$ & $1.94 \mathrm{E}-2$ & $1.68 \mathrm{E}-3$ & 0.06 & $3.47 \mathrm{E}-6$ \\
\hline & $14154 \mathrm{C}-2$ & $\sim 17,395$ & $2.07 \mathrm{E}+0$ & $1.20 \mathrm{E}-2$ & $1.86 \mathrm{E}-3$ & 2.08 & --- \\
\hline & $14154 \mathrm{C}-3$ & $\sim 17,395$ & $7.98 \mathrm{E}-2$ & $3.18 \mathrm{E}-2$ & 4.43E-4 & 0.11 & $6.42 \mathrm{E}-6$ \\
\hline & $14154 \mathrm{C}-4$ & $\sim 17,395$ & $2.07 \mathrm{E}+0$ & $3.91 \mathrm{E}-2$ & $2.11 \mathrm{E}-4$ & 2.11 & --- \\
\hline & $14155 \mathrm{C}-1$ & $\sim 17,100$ & $1.13 \mathrm{E}+0$ & $3.28 \mathrm{E}-3$ & $2.44 \mathrm{E}-4$ & 1.13 & -- \\
\hline & $14155 \mathrm{C}-2$ & $\sim 17,100$ & $1.14 \mathrm{E}+0$ & $4.28 \mathrm{E}-3$ & $4.20 \mathrm{E}-4$ & 1.15 & --- \\
\hline & $14155 \mathrm{C}-3$ & $\sim 17,100$ & $2.85 \mathrm{E}+0$ & $4.19 \mathrm{E}-3$ & $1.93 \mathrm{E}-4$ & 2.85 & --- \\
\hline & $14155 \mathrm{C}-4$ & $\sim 17,100$ & $3.83 \mathrm{E}-2$ & $2.45 \mathrm{E}-4$ & $2.27 \mathrm{E}-4$ & 0.04 & $2.25 \mathrm{E}-6$ \\
\hline & $14155 \mathrm{C}-5$ & $\sim 17,100$ & $1.10 \mathrm{E}+0$ & $4.53 \mathrm{E}-3$ & $4.04 \mathrm{E}-5$ & 1.10 & --- \\
\hline & $14155 \mathrm{C}-6$ & $\sim 17,100$ & $3.23 \mathrm{E}-2$ & $9.55 \mathrm{E}-4$ & $1.07 \mathrm{E}-5$ & 0.03 & $1.94 \mathrm{E}-6$ \\
\hline & $14155 \mathrm{C}-7$ & $\sim 17,100$ & $1.03 \mathrm{E}+0$ & $5.11 \mathrm{E}-3$ & $6.40 \mathrm{E}-5$ & 1.03 & --- \\
\hline & $14155 \mathrm{C}-8$ & $\sim 17,100$ & $1.04 \mathrm{E}+0$ & $4.89 \mathrm{E}-3$ & $1.16 \mathrm{E}-4$ & 1.04 & --- \\
\hline
\end{tabular}

Note: Uranium content in each leach is reported in kernel equivalents.

${ }^{a}$ The number of particles per clutch was estimated from a determination of the average number of particles per compact, namely 3479 for Batch 14154 and 3420 for Batch 14155 (Marshall 2019).

${ }^{b}$ Gray shading indicates that the water rinse was not added to the total.

${ }^{c}$ Individual DUF ${ }_{\text {Post }}$ is the postburn leach fraction of exposed uranium in each clutch with $<0.5$ exposed kernel equivalents.

Similar to what was observed in the $25 \%$ PF compact analysis, the calculated DUF Pre $_{\text {and }}$ DUF $F_{\text {post }}$ values for individual clutches were fairly consistent except for two significant outliers in the preburn leach of Clutch 14155C-2 and the postburn leach of Clutch 14154C-3. Table 5-3 shows the DUF results based on all available DUF data in Table 5-1 and Table 5-2 vs. a reduced data set in which these two outliers were excluded using a filter criteria of $<10 \times \mathrm{MAD}$ on the pooled data as described in Section 4.1. As for the $25 \% \mathrm{PF}$ compacts, the outlier contribution to the $\mathrm{DUF}_{\text {Total }}$ measured for the $40 \% \mathrm{PF}$ compacts resulted in an upper bound on the $95 \%$ confidence interval of the mean value for the sampled compacts that was slightly above the AGR-5/6/7 specified limit of $\leq 1 \mathrm{E}-5$.

Table 5-3. Dispersed uranium in $40 \% \mathrm{PF}$ compacts

\begin{tabular}{llccc}
\hline & & DUFPre & DUFPost & DUFTotal \\
\hline \multirow{3}{*}{ All data } & Measured mean & $3.86 \mathrm{E}-6$ & $3.14 \mathrm{E}-6$ & $7.00 \mathrm{E}-6$ \\
& Standard deviation & $4.19 \mathrm{E}-6$ & $1.70 \mathrm{E}-6$ & --- \\
& $95 \%$ confidence limit & $\leq 6.95 \mathrm{E}-6$ & $\leq 4.28 \mathrm{E}-6$ & $\leq 1.04 \mathrm{E}-5$ \\
\hline \multirow{2}{*}{ All data } & Measured median & $2.51 \mathrm{E}-6$ & $2.21 \mathrm{E}-6$ & - \\
& Median absolute deviation & $4.30 \mathrm{E}-7$ & $3.13 \mathrm{E}-7$ & - \\
\hline \multirow{3}{*}{$<10 \times$ MAD filtered data $^{a}{ }^{a}$} & Measured mean & $2.28 \mathrm{E}-6$ & $2.67 \mathrm{E}-6$ & $4.95 \mathrm{E}-6$ \\
& Standard deviation & $3.75 \mathrm{E}-7$ & $1.15 \mathrm{E}-6$ & - \\
& $95 \%$ confidence limit & $\leq 2.60 \mathrm{E}-6$ & $\leq 3.51 \mathrm{E}-6$ & $\leq 5.86 \mathrm{E}-6$ \\
\hline
\end{tabular}

${ }^{a}$ The $<10 \times$ MAD filtered data do not include $14155 \mathrm{C}-2$ preburn and $14154 \mathrm{C}-3$ postburn data. 
The measured mean $\mathrm{DUF}_{\text {Total }}$ for the $<10 \times$ MAD filtered data set from the $40 \% \mathrm{PF}$ compact analysis

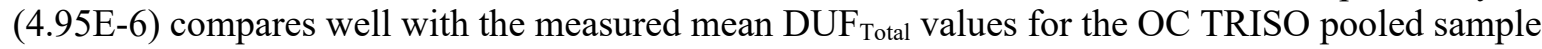
reported in Table 3-3 (5.28E-6) and the $<10 \times$ MAD filtered data set from the $25 \%$ PF compact sample reported in Table 4-3 (5.02E-6). This further reinforces the conclusions that there was a component of the total DUF uniformly distributed throughout the compacts and that this component was no higher than what was in the particles used to make the compacts. As observed when comparing the OC TRISO to the $25 \% \mathrm{PF}$ compacts, the leachability of the uniformly dispersed uranium appeared different in the $40 \% \mathrm{PF}$ compacts, presumably because of the thermal treatment of the compacts during processing. In the $40 \% \mathrm{PF}$ compacts, $\sim 46 \%$ of the $<10 \times$ MAD filtered DUF was detected in the preburn leach compared to $\sim 96 \%$ in the OC TRISO.

Table 5-4 shows the calculated EKF and SDF for the 40\% PF compacts based on the data in Table 5-1 and Table 5-2. The 95\% confidence limits in the table correspond to the true defect fractions in the sampled population that yield a cumulative binomial distribution value of 0.95 for the observed number of defects and sample size. These values are the lowest tolerance limits for which the compact lot would be deemed acceptable at $95 \%$ confidence based on the sample that was measured. Results are provided for Batches $14154 \mathrm{C}$ and $14155 \mathrm{C}$ separately and as a pooled data set. Using the comparison method described in Appendix A and the data in Table 5-4 results in odds of 1.3:1 that the EKF for Batch 14155C was $>1 \mathrm{E}-5$ higher than that in Batch $14154 \mathrm{C}$, and it also results in odds of 0.95:1 that the SDF for Batch 14155C was $>2 \mathrm{E}-5$ higher than that in Batch 14154C. While the defect fractions in Batch 14155C may be marginally higher than those in Batch $14154 \mathrm{C}$, these weak odds indicate that the difference is not likely to be significant with respect to the measured defect fractions. Pooling the data should not skew the data analyses more than $\sim 1 \mathrm{E}-5$, and it is statistically favorable to pool the data to reduce the uncertainty associated with the sample sizes. The SDF data for Batch 14154C indicate that the sampled population satisfied the specified limit of SDF $\leq 1 \mathrm{E}-4$ at $95 \%$ confidence, as did the pooled population. The available SDF data for Batch 14155C was insufficient to show that the sampled population satisfied the specification, although it would pass a specified limit of SDF $\leq 1 \mathrm{E}-4$ with $93.7 \%$ confidence, and additional sampling would most likely result in a positive acceptance test. Both individual batches and the pooled population failed to meet the specification of EKF $\leq 5 \mathrm{E}-5$ at $95 \%$ confidence, and there is no indication that additional sampling would change this rejection result, given that the measured EKF values were all higher than the specified limit.

Table 5-4. Defect fractions in $40 \%$ PF compacts

\begin{tabular}{|c|c|c|c|}
\hline Batch & & EKF & SDF \\
\hline \multirow{4}{*}{$14154 \mathrm{C}$} & Number of defects & 14 & 8 \\
\hline & Number of particles & $\sim 208,740$ & $\sim 208,740$ \\
\hline & Measured defect fraction & $6.71 \mathrm{E}-5$ & $3.83 \mathrm{E}-5$ \\
\hline & $95 \%$ confidence limit & $\leq 1.05 \mathrm{E}-4$ & $\leq 6.92 \mathrm{E}-5$ \\
\hline \multirow{4}{*}{$14155 \mathrm{C}$} & Number of defects & 11 & 8 \\
\hline & Number of particles & $\sim 136,800$ & $\sim 136,800$ \\
\hline & Measured defect fraction & $8.04 \mathrm{E}-5$ & $5.85 \mathrm{E}-5$ \\
\hline & $95 \%$ confidence limit & $\leq 1.34 \mathrm{E}-4$ & $\leq 1.06 \mathrm{E}-4$ \\
\hline \multirow{4}{*}{ Pooled } & Number of defects & 25 & 16 \\
\hline & Number of particles & $\sim 345,540$ & $\sim 345,540$ \\
\hline & Measured defect fraction & $7.24 \mathrm{E}-5$ & 4.63E-5 \\
\hline & $95 \%$ confidence limit & $\leq 1.02 \mathrm{E}-4$ & $\leq 7.04 \mathrm{E}-5$ \\
\hline
\end{tabular}

The measured defect fractions for EKF and SDF reported in Table 5-4 for the individual batches and the pooled sample of 100 analyzed 40\% PF compacts are higher than the EKF and SDF reported in Table 3-4 for the OC TRISO. Using the comparison method described in Appendix A and the data in Table 3-4 and 
Table 5-4, it can be shown that there is strong evidence that the pooled population of $40 \% \mathrm{PF}$ compacts was higher than the pooled population of OC TRISO, with odds of 1,463:1 for a margin of $>1 \mathrm{E}-5,540: 1$ for a margin of $>2 \mathrm{E}-5$, and $46: 1$ for a margin of $>4 \mathrm{E}-5$. This indicates that the $40 \%$ PF compacting process was damaging the TRISO coatings, and kernels were exposed. There was also a less dramatic increase in SDF, indicating that the SiC layers in some particles were broken, but at least one of the pyrocarbon coatings remained liquid tight until after the burn. The measured results indicate odds of $6.0: 1$ that the SDF in the pooled population of $40 \%$ PF compacts was $>2 \mathrm{E}-5$ higher than the SDF in the pooled population of OC TRISO.

Table 5-1 shows the preburn leach results for the eight compact clutches in the first test series. There were ten exposed kernels in the first group of four compacts and only one in the second group. This result is discussed in ORNL/TM-2018/744 as an unlikely distribution if the failure mechanism were dependent on a particle attribute and only an $\sim 10 \%$ probable distribution if the failure mechanism was dependent on variability in processing between individual compacts. This raised questions regarding the possibility of the observed particle defects being an artifact of the LBL performed on the first group in the first test series. Given the agreement between the reported EKF measured by BWXT NOG and the cumulative results for the ORNL measured EKF for the first test series of 40 of the $40 \%$ PF compacts and the fact that the ORNL results were based on an insufficient sample size, ORNL/TM-2018/744 recommends that additional samples be analyzed to determine if the improbable distribution was real or if it was an artifact of the LBL process. The number and distribution of exposed kernels in the preburn leach analysis of the second test series of 60 additional $40 \%$ PF compacts provides evidence that the EKF determined from the 40 compacts in the first test series was accurate and does not support a conclusion that the 10 defects measured in the first group represent an LBL artifact. In fact, the measured EKF from the first test series reported in ORNL/TM-2018/744 (7.90E-5) is nearly the same as the results for the pooled data reported in Table 5-4.

\subsection{COMPARISON BETWEEN ORNL AND BWXT NOG LBL OF 40\% PF COMPACTS}

Table 5-5 shows the EKF and SDF data for the 40\% PF compacts based on the BWXT NOG analyses and the ORNL analyses. The overall comparison is similar to the comparison of the LBL results from the analyses of the $25 \%$ PF compacts discussed in Section 4.2 in that the EKF data from the two independent analyses compare fairly well, while there is a clear discrepancy in the SDF data. As observed in the ORNL data, the BWXT NOG analyses indicated that the Batch 14155C EKF may be slightly higher than the Batch 14154C EKF. Using the comparison method described in Appendix A and the BWXT NOG data in Table 5-5, the odds are 1.3:1 that the EKF in Batch $14155 \mathrm{C}$ was $>1 \mathrm{E}-5$ higher than the EKF in Batch 14154C. However, as argued for the ORNL data in Section 5.1, even with this weak indication from the analyzed samples that the defect fractions in Batch $14155 \mathrm{C}$ may be marginally higher, pooling the BWXT data should not skew the data analyses more than $\sim 1 \mathrm{E}-5$, and it is statistically favorable to pool the data to reduce the uncertainty associated with the sample sizes. The measured and upper limits for the $95 \%$ confidence intervals for EKF in the pooled populations analyzed by BWXT NOG and ORNL were nearly identical. Pooling all the EKF results in Table 5-5 results in a measured EKF of 6.95E-5 (42 defects in 604,105 particles), and the pooled data indicates that the pooled population would pass an acceptance criteria of $\leq 9.0 \mathrm{E}-5$ with $95 \%$ confidence. The pooled population does not meet the specified criteria of $\mathrm{EKF} \leq 5 \mathrm{E}-5$ at $95 \%$ confidence.

Comparison of the SDF data shows that the BWXT NOG measured results were slightly higher, but the differences were minor when used to calculate the confidence intervals for the sample populations. Using the comparison method described in Appendix A and the BWXT NOG data in Table 5-5, the odds are 1.3:1 that the SDF in the BWXT NOG pooled sample was $>2 \mathrm{E}-5$ higher than the SDF in the ORNL pooled sample. The pooled SDF data from the ORNL analysis satisfy the specification of SDF $\leq 1 \mathrm{E}-4$ at $95 \%$ confidence, while the pooled SDF data from BWXT NOG analysis do not. Pooling all the SDF data 
results in a measured defect fraction of 5.63E-5 (34 defects out of 604,105 particles), and the pooled population would pass an acceptance criteria of $\leq 7.5 \mathrm{E}-5$ at $95 \%$ confidence.

Table 5-5. Comparison of $40 \%$ PF compact LBL results

\begin{tabular}{|c|c|c|c|c|c|c|c|}
\hline & \multicolumn{3}{|c|}{ BWXT NOG data $^{a}$} & \multicolumn{3}{|c|}{ ORNL data } \\
\hline & & $14154 \mathrm{C}$ & $14155 \mathrm{C}$ & Pooled & $14154 \mathrm{C}$ & $14155 \mathrm{C}$ & Pooled \\
\hline \multirow{4}{*}{ EKF } & Number of defects & 7 & 10 & 17 & 14 & 11 & 25 \\
\hline & Number of particles & $\sim 121,765$ & $\sim 136,800$ & $\sim 258,565$ & $\sim 208,740$ & $\sim 136,800$ & $\sim 345,540$ \\
\hline & Measured defect fraction & $5.75 \mathrm{E}-5$ & $7.31 \mathrm{E}-5$ & $6.57 \mathrm{E}-5$ & $6.71 \mathrm{E}-5$ & $8.04 \mathrm{E}-5$ & $7.24 \mathrm{E}-5$ \\
\hline & $95 \%$ confidence limit & $\leq 1.08 \mathrm{E}-4$ & $\leq 1.24 \mathrm{E}-4$ & $\leq 9.87 \mathrm{E}-5$ & $\leq 1.05 \mathrm{E}-4$ & $\leq 1.34 \mathrm{E}-4$ & $\leq 1.02 \mathrm{E}-4$ \\
\hline \multirow{4}{*}{ SDF } & Number of defects & 6 & 12 & 18 & 8 & 8 & 16 \\
\hline & Number of particles & $\sim 121,765$ & $\sim 136,800$ & $\sim 258,565$ & $\sim 208,740$ & $\sim 136,800$ & $\sim 345,540$ \\
\hline & Measured defect fraction & $4.93 \mathrm{E}-5$ & $8.77 \mathrm{E}-5$ & $6.96 \mathrm{E}-5$ & $3.83 \mathrm{E}-5$ & $5.85 \mathrm{E}-5$ & 4.63E-5 \\
\hline & $95 \%$ confidence limit & $\leq 9.73 \mathrm{E}-5$ & $\leq 1.43 \mathrm{E}-4$ & $\leq 1.04 \mathrm{E}-4$ & $\leq 6.92 \mathrm{E}-5$ & $\leq 1.06 \mathrm{E}-4$ & $\leq 7.04 \mathrm{E}-5$ \\
\hline
\end{tabular}

${ }^{a}$ The BWXT NOG pooled data was extracted from INL/EXT-18-45110 (Marshall 2018), and the BWXT NOG batch data was extracted from the spreadsheet used for that report (Marshall 2019).

As mentioned in Section 4.2, there is not sufficient information currently available for a detailed comparison of the DUF results. The reported results for the BWXT NOG analysis of DUF in the $40 \%$ PF compacts of $\leq 7.26 \mathrm{E}-5$ at $95 \%$ confidence (Marshall 2018) were higher than those determined from the ORNL analyses (Table 5-3).

\subsection{BL ANALYSIS FOR EXPOSED URANIUM IN 40\% PF COMPACTS}

To explore whether the LBL procedure may have introduced significant particle damage that could artificially elevate defect fractions in the $40 \%$ PF compact analysis, 80 compacts were analyzed using an optional burn-leach procedure according to DAM-26. With this optional procedure, electrolytic deconsolidation and preburn leaching were completely skipped. Compact clutches were loaded into quartz flasks and heated to $750^{\circ} \mathrm{C}$ in air to burn off all exposed carbon. The resultant burned-back particles and residual ash were subjected to the standard postburn leach process. This isolated the analysis from any possible particle damage during deconsolidation or preburn leaching. It was conjectured in ORNL/TM-2018/744 that particle damage may have occurred during preburn leaching due to the challenge of working with the digested AGR-5/6/7 matrix, which produced a very viscous suspension in the acid that complicated separation of the coated particles from the leach acid and increased the centrifuge time required to extract a suitable liquid sample of the acid for mass spectrometry. By skipping the deconsolidation and preburn leaching, this difficulty was eliminated because all matrix graphite was removed by oxidization during the burn. Decanting acid from a vessel containing burned-back particles was relatively easy, and the likelihood of damaging particles was minimal. Appendix E contains copies of the postburn leach DRFs for each analyzed clutch, as well as the IRFs that summarize the data.

Table 5-6 shows the amount of uranium (in kernel equivalents) detected in each solution collected using the burn-leach procedure on 40 of the $40 \%$ PF compacts, which were analyzed in clutches of five compacts each, and in groups of four clutches at a time. The decreasing amount of uranium as leaching progressed through the first and second 24-hour leaches and the water rinse showed that leaching was effective and complete. Water rinse data were not included in the total because they were $\leq 10 \%$ of the second leach or $\leq 1 \%$ of the average uranium per kernel. Some of the values for total leached uranium reported in Table 5-6 deviate significantly from whole numbers. This could be related to the DUF outliers observed in the LBL analysis discussed in Sections 4.1 and 5.1. 
Table 5-6. Uranium leached from 40\% PF compacts using burn-leach procedure

\begin{tabular}{|c|c|c|c|c|c|c|c|}
\hline Series & Clutch & Particles $^{a}$ & First leach & Second leach & $\mathrm{H}_{2} \mathrm{O}$ rinse ${ }^{b}$ & Total & DUFTotal $^{c}$ \\
\hline \multirow{8}{*}{1} & 14154D-1 & $\sim 17,395$ & $3.32 \mathrm{E}+0$ & $1.47 \mathrm{E}-2$ & $8.08 \mathrm{E}-5$ & 3.33 & --- \\
\hline & $14154 \mathrm{D}-2$ & $\sim 17,395$ & $1.19 \mathrm{E}-1$ & $9.18 \mathrm{E}-4$ & $2.88 \mathrm{E}-5$ & 0.12 & $6.88 \mathrm{E}-6$ \\
\hline & 14154D-3 & $\sim 17,395$ & $2.19 \mathrm{E}+0$ & $1.16 \mathrm{E}-2$ & $8.48 \mathrm{E}-5$ & 2.21 & --- \\
\hline & $14154 \mathrm{D}-4$ & $\sim 17,395$ & $2.22 \mathrm{E}+0$ & $1.28 \mathrm{E}-2$ & $6.57 \mathrm{E}-5$ & 2.24 & --- \\
\hline & 14154D-5 & $\sim 17,395$ & $2.74 \mathrm{E}+0$ & $1.14 \mathrm{E}-2$ & $1.19 \mathrm{E}-4$ & 2.75 & --- \\
\hline & 14154D-6 & $\sim 17,395$ & $3.28 \mathrm{E}+0$ & $1.53 \mathrm{E}-2$ & $1.74 \mathrm{E}-4$ & 3.29 & --- \\
\hline & 14154D-7 & $\sim 17,395$ & $6.94 \mathrm{E}-2$ & $6.36 \mathrm{E}-4$ & $1.14 \mathrm{E}-5$ & 0.07 & $4.03 \mathrm{E}-6$ \\
\hline & $14154 \mathrm{D}-8$ & $\sim 17,395$ & $1.12 \mathrm{E}+0$ & $6.63 \mathrm{E}-3$ & $4.49 \mathrm{E}-5$ & 1.13 & -- \\
\hline \multirow{8}{*}{2} & $14155 \mathrm{D}-1$ & $\sim 17,100$ & $2.20 \mathrm{E}+0$ & $7.54 \mathrm{E}-3$ & $7.72 \mathrm{E}-5$ & 2.21 & --- \\
\hline & $14155 \mathrm{D}-2$ & $\sim 17,100$ & $1.46 \mathrm{E}+0$ & $6.19 \mathrm{E}-3$ & $6.50 \mathrm{E}-5$ & 1.47 & --- \\
\hline & $14155 \mathrm{D}-3$ & $\sim 17,100$ & $1.25 \mathrm{E}+0$ & $5.58 \mathrm{E}-3$ & $7.56 \mathrm{E}-5$ & 1.26 & --- \\
\hline & $14155 \mathrm{D}-4$ & $\sim 17,100$ & $2.13 \mathrm{E}+0$ & $9.92 \mathrm{E}-3$ & $6.90 \mathrm{E}-5$ & 2.14 & --- \\
\hline & 14155D-5 & $\sim 17,100$ & $1.01 \mathrm{E}+0$ & $5.23 \mathrm{E}-3$ & $2.95 \mathrm{E}-5$ & 1.01 & --- \\
\hline & 14155D-6 & $\sim 17,100$ & $1.53 \mathrm{E}+0$ & $7.84 \mathrm{E}-3$ & $3.54 \mathrm{E}-5$ & $1.54^{d}$ & --- \\
\hline & 14155D-7 & $\sim 17,100$ & $2.89 \mathrm{E}+0$ & $1.48 \mathrm{E}-2$ & 7.61E-5 & 2.90 & --- \\
\hline & $14155 \mathrm{D}-8$ & $\sim 17,100$ & $8.32 \mathrm{E}-2$ & 7.94E-4 & $2.64 \mathrm{E}-5$ & 0.08 & $4.91 \mathrm{E}-6$ \\
\hline
\end{tabular}

Note: Uranium content in each leach is reported in kernel equivalents.

${ }^{a}$ The number of particles per clutch was estimated from a determination of the average number of particles per compact, namely 3479 for Batch 14154 and 3420 for Batch 14155 (Marshall 2019).

${ }^{b}$ Gray shading indicates that the water rinse was not added to the total.

${ }^{c}$ Individual DUF Total $_{\text {is }}$ the fraction of exposed uranium in each clutch with $<0.5$ exposed kernel equivalents.

${ }^{d}$ Clutch 14155D-6 was counted as having one defect because the total leached uranium was $<1.5$ after subtraction of mean DUF according to specified procedure described in Section 2.

Because detection of the dispersed uranium during BL analysis is not split between a preburn and postburn leach series, $\mathrm{DUF}_{\text {Total }}$ is more directly measured but is only available for clutches which do not have an exposed-kernel defect or a SiC defect. As expected from the LBL presented in Table 5-1 and Table 5-2, there were only a few clutches that met the criteria of $<0.5$ kernel equivalents of total leached

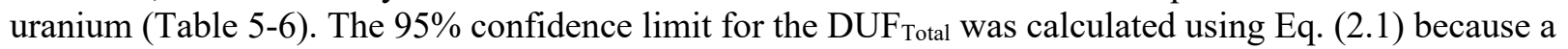
value for the standard deviation was available. Table 5-7 summarizes the dispersed uranium analysis results. The measured mean DUF ${ }_{\text {Total }}$ for the BL analysis (5.27E-6) compares well with the $<10 \times \mathrm{MAD}$ filtered value obtained with LBL analysis of the other $40 \%$ PF compacts (4.95E-6), as well as the $<10 \times \mathrm{MAD}$ filtered value for the $25 \%$ PF compacts $(5.02 \mathrm{E}-5)$ and the OC TRISO DUF Total of 5.28E-6.

Table 5-7. Dispersed uranium in $40 \% \mathrm{PF}$ compacts

\begin{tabular}{lccc}
\hline & LBL DUFTotal & LBL $<10 \times$ MAD filtered DUFTotal & BL DUFTotal \\
\hline Measured mean & $7.00 \mathrm{E}-6$ & $4.95 \mathrm{E}-6$ & $5.27 \mathrm{E}-6$ \\
Standard deviation & --- & --- & $1.46 \mathrm{E}-6$ \\
$95 \%$ confidence limit & $\leq 1.04 \mathrm{E}-5$ & $\leq 5.86 \mathrm{E}-6$ & $\leq 7.74 \mathrm{E}-6$ \\
\hline
\end{tabular}

While the BL procedure does not distinguish between exposed-kernel (preburn-leach) defects and SiC (postburn-leach) defects, the number of exposed kernels detected in the BL solutions should equal the sum of these two types of defects. Table 5-8 compares the combined EKF+SDF determined by LBL versus $\mathrm{BL}$ of the $40 \% \mathrm{PF}$ compacts. Results are provided for compacting runs 14154 and 14155 separately and as a pooled data set. The LBL was performed on Batches $14154 \mathrm{C}$ and $14155 \mathrm{C}$, while the BL was performed on Batches 14154D and 14155D, where different letter suffixes indicate different furnace runs for carbonization and heat treatment. 
Table 5-8. Combined defect fractions in $40 \%$ PF compacts

\begin{tabular}{clcc}
\hline Batch & & LBL EKF+SDF & BL EKF+SDF \\
\hline \multirow{4}{*}{14154} & $14154 \mathrm{C}$ & $14154 \mathrm{D}$ \\
& Sampled batches & $14155 \mathrm{C}$ & $14155 \mathrm{D}$ \\
\hline \multirow{4}{*}{14155} & Number of defects & 22 & 14 \\
& Number of particles & $\sim 208,740$ & $\sim 139,160$ \\
& Measured defect fraction & $1.05 \mathrm{E}-4$ & $1.01 \mathrm{E}-4$ \\
& $95 \%$ confidence limit & $\leq 1.51 \mathrm{E}-4$ & $\leq 1.58 \mathrm{E}-4$ \\
\hline & Number of defects & 19 & 11 \\
& Number of particles & $\sim 136,800$ & $\sim 136,800$ \\
& Measured defect fraction & $1.39 \mathrm{E}-4$ & $8.04 \mathrm{E}-5$ \\
& $95 \%$ confidence limit & $\leq 2.04 \mathrm{E}-4$ & $\leq 1.34 \mathrm{E}-4$ \\
\hline \multirow{4}{*}{ Pooled 4} & 41 & 25 \\
& Number of defects & $\sim 345,540$ & $\sim 275,960$ \\
& Number of particles & $1.19 \mathrm{E}-4$ & $9.06 \mathrm{E}-5$ \\
& Measured defect fraction & $\leq 1.54 \mathrm{E}-4$ & $\leq 1.27 \mathrm{E}-4$ \\
\hline & $95 \%$ confidence limit & & \\
\hline
\end{tabular}

The measured EKF+SDF values from the LBL analysis of Batch $14154 \mathrm{C}$ and the BL analysis of Batch 14154D were almost identical. The method described in Appendix A was used to compare the true $\mathrm{EKF}+\mathrm{SDF}$ in the Batch 14154C population sampled with LBL analysis to that in the Batch 14154D population sampled with BL analysis based on the data in Table 5-8. This resulted in odds of 0.28:1 that Batch 14154C was $>3 \mathrm{E}-5$ higher than Batch 14154D, 0.22:1 that Batch 14154D was $>3 \mathrm{E}-5$ higher than Batch $14154 \mathrm{C}$, and 1.5:1 that the two sampled population were within 3.5E-5. This supports a conclusion that there was not significant damage to the particles during LBL of compacts from Batch 14154C. However, the measured EKF+SDF for Batch 14155C analyzed with LBL was higher than the measured BL value for Batch $14155 \mathrm{D}$, and the Wilson score comparison yields odds of 3.1:1 that the Batch 14155C population sampled with LBL analysis had an EKF+SDF that was $>3 \mathrm{E}-5$ higher than the Batch 14155D population sampled with BL analysis. This suggests particles may have been damaged in the LBL of compacts from Batch 14155C unless the defect population in Batch 14155C was significantly higher than in Batch $14155 \mathrm{D}$, which is unlikely given that any possible variation between furnace runs is not expected to have significantly impacted the defect fractions. It is possible that this result is biased by the limited sample sizes. Comparison of the pooled results indicates odds of $0.86: 1$ that the true EKF+SDF in the pooled population sampled with LBL analysis was $>3 \mathrm{E}-5$ higher than the true EKF+SDF in the pooled population sampled with BL analysis, and odds are 1.1:1 that the two populations had an $\mathrm{EKF}+\mathrm{SDF}$ within the $3 \mathrm{E}-5$ margin.

\subsection{X-RAY ANALYSIS OF DEFECTIVE PARTICLES IN 40\% PF COMPACTS}

After LBL, particles from three $40 \% \mathrm{PF}$ compact clutches were examined by $\mathrm{x}$-ray radiography to identify any leached particles having a SiC shell that was still in one piece. Clutch 14155C-4 exhibited 2.08 kernel equivalents in the preburn leach and 0.04 kernel equivalents in the postburn leach. No leached particles with intact $\mathrm{SiC}$ shells were identified from the radiography survey, but there was one $\mathrm{SiC}$ hemispherical shell and five $\mathrm{SiC}$ fragments observed that looked to be consistent with the debris from two particles. Clutch 14155C-4 exhibited 0.05 kernel equivalents in the preburn leach and 2.85 kernel equivalents in the postburn leach. No leached particles with intact $\mathrm{SiC}$ shells were identified from the radiography survey, and only one small $\mathrm{SiC}$ fragment was found. Clutch $14155 \mathrm{C}-1$ exhibited 4.46 kernel equivalents in the preburn leach and 1.13 kernel equivalents in the postburn leach. Six SiC fragments were observed that looked to be consistent with the debris from at least two particles. Two intact SiC shell with no remaining kernel or pyrocarbon material were found and further examined with XCT. 
Figure 5-1 shows x-ray tomograms of the two intact SiC shells found after LBL of Clutch 14155C-1. One shell had a crack in the SiC traversing about one-quarter of the circumference. The other shell had a hole indicative of localized $\mathrm{SiC}$ degradation similar to that observed in the $25 \%$ compact particle shown in Figure 4-1. The SiC crack may have been introduced during compacting. The hole was probably the result of reaction with a metallic inclusion during the compact heat treatment. Figure 5-2 shows SiC degradation that was observed during defective IPyC analysis of particles from the AGR-5/6/7 TRISO fuel composite (Helmreich et al. 2017a, Helmreich et al. 2017b). For the defective IPyC analysis, the as-fabricated TRISO particles were heat treated for one hour at $1,800^{\circ} \mathrm{C}$ to simulate the heat treatment that is performed during compact fabrication. Similar degradation of $\mathrm{SiC}$ was observed after $1,800^{\circ} \mathrm{C}$ safety testing of AGR-2 Compact 2-3-2 (Hunn et al. 2018b) due to reaction with molybdenum, where the molybdenum presumably came from the hot-sampling cup in the BWXT NOG coater.

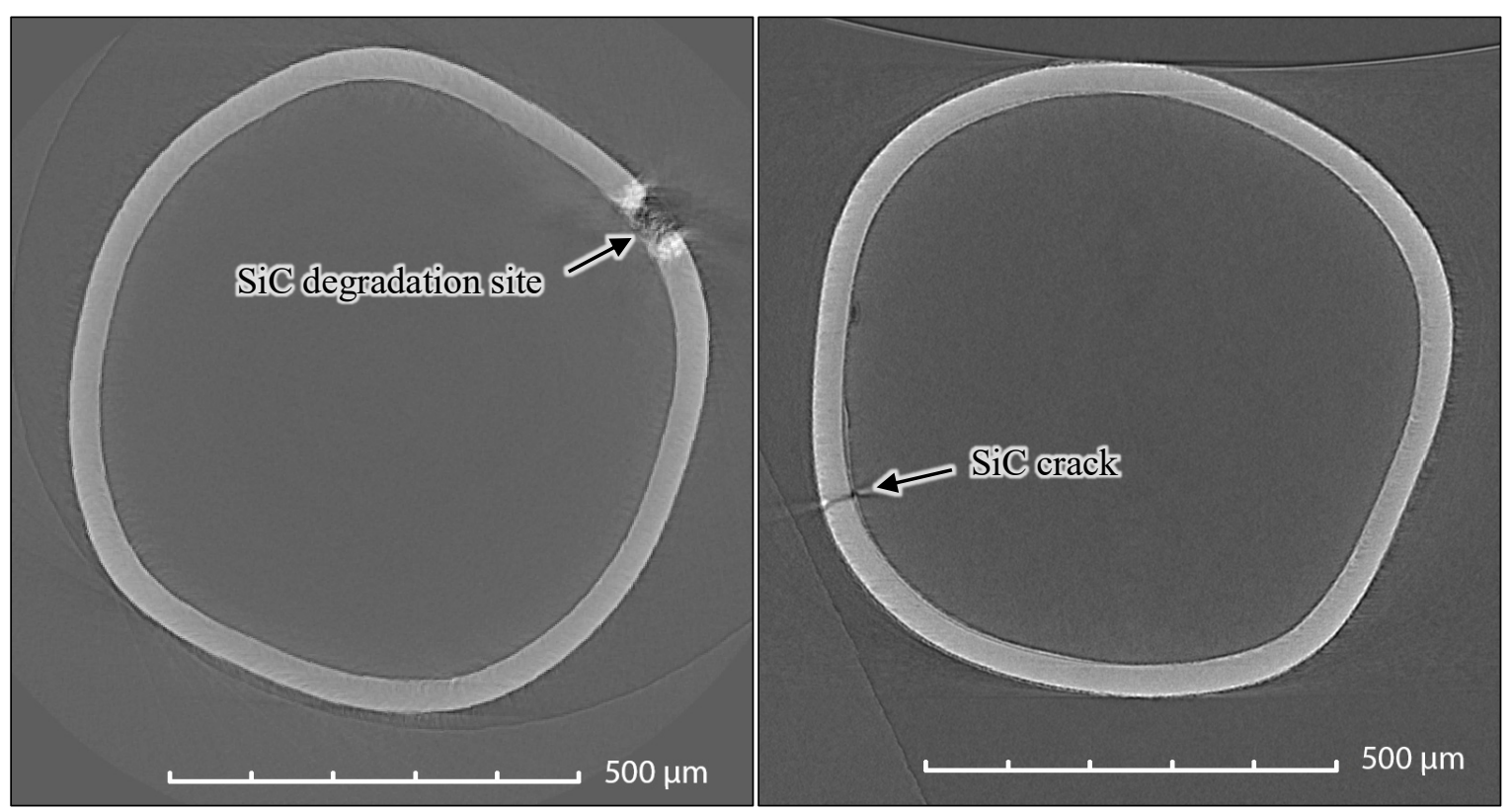

Figure 5-1. X-ray tomograms of SiC shells from two particle from Clutch $14155 \mathrm{C}-1$.

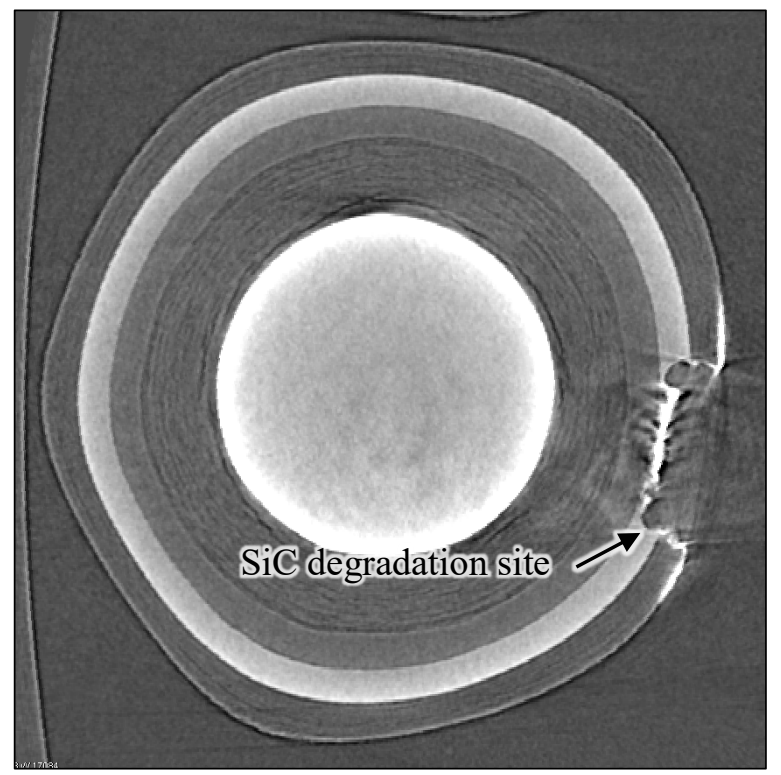

Figure 5-2. X-ray tomogram of particle from AGR-5/6/7 TRISO composite with degraded $\mathrm{SiC}$ (Helmreich et al. 2017b, Figure 4-7). 
Two other particles were identified during the radiography survey of the particles from Clutch 14155C-1. These particles still had kernels and internal pyrocarbon but were examined by XCT to look for evidence of partial leaching. Figure 5-3 shows tomograms of these particles. There were no indications of defects in the $\mathrm{SiC}$ or signs of acid leaching. One particle had a large soot inclusion that compromised the IPyC coating and probably allowed $\mathrm{HCl}$ penetration during $\mathrm{SiC}$ coating that resulted in uranium dispersion during heat treatment. The other particle had an abnormal or missing IPyC layer that similarly resulted in uranium dispersion.
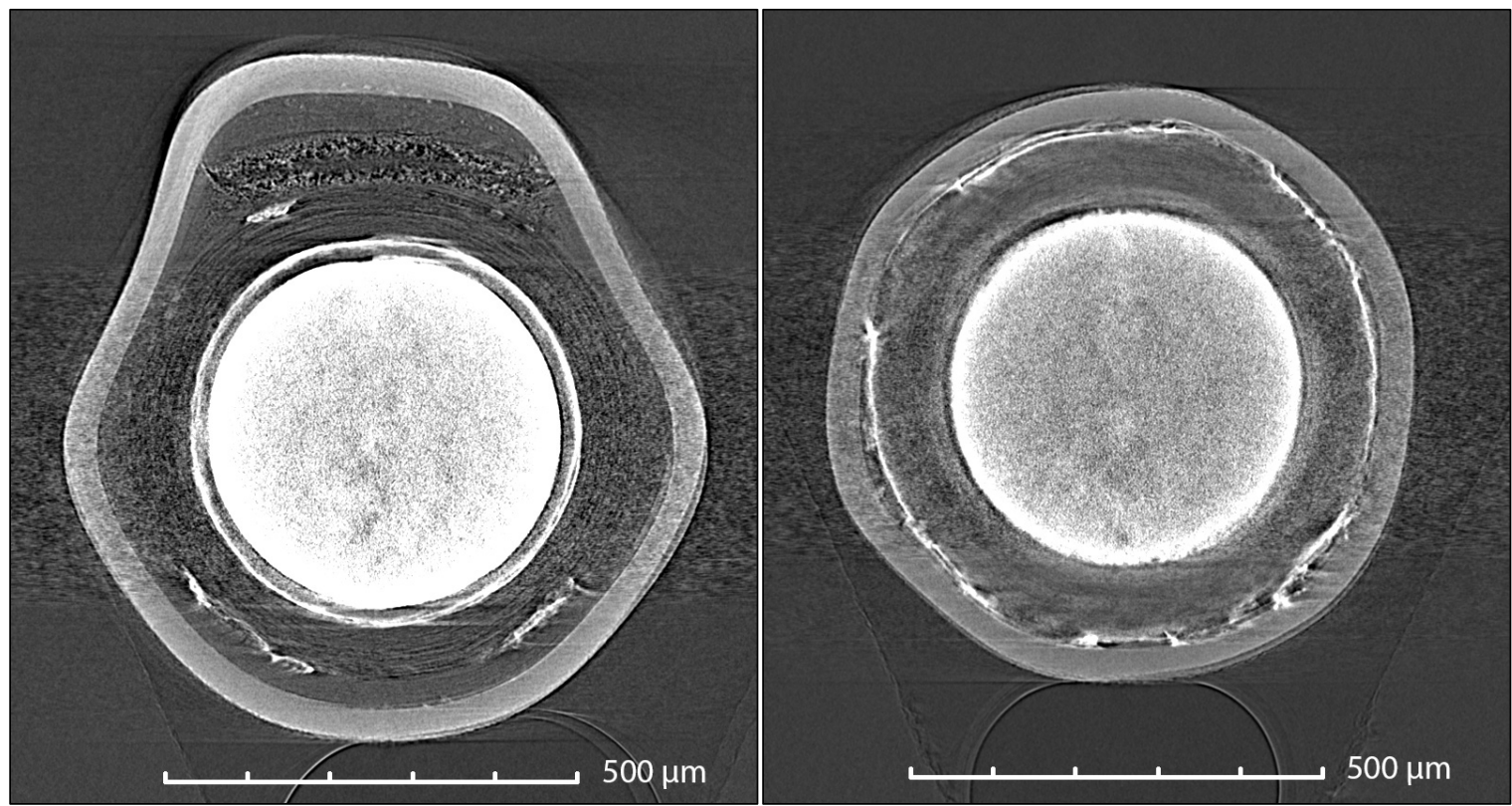

Figure 5-3. X-ray tomograms of two particle from Clutch 14155C-1 with defective IPyC but no indication of partial leaching. 


\section{CONCLUSION}

Confirmatory LBL was completed on $10040 \%$ PF compacts and 60 25\% PF compacts taken from compact batches used for the AGR-5/6/7 irradiation test. Data from this confirmatory analysis were compared to data from the LBL analysis performed at BWXT NOG. Additional LBL was performed on OC TRISO taken from the composite used to form the $40 \%$ PF compacts to explore whether overcoating or compacting was responsible for the elevated EKF observed in the $40 \%$ PF compacts. To investigate the effect of the difficulties experienced when working with the digested matrix slurry during preburn leaching, BL analysis was performed on $8040 \%$ PF compacts to acquire data without having to work with leachates containing digested matrix.

The LBL analysis of the OC TRISO showed that overcoating did not introduce significant damage to the TRISO particles. Statistical comparison of the EKF and SDF in the OC TRISO samples with the EKF and SDF in the TRISO samples showed similar defect fractions in the sampled populations. The OC TRISO LBL analysis also provided evidence that the DUF was a combination of uniformly distributed uranium contamination combined with high concentrations of uranium in some of the compacts. Although this localized contamination complicated the analysis, consistency was observed between the DUF in the OC TRISO and the DUF in the two types of compacts. Comparison to the TRISO particles was limited by the available data, but it is probable that uranium contamination in the TRISO particles was the source of all observed DUF.

The ORNL and BWXT NOG results for EKF were sufficiently consistent to allow them to be pooled for statistical analysis of the limit on the EKF in the $25 \% \mathrm{PF}$ and $40 \% \mathrm{PF}$ pooled samples. While there was some variation in the observed defect fractions for the analyzed samples of TRISO, OC TRISO, and $25 \%$ $\mathrm{PF}$ compacts, there were no strong indications for significant statistical differences after accounting for the sample sizes. The TRISO, OC TRISO, and 25\% PF compacts were all found to have acceptable values for EKF compared to the AGR-5/6/7 specified limit of EKF $\leq 5 \mathrm{E}-5$ at $95 \%$ confidence. However, the EKF for the $40 \%$ PF compacts clearly indicated that TRISO particles were damaged during compacting, and the $40 \%$ PF compacts did not satisfy the specification limit on EKF.

The ORNL confirmatory analysis indicated a high probability that there was a significant positive bias in the BWXT NOG results for SDF in the 25\% PF compact Batch 14156C and a smaller bias in the $25 \% \mathrm{PF}$ compact Batch 14157C. The BWXT NOG SDF data suggests that the $25 \%$ PF compacting process introduced damage to the $\mathrm{SiC}$ that elevated the SDF above the fraction observed in the TRISO particles but not to the entire TRISO coating, since the EKF values were not elevated. This is unlikely. The ORNL SDF data indicates that no significant damage was introduced in the SiC layer during compacting of the $25 \%$ PF compacts. Pooling of the results for the analysis of the SDF in the $25 \%$ PF compacts is not recommended. For the $40 \%$ PF compacts, there was a slight discrepancy between the BWXT NOG SDF data and the confirmatory analysis performed by ORNL, with the BWXT NOG SDF data being slightly higher. However, for the available data, pooling the 40\% PF compact SDF data from BWXT NOG and ORNL did not adversely impact the upper limit on the $95 \%$ confidence interval.

Comparison between LBL and BL results for the $40 \%$ PF compacts was somewhat inconclusive. When data were grouped into two sets that corresponded with different compacting runs, one set (compacting run 14154) gave no indication that particle damage may have occurred during deconsolidation and preburn leaching. However, the other set (compacting run 14155) showed some indication that the combined EKF+SDF measured by LBL was higher than that measured by BL. This difference was not as statistically significant when the data from the two compacting runs were pooled. It is possible that the source of the EKF defects in the 40\% PF compacts may be affecting the statistical calculations in this comparison. The assumption that each TRISO particle is an independent sample is probably flawed if the damage is occurring during compacting and varying from compact to compact. Under those conditions, the statistics may need to be adjusted to account for the number of compacts in the sample. 


\section{REFERENCES}

Brown, L. D. and T. T. Cai. 2001. "Interval Estimation for a Binomial Proportion.” Statist. Sci. 16, 101133.

Cai, T. T. 2005. "One-sided Confidence Intervals in Discrete Distributions.” J. Statist. Plan. and Inf. 131, 63-88.

Einerson, J. J. 2005. Statistical Methods Handbook for Advanced Gas Reactor Fuel Materials. INL/EXT05-00349, Revision 0. Idaho Falls, Idaho: Idaho National Laboratory.

Helmreich, G. W., J. D. Hunn, D. J. Skitt, J. A. Dyer, and A. T. Schumacher. 2017a. Acceptance Test Data for the AGR-5/6/7 Irradiation Test Fuel Composite-Defective IPyC and Pyrocarbon Anisotropy. ORNL/TM-2017/037. Oak Ridge, Tennessee: Oak Ridge National Laboratory.

Helmreich, G. W., J. D. Hunn, D. J. Skitt, J. A. Dyer, and A. T. Schumacher. 2017b. X-ray Analysis of Defects and Anomalies in AGR-5/6/7 TRISO Particles. ORNL/TM-2017/038. Oak Ridge, Tennessee: Oak Ridge National Laboratory.

Hunn, J. D. 2017. Data Acquisition Method: Estimation of Average Particle Weight. AGR-CHAR-DAM22, Revision 23. Oak Ridge, Tennessee: Oak Ridge National Laboratory.

Hunn, J. D. and F. C. Montgomery. 2018a. Data Acquisition Method: Compact Leach-Burn-Leach. AGRCHAR-DAM-26, Revision 3. Oak Ridge, Tennessee: Oak Ridge National Laboratory.

Hunn, J. D. and F. C. Montgomery. 2018b. Data Acquisition Method: Particle Leach-Burn-Leach. AGRCHAR-DAM-21, Revision 2. Oak Ridge, Tennessee: Oak Ridge National Laboratory.

Hunn, J. D., F. C. Montgomery , J. A. Dyer, T. J. Keever, and G. W. Helmreich. 2018a. Confirmatory LBL Analysis of AGR-5/6/7 Compacts and Overcoated Particles. ORNL/TM-2018/774. Oak Ridge, Tennessee: Oak Ridge National Laboratory.

Hunn, J. D., R. N. Morris, F. C. Montgomery, T. J. Gerczak, D. J. Skitt, G. W. Helmreich, B. D. Eckhart, and Z. M. Burns. 2018b. Safety-Testing and Post-Safety-Test Examination of AGR-2 UCO Compact 2-3-2 and AGR-2 UO ${ }_{2}$ Compact 3-4-1. ORNL/TM-2018/956, Revision 0. Oak Ridge, TN: Oak Ridge National Laboratory.

Newcombe, R. G. 1998. "Two-sided Confidence Intervals for the Single Proportion: Comparison of Seven Methods." Statist. Med. 17, 857-872.

Lybeck, N. J., and J. J. Einerson. 2016. Statistical Sampling Plan for AGR-5/6/7 Fuel Materials. PLN-4352, Revision 5. Idaho Falls, Idaho: Idaho National Laboratory.

Marshall, D. W. 2017. AGR-5/6/7 Fuel Specification. SPC-1352, Revision 8. Idaho Falls, Idaho: Idaho National Laboratory.

Marshall, D. W. 2018. Confirmatory Defect Analyses of AGR-5/6/7 Fuel. INL/EXT-18-45110, Revision 0. Idaho Falls, Idaho: Idaho National Laboratory.

Marshall, D. W. 2019. "Fuel Summary." Personal communication by e-mail on April 16, 2019 with an attached spreadsheet that was used for INL/EXT-18-45110, Revision 0 (Marshall 2018).

Wallis, S. A. 2013. "Binomial Confidence Intervals and Contingency Tests: Mathematical Fundamentals and the Evaluation of Alternate Methods." J. Quant. Ling. 20, 178-208.

Wilson, E. B. 1927. "Probable Inference, the Law of Succession, and Statistical Inference." J. Am. Statist. Assoc. 22, 209-212. 



\section{APPENDIX A. COMPARISON OF EKF AND SDF MEASUREMENTS}





\section{APPENDIX A. COMPARISON OF EKF AND SDF MEASUREMENTS}

This Appendix explains the method used in this report to compare the results of the LBL analyses performed at BWXT NOG and ORNL in a way that accounts for the variations inherent in the statistical sampling. The basic approach involves estimating the probability that the measured defect fractions in two independent samples indicate significantly different values for the true defect fraction. For samples extracted from different populations, this can provide a measure of the likelihood that the sampled populations have significantly different true defect fractions. For samples taken from the same or similar populations, this provides an indication of whether one of the two measurements may have been flawed or the result of an unrepresentative sample.

As discussed in the Statistical Sampling Plan for AGR-5/6/7 Fuel Materials (Lybeck and Einerson 2016) and the AGR-5/6/7 Fuel Specification (Marshal 2017), exposed kernel defects and SiC defects are treated as TRISO particle attribute properties, and statistical sampling is used for acceptance testing. While the hyperbolic distribution more accurately describes sampling without replacement, which is the case for destructive analyses like LBL, the binomial distribution is a sufficient approximation if the total number of particles in the sampled population is much greater than the sampled number (Einerson 2005). The AGR program has adopted the cumulative distribution function of the binomial distribution as the primary statistical method to determine with $95 \%$ confidence if a population of particles has an EKF or SDF below a specified upper limit.

The probability that the number of defects observed in two independent samples indicate that a significant difference in the true defect fraction may be considered by constructing a stepwise approximation for each sample of the cumulative probability that the true defect fraction of the sampled population is less than a specific value over the range of all possible true defect fractions (i.e., $0-1$ ). This is done by calculating a series of one-sided confidence intervals based on the observation of $k$ defective particles in an analyzed sample of $n$ particles over a stepwise series of confidence values from $0-100 \%$, where each confidence interval represents the cumulative probability indicated by the associated sample that the true defect fraction in the sampled population is less than the interval's upper limit. Several methods for calculating binomial distribution confidence intervals from a single sample have been developed. The Wilson score interval with continuity correction has been compared to and recommended over other commonly used intervals, particularly for lots with very low defect fractions (Wilson 1927, Wallis 2013, Newcombe 1998, Brown and Cai 2001) and will be used herein. Cai (2005) has identified weaknesses when the score interval is applied to the approximation of one-sided intervals vs. two-sided intervals (as discussed in the other references), so it may be of value to consider other approaches to confirm or refine the method used for the comparisons in this report. However, the weaknesses identified by Cai are not likely to impact the comparisons made herein. The one-sided upper bound for the Wilson score interval with continuity correction is defined by Equation A-1, where $p=k / n$ is the measured defect fraction in the sample, and $z_{\alpha}$ is the value of the cumulative distribution function of the normal distribution for a given cumulative probability that the true defect fraction in the sampled population is less than $w^{+}$. The critical value $z_{\alpha}$ is the same value used to calculate the one-sided tolerance factor applied by the AGR program to tolerance interval acceptance testing for normal distributions of variable properties (Einerson 2005):

$$
w^{+} \equiv \min \left(0, \frac{2 n p+z_{\alpha}^{2}+z_{\alpha} \sqrt{4 n p(1-p)+z_{\alpha}^{2}-n^{-1}-4 p+2}+1}{2\left(n+z_{\alpha}^{2}\right)}\right) .
$$

For each sample selected for comparison, Microsoft Excel was used to construct an array for $w^{+}$over a stepwise series of confidence values from $0-100 \%$. A 10,000-element array of confidence values from $0.01-100 \%$ with a constant stepsize of $0.01 \%$ was generated, and $z_{\alpha}$ was calculated for each element 
using the NORM.S.INV function. For the confidence value of $100 \%, 1 \mathrm{E} 9$ was used to represent $z_{\alpha}=\infty$. The measured defect fraction for the sample, $p=k / n$, was used to calculate $w^{+}$for each value in the $z_{\alpha}$ array. The resultant $w^{+}$array was a stepwise approximation based on the measured sample of the cumulative probability that the true defect fraction of the sampled population was less than $w^{+}$over the range of all possible true defect fractions. The stepsize of the $w^{+}$array was not constant, but nevertheless, it covered the full range of possible values from $0-1$.

To compare the LBL analysis results of two samples, the $w^{+}$arrays for the two samples were used to estimate the probability that the true defect fraction indicated by Sample 2 was greater than that indicated by Sample 1 by more than a selected margin of $\Delta$. The selected margin was typically chosen to be equal to $20 \%$ of that specified in the AGR-5/6/7 Fuel Specification as the upper limit at $95 \%$ confidence, i.e., $\mathrm{EKF} \leq 5 \mathrm{E}-5$ or SDF $\leq 1 \mathrm{E}-4$. A margin less than this can be considered to result in an insignificant difference when the results of the two analyses are applied to determine if the measured population satisfies the specified limit.

The probability that the true defect fraction indicated by Sample 2 is greater than the true defect fraction indicated by Sample 1 by more than a specified margin of $\Delta$ is given by Eq. (A-2). The term $C\left(w_{1, i}^{+}\right)$is the confidence (probability) based on Sample 1 that the true defect fraction in the population is less than the $i^{\text {th }}$ element in the Sample $1 w^{+}$array. The difference between $C\left(w_{1, i}^{+}\right)$and the probability associated with the next lower element in the Sample $1 w^{+}$array, $C\left(w_{1, i-1}^{+}\right)$is the probability based on Sample 1 that the true defect fraction in the population is between $w_{1, i-1}^{+}$. and $w_{1, i}^{+}$. For the summation indices $i=$ 1 to $N$, where $N$ is the number of elements in the Sample $1 w^{+}$array, the set of multiplicands $\left[C\left(w_{1, i}^{+}\right)-C\left(w_{1, i-1}^{+}\right)\right]$in the summed product is a stepwise approximation based on Sample 1 of the probability for all possible true defect fractions from $0-1$ and sums to $100 \%$. The term $C\left(w_{2, m}^{+}\right)$is the probability based on Sample 2 that the true defect fraction is less than the lowest element in the Sample 2 $w^{+}$array that is greater than the $i^{t h}$ element in the Sample $1 w^{+}$array by a margin of at least $\Delta$. The multiplier $\left[1-C\left(w_{2, m}^{+}\right)\right]$is the complement of $C\left(w_{2, m}^{+}\right)$, or the probability based on Sample 2 that the true defect fraction is greater or equal to $w_{2, m}^{+}$.

$$
\begin{gathered}
\operatorname{Probability}(2>1+\Delta)=\sum_{i=1}^{N}\left\{\left[C\left(w_{1, i}^{+}\right)-C\left(w_{1, i-1}^{+}\right)\right] \times\left[1-C\left(w_{2, m}^{+}\right)\right]\right\}, \\
\text {where } w_{2, m}^{+}=\min \left[w_{2, j}^{+}>\left(w_{1, i}^{+}+\Delta\right)\right] \text { for } j=1 \text { to } N
\end{gathered}
$$

Equation (A-3) converts Probability $(2>1+\Delta)$ to a measure of the odds, which provides a more intuitive perception of certainty. A probability of $50 \%$ in Eq. (A-2) corresponds to odds of 1:1 that the true defect fraction indicated by Sample 2 is greater than the true defect fraction indicated by Sample 1 by more than the specified margin of $\Delta$. In this case, there are equal odds for the complement condition that Sample 2 is not greater than the true defect fraction indicated by Sample 1 by more than $\Delta$. Therefore, there is no certainty that one condition is more likely than the other. In contrast, a probability of $100 \%$ in Eq. (A-2) corresponds to infinite certainty that the true defect fraction indicated by Sample 2 is greater than the true defect fraction indicated by Sample 1 by more than the specified margin of $\Delta$.

$$
\operatorname{odds}(2>1+\Delta)=\frac{\text { Probability }(2>1+\Delta)}{1-\operatorname{Probability}(2>1+\Delta)}
$$


APPENDIX B. REPORT FORMS FOR OVERCOATED PARTICLE LBL 

Inspection Report Form IRF-C: Summary of Pre-burn Leach Uranium

\begin{tabular}{|r|l|}
\hline Procedure: & AGR-CHAR-DAM-21 Rev. 2 \\
\hline Operator: & Montgomery/Dyer/Helmreich \\
\hline Particle lot ID: & BWXT J52R-16-11034 \\
\hline Particle lot description: & AGR-5/6/7 over-coated particles, $40 \%$ packing fraction \\
\hline
\end{tabular}

\begin{tabular}{|r|c|c|c|c|c|}
\hline Particle clutch ID: & $11034-01$ & $11034-02$ & $11034-03$ & $11034-04$ & Total \\
\hline \hline Number of particles: & 17627 & 18614 & 17972 & 17826 & 72039 \\
\hline Equivalent number of leached kernels: & $9.0 \mathrm{E}-02$ & $9.6 \mathrm{E}-02$ & $9.2 \mathrm{E}-02$ & $9.7 \mathrm{E}-02$ & $3.7 \mathrm{E}-01$ \\
\hline
\end{tabular}

\section{Comments}

Data has been verified.

Tred c. Montgomery

$2-8-2018$

Operator

$\frac{2-8-2018}{\text { Date }}$




\begin{tabular}{|r|l|}
\hline Procedure: & AGR-CHAR-DAM-21 Rev. 2 \\
\hline Operator: & Montgomery \\
\hline Particle lot ID: & BWXT J52R-16-11035 \\
\hline Particle lot description: & AGR-5/6/7 overcoated particles, 40\% packing fraction \\
\hline
\end{tabular}

\begin{tabular}{|r|c|c|c|c|c|}
\hline Particle sample ID: & $11035-01$ & $11035-02$ & $11035-03$ & $11035-04$ & Total \\
\hline \hline Number of particles: & 17409 & 17368 & 17369 & 17378 & 69524 \\
\hline Equivalent number of leached kernels: & $8.8 \mathrm{E}-02$ & $8.6 \mathrm{E}-02$ & $8.6 \mathrm{E}-02$ & $8.5 \mathrm{E}-02$ & $3.5 \mathrm{E}-01$ \\
\hline
\end{tabular}

Fred C. Montgomens

Operator
$4-18-2019$

Date 
Inspection Report Form IRF-C: Summary of Pre-burn Leach Uranium

Procedure: AGR-CHAR-DAM-21 Rev. 2

Operator: Montgomery

Particle lot ID: BWXT J52R-16-11035

Particle lot description: AGR-5/6/7 overcoated particles, $40 \%$ packing fraction

\begin{tabular}{|r|c|c|c|c|c|}
\hline Particle sample ID: & $11035-05$ & $11035-06$ & $11035-07$ & $11035-08$ & Total \\
\hline \hline Number of particles: & 17389 & 17364 & 17395 & 17371 & 69519 \\
\hline Equivalent number of leached kernels: & $8.9 \mathrm{E}-02$ & $8.4 \mathrm{E}-02$ & $9.2 \mathrm{E}-02$ & $9.0 \mathrm{E}-02$ & $3.6 \mathrm{E}-01$ \\
\hline
\end{tabular}

Comments

Fied C, montgrmevy

$4-18-2019$

Date 


\section{Inspection Report Form IRF-D: Summary of Post-Burn Leach Uranium}

\begin{tabular}{|r|l|}
\hline Procedure: & AGR-CHAR-DAM-21 Rev. 2 \\
\hline Operator: & Montgomery/Dyer/Helmreich \\
\hline Particle lot ID: & BWXT J52R-16-11034 \\
\hline Particle lot description: & AGR-5/6/7 over-coated particles, $40 \%$ packing fraction \\
\hline
\end{tabular}

\begin{tabular}{|r|c|c|c|c|c|}
\hline Particle clutch ID: & $11034-01$ & $11034-02$ & $11034-03$ & $11034-04$ & Total \\
\hline \hline Number of particles: & 17627 & 18614 & 17972 & 17826 & 72039 \\
\hline Equivalent number of leached kernels: & $3.7 \mathrm{E}-03$ & $2.9 \mathrm{E}-03$ & $3.6 \mathrm{E}-03$ & $1.2 \mathrm{E}+00$ & $1.2 \mathrm{E}+00$ \\
\hline
\end{tabular}

\section{Comments}

Data has been verified.

\section{Fied C. montgomer Operator}

$2-8-2018$

\section{Date}


Inspection Report Form IRF-D: Summary of Post-Burn Leach Uranium

Procedure: AGR-CHAR-DAM-21 Rev. 2

Operator: Montgomery

Particle lot ID: BWXT J52R-16-11035

Particle lot description: AGR $-5 / 6 / 7$ overcoated particles, $40 \%$ packing fraction

\begin{tabular}{|r|c|c|c|c|c|}
\hline Particle sample ID: & $11035-01$ & $11035-02$ & $11035-03$ & $11035-04$ & Total \\
\hline \hline Number of particles: & 17409 & 17368 & 17369 & 17378 & 69524 \\
\hline Equivalent number of leached kernels: & $2.1 \mathrm{E}-03$ & $2.6 \mathrm{E}-03$ & $2.3 \mathrm{E}-03$ & $2.4 \mathrm{E}-03$ & $9.4 \mathrm{E}-03$ \\
\hline
\end{tabular}

Comments

Fied c. Montgomem

Date 
Procedure: AGR-CHAR-DAM-21 Rev. 2

Operator: Montgomery

Particle lot ID: BWXT J52R-16-11035

Particle lot description: AGR-5/6/7 overcoated particles, $40 \%$ packing fraction

\begin{tabular}{|r|c|c|c|c|c|}
\hline Particle sample ID: & $11035-05$ & $11035-06$ & $11035-07$ & $11035-08$ & Total \\
\hline \hline Number of particles: & 17389 & 17364 & 17395 & 17371 & 69519 \\
\hline Equivalent number of leached kernels: & $1.8 \mathrm{E}-03$ & $3.7 \mathrm{E}-03$ & $1.0 \mathrm{E}+00$ & $8.2 \mathrm{E}-03$ & $1.0 \mathrm{E}+00$ \\
\hline
\end{tabular}

Comments

7.ed c. Montgomery

Operator
$4-18-2019$

Date 
Data Report Form DRF-21A: Pre-Bum Leach Uranium and Impurities

\begin{tabular}{|c|c|}
\hline $\begin{array}{r}\text { Procedure: } \\
\text { Operator: } \\
\text { Particle lot ID: } \\
\text { Particle lot description: } \\
\text { Particle clutch ID: } \\
\end{array}$ & $\begin{array}{l}\text { AGR-CHAR-DAM-21 Rev. } 2 \\
\text { Montgomery/Dyer/Helm reich } \\
\text { BWXT J52R-16-11034 } \\
\text { AGR-5/6/7 over-coated particles, } 40 \% \text { packing fraction } \\
11034-01\end{array}$ \\
\hline DRF filename: & 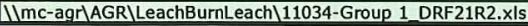 \\
\hline
\end{tabular}

\begin{tabular}{|r|c|}
\hline Average weight per particle, mean value (g): & $2.046 \mathrm{E}-03$ \\
\hline Average weight per particle, uncertainty in mean (g): & $1.27 \mathrm{E}-05$ \\
\hline Weight of particle clutch (g): & 36.0677 \\
\hline Approximate number of particles in clutch: & 17627 \\
\hline Uncertainty in number of particles: & 109 \\
\hline Average weight uranium per particle, mean value $(\mathrm{g}):$ & $3.94 \mathrm{~g}-04$ \\
\hline Average weight uranium per particle, uncertainty in mean $(\mathrm{g}):$ & $3.94 \mathrm{E}-06$ \\
\hline
\end{tabular}

\begin{tabular}{|c|c|c|c|c|}
\hline & & & \\
\hline & & First Leach & Second Leach & Total \\
\hline & $\begin{array}{r}\text { Pre-bum leach solution ID: } \\
\text { Total volume of leach solution (ml): }\end{array}$ & $\begin{array}{l}\text { L17091901 } \\
94.0\end{array}$ & $\frac{\mathrm{L} \text { L17092101 }}{103.5}$ & \\
\hline & . & & & \\
\hline & Radiochemical laboratory analysis number: & $17665-001$ & $17665-006$ & \\
\hline & Measured uranium concentration $(\mathrm{\mu g} / \mathrm{ml})$ : & $3.32 \mathrm{E}-01$ & $3.99 \mathrm{E}-02$ & \\
\hline & Uncertainty in uranium concentration $(\mathrm{\mu g} / \mathrm{ml})$ : & $3.32 \mathrm{E}-02$ & $3.99 \mathrm{E}-03$ & \\
\hline & $\begin{array}{l}\text { Weight uranium leached }(g): \\
\text { Uncertainty in wejight uranium leached ( }(0) \text { : }\end{array}$ & $\frac{3.12 \mathrm{E}-05}{3.05}$ & $4.13 E-06$ & $3.53 \mathrm{E}-05$ \\
\hline & $\begin{array}{l}\text { Uncertainty in weight uranium leached (g): } \\
\text { Equivalent number of leached kemels: }\end{array}$ & $\frac{3.13 \mathrm{E}-06}{7.92 \mathrm{E}-02}$ & $4.14 \mathrm{E}-07$ & $3.16 \mathrm{E}-06$ \\
\hline & Uncertainty in equivalent number of leached kemels: & $\frac{1.92 \mathrm{E}-02}{7.98 \mathrm{E}-03}$ & $\frac{1.05-02}{1.06 E-03}$ & $\frac{8.97-02}{8.06 E-03}$ \\
\hline \multirow{5}{*}{$\mathrm{Fe}$} & & & & \\
\hline & $\begin{array}{l}\text { Measured concentration of impurity in sample }(\mu \mathrm{g} / \mathrm{ml}) \text { : } \\
\text { Uncorrected weight of impurity in sample }(\mu \mathrm{g}) \text { : }\end{array}$ & & & $\mathrm{Fe}$ \\
\hline & $\begin{array}{r}\text { Weight of impurity in blank }(\mu g) \text { : } \\
\end{array}$ & & & \\
\hline & Minimum corrected weight of impurity in sample $(\mu \mathrm{gg})$ : & & & \\
\hline & Maximum corrected weight of impurity in sample $(\mu \mathrm{g})$ : & & & \\
\hline \multirow{4}{*}{ Cr } & Measured concentration of impurity in sample $(\mu \mathrm{g} / \mathrm{ml})$ : & & & $c_{r}$ \\
\hline & $\begin{array}{l}\text { Uncorrected weight of impurity in sample }(\mathrm{g}) \text { : } \\
\text { Weight of impurity in blank }(\mathrm{g}) \mathrm{S} \text { : }\end{array}$ & & & \\
\hline & Minimum corrected weight of impurity in sample $(\mu g)$ : & & & \\
\hline & Maximum corrected weight of impurity in sample $(\mu g)$ : & & & \\
\hline \multirow{5}{*}{ Mn } & Measured concentration of impurity in sample $(\mu \mathrm{g} / \mathrm{ml})$ : & & & Mn \\
\hline & Uncorrected weight of impurity in sample $(\mu \mathrm{g})$ : & & & \\
\hline & Weight of impurity in blank $(\mu \mathrm{g})$ : & & & \\
\hline & Minimum corrected weight of impurity in sample $(\mu g)$ : & & & \\
\hline & Maximum corrected weight of impurity in sample $(\mu g)$ : & & & \\
\hline \multirow{5}{*}{ co } & Measured concentration of impurity in sample $(\mathrm{\mu g} / \mathrm{ml})$ : & & & co \\
\hline & Uncorrected weight of impurity in sample $(\mu g)$ : & & & \\
\hline & & & & \\
\hline & Minimum corrected weight of impurity in sample $(\mu g)$ : & & & \\
\hline & Maximum corrected weight of impurity in sample $(\mu g)$ : & & & \\
\hline \multirow{4}{*}{$\mathrm{Ni}$} & Measured concentration of impurity in sample $(\mu \mathrm{g} / \mathrm{ml})$ : & & & $\mathbf{N i}$ \\
\hline & Uncorrected weight of impurity in sample $(\mu g)$ : & & & \\
\hline & Minimum corrected weight of impurity in sample $(\mu g)$ : & & & \\
\hline & Maximum corrected weight of impurity in sample $(\mu \mathrm{g})$ : & & & \\
\hline \multirow{4}{*}{ са } & Measured concentration of impurity in sample $(\mu \mathrm{g} / \mathrm{ml})$ : & & & $\mathrm{Ca}$ \\
\hline & Uncorrected weight of impurity in sample $(\mathrm{Hg})$ : & & & \\
\hline & Minimum corrected weight of impurity in sample $(\mu g)$ : & & & \\
\hline & Maximum corrected weight of impurity in sample $(\mu g)$ : & & & \\
\hline \multirow{4}{*}{ Al } & Measured concentration of impurity in sample $(\mu \mathrm{g} / \mathrm{ml})$ : & & & Al \\
\hline & Uncorrected weight of impurity in sample $(\mu \mathrm{\mu})$ : & & & \\
\hline & 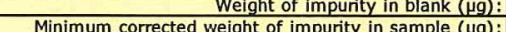 & & & \\
\hline & & & & \\
\hline \multirow{5}{*}{$\mathbf{T i}$} & Measured concentration of impurity in sample $(\mathrm{\mu g} / \mathrm{ml})$ : & & & $\mathbf{T i}$ \\
\hline & Uncorrected weight of impurity in sample & & & \\
\hline & Weight of impurity in blank $(\mu g)$ : & & & \\
\hline & ht of impurity in sample & & & \\
\hline & Maximum corrected weight of impurity in sample $(\mu q)$ : & & & \\
\hline \multirow{4}{*}{ v } & Measured concentration of impurity in sample $(\mathrm{\mu g} / \mathrm{ml})$ : & & & $\mathbf{v}$ \\
\hline & Incorrected weight of impurity in sample $(\mu \mathrm{g})$ : & & & \\
\hline & $\begin{array}{l}\text { Weight of impunty in blank }(g) \text { : } \\
\text { Minimum corrected weight of impurity in sample }(\mu g) \text { : }\end{array}$ & & & \\
\hline & Maximum corrected weight of impurity in sample $(\mathrm{Hg})$ : & & & \\
\hline
\end{tabular}

FCM checked the data against the Official Results of Analyses for RMAL17665 on 2/5/2018.

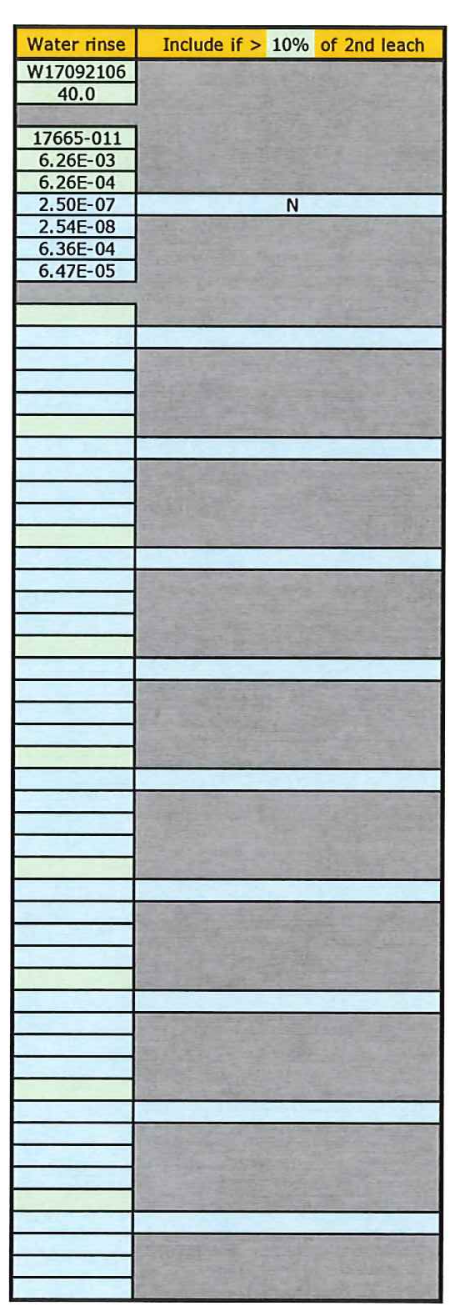

\section{Fied C. Montgomeyy $\frac{2-8-2018}{\text { Date }}$}


Data Report Form DRF-21A: Pre-Bum Leach Uranium and Impurities

\begin{tabular}{|c|c|}
\hline \begin{tabular}{r|} 
Procedure: \\
Operator:
\end{tabular} & \begin{tabular}{|l|} 
AGR-CHAR-DAM-21 Rev. 2 \\
Montgomery/Dyer/Helmreich
\end{tabular} \\
\hline Particle lot ID: & BWXT J52R-16-11034 \\
\hline Particle lot description: & AGR- $5 / 6 / 7$ over-coated particles, $40 \%$ packing fraction \\
\hline Particle clutch ID: & $11034-02$ \\
\hline DRF filename: & |Imc-agr|AGR\LeachBurnLeach|11034-Group 1 DRF21R2.xls \\
\hline
\end{tabular}

\begin{tabular}{|r|c|}
\hline Average weight per particle, mean value $(\mathrm{g}):$ & $2.05 \mathrm{E}-03$ \\
\hline Average weight per particle, uncertainty in mean $(\mathrm{g}):$ & $1.27 \mathrm{E}-05$ \\
\hline Weight of particle clutch $(\mathrm{g}):$ & 38.0877 \\
\hline Approximate number of particles in clutch: & 18614 \\
\hline Uncertainty in number of particles: & 115 \\
\hline Average weight uranium per particle, mean value $(\mathrm{g}):$ & $3.94 \mathrm{E}-04$ \\
\hline Average weight uranium per particle, uncertainty in mean $(\mathrm{g}):$ & $3.94 \mathrm{E}-06$ \\
\hline
\end{tabular}

\begin{tabular}{|c|c|c|c|c|}
\hline & First Leach & Second Leach & Total \\
\hline & Pre-bum leach solution ID: & L17091902 & L17092102 & \\
\hline & Total volume of leach solution $(\mathrm{ml})$ : & 83.0 & 105.0 & \\
\hline & Radiochemical laboratory analysis number: & $17665-002$ & $17665-007$ & \\
\hline & Measured uranium concentration $(\mu \mathrm{g} / \mathrm{ml})$ : & $3.81 \mathrm{E}-01$ & $\frac{1005 \mathrm{E}-02}{6}$ & \\
\hline & Uncertainty in uranium concentration $(\mu \mathrm{g} / \mathrm{ml})$ : & $3.81 \mathrm{E}-02$ & $6.05 \mathrm{E}-03$ & \\
\hline & Weight uranium leached $(g)$ : & $3.16 \mathrm{E}-05$ & $6.35 \mathrm{E}-06$ & $3.80 \mathrm{E}-05$ \\
\hline & Uncertainty in weight uranium leached $(\mathrm{g})$ : & $3.17 \mathrm{E}-06$ & $6.36 \mathrm{E}-07$ & $3.24 \mathrm{E}-06$ \\
\hline & Equivalent number of leached kemels: & $8.03 \mathrm{E}-02$ & $1.61 \mathrm{E}-02$ & $9.64 \mathrm{E}-02$ \\
\hline & Uncertainty in equivalent number of leached kernels: & $8.09 \mathrm{E}-03$ & $1.62 \mathrm{E}-03$ & $8.27 \mathrm{E}-03$ \\
\hline \multirow{5}{*}{$\mathbf{F e}$} & Measured concentration of impurity in sample $(\mu \mathrm{g} / \mathrm{ml})$ : & & & $\mathbf{F e}$ \\
\hline & Uncorrected weight of impurity in sample $(\mu g)$ : & & & \\
\hline & Weight of impurity in blank $(\mu g)$ : & & & \\
\hline & Minimum corrected weight of impurity in sample $(\mu g)$ : & & & \\
\hline & Maximum corrected weight of impurity in sample $(\mu \mathrm{g})$ : & & & \\
\hline \multirow{5}{*}{$\mathbf{C r}$} & Measured concentration of impurity in sample $(\mu \mathrm{g} / \mathrm{ml})$ : & & & $\mathrm{Cr}$ \\
\hline & Uncorrected weight of impurity in sample $(\mu g)$ : & & & \\
\hline & Weight of impurity in blank $(\mu \mathrm{g})$ : & & & \\
\hline & Minimum corrected weight of impurity in sample $(\mu g)$ : & & & \\
\hline & Maximum corrected weight of impurity in sample $(\mu g)$ : & & & \\
\hline \multirow{5}{*}{ Mn } & Measured concentration of impurity in sample $(\mu \mathrm{g} / \mathrm{ml})$ : & & & Mn \\
\hline & Uncorrected weight of impurity in sample $(\mu g)$ : & & & \\
\hline & Weight of impurity in blank $(\mu g)$ : & & & \\
\hline & Minimum corrected weight of impurity in sample $(\mu g)$ : & & & \\
\hline & Maximum corrected weight of impurity in sample $(\mu g)$ : & & & \\
\hline \multirow{5}{*}{ Co } & Measured concentration of impurity in sample $(\mu \mathrm{g} / \mathrm{ml})$ : & & & Co \\
\hline & Uncorrected weight of impurity in sample $(\mu \mathrm{g})$ : & & & \\
\hline & Weight of impurity in blank $(\mu g)$ : & & & \\
\hline & Minimum corrected weight of impurity in sample $(\mu \mathrm{g})$ : & & & \\
\hline & Maximum corrected weight of impurity in sample $(\mu g)$ : & & & \\
\hline \multirow{5}{*}{$\mathbf{N i}$} & Measured concentration of impurity in sample $(\mu \mathrm{g} / \mathrm{ml})$ : & & & $\mathrm{Ni}$ \\
\hline & Uncorrected weight of impurity in sample $(\mu \mathrm{g})$ : & & & \\
\hline & Weight of impurity in blank $(\mu \mathrm{g})$ : & & & \\
\hline & Minimum corrected weight of impurity in sample $(\mu g)$ : & & & \\
\hline & Maximum corrected weight of impurity in sample $(\mu \mathrm{g})$ : & & & \\
\hline \multirow{5}{*}{$\mathbf{C a}$} & Measured concentration of impurity in sample $(\mu \mathrm{g} / \mathrm{ml})$ : & & & $\mathbf{C a}$ \\
\hline & Uncorrected weight of impurity in sample $(\mu g)$ : & & & \\
\hline & Weight of impurity in blank $(\mu g)$ : & & & \\
\hline & Minimum corrected weight of impurity in sample $(\mu g)$ : & & & \\
\hline & Maximum corrected weight of impurity in sample $(\mu \mathrm{g})$ : & & & \\
\hline \multirow{5}{*}{ Al } & Measured concentration of impurity in sample $(\mu \mathrm{g} / \mathrm{ml})$ : & & & Al \\
\hline & Uncorrected weight of impurity in sample $(\mu \mathrm{g})$ : & & & \\
\hline & Weight of impurity in blank $(\mu \mathrm{g})$ : & & & \\
\hline & Minimum corrected weight of impurity in sample $(\mu g)$ : & & & \\
\hline & Maximum corrected weight of impurity in sample $(\mu g)$ : & & & \\
\hline \multirow{5}{*}{$\mathbf{T i}$} & Measured concentration of impurity in sample $(\mu \mathrm{g} / \mathrm{ml})$ : & & & Ti \\
\hline & Uncorrected weight of impurity in sample $(\mu \mathrm{g})$ : & & & \\
\hline & Weight of impurity in blank $(\mu g)$ : & & & \\
\hline & Minimum corrected weight of impurity in sample $(\mu g)$ : & & & \\
\hline & Maximum corrected weight of impurity in sample $(\mu g)$ : & & & \\
\hline \multirow{5}{*}{$\mathbf{v}$} & Measured concentration of impurity in sample $(\mu \mathrm{g} / \mathrm{ml})$ : & & & $\mathbf{v}$ \\
\hline & Uncorrected weight of impurity in sample $(\mu \mathrm{g})$ : & & & \\
\hline & Weight of impurity in blank $(\mu \mathrm{g})$ : & & & \\
\hline & Minimum corrected weight of impurity in sample $(\mu g)$ : & & & \\
\hline & Maximum corrected weight of impurity in sample $(\mu \mathrm{g})$ : & & & \\
\hline
\end{tabular}

FCM checked the data against the Official Results of Analyses for RMAL17665 on 2/5/2018.

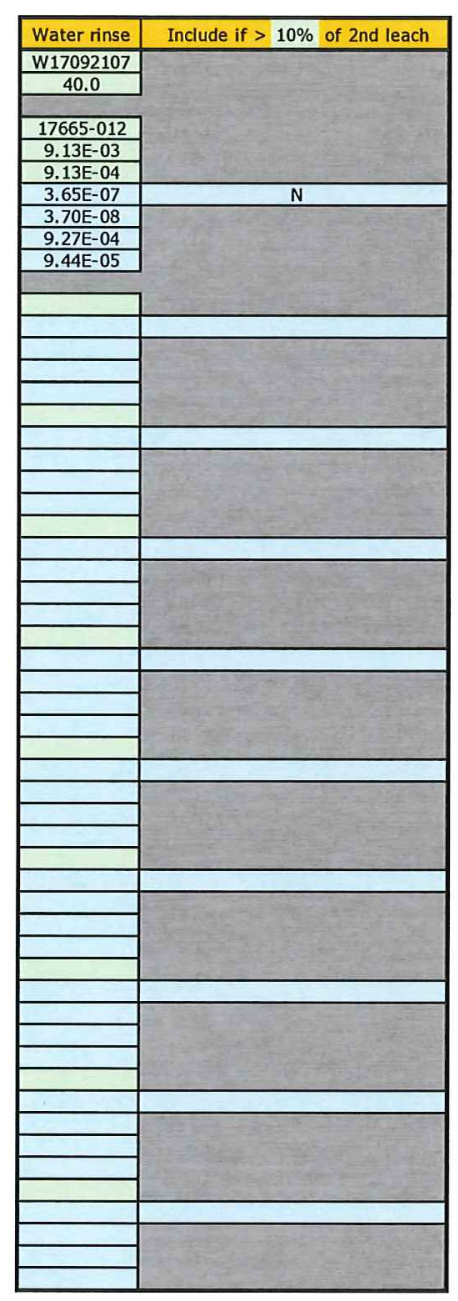


Data Report Form DRF-21A: Pre-Bum Leach Uranium and Impurities

\begin{tabular}{|r|l|}
\hline Procedure: & AGR-CHAR-DAM-21 Rev. 2 \\
\hline Operator: & Montgomery/Dyer/Helmreich \\
\hline Particle lot ID: & BWXT J52R-16-11034 \\
\hline Particle lot description: & AGR-5/6/7 over-coated particles, 40\% packing fraction \\
\hline Particle clutch ID: & $11034-03$ \\
\hline DRF filename: & IIImC-agr/AGRILeachBurnLeach111034-Group 1_DRF21R2.xls \\
\hline
\end{tabular}

\begin{tabular}{|r|c|}
\hline Average weight per particle, mean value $(\mathrm{g}):$ & $2.05 \mathrm{E}-03$ \\
\hline Average weight per particle, uncertainty in mean $(\mathrm{g}):$ & $1.27 \mathrm{E}-05$ \\
\hline Weight of particle clutch $(\mathrm{g}):$ & 36.7740 \\
\hline Approximate number of particles in clutch: & 17972 \\
\hline Uncertainty in number of particles: & 111 \\
\hline Average weight uranium per particle, mean value $(\mathrm{g}):$ & $3.94 \mathrm{E}-04$ \\
\hline Average weight uranium per particle, uncertainty in mean $(\mathrm{g}):$ & $3.94 \mathrm{E}-06$ \\
\hline
\end{tabular}

\begin{tabular}{|c|c|c|c|c|}
\hline & First Leach & Second Leach & Total \\
\hline & Pre-bum leach solution ID: & L17091903 & L17092103 & \\
\hline & Total volume of leach solution $(\mathrm{ml})$ : & 92.0 & 87.5 & \\
\hline & Radiochemical laboratory analysis number: & $17665-003$ & $17665-008$ & \\
\hline & Measured uranium concentration $(\mu \mathrm{g} / \mathrm{ml})$ : & $3.45 \mathrm{E}-01$ & $4.96 \mathrm{E}-02$ & \\
\hline & Uncertainty in uranium concentration $(\mu \mathrm{g} / \mathrm{ml})$ : & $3.45 \mathrm{E}-02$ & $4.96 \mathrm{E}-03$ & \\
\hline & Weight uranium leached $(\mathrm{g})$ : & $3.17 \mathrm{E}-05$ & $4.34 \mathrm{E}-06$ & $3.61 \mathrm{E}-05$ \\
\hline & Uncertainty in weight uranium leached $(\mathrm{g})$ : & $3.18 \mathrm{E}-06$ & $4.35 \mathrm{E}-07$ & $3.21 \mathrm{E}-06$ \\
\hline & Equivalent number of leached kemels: & $8.06 \mathrm{E}-02$ & $1.10 \mathrm{E}-02$ & $9.16 \mathrm{E}-02$ \\
\hline & Uncertainty in equivalent number of leached kemels: & $8.12 \mathrm{E}-03$ & $1.11 \mathrm{E}-03$ & $8.20 \mathrm{E}-03$ \\
\hline \multirow{5}{*}{$\mathbf{F e}$} & Measured concentration of impurity in sample $(\mu \mathrm{g} / \mathrm{ml})$ : & & & $\mathbf{F e}$ \\
\hline & Uncorrected weight of impurity in sample $(\mu \mathrm{g})$ : & & & \\
\hline & Weight of impurity in blank $(\mu \mathrm{g})$ : & & & \\
\hline & Minimum corrected weight of impurity in sample $(\mu g)$ : & & & \\
\hline & Maximum corrected weight of impurity in sample $(\mu \mathrm{g})$ : & & & \\
\hline \multirow{5}{*}{$\mathrm{Cr}$} & Measured concentration of impurity in sample $(\mu \mathrm{g} / \mathrm{ml})$ : & & & Cr \\
\hline & Uncorrected weight of impurity in sample $(\mu \mathrm{g})$ : & & & \\
\hline & Weight of impurity in blank $(\mu g)$ : & & & \\
\hline & Minimum corrected weight of impurity in sample $(\mu \mathrm{g})$ : & & & \\
\hline & Maximum corrected weight of impurity in sample ( $\mathrm{\mu g})$ : & & & \\
\hline \multirow{5}{*}{ Mn } & Measured concentration of impurity in sample $(\mu \mathrm{g} / \mathrm{ml})$ : & & & Mn \\
\hline & Uncorrected weight of impurity in sample $(\mu g)$ : & & & \\
\hline & Weight of impurity in blank $(\mu \mathrm{g})$ : & & & \\
\hline & Minimum corrected weight of impurity in sample $(\mu \mathrm{g})$ : & & & \\
\hline & Maximum corrected weight of impurity in sample ( $\mathrm{\mu g})$ : & & & \\
\hline \multirow{5}{*}{ Co } & Measured concentration of impurity in sample $(\mu \mathrm{g} / \mathrm{ml})$ : & & & Co \\
\hline & Uncorrected weight of impurity in sample $(\mu \mathrm{g})$ : & & & \\
\hline & Weight of impurity in blank $(\mu g)$ : & & & \\
\hline & Minimum corrected weight of impurity in sample $(\mu \mathrm{\mu g})$ : & & & \\
\hline & Maximum corrected weight of impurity in sample $(\mu \mathrm{g})$ : & & & \\
\hline \multirow{5}{*}{$\mathrm{Ni}$} & Measured concentration of impurity in sample $(\mu \mathrm{g} / \mathrm{ml})$ : & & & $\mathrm{Ni}$ \\
\hline & Uncorrected weight of impurity in sample $(\mu g)$ : & & & \\
\hline & Weight of impurity in blank $(\mu \mathrm{g})$ : & & & \\
\hline & Minimum corrected weight of impurity in sample $(\mu \mathrm{g})$ : & & & \\
\hline & Maximum corrected weight of impurity in sample $(\mu g)$ : & & & \\
\hline \multirow{5}{*}{$\mathbf{C a}$} & Measured concentration of impurity in sample $(\mu \mathrm{g} / \mathrm{ml})$ : & & & $\mathbf{C a}$ \\
\hline & Uncorrected weight of impurity in sample $(\mu g)$ : & & & \\
\hline & Weight of impurity in blank $(\mu \mathrm{g})$ : & & & \\
\hline & Minimum corrected weight of impurity in sample $(\mu g)$ : & & & \\
\hline & Maximum corrected weight of impurity in sample $(\mu g)$ : & & & \\
\hline \multirow{5}{*}{ Al } & Measured concentration of impurity in sample $(\mu \mathrm{g} / \mathrm{ml})$ : & & & Al \\
\hline & Uncorrected weight of impurity in sample $(\mu g)$ : & & & \\
\hline & Weight of impurity in blank $(\mu \mathrm{g})$ : & & & \\
\hline & Minimum corrected weight of impurity in sample $(\mu \mathrm{g})$ : & & & \\
\hline & Maximum corrected weight of impurity in sample $(\mu g)$ : & & & \\
\hline \multirow{5}{*}{$\mathbf{T i}$} & Measured concentration of impurity in sample $(\mu \mathrm{g} / \mathrm{ml})$ : & & & $\overline{T i}$ \\
\hline & Uncorrected weight of impurity in sample $(\mu g)$ : & & & \\
\hline & Weight of impurity in blank $(\mu \mathrm{g})$ : & & & \\
\hline & Minimum corrected weight of impurity in sample $(\mu \mathrm{g})$ : & & & \\
\hline & Maximum corrected weight of impurity in sample $(\mu g)$ : & & & \\
\hline \multirow{5}{*}{$\mathbf{v}$} & Measured concentration of impurity in sample $(\mu \mathrm{g} / \mathrm{ml})$ : & & & $\mathbf{v}$ \\
\hline & Uncorrected weight of impurity in sample $(\mu g)$ : & & & \\
\hline & Weight of impurity in blank $(\mu \mathrm{g}):$ & & & \\
\hline & Minimum corrected weight of impurity in sample $(\mu \mathrm{g})$ : & & & \\
\hline & Maximum corrected weight of impurity in sample $(\mu g)$ : & & & \\
\hline
\end{tabular}

FCM checked the data against the Official Results of Analyses for RMAL17665 on 2/5/2018.

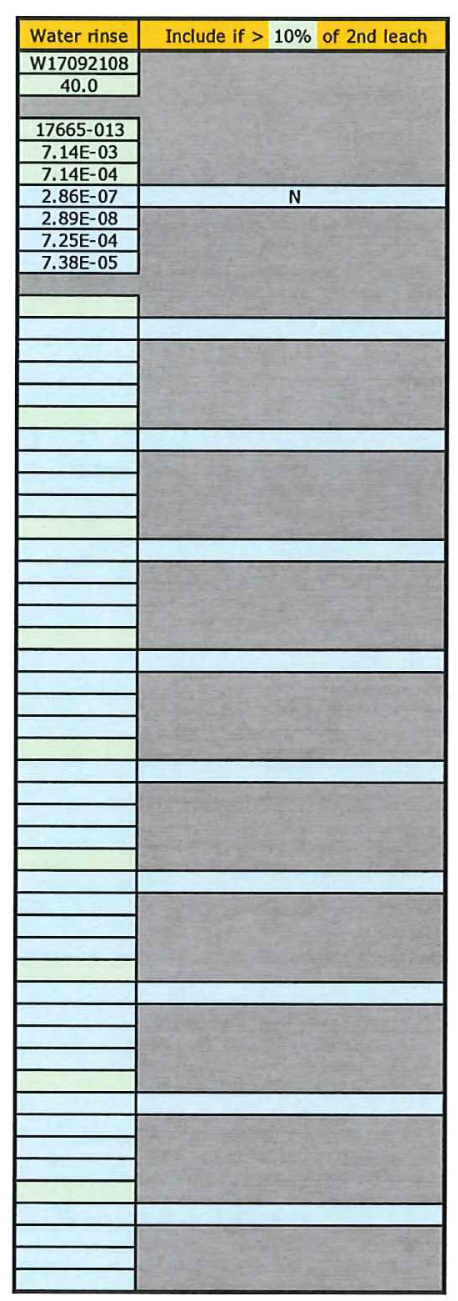
.

Feed c. Montgomeen

$2-8-2018$ 
Data Report Form DRF-21A:-Pre-Bum Leach Uranium and Impurities

\begin{tabular}{|r|l|}
\hline Procedure: & AGR-CHAR-DAM-21 Rev. 2 \\
\hline Operator: & Montgomery/Dyer/Helmreich \\
\hline Particle lot ID: & BWXT J52R-16-11034 \\
\hline Particle lot description: & AGR-5/6/7 over-coated particles, $40 \%$ packing fraction \\
\hline Particle clutch ID: & $11034-04$ \\
\hline DRF filename: & IIImC-agr|AGRILeachBurnLeachl11034-Group 1_DRF21R2.x/s \\
\hline
\end{tabular}

\begin{tabular}{|r|c|}
\hline Average weight per particle, mean value $(\mathrm{g}):$ & $2.05 \mathrm{E}-03$ \\
\hline Average weight per particle, uncertainty in mean $(\mathrm{g}):$ & $1.27 \mathrm{E}-05$ \\
\hline Weight of particle clutch $(\mathrm{g}):$ & 36.4763 \\
\hline Approximate number of particles in clutch: & 17826 \\
\hline Uncertainty in number of particles: & 110 \\
\hline Average weight uranium per particle, mean value $(\mathrm{g}):$ & $3.94 \mathrm{E}-04$ \\
\hline Average weight uranium per particle, uncertainty in mean $(\mathrm{g}):$ & $3.94 \mathrm{E}-06$ \\
\hline
\end{tabular}

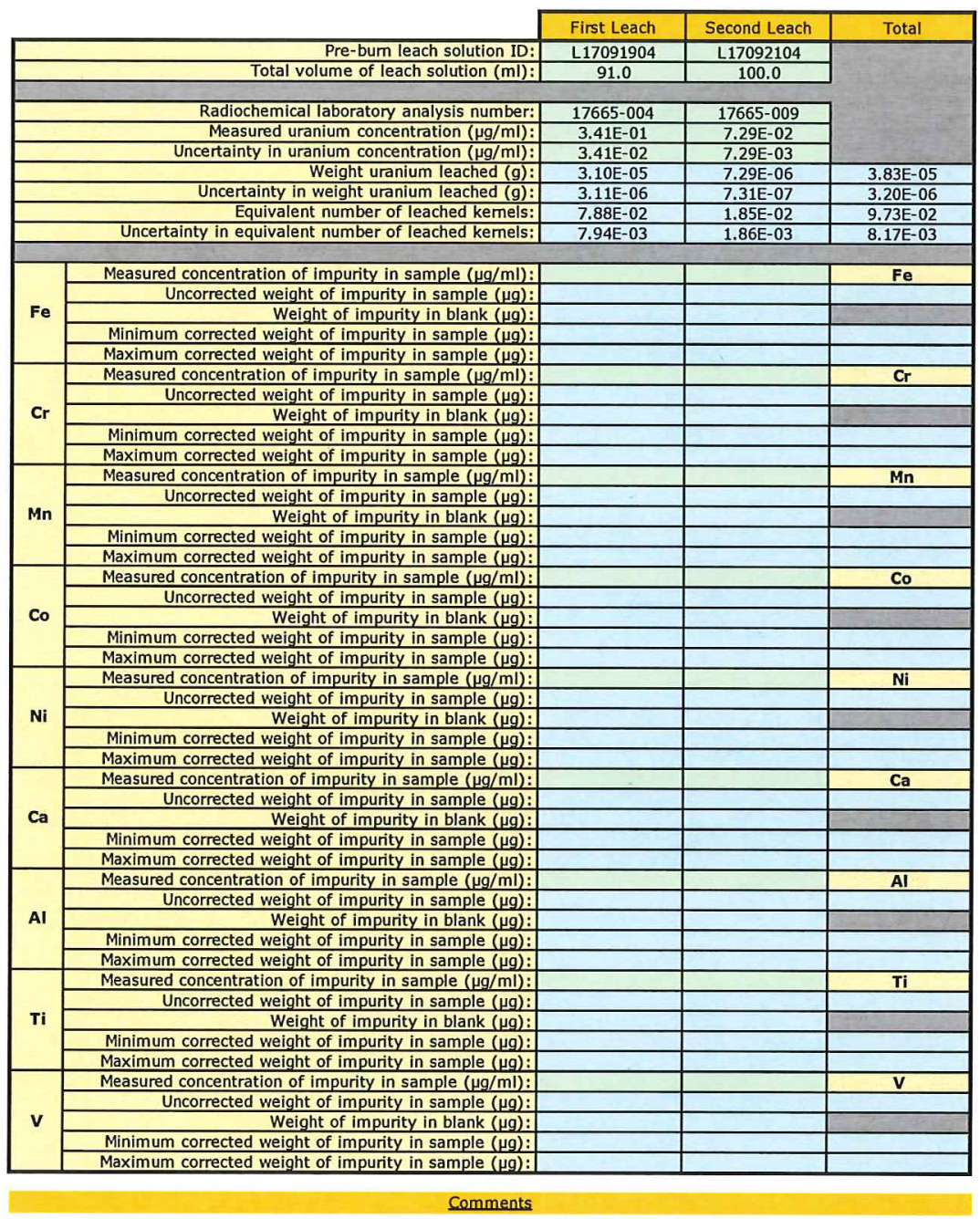

FCM checked the data against the Official Results of Analyses for RMAL17665 on 2/5/2018.

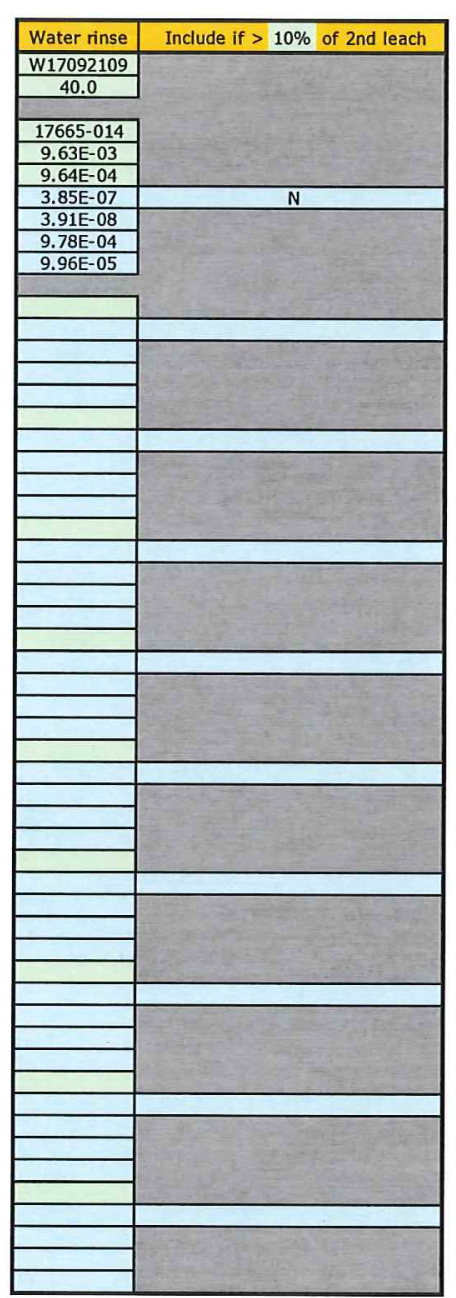

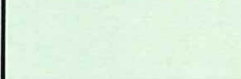

Ferd c. unontgomery $2-8-2018$ 
Data Report Form DRF-21A: Pre-Bum Leach Uranium and Impurities

\begin{tabular}{|c|c|}
\hline Procedure: & AGR-CHAR-DAM-21 Rev. 2 \\
\hline Operator: & Montgomery/Dyer/Helmreich \\
\hline Particle lot ID: & BWXT J52R-16-11034 \\
\hline Particle lot description: & AGR- $5 / 6 / 7$ over-coated particles, $40 \%$ packing fraction \\
\hline Particle clutch ID: & Pre-burn leach blank \\
\hline DRF filename: & IIImc-agr|AGRILeachBurnLeach|11034-Group 1 DRF21R2,xls \\
\hline
\end{tabular}

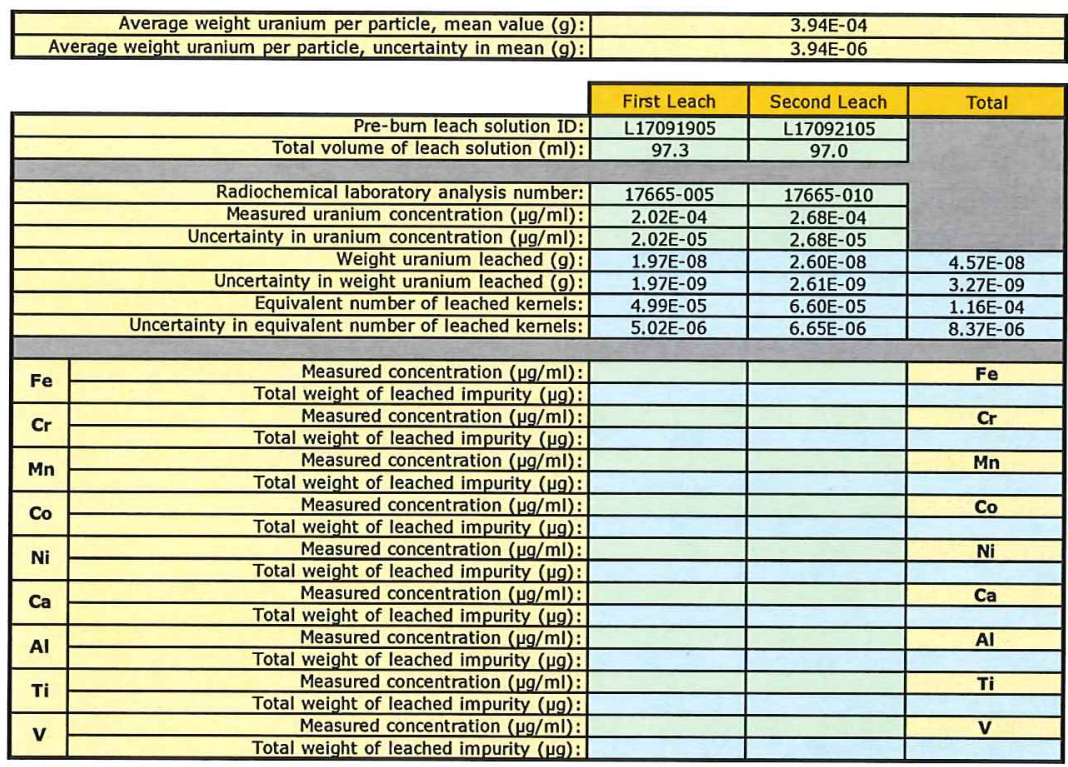

comments

FCM checked the data against the Official Results of Analyses for RMAL17665 on 2/5/2018.

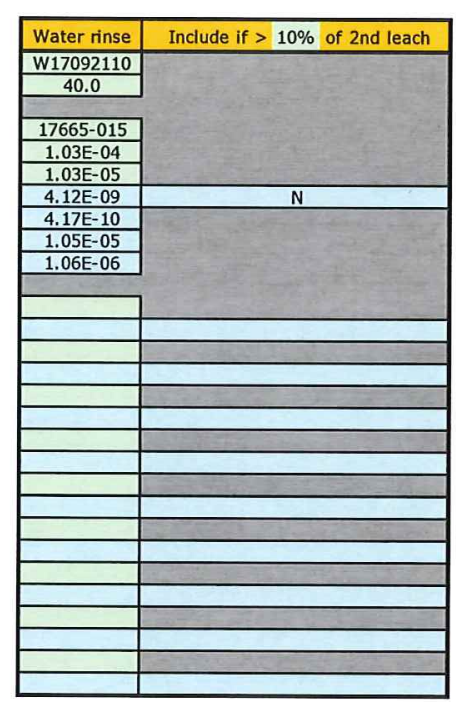

\section{Fied C. Mmtgomem $\quad \frac{2-8-2018}{\text { opeatar }}$}


Data Report Form DRF-21B: Post-Bum Leach Uranium and Impurities

\begin{tabular}{|r|l|}
\hline Procedure: & AGR-CHAR-DAM-21 Rev. 2 \\
\hline Operator: & Montgomery/Dyer/Helmreich \\
\hline Particle lot ID: & BWXT J52R-16-11034 \\
\hline Particle lot description: & AGR-5/6/7 over-coated particles, 40\% packing fraction \\
\hline Particle clutch ID: & $11034-01$ \\
\hline DRF filename: & IImc-agr)AGRILeachBurnLeachl11034-Group 1_DRF21R2.xIs \\
\hline
\end{tabular}

\begin{tabular}{|r|c|}
\hline Average weight per particle, mean value $(\mathrm{g}):$ & $2.046 \mathrm{E}-03$ \\
\hline Average weight per particle, uncertainty in mean $(\mathrm{g}):$ & $1.27 \mathrm{E}-05$ \\
\hline Weight of particle clutch $(\mathrm{g}):$ & 36.0677 \\
\hline Approximate number of particles in clutch: & 17627 \\
\hline Uncertainty in number of particles: & 109 \\
\hline Average weight uranium per particle, mean value $(\mathrm{g}):$ & $3.94 \mathrm{E}-04$ \\
\hline Average weight uranium per particle, uncertainty in mean $(\mathrm{g}):$ & $3.94 \mathrm{E}-06$ \\
\hline
\end{tabular}

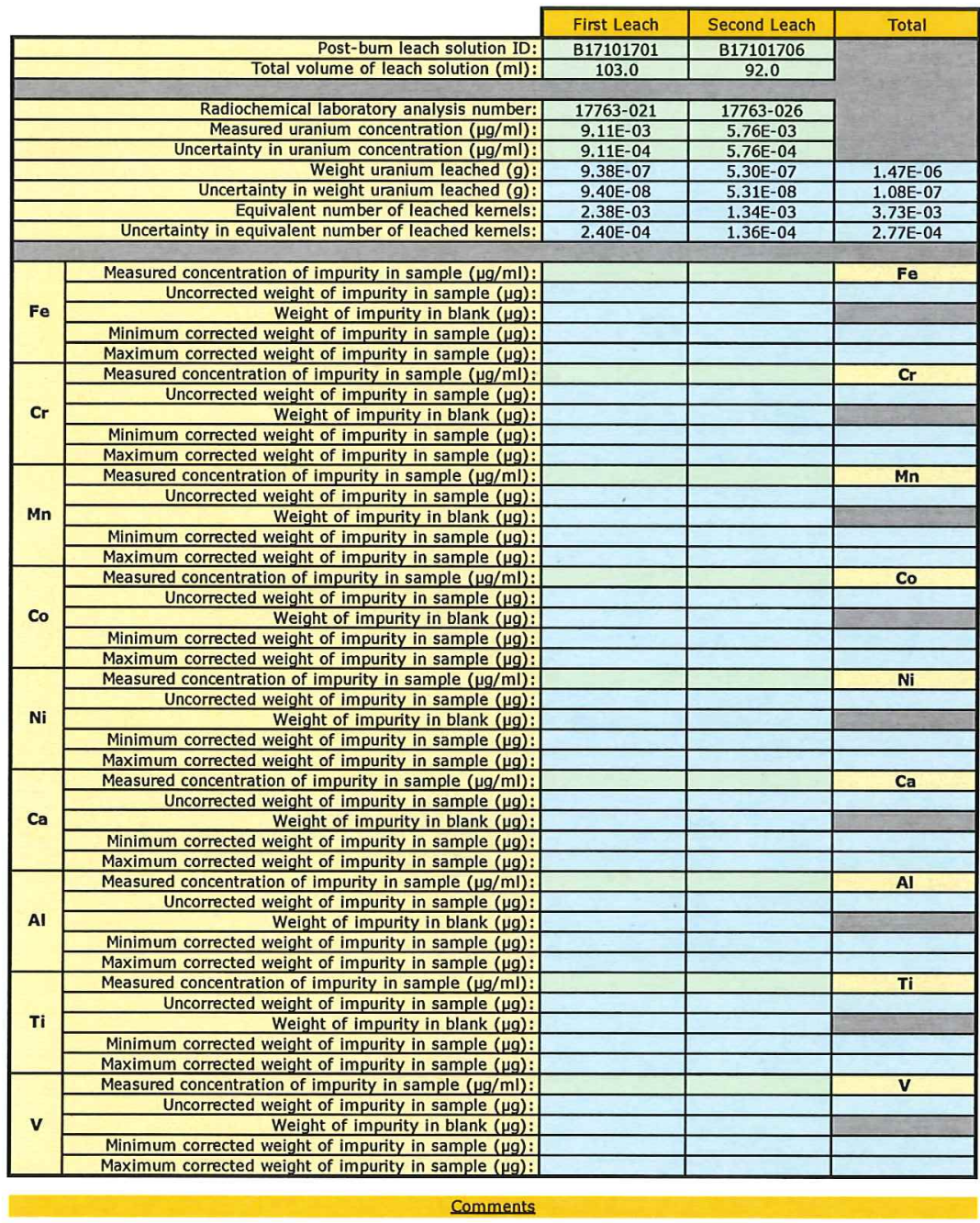

FCM checked the data against the Official Results of Analyses for RMAL17763 on 2/5/2018.

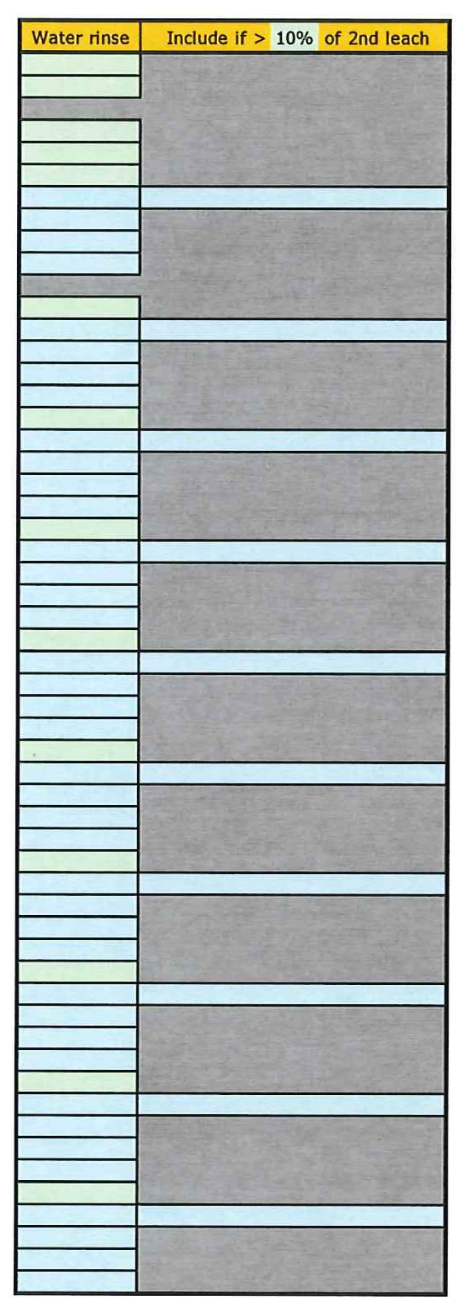

FCMchecked the data aganst the Officia Results of Analyses for RMAL17/63 on 2/5/2018.

7 teed c. Montgomey $\frac{2-8-2018}{\text { operare }}$ 
Data Report Form DRF-21B: Post-Bum Leach Uranium and Impurities

\begin{tabular}{|r|l|}
\hline Procedure: & AGR-CHAR-DAM-21 Rev. 2 \\
\hline Operator: & Montgomery/Dyer/Helmreich \\
\hline Particle lot ID: & BWXT J52R-16-11034 \\
\hline Particle lot description: & AGR-5/6/7 over-coated particles, 40\% packing fraction \\
\hline Particle clutch ID: & $11034-02$ \\
\hline DRF filename: & MIIC-agr)AGRILeachBurnLeachl11034-Group 1 DRF21R2.x/s \\
\hline
\end{tabular}

\begin{tabular}{|r|c|}
\hline Average weight per particle, mean value $(\mathrm{g}):$ & $2.046 \mathrm{E}-03$ \\
\hline Average weight per particle, & $1.27 \mathrm{E}-05$ \\
\hline Weight of painty in mean $(\mathrm{g}):$ & 36.0677 \\
\hline Approximate clutch $(\mathrm{g}):$ & 17627 \\
\hline Uncertainber of particles in clutch: & 109 \\
\hline Average weight uranium per particle, mean particles: & $3.94 \mathrm{E}-04$ \\
\hline Average weight uranium per particle, uncertainty in mean $(\mathrm{g}):$ & $3.94 \mathrm{~g}-06$ \\
\hline
\end{tabular}
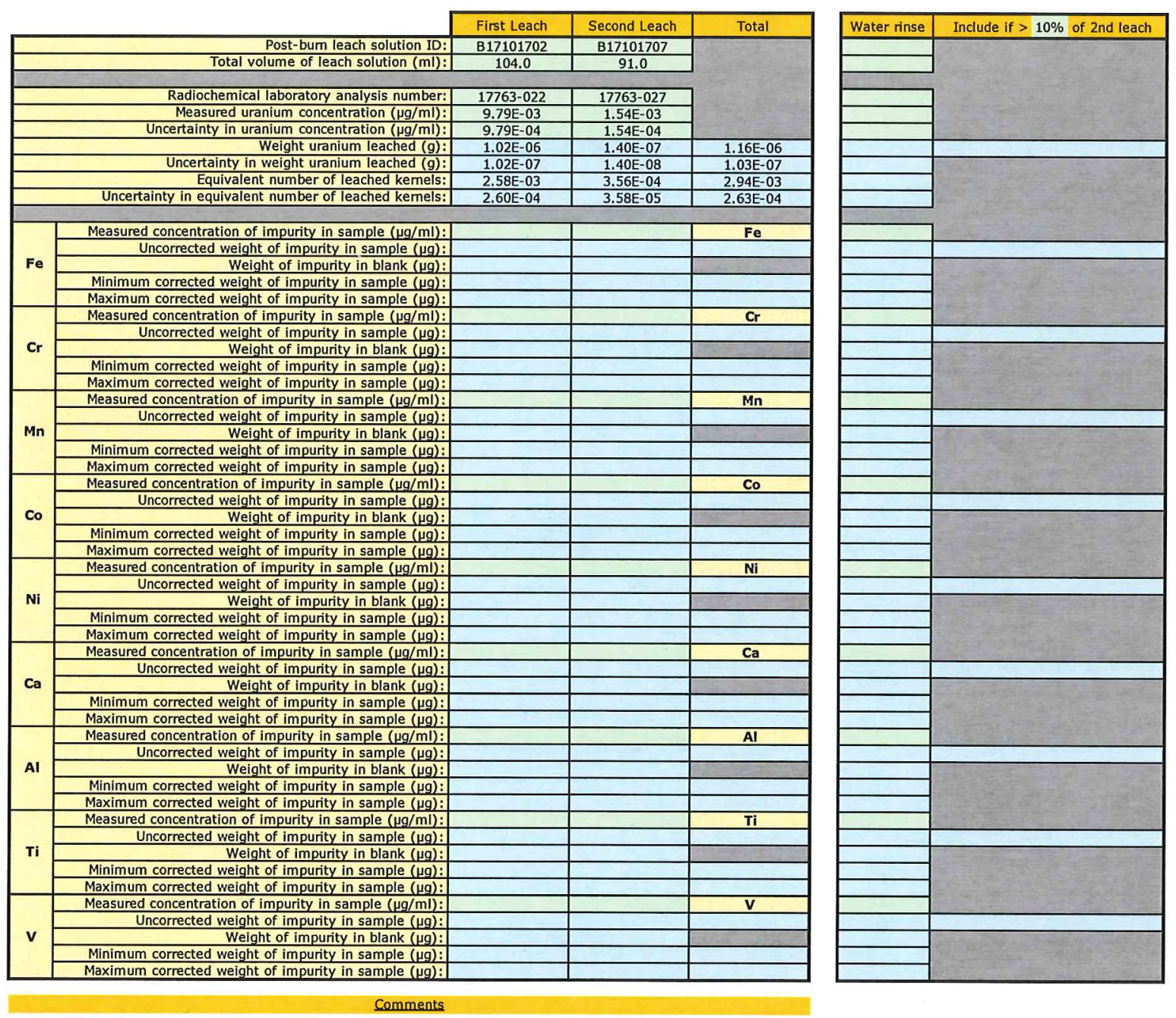

FCM checked the data against the Official Results of Analyses for RMAL17763 on 2/5/2018.

\section{Feed C. Montgomeny $\frac{2-8-2018}{\text { opentor }}$}


Data Report Form DRF-218: Post-Bum Leach Uranium and Impurities

\begin{tabular}{|r|l|}
\hline Procedure: & AGR-CHAR-DAM-21 Rev. 2 \\
\hline Operator: & Montgomery/Dyer/Helmreich \\
\hline Particle lot ID: & BWXT J52R-16-11034 \\
\hline Particle lot description: & AGR-5/6/7 over-coated particles, 40\% packing fraction \\
\hline Particle clutch ID: & $11034-03$ \\
\hline DRF filename: & IImc-agr|AGR/LeachBurnLeach।11034-Group 1 DRF21R2.xls \\
\hline
\end{tabular}

\begin{tabular}{|r|c|}
\hline Average weight per particle, mean value $(\mathrm{g}):$ & $2.046 \mathrm{E}-03$ \\
\hline Average weight per particle, uncertainty in mean $(\mathrm{g}):$ & $1.27 \mathrm{E}-05$ \\
\hline Weight of particle clutch $(\mathrm{g}):$ & 36.0677 \\
\hline Approximate number of particles in clutch: & 17627 \\
\hline Uncertainty in number of particles: & 109 \\
\hline Average weight uranium per particle, mean value $(\mathrm{g}):$ & $3.94 \mathrm{E}-04$ \\
\hline Average weight uranium per particle, uncertainty in mean $(\mathrm{g}):$ & $3.94 \mathrm{E}-06$ \\
\hline
\end{tabular}

\begin{tabular}{|c|c|c|c|c|}
\hline & First Leach & Second Leach & Total \\
\hline & Post-burn leach solution ID: & B17101703 & B17101708 & \\
\hline & Total volume of leach solution $(\mathrm{ml})$ : & 104.0 & 106.0 & \\
\hline & Radiochemical laboratory analysis number: & $17763-023$ & $17763-028$ & \\
\hline & Measured uranium concentration $(\mu \mathrm{g} / \mathrm{ml})$ : & $1.14 \mathrm{E}-02$ & $2.05 \mathrm{E}-03$ & \\
\hline & Uncertainty in uranium concentration $(\mu \mathrm{g} / \mathrm{ml})$ : & $1.14 \mathrm{E}-03$ & $2.05 \mathrm{E}-04$ & \\
\hline & Weight uranium leached $(\mathbf{g})$ : & $1.19 \mathrm{E}-06$ & $2.17 \mathrm{E}-07$ & $1.40 \mathrm{E}-06$ \\
\hline & Uncertainty in weight uranlum leached (g): & 1.19E-07 & $2.18 \mathrm{E}-08$ & $1.21 \mathrm{E}-07$ \\
\hline & Equivalent number of leached kemels: & $3.01 \mathrm{E}-03$ & $5.52 \mathrm{E}-04$ & $3.56 \mathrm{E}-03$ \\
\hline & Uncertainty in equivalent number of leached kemels: & $3.03 \mathrm{E}-04$ & $5.55 \mathrm{E}-05$ & $3.09 \mathrm{E}-04$ \\
\hline \multirow{5}{*}{$\mathbf{F e}$} & Measured concentration of impurity in sample $(\mu \mathrm{g} / \mathrm{ml})$ : & & & $\mathbf{F e}$ \\
\hline & Uncorrected weight of impurity in sample $(\mu \mathrm{g})$ : & & & \\
\hline & Weight of impurity in blank ( $\mu \mathrm{g})$ : & & & \\
\hline & Minimum corrected weight of impurity in sample $(\mu g)$ : & & & \\
\hline & Maximum corrected weight of impurity in sample $(\boldsymbol{\mu g})$ : & & & \\
\hline \multirow{5}{*}{$\mathbf{C r}$} & Measured concentration of impurity in sample $(\mu \mathrm{g} / \mathrm{ml})$ : & & & $\mathrm{Cr}_{\mathbf{r}}$ \\
\hline & Uncorrected weight of impurity in sample $(\mu g)$ : & & & \\
\hline & Weight of impurity in blank $(\mu \mathrm{g})$ : & & & \\
\hline & Minimum corrected weight of impurity in sample $(\mu \mathrm{g})$ : & & & \\
\hline & Maximum corrected weight of impurity in sample $(\mu \mathrm{g})$ : & & & \\
\hline \multirow{5}{*}{ Mn } & Measured concentration of impurity in sample $(\mu \mathrm{g} / \mathrm{m} / \mathrm{ml}$ : & & & $\mathrm{Mn}$ \\
\hline & Uncorrected weight of impurity in sample $(\mu \mathrm{g})$ : & & & \\
\hline & Weight of impurity in blank $(\mu g)$ : & & & \\
\hline & Minimum corrected weight of impurity in sample $(\mu \mathrm{g})$ : & & & \\
\hline & Maximum corrected weight of impurity in sample $(\mu \mathrm{g})$ : & & & \\
\hline \multirow{5}{*}{ co } & Measured concentration of impurity in sample $(\mathrm{\mu g} / \mathrm{ml})$ : & & & Co \\
\hline & Uncorrected weight of impurity in sample $(\mu \mathrm{g})$ : & & & \\
\hline & Weight of impurity in blank $(\mu \mathrm{g})$ : & & & \\
\hline & Minimum corrected weight of impurity in sample $(\mu \mathrm{g})$ : & & & \\
\hline & Maximum corrected weight of impurity in sample $(\mu \mathrm{g})$ : & & & \\
\hline \multirow{5}{*}{$\mathrm{Ni}$} & Measured concentration of impurity in sample $(\mathrm{\mu g} / \mathrm{ml})$ : & & & NII \\
\hline & Uncorrected weight of impurity in sample $(\mu \mathrm{g})$ : & & & \\
\hline & Weight of impurity in blank $(\mu \mathrm{g})$ : & & & \\
\hline & Minimum corrected weight of impurity in sample $(\mu \mathrm{g})$ : & & & \\
\hline & Maximum corrected weight of impurity in sample $(\mu \mathrm{g})$ : & & & \\
\hline \multirow{5}{*}{$\mathbf{C a}$} & Measured concentration of impurity in sample $(\mathrm{\mu g} / \mathrm{ml})$ : & & & $\mathbf{C a}$ \\
\hline & Uncorrected weight of impurity in sample $(\mu g)$ : & & & \\
\hline & Weight of impurity in blank $(\mu g)$ : & & & \\
\hline & Minimum corrected weight of impurity in sample $(\mu \mathrm{g})$ : & & & \\
\hline & Maximum corrected weight of impurity in sample $(\mu \mathrm{g})$ : & & & \\
\hline \multirow{5}{*}{ Al } & Measured concentration of impurity in sample $(\mu \mathrm{g} / \mathrm{ml})$ : & & & Al \\
\hline & Uncorrected weight of impurity in sample $(\mu g)$ : & & & \\
\hline & Weight of impurity in blank $(\mu \mathrm{g})$ : & & & \\
\hline & Minimum corrected weight of impurity in sample $(\mu \mathrm{g})$; & & & \\
\hline & Maximum corrected weight of impurity in sample $(\mu \mathrm{g})$ : & & & \\
\hline \multirow{5}{*}{$\mathbf{T i}$} & Measured concentration of impurity in sample $(\mu \mathrm{g} / \mathrm{ml})$ : & & & $\mathbf{T i}$ \\
\hline & Uncorrected weight of impurity in sample $(\mu \mathrm{g})$ : & & & \\
\hline & Weight of impurity in blank $(\mu \mathrm{g})$ : & & & \\
\hline & Minimum corrected weight of impurity in sample $(\mu g)$ : & & & \\
\hline & Maximum corrected weight of impurity in sample $(\mu \mathrm{g})$ : & & & \\
\hline \multirow{5}{*}{ v } & Measured concentration of impurity in sample $(\mathrm{\mu g} / \mathrm{ml})$ : & & & $\overline{\mathbf{v}}$ \\
\hline & Uncorrected weight of impurity in sample $(\mu \mathrm{g})$ : & & & \\
\hline & Weight of impurity in blank $(\mu \mathrm{g})$ : & & & \\
\hline & Minimum corrected weight of impurity in sample $(\mu \mathrm{gg})$ : & & & \\
\hline & Maximum corrected weight of impurity in sample $(\mu \mathrm{g})$ : & & & \\
\hline
\end{tabular}

comments

FCM checked the data against the Official Results of Analyses for RMAL17763 on 2/5/2018.

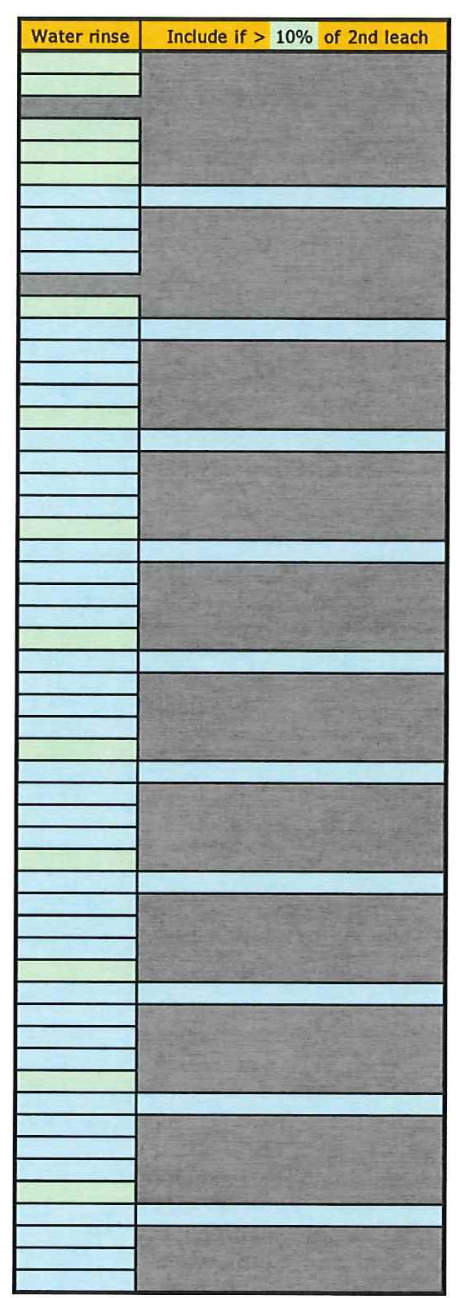

\section{Fred c. montgonney}

$2-8-2018$ 
Data Report Form DRF-218: Post-Bum Leach Uranium and Impurities

\begin{tabular}{|r|l|}
\hline Procedure: & AGR-CHAR-DAM-21 Rev. 2 \\
\hline Operator: & Montgomery/Dyer/Helmreich \\
\hline Particle lot ID: & BWXT J52R-16-11034 \\
\hline Particle lot description: & AGR-5/6/7 over-coated particles, $40 \%$ packing fraction \\
\hline Particle clutch ID: & $11034-04$ \\
\hline DRF filename: & IImC-agr|AGRILeachBurnLeach111034-Group 1_DRF21R2.xls \\
\hline
\end{tabular}

\begin{tabular}{|r|c|}
\hline Average weight per particle, mean value $(\mathrm{g}):$ & $2.046 \mathrm{E}-03$ \\
\hline Average weight per particle, uncertainty in mean $(\mathrm{g}):$ & $1.27 \mathrm{E}-05$ \\
\hline Weight of particle clutch $(\mathrm{g}):$ & 36.0677 \\
\hline Approximate number of particles in clutch: & 17627 \\
\hline Uncertainty in number of particles: & 109 \\
\hline Average weight uranium per particle, mean value $(\mathrm{g}):$ & $3.94 \mathrm{E}-04$ \\
\hline Average weight uranium per particle, uncertainty in mean $(\mathrm{g}):$ & $3.94 \mathrm{E}-06$ \\
\hline
\end{tabular}
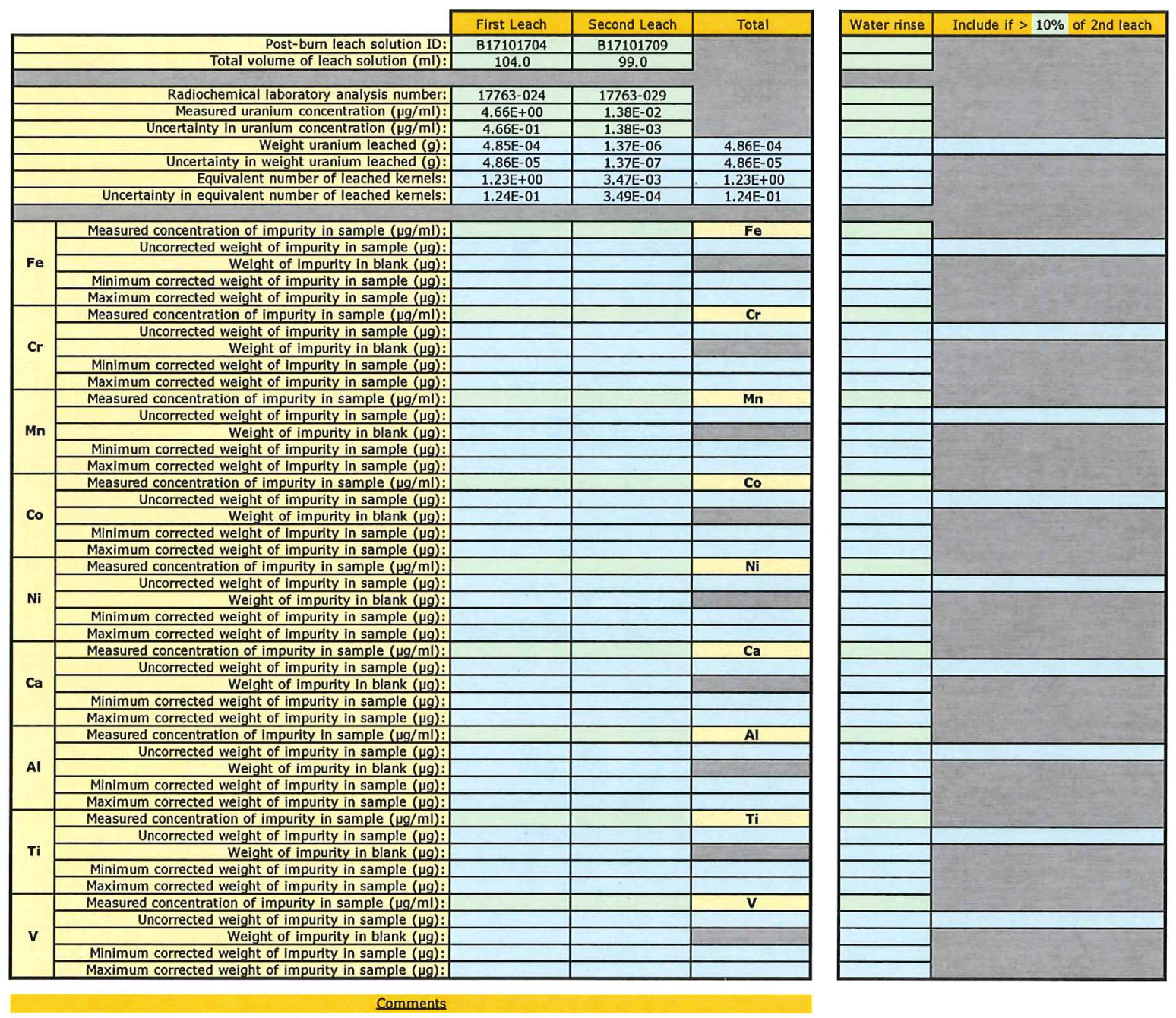

FCM checked the data against the Official Results of Analyses for RMAL17763 on 2/5/2018.

Fied C. Montgomeay $\frac{2-8-2018}{\text { openater }}$


Data Report Form DRF-21B: Post-Bum Leach Uranium and Impurities
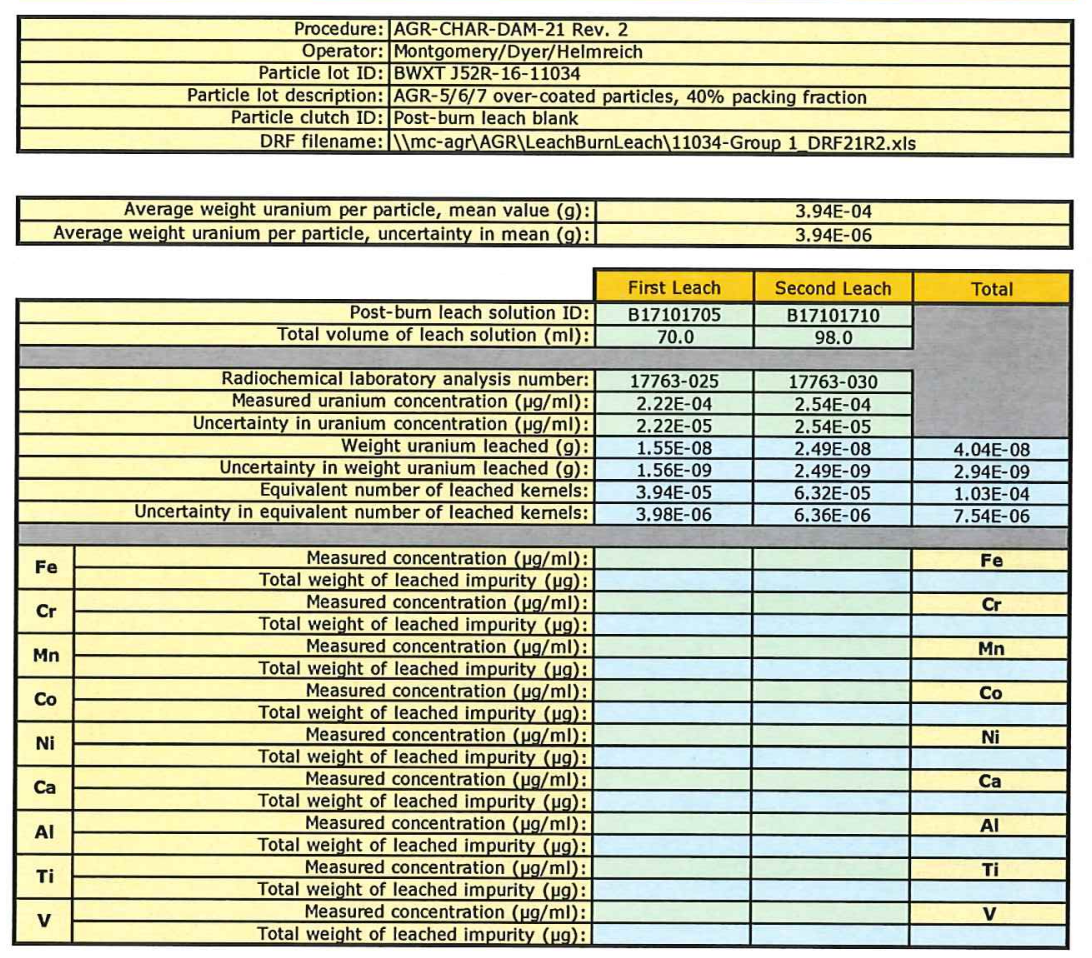

comments

FCM checked the data against the Official Results of Analyses for RMAL17763 on 2/5/2018.

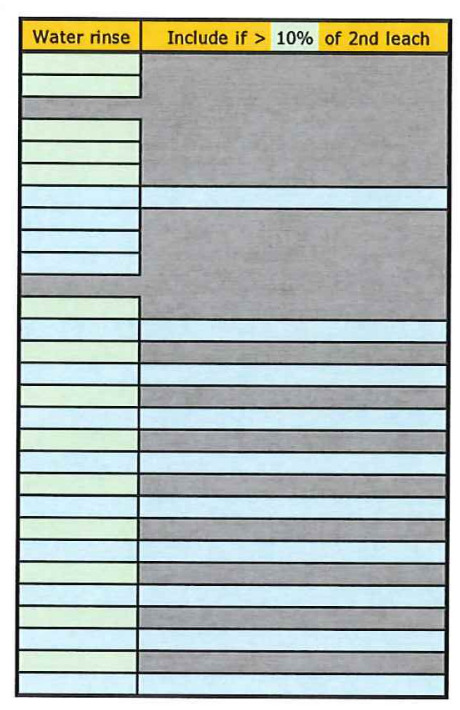

Feed C. Montgomemy $\frac{2-8-2018}{\text { openter }}$ 
Data Report Form DRF-21A: Pre-Burn Leach Uranium and Impurities

\begin{tabular}{|r|r|}
\hline Procedure: & AGR-CHAR-DAM-21 Rev. 2 \\
\hline Operator: & Montgomery \\
\hline Particle lot ID: & BWXT J52R-16-11035 \\
\hline Particle lot description: & AGR-5/6/7 overcoated particles, 40\% packing fraction \\
\hline Particle sample ID: & $11035-01$ \\
\hline DRF filename: & 11035 PF40 overcoated particles-Group 1_DLBL_ICPMS_DRF21R2.xIs \\
\hline
\end{tabular}

\begin{tabular}{|c|c|c|c|c|}
\hline \multicolumn{2}{|r|}{ Average weight per particle, mean value $(\mathrm{g})$ : } & \multicolumn{3}{|c|}{$2.010 \mathrm{E}-03$} \\
\hline & Average weight per particle, uncertainty in mean (g): & & $6.4 \mathrm{E}-06$ & \\
\hline & Weight of particle sample $(\mathrm{g})$ : & & 34.9930 & \\
\hline & Approximate number of particles in sample: & \multirow{2}{*}{\multicolumn{3}{|c|}{$\frac{17409}{55}$}} \\
\hline & Uncertainty in number of particles: & & & \\
\hline & Average weight uranium per particle, mean value $(\mathrm{g})$ : & \multirow{2}{*}{\multicolumn{3}{|c|}{$\begin{array}{l}3.94 \mathrm{E}-04 \\
3.94 \mathrm{E}-06\end{array}$}} \\
\hline \multicolumn{2}{|r|}{ Average weight uranium per particle, uncertainty in mean $(\mathrm{g})$ : } & & & \\
\hline & & First Leach & Second Leach & Total \\
\hline & Pre-burn leach solution ID: & L18121301 & L18121701 & \\
\hline & Total volume of leach solution $(\mathrm{ml})$ : & 112.0 & 133.0 & \\
\hline & RMAL analysis number: & $18947-001$ & $18947-005$ & \\
\hline & Measured uranium concentration $(\mu \mathrm{g} / \mathrm{ml})$ : & $2.93 \mathrm{E}-01$ & $1.38 \mathrm{E}-02$ & \\
\hline & Uncertainty in uranium concentration $(\mu \mathrm{g} / \mathrm{ml})$ : & $2.93 \mathrm{E}-02$ & $1.38 \mathrm{E}-03$ & \\
\hline & Weight uranium leached $(\mathrm{g})$ : & $3.28 \mathrm{E}-05$ & $1.84 \mathrm{E}-06$ & $3.47 E-05$ \\
\hline & Uncertainty in weight uranium leached $(\mathrm{g})$ : & $3.29 \mathrm{E}-06$ & $1.84 \mathrm{E}-07$ & $3.29 \mathrm{E}-06$ \\
\hline & Equivalent number of leached kernels: & $8.33 \mathrm{E}-02$ & $4.66 \mathrm{E}-03$ & $8.79 \mathrm{E}-02$ \\
\hline & Uncertainty in equivalent number of leached kernels: & $8.38 \mathrm{E}-03$ & $4.69 \mathrm{E}-04$ & $8.40 \mathrm{E}-03$ \\
\hline \multirow{5}{*}{$\mathbf{F e}$} & Measured concentration of impurity in sample $(\mu \mathrm{g} / \mathrm{ml})$ : & & & $\mathbf{F e}$ \\
\hline & Uncorrected weight of impurity in sample $(\mu \mathrm{g})$ : & & & \\
\hline & $\begin{array}{c}\text { Weight of impurity in blank }(\mu \mathrm{g}) \text { : } \\
\text {. }\end{array}$ & & & \\
\hline & Minimum corrected weight of impurity in sample $(\mu \mathrm{g})$ : & & & \\
\hline & Maximum corrected weight of impurity in sample $(\mu g)$ : & & & \\
\hline \multirow{5}{*}{$\mathbf{C r}$} & Measured concentration of impurity in sample $(\mu \mathrm{g} / \mathrm{ml})$ : & & & $\mathrm{Cr}$ \\
\hline & Uncorrected weight of impurity in sample $(\mu \mathrm{g})$ : & & & \\
\hline & Weight of impurity in blank $(\mu \mathrm{g})$ : & & & \\
\hline & Minimum corrected weight of impurity in sample $(\mu g)$ : & & & \\
\hline & Maximum corrected weight of impurity in sample $(\mu \mathrm{g})$ : & & & \\
\hline \multirow{5}{*}{ Mn } & Measured concentration of impurity in sample $(\mu \mathrm{g} / \mathrm{ml})$ : & & & Mn \\
\hline & Uncorrected weight of impurity in sample $(\mu g)$ : & & & \\
\hline & Weight of impurity in blank $(\mu g)$ : & & & \\
\hline & Minimum corrected weight of impurity in sample $(\mu \mathrm{g})$ : & & & \\
\hline & Maximum corrected weight of impurity in sample $(\mu \mathrm{g})$ : & & & \\
\hline \multirow{5}{*}{ Co } & Measured concentration of impurity in sample $(\mu \mathrm{g} / \mathrm{ml})$ : & & & Co \\
\hline & Uncorrected weight of impurity in sample $(\mu \mathrm{g})$ : & & & \\
\hline & Weight of impurity in blank $(\mu \mathrm{g})$ : & & & \\
\hline & Minimum corrected weight of impurity in sample $(\mu g)$ : & & & \\
\hline & Maximum corrected weight of impurity in sample $(\mu \mathrm{g})$ : & & & \\
\hline \multirow{5}{*}{$\mathbf{N i}$} & Measured concentration of impurity in sample $(\mu \mathrm{g} / \mathrm{ml})$ : & & & $\mathbf{N i}$ \\
\hline & Uncorrected weight of impurity in sample $(\mu \mathrm{g})$ : & & & \\
\hline & Weight of impurity in blank $(\mu \mathrm{g})$ : & & & \\
\hline & Minimum corrected weight of impurity in sample $(\mu \mathrm{g})$ : & & & \\
\hline & Maximum corrected weight of impurity in sample $(\mu \mathrm{g})$ : & & & \\
\hline \multirow{5}{*}{$\mathbf{C a}$} & Measured concentration of impurity in sample $(\mu \mathrm{g} / \mathrm{ml})$ : & & & $\mathbf{C a}$ \\
\hline & Uncorrected weight of impurity in sample $(\mu \mathrm{g})$ : & & & \\
\hline & Weight of impurity in blank $(\mu \mathrm{g})$ : & & & \\
\hline & Minimum corrected weight of impurity in sample $(\mu \mathrm{g}):$ & & & \\
\hline & Maximum corrected weight of impurity in sample $(\mu \mathrm{g})$ : & & & \\
\hline \multirow{5}{*}{ Al } & Measured concentration of impurity in sample $(\mu \mathrm{g} / \mathrm{ml})$ : & & & Al \\
\hline & Uncorrected weight of impurity in sample $(\mu \mathrm{g})$ : & & & \\
\hline & Weight of impurity in blank $(\mu \mathrm{g})$ : & & & \\
\hline & Minimum corrected weight of impurity in sample $(\mu \mathrm{g})$ : & & & \\
\hline & Maximum corrected weight of impurity in sample $(\mu \mathrm{g}):$ & & & \\
\hline & Measured concentration of impurity in sample $(\mu \mathrm{g} / \mathrm{ml})$ : & & & $\mathbf{T i}$ \\
\hline & Uncorrected weight of impurity in sample $(\mu \mathrm{g})$ : & & & \\
\hline Ti & Weight of impurity in blank $(\mu \mathrm{g})$ : & & & \\
\hline & Minimum corrected weight of impurity in sample $(\mu \mathrm{g})$ : & & & \\
\hline & Maximum corrected weight of impurity in sample $(\mu \mathrm{g})$ : & & & \\
\hline & Measured concentration of impurity in sample $(\mu \mathrm{g} / \mathrm{ml})$ : & & & $\mathbf{v}$ \\
\hline & Uncorrected weight of impurity in sample $(\mu \mathrm{g})$ : & & & \\
\hline $\mathbf{v}$ & Weight of impurity in blank $(\mu \mathrm{g})$ : & & & \\
\hline & Minimum corrected weight of impurity in sample $(\mu \mathrm{g})$ : & & & \\
\hline & Maximum corrected weight of impurity in sample $(\mu \mathrm{g})$ : & & & \\
\hline
\end{tabular}

\section{comments}

Leached in Vessel RB\#2 (previously used for 14155D-Group 1 Clutch 1)

FCM checked the recorded data against the official Results of Analysis for RMAL18947 on 3/26/2019.

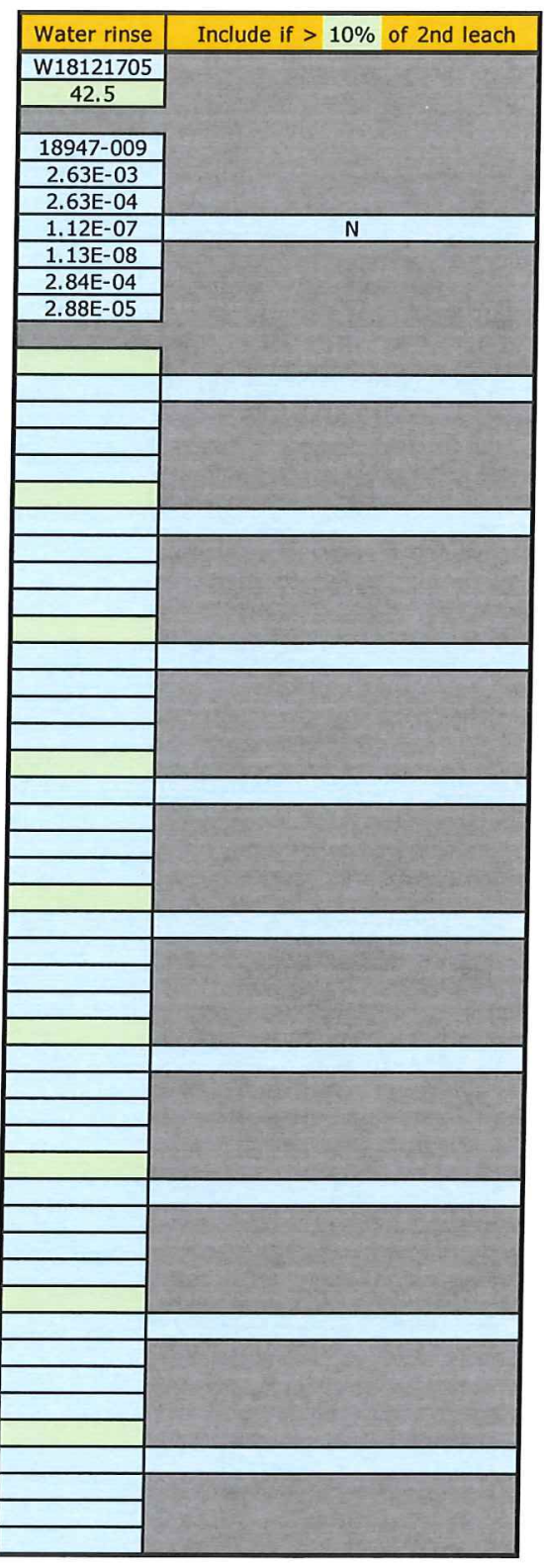

\section{7red c. Montgomery}




\section{Data Report Form DRF-21A: Pre-Burn Leach Uranium and Impurities}

\begin{tabular}{|r|l|}
\hline Procedure: & AGR-CHAR-DAM-21 Rev, 2 \\
\hline Operator: & Montgomery \\
\hline Particle lot ID: & BWXT J52R-16-11035 \\
\hline Particle lot description: & AGR-5/6/7 overcoated particles, 40\% packing fraction \\
\hline Particle sample ID: & $11035-02$ \\
\hline DRF filename: & 11035 PF40 overcoated particles-Group 1_DLBL_ICPMS_DRF21R2.xIs \\
\hline
\end{tabular}

\begin{tabular}{|c|c|c|c|c|}
\hline \multicolumn{2}{|r|}{ Average weight per particle, mean value $(\mathrm{g}):$} & \multicolumn{3}{|c|}{$2.010 \mathrm{E}-03$} \\
\hline & Average weight per particle, uncertainty in mean (g): & \multicolumn{3}{|c|}{$6.4 \mathrm{E}-06$} \\
\hline & Weight of particle sample $(\mathrm{g})$ : & \multicolumn{3}{|c|}{34.9102} \\
\hline & Approximate number of particles in sample: & \multicolumn{3}{|c|}{17368} \\
\hline & Uncertainty in number of particles: & \multirow{2}{*}{\multicolumn{3}{|c|}{$\begin{array}{ll}55 \\
3.94 \mathrm{E}-04\end{array}$}} \\
\hline & Average weight uranium per particle, mean value $(\mathrm{g})$ : & & & \\
\hline \multicolumn{2}{|r|}{ Average weight uranium per particle, uncertainty in mean $(\mathrm{g})$ : } & \multicolumn{3}{|c|}{$3.94 \mathrm{E}-06$} \\
\hline & & First Leach & Second Leach & Total \\
\hline & Pre-burn leach solution ID: & L18121302 & L18121702 & \\
\hline & Total volume of leach solution $(\mathrm{ml})$ : & 117.0 & 130.0 & \\
\hline & RMAL analysis number: & $18947-002$ & $18947-006$ & \\
\hline & Measured uranium concentration $(\mu \mathrm{g} / \mathrm{ml})$ : & $2.77 \mathrm{E}-01$ & $1.10 \mathrm{E}-02$ & \\
\hline & Uncertainty in uranium concentration $(\mu \mathrm{g} / \mathrm{ml})$ : & $2.77 \mathrm{E}-02$ & $1.10 \mathrm{E}-03$ & \\
\hline & Weight uranium leached $(\mathrm{g})$ : & $3.24 \mathrm{E}-05$ & $1.43 \mathrm{E}-06$ & $3.38 \mathrm{E}-05$ \\
\hline & Uncertainty in weight uranium leached $(\mathrm{g})$ : & $3.25 \mathrm{E}-06$ & $1.43 \mathrm{E}-07$ & $3.25 \mathrm{E}-06$ \\
\hline & Equivalent number of leached kernels: & $8.23 \mathrm{E}-02$ & $3.63 \mathrm{E}-03$ & $8.59 \mathrm{E}-02$ \\
\hline & Uncertainty in equivalent number of leached kernels: & $8.28 \mathrm{E}-03$ & $3.65 \mathrm{E}-04$ & $8.29 \mathrm{E}-03$ \\
\hline \multirow{5}{*}{$\mathbf{F e}$} & Measured concentration of impurity in sample $(\mu \mathrm{g} / \mathrm{ml})$ : & & & \\
\hline & Uncorrected weight of impurity in sample $(\mu \mathrm{g})$ : & & & $\mathrm{Fe}$ \\
\hline & Weight of impurity in blank $(\mu g)$ : & & & \\
\hline & Minimum corrected weight of impurity in sample $(\mu \mathrm{g})$ : & & & \\
\hline & Maximum corrected weight of impurity in sample $(\mu \mathrm{g})$ : & & & \\
\hline \multirow{5}{*}{$\mathrm{Cr}$} & Measured concentration of impurity in sample $(\mu \mathrm{g} / \mathrm{ml})$ : & & & $\mathrm{Cr}$ \\
\hline & Uncorrected weight of impurity in sample $(\mu \mathrm{g})$ : & & & \\
\hline & Weight of impurity in blank $(\mu \mathrm{g})$ : & & & \\
\hline & Minimum corrected weight of impurity in sample $(\mu \mathrm{g})$ : & & & \\
\hline & Maximum corrected weight of impurity in sample $(\mu \mathrm{g})$ : & & & \\
\hline \multirow{5}{*}{ Mn } & Measured concentration of impurity in sample $(\mu \mathrm{g} / \mathrm{ml})$ : & & & Mn \\
\hline & Uncorrected weight of impurity in sample $(\mu \mathrm{g})$ : & & & \\
\hline & Weight of impurity in blank $(\mu \mathrm{g})$ : & & & \\
\hline & Minimum corrected weight of impurity in sample $(\mu g)$ : & & & \\
\hline & Maximum corrected weight of impurity in sample $(\mu \mathrm{g})$ : & & & \\
\hline \multirow{5}{*}{ Co } & Measured concentration of impurity in sample $(\mu \mathrm{g} / \mathrm{ml})$ : & & & Co \\
\hline & Uncorrected weight of impurity in sample $(\mu \mathrm{g})$ : & & & \\
\hline & Weight of impurity in blank $(\mu \mathrm{g})$ : & & & \\
\hline & Minimum corrected weight of impurity in sample $(\mu \mathrm{g})$ : & & & \\
\hline & Maximum corrected weight of impurity in sample $(\mu \mathrm{g})$ : & & & \\
\hline \multirow{5}{*}{$\mathbf{N i}$} & Measured concentration of impurity in sample $(\mu \mathrm{g} / \mathrm{ml})$ : & & & $\mathrm{Ni}$ \\
\hline & Uncorrected weight of impurity in sample $(\mu \mathrm{g})$ : & & & \\
\hline & Weight of impurity in blank $(\mu \mathrm{g})$ : & & & \\
\hline & Minimum corrected weight of impurity in sample $(\mu g)$ : & & & \\
\hline & Maximum corrected weight of impurity in sample $(\mu g)$ : & & & \\
\hline \multirow{5}{*}{$\mathrm{Ca}$} & Measured concentration of impurity in sample $(\mu \mathrm{g} / \mathrm{ml})$ : & & & $\mathbf{C a}$ \\
\hline & Uncorrected weight of impurity in sample $(\mu \mathrm{g})$ : & & & \\
\hline & Weight of impurity in blank $(\mu \mathrm{g})$ : & & & \\
\hline & Minimum corrected weight of impurity in sample $(\mu \mathrm{g})$ : & & & \\
\hline & Maximum corrected weight of impurity in sample $(\mu \mathrm{g})$ : & & & \\
\hline \multirow{5}{*}{ Al } & Measured concentration of impurity in sample $(\mu \mathrm{g} / \mathrm{ml})$ : & & & Al \\
\hline & Uncorrected weight of impurity in sample $(\mu \mathrm{g})$ : & & & \\
\hline & Weight of impurity in blank $(\mu \mathrm{g})$ : & & & \\
\hline & Minimum corrected weight of impurity in sample $(\mu \mathrm{g})$ : & & & \\
\hline & Maximum corrected weight of impurity in sample $(\mu \mathrm{g})$ : & & & \\
\hline \multirow{5}{*}{$\mathbf{T i}$} & Measured concentration of impurity in sample $(\mu \mathrm{g} / \mathrm{ml})$ : & & & Ti \\
\hline & Uncorrected weight of impurity in sample $(\mu \mathrm{g})$ : & & & \\
\hline & Weight of impurity in blank $(\mu \mathrm{g}):$ & & & \\
\hline & Minimum corrected weight of impurity in sample $(\mu \mathrm{g}):$ & & & \\
\hline & Maximum corrected weight of impurity in sample $(\mu \mathrm{g}):$ & & & \\
\hline & Measured concentration of impurity in sample $(\mu \mathrm{g} / \mathrm{ml})$ : & & & $\mathbf{v}$ \\
\hline & Uncorrected weight of impurity in sample $(\mu \mathrm{g})$ : & & & \\
\hline v & Weight of impurity in blank $(\mu \mathrm{g})$ : & & & \\
\hline & Minimum corrected weight of impurity in sample $(\mu \mathrm{g})$ : & & & \\
\hline & Maximum corrected weight of impurity in sample $(\mu \mathrm{g}):$ & & & \\
\hline
\end{tabular}

Comments

Leached in Vessel RB\#3 (previously used for 14155D-Group 1 Clutch 2).

FCM checked the recorded data against the official Results of Analysis for RMAL18947 on 3/26/2019.

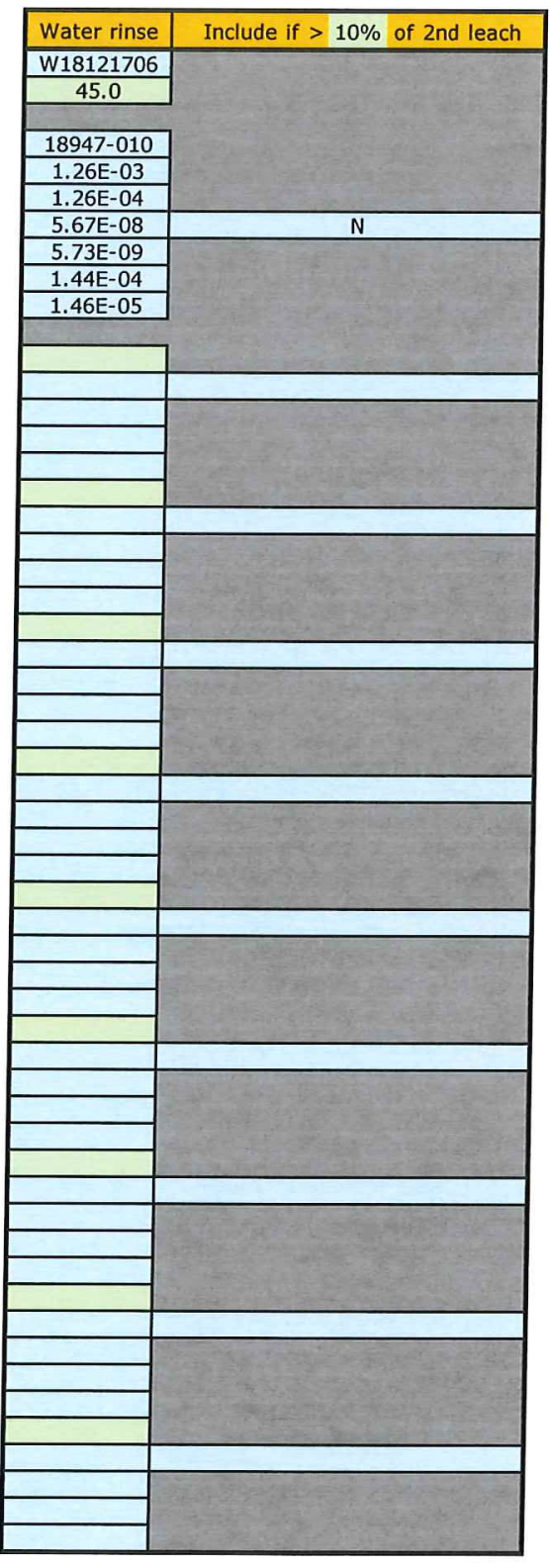




\section{Data Report Form DRF-21A: Pre-Burn Leach Uranium and Impurities}

\begin{tabular}{|r|l|}
\hline Procedure: & AGR-CHAR-DAM-21 Rev. 2 \\
\hline Operator: & Montgomery \\
\hline Particle lot ID: & BWXT J52R-16-11035 \\
\hline Particle lot description: & AGR-5/6/7 overcoated particles, 40\% packing fraction \\
\hline Particle sample ID: & $11035-03$ \\
\hline DRF filename: & 11035 PF40 overcoated particles-Group 1_DLBL_ICPMS_DRF21R2.xIs \\
\hline
\end{tabular}

\begin{tabular}{|r|c|}
\hline Average weight per particle, mean value $(\mathrm{g}):$ & $2.010 \mathrm{E}-03$ \\
\hline Average weight per particle, uncertainty in mean $(\mathrm{g}):$ & $6.4 \mathrm{E}-06$ \\
\hline Weight of particle sample $(\mathrm{g}):$ & 34.9109 \\
\hline Approximate number of particles in sample: & 17369 \\
\hline Uncertainty in number of particles: & 55 \\
\hline Average weight uranium per particle, mean value $(\mathrm{g}):$ & $3.94 \mathrm{E}-04$ \\
\hline Average weight uranium per particle, uncertainty in mean $(\mathrm{g}):$ & $3.94 \mathrm{E}-06$ \\
\hline
\end{tabular}

\begin{tabular}{|c|c|c|c|c|}
\hline & & & \\
\hline & & First Leach & Second Leach & Total \\
\hline \multirow{2}{*}{\multicolumn{2}{|c|}{\begin{tabular}{|c|c} 
Pre-burn leach solution ID \\
Total volume of leach solution $(\mathrm{ml})$ \\
\end{tabular}}} & L18121303 & L18121703 & \\
\hline & & 113.0 & 137.0 & \\
\hline \multicolumn{2}{|c|}{ RMAL analysis number: } & $18947-003$ & $18947-007$ & \\
\hline \multirow{2}{*}{\multicolumn{2}{|c|}{$\begin{array}{c}\text { Measured uranium concentration }(\mu \mathrm{g} / \mathrm{ml}) \text { : } \\
\text { Uncertainty in uranium concentration }(\mu \mathrm{g} / \mathrm{ml}) \text { : }\end{array}$}} & $2.86 \mathrm{E}-01$ & $1.18 \mathrm{E}-02$ & \\
\hline & & $2.86 \mathrm{E}-02$ & $1.18 \mathrm{E}-03$ & \\
\hline \multicolumn{2}{|r|}{ Weight uranium leached $(g)$ : } & $3.23 \mathrm{E}-05$ & $1.62 \mathrm{E}-06$ & $3.39 \mathrm{E}-05$ \\
\hline \multirow{2}{*}{\multicolumn{2}{|c|}{$\begin{array}{r}\text { Uncertainty in weight uranium leached }(\mathrm{g}): \\
\text { Equivalent number of leached kernels: }\end{array}$}} & $3.24 \mathrm{E}-06$ & $1.62 \mathrm{E}-07$ & $3.24 \mathrm{E}-06$ \\
\hline & & $8.20 \mathrm{E}-02$ & $4.10 \mathrm{E}-03$ & $8.61 \mathrm{E}-02$ \\
\hline \multicolumn{2}{|c|}{ Uncertainty in equivalent number of leached kernels: } & $8.26 \mathrm{E}-03$ & $4.13 \mathrm{E}-04$ & $8.27 \mathrm{E}-03$ \\
\hline \multirow{5}{*}{$\mathrm{Fe}$} & Measured concentration of impurity in sample $(\mu \mathrm{g} / \mathrm{ml})$ & & & $\mathbf{F e}$ \\
\hline & Uncorrected weight of impurity in sample $(\mu \mathrm{g})$ : & & & \\
\hline & Weight of impurity in blank $(\mu \mathrm{g})$ : & & & \\
\hline & Minimum corrected weight of impurity in sample $(\mu \mathrm{g})$ : & & & \\
\hline & Maximum corrected weight of impurity in sample $(\mu \mathrm{g})$ : & & & \\
\hline \multirow{5}{*}{$\mathrm{Cr}$} & Measured concentration of impurity in sample $(\mu \mathrm{g} / \mathrm{ml})$ : & & & $\mathbf{C r}$ \\
\hline & Uncorrected weight of impurity in sample $(\mu \mathrm{g})$ : & & & \\
\hline & Weight of impurity in blank $(\mu g)$ : & & & \\
\hline & Minimum corrected weight of impurity in sample $(\mu \mathrm{g})$ : & & & \\
\hline & Maximum corrected weight of impurity in sample $(\mu g)$ : & & & \\
\hline \multirow{5}{*}{ Mn } & Measured concentration of impurity in sample $(\mu \mathrm{g} / \mathrm{ml})$ : & & & Mn \\
\hline & Uncorrected weight of impurity in sample $(\mu \mathrm{g})$ : & & & \\
\hline & Weight of impurity in blank $(\mu \mathrm{g})$ : & & & \\
\hline & Minimum corrected weight of impurity in sample $(\mu \mathrm{g})$ : & & & \\
\hline & Maximum corrected weight of impurity in sample $(\mu g)$ : & & & \\
\hline \multirow{5}{*}{ Co } & Measured concentration of impurity in sample $(\mu \mathrm{g} / \mathrm{ml})$ : & & & Co \\
\hline & Uncorrected weight of impurity in sample $(\mu \mathrm{g})$ : & & & \\
\hline & Weight of impurity in blank $(\mu \mathrm{g})$ : & & & \\
\hline & Minimum corrected weight of impurity in sample $(\mu g)$ : & & & \\
\hline & Maximum corrected weight of impurity in sample $(\mu g)$ : & & & \\
\hline \multirow{5}{*}{$\mathbf{N i}$} & Measured concentration of impurity in sample $(\mu \mathrm{g} / \mathrm{ml})$ : & & & $\mathrm{Ni}$ \\
\hline & Uncorrected weight of impurity in sample $(\mu \mathrm{g})$ : & & & \\
\hline & Weight of impurity in blank $(\mu \mathrm{g})$ : & & & \\
\hline & Minimum corrected weight of impurity in sample $(\mu g)$ : & & & \\
\hline & Maximum corrected weight of impurity in sample $(\mu g)$ : & & & \\
\hline \multirow{5}{*}{$\mathbf{C a}$} & Measured concentration of impurity in sample $(\mu \mathrm{g} / \mathrm{ml})$ : & & & $\mathrm{Ca}$ \\
\hline & Uncorrected weight of impurity in sample $(\mu \mathrm{g})$ : & & & \\
\hline & Weight of impurity in blank $(\mu \mathrm{g})$ : & & & \\
\hline & Minimum corrected weight of impurity in sample $(\mu \mathrm{g})$ : & & & \\
\hline & Maximum corrected weight of impurity in sample $(\mu \mathrm{g})$ : & & & \\
\hline \multirow{5}{*}{ Al } & Measured concentration of impurity in sample $(\mu \mathrm{g} / \mathrm{ml})$ : & & & Al \\
\hline & Uncorrected weight of impurity in sample $(\mu g)$ : & & & \\
\hline & Weight of impurity in blank $(\mu \mathrm{g})$ : & & & \\
\hline & Minimum corrected weight of impurity in sample $(\mu \mathrm{g})$ : & & & \\
\hline & Maximum corrected weight of impurity in sample $(\mu \mathrm{g})$ : & & & \\
\hline \multirow{5}{*}{$\mathrm{Ti}$} & Measured concentration of impurity in sample $(\mu \mathrm{g} / \mathrm{ml})$ : & & & $\mathbf{T i}$ \\
\hline & Uncorrected weight of impurity in sample $(\mu \mathrm{g})$ : & & & \\
\hline & Weight of impurity in blank $(\mu \mathrm{g})$ : & & & \\
\hline & Minimum corrected weight of impurity in sample $(\mu \mathrm{g}):$ & & & \\
\hline & Maximum corrected weight of impurity in sample $(\mu \mathrm{g})$ : & & & \\
\hline \multirow{5}{*}{$\mathbf{v}$} & Measured concentration of impurity in sample $(\mu \mathrm{g} / \mathrm{ml})$ : & & & $\mathbf{v}$ \\
\hline & Uncorrected weight of impurity in sample $(\mu \mathrm{g})$ : & & & \\
\hline & Weight of impurity in blank $(\mu \mathrm{g})$ : & & & \\
\hline & Minimum corrected weight of impurity in sample $(\mu \mathrm{g})$ : & & & \\
\hline & Maximum corrected weight of impurity in sample $(\mu \mathrm{g})$ : & & & \\
\hline
\end{tabular}

\section{comments}

Leached in Vessel RB\#11 (previously used for 14155D-Group 1 Clutch 3).

FCM checked the recorded data against the official Results of Analysis for RMAL18947 on 3/26/2019.

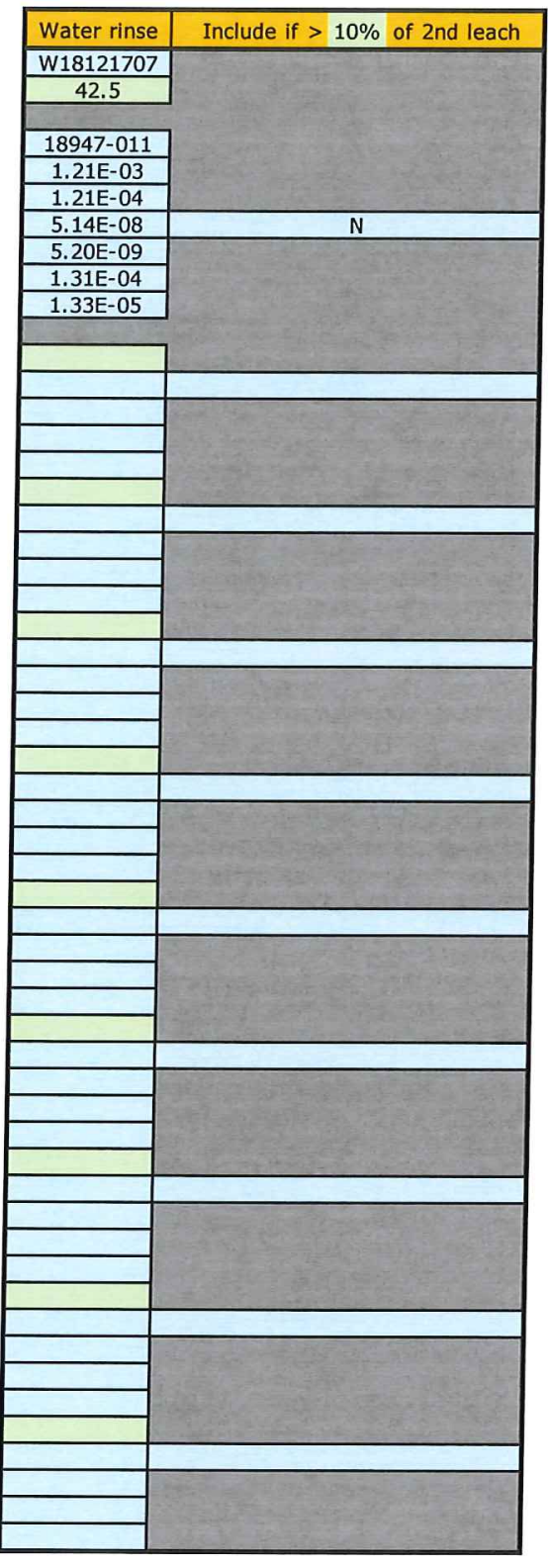




\section{Data Report Form DRF-21A: Pre-Burn Leach Uranium and Impurities}

\begin{tabular}{|r|l|}
\hline Procedure: & AGR-CHAR-DAM-21 Rev. 2 \\
\hline Operator: & Montgomery \\
\hline Particle lot ID: & BWXT J52R-16-11035 \\
\hline Particle lot description: & AGR-5/6/7 overcoated particles, 40\% packing fraction \\
\hline Particle sample ID: & $11035-04$ \\
\hline DRF filename: & 11035 PF40 overcoated particles-Group 1_DLBL_ICPMS_DRF21R2.xIs \\
\hline
\end{tabular}

\begin{tabular}{|c|c|c|c|c|}
\hline \multicolumn{2}{|r|}{$\begin{array}{ll}\text { Average weight per particle, mean value }(\mathrm{g}): \\
\end{array}$} & \multicolumn{3}{|c|}{$2.010 \mathrm{E}-03$} \\
\hline & Average weight per particle, uncertainty in mean $(g)$ : & \multicolumn{3}{|c|}{$6.4 \mathrm{E}-06$} \\
\hline & Weight of particle sample $(\mathrm{g})$ : & \multicolumn{3}{|c|}{34.9301} \\
\hline & Approximate number of particles in sample: & \multicolumn{3}{|c|}{17378} \\
\hline & Uncertainty in number of particles: & \multicolumn{3}{|c|}{55} \\
\hline & Average weight uranium per particle, mean value $(\mathrm{g})$ : & \multicolumn{3}{|c|}{$3.94 \mathrm{E}-04$} \\
\hline \multicolumn{2}{|r|}{ Average weight uranium per particle, uncertainty in mean (g): } & \multicolumn{3}{|c|}{$3.94 \mathrm{E}-06$} \\
\hline & & First Leach & Second Leach & Total \\
\hline & Pre-burn leach solution ID: & L18121304 & L18121704 & \\
\hline & Total volume of leach solution $(\mathrm{ml})$ : & 103.0 & 142.0 & \\
\hline & RMAL analysis number: & $18947-004$ & $18947-008$ & \\
\hline & Measured uranium concentration $(\mu \mathrm{g} / \mathrm{ml})$ : & $3.04 \mathrm{E}-01$ & $1.62 \mathrm{E}-02$ & \\
\hline & Uncertainty in uranium concentration $(\mu \mathrm{g} / \mathrm{ml})$ : & $3.04 \mathrm{E}-02$ & $1.62 \mathrm{E}-03$ & \\
\hline & Weight uranium leached $(\mathrm{g})$ : & $3.13 \mathrm{E}-05$ & $2.30 \mathrm{E}-06$ & $3.36 \mathrm{E}-05$ \\
\hline & Uncertainty in weight uranium leached $(\mathrm{g})$ : & $3.14 \mathrm{E}-06$ & $2.30 \mathrm{E}-07$ & $3.15 \mathrm{E}-06$ \\
\hline & Equivalent number of leached kernels: & $7.95 \mathrm{E}-02$ & $5.84 \mathrm{E}-03$ & $8.53 \mathrm{E}-02$ \\
\hline & Uncertainty in equivalent number of leached kernels: & $8.00 \mathrm{E}-03$ & 5.87E-04 & $8.03 E-03$ \\
\hline \multirow{5}{*}{$\mathbf{F e}$} & Measured concentration of impurity in sample $(\mu \mathrm{g} / \mathrm{ml})$ & & & $\mathbf{F e}$ \\
\hline & Uncorrected weight of impurity in sample $(\mu \mathrm{g})$ : & & & \\
\hline & Weight of impurity in blank $(\mu \mathrm{g})$ : & & & \\
\hline & Minimum corrected weight of impurity in sample $(\mu \mathrm{g})$ : & & & \\
\hline & Maximum corrected weight of impurity in sample $(\mu \mathrm{g})$ : & & & \\
\hline \multirow{5}{*}{$\mathbf{C r}$} & Measured concentration of impurity in sample $(\mu \mathrm{g} / \mathrm{ml})$ : & & & Cr \\
\hline & Uncorrected weight of impurity in sample $(\mu \mathrm{g})$ : & & & \\
\hline & Weight of impurity in blank $(\mu \mathrm{g})$ : & & & \\
\hline & Minimum corrected weight of impurity in sample $(\mu \mathrm{g})$ : & & & \\
\hline & Maximum corrected weight of impurity in sample $(\mu \mathrm{g})$ : & & & \\
\hline \multirow{5}{*}{ Mn } & Measured concentration of impurity in sample $(\mu \mathrm{g} / \mathrm{ml})$ : & & & Mn \\
\hline & Uncorrected weight of impurity in sample $(\mu \mathrm{g})$ : & & & \\
\hline & Weight of impurity in blank $(\mu \mathrm{g})$ : & & & \\
\hline & Minimum corrected weight of impurity in sample $(\mu \mathrm{g})$ : & & & \\
\hline & Maximum corrected weight of impurity in sample $(\mu \mathrm{g})$ : & & & \\
\hline \multirow{5}{*}{ Co } & Measured concentration of impurity in sample $(\mu \mathrm{g} / \mathrm{ml})$ : & & & Co \\
\hline & Uncorrected weight of impurity in sample $(\mu \mathrm{g})$ : & & & \\
\hline & Weight of impurity in blank $(\mu \mathrm{g})$ : & & & \\
\hline & Minimum corrected weight of impurity in sample $(\mu \mathrm{g})$ : & & & \\
\hline & Maximum corrected weight of impurity in sample $(\mu g)$ : & & & \\
\hline \multirow{5}{*}{$\mathbf{N i}$} & Measured concentration of impurity in sample $(\mu \mathrm{g} / \mathrm{ml})$ : & & & $\mathrm{Ni}$ \\
\hline & Uncorrected weight of impurity in sample $(\mu \mathrm{g})$ : & & & \\
\hline & Weight of impurity in blank $(\mu \mathrm{g})$ : & & & \\
\hline & Minimum corrected weight of impurity in sample $(\mu \mathrm{g})$ : & & & \\
\hline & Maximum corrected weight of impurity in sample $(\mu \mathrm{g})$ : & & & \\
\hline \multirow{5}{*}{ Ca } & Measured concentration of impurity in sample $(\mu \mathrm{g} / \mathrm{ml})$ : & & & $\mathbf{C a}$ \\
\hline & Uncorrected weight of impurity in sample $(\mu \mathrm{g})$ : & & & \\
\hline & Weight of impurity in blank $(\mu \mathrm{g})$ : & & & \\
\hline & Minimum corrected weight of impurity in sample $(\mu \mathrm{g})$ : & & & \\
\hline & Maximum corrected weight of impurity in sample $(\mu \mathrm{g})$ : & & & \\
\hline \multirow{5}{*}{ Al } & Measured concentration of impurity in sample $(\mathrm{\mu g} / \mathrm{ml})$ : & & & Al \\
\hline & Uncorrected weight of impurity in sample $(\mu \mathrm{g})$ : & & & \\
\hline & Weight of impurity in blank $(\mu \mathrm{g})$ : & & & \\
\hline & Minimum corrected weight of impurity in sample $(\mu \mathrm{g})$ : & & & \\
\hline & Maximum corrected weight of impurity in sample $(\mu \mathrm{g})$ : & & & \\
\hline & Measured concentration of impurity in sample $(\mu \mathrm{g} / \mathrm{ml})$ : & & & Ti \\
\hline & Uncorrected weight of impurity in sample $(\mu \mathrm{g})$ : & & & \\
\hline Ti & Weight of impurity in blank $(\mu \mathrm{g})$ : & & & \\
\hline & Minimum corrected weight of impurity in sample $(\mu \mathrm{g})$ : & & & \\
\hline & Maximum corrected weight of impurity in sample $(\mu \mathrm{g})$ : & & & \\
\hline & Measured concentration of impurity in sample $(\mu \mathrm{g} / \mathrm{ml})$ : & & & $\mathbf{v}$ \\
\hline & Uncorrected weight of impurity in sample $(\mu \mathrm{g})$ : & & & \\
\hline v & Weight of impurity in blank $(\mu \mathrm{g})$ : & & & \\
\hline & Minimum corrected weight of impurity in sample $(\mu \mathrm{g})$ : & & & \\
\hline & Maximum corrected weight of impurity in sample $(\mu \mathrm{g})$ : & & & \\
\hline
\end{tabular}

comments

Leached in Vessel FB\#2 (previously used for 14155D-Group 1 Clutch 4).

FCM checked the recorded data against the official Results of Analysis for RMAL18947 on 3/26/2019.

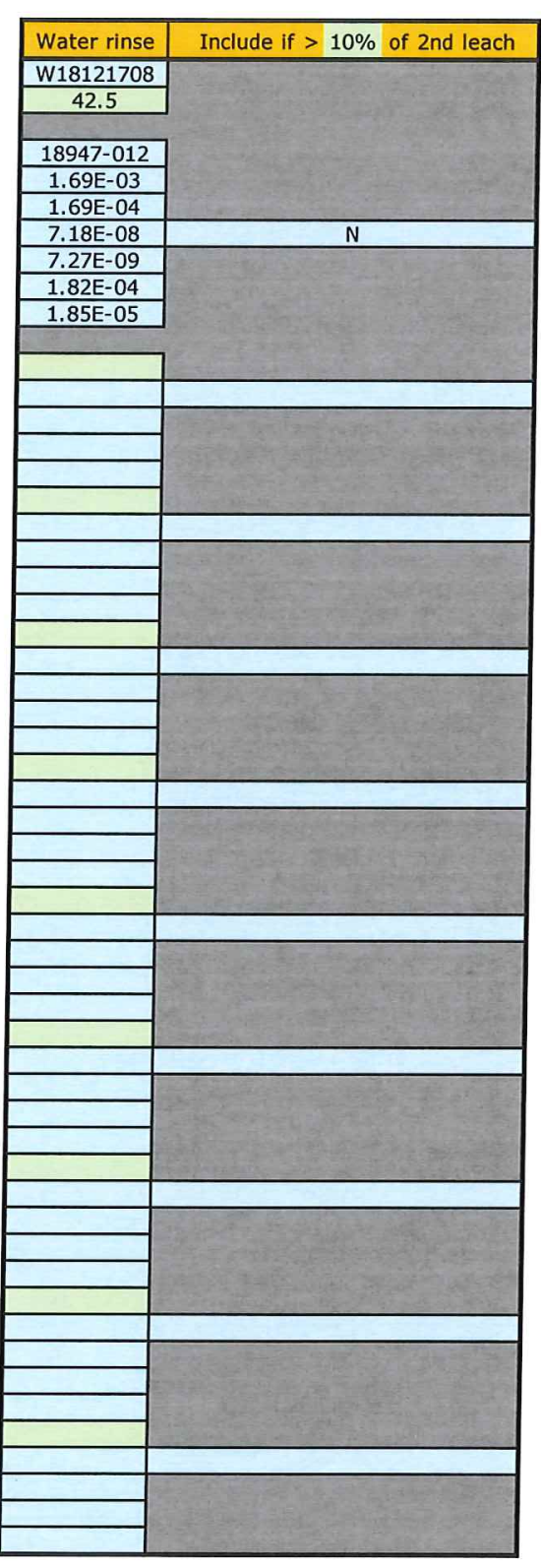




\section{Data Report Form DRF-21B: Post-Burn Leach Uranium and Impurities}

\begin{tabular}{|r|l|}
\hline Procedure: & AGR-CHAR-DAM-21 Rev. 2 \\
\hline Operator: & Montgomery \\
\hline Particle lot ID: & BWXT J52R-16-11035 \\
\hline Particle lot description: & AGR-5/6/7 overcoated particles, 40\% packing fraction \\
\hline Particle sample ID: & $11035-01$ \\
\hline DRF filename: & 11035 PF 40 overcoated particles-Group 1_DLBL_ICPMS_DRF21R2.xIs \\
\hline
\end{tabular}

\begin{tabular}{|r|c|}
\hline Average weight per particle, mean value $(\mathrm{g}):$ & $2.010 \mathrm{E}-03$ \\
\hline Average weight per particle, uncertainty in mean $(\mathrm{g}):$ & $6.4 \mathrm{E}-06$ \\
\hline Weight of particle sample $(\mathrm{g}):$ & 34.9930 \\
\hline Approximate number of particles in sample: & 17409 \\
\hline Uncertainty in number of particles: & 55 \\
\hline Average weight uranium per particle, mean value $(\mathrm{g}):$ & $3.94 \mathrm{E}-04$ \\
\hline Average weight uranium per particle, uncertainty in mean $(\mathrm{g}):$ & $3.94 \mathrm{E}-06$ \\
\hline
\end{tabular}

\begin{tabular}{|c|c|c|c|c|}
\hline & First Leach & Second Leach & Total \\
\hline & Post-burn leach solution ID: & B18123101 & B19010201 & \\
\hline & Total volume of leach solution $(\mathrm{ml})$ : & 61.5 & 65.0 & \\
\hline & RMAL analysis number: & $19027-001$ & $19027-005$ & \\
\hline & Measured uranium concentration $(\mu \mathrm{g} / \mathrm{ml})$ : & $1.00 \mathrm{E}-02$ & $3.36 \mathrm{E}-03$ & \\
\hline & Uncertainty in uranium concentration $(\mu \mathrm{g} / \mathrm{ml})$ : & $1.00 \mathrm{E}-03$ & $3.36 \mathrm{E}-04$ & \\
\hline & Weight uranium leached $(\mathrm{g})$ : & $6.15 \mathrm{E}-07$ & $2.18 \mathrm{E}-07$ & $8.33 \mathrm{E}-07$ \\
\hline & Uncertainty in weight uranium leached $(\mathrm{g})$ : & $6.18 \mathrm{E}-08$ & $2.19 \mathrm{E}-08$ & $6.56 \mathrm{E}-08$ \\
\hline & Equivalent number of leached kernels: & $1.56 \mathrm{E}-03$ & $5.54 \mathrm{E}-04$ & $2.12 \mathrm{E}-03$ \\
\hline & Uncertainty in equivalent number of leached kernels: & $1.58 \mathrm{E}-04$ & $5.60 \mathrm{E}-05$ & $1.68 \mathrm{E}-04$ \\
\hline \multirow{5}{*}{$\mathbf{F e}$} & & & & \\
\hline & $\begin{array}{r}\text { Measured concentration of impurity in sample }(\mu \mathrm{g} / \mathrm{ml}) \text { : } \\
\text { Uncorrected weight of impurity in sample }(\mu \mathrm{g}):\end{array}$ & & & $\mathbf{F e}$ \\
\hline & Weight of impurity in blank $(\mu \mathrm{g})$ : & & & \\
\hline & Minimum corrected weight of impurity in sample $(\mu \mathrm{g})$ : & & & \\
\hline & Maximum corrected weight of impurity in sample $(\mu g)$ : & & & \\
\hline \multirow{5}{*}{$\mathrm{Cr}$} & Measured concentration of impurity in sample $(\mu \mathrm{g} / \mathrm{ml})$ : & & & $\mathbf{C r}$ \\
\hline & Uncorrected weight of impurity in sample $(\mu \mathrm{g})$ : & & & \\
\hline & Weight of impurity in blank $(\mu \mathrm{g})$ : & & & \\
\hline & Minimum corrected weight of impurity in sample $(\mu \mathrm{g})$ : & & & \\
\hline & Maximum corrected weight of impurity in sample $(\mu \mathrm{g})$ : & & & \\
\hline \multirow{5}{*}{ Mn } & Measured concentration of impurity in sample $(\mu \mathrm{g} / \mathrm{ml})$ : & & & Mn \\
\hline & Uncorrected weight of impurity in sample $(\mu \mathrm{g})$ : & & & \\
\hline & Weight of impurity in blank $(\mu \mathrm{g})$ : & & & \\
\hline & Minimum corrected weight of impurity in sample $(\mu \mathrm{g})$ : & & & \\
\hline & Maximum corrected weight of impurity in sample $(\mu \mathrm{g})$ : & & & \\
\hline \multirow{5}{*}{ co } & Measured concentration of impurity in sample $(\mu \mathrm{g} / \mathrm{ml})$ : & & & Co \\
\hline & Uncorrected weight of impurity in sample $(\mu \mathrm{g})$ : & & & \\
\hline & Weight of impurity in blank $(\mu \mathrm{g})$ : & & & \\
\hline & Minimum corrected weight of impurity in sample $(\mu \mathrm{g})$ : & & & \\
\hline & Maximum corrected weight of impurity in sample $(\mu \mathrm{g})$ : & & & \\
\hline \multirow{5}{*}{$\mathbf{N i}$} & Measured concentration of impurity in sample $(\mathrm{\mu g} / \mathrm{ml})$ : & & & $\mathbf{N i}$ \\
\hline & Uncorrected weight of impurity in sample $(\mu \mathrm{g})$ : & & & \\
\hline & Weight of impurity in blank $(\mu \mathrm{g})$ : & & & \\
\hline & Minimum corrected weight of impurity in sample $(\mathrm{\mu g})$ : & & & \\
\hline & Maximum corrected weight of impurity in sample $(\mu \mathrm{g})$ : & & & \\
\hline \multirow{5}{*}{$\mathrm{Ca}$} & Measured concentration of impurity in sample $(\mu \mathrm{g} / \mathrm{ml})$ : & & & $\mathrm{Ca}$ \\
\hline & Uncorrected weight of impurity in sample $(\mu \mathrm{g})$ : & & & \\
\hline & Weight of impurity in blank $(\mu \mathrm{g})$ : & & & \\
\hline & Minimum corrected weight of impurity in sample $(\mu g)$ : & & & \\
\hline & Maximum corrected weight of impurity in sample $(\mu \mathrm{g})$ : & & & \\
\hline \multirow{5}{*}{ Al } & Measured concentration of impurity in sample $(\mu \mathrm{g} / \mathrm{ml}):$ & & & Al \\
\hline & Uncorrected weight of impurity in sample $(\mu \mathrm{g})$ : & & & \\
\hline & Weight of impurity in blank $(\mu \mathrm{g})$ : & & & \\
\hline & Minimum corrected weight of impurity in sample $(\mu \mathrm{g}):$ & & & \\
\hline & Maximum corrected weight of impurity in sample $(\mu \mathrm{g})$ : & & & \\
\hline \multirow{5}{*}{$\mathbf{T i}$} & Measured concentration of impurity in sample $(\mu \mathrm{g} / \mathrm{ml})$ : & & & $\mathrm{Ti}$ \\
\hline & Uncorrected weight of impurity in sample $(\mu \mathrm{g})$ : & & & \\
\hline & Weight of impurity in blank $(\mu \mathrm{g})$ : & & & \\
\hline & Minimum corrected weight of impurity in sample $(\mu \mathrm{g})$ : & & & \\
\hline & Maximum corrected weight of impurity in sample $(\mu \mathrm{g})$ : & & & \\
\hline \multirow{5}{*}{$\mathbf{v}$} & Measured concentration of impurity in sample $(\mathrm{\mu g} / \mathrm{ml}):$ & & & $\mathbf{v}$ \\
\hline & Uncorrected weight of impurity in sample $(\mu \mathrm{g})$ : & & & \\
\hline & Weight of impurity in blank $(\mu \mathrm{g}):$ & & & \\
\hline & Minimum corrected weight of impurity in sample $(\mu \mathrm{g})$ : & & & \\
\hline & Maximum corrected weight of impurity in sample $(\mu \mathrm{g}):$ & & & \\
\hline
\end{tabular}

comments

FCM checked the recorded data against the official Results of Analysis for RMAL19027 on 3/26/2019.

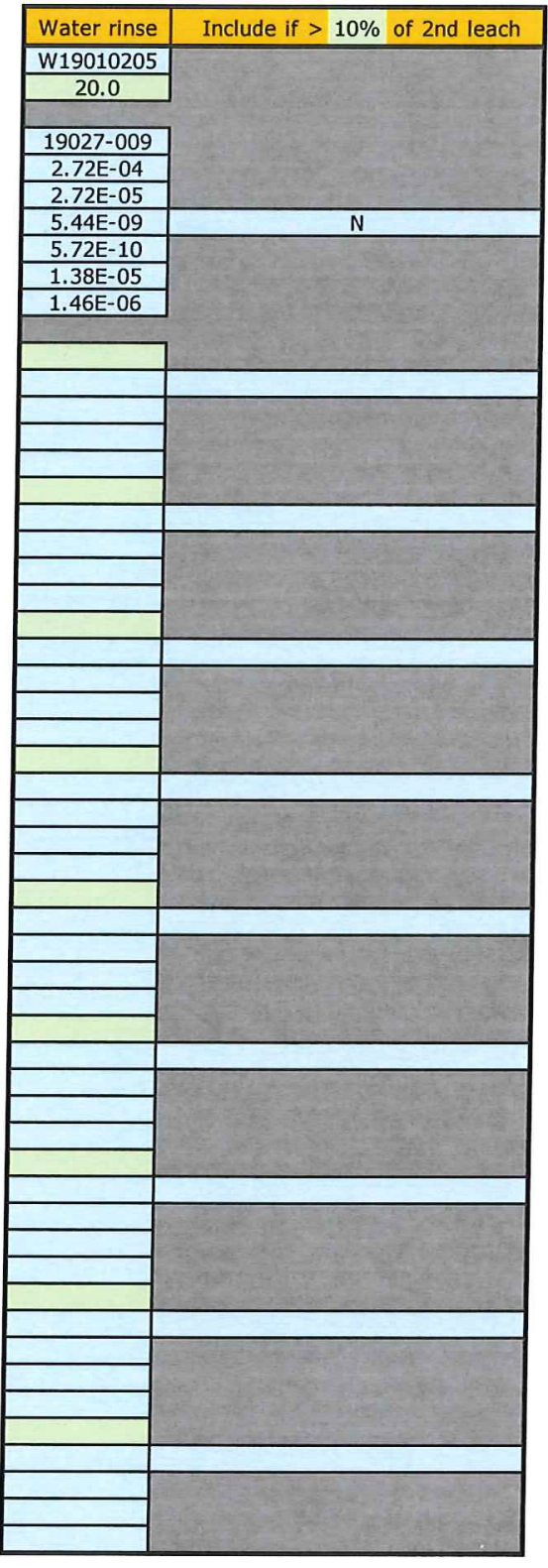

7.ed c. Montgomery 


\section{Data Report Form DRF-21B: Post-Burn Leach Uranium and Impurities}

\begin{tabular}{|r|l|}
\hline Procedure: & AGR-CHAR-DAM-21 Rev. 2 \\
\hline Operator: & Montgomery \\
\hline Particle lot ID: & BWXT J52R-16-11035 \\
\hline Particle lot description: & AGR-5/6/7 overcoated particles, 40\% packing fraction \\
\hline Particle sample ID: & $11035-02$ \\
\hline DRF filename: & 11035 PF 40 overcoated particles-Group 1_DLBL_ICPMS_DRF21R2.xIs \\
\hline
\end{tabular}

\begin{tabular}{|c|c|c|c|c|}
\hline \multicolumn{2}{|r|}{$\begin{array}{ll}\text { Average weight per particle, mean value }(\mathrm{g}) \text { : }\end{array}$} & \multicolumn{3}{|c|}{$2.010 \mathrm{E}-03$} \\
\hline & Average weight per particle, uncertainty in mean $(\mathrm{g})$ : & \multicolumn{3}{|c|}{$6.4 \mathrm{E}-06$} \\
\hline & Weight of particle sample $(\mathrm{g})$ : & \multicolumn{3}{|c|}{34.9930} \\
\hline & Approximate number of particles in sample: & \multicolumn{3}{|c|}{17409} \\
\hline & Uncertainty in number of particles: & \multicolumn{3}{|c|}{55} \\
\hline & Average weight uranium per particle, mean value $(\mathrm{g})$ : & \multicolumn{3}{|c|}{$3.94 \mathrm{E}-04$} \\
\hline \multicolumn{2}{|r|}{ Average weight uranium per particle, uncertainty in mean (g): } & \multicolumn{3}{|c|}{$3.94 \mathrm{E}-06$} \\
\hline & & First Leach & Second Leach & Total \\
\hline & Post-burn leach solution ID: & B18123102 & B19010202 & \\
\hline & Total volume of leach solution $(\mathrm{ml})$ : & 58.8 & 64.8 & \\
\hline & RMAL analysis number: & $19027-002$ & $19027-006$ & \\
\hline & Measured uranium concentration $(\mu \mathrm{g} / \mathrm{ml})$ : & $1.11 \mathrm{E}-02$ & $5.89 \mathrm{E}-03$ & \\
\hline & Uncertainty in uranium concentration $(\mu \mathrm{g} / \mathrm{ml})$ : & $1.11 \mathrm{E}-03$ & $5.89 \mathrm{E}-04$ & \\
\hline & Weight uranium leached $(\mathrm{g})$ : & $6.53 \mathrm{E}-07$ & $3.82 \mathrm{E}-07$ & $1.03 \mathrm{E}-06$ \\
\hline & Uncertainty in weight uranium leached $(\mathrm{g})$ : & $6.57 \mathrm{E}-08$ & $3.84 \mathrm{E}-08$ & $7.60 \mathrm{E}-08$ \\
\hline & Equivalent number of leached kernels: & $1.66 \mathrm{E}-03$ & $9.69 \mathrm{E}-04$ & $2.63 \mathrm{E}-03$ \\
\hline & Uncertainty in equivalent number of leached kernels: & $1.67 \mathrm{E}-04$ & $9.78 \mathrm{E}-05$ & $1.95 \mathrm{E}-04$ \\
\hline \multirow{5}{*}{$\mathbf{F e}$} & Measured concentration of impurity in sample $(\mu \mathrm{g} / \mathrm{ml})$ : & & & $\mathbf{F e}$ \\
\hline & Uncorrected weight of impurity in sample $(\mu \mathrm{g})$ : & & & \\
\hline & Weight of impurity in blank $(\mu \mathrm{g})$ : & & & \\
\hline & Minimum corrected weight of impurity in sample $(\mu \mathrm{g})$ : & & & \\
\hline & Maximum corrected weight of impurity in sample $(\mu \mathrm{g})$ : & & & \\
\hline \multirow{5}{*}{$\mathrm{Cr}$} & Measured concentration of impurity in sample $(\mu \mathrm{g} / \mathrm{ml})$ : & & & $\mathbf{C r}$ \\
\hline & Uncorrected weight of impurity in sample $(\mu \mathrm{g})$ : & & & \\
\hline & Weight of impurity in blank $(\mu \mathrm{g})$ : & & & \\
\hline & Minimum corrected weight of impurity in sample $(\mu \mathrm{g})$ : & & & \\
\hline & Maximum corrected weight of impurity in sample $(\mu \mathrm{g})$ : & & & \\
\hline \multirow{5}{*}{ Mn } & Measured concentration of impurity in sample $(\mu \mathrm{g} / \mathrm{ml})$ : & & & Mn \\
\hline & Uncorrected weight of impurity in sample $(\mu \mathrm{g})$ : & & & \\
\hline & Weight of impurity in blank $(\mu \mathrm{g})$ : & & & \\
\hline & Minimum corrected weight of impurity in sample $(\mu \mathrm{g})$ : & & & \\
\hline & Maximum corrected weight of impurity in sample $(\mu \mathrm{g})$ : & & & \\
\hline \multirow{5}{*}{ Co } & Measured concentration of impurity in sample $(\mu \mathrm{g} / \mathrm{ml})$ : & & & Co \\
\hline & Uncorrected weight of impurity in sample $(\mu \mathrm{g})$ : & & & \\
\hline & Weight of impurity in blank $(\mu \mathrm{g})$ : & & & \\
\hline & Minimum corrected weight of impurity in sample $(\mu \mathrm{g})$ : & & & \\
\hline & Maximum corrected weight of impurity in sample $(\mu \mathrm{g})$ : & & & \\
\hline \multirow{5}{*}{$\mathbf{N i}$} & Measured concentration of impurity in sample $(\mu \mathrm{g} / \mathrm{ml})$ : & & & $\mathrm{Ni}$ \\
\hline & Uncorrected weight of impurity in sample $(\mu \mathrm{g})$ : & & & \\
\hline & Weight of impurity in blank $(\mu \mathrm{g})$ : & & & \\
\hline & Minimum corrected weight of impurity in sample $(\mu \mathrm{g})$ : & & & \\
\hline & Maximum corrected weight of impurity in sample $(\mu \mathrm{g})$ : & & & \\
\hline \multirow{5}{*}{ Ca } & Measured concentration of impurity in sample $(\mu \mathrm{g} / \mathrm{ml})$ : & & & $\mathbf{C a}$ \\
\hline & Uncorrected weight of impurity in sample $(\mu \mathrm{g})$ : & & & \\
\hline & Weight of impurity in blank $(\mu \mathrm{g})$ : & & & \\
\hline & Minimum corrected weight of impurity in sample $(\mu \mathrm{g})$ : & & & \\
\hline & Maximum corrected weight of impurity in sample $(\mu \mathrm{g})$ : & & & \\
\hline \multirow{5}{*}{ AI } & Measured concentration of impurity in sample $(\mu \mathrm{g} / \mathrm{ml})$ : & & & Al \\
\hline & Uncorrected weight of impurity in sample $(\mu \mathrm{g})$ : & & & \\
\hline & Weight of impurity in blank $(\mu \mathrm{g})$ : & & & \\
\hline & Minimum corrected weight of impurity in sample $(\mu \mathrm{g})$ : & & & \\
\hline & Maximum corrected weight of impurity in sample $(\mu \mathrm{g})$ : & & & \\
\hline & Measured concentration of impurity in sample $(\mu \mathrm{g} / \mathrm{ml})$ : & & & Ti \\
\hline & Uncorrected weight of impurity in sample $(\mu \mathrm{g})$ : & & & \\
\hline Ti & Weight of impurity in blank $(\mu \mathrm{g})$ : & & & \\
\hline & Minimum corrected weight of impurity in sample $(\mu \mathrm{g})$ : & & & \\
\hline & Maximum corrected weight of impurity in sample $(\mu \mathrm{g})$ : & & & \\
\hline & Measured concentration of impurity in sample $(\mu \mathrm{g} / \mathrm{ml})$ : & & & $\mathbf{v}$ \\
\hline & Uncorrected weight of impurity in sample $(\mu \mathrm{g})$ : & & & \\
\hline v & Weight of impurity in blank $(\mu \mathrm{g})$ : & & & \\
\hline & Minimum corrected weight of impurity in sample $(\mu \mathrm{g})$ : & & & \\
\hline & Maximum corrected weight of impurity in sample $(\mu \mathrm{g}):$ & & & \\
\hline
\end{tabular}

Comments

\begin{tabular}{|l|}
\hline FCM checked the recorded data against the official Results of Analysis for RMAL19027 on 3/26/2019. \\
\hline
\end{tabular}

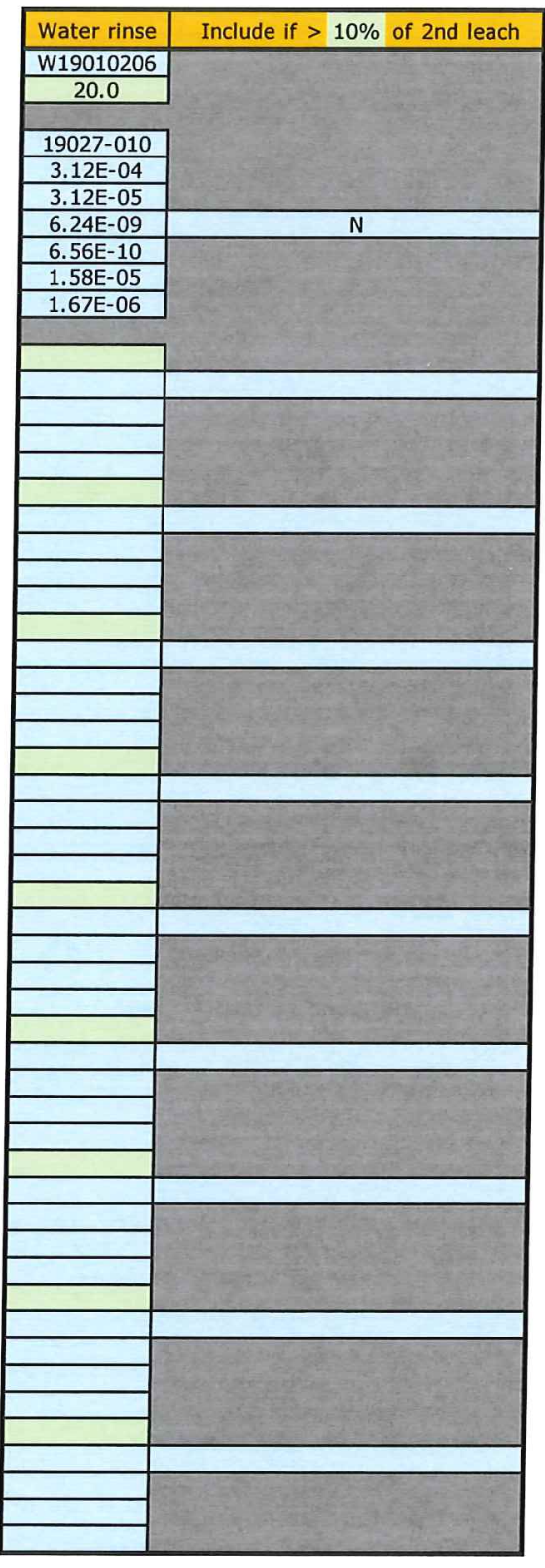

Fied c. Montgomeny

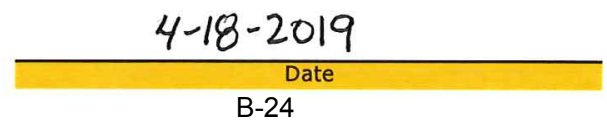




\section{Data Report Form DRF-21B: Post-Burn Leach Uranium and Impurities}

\begin{tabular}{|r|l|}
\hline Procedure: & AGR-CHAR-DAM-21 Rev. 2 \\
\hline Operator: & Montgomery \\
\hline Particle lot ID: & BWXT J52R-16-11035 \\
\hline Particle lot description: & AGR-5/6/7 overcoated particles, 40\% packing fraction \\
\hline Particle sample ID: & $11035-03$ \\
\hline DRF filename: & 11035 PF40 overcoated particles-Group 1_DLBL_ICPMS_DRF21R2.xIs \\
\hline
\end{tabular}

\begin{tabular}{|r|c|}
\hline Average weight per particle, mean value $(\mathrm{g}):$ & $2.010 \mathrm{E}-03$ \\
\hline Average weight per particle, uncertainty in mean $(\mathrm{g}):$ & $6.4 \mathrm{E}-06$ \\
\hline Weight of particle sample $(\mathrm{g}):$ & 34.9930 \\
\hline Approximate number of particles in sample: & 17409 \\
\hline Uncertainty in number of particles: & 55 \\
\hline Average weight uranium per particle, mean value $(\mathrm{g}):$ & $3.94 \mathrm{E}-04$ \\
\hline Average weight uranium per particle, uncertainty in mean $(\mathrm{g}):$ & $3.94 \mathrm{E}-06$ \\
\hline
\end{tabular}

\begin{tabular}{|c|c|c|c|c|}
\hline & First Leach & Second Leach & Total \\
\hline \multirow{2}{*}{\multicolumn{2}{|c|}{$\begin{array}{c}\text { Post-burn leach solution ID: } \\
\text { Total volume of leach solution }(\mathrm{ml}) \text { : }\end{array}$}} & B18123103 & B19010203 & \\
\hline & & 61.0 & 63.2 & \\
\hline & & & \\
\hline \multicolumn{2}{|c|}{$\begin{array}{c}\text { RMAL analysis number: } \\
\text { Measured uranium concentration }(\mu \mathrm{g} / \mathrm{ml})\end{array}$} & $\frac{19027-003}{1.18 \mathrm{E}-02}$ & $\frac{19027-007}{2.92 \mathrm{E}-03}$ & \\
\hline \multirow{2}{*}{\multicolumn{2}{|c|}{$\begin{array}{l}\text { Uncertainty in uranium concentration }(\mathrm{\mu g} / \mathrm{ml}) \text { : } \\
\text { Weight uranium leached }(\mathrm{g}) \text { : }\end{array}$}} & $\begin{array}{l}1.18 \mathrm{E}-02 \\
1.18 \mathrm{E}-03\end{array}$ & $\frac{2.92 \mathrm{E}-03}{2.92 \mathrm{E}-04}$ & \\
\hline & & $7.20 \mathrm{E}-07$ & $1.85 \mathrm{E}-07$ & $9.04 \mathrm{E}-07$ \\
\hline \multicolumn{2}{|r|}{ Uncertainty in weight uranium leached $(\mathrm{g})$ : } & $7.24 \mathrm{E}-08$ & $1.86 \mathrm{E}-08$ & $7.47 \mathrm{E}-08$ \\
\hline \multicolumn{2}{|r|}{ Equivalent number of leached kernels: } & $1.83 \mathrm{E}-03$ & $4.68 \mathrm{E}-04$ & $2.30 \mathrm{E}-03$ \\
\hline \multicolumn{2}{|r|}{ Uncertainty in equivalent number of leached kernels: } & $1.85 \mathrm{E}-04$ & $4.73 \mathrm{E}-05$ & $1.91 \mathrm{E}-04$ \\
\hline \multirow{5}{*}{$\mathbf{F e}$} & Measured concentration of impurity in sample $(\mu \mathrm{g} / \mathrm{ml})$ : & & & $\mathbf{F e}$ \\
\hline & Uncorrected weight of impurity in sample $(\mu \mathrm{g})$ : & & & \\
\hline & Weight of impurity in blank $(\mu \mathrm{g})$ : & & & \\
\hline & Minimum corrected weight of impurity in sample $(\mu \mathrm{g})$ : & & & \\
\hline & Maximum corrected weight of impurity in sample $(\mu g)$ : & & & \\
\hline \multirow{5}{*}{$\mathrm{Cr}$} & Measured concentration of impurity in sample $(\mathrm{\mu g} / \mathrm{ml})$ : & & & $\mathrm{Cr}$ \\
\hline & Uncorrected weight of impurity in sample $(\mu \mathrm{g})$ : & & & \\
\hline & Weight of impurity in blank $(\mu \mathrm{g})$ : & & & \\
\hline & Minimum corrected weight of impurity in sample $(\mu \mathrm{g})$ : & & & \\
\hline & Maximum corrected weight of impurity in sample $(\mu \mathrm{g})$ : & & & \\
\hline \multirow{5}{*}{ Mn } & Measured concentration of impurity in sample $(\mu \mathrm{g} / \mathrm{ml})$ : & & & Mn \\
\hline & Uncorrected weight of impurity in sample $(\mu \mathrm{g})$ : & & & \\
\hline & Weight of impurity in blank $(\mu \mathrm{g})$ : & & & \\
\hline & Minimum corrected weight of impurity in sample $(\mu \mathrm{g})$ : & & & \\
\hline & Maximum corrected weight of impurity in sample $(\mu \mathrm{g})$ : & & & \\
\hline \multirow{5}{*}{ Co } & Measured concentration of impurity in sample $(\mu \mathrm{g} / \mathrm{ml})$ : & & & Co \\
\hline & Uncorrected weight of impurity in sample $(\mu \mathrm{g})$ : & & & \\
\hline & Weight of impurity in blank $(\mu \mathrm{g})$ : & & & \\
\hline & Minimum corrected weight of impurity in sample $(\mu \mathrm{g})$ : & & & \\
\hline & Maximum corrected weight of impurity in sample $(\mu \mathrm{g})$ : & & & \\
\hline \multirow{5}{*}{$\mathbf{N i}$} & Measured concentration of impurity in sample $(\mu \mathrm{g} / \mathrm{ml})$ : & & & $\mathrm{Ni}$ \\
\hline & Uncorrected weight of impurity in sample $(\mu g)$ : & & & \\
\hline & Weight of impurity in blank $(\mu \mathrm{g})$ : & & & \\
\hline & Minimum corrected weight of impurity in sample $(\mathrm{\mu g})$ : & & & \\
\hline & Maximum corrected weight of impurity in sample $(\mu \mathrm{g})$ : & & & \\
\hline \multirow{5}{*}{$\mathrm{Ca}$} & Measured concentration of impurity in sample $(\mu \mathrm{g} / \mathrm{ml})$ : & & & $\mathrm{Ca}$ \\
\hline & Uncorrected weight of impurity in sample $(\mu \mathrm{g})$ : & & & \\
\hline & Weight of impurity in blank $(\mu \mathrm{g})$ : & & & \\
\hline & Minimum corrected weight of impurity in sample $(\mu \mathrm{g})$ : & & & \\
\hline & Maximum corrected weight of impurity in sample $(\mu \mathrm{g})$ : & & & \\
\hline \multirow{5}{*}{ AI } & Measured concentration of impurity in sample $(\mu \mathrm{g} / \mathrm{ml})$ : & & & Al \\
\hline & Uncorrected weight of impurity in sample $(\mu \mathrm{g})$ : & & & \\
\hline & Weight of impurity in blank $(\mu \mathrm{g})$ : & & & \\
\hline & Minimum corrected weight of impurity in sample $(\mu \mathrm{g}):$ & & & \\
\hline & Maximum corrected weight of impurity in sample $(\mu \mathrm{g})$ : & & & \\
\hline \multirow{5}{*}{$\mathbf{T i}$} & Measured concentration of impurity in sample $(\mu \mathrm{g} / \mathrm{ml})$ : & & & $\mathrm{Ti}$ \\
\hline & Uncorrected weight of impurity in sample $(\mu \mathrm{g})$ : & & & \\
\hline & Weight of impurity in blank $(\mu \mathrm{g})$ : & & & \\
\hline & Minimum corrected weight of impurity in sample $(\mu \mathrm{g}):$ & & & \\
\hline & Maximum corrected weight of impurity in sample $(\mu \mathrm{g})$ : & & & \\
\hline \multirow{5}{*}{$\mathbf{v}$} & Measured concentration of impurity in sample $(\mu \mathrm{g} / \mathrm{ml}):$ & & & $\mathbf{v}$ \\
\hline & Uncorrected weight of impurity in sample $(\mu \mathrm{g})$ : & & & \\
\hline & Weight of impurity in blank $(\mu \mathrm{g})$ : & & & \\
\hline & Minimum corrected weight of impurity in sample $(\mu \mathrm{g})$ : & & & \\
\hline & Maximum corrected weight of impurity in sample $(\mu \mathrm{g}):$ & & & \\
\hline
\end{tabular}

Comments

FCM checked the recorded data against the official Results of Analysis for RMAL19027 on 3/26/2019.

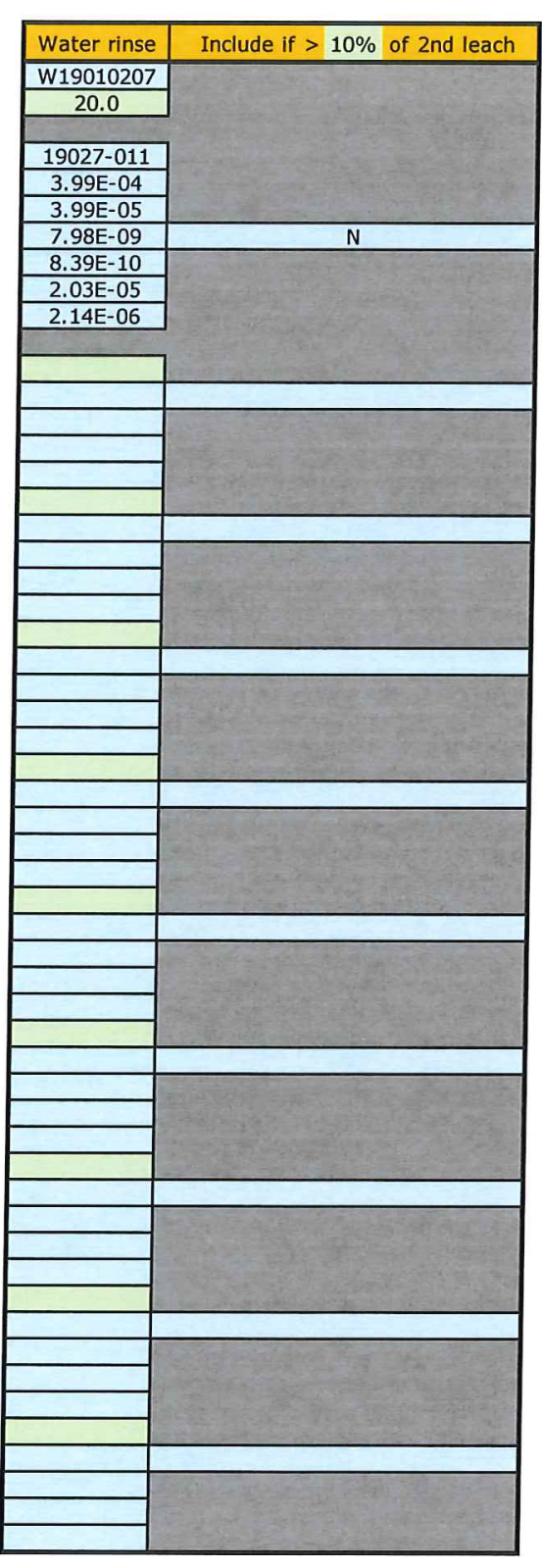


Data Report Form DRF-21B: Post-Burn Leach Uranium and Impurities

\begin{tabular}{|r|l|}
\hline Procedure: & AGR-CHAR-DAM-21 Rev. 2 \\
\hline Operator: & Montgomery \\
\hline Particle lot ID: & BWXT J52R-16-11035 \\
\hline Particle lot description: & AGR-5/6/7 overcoated particles, 40\% packing fraction \\
\hline Particle sample ID: & $11035-04$ \\
\hline DRF filename: & 11035 PF40 overcoated particles-Group 1_DLBL_ICPMS_DRF21R2.xIs \\
\hline
\end{tabular}

\begin{tabular}{|c|c|c|c|c|}
\hline \multicolumn{2}{|r|}{$\begin{array}{ll}\text { Average weight per particle, mean value }(\mathrm{g}) \text { : }\end{array}$} & \multicolumn{3}{|c|}{$2.010 \mathrm{E}-03$} \\
\hline & Average weight per particle, uncertainty in mean $(\mathrm{g})$ : & \multicolumn{3}{|c|}{$6.4 \mathrm{E}-06$} \\
\hline & Weight of particle sample $(\mathrm{g})$ : & \multicolumn{3}{|c|}{34.9930} \\
\hline & Approximate number of particles in sample: & \multicolumn{3}{|c|}{17409} \\
\hline & Uncertainty in number of particles: & \multicolumn{3}{|c|}{55} \\
\hline & Average weight uranium per particle, mean value $(\mathrm{g})$ : & \multicolumn{3}{|c|}{$3.94 \mathrm{E}-04$} \\
\hline \multicolumn{2}{|r|}{ Average weight uranium per particle, uncertainty in mean $(g)$ : } & \multicolumn{3}{|c|}{$3.94 \mathrm{E}-06$} \\
\hline & & First Leach & Second Leach & Total \\
\hline & Post-burn leach solution ID: & B18123104 & B19010204 & \\
\hline & Total volume of leach solution $(\mathrm{ml})$ : & 60.8 & 64.8 & \\
\hline & RMAL analysis number: & & & \\
\hline & Measured uranium concentration $(\mu \mathrm{g} / \mathrm{ml})$ : & $\frac{1902 /-004}{1.36 \mathrm{E}-02}$ & $\frac{19027-008}{1.58 \mathrm{E}-03}$ & \\
\hline & Uncertainty in uranium concentration $(\mu \mathrm{g} / \mathrm{ml})$ : & $1.36 \mathrm{E}-03$ & $1.58 \mathrm{E}-04$ & \\
\hline & Weight uranium leached $(\mathrm{g})$ : & $8.27 \mathrm{E}-07$ & $1.02 \mathrm{E}-07$ & $9.29 \mathrm{E}-07$ \\
\hline & Uncertainty in weight uranium leached $(\mathrm{g})$ : & $8.32 \mathrm{E}-08$ & $1.03 \mathrm{E}-08$ & $8.38 \mathrm{E}-08$ \\
\hline & Equivalent number of leached kernels: & $2.10 \mathrm{E}-03$ & $2.60 \mathrm{E}-04$ & $2.36 \mathrm{E}-03$ \\
\hline & Uncertainty in equivalent number of leached kernels: & $2.12 \mathrm{E}-04$ & $2.62 \mathrm{E}-05$ & $2.14 \mathrm{E}-04$ \\
\hline \multirow{5}{*}{$\mathbf{F e}$} & Measured concentration of impurity in sample $(\mu \mathrm{g} / \mathrm{ml})$ : & & & $\mathrm{Fe}$ \\
\hline & Uncorrected weight of impurity in sample $(\mu \mathrm{g})$ : & & & \\
\hline & Weight of impurity in blank $(\mu \mathrm{g})$ : & & & \\
\hline & Minimum corrected weight of impurity in sample $(\mu \mathrm{g})$ : & & & \\
\hline & Maximum corrected weight of impurity in sample $(\mu \mathrm{g})$ : & & & \\
\hline \multirow{5}{*}{$\mathrm{Cr}$} & Measured concentration of impurity in sample $(\mu \mathrm{g} / \mathrm{ml})$ : & & & $\mathbf{C r}$ \\
\hline & Uncorrected weight of impurity in sample $(\mu \mathrm{g})$ : & & & \\
\hline & Weight of impurity in blank $(\mu \mathrm{g})$ : & & & \\
\hline & Minimum corrected weight of impurity in sample $(\mu \mathrm{g})$ : & & & \\
\hline & Maximum corrected weight of impurity in sample $(\mu g)$ : & & & \\
\hline \multirow{5}{*}{ Mn } & Measured concentration of impurity in sample $(\mu \mathrm{g} / \mathrm{ml})$ : & & & Mn \\
\hline & Uncorrected weight of impurity in sample $(\mu \mathrm{g})$ : & & & \\
\hline & Weight of impurity in blank $(\mu \mathrm{g})$ : & & & \\
\hline & Minimum corrected weight of impurity in sample $(\mu \mathrm{g})$ : & & & \\
\hline & Maximum corrected weight of impurity in sample $(\mu \mathrm{g})$ : & & & \\
\hline \multirow{5}{*}{ Co } & Measured concentration of impurity in sample $(\mu \mathrm{g} / \mathrm{ml})$ : & & & Co \\
\hline & Uncorrected weight of impurity in sample $(\mu \mathrm{g})$ : & & & \\
\hline & Weight of impurity in blank $(\mu \mathrm{g})$ : & & & \\
\hline & Minimum corrected weight of impurity in sample $(\mu \mathrm{g})$ : & & & \\
\hline & Maximum corrected weight of impurity in sample $(\mu g)$ : & & & \\
\hline \multirow{5}{*}{$\mathbf{N i}$} & Measured concentration of impurity in sample $(\mu \mathrm{g} / \mathrm{ml})$ : & & & $\mathrm{Ni}$ \\
\hline & Uncorrected weight of impurity in sample $(\mu \mathrm{g})$ : & & & \\
\hline & Weight of impurity in blank $(\mu \mathrm{g})$ : & & & \\
\hline & Minimum corrected weight of impurity in sample $(\mu \mathrm{g})$ : & & & \\
\hline & Maximum corrected weight of impurity in sample $(\mu g)$ : & & & \\
\hline \multirow{5}{*}{$\mathbf{C a}$} & Measured concentration of impurity in sample $(\mu \mathrm{g} / \mathrm{ml})$ : & & & $\mathrm{Ca}$ \\
\hline & Uncorrected weight of impurity in sample $(\mu \mathrm{g})$ : & & & \\
\hline & Weight of impurity in blank $(\mu \mathrm{g})$ : & & & \\
\hline & Minimum corrected weight of impurity in sample $(\mu \mathrm{g})$ : & & & \\
\hline & Maximum corrected weight of impurity in sample $(\mu \mathrm{g})$ : & & & \\
\hline \multirow{5}{*}{ Al } & Measured concentration of impurity in sample $(\mu \mathrm{g} / \mathrm{ml})$ : & & & Al \\
\hline & Uncorrected weight of impurity in sample $(\mu \mathrm{g})$ : & & & \\
\hline & Weight of impurity in blank $(\mu \mathrm{gg})$ : & & & \\
\hline & Minimum corrected weight of impurity in sample $(\mu \mathrm{g})$ : & & & \\
\hline & Maximum corrected weight of impurity in sample $(\mu \mathrm{g})$ : & & & \\
\hline & Measured concentration of impurity in sample $(\mu \mathrm{g} / \mathrm{ml})$ : & & & $\mathbf{T i}$ \\
\hline & Uncorrected weight of impurity in sample $(\mu \mathrm{g})$ : & & & \\
\hline Ti & Weight of impurity in blank $(\mu \mathrm{g}):$ & & & \\
\hline & Minimum corrected weight of impurity in sample $(\mu \mathrm{g})$ : & & & \\
\hline & Maximum corrected weight of impurity in sample $(\mu \mathrm{g})$ : & & & \\
\hline & Measured concentration of impurity in sample $(\mu \mathrm{g} / \mathrm{ml})$ : & & & $\mathbf{V}$ \\
\hline & Uncorrected weight of impurity in sample $(\mu \mathrm{g})$ : & & & \\
\hline v & Weight of impurity in blank $(\mu \mathrm{g})$ : & & & \\
\hline & Minimum corrected weight of impurity in sample $(\mu \mathrm{g})$ : & & & \\
\hline & Maximum corrected weight of impurity in sample $(\mu \mathrm{g})$ : & & & \\
\hline
\end{tabular}

comments

FCM checked the recorded data against the of ficial Results of Analysis for RMAL19027 on 3/26/2019.

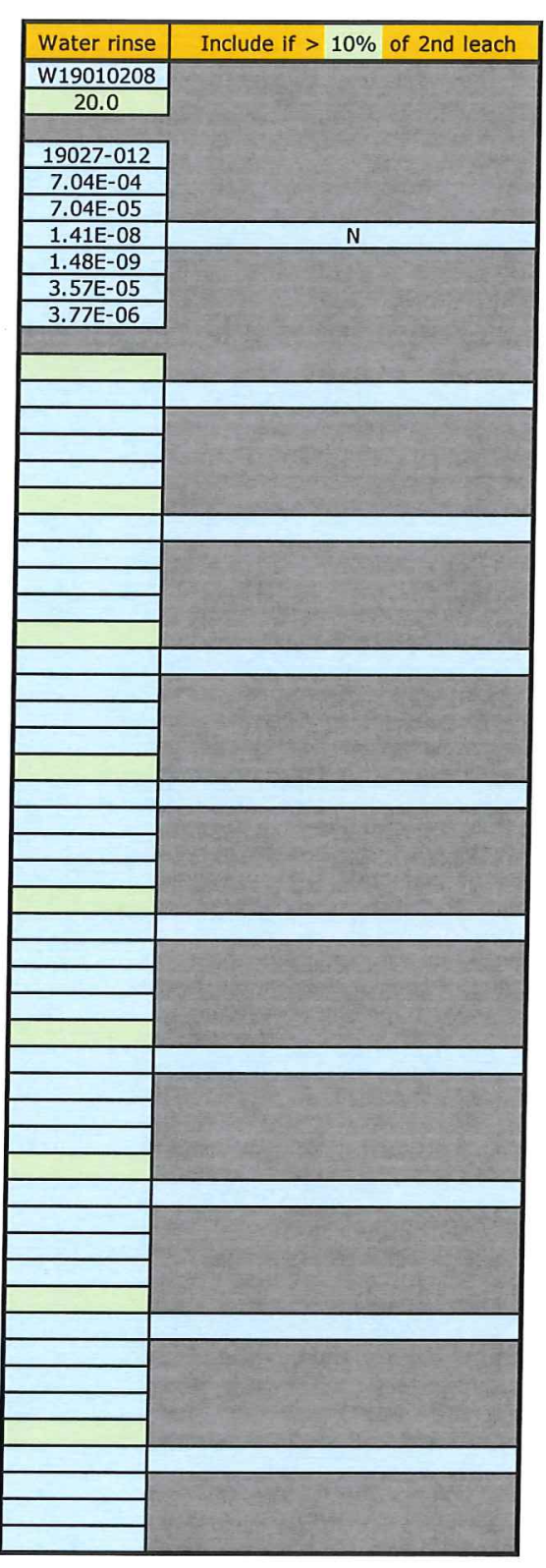


Data Report Form DRF-21A: Pre-Burn Leach Uranium and Impurities

\begin{tabular}{|r|l|}
\hline Procedure: & AGR-CHAR-DAM-21 Rev. 2 \\
\hline Operator: & Montgomery \\
\hline Particle lot ID: & BWXT J52R-16-11035 \\
\hline Particle lot description: & AGR-5/6/7 overcoated particles, 40\% packing fraction \\
\hline Particle sample ID: & $11035-05$ \\
\hline DRF filename: & 11035 PF 40 overcoated particles-Group 2_DLBL_ICPMS_DRF21R2.xIs \\
\hline
\end{tabular}

\begin{tabular}{|c|c|c|c|c|}
\hline & Average weight per particle, mean value $(g)$ : & & $2.010 \mathrm{E}-03$ & \\
\hline & Average weight per particle, uncertainty in mean $(\mathrm{g})$ : & & $6.4 \mathrm{E}-06$ & \\
\hline & Weight of particle sample $(\mathrm{g})$ : & & 34.9526 & \\
\hline & Approximate number of particles in sample: & & 17389 & \\
\hline & Uncertainty in number of particles: & & 55 & \\
\hline & Average weight uranium per particle, mean value $(\mathrm{g})$ : & & $3.94 \mathrm{E}-04$ & \\
\hline & age weight uranium per particle, uncertainty in mean $(g)$ : & & $3.94 \mathrm{E}-06$ & \\
\hline & & First Leach & Second Leach & Total \\
\hline & Pre-burn leach solution ID: & L19032101 & $\underline{L 19032501}$ & \\
\hline & Total volume of leach solution $(\mathrm{ml})$ : & 100.0 & 134.0 & \\
\hline & RMAL analysis number: & $19232-001$ & $19232-003$ & \\
\hline & Measured uranium concentration $(\mu \mathrm{g} / \mathrm{ml})$ : & $3.23 \mathrm{E}-01$ & $2.17 \mathrm{E}-02$ & \\
\hline & Uncertainty in uranium concentration $(\mu \mathrm{g} / \mathrm{ml})$ : & $3.23 \mathrm{E}-02$ & $2.17 \mathrm{E}-03$ & \\
\hline & Weight uranium leached $(g)$ : & $3.23 \mathrm{E}-05$ & $2.91 \mathrm{E}-06$ & $3.52 \mathrm{E}-05$ \\
\hline & Uncertainty in weight uranium leached $(\mathrm{g})$ : & $3.24 \mathrm{E}-06$ & $2.91 \mathrm{E}-07$ & $3.25 \mathrm{E}-06$ \\
\hline & Equivalent number of leached kernels: & $8.20 \mathrm{E}-02$ & $7.38 \mathrm{E}-03$ & $8.94 \mathrm{E}-02$ \\
\hline & Uncertainty in equivalent number of leached kernels: & $8.26 \mathrm{E}-03$ & $7.43 \mathrm{E}-04$ & $8.30 \mathrm{E}-03$ \\
\hline & Measured concentration of impurity in sample $(\mu \mathrm{g} / \mathrm{ml})$ : & & & \\
\hline & Uncorrected weight of impurity in sample $(\mu \mathrm{g})$ : & & & $\mathbf{F e}$ \\
\hline $\mathbf{F e}$ & Weight of impurity in blank $(\mu \mathrm{g})$ : & & & \\
\hline & Minimum corrected weight of impurity in sample $(\mu \mathrm{g})$ : & & & \\
\hline & Maximum corrected weight of impurity in sample $(\mu \mathrm{g})$ : & & & \\
\hline & Measured concentration of impurity in sample $(\mu \mathrm{g} / \mathrm{ml})$ : & & & $\mathbf{C r}$ \\
\hline & Uncorrected weight of impurity in sample $(\mu \mathrm{g})$ : & & & \\
\hline Cr & Weight of impurity in blank $(\mu \mathrm{g})$ : & & & \\
\hline & Minimum corrected weight of impurity in sample $(\mu \mathrm{g})$ : & & & \\
\hline & Maximum corrected weight of impurity in sample $(\mu \mathrm{g})$ : & & & \\
\hline & Measured concentration of impurity in sample $(\mu \mathrm{g} / \mathrm{ml})$ : & & & Mn \\
\hline & Uncorrected weight of impurity in sample $(\mu \mathrm{g})$ : & & & \\
\hline Mn & Weight of impurity in blank $(\mu \mathrm{g})$ : & & & \\
\hline & Minimum corrected weight of impurity in sample $(\mu \mathrm{g})$ : & & & \\
\hline & Maximum corrected weight of impurity in sample $(\mu \mathrm{g})$ : & & & \\
\hline & Measured concentration of impurity in sample $(\mu \mathrm{g} / \mathrm{ml})$ : & & & Co \\
\hline & Uncorrected weight of impurity in sample $(\mu \mathrm{g})$ : & & & \\
\hline Co & Weight of impurity in blank $(\mu \mathrm{g})$ : & & & \\
\hline & Minimum corrected weight of impurity in sample $(\mu \mathrm{g})$ : & & & \\
\hline & Maximum corrected weight of impurity in sample $(\mu \mathrm{g})$ : & & & \\
\hline & Measured concentration of impurity in sample $(\mu \mathrm{g} / \mathrm{ml})$ : & & & $\mathrm{Ni}$ \\
\hline & Uncorrected weight of impurity in sample $(\mu \mathrm{g})$ : & & & \\
\hline $\mathbf{N i}$ & Weight of impurity in blank $(\mu \mathrm{g})$ : & & & \\
\hline & Minimum corrected weight of impurity in sample $(\mu \mathrm{g})$ : & & & \\
\hline & Maximum corrected weight of impurity in sample $(\mu g)$ : & & & \\
\hline & Measured concentration of impurity in sample $(\mu \mathrm{g} / \mathrm{ml})$ : & & & $\mathbf{C a}$ \\
\hline & Uncorrected weight of impurity in sample $(\mu \mathrm{g})$ : & & & \\
\hline $\mathrm{Ca}$ & Weight of impurity in blank $(\mu \mathrm{g})$ : & & & \\
\hline & Minimum corrected weight of impurity in sample $(\mu \mathrm{g})$ : & & & \\
\hline & Maximum corrected weight of impurity in sample $(\mu \mathrm{g}):$ & & & \\
\hline & Measured concentration of impurity in sample $(\mu \mathrm{g} / \mathrm{ml})$ : & & & Al \\
\hline & Uncorrected weight of impurity in sample $(\mu \mathrm{g})$ : & & & \\
\hline Al & Weight of impurity in blank $(\mu \mathrm{g})$ : & & & \\
\hline & Minimum corrected weight of impurity in sample $(\mu \mathrm{g})$ : & & & \\
\hline & Maximum corrected weight of impurity in sample $(\mu g)$ : & & & \\
\hline & Measured concentration of impurity in sample $(\mu \mathrm{g} / \mathrm{ml})$ : & & & $\mathbf{T i}$ \\
\hline & Uncorrected weight of impurity in sample $(\mu \mathrm{g})$ : & & & \\
\hline Ti & Weight of impurity in blank $(\mu \mathrm{g})$ : & & & \\
\hline & Minimum corrected weight of impurity in sample $(\mu \mathrm{g})$ : & & & \\
\hline & Maximum corrected weight of impurity in sample $(\mu \mathrm{g})$ : & & & \\
\hline & Measured concentration of impurity in sample $(\mu \mathrm{g} / \mathrm{ml})$ : & & & $\mathbf{v}$ \\
\hline & Uncorrected weight of impurity in sample $(\mu \mathrm{g})$ : & & & \\
\hline v & Weight of impurity in blank $(\mu \mathrm{g}):$ & & & \\
\hline & Minimum corrected weight of impurity in sample $(\mu \mathrm{g})$ : & & & \\
\hline & Maximum corrected weight of impurity in sample $(\mu \mathrm{g})$ : & & & \\
\hline
\end{tabular}

Comments

Leached in Vessel \#51 (previously unused).

FCM checked the recorded data against the official Results of Analysis for RMAL19232 on 4/12/2019.

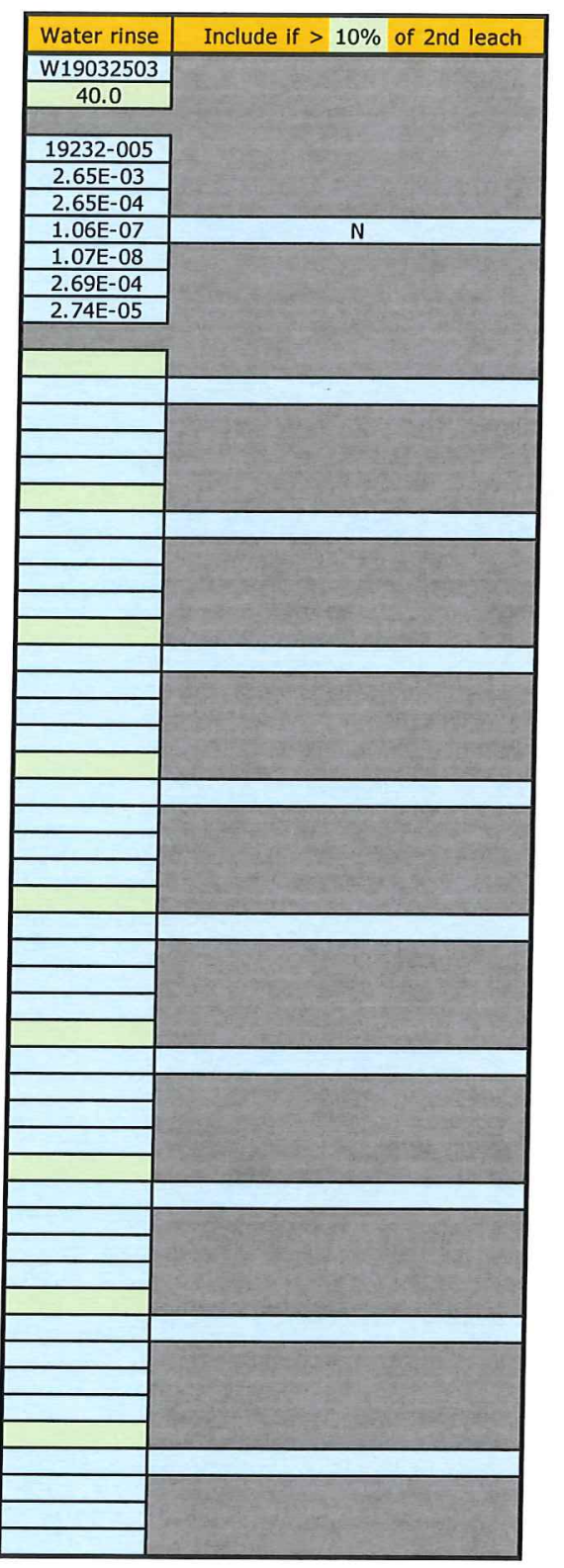


Data Report Form DRF-21A: Pre-Burn Leach Uranium and Impurities

\begin{tabular}{|r|l|}
\hline Procedure: & AGR-CHAR-DAM-21 Rev. 2 \\
\hline Operator: & Montgomery \\
\hline Particle lot ID: & BWXT J52R-16-11035 \\
\hline Particle lot description: & AGR-5/6/7 overcoated particles, 40\% packing fraction \\
\hline Particle sample ID: & $11035-06$ \\
\hline DRF filename: & 11035 PF40 overcoated particles-Group 2_DLBL_ICPMS DRF21R2.xls \\
\hline
\end{tabular}

\begin{tabular}{|c|c|c|c|c|}
\hline \multicolumn{2}{|c|}{ Average weight per particle, mean value $(g):$} & \multicolumn{3}{|c|}{$2.010 \mathrm{E}-03$} \\
\hline & Average weight per particle, uncertainty in mean $(\mathrm{g})$ : & \multicolumn{3}{|c|}{$6.4 \mathrm{E}-06$} \\
\hline & Weight of particle sample $(\mathrm{g})$ : & \multicolumn{3}{|c|}{34.9015} \\
\hline & Approximate number of particles in sample: & \multicolumn{3}{|c|}{17364} \\
\hline & Uncertainty in number of particles: & \multicolumn{3}{|c|}{55} \\
\hline & Average weight uranium per particle, mean value $(\mathrm{g})$ : & \multicolumn{3}{|c|}{$3.94 \mathrm{E}-04$} \\
\hline \multicolumn{2}{|r|}{ Average weight uranium per particle, uncertainty in mean $(\mathrm{g})$ : } & \multicolumn{3}{|c|}{$3.94 \mathrm{E}-06$} \\
\hline & & First Leach & Second Leach & Total \\
\hline & Pre-burn leach solution ID: & L19032102 & L19032502 & \\
\hline & Total volume of leach solution $(\mathrm{ml})$ : & 102.0 & 136.0 & \\
\hline & RMAL analysis number: & $19232-002$ & $19232-004$ & \\
\hline & Measured uranium concentration $(\mu \mathrm{g} / \mathrm{ml})$ : & $3.01 \mathrm{E}-01$ & $1.74 \mathrm{E}-02$ & \\
\hline & Uncertainty in uranium concentration $(\mu \mathrm{g} / \mathrm{ml})$ : & $3.01 \mathrm{E}-02$ & $1.74 \mathrm{E}-03$ & \\
\hline & Weight uranium leached $(g)$ : & $3.07 E-05$ & $2.37 \mathrm{E}-06$ & $3.31 \mathrm{E}-05$ \\
\hline & Uncertainty in weight uranium leached $(g)$ : & $3.08 \mathrm{E}-06$ & $2.37 E-07$ & $3.09 \mathrm{E}-06$ \\
\hline & Equivalent number of leached kernels: & $7.79 \mathrm{E}-02$ & $6.01 \mathrm{E}-03$ & $8.39 \mathrm{E}-02$ \\
\hline & Uncertainty in equivalent number of leached kernels: & $7.85 \mathrm{E}-03$ & $6.04 \mathrm{E}-04$ & $7.88 \mathrm{E}-03$ \\
\hline \multirow{5}{*}{$\mathbf{F e}$} & Measured concentration of impurity in sample $(\mu \mathrm{g} / \mathrm{ml})$ : & & & $\mathbf{F e}$ \\
\hline & Uncorrected weight of impurity in sample $(\mu \mathrm{g})$ : & & & \\
\hline & Weight of impurity in blank $(\mu \mathrm{g})$ : & & & \\
\hline & Minimum corrected weight of impurity in sample $(\mu \mathrm{g})$ : & & & \\
\hline & Maximum corrected weight of impurity in sample $(\mu \mathrm{g})$ : & & & \\
\hline \multirow{5}{*}{$\mathbf{C r}$} & Measured concentration of impurity in sample $(\mu \mathrm{g} / \mathrm{ml})$ : & & & $\mathrm{Cr}$ \\
\hline & Uncorrected weight of impurity in sample $(\mu \mathrm{g})$ : & & & \\
\hline & Weight of impurity in blank $(\mu \mathrm{g})$ : & & & \\
\hline & Minimum corrected weight of impurity in sample $(\mu g)$ : & & & \\
\hline & Maximum corrected weight of impurity in sample $(\mu \mathrm{g})$ : & & & \\
\hline \multirow{5}{*}{ Mn } & Measured concentration of impurity in sample $(\mu \mathrm{g} / \mathrm{ml})$ : & & & Mn \\
\hline & Uncorrected weight of impurity in sample $(\mu \mathrm{g})$ : & & & \\
\hline & Weight of impurity in blank $(\mu \mathrm{g})$ : & & & \\
\hline & Minimum corrected weight of impurity in sample $(\mu g)$ : & & & \\
\hline & Maximum corrected weight of impurity in sample $(\mu \mathrm{g})$ : & & & \\
\hline \multirow{5}{*}{ Co } & Measured concentration of impurity in sample $(\mu \mathrm{g} / \mathrm{ml})$ : & & & Co \\
\hline & Uncorrected weight of impurity in sample $(\mu \mathrm{g})$ : & & & \\
\hline & Weight of impurity in blank $(\mu \mathrm{g})$ : & & & \\
\hline & Minimum corrected weight of impurity in sample $(\mu \mathrm{g})$ : & & & \\
\hline & Maximum corrected weight of impurity in sample $(\mu \mathrm{g})$ : & & & \\
\hline \multirow{5}{*}{$\mathbf{N i}$} & Measured concentration of impurity in sample $(\mu \mathrm{g} / \mathrm{ml})$ : & & & $\mathbf{N i}$ \\
\hline & Uncorrected weight of impurity in sample $(\mu \mathrm{g})$ : & & & \\
\hline & Weight of impurity in blank $(\mu \mathrm{g})$ : & & & \\
\hline & Minimum corrected weight of impurity in sample $(\mu \mathrm{g})$ : & & & \\
\hline & Maximum corrected weight of impurity in sample $(\mu \mathrm{g})$ : & & & \\
\hline \multirow{5}{*}{$\mathrm{Ca}$} & Measured concentration of impurity in sample $(\mathrm{\mu g} / \mathrm{ml})$ : & & & $\mathrm{Ca}$ \\
\hline & Uncorrected weight of impurity in sample $(\mu \mathrm{g})$ : & & & \\
\hline & Weight of impurity in blank $(\mu \mathrm{g})$ : & & & \\
\hline & Minimum corrected weight of impurity in sample $(\mu \mathrm{g})$ : & & & \\
\hline & Maximum corrected weight of impurity in sample $(\mu \mathrm{g})$ : & & & \\
\hline \multirow{5}{*}{ Al } & Measured concentration of impurity in sample $(\mu \mathrm{g} / \mathrm{ml})$ : & & & Al \\
\hline & Uncorrected weight of impurity in sample $(\mu \mathrm{g})$ : & & & \\
\hline & Weight of impurity in blank $(\mu \mathrm{g})$ : & & & \\
\hline & Minimum corrected weight of impurity in sample $(\mu \mathrm{g})$ : & & & \\
\hline & Maximum corrected weight of impurity in sample $(\mu \mathrm{g})$ : & & & \\
\hline & Measured concentration of impurity in sample $(\mu \mathrm{g} / \mathrm{ml})$ : & & & $\mathbf{T i}$ \\
\hline & Uncorrected weight of impurity in sample $(\mu \mathrm{g})$ : & & & \\
\hline Ti & Weight of impurity in blank $(\mu \mathrm{g})$ : & & & \\
\hline & Minimum corrected weight of impurity in sample $(\mu \mathrm{g})$ : & & & \\
\hline & Maximum corrected weight of impurity in sample $(\mu \mathrm{g})$ : & & & \\
\hline & Measured concentration of impurity in sample $(\mu \mathrm{g} / \mathrm{ml})$ : & & & v \\
\hline & Uncorrected weight of impurity in sample $(\mu \mathrm{g})$ : & & & \\
\hline v & Weight of impurity in blank $(\mu \mathrm{g})$ : & & & \\
\hline & Minimum corrected weight of impurity in sample $(\mu \mathrm{g})$ : & & & \\
\hline & Maximum corrected weight of impurity in sample $(\mu \mathrm{g})$ : & & & \\
\hline
\end{tabular}

comments

Leached in Vessel \#52 (previously unused).

FCM checked the recorded data against the official Results of Analysis for RMAL19232 on 4/12/2019.

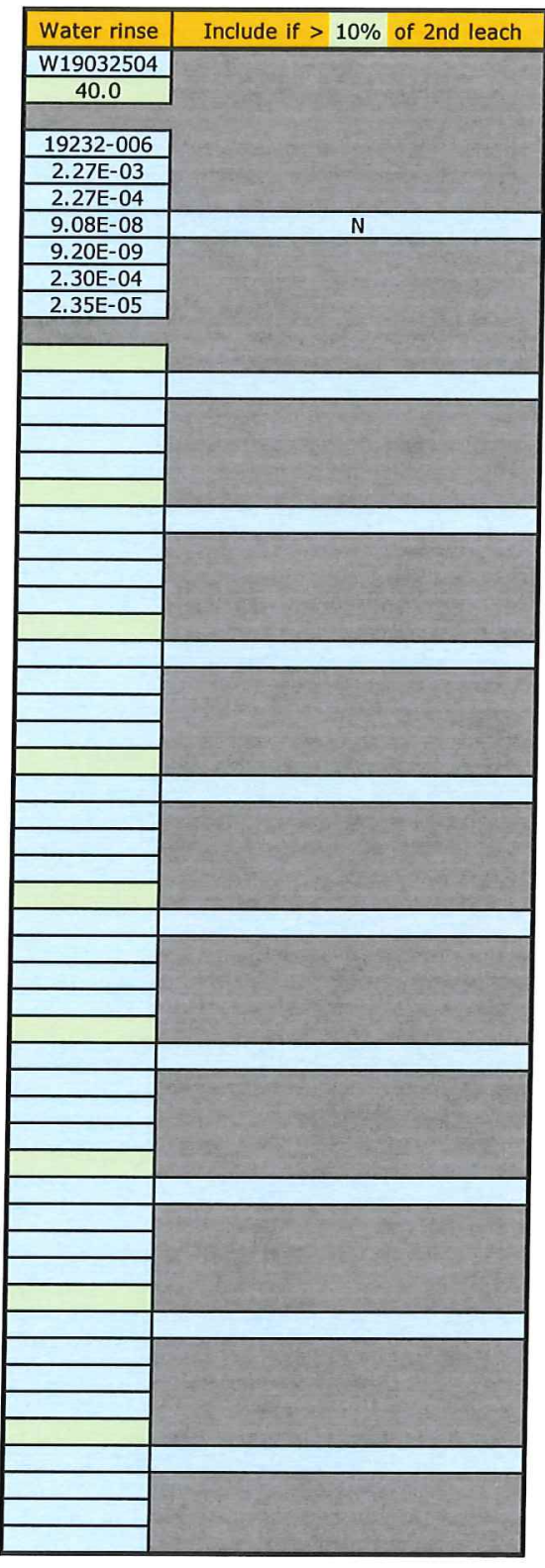


Data Report Form DRF-21A: Pre-Burn Leach Uranium and Impurities

Procedure: AGR-CHAR-DAM-21 Rev. 2

Operator: Montgomery

Particle lot ID: BWXT J52R-16-11035

Particle lot description: AGR-5/6/7 overcoated particles, $40 \%$ packing fraction

Particle sample ID: $11035-07$

DRF filename: 11035_PF40 overcoated particles-Group 2_DLBL_ICPMS_DRF21R2.xIs

\begin{tabular}{|r|c|}
\hline Average weight per particle, mean value $(\mathrm{g}):$ & $2.010 \mathrm{E}-03$ \\
\hline Average weight per particle, uncertainty in mean $(\mathrm{g})$ & $6.4 \mathrm{E}-06$ \\
\hline Weight of particle sample $(\mathrm{g}:$ & 34.9633 \\
\hline Approximate number of particles in sample: & 17395 \\
\hline Uncertainty in number of particles: & 55 \\
\hline Average weight uranium per particle, mean value $(\mathrm{g}):$ & $3.94 \mathrm{E}-04$ \\
\hline Average weight uranium per particle, uncertainty in mean $(\mathrm{g}):$ & $3.94 \mathrm{E}-06$ \\
\hline
\end{tabular}

\begin{tabular}{|c|c|c|c|c|}
\hline & \\
\hline & & First Leach & Second Leach & Total \\
\hline \multirow{2}{*}{\multicolumn{2}{|c|}{ 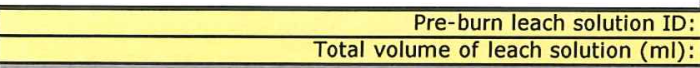 }} & L19032601 & L19032801 & \\
\hline & & 135.0 & 168.0 & \\
\hline \multirow{2}{*}{\multicolumn{2}{|c|}{$\begin{array}{r}\text { RMAL analysis number: } \\
\text { Measured uranium concentration }(\mu \mathrm{g} / \mathrm{ml}) \text { : }\end{array}$}} & $19240-001$ & $19240-003$ & \\
\hline \multirow{2}{*}{\multicolumn{2}{|c|}{$\begin{array}{c}\text { Measured uranium concentration }(\mu \mathrm{g} / \mathrm{ml}) \text { : } \\
\text { Uncertainty in uranium concentration }(\mu \mathrm{g} / \mathrm{ml}) \text { : }\end{array}$}} & $2.56 \mathrm{E}-01$ & $9.72 \mathrm{E}-03$ & \\
\hline & & $2.56 \mathrm{E}-02$ & $9.72 \mathrm{E}-04$ & \\
\hline \multirow{2}{*}{\multicolumn{2}{|c|}{\begin{tabular}{|c|} 
Weight uranium leached $(\mathrm{g}):$ \\
Uncertainty in weight uranium leached $(\mathrm{g}):$
\end{tabular}}} & $3.46 \mathrm{E}-05$ & $1.63 \mathrm{E}-06$ & $3.62 \mathrm{E}-05$ \\
\hline & & $3.46 \mathrm{E}-06$ & $1.63 \mathrm{E}-07$ & $3.46 \mathrm{E}-06$ \\
\hline \multirow{2}{*}{\multicolumn{2}{|c|}{$\begin{array}{c}\text { Equivalent number of leached kernels: } \\
\text { Uncertainty in equivalent number of leached kernels: }\end{array}$}} & $8.77 \mathrm{E}-02$ & $4.14 \mathrm{E}-03$ & $9.19 \mathrm{E}-02$ \\
\hline \multirow{2}{*}{\multicolumn{2}{|c|}{ 1 t }} & $8.83 \mathrm{E}-03$ & $4.17 \mathrm{E}-04$ & $8.84 \mathrm{E}-03$ \\
\hline & & & & $\mathrm{Fe}$ \\
\hline \multirow{4}{*}{$\mathbf{F e}$} & Uncorrected weight of impurity in sample $(\mu \mathrm{g})$ : & & & \\
\hline & Weight of impurity in blank $(\mu \mathrm{g})$ : & & & \\
\hline & Minimum corrected weight of impurity in sample $(\mu \mathrm{g})$ : & & & \\
\hline & Maximum corrected weight of impurity in sample $(\mu \mathrm{g})$ : & & & \\
\hline \multirow{5}{*}{$\mathrm{Cr}$} & Measured concentration of impurity in sample $(\mu \mathrm{g} / \mathrm{ml})$ : & & & $\mathrm{Cr}$ \\
\hline & Uncorrected weight of impurity in sample $(\mu \mathrm{g})$ : & & & \\
\hline & Weight of impurity in blank $(\mu \mathrm{g})$ : & & & \\
\hline & Minimum corrected weight of impurity in sample $(\mu \mathrm{g})$ : & & & \\
\hline & Maximum corrected weight of impurity in sample $(\mu \mathrm{g})$ : & & & \\
\hline \multirow{5}{*}{ Mn } & Measured concentration of impurity in sample $(\mu \mathrm{g} / \mathrm{ml})$ : & & & $\mathrm{Mn}$ \\
\hline & Uncorrected weight of impurity in sample $(\mu \mathrm{g})$ : & & & \\
\hline & Weight of impurity in blank $(\mu g)$ : & & & \\
\hline & Minimum corrected weight of impurity in sample $(\mu g)$ : & & & \\
\hline & Maximum corrected weight of impurity in sample $(\mu g)$ : & & & \\
\hline \multirow{5}{*}{ Co } & Measured concentration of impurity in sample $(\mu \mathrm{g} / \mathrm{ml})$ : & & & Co \\
\hline & Uncorrected weight of impurity in sample $(\mu \mathrm{g})$ : & & & \\
\hline & Weight of impurity in blank $(\mu \mathrm{g})$ : & & & \\
\hline & Minimum corrected weight of impurity in sample $(\mu \mathrm{g})$ : & & & \\
\hline & Maximum corrected weight of impurity in sample $(\mu \mathrm{g})$ : & & & \\
\hline \multirow{5}{*}{$\mathbf{N i}$} & Measured concentration of impurity in sample $(\mu \mathrm{g} / \mathrm{ml})$ : & & & $\mathrm{Ni}$ \\
\hline & Uncorrected weight of impurity in sample $(\mu \mathrm{g})$ : & & & \\
\hline & Weight of impurity in blank $(\mu \mathrm{g})$ : & & & \\
\hline & Minimum corrected weight of impurity in sample $(\mu \mathrm{g})$ : & & & \\
\hline & Maximum corrected weight of impurity in sample $(\mu g)$ : & & & \\
\hline \multirow{5}{*}{$\mathrm{Ca}$} & Measured concentration of impurity in sample $(\mu \mathrm{g} / \mathrm{ml})$ : & & & $\mathrm{Ca}$ \\
\hline & Uncorrected weight of impurity in sample $(\mu \mathrm{g})$ : & & & \\
\hline & Weight of impurity in blank $(\mu \mathrm{g}):$ & & & \\
\hline & Minimum corrected weight of impurity in sample $(\mu \mathrm{g})$ : & & & \\
\hline & Maximum corrected weight of impurity in sample $(\mu \mathrm{g}):$ & & & \\
\hline \multirow{5}{*}{ Al } & Measured concentration of impurity in sample $(\mu \mathrm{g} / \mathrm{ml})$ : & & & Al \\
\hline & Uncorrected weight of impurity in sample $(\mu \mathrm{g})$ : & & & \\
\hline & Weight of impurity in blank $(\mu \mathrm{g})$ : & & & \\
\hline & Minimum corrected weight of impurity in sample $(\mu \mathrm{g})$ : & & & \\
\hline & Maximum corrected weight of impurity in sample $(\mu \mathrm{g})$ : & & & \\
\hline \multirow{5}{*}{$\mathbf{T i}$} & Measured concentration of impurity in sample $(\mu \mathrm{g} / \mathrm{ml}):$ & & & Ti \\
\hline & Uncorrected weight of impurity in sample $(\mu \mathrm{g})$ : & & & \\
\hline & Weight of impurity in blank $(\mu \mathrm{g})$ : & & & \\
\hline & Minimum corrected weight of impurity in sample $(\mu \mathrm{g}):$ & & & \\
\hline & Maximum corrected weight of impurity in sample $(\mu \mathrm{g})$ : & & & \\
\hline \multirow{5}{*}{ v } & Measured concentration of impurity in sample $(\mu \mathrm{g} / \mathrm{ml})$ : & & & $\mathbf{v}$ \\
\hline & Uncorrected weight of impurity in sample $(\mu \mathrm{g})$ : & & & \\
\hline & Weight of impurity in blank $(\mu \mathrm{g}):$ & & & \\
\hline & Minimum corrected weight of impurity in sample $(\mu \mathrm{g}):$ & & & \\
\hline & Maximum corrected weight of impurity in sample $(\mu \mathrm{g}):$ & & & \\
\hline
\end{tabular}

comments

Leached in Vessel \#53 (previously unused)

FCM checked the recorded data against the official Results of Analysis for RMAL19240 on 4/12/2019.

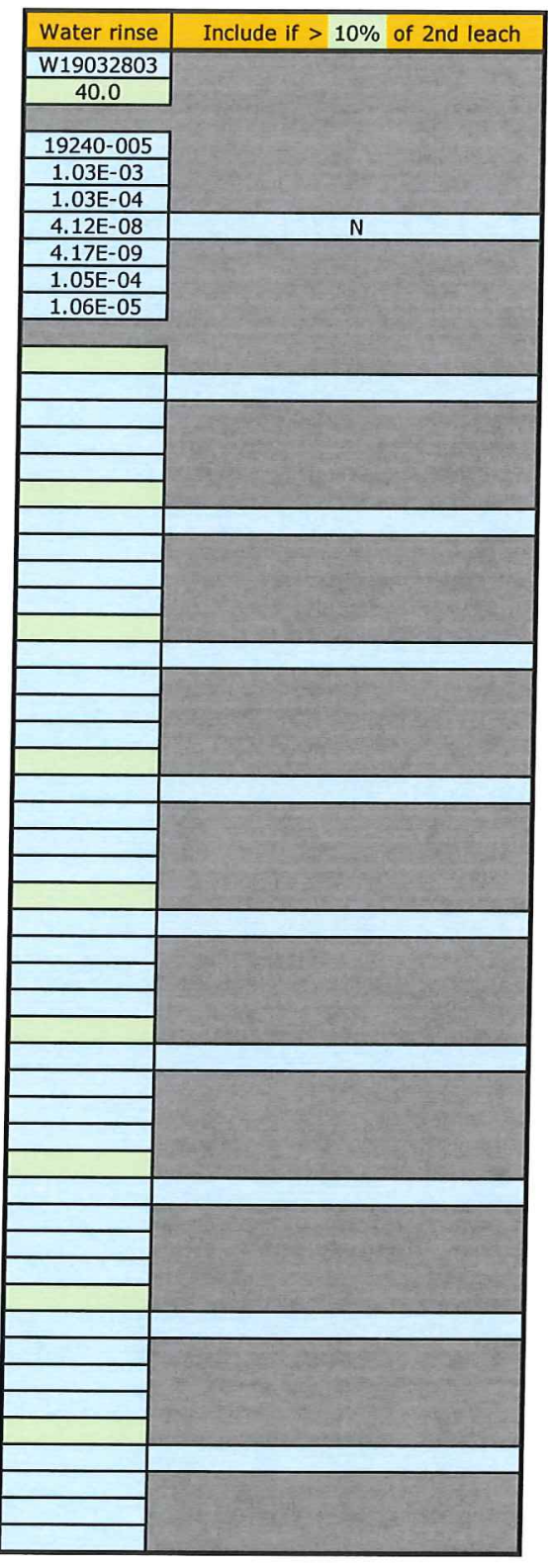


Data Report Form DRF-21A: Pre-Burn Leach Uranium and Impurities

\begin{tabular}{|r|l|}
\hline Procedure: & AGR-CHAR-DAM-21 Rev. 2 \\
\hline Operator: & Montgomery \\
\hline Particle lot ID: & BWXT J52R-16-11035 \\
\hline Particle lot description: & AGR-5/6/7 overcoated particles, 40\% packing fraction \\
\hline Particle sample ID: & $11035-08$ \\
\hline DRF filename: & 11035 PF 40 overcoated particles-Group 2_DLBL_ICPMS_DRF21R2.xls \\
\hline
\end{tabular}

\begin{tabular}{|c|c|c|c|c|}
\hline \multicolumn{2}{|c|}{ Average weight per particle ${ }_{t}$ mean value $(\mathrm{g})$ : } & \multicolumn{3}{|c|}{$2.010 \mathrm{E}-03$} \\
\hline & Average weight per particle, uncertainty in mean $(\mathrm{g})$ : & \multicolumn{3}{|c|}{$6.4 \mathrm{E}-06$} \\
\hline & Weight of particle sample $(\mathrm{g})$ : & \multicolumn{3}{|c|}{34.9150} \\
\hline & Approximate number of particles in sample: & \multicolumn{3}{|c|}{17371} \\
\hline & Uncertainty in number of particles: & \multicolumn{3}{|c|}{55} \\
\hline & Average weight uranium per particle, mean value $(g)$ : & \multicolumn{3}{|c|}{$3.94 \mathrm{E}-04$} \\
\hline \multicolumn{2}{|r|}{ Average weight uranium per particle, uncertainty in mean $(g)$ : } & \multicolumn{3}{|c|}{$3.94 \mathrm{E}-06$} \\
\hline & & First Leach & Second Leach & Total \\
\hline & Pre-burn leach solution ID: & L19032602 & L19032802 & \\
\hline & Total volume of leach solution (ml): & 133.0 & 169.0 & \\
\hline & RMAL analysis number: & $19240-002$ & $19240-004$ & \\
\hline & Measured uranium concentration $(\mu \mathrm{g} / \mathrm{ml})$ : & $2.54 \mathrm{E}-01$ & $1.05 \mathrm{E}-02$ & \\
\hline & Uncertainty in uranium concentration $(\mu \mathrm{g} / \mathrm{ml})$ : & $2.54 \mathrm{E}-02$ & $1.05 \mathrm{E}-03$ & \\
\hline & Weight uranium leached $(g)$ : & $3.38 \mathrm{E}-05$ & $1.77 \mathrm{E}-06$ & $3.56 \mathrm{E}-05$ \\
\hline & Uncertainty in weight uranium leached $(\mathrm{g})$ : & $3.38 \mathrm{E}-06$ & $1.78 \mathrm{E}-07$ & $3.39 \mathrm{E}-06$ \\
\hline & Equivalent number of leached kernels: & $8.57 \mathrm{E}-02$ & $4.50 \mathrm{E}-03$ & $9.02 \mathrm{E}-02$ \\
\hline & Uncertainty in equivalent number of leached kernels: & $8.63 \mathrm{E}-03$ & $4.53 \mathrm{E}-04$ & $8.64 \mathrm{E}-03$ \\
\hline \multirow{5}{*}{$\mathbf{F e}$} & Measured concentration of impurity in sample $(\mu \mathrm{g} / \mathrm{ml})$ : & & & $\mathrm{Fe}$ \\
\hline & Uncorrected weight of impurity in sample $(\mu \mathrm{g})$ : & & & \\
\hline & Weight of impurity in blank $(\mu \mathrm{g})$ : & & & \\
\hline & Minimum corrected weight of impurity in sample $(\mu \mathrm{g})$ : & & & \\
\hline & Maximum corrected weight of impurity in sample $(\mu \mathrm{g})$ : & & & \\
\hline \multirow{5}{*}{$\mathbf{C r}$} & Measured concentration of impurity in sample $(\mu \mathrm{g} / \mathrm{ml})$ : & & & $\mathrm{Cr}$ \\
\hline & Uncorrected weight of impurity in sample $(\mu \mathrm{g})$ : & & & \\
\hline & Weight of impurity in blank $(\mu \mathrm{g})$ : & & & \\
\hline & Minimum corrected weight of impurity in sample $(\mu \mathrm{g})$ : & & & \\
\hline & Maximum corrected weight of impurity in sample $(\mu \mathrm{g})$ : & & & \\
\hline \multirow{5}{*}{ Mn } & Measured concentration of impurity in sample $(\mu \mathrm{g} / \mathrm{ml})$ : & & & Mn \\
\hline & Uncorrected weight of impurity in sample $(\mu \mathrm{g})$ : & & & \\
\hline & Weight of impurity in blank $(\mu \mathrm{g})$ : & & & \\
\hline & Minimum corrected weight of impurity in sample $(\mu \mathrm{g})$ : & & & \\
\hline & Maximum corrected weight of impurity in sample $(\mu \mathrm{g})$ : & & & \\
\hline \multirow{5}{*}{ Co } & Measured concentration of impurity in sample $(\mu \mathrm{g} / \mathrm{ml})$ : & & & Co \\
\hline & Uncorrected weight of impurity in sample $(\mu \mathrm{g})$ : & & & \\
\hline & Weight of impurity in blank $(\mu g)$ : & & & \\
\hline & Minimum corrected weight of impurity in sample $(\mu g)$ : & & & \\
\hline & Maximum corrected weight of impurity in sample $(\mu \mathrm{g})$ : & & & \\
\hline \multirow{5}{*}{$\mathbf{N i}$} & Measured concentration of impurity in sample $(\mu \mathrm{g} / \mathrm{ml})$ : & & & $\mathrm{Ni}$ \\
\hline & Uncorrected weight of impurity in sample $(\mu \mathrm{g})$ : & & & \\
\hline & Weight of impurity in blank $(\mu g)$ : & & & \\
\hline & Minimum corrected weight of impurity in sample $(\mu \mathrm{g})$ : & & & \\
\hline & Maximum corrected weight of impurity in sample $(\mu \mathrm{g})$ : & & & \\
\hline \multirow{5}{*}{ Ca } & Measured concentration of impurity in sample $(\mathrm{\mu g} / \mathrm{ml})$ : & & & Ca \\
\hline & Uncorrected weight of impurity in sample $(\mu \mathrm{g})$ : & & & \\
\hline & Weight of impurity in blank $(\mu g)$ : & & & \\
\hline & Minimum corrected weight of impurity in sample $(\mu \mathrm{g})$ : & & & \\
\hline & Maximum corrected weight of impurity in sample $(\mu g)$ : & & & \\
\hline \multirow{5}{*}{ Al } & Measured concentration of impurity in sample $(\mathrm{\mu g} / \mathrm{ml})$ : & & & $\overline{A l}$ \\
\hline & Uncorrected weight of impurity in sample $(\mu \mathrm{g})$ : & & & \\
\hline & Weight of impurity in blank $(\mu \mathrm{g}):$ & & & \\
\hline & Minimum corrected weight of impurity in sample $(\mu \mathrm{g})$ : & & & \\
\hline & Maximum corrected weight of impurity in sample $(\mu \mathrm{g})$ : & & & \\
\hline & Measured concentration of impurity in sample $(\mu \mathrm{g} / \mathrm{ml})$ : & & & Ti \\
\hline & Uncorrected weight of impurity in sample $(\mu \mathrm{g}):$ & & & \\
\hline Ti & Weight of impurity in blank $(\mu \mathrm{g})$ : & & & \\
\hline & Minimum corrected weight of impurity in sample $(\mu \mathrm{g})$ : & & & \\
\hline & Maximum corrected weight of impurity in sample $(\mu \mathrm{g})$ : & & & \\
\hline & Measured concentration of impurity in sample $(\mu \mathrm{g} / \mathrm{ml})$ : & & & $\mathbf{v}$ \\
\hline & Uncorrected weight of impurity in sample $(\mu \mathrm{g})$ : & & & \\
\hline v & Weight of impurity in blank $(\mu \mathrm{g})$ : & & & \\
\hline & Minimum corrected weight of impurity in sample $(\mu \mathrm{g})$ : & & & \\
\hline & Maximum corrected weight of impurity in sample $(\mu \mathrm{g}):$ & & & \\
\hline
\end{tabular}

comments

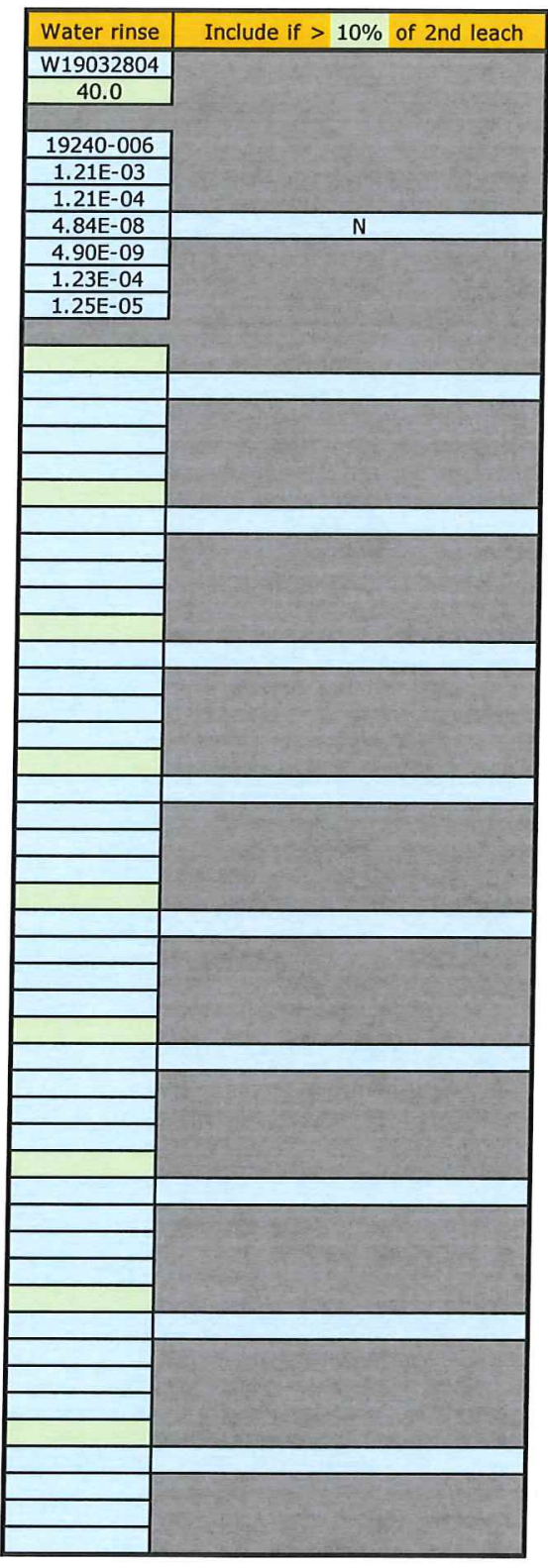

Leached in Vessel \#54 (previously unused).

FCM checked the recorded data against the official Results of Analysis for RMAL19240 on 4/12/2019.

\section{Fied. c. Montgomeres} operator
$4-18-2019$

B-30 


\section{Data Report Form DRF-21B: Post-Burn Leach Uranium and Impurities}

\begin{tabular}{|r|l|}
\hline Procedure: & AGR-CHAR-DAM-21 Rev. 2 \\
\hline Operator: & Montgomery \\
\hline Particle lot ID: & BWXT J52R-16-11035 \\
\hline Particle lot description: & AGR-5/6/7 overcoated particles, 40\% packing fraction \\
\hline Particle sample ID: & $11035-05$ \\
\hline DRF filename: & 11035 PF40 overcoated particles-Group 2_DLBL_ICPMS_DRF21R2.xIs \\
\hline
\end{tabular}

\begin{tabular}{|r|c|}
\hline Average weight per particle, mean value $(\mathrm{g}):$ & $2.010 \mathrm{E}-03$ \\
\hline Average weight per particle, uncertainty in mean $(\mathrm{g}):$ & $6.4 \mathrm{E}-06$ \\
\hline Weight of particle sample $(\mathrm{g}):$ & 34.9526 \\
\hline Approximate number of particles in sample: & 17389 \\
\hline Uncertainty in number of particles: & 55 \\
\hline Average weight uranium per particle, mean value $(\mathrm{g}):$ & $3.94 \mathrm{E}-04$ \\
\hline Average weight uranium per particle, uncertainty in mean $(\mathrm{g}):$ & $3.94 \mathrm{E}-06$ \\
\hline
\end{tabular}

\begin{tabular}{|c|c|c|c|c|}
\hline & First Leach & Second Leach & Total \\
\hline \multirow{2}{*}{\multicolumn{2}{|c|}{$\begin{array}{cc}\text { Post-burn leach solution ID: } & \text { Total volume of leach solution }(\mathrm{ml}):\end{array}$}} & B19040201 & B19040401 & \\
\hline & & 55.0 & 59.5 & \\
\hline \multicolumn{2}{|c|}{ RMAL analysis number: } & $19263-001$ & $19263-005$ & \\
\hline \multirow{2}{*}{\multicolumn{2}{|c|}{$\begin{array}{c}\text { Measured uranium concentration }(\mu \mathrm{g} / \mathrm{ml}) \text { : } \\
\text { Uncertainty in uranium concentration }(\mu \mathrm{g} / \mathrm{ml}) \text { : }\end{array}$}} & $\frac{1.23 \mathrm{E}-02}{1.02}$ & $\frac{1505-005}{2.48 \mathrm{E}-04}$ & \\
\hline & & $1.23 \mathrm{E}-03$ & $2.48 \mathrm{E}-05$ & \\
\hline \multicolumn{2}{|c|}{ Weight uranium leached $(\mathrm{g})$ : } & $6.77 \mathrm{E}-07$ & $1.48 \mathrm{E}-08$ & $6.91 \mathrm{E}-07$ \\
\hline \multicolumn{2}{|c|}{$\begin{array}{l}\text { Uncertainty in weight uranium leached }(\mathrm{g}) \text { : } \\
\end{array}$} & $6.81 \mathrm{E}-08$ & $1.48 \mathrm{E}-09$ & $6.81 \mathrm{E}-08$ \\
\hline \multirow{2}{*}{\multicolumn{2}{|c|}{$\begin{array}{c}\text { Equivalent number of leached kernels: } \\
\text { Uncertainty in equivalent number of leached kernels: }\end{array}$}} & $1.72 \mathrm{E}-03$ & $3.75 \mathrm{E}-05$ & $1.75 \mathrm{E}-03$ \\
\hline & & $1.74 \mathrm{E}-04$ & $3.79 \mathrm{E}-06$ & $1.74 \mathrm{E}-04$ \\
\hline \multirow{5}{*}{$\mathbf{F e}$} & Measured concentration of impurity in sample $(\mu \mathrm{g} / \mathrm{ml})$ : & & & $F$ \\
\hline & Uncorrected weight of impurity in sample $(\mu \mathrm{g})$ : & & & \\
\hline & Weight of impurity in blank $(\mu \mathrm{g})$ : & & & \\
\hline & Minimum corrected weight of impurity in sample $(\mu g)$ : & & & \\
\hline & Maximum corrected weight of impurity in sample $(\mu \mathrm{g})$ : & & & \\
\hline \multirow{5}{*}{$\mathbf{C r}$} & Measured concentration of impurity in sample $(\mu \mathrm{g} / \mathrm{ml})$ : & & & $\mathbf{C r}$ \\
\hline & Uncorrected weight of impurity in sample $(\mu \mathrm{g})$ : & & & \\
\hline & Weight of impurity in blank $(\mu \mathrm{g})$ : & & & \\
\hline & Minimum corrected weight of impurity in sample $(\mu \mathrm{g})$ : & & & \\
\hline & Maximum corrected weight of impurity in sample $(\mu \mathrm{g})$ : & & & \\
\hline \multirow{5}{*}{ Mn } & Measured concentration of impurity in sample $(\mu \mathrm{g} / \mathrm{ml})$ : & & & Mn \\
\hline & Uncorrected weight of impurity in sample $(\mu \mathrm{g})$ : & & & \\
\hline & Weight of impurity in blank $(\mu \mathrm{g})$ : & & & \\
\hline & Minimum corrected weight of impurity in sample $(\mu \mathrm{g})$ : & & & \\
\hline & Maximum corrected weight of impurity in sample $(\mu g)$ : & & & \\
\hline \multirow{5}{*}{ Co } & Measured concentration of impurity in sample $(\mu \mathrm{g} / \mathrm{ml})$ : & & & Co \\
\hline & Uncorrected weight of impurity in sample $(\mu g)$ : & & & \\
\hline & Weight of impurity in blank $(\mu \mathrm{g})$ : & & & \\
\hline & Minimum corrected weight of impurity in sample $(\mu \mathrm{g}):$ & & & \\
\hline & Maximum corrected weight of impurity in sample $(\mu \mathrm{g})$ : & & & \\
\hline \multirow{5}{*}{$\mathbf{N i}$} & Measured concentration of impurity in sample $(\mu \mathrm{g} / \mathrm{ml})$ : & & & $\mathbf{N i}$ \\
\hline & Uncorrected weight of impurity in sample $(\mu \mathrm{g})$ : & & & \\
\hline & Weight of impurity in blank $(\mu g)$ : & & & \\
\hline & Minimum corrected weight of impurity in sample $(\mu g)$ : & & & \\
\hline & Maximum corrected weight of impurity in sample $(\mu g)$ : & & & \\
\hline \multirow{5}{*}{ Ca } & Measured concentration of impurity in sample $(\mu \mathrm{g} / \mathrm{ml})$ : & & & $\mathrm{Ca}$ \\
\hline & Uncorrected weight of impurity in sample $(\mu \mathrm{g})$ : & & & \\
\hline & Weight of impurity in blank $(\mu \mathrm{g})$ : & & & \\
\hline & Minimum corrected weight of impurity in sample $(\mu g)$ : & & & \\
\hline & Maximum corrected weight of impurity in sample $(\mu \mathrm{g})$ : & & & \\
\hline \multirow{5}{*}{ Al } & Measured concentration of impurity in sample $(\mathrm{\mu g} / \mathrm{ml}):$ & & & Al \\
\hline & Uncorrected weight of impurity in sample $(\mu \mathrm{g})$ : & & & \\
\hline & Weight of impurity in blank $(\mu \mathrm{g})$ : & & & \\
\hline & Minimum corrected weight of impurity in sample $(\mu g)$ : & & & \\
\hline & Maximum corrected weight of impurity in sample $(\mu g)$ : & & & \\
\hline \multirow{5}{*}{$\mathbf{T i}$} & Measured concentration of impurity in sample $(\mu \mathrm{g} / \mathrm{ml})$ : & & & $\mathrm{Ti}$ \\
\hline & Uncorrected weight of impurity in sample $(\mu \mathrm{g})$ : & & & \\
\hline & Weight of impurity in blank $(\mu \mathrm{g})$ : & & & \\
\hline & Minimum corrected weight of impurity in sample $(\mu \mathrm{g}):$ & & & \\
\hline & Maximum corrected weight of impurity in sample $(\mu \mathrm{g})$ : & & & \\
\hline \multirow{5}{*}{$\mathbf{v}$} & Measured concentration of impurity in sample $(\mu \mathrm{g} / \mathrm{m} / \mathrm{ml}$ : & & & $\mathbf{V}$ \\
\hline & Uncorrected weight of impurity in sample $(\mu \mathrm{g})$ : & & & \\
\hline & Weight of impurity in blank $(\mu \mathrm{g})$ : & & & \\
\hline & Minimum corrected weight of impurity in sample $(\mu \mathrm{g})$ : & & & \\
\hline & Maximum corrected weight of impurity in sample $(\mu \mathrm{g}):$ & & & \\
\hline
\end{tabular}

\section{comments}

FCM checked the recorded data against the official Results of Analysis for RMAL19263 on 4/12/2019.

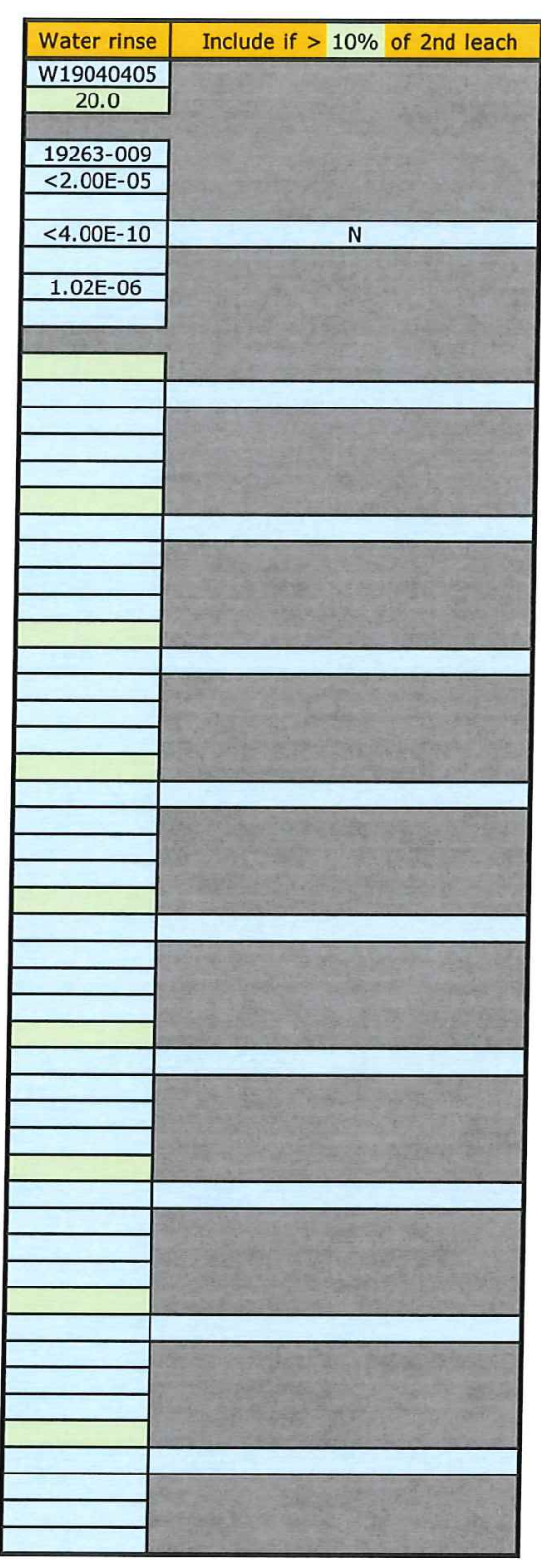

Feed C. Montgomeuy operator
$4-18-2019$

B-31 
Data Report Form DRF-21B: Post-Burn Leach Uranium and Impurities

\begin{tabular}{|r|l|}
\hline Procedure: & AGR-CHAR-DAM-21 Rev. 2 \\
\hline Operator: & Montgomery \\
\hline Particle lot ID: & BWXT J52R-16-11035 \\
\hline Particle lot description: & AGR-5/6/7 overcoated particles, 40\% packing fraction \\
\hline Particle sample ID: & $11035-06$ \\
\hline DRF filename: & 11035 PF40 overcoated particles-Group 2_DLBL_ICPMS_DRF21R2.xIs \\
\hline
\end{tabular}

\begin{tabular}{|c|c|c|c|c|}
\hline & Average weight per particle, mean value $(\mathrm{g})$ : & & $2.010 \mathrm{E}-03$ & \\
\hline & Average weight per particle, uncertainty in mean (g): & & $6.4 \mathrm{E}-06$ & \\
\hline & Weight of particle sample $(\mathrm{g})$ : & & 34.9526 & \\
\hline & Approximate number of particles in sample: & & 17389 & \\
\hline & Uncertainty in number of particles: & & 55 & \\
\hline & Average weight uranium per particle, mean value $(\mathrm{g})$ : & & $3.94 \mathrm{E}-04$ & \\
\hline & rage weight uranium per particle, uncertainty in mean $(\mathrm{g})$ : & & $3.94 \mathrm{E}-06$ & \\
\hline & & First Leach & Second Leach & Total \\
\hline & Post-burn leach solution ID: & B19040202 & B19040402 & \\
\hline & Total volume of leach solution (ml): & 55.8 & 59.3 & \\
\hline & RMAL analysis number: & $19263-002$ & $19263-006$ & \\
\hline & Measured uranium concentration $(\mu \mathrm{g} / \mathrm{ml})$ : & $2.54 \mathrm{E}-02$ & $6.35 \mathrm{E}-04$ & \\
\hline & Uncertainty in uranium concentration $(\mu \mathrm{g} / \mathrm{ml})$ : & $2.54 \mathrm{E}-03$ & $6.35 \mathrm{E}-05$ & \\
\hline & Weight uranium leached $(\mathrm{g})$ : & $1.42 \mathrm{E}-06$ & $3.77 \mathrm{E}-08$ & $1.45 \mathrm{E}-06$ \\
\hline & Uncertainty in weight uranium leached $(\mathrm{g})$ : & $1.43 \mathrm{E}-07$ & $3.79 \mathrm{E}-09$ & $1.43 \mathrm{E}-07$ \\
\hline & Equivalent number of leached kernels: & $3.60 \mathrm{E}-03$ & $9.56 \mathrm{E}-05$ & $3.69 \mathrm{E}-03$ \\
\hline & Uncertainty in equivalent number of leached kernels: & $3.64 \mathrm{E}-04$ & $9.66 \mathrm{E}-06$ & $3.64 \mathrm{E}-04$ \\
\hline & Measured concentration of impurity in sample $(\mu \mathrm{g} / \mathrm{ml})$ : & & & \\
\hline & Uncorrected weight of impurity in sample $(\mu \mathrm{g})$ : & & & Fe \\
\hline $\mathbf{F e}$ & Weight of impurity in blank $(\mu \mathrm{g})$ : & & & \\
\hline & Minimum corrected weight of impurity in sample $(\mu \mathrm{g})$ : & & & \\
\hline & Maximum corrected weight of impurity in sample $(\mu \mathrm{g})$ : & & & \\
\hline & Measured concentration of impurity in sample $(\mu \mathrm{g} / \mathrm{ml})$ : & & & $\mathbf{C r}$ \\
\hline & Uncorrected weight of impurity in sample $(\mu \mathrm{g})$ : & & & \\
\hline $\mathbf{C r}$ & Weight of impurity in blank $(\mu g)$ : & & & \\
\hline & Minimum corrected weight of impurity in sample $(\mu \mathrm{g})$ : & & & \\
\hline & Maximum corrected weight of impurity in sample $(\mu \mathrm{g})$ : & & & \\
\hline & Measured concentration of impurity in sample $(\mu \mathrm{g} / \mathrm{ml})$ : & & & Mn \\
\hline & Uncorrected weight of impurity in sample $(\mu \mathrm{g})$ : & & & \\
\hline Mn & Weight of impurity in blank $(\mu \mathrm{g})$ : & & & \\
\hline & Minimum corrected weight of impurity in sample $(\mu \mathrm{g})$ : & & & \\
\hline & Maximum corrected weight of impurity in sample $(\mu \mathrm{g})$ : & & & \\
\hline & Measured concentration of impurity in sample $(\mu \mathrm{g} / \mathrm{ml})$ : & & & Co \\
\hline & Uncorrected weight of impurity in sample $(\mu \mathrm{g})$ : & & & \\
\hline Co & Weight of impurity in blank $(\mu \mathrm{g}):$ & & & \\
\hline & Minimum corrected weight of impurity in sample $(\mu \mathrm{g})$ : & & & \\
\hline & Maximum corrected weight of impurity in sample $(\mu \mathrm{g})$ : & & & \\
\hline & Measured concentration of impurity in sample $(\mu \mathrm{g} / \mathrm{ml})$ : & & & $\mathrm{Ni}$ \\
\hline & Uncorrected weight of impurity in sample $(\mu \mathrm{g})$ : & & & \\
\hline $\mathbf{N i}$ & Weight of impurity in blank $(\mu \mathrm{g})$ : & & & \\
\hline & Minimum corrected weight of impurity in sample $(\mu \mathrm{g})$ : & & & \\
\hline & Maximum corrected weight of impurity in sample $(\mu g)$ : & & & \\
\hline & Measured concentration of impurity in sample $(\mu \mathrm{g} / \mathrm{ml})$ : & & & $\mathbf{C a}$ \\
\hline & Uncorrected weight of impurity in sample $(\mu \mathrm{g})$ : & & & \\
\hline Ca & Weight of impurity in blank $(\mu \mathrm{g})$ : & & & \\
\hline & Minimum corrected weight of impurity in sample $(\mu \mathrm{g})$ : & & & \\
\hline & Maximum corrected weight of impurity in sample $(\mu \mathrm{g})$ : & & & \\
\hline & Measured concentration of impurity in sample $(\mathrm{\mu g} / \mathrm{ml})$ : & & & AI \\
\hline & Uncorrected weight of impurity in sample $(\mu \mathrm{g})$ : & & & \\
\hline Al & Weight of impurity in blank $(\mu \mathrm{g})$ : & & & \\
\hline & Minimum corrected weight of impurity in sample $(\mu \mathrm{g})$ : & & & \\
\hline & Maximum corrected weight of impurity in sample $(\mu \mathrm{g})$ : & & & \\
\hline & Measured concentration of impurity in sample $(\mu \mathrm{g} / \mathrm{ml})$ : & & & $\mathbf{T i}$ \\
\hline & Uncorrected weight of impurity in sample $(\mu \mathrm{g})$ : & & & \\
\hline $\mathbf{T i}$ & Weight of impurity in blank $(\mu \mathrm{g})$ : & & & \\
\hline & Minimum corrected weight of impurity in sample $(\mu \mathrm{g})$ : & & & \\
\hline & Maximum corrected weight of impurity in sample $(\mu \mathrm{g})$ : & & & \\
\hline & Measured concentration of impurity in sample $(\mathrm{\mu g} / \mathrm{ml})$ : & & & $\mathbf{v}$ \\
\hline & Uncorrected weight of impurity in sample $(\mu \mathrm{g})$ : & & & \\
\hline v & Weight of impurity in blank $(\mu \mathrm{g})$ : & & & \\
\hline & Minimum corrected weight of impurity in sample $(\mu \mathrm{g})$ : & & & \\
\hline & Maximum corrected weight of impurity in sample $(\mu \mathrm{g})$ : & & & \\
\hline
\end{tabular}

Comments

FCM checked the recorded data against the official Results of Analysis for RMAL19263 on 4/12/2019.

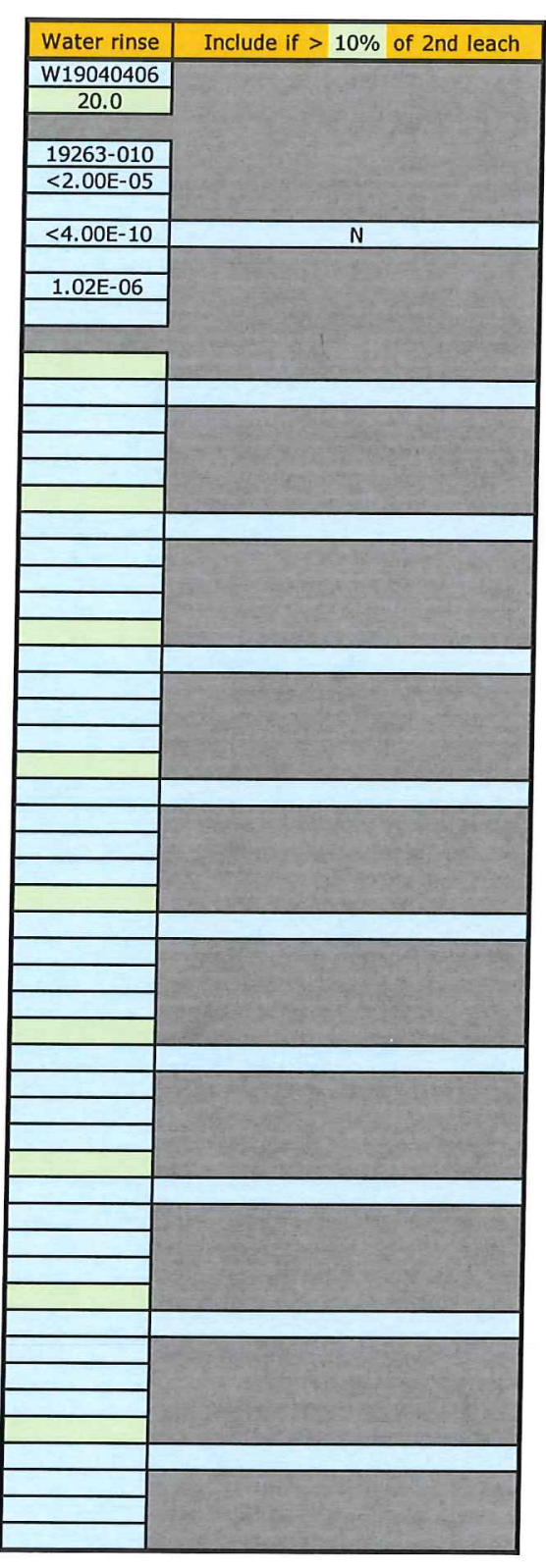




\section{Data Report Form DRF-21B: Post-Burn Leach Uranium and Impurities}

\begin{tabular}{|r|l|}
\hline Procedure: & AGR-CHAR-DAM-21 Rev. 2 \\
\hline Operator: & Montgomery \\
\hline Particle lot ID: & BWXT J52R-16-11035 \\
\hline Particle lot description: & AGR-5/6/7 overcoated particles, 40\% packing fraction \\
\hline Particle sample ID: & $11035-07$ \\
\hline DRF filename: & 11035 PF40 overcoated particles-Group 2_DLBL_ICPMS_DRF21R2.xls \\
\hline
\end{tabular}

\begin{tabular}{|r|c|}
\hline Average weight per particle, mean value $(\mathrm{g}):$ & $2.010 \mathrm{E}-03$ \\
\hline Average weight per particle, uncertainty in mean $(\mathrm{g})$ & $6.4 \mathrm{E}-06$ \\
\hline Weight of particle sample $(\mathrm{g}):$ & 34.9526 \\
\hline Approximate number of particles in sample: & 17389 \\
\hline Uncertainty in number of particles: & 55 \\
\hline Average weight uranium per particle, mean value $(\mathrm{g}):$ & $3.94 \mathrm{E}-04$ \\
\hline Average weight uranium per particle, uncertainty in mean $(\mathrm{g}):$ & $3.94 \mathrm{E}-06$ \\
\hline
\end{tabular}

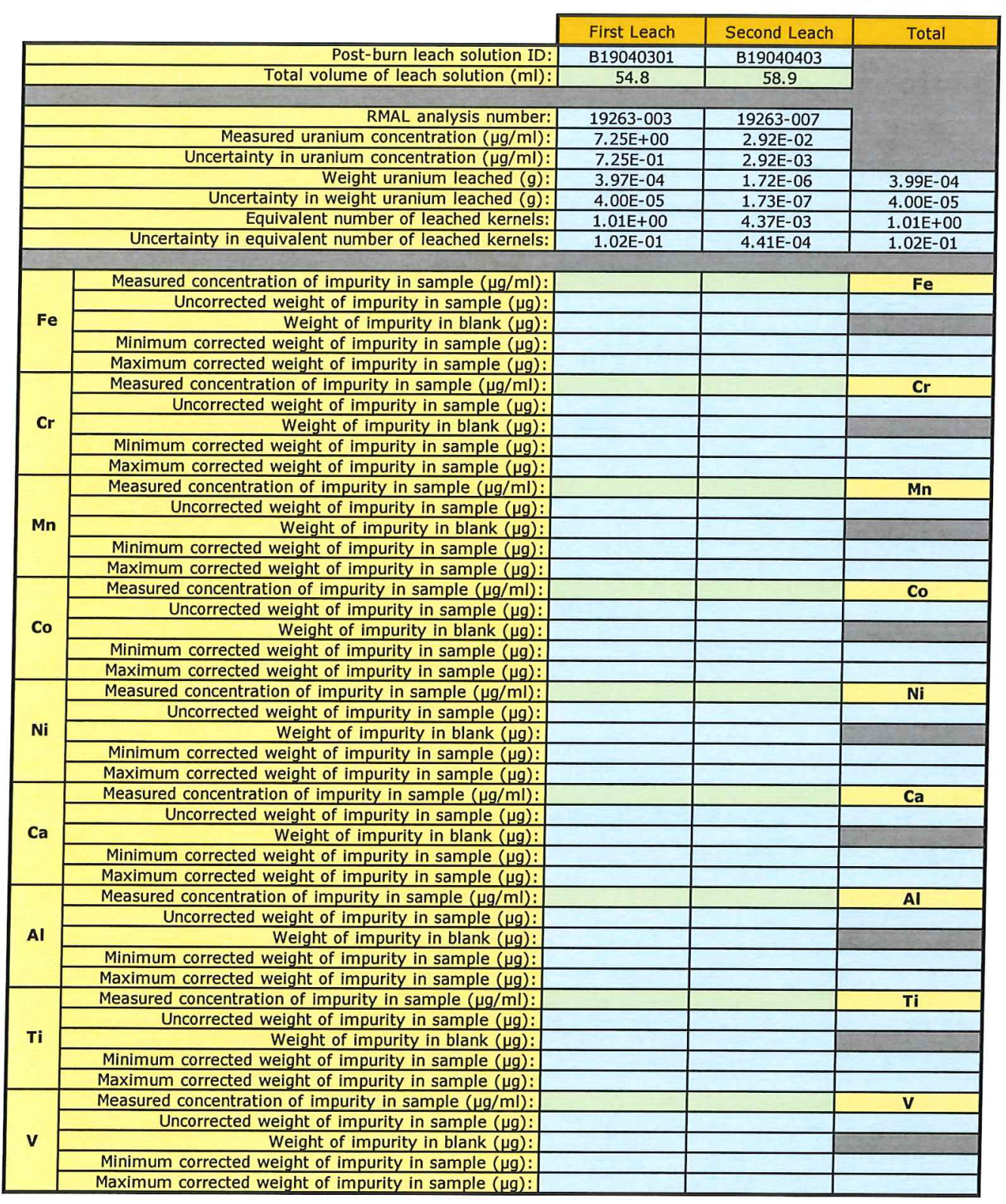

\section{comments}

FCM checked the recorded data against the official Results of Analysis for RMAL19263 on 4/12/2019.

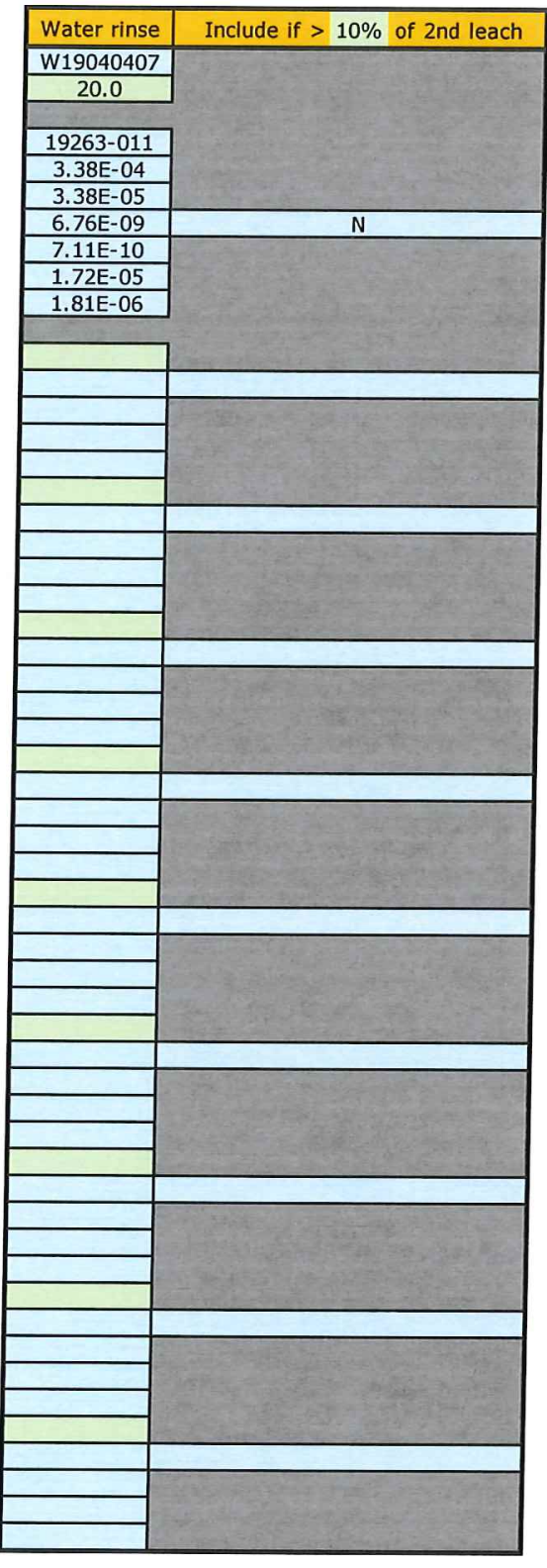




\section{Data Report Form DRF-21B: Post-Burn Leach Uranium and Impurities}

Procedure: $\mid$ AGR-CHAR-DAM-21 Rev. 2

Operator: Montgomery

Particle lot ID: BWXT J52R-16-11035

Particle lot description: AGR-5/6/7 overcoated particles, $40 \%$ packing fraction

Particle sample ID: $11035-08$

DRF filename: 11035_PF40 overcoated particles-Group 2_DLBL_ICPMS_DRF21R2.xIs

\section{Average weight per particle, mean value $(\mathrm{g})$ : Average weight per particle, uncertainty in mean $(g)$ : Approximate number of particles in sample: Uncertainty in number of particles: \\ Average weight uranium per particle, mean value $(g)$ : Average weight uranium per particle, uncertainty in mean $(g)$ :}

\begin{tabular}{|c|c|c|c|c|}
\hline & First Leach & Second Leach & Total \\
\hline & Post-burn leach solution ID: & B19040302 & B19040404 & \\
\hline & Total volume of leach solution $(\mathrm{ml})$ : & 56.5 & 58.5 & \\
\hline & RMAL analysis number: & $19263-004$ & $19263-008$ & \\
\hline & Measured uranium concentration $(\mu \mathrm{g} / \mathrm{ml})$ : & $5.62 \mathrm{E}-02$ & $1.18 \mathrm{E}-03$ & \\
\hline & Uncertainty in uranium concentration $(\mu \mathrm{g} / \mathrm{ml})$ : & $5.62 \mathrm{E}-03$ & $1.18 \mathrm{E}-04$ & \\
\hline & Weight uranium leached $(\mathrm{g})$ : & $3.18 \mathrm{E}-06$ & $6.90 \mathrm{E}-08$ & $3.24 \mathrm{E}-06$ \\
\hline & Uncertainty in weight uranium leached $(\mathrm{g})$ : & $3.20 \mathrm{E}-07$ & $6.95 \mathrm{E}-09$ & $3.20 \mathrm{E}-07$ \\
\hline & Equivalent number of leached kernels: & $8.06 \mathrm{E}-03$ & $1.75 \mathrm{E}-04$ & $8.23 \mathrm{E}-03$ \\
\hline & Uncertainty in equivalent number of leached kernels: & $8.15 \mathrm{E}-04$ & $1.77 \mathrm{E}-05$ & $8.16 \mathrm{E}-04$ \\
\hline \multirow{5}{*}{$\mathbf{F e}$} & Measured concentration of impurity in sample $(\mu \mathrm{g} / \mathrm{ml})$ : & & & $\mathrm{Fe}$ \\
\hline & Uncorrected weight of impurity in sample $(\mu \mathrm{g})$ : & & & \\
\hline & $\begin{array}{r}\text { Weight of impurity in blank }(\mu \mathrm{g}) \text { : } \\
\text {. }\end{array}$ & & & \\
\hline & Minimum corrected weight of impurity in sample $(\mu g)$ : & & & \\
\hline & Maximum corrected weight of impurity in sample $(\mu \mathrm{g})$ : & & & \\
\hline \multirow{5}{*}{$\mathrm{Cr}$} & Measured concentration of impurity in sample $(\mu \mathrm{g} / \mathrm{ml})$ : & & & $\mathbf{C r}$ \\
\hline & Uncorrected weight of impurity in sample $(\mu \mathrm{g})$ : & & & \\
\hline & Weight of impurity in blank $(\mu \mathrm{g})$ : & & & \\
\hline & Minimum corrected weight of impurity in sample $(\mu g)$ : & & & \\
\hline & Maximum corrected weight of impurity in sample $(\mu \mathrm{g})$ : & & & \\
\hline \multirow{5}{*}{ Mn } & Measured concentration of impurity in sample $(\mu \mathrm{g} / \mathrm{ml})$ : & & & Mn \\
\hline & Uncorrected weight of impurity in sample $(\mu \mathrm{g})$ : & & & \\
\hline & Weight of impurity in blank $(\mu \mathrm{g})$ : & & & \\
\hline & Minimum corrected weight of impurity in sample $(\mu g)$ : & & & \\
\hline & Maximum corrected weight of impurity in sample $(\mu \mathrm{g})$ : & & & \\
\hline \multirow{5}{*}{ Co } & Measured concentration of impurity in sample $(\mu \mathrm{g} / \mathrm{ml})$ : & & & Co \\
\hline & Uncorrected weight of impurity in sample $(\mu \mathrm{g})$ : & & & \\
\hline & Weight of impurity in blank $(\mu \mathrm{g})$ : & & & \\
\hline & Minimum corrected weight of impurity in sample $(\mu \mathrm{g})$ : & & & \\
\hline & Maximum corrected weight of impurity in sample $(\mu g)$ : & & & \\
\hline \multirow{5}{*}{$\mathbf{N i}$} & Measured concentration of impurity in sample $(\mu \mathrm{g} / \mathrm{ml})$ : & & & $\mathrm{Ni}$ \\
\hline & Uncorrected weight of impurity in sample $(\mu \mathrm{g})$ : & & & \\
\hline & Weight of impurity in blank $(\mu g)$ : & & & \\
\hline & Minimum corrected weight of impurity in sample $(\mu g)$ : & & & \\
\hline & Maximum corrected weight of impurity in sample $(\mu \mathrm{g})$ : & & & \\
\hline \multirow{5}{*}{$\mathrm{Ca}$} & Measured concentration of impurity in sample $(\mu \mathrm{g} / \mathrm{ml})$ : & & & $\mathbf{C a}$ \\
\hline & Uncorrected weight of impurity in sample $(\mu \mathrm{g})$ : & & & \\
\hline & Weight of impurity in blank $(\mu \mathrm{g})$ : & & & \\
\hline & Minimum corrected weight of impurity in sample $(\mu g)$ : & & & \\
\hline & Maximum corrected weight of impurity in sample $(\mu g)$ : & & & \\
\hline \multirow{5}{*}{ Al } & Measured concentration of impurity in sample $(\mu \mathrm{g} / \mathrm{ml})$ : & & & Al \\
\hline & Uncorrected weight of impurity in sample $(\mu \mathrm{g})$ : & & & \\
\hline & Weight of impurity in blank $(\mu \mathrm{g})$ : & & & \\
\hline & Minimum corrected weight of impurity in sample $(\mu \mathrm{g})$ : & & & \\
\hline & Maximum corrected weight of impurity in sample $(\mu \mathrm{g})$ : & & & \\
\hline \multirow{5}{*}{$\mathbf{T i}$} & Measured concentration of impurity in sample $(\mu \mathrm{g} / \mathrm{ml})$ : & & & Ti \\
\hline & Uncorrected weight of impurity in sample $(\mu \mathrm{g})$ : & & & \\
\hline & Weight of impurity in blank $(\mu \mathrm{g})$ : & & & \\
\hline & Minimum corrected weight of impurity in sample $(\mu \mathrm{g})$ : & & & \\
\hline & Maximum corrected weight of impurity in sample $(\mu \mathrm{g})$ : & & & \\
\hline \multirow{5}{*}{$\mathbf{v}$} & Measured concentration of impurity in sample $(\mu \mathrm{g} / \mathrm{ml})$ : & & & $\mathbf{v}$ \\
\hline & Uncorrected weight of impurity in sample $(\mu \mathrm{g})$ : & & & \\
\hline & Weight of impurity in blank $(\mu \mathrm{g})$ : & & & \\
\hline & Minimum corrected weight of impurity in sample $(\mu \mathrm{g})$ : & & & \\
\hline & Maximum corrected weight of impurity in sample $(\mu \mathrm{g}):$ & & & \\
\hline
\end{tabular}

FCM checked the recorded data against the official Results of Analysis for RMAL19263 on 4/12/2019.

\section{comments}

\begin{tabular}{c}
\hline $2.010 \mathrm{E}-03$ \\
$6.4 \mathrm{E}-06$ \\
34.9526 \\
17389 \\
55 \\
$3.94 \mathrm{E}-04$ \\
$3.94 \mathrm{E}-06$ \\
\hline
\end{tabular}

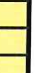

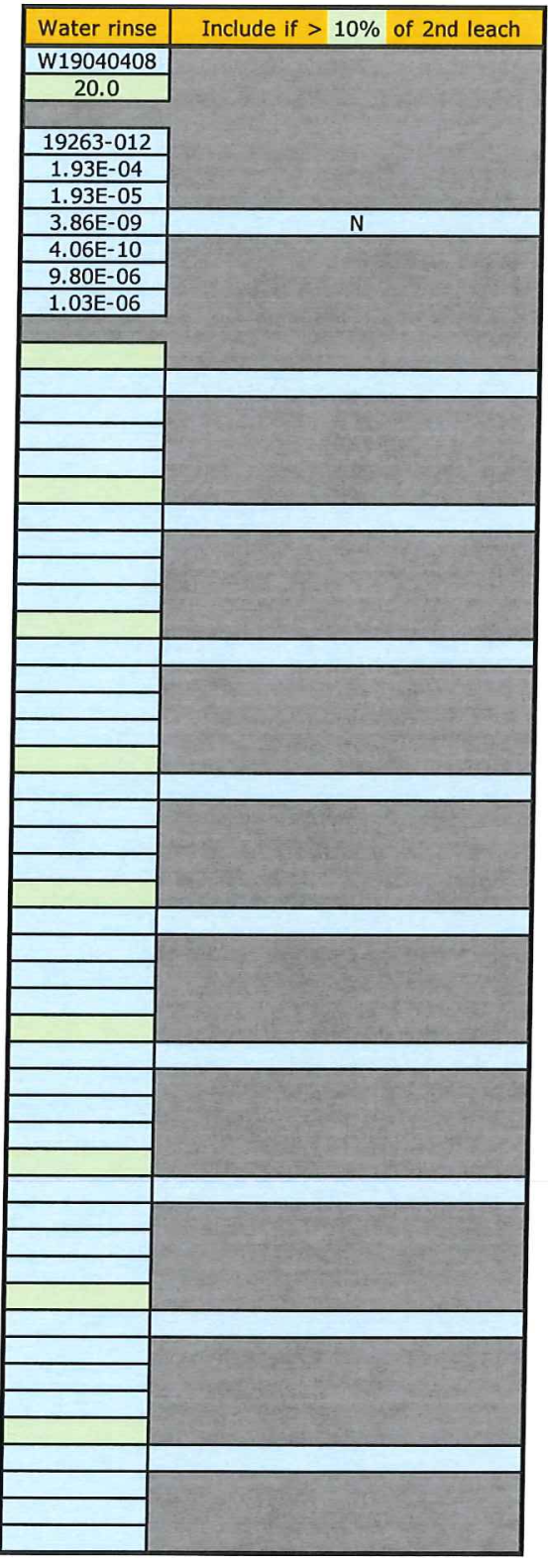




\section{Data Report Form DRF-22: Estimation of Average Particle Weight}

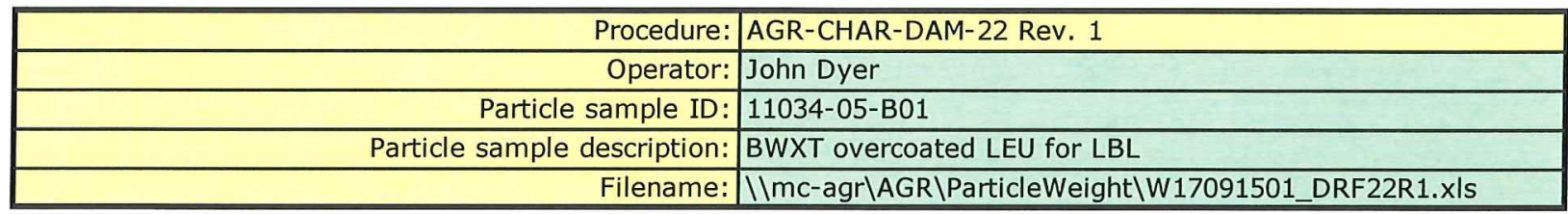

\begin{tabular}{|r|c|c|c|c|c|}
\hline & Sample 1 & Sample 2 & Sample 3 & Sample 4 & Sample 5 \\
\hline Weight of particles $(\mathrm{g}):$ & 0.3338 & 0.3362 & 0.3026 & 0.3262 & 0.3356 \\
\hline Number of particles: & 163 & 162 & 146 & 162 & 166 \\
\hline Average weight/particle (g): & $2.048 \mathrm{E}-03$ & $2.075 \mathrm{E}-03$ & $2.073 \mathrm{E}-03$ & $2.014 \mathrm{E}-03$ & $2.022 \mathrm{E}-03$ \\
\hline
\end{tabular}

Mean average weight/particle $(\mathrm{g}): 2.046 \mathrm{E}-03$

\begin{tabular}{lll} 
Standard error in mean average weight/particle $(\mathrm{g}):$ & $1.27 \mathrm{E}-05$ \\
\hline
\end{tabular}
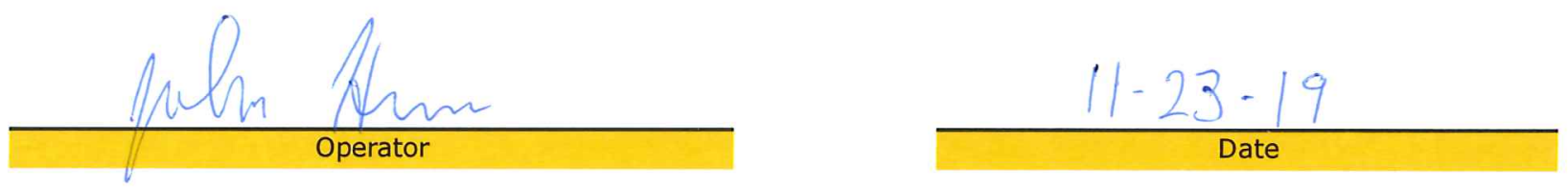


\section{Data Report Form DRF-22: Estimation of Average Particle Weight}

\begin{tabular}{|r|l|}
\hline Procedure: & AGR-CHAR-DAM-22 Rev. 2 \\
\hline Operator: & John Hunn/Brian Eckhart \\
\hline Particle sample ID: & J52R-16-11035-B00 \\
\hline Particle sample description: & BWXT Overcoated particles \\
\hline Filename: & $\backslash \backslash$ IIC-agr\AGR\ParticleWeight\W18120603_DRF22R2.xIs \\
\hline
\end{tabular}

\begin{tabular}{|r|c|c|c|c|c|}
\hline & Sample 1 & Sample 2 & Sample 3 & Sample 4 & Sample 5 \\
\hline Weight of particles (g): & 0.4350 & 0.4957 & 0.3686 & 0.3644 & 0.4293 \\
\hline Number of particles: & 217 & 246 & 183 & 182 & 213 \\
\hline Average weight/particle (g): & $2.005 \mathrm{E}-03$ & $2.015 \mathrm{E}-03$ & $2.014 \mathrm{E}-03$ & $2.002 \mathrm{E}-03$ & $2.015 \mathrm{E}-03$ \\
\hline
\end{tabular}

Mean average weight/particle $(\mathrm{g}): 2.010 \mathrm{E}-03$

Standard deviation in average weight/particle $(\mathrm{g}): 6.379 \mathrm{E}-06$

Standard error in mean average weight/particle $(\mathrm{g}): 2.85 \mathrm{E}-06$

\section{Comments}

Sample 3 had a large particle.

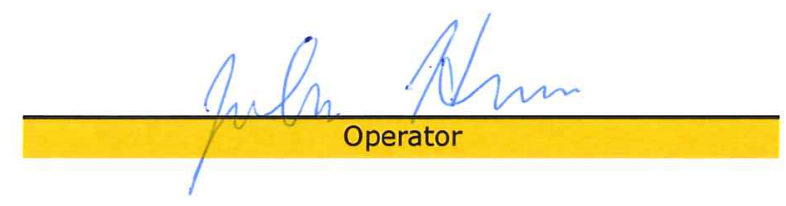

$\frac{12-6-18}{\text { Date }}$


APPENDIX C. REPORT FORMS FOR 25\% PF COMPACT LBL 

Inspection Report Form IRF-B:-Summary of Impurites Outside_SiC - Maximum Corrected Values

\begin{tabular}{|c|c|c|c|c|c|c|}
\hline Procedure: & \multicolumn{6}{|c|}{ AGR-CHAR-DAM-26 Rev. 3} \\
\hline Operator: & \multicolumn{6}{|c|}{ Montgomery/Dyer } \\
\hline Compact lot ID: & \multicolumn{6}{|c|}{ B\&W J52R-16-14156C and B\&W J52R-16-14156D } \\
\hline Compact lot description: & \multicolumn{6}{|c|}{ AGR-5/6/7 compacts, $25 \%$ packing fraction } \\
\hline Compact ID numbers: & \begin{tabular}{|c|}
1225,1287 \\
1303,1802, \\
1829 \\
\end{tabular} & $\begin{array}{c}1227,1241 \\
1264,1819 \\
1831 \\
\end{array}$ & $\begin{array}{c}1223,1309 \\
1319,1800 \\
1805 \\
\end{array}$ & $\begin{array}{c}1221,1240 \\
1243,1266 \\
1316 \\
\end{array}$ & Mean & $\begin{array}{l}\text { Standard } \\
\text { Deviation }\end{array}$ \\
\hline Number of compacts: & 5 & 5 & 5 & 5 & & \\
\hline \multicolumn{7}{|l|}{ Iron } \\
\hline Pre-burn leach (DRF-26A) $(\mu g)$ : & 170.56 & 160.90 & 177.34 & 160.64 & & \\
\hline Post-burn leach (DRF-26B) $(\mu \mathrm{g})$ : & 230.44 & 254.08 & 193.39 & 205.11 & & \\
\hline Total leached $(\mu \mathrm{g})$ : & 401.00 & 414.98 & 370.72 & 365.75 & & \\
\hline Fe outside SiC ( $\mu \mathrm{g} /$ compact): & 80.20 & 83.00 & $\mathbf{7 4 . 1 4}$ & 73.15 & 77.62 & 4.75 \\
\hline \multicolumn{7}{|l|}{ Chromium } \\
\hline Pre-burn leach (DRF-26A) ( $\mu \mathrm{g})$ : & 1.88 & 1.69 & 1.95 & 1.50 & & \\
\hline Post-burn leach (DRF-26B) $(\mu \mathrm{g})$ : & 0.36 & 0.15 & 0.17 & 0.14 & & \\
\hline Total leached $(\mu \mathrm{g})$ : & 2.25 & 1.84 & 2.13 & 1.64 & & \\
\hline Cr outside SiC ( $\mu \mathrm{g} /$ compact): & 0.45 & 0.37 & 0.43 & 0.33 & 0.39 & 0.06 \\
\hline \multicolumn{7}{|l|}{ Manganese } \\
\hline Pre-burn leach (DRF-26A) $(\mu \mathrm{g})$ : & 2.86 & 2.58 & 2.66 & 2.48 & & \\
\hline Post-burn leach (DRF-26B) $(\mu \mathrm{g})$ : & 0.14 & 0.17 & 0.16 & 0.17 & & \\
\hline Total leached $(\mu \mathrm{g})$ : & 3.00 & 2.75 & 2.81 & 2.65 & & \\
\hline Mn outside SiC ( $\mu \mathrm{g} /$ compact): & 0.60 & 0.55 & 0.56 & 0.53 & 0.561 & 0.029 \\
\hline \multicolumn{7}{|l|}{ Cobalt } \\
\hline Pre-burn leach $(D R F-26 A)(\mu g):$ & 0.06 & 0.05 & 0.06 & 0.08 & & \\
\hline Post-burn leach (DRF-26B) $(\mu \mathrm{g})$ : & 0.18 & 0.17 & 0.12 & 0.13 & & \\
\hline Total leached $(\mu \mathrm{g}):$ & 0.24 & 0.22 & 0.18 & 0.21 & & \\
\hline Co outside SiC ( $\mu \mathrm{g} /$ compact): & 0.048 & 0.044 & 0.036 & 0.042 & 0.043 & 0.005 \\
\hline \multicolumn{7}{|l|}{ Nickel } \\
\hline Pre-burn leach $(D R F-26 A)(\mu g):$ & 2.89 & 2.41 & 2.69 & 3.44 & & \\
\hline Post-burn leach (DRF-26B) $(\mu \mathrm{g}):$ & 2.36 & 2.56 & 4.27 & 4.21 & & \\
\hline Total leached $(\mu \mathrm{g}):$ & 5.25 & 4.98 & 6.96 & 7.65 & & \\
\hline Ni outside SiC ( $\mu \mathrm{g} /$ compact): & 1.05 & 1.00 & 1.39 & 1.53 & 1.24 & 0.26 \\
\hline \multicolumn{7}{|l|}{ Transition Metals } \\
\hline $\mathrm{Cr}+\mathrm{Mn}+\mathrm{Co}+\mathrm{Ni}$ outside SiC ( $\mu \mathrm{g} /$ compact): & 2.15 & 1.96 & 2.42 & 2.43 & 2.24 & 0.23 \\
\hline \multicolumn{7}{|l|}{ Calcium } \\
\hline Pre-burn leach (DRF-26A) $(\mu g)$ : & 622.90 & 574.91 & 628.06 & 641.30 & & \\
\hline Post-burn leach (DRF-26B) $(\mu g)$ : & 47.26 & 67.76 & 49.95 & 72.16 & & \\
\hline Total leached $(\mu \mathrm{g}):$ & 670.16 & 642.67 & 678.01 & 713.46 & & \\
\hline Ca outside SiC ( $\mu \mathrm{g} /$ compact): & 134.03 & 128.53 & 135.60 & 142.69 & 135.21 & 5.83 \\
\hline \multicolumn{7}{|l|}{ Aluminum } \\
\hline Pre-burn leach (DRF-26A) $(\mu g):$ & 794.67 & 744.73 & 783.94 & 773.60 & & \\
\hline Post-burn leach (DRF-26B) $(\mu g)$ : & 29.36 & 85.65 & 33.55 & 90.58 & & \\
\hline Total leached $(\mu g):$ & 824.03 & 830.37 & 817.49 & 864.17 & & \\
\hline Al outside SiC $(\mu \mathrm{g} /$ compact): & 164.81 & 166.07 & 163.50 & 172.83 & 166.80 & 4.16 \\
\hline \multicolumn{7}{|l|}{ Titanium } \\
\hline Pre-burn leach (DRF-26A) $(\mu \mathrm{g})$ : & 33.92 & 34.63 & 57.64 & 24.62 & & \\
\hline Post-burn leach (DRF-26B) $(\mu \mathrm{g})$ : & 16.44 & 27.25 & 22.57 & 25.17 & & \\
\hline Total leached $(\mu g)$ : & 50.36 & 61.88 & 80.22 & 49.79 & & \\
\hline Ti outside SiC ( $\mu \mathrm{g} /$ compact): & 10.07 & 12.38 & 16.04 & 9.96 & 12.11 & 2.85 \\
\hline \multicolumn{7}{|l|}{ Vanadium } \\
\hline Pre-burn leach (DRF-26A) $(\mu \mathrm{g}):$ & 20.98 & 19.60 & 21.10 & 19.60 & & \\
\hline Post-burn leach (DRF-26B) $(\mu g)$ : & 6.74 & 7.72 & 6.32 & 7.16 & & \\
\hline Total leached $(\mu \mathrm{g})$ : & 27.72 & 27.31 & 27.42 & 26.76 & & \\
\hline V outside SiC $(\mu \mathrm{g} /$ compact): & 5.54 & 5.46 & 5.48 & 5.35 & 5.46 & 0.08 \\
\hline \multicolumn{7}{|l|}{ Titanium and Vanadium } \\
\hline$T i+V$ outside $S i C$ ( $\mu /$ /compact): & 15.62 & 17.84 & 21.53 & 15.31 & 17.57 & 2.87 \\
\hline
\end{tabular}

Comments

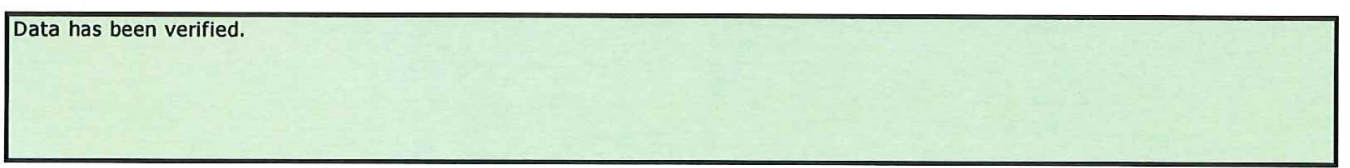

teed C. Montgomem

$2.8-2018$ 
Procedure: AGR-CHAR-DAM-26 Rev. 3

Operator: Montgomery/Dyer

Compact lot ID: B\&W J52R-16-14156C and B\&W J52R-16-14156D

Compact lot description: AGR-5/6/7 compacts, $25 \%$ packing fraction

\begin{tabular}{|r|c|c|c|c|c|}
\hline Compact ID numbers: & $\begin{array}{c}1225,1287, \\
1303,1802, \\
1829\end{array}$ & $\begin{array}{c}1227,1241, \\
1264,1819, \\
1831\end{array}$ & $\begin{array}{c}1223,1309, \\
1319,1800, \\
1805\end{array}$ & $\begin{array}{c}1221,1240, \\
1243,1266, \\
1316\end{array}$ & Total \\
\hline \hline Number of compacts: & 5 & 5 & 5 & 5 & 20 \\
\hline Equivalent number of leached kernels: & $4.3 \mathrm{E}-02$ & $3.5 \mathrm{E}-02$ & $2.2 \mathrm{E}-01$ & $7.6 \mathrm{E}-02$ & $3.7 \mathrm{E}-01$ \\
\hline
\end{tabular}

\section{Comments}

2/05/2018 Pre-burn data has been verified

Fred c. Montgomem

Operator
$2-8-2018$

Date 
Procedure: AGR-CHAR-DAM-26 Rev. 3

Operator: Montgomery/Dyer

Compact lot ID: B\&W J52R-16-14156C and B\&W J52R-16-14156D

Compact lot description: $A G R-5 / 6 / 7$ compacts, $25 \%$ packing fraction

\begin{tabular}{|r|c|c|c|c|c|}
\hline Compact ID numbers: & $\begin{array}{c}1233,1254, \\
1287,1291, \\
1821\end{array}$ & $\begin{array}{c}1236,1305, \\
1321,1807, \\
1808\end{array}$ & $\begin{array}{c}1257,1258, \\
1285,1298, \\
1324\end{array}$ & $\begin{array}{c}1277,1279, \\
1314,1812, \\
1828\end{array}$ & Total \\
\hline \hline Number of compacts: & 5 & 5 & 5 & 5 & 20 \\
\hline Equivalent number of leached kernels: & $4.6 \mathrm{E}-02$ & $9.5 \mathrm{E}-01$ & $3.1 \mathrm{E}-02$ & $3.7 \mathrm{E}-02$ & $1.1 \mathrm{E}+00$ \\
\hline
\end{tabular}

Comments

Data has been verified.

Faed c. Montaomen

Operator
$2-8 \cdot 2018$

Date 
Inspection Report Form IRF-C: Summary of Pre-burn Leach Uranium

Procedure: AGR-CHAR-DAM-26 Rev. 3

Operator: Montgomery

Compact lot ID: BWXT J52R-16-14156D

Compact lot description: $A G R-5 / 6 / 7$ compacts, $25 \%$ packing fraction

\begin{tabular}{|r|c|c|c|c|c|}
\hline Compact ID numbers: & $\begin{array}{c}1801,1834, \\
1818,1826, \\
1830\end{array}$ & $\begin{array}{c}1809,1817, \\
1823,1803, \\
1833\end{array}$ & $\begin{array}{c}1832,1825, \\
1820,1835, \\
1815\end{array}$ & $\begin{array}{c}1816,1813, \\
1822,1827, \\
1814\end{array}$ & Total \\
\hline \hline Number of compacts: & 5 & 5 & 5 & 5 & 20 \\
\hline Equivalent number of leached kernels: & $4.1 \mathrm{E}-02$ & $4.4 \mathrm{E}-02$ & $5.2 \mathrm{E}-02$ & $3.4 \mathrm{E}-02$ & $1.7 \mathrm{E}-01$ \\
\hline
\end{tabular}

Comments

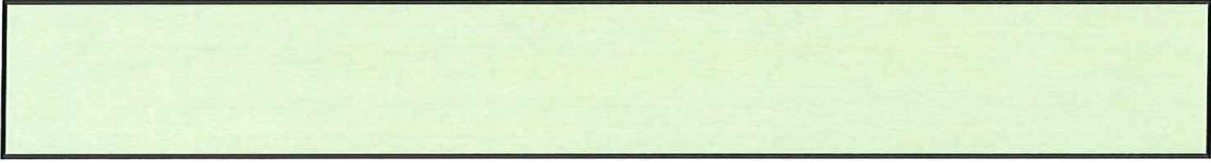

7.ed c. Montgomem

$4-18-2019$

operator

$\frac{4-18-2019}{\text { Date }}$




\begin{tabular}{|r|l|}
\hline Procedure: & AGR-CHAR-DAM-26 Rev. 3 \\
\hline Operator: & Montgomery/Dyer \\
\hline Compact lot ID: & B\&W J52R-16-14156C and B\&W J52R-16-14156D \\
\hline Compact lot description: & AGR-5/6/7 compacts, 25\% packing fraction \\
\hline
\end{tabular}

\begin{tabular}{|r|c|c|c|c|c|}
\hline Compact ID numbers: & $\begin{array}{c}1225,1287, \\
1303,1802, \\
1829\end{array}$ & $\begin{array}{c}1227,1241, \\
1264,1819, \\
1831\end{array}$ & $\begin{array}{c}1223,1309, \\
1319,1800, \\
1805\end{array}$ & $\begin{array}{c}1221,1240, \\
1243,1266, \\
1316\end{array}$ & Total \\
\hline \hline Number of compacts: & 5 & 5 & 5 & 5 & 20 \\
\hline Equivalent number of leached kernels: & $1.3 \mathrm{E}-02$ & $1.4 \mathrm{E}-02$ & $1.3 \mathrm{E}-01$ & $1.3 \mathrm{E}-02$ & $1.7 \mathrm{E}-01$ \\
\hline
\end{tabular}

\section{Comments}

2/07/2018 Post-burn data has been verified.

Fred c. montgomery
2.8 .2018

Date 
Inspection Report Form IRF-D: Summary of Post-Burn Leach Uranium

\begin{tabular}{|r|l|}
\hline Procedure: & AGR-CHAR-DAM-26 Rev. 3 \\
\hline Operator: & Montgomery/Dyer \\
\hline Compact lot ID: & B\&W J52R-16-14156C and B\&W J52R-16-14156D \\
\hline Compact lot description: & AGR-5/6/7 compacts, $25 \%$ packing fraction \\
\hline
\end{tabular}

\begin{tabular}{|r|c|c|c|c|c|}
\hline Compact ID numbers: & $\begin{array}{c}1233,1254, \\
1287,1291, \\
1821\end{array}$ & $\begin{array}{c}1236,1305, \\
1321,1807, \\
1808\end{array}$ & $\begin{array}{c}1257,1258, \\
1285,1298, \\
1324\end{array}$ & $\begin{array}{c}1277,1279, \\
1314,1812, \\
1828\end{array}$ & Total \\
\hline \hline Number of compacts: & 5 & 5 & 5 & 5 & 20 \\
\hline Equivalent number of leached kernels: & $1.2 \mathrm{E}+00$ & $2.2 \mathrm{E}+00$ & $1.5 \mathrm{E}-02$ & $1.6 \mathrm{E}-02$ & $3.4 \mathrm{E}+00$ \\
\hline
\end{tabular}

\section{Comments}

Data has been verified.

Fred c. Montgomeuy Operator
$2-8.2018$

Date 
Inspection Report Form IRF-D: Summary of Post-Burn Leach Uranium

\begin{tabular}{|c|c|c|c|c|c|}
\hline Procedure: & \multicolumn{5}{|c|}{ AGR-CHAR-DAM-26 Rev. 3} \\
\hline Operator: & \multicolumn{5}{|l|}{ Montgomery } \\
\hline Compact lot ID: & \multicolumn{5}{|c|}{ BWXT J52R-16-14156D } \\
\hline Compact lot description: & \multicolumn{5}{|c|}{ AGR- $5 / 6 / 7$ compacts, $25 \%$ packing fraction } \\
\hline Compact ID numbers: & $\begin{array}{c}1801,1834 \\
1818,1826 \\
1830 \\
\end{array}$ & $\begin{array}{c}1809,1817, \\
1823,1803, \\
1833 \\
\end{array}$ & $\begin{array}{c}1832,1825, \\
1820,1835, \\
1815 \\
\end{array}$ & $\begin{array}{c}1816,1813 \\
1822,1827 \\
1814 \\
\end{array}$ & Total \\
\hline Number of compacts: & 5 & 5 & 5 & 5 & 20 \\
\hline Equivalent number of leached kernels: & $1.3 \mathrm{E}-02$ & $2.5 \mathrm{E}-01$ & $1.2 \mathrm{E}-02$ & $1.3 \mathrm{E}-02$ & $2.8 \mathrm{E}-01$ \\
\hline
\end{tabular}

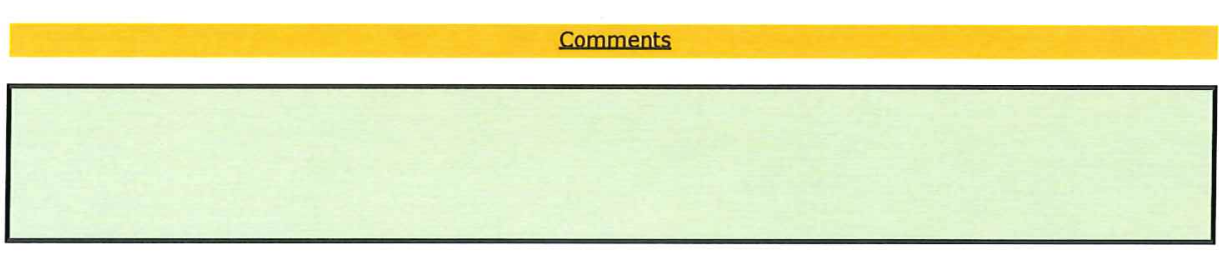

7red c. montgomery

$4,18-2019$

Operator

Date 
Data Report Form DRF-26A: Pre-Bum Leach Uranium and Impurities

\begin{tabular}{|r|l|}
\hline Procedure: & AGR-CHAR-DAM-26 Rev. 3 \\
\hline Operator: & Montgomery/Dyer \\
\hline Compact lot ID: & B\&W J52R-16-14156C and B\&W J52R-16-14156D \\
\hline Compact lot description: & AGR-5/6/7 compacts, 25\% packing fraction \\
\hline Compact ID numbers: & $1225,1287,1303,1802,1829$ \\
\hline DRF filename: & IIImC-agr/AGRILeachBurnLeach 14156 C \&D-Group 1 DRF26R3.xIs \\
\hline
\end{tabular}

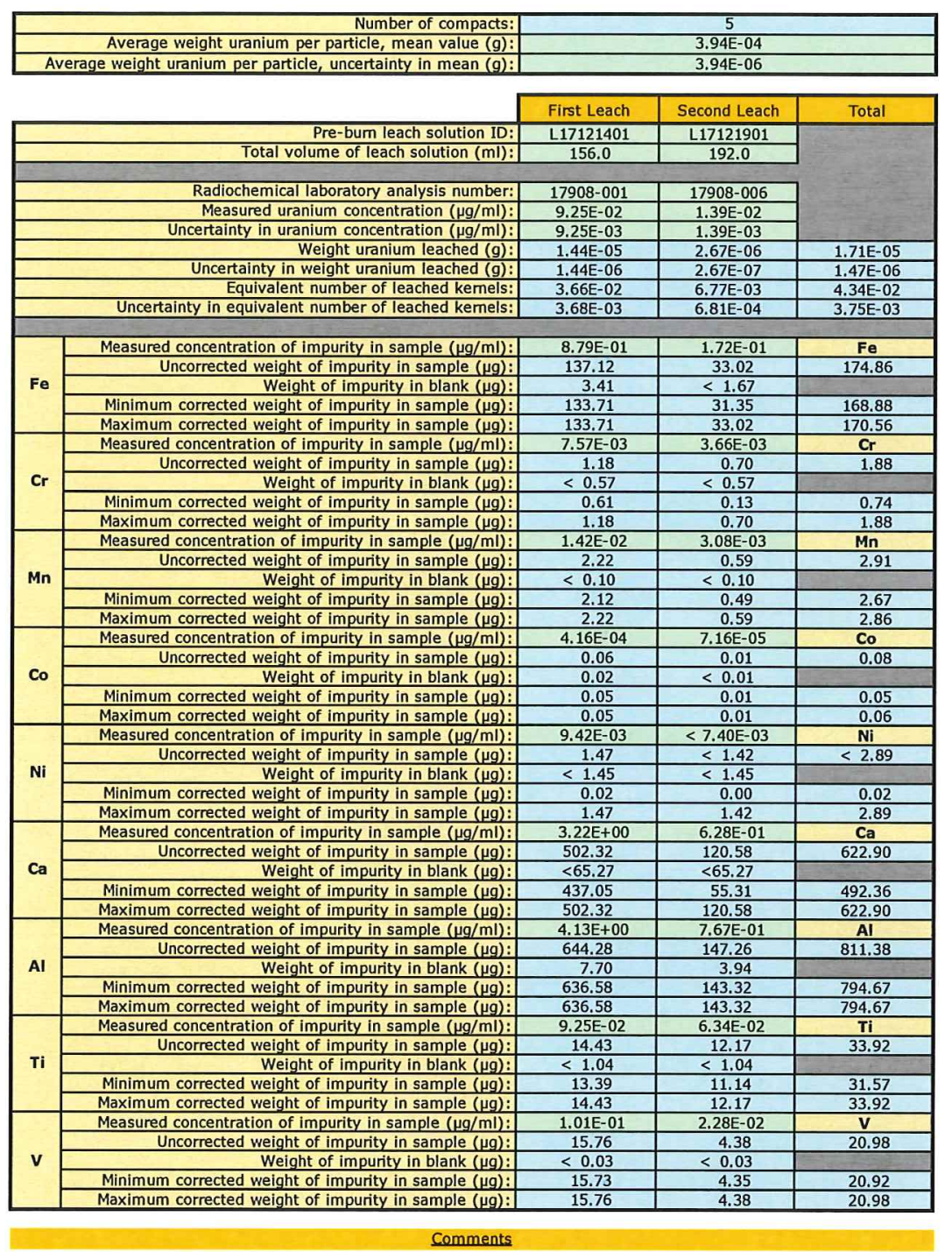

comments

FCM checked the data against the Official Results of Analyses report for RMAL17908 on 2/5/2018.

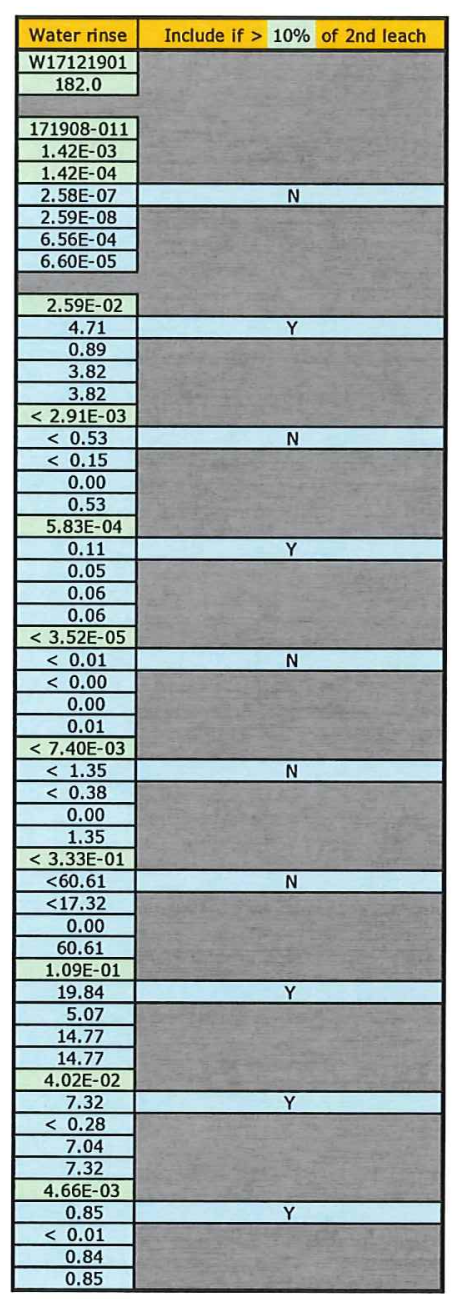

Foed c. Montgomem

$2-8.2018$ 
Data Report Form DRF-26A: Pre-Bum Leach Uranium and Impurities

\begin{tabular}{|r|l|}
\hline Procedure: & AGR-CHAR-DAM-26 Rev. 3 \\
\hline Operator: & Montgomery/Dyer \\
\hline Compact lot ID: & B\&W J52R-16-14156C and B\&W J52R-16-14156D \\
\hline Compact lot description: & AGR-5/6/7 compacts, 25\% packing fraction \\
\hline Compact ID numbers: & $1227,1241,1264,1819,1831$ \\
\hline DRF filename: & \mc-agr/AGRILeachBurnLeachl14156C\&D-Group 1 DRF26R3.xIs \\
\hline
\end{tabular}

\begin{tabular}{|c|c|c|c|c|}
\hline \multicolumn{2}{|r|}{ Number of compacts: } & \multicolumn{3}{|c|}{5} \\
\hline \multirow{2}{*}{\multicolumn{2}{|c|}{$\begin{array}{l}\text { Average weight uranium per particle, mean value }(g) \text { : } \\
\text { Average weight uranium per particle, uncertainty in mean }(g) \text { : }\end{array}$}} & \\
\hline & & \multicolumn{3}{|c|}{$3.94 \mathrm{E}-06$} \\
\hline & First Leach & Second Leach & Total \\
\hline & Pre-burn leach solution ID: & L17121402 & L17121902 & \\
\hline & Total volume of leach solution (ml): & 144.0 & 182.0 & \\
\hline & Radiochemical laboratory analysis number: & $17908-002$ & $17908-007$ & \\
\hline & Measured uranium concentration $(\mu \mathrm{g} / \mathrm{ml})$ : & $7.94 \mathrm{E}-02$ & $1.30 \mathrm{E}-02$ & \\
\hline & Uncertainty in uranium concentration $(\mathrm{\mu g} / \mathrm{ml})$ : & $7.94 \mathrm{E}-03$ & $1.30 \mathrm{E}-03$ & \\
\hline & Weight uranium leached $(\mathrm{g})$ : & $1.14 \mathrm{E}-05$ & $2.37 \mathrm{E}-06$ & $1.38 \mathrm{E}-05$ \\
\hline & Uncertainty in weight uranium leached (g): & $1.14 \mathrm{E}-06$ & $2.37 \mathrm{E}-07$ & $1.17 \mathrm{E}-06$ \\
\hline & Equivalent number of leached kemels: & $2.90 \mathrm{E}-02$ & $6.01 \mathrm{E}-03$ & $3.50 \mathrm{E}-02$ \\
\hline & Uncertainty in equivalent number of leached kemels: & $2.92 \mathrm{E}-03$ & $6.04 \mathrm{E}-04$ & $2.99 \mathrm{E}-03$ \\
\hline \multirow{5}{*}{$\mathbf{F e}$} & Measured concentration of impurity in sample $(\mu \mathrm{g} / \mathrm{ml})$ : & $9.01 \mathrm{E}-01$ & $1.74 \mathrm{E}-01$ & $\overline{F e}$ \\
\hline & Uncorrected weight of impurity in sample $(\mu g)$ : & 129.74 & 31.67 & 165.21 \\
\hline & Weight of impurity in blank $(\mu g)$ : & 3.41 & $<1.67$ & \\
\hline & Minimum corrected weight of impurity in sample $(\mu g)$ : & 126.33 & 29.99 & 159.23 \\
\hline & Maximum corrected weight of impurity in sample $(\mu g)$ : & 126.33 & 31.67 & 160.90 \\
\hline \multirow{5}{*}{ Cr } & Measured concentration of impurity in sample $(\mu \mathrm{g} / \mathrm{ml})$ : & $7.30 \mathrm{E}-03$ & $3.51 E-03$ & $\mathrm{Cr}$ \\
\hline & Uncorrected weight of impurity in sample $(\mu g)$ : & 1.05 & 0.64 & 1.69 \\
\hline & Weight of impurity in blank $(\mu g)$ : & $<0.57$ & $<0.57$ & \\
\hline & Minimum corrected weight of impurity in sample $(\mu g)$ : & 0.48 & 0.07 & 0.55 \\
\hline & Maximum corrected weight of impurity in sample $(\mu g)$ : & 1.05 & 0.64 & 1.69 \\
\hline \multirow{5}{*}{ Mn } & Measured concentration of impurity in sample $(\mathrm{\mu g} / \mathrm{ml})$ : & $1.47 \mathrm{E}-02$ & $2.55 \mathrm{E}-03$ & Mn \\
\hline & Uncorrected weight of impurity in sample $(\mu g)$ : & 2.12 & 0.46 & 2.58 \\
\hline & Weight of impurity in blank $(\mu \mathrm{g})$ : & $<0.10$ & $<0.10$ & \\
\hline & Minimum corrected weight of impurity in sample $(\mu \mathrm{g})$ : & 2.02 & 0.37 & 2.39 \\
\hline & Maximum corrected weight of impurity in sample ( $\mu \mathrm{g})$ : & 2.12 & 0.46 & 2.58 \\
\hline \multirow{5}{*}{ co } & Measured concentration of impurity in sample $(\mu \mathrm{g} / \mathrm{ml})$ : & $3.91 \mathrm{E}-04$ & $6.52 \mathrm{E}-05$ & Co \\
\hline & Uncorrected weight of impurity in sample $(\mu \mathrm{g})$ : & 0.06 & 0.01 & 0.07 \\
\hline & Weight of impurity in blank $(\mu \mathrm{g})$ : & 0.02 & $<0.01$ & \\
\hline & Minimum corrected weight of impurity in sample $(\mu \mathrm{g})$ : & 0.04 & 0.00 & 0.04 \\
\hline & Maximum corrected weight of impurity in sample $(\mu \mathrm{pg})$ : & 0.04 & 0.01 & 0.05 \\
\hline \multirow{5}{*}{$\mathbf{N i}$} & Measured concentration of impurity in sample $(\mu \mathrm{g} / \mathrm{ml})$ : & $<7.40 \mathrm{E}-03$ & $<7.40 \mathrm{E}-03$ & $\mathrm{Ni}$ \\
\hline & Uncorrected weight of impurity in sample ( $\mu \mathrm{g})$ : & $<1.07$ & $<1.35$ & $<2.41$ \\
\hline & Weight of impurity in blank $(\mu \mathrm{g})$ : & $<1.45$ & $<1.45$ & \\
\hline & Minimum corrected weight of impurity in sample $(\mu \mathrm{gg})$ : & 0.00 & 0.00 & 0.00 \\
\hline & Maximum corrected weight of impurity in sample $(\mu g)$ : & 1.07 & 1.35 & 2.41 \\
\hline \multirow{5}{*}{$\mathrm{Ca}$} & Measured concentration of impurity in sample $(\mu \mathrm{g} / \mathrm{ml})$ : & $3.20 E+00$ & $6.27 \mathrm{E}-01$ & $\mathbf{C a}$ \\
\hline & Uncorrected weight of impurity in sample $(\mu g)$ : & 460.80 & 114.11 & 574.91 \\
\hline & Weight of impurity in blank $(\mu g)$ : & $<65.27$ & $<65.27$ & \\
\hline & Minimum corrected weight of impurity in sample $(\mu g)$ : & 395.53 & 48.85 & 444.38 \\
\hline & Maximum corrected weight of impurity in sample $(\mu g)$ : & 460.80 & 114.11 & 574.91 \\
\hline \multirow{5}{*}{ Al } & Measured concentration of impurity in sample $(\mu \mathrm{g} / \mathrm{ml})$ : & $4.16 \mathrm{E}+00$ & $8.05 \mathrm{E}-01$ & Al \\
\hline & Uncorrected weight of impurity in sample $(\mu g)$ : & 599.04 & 146.51 & 761.44 \\
\hline & Weight of impurity in blank $(\mu g)$ : & 7.70 & 3.94 & \\
\hline & Minimum corrected weight of impurity in sample $(\mu g)$ : & 591.34 & 142.57 & 744.73 \\
\hline & Maximum corrected weight of impurity in sample $(\mu g)$ : & 591.34 & 142.57 & 744.73 \\
\hline \multirow{5}{*}{$\mathbf{T i}$} & Measured concentration of impurity in sample $(\mu \mathrm{g} / \mathrm{ml})$ : & $1.01 \mathrm{E}-01$ & $7.08 \mathrm{E}-02$ & $\mathrm{Ti}$ \\
\hline & Uncorrected weight of impurity in sample $(\mu \mathrm{g})$ : & 14.54 & 12.89 & 34.63 \\
\hline & Weight of impurity in blank $(\mu \mathrm{g})$ : & $<1.04$ & $<1.04$ & \\
\hline & Minimum corrected weight of impurity in sample $(\mu g)$ : & 13.51 & 11.85 & 32.28 \\
\hline & Maximum corrected weight of impurity in sample $(\mu g)$ : & 14.54 & 12.89 & 34.63 \\
\hline \multirow{5}{*}{$\mathbf{v}$} & Measured concentration of impurity in sample $(\mu \mathrm{g} / \mathrm{ml})$ : & $9,90 \mathrm{E}-02$ & $2.48 \mathrm{E}-02$ & $\mathbf{v}$ \\
\hline & Uncorrected weight of impurity in sample $(\mu \mathrm{g})$ : & 14.26 & 4.51 & 19.60 \\
\hline & Weight of impurity in blank $(\mu \mathrm{g})$ : & $<0.03$ & $<0.03$ & \\
\hline & Minimum corrected weight of impurity in sample $(\mu g)$ : & 14.23 & 4.49 & 19.54 \\
\hline & Maximum corrected weight of impurity in sample $(\mu \mathrm{g}):$ & 14.26 & 4.51 & 19.60 \\
\hline
\end{tabular}

comments

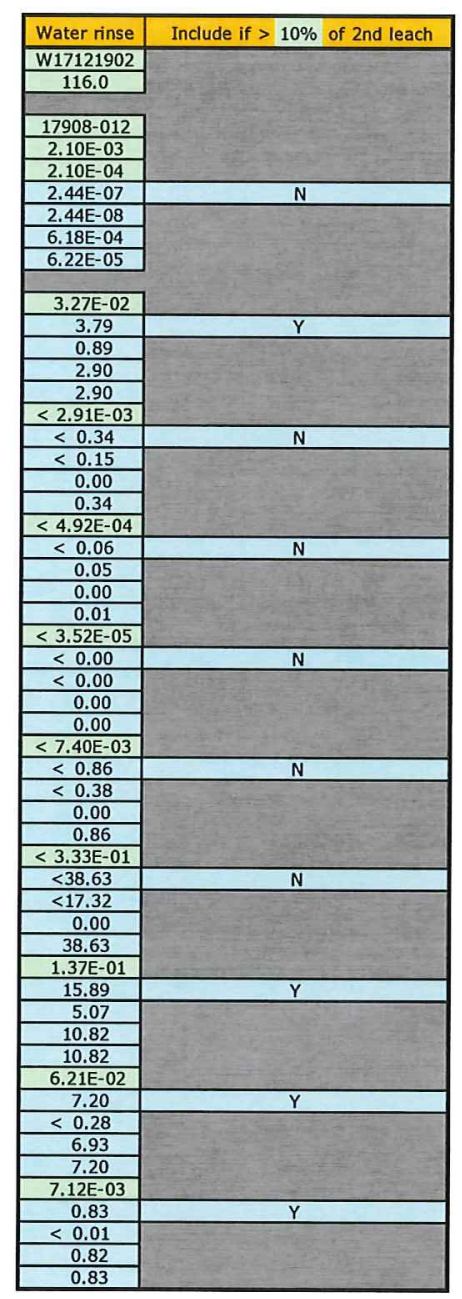

FCM checked the data against the Official Results of Analyses report for RMAL17908 on 2/5/2018.

\section{Fued C. Muntgomem $2-8-18$}


Data Report Form DRF-26A: Pre-Bum Leach Uranium and Impurities

\begin{tabular}{|c|c|}
\hline Procedure: & AGR-CHAR-DAM-26 Rev. 3 \\
\hline Operator: & Montgomery/Dyer \\
\hline Compact lot ID: & $B \& W J 52 R-16-14156 C$ and $B \& W J 52 R-16-14156 D$ \\
\hline Compact lot description: & AGR-5/6/7 compacts, $25 \%$ packing fraction \\
\hline Compact ID numbers: & $1223,1309,1319,1800,1805$ \\
\hline DRF filename: & IImc-agr|AGRILeachBurnLeach 14156C\&D-Group 1 DRF26R3.x/s \\
\hline
\end{tabular}

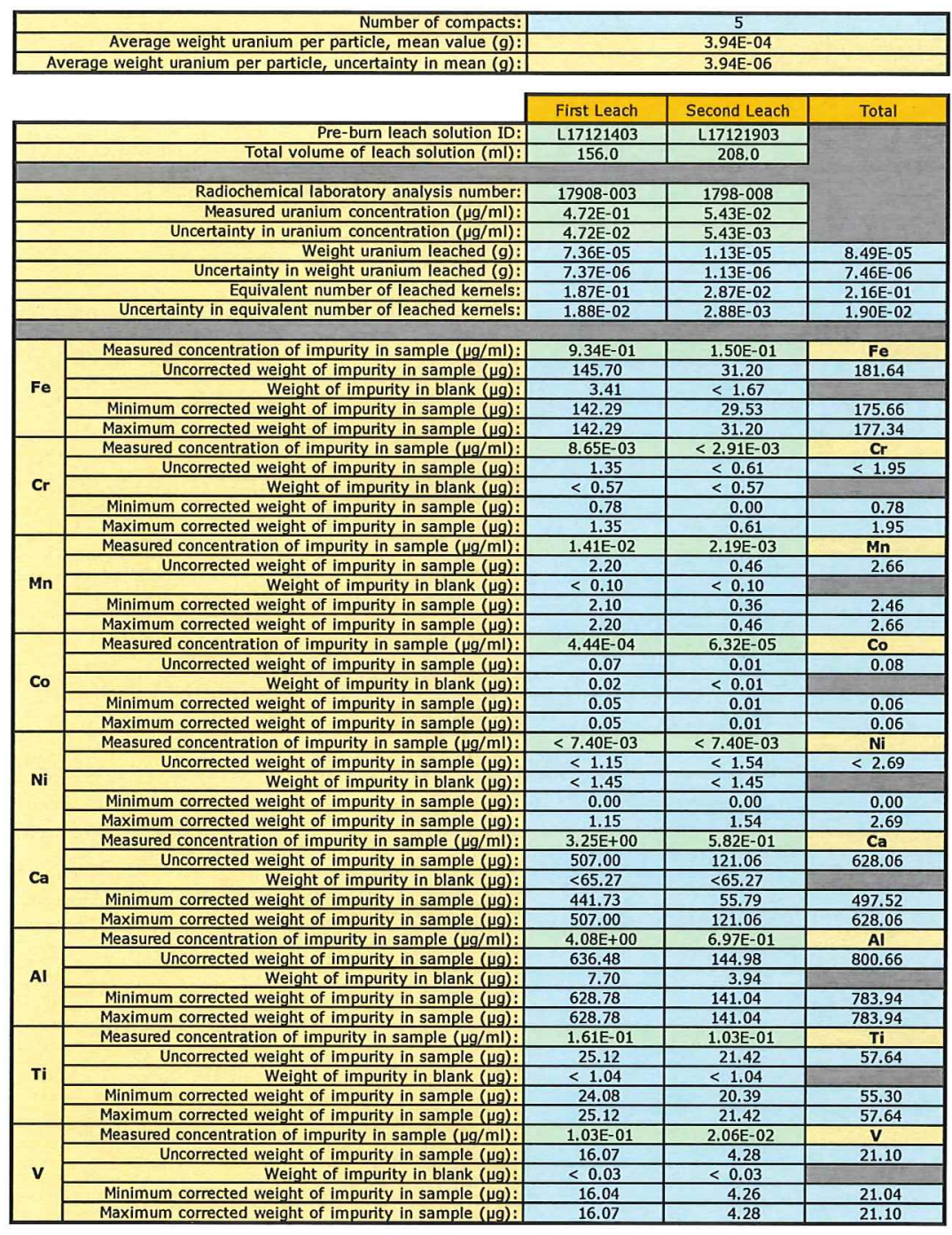

comments

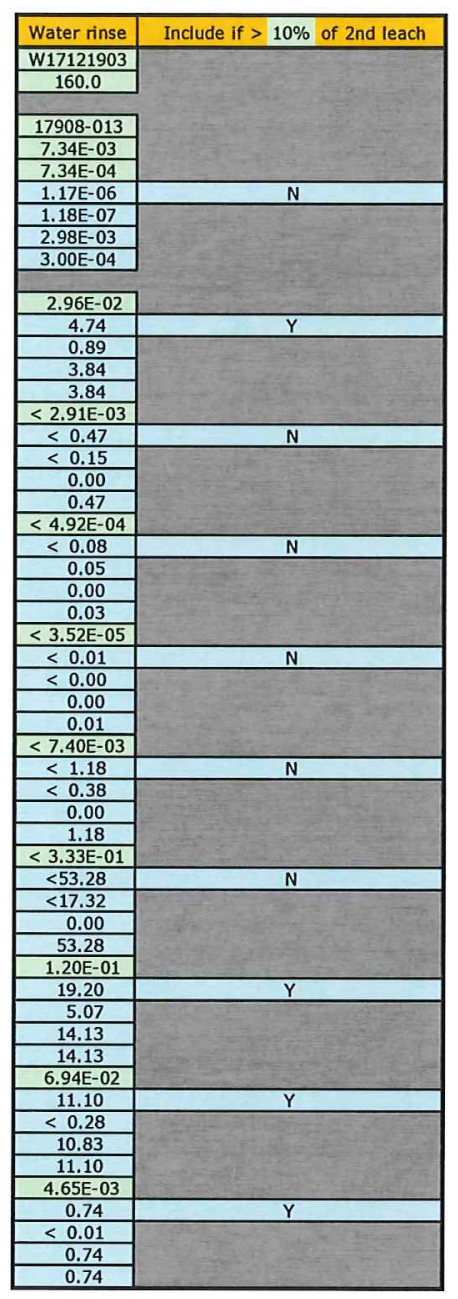

FCM checked the data against the Official Results of Analyses report for RMAL17908 on 2/5/2018.

\section{Fred c. Montgomem $\frac{2-8-2018}{\text { operator }}$}


Data Report Form DRF-26A:-Pre-Bum Leach Uranium and Impurities

\begin{tabular}{|r|l|}
\hline Procedure: & AGR-CHAR-DAM-26 Rev. 3 \\
\hline Operator: & Montgomery/Dyer \\
\hline Compact lot ID: & B\&W J52R-16-14156C and B\&W J52R-16-14156D \\
\hline Compact lot description: & AGR-5/6/7 compacts, 25\% packing fraction \\
\hline Compact ID numbers: & $1221,1240,1243,1266,1316$ \\
\hline DRF filename: & |Imc-agr|AGR/LeachBurnLeach 14156C\&D-Group 1 DRF26R3.xIs \\
\hline
\end{tabular}

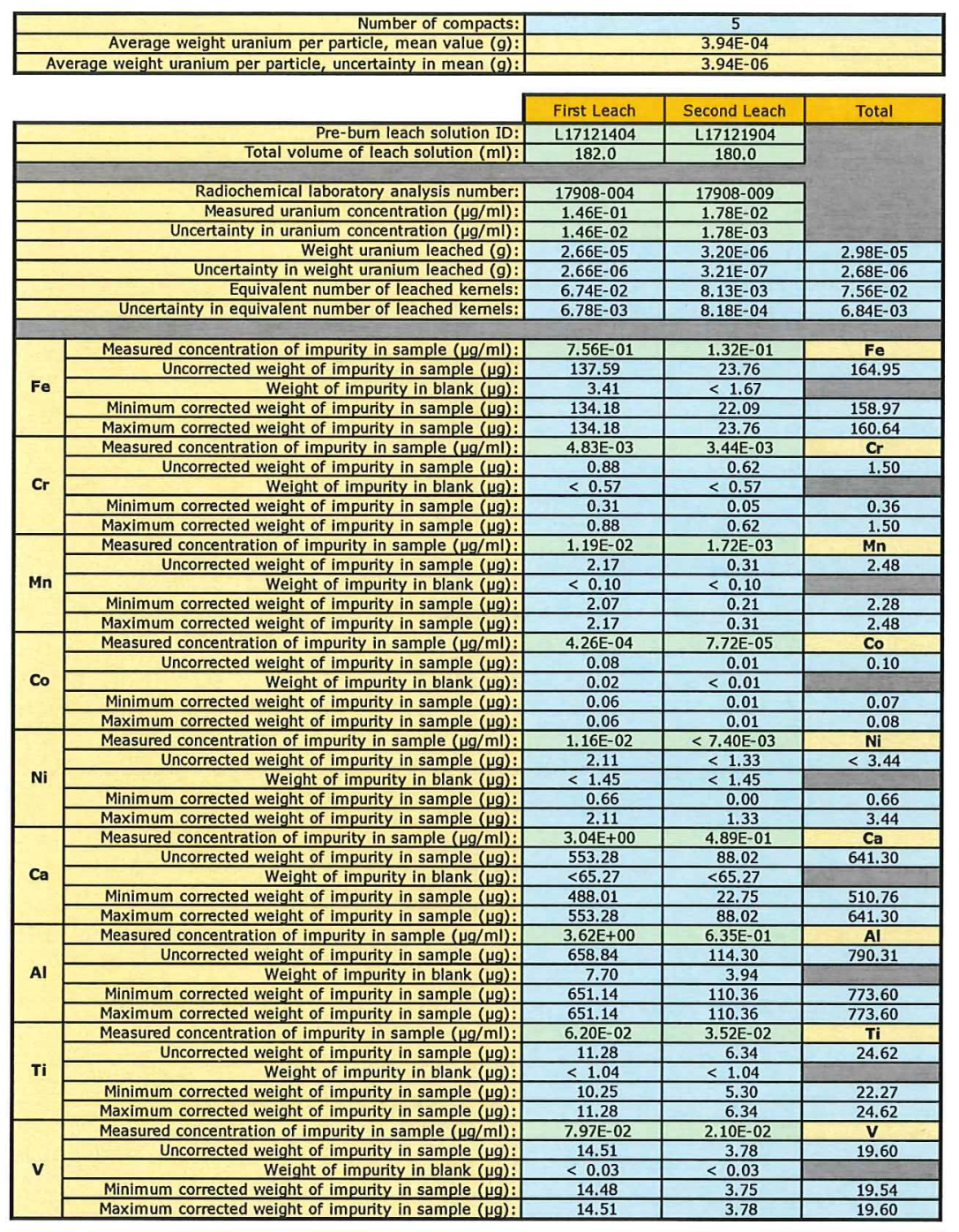

Comments

FCM checked the data against the Official Results of Analyses report for RMAL17908 on 2/5/2018

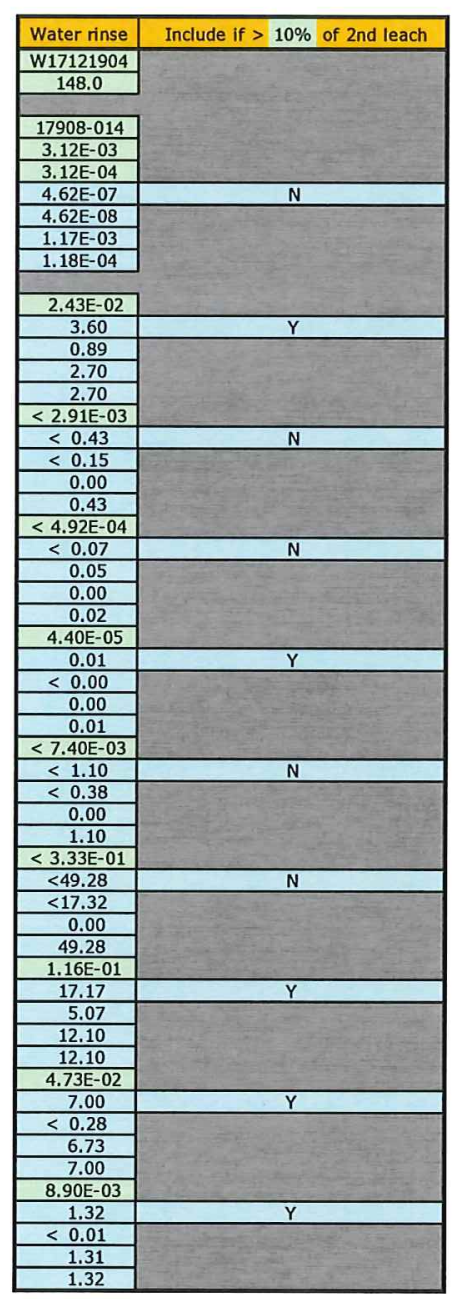

\section{Fied c. Montgorney}

$2-8-2018$ 


\section{Data Report Form DRF-26A: Pre-Burn Leach Uranium and Impurities}

\begin{tabular}{|c|c|}
\hline Procedure: & AGR-CHAR-DAM-26 Rev. 3 \\
\hline Operator: & Montgomery/Dyer \\
\hline Compact lot ID: & B\&W J52R-16-14156C and B\&W J52R-16-14156D \\
\hline Compact lot description: & AGR-5/6/7 compacts, $25 \%$ packing fraction \\
\hline Compact ID numbers: & Pre-burn leach blank \\
\hline DRF filename: & 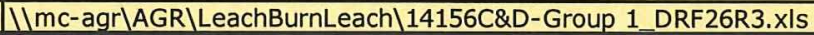 \\
\hline
\end{tabular}

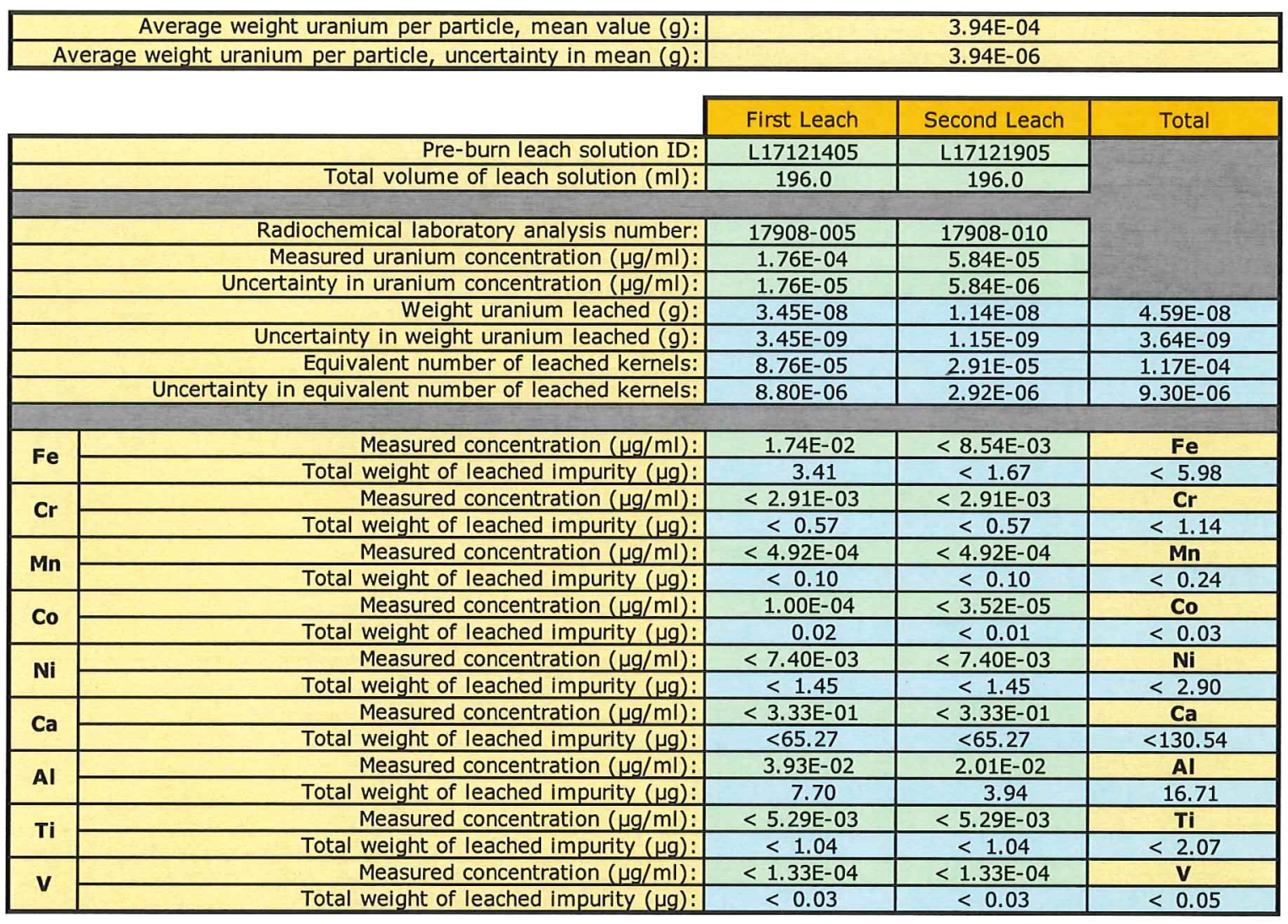

\section{Comments}

FCM checked the data against the Official Results of Analyses report for RMAL17908 on 2/5/2018.

Faed c. Montgomery
$2-8-2018$

Date 
Data Report Form DRF-26B: Post-Bum Leach Uranium and Impurities

\begin{tabular}{|r|l|}
\hline Procedure: & AGR-CHAR-DAM-26 Rev. 3 \\
\hline Operator: & Montgomery/Dyer \\
\hline Compact lot ID: & B\&W J52R-16-14156C and B\&W J52R-16-14156D \\
\hline Compact lot description: & AGR-5/6/7 compacts, 25\% packing fraction \\
\hline Compact ID numbers: & $1225,1287,1303,1802,1829$ \\
\hline DRF filename: & IImc-agr|AGRILeachBurnLeach 14156C\&D-Group 1_DRF26R3.xIs \\
\hline
\end{tabular}

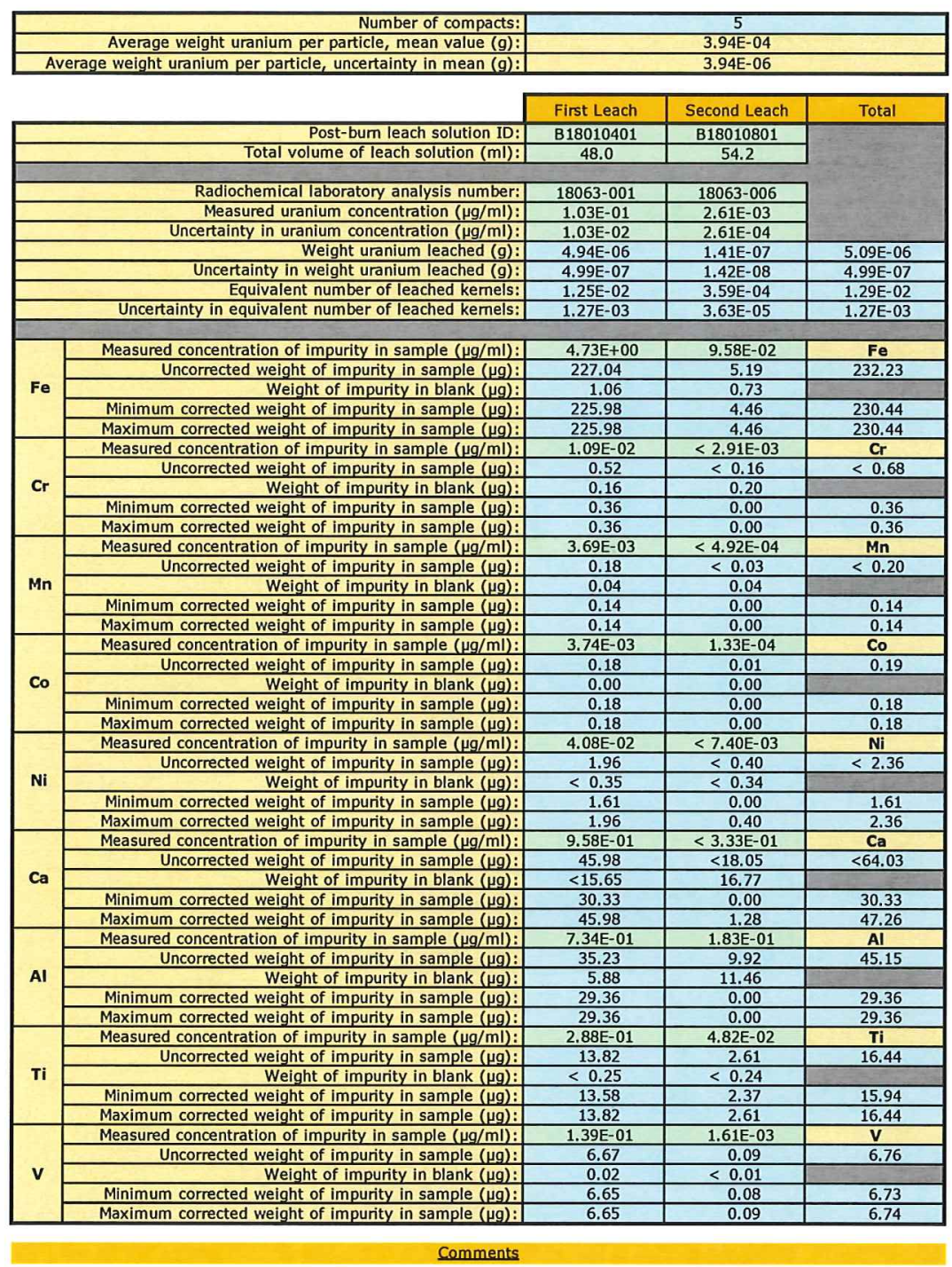

comments

FCM checked the data against the Official Results of Analyses report for RMAL18063 on 2/7/2018.

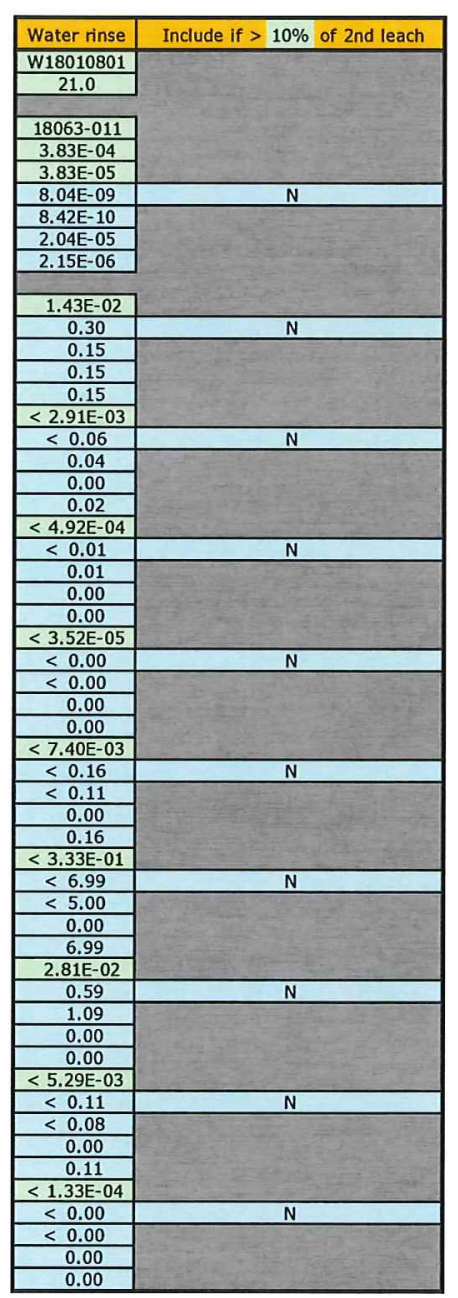

Fued C. Montgomeey
$2-8-2018$ 
Data Report Form DRF-26B: Post-Bum Leach Uranium and Impurities

\begin{tabular}{|c|c|}
\hline Procedure: & AGR-CHAR-DAM-26 Rev. 3 \\
\hline Operator: & Montgomery/Dyer \\
\hline Compact lot ID: & $B \& W$ J52R-16-14156C and B\&W J52R-16-14156D \\
\hline Compact lot description: & AGR-5/6/7 compacts, $25 \%$ packing fraction \\
\hline Compact ID numbers: & $1227,1241,1264,1819,1831$ \\
\hline DRF filename: & IImc-agr|AGR\LeachBurnLeach $\backslash 14156 C \&$ D-Group 1_DRF26R3.x/s \\
\hline
\end{tabular}
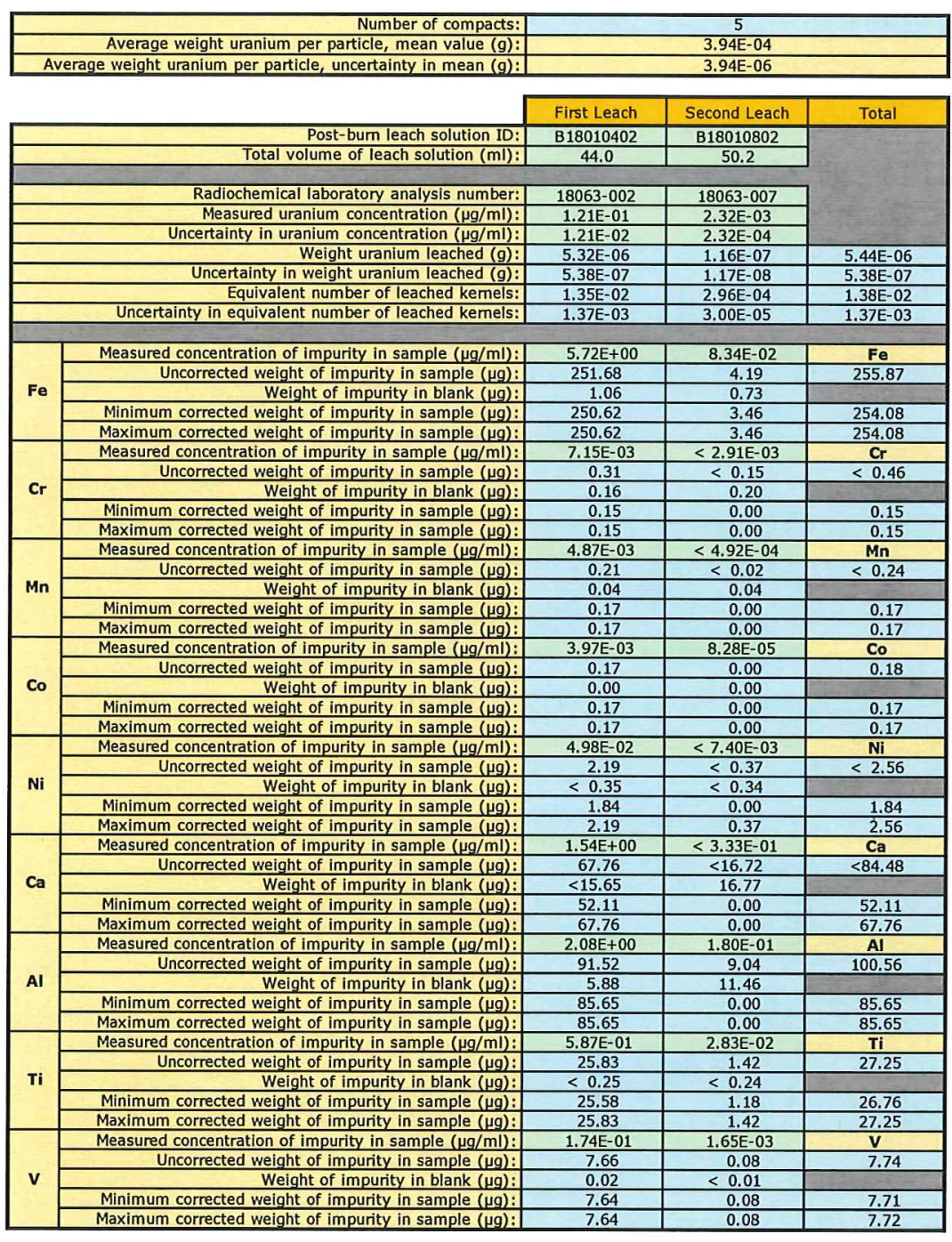

comments

FCM checked the data against the Official Results of Analyses report for RMAL18063 on 2/7/2018.

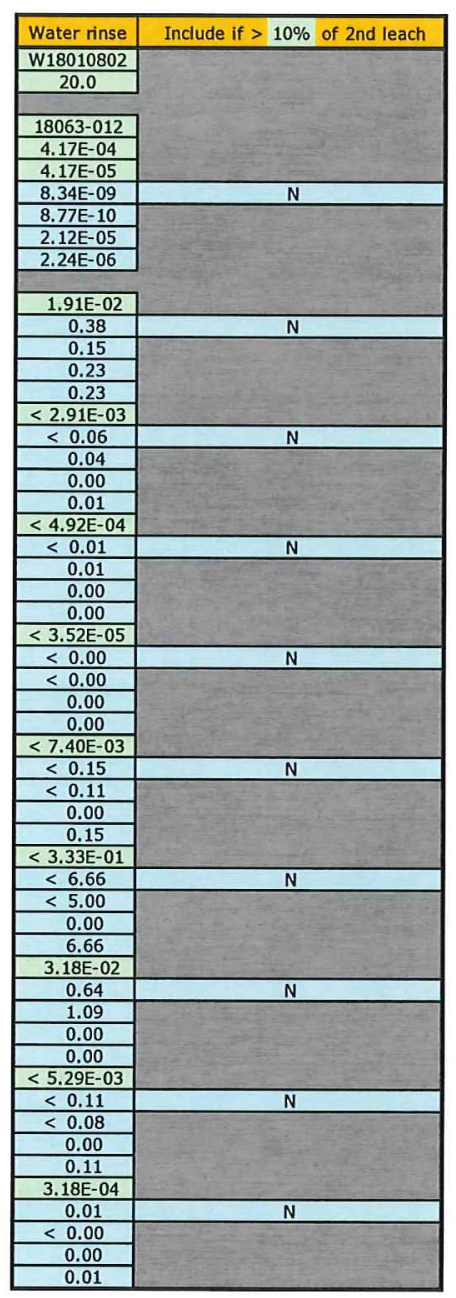

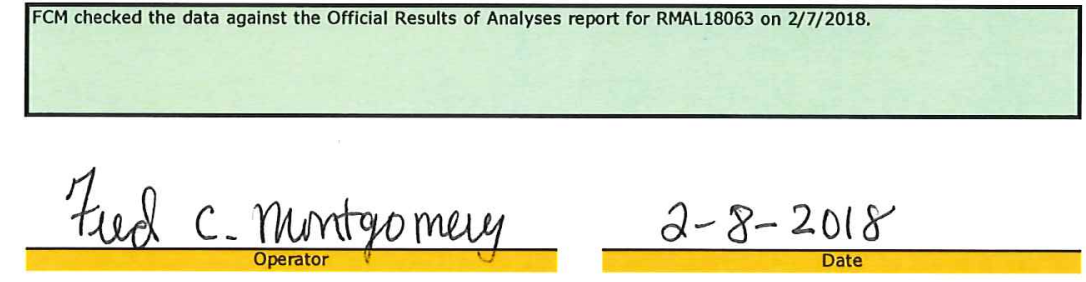


Data Report Form DRF-26B: Post-Bum Leach Uranium and Impurities

\begin{tabular}{|r|l|}
\hline Procedure: & AGR-CHAR-DAM-26 Rev. 3 \\
\hline Operator: & Montgomery/Dyer \\
\hline Compact lot ID: & B\&W J52R-16-14156C and B\&W J52R-16-14156D \\
\hline Compact lot description: & AGR-5/6/7 compacts, 25\% packing fraction \\
\hline Compact ID numbers: & $1223,1309,1319,1800,1805$ \\
\hline DRF filename: & 1Imc-agr/AGRILeachBumLeach 14156C\&D-Group 1_DRF26R3.xIs \\
\hline
\end{tabular}

\begin{tabular}{|r|r|}
\hline Number of compacts: & 5 \\
\hline Average weight uranium per particle, mean value $(\mathbf{g}):$ & $3.94 \mathrm{E}-04$ \\
\hline Average weight uranium per particle, uncertainty in mean $(\mathbf{g}):$ & $3.94 \mathrm{E}-06$ \\
\hline
\end{tabular}

\begin{tabular}{|c|c|c|c|c|}
\hline & & & \\
\hline & & First Leach & Second Leach & Total \\
\hline \multirow{2}{*}{\multicolumn{2}{|c|}{$\begin{array}{cc} & \text { Post-bum leach solution ID: } \\
\text { Total volume of leach solution }(\mathrm{ml}):\end{array}$}} & B18010403 & 818010803 & \\
\hline & & 45.0 & 49.8 & \\
\hline \multicolumn{2}{|c|}{ Radiochemical laboratory analysis number: } & $18063-003$ & $18063-008$ & \\
\hline \multicolumn{2}{|r|}{ Measured uranium concentration $(\mu \mathrm{g} / \mathrm{ml})$ : } & $1.13 E+00$ & $1.83 \mathrm{E}-03$ & \\
\hline \multirow{2}{*}{\multicolumn{2}{|c|}{$\begin{array}{r}\text { Uncertainty in uranium concentration }(\mu \mathrm{g} / \mathrm{ml}) \text { : } \\
\text { Weight uranium leached }(\mathrm{g}) \text { : }\end{array}$}} & $1.13 \mathrm{E}-01$ & $1.83 \mathrm{E}-04$ & \\
\hline & & $5.09 \mathrm{E}-05$ & $9.11 \mathrm{E}-08$ & $5.09 \mathrm{E}-05$ \\
\hline \multicolumn{2}{|r|}{ Uncertainty in weight uranium leached $(\mathrm{g})$ : } & $5.14 \mathrm{E}-06$ & $9.19 \mathrm{E}-09$ & $5.14 \mathrm{E}-06$ \\
\hline \multicolumn{2}{|c|}{ Equivalent number of leached kemels: } & $1.29 \mathrm{E}-01$ & $2.31 \mathrm{E}-04$ & $1.29 \mathrm{E}-01$ \\
\hline \multicolumn{2}{|c|}{ Uncertainty in equivalent number of leached kemels: } & $1.31 \mathrm{E}-02$ & $2.34 \mathrm{E}-05$ & $1.31 \mathrm{E}-02$ \\
\hline \multirow{5}{*}{$\mathrm{Fe}$} & Measured concentration of impurity in sample $(\mu \mathrm{g} / \mathrm{ml})$ : & $4.25 \mathrm{E}+00$ & $7.14 \mathrm{E}-02$ & $\mathbf{F e}$ \\
\hline & Uncorrected weight of impurity in sample $(\mu g)$ : & 191.25 & 3.56 & 195.32 \\
\hline & Weight of impurity in blank $(\mu \mathrm{g})$ : & 1.06 & 0.73 & \\
\hline & Minimum corrected weight of impurity in sample $(\mu g)$ : & 190.19 & 2.83 & 193.39 \\
\hline & Maximum corrected weight of impurity in sample $(\mu g)$ : & 190.19 & 2.83 & 193.39 \\
\hline \multirow{5}{*}{$\mathrm{Cr}$} & Measured concentration of impurity in sample $(\mathrm{\mu g} / \mathrm{ml})$ : & $7.43 \mathrm{E}-03$ & $<2.91 \mathrm{E}-03$ & $\mathrm{Cr}$ \\
\hline & Uncorrected weight of impurity in sample $(\mu g)$ : & 0.33 & $<0.14$ & $<0.48$ \\
\hline & Weight of impurity in blank $(\mu g)$ : & 0.16 & 0.20 & \\
\hline & Minimum corrected weight of impurity in sample $(\mu \mathrm{g})$ : & 0.17 & 0.00 & 0.17 \\
\hline & Maximum corrected weight of impurity in sample $(\mu g)$ : & 0.17 & 0.00 & 0.17 \\
\hline \multirow{5}{*}{ Mn } & Measured concentration of impurity in sample $(\mu \mathrm{g} / \mathrm{ml})$ : & $4.44 \mathrm{E}-03$ & $4.97 \mathrm{E}-04$ & Mn \\
\hline & Uncorrected weight of impurity in sample $(\mu \mathrm{g})$ : & 0.20 & 0.02 & 0.22 \\
\hline & Weight of impurity in blank $(\mu g)$ : & 0.04 & 0.04 & \\
\hline & Minimum corrected weight of impurity in sample $(\mu \mathrm{g})$ : & 0.16 & 0.00 & 0.16 \\
\hline & Maximum corrected weight of impurity in sample $(\mu g)$ : & 0.16 & 0.00 & 0.16 \\
\hline \multirow{5}{*}{ Co } & Measured concentration of impurity in sample $(\mu \mathrm{g} / \mathrm{ml})$ : & $2.68 \mathrm{E}-03$ & $8.72 \mathrm{E}-05$ & Co \\
\hline & Uncorrected weight of impurity in sample $(\mu \mathrm{g})$ : & 0.12 & 0.00 & 0.12 \\
\hline & Weight of impurity in blank $(\mu g)$ : & 0.00 & 0.00 & \\
\hline & Minimum corrected weight of impurity in sample $(\mu \mathrm{g})$ & 0.12 & 0.00 & 0.12 \\
\hline & Maximum corrected weight of impurity in sample $(\mu g)$ : & 0.12 & 0.00 & 0.12 \\
\hline \multirow{5}{*}{$\mathrm{Ni}$} & Measured concentration of impurity in sample $(\mu \mathrm{g} / \mathrm{ml})$ : & $5.17 \mathrm{E}-02$ & $3.90 \mathrm{E}-02$ & $\mathrm{Ni}$ \\
\hline & Uncorrected weight of impurity in sample $(\mu g)$ : & 2.33 & 1.94 & 4.27 \\
\hline & Weight of impurity in blank $(\mu g)$ : & $<0.35$ & $<0.34$ & \\
\hline & Minimum corrected weight of impurity in sample $(\mu g)$ : & 1.98 & 1.60 & 3.58 \\
\hline & Maximum corrected weight of impurity in sample $(\mu g)$ : & 2.33 & 1.94 & 4.27 \\
\hline \multirow{5}{*}{$\mathrm{Ca}$} & Measured concentration of impurity in sample $(\mu \mathrm{g} / \mathrm{ml})$ : & $1.11 \mathrm{E}+00$ & $<3.33 \mathrm{E}-01$ & $\mathbf{C a}$ \\
\hline & Uncorrected weight of impurity in sample $(\mu g)$ : & 49.95 & $<16.58$ & $<66.53$ \\
\hline & Weight of impurity in blank $(\mu g)$ : & $<15.65$ & 16.77 & \\
\hline & Minimum corrected weight of impurity in sample $(\mu g)$ : & 34.30 & 0.00 & 34.30 \\
\hline & Maximum corrected weight of impurity in sample $(\mu g)$ : & 49.95 & 0.00 & 49.95 \\
\hline \multirow{5}{*}{ Al } & Measured concentration of impurity in sample $(\mu \mathrm{g} / \mathrm{ml})$ : & $8.76 \mathrm{E}-01$ & $1.46 \mathrm{E}-01$ & Al \\
\hline & Uncorrected weight of impurity in sample $(\mu \mathrm{g})$ : & 39.42 & 7.27 & 46.69 \\
\hline & Weight of impurity in blank $(\mu \mathrm{g}):$ & 5.88 & 11.46 & \\
\hline & Minimum corrected weight of impurity in sample $(\mu g)$ : & 33.55 & 0.00 & 33.55 \\
\hline & Maximum corrected weight of impurity in sample $(\mu g)$ : & 33.55 & 0.00 & 33.55 \\
\hline \multirow{5}{*}{$\mathbf{T i}$} & Measured concentration of impurity in sample $(\mathrm{pg} / \mathrm{ml})$ : & $4.58 \mathrm{E}-01$ & $3.94 \mathrm{E}-02$ & $\mathrm{Ti}$ \\
\hline & Uncorrected weight of impurity in sample $(\mu \mathrm{g})$ : & 20.61 & 1.96 & 22.57 \\
\hline & Weight of impurity in blank $(\mu \mathrm{g})$ : & $<0.25$ & $<0.24$ & \\
\hline & Minimum corrected weight of impurity in sample $(\mu \mathrm{g})$ : & 20.36 & 1.72 & 22.08 \\
\hline & Maximum corrected weight of impurity in sample $(\mu \mathrm{g})$ : & 20.61 & 1.96 & 22.57 \\
\hline \multirow{5}{*}{ v } & Measured concentration of impurity in sample $(\mu \mathrm{g} / \mathrm{ml})$ : & $1.40 \mathrm{E}-01$ & $8.34 \mathrm{E}-04$ & $\mathbf{v}$ \\
\hline & Uncorrected weight of impurity in sample $(\mu \mathrm{g})$ : & 6.30 & 0.04 & 6.34 \\
\hline & Weight of impurity in blank $(\mu \mathrm{g})$ : & 0.02 & $<0.01$ & \\
\hline & Minimum corrected weight of impurity in sample $(\mu \mathrm{g})$ : & 6.28 & 0.04 & 6.32 \\
\hline & Maximum corrected weight of impurity in sample $(\mu \mathrm{g})$ : & 6.28 & 0.04 & 6.32 \\
\hline
\end{tabular}

comments

FCM checked the data against the Official Results of Analyses report for RMAL18063 on 2/7/2018.

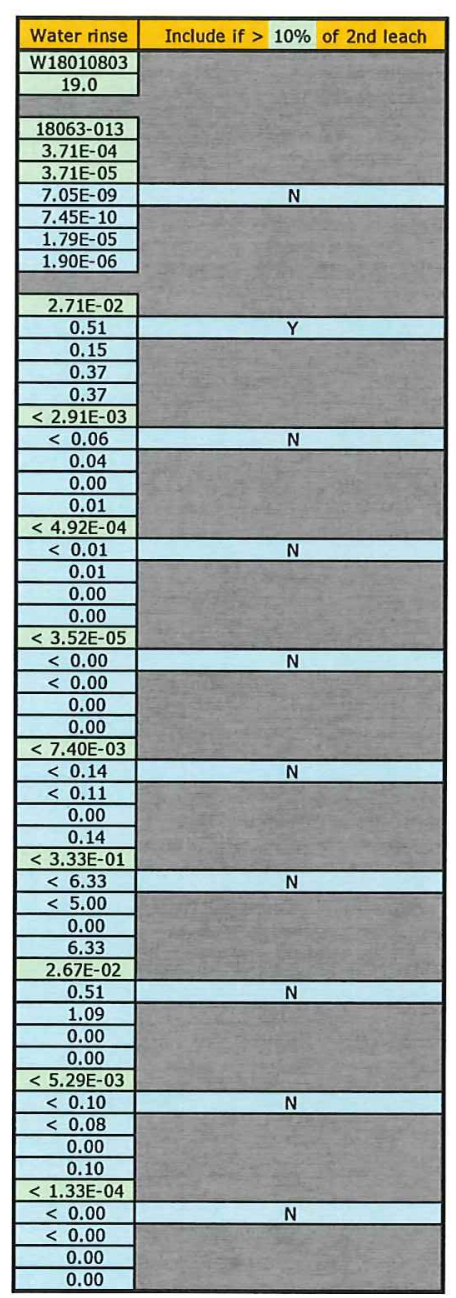

tied C. Montgomery
$2-8-2018$ 
Data Report Form DRF-26B: Post-Bum Leach Uranium and Impurities
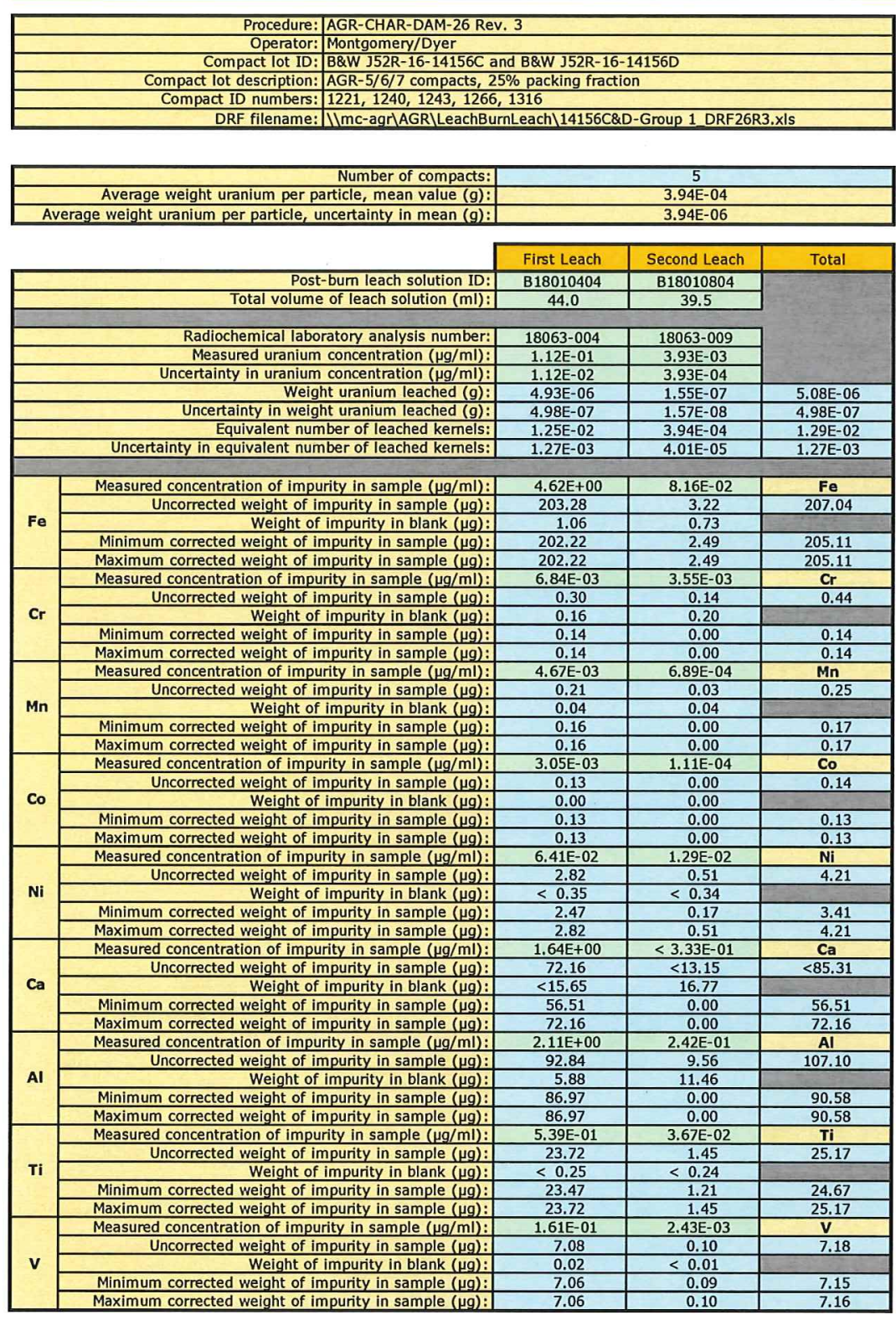

comments

FCM checked the data against the Official Results of Analyses report for RMAL18063 on 2/7/2018.

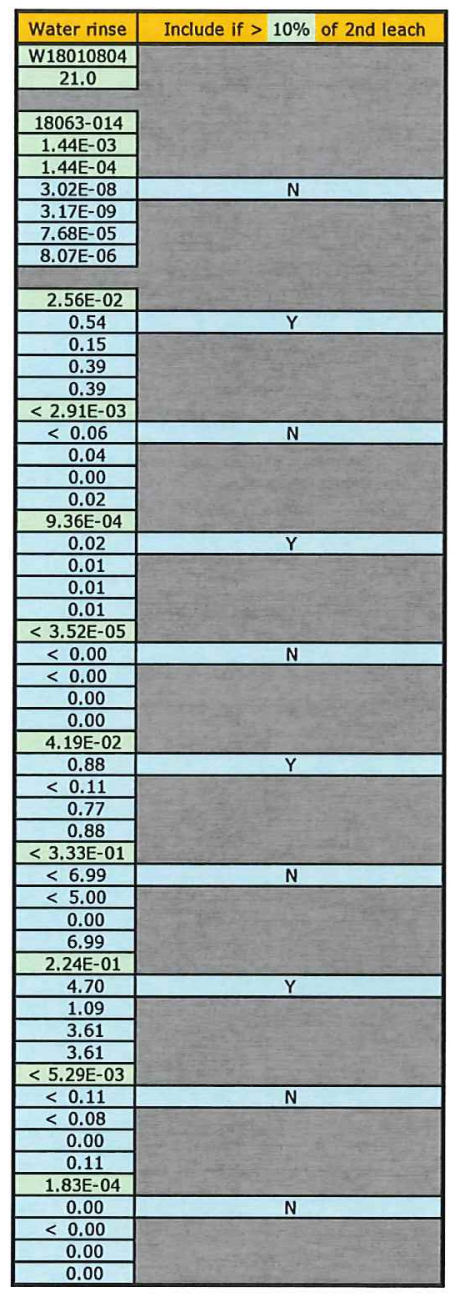

\section{Fied C. Montgomem $\quad 2-8.2018$}


Data Report Form DRF-26B: Post-Bum Leach Uranium and Impurities

\begin{tabular}{|c|c|}
\hline Procedure: & AGR-CHAR-DAM-26 Rev. 3 \\
\hline Operator: & Montgomery/Dyer \\
\hline Compact lot ID: & B\&W J52R-16-14156C and B\&W J52R-16-14156D \\
\hline Compact lot description: & AGR-5/6/7 compacts, $25 \%$ packing fraction \\
\hline Compact ID numbers: & Post-burn leach blank \\
\hline DRF filename: & 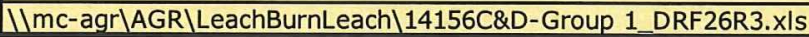 \\
\hline
\end{tabular}

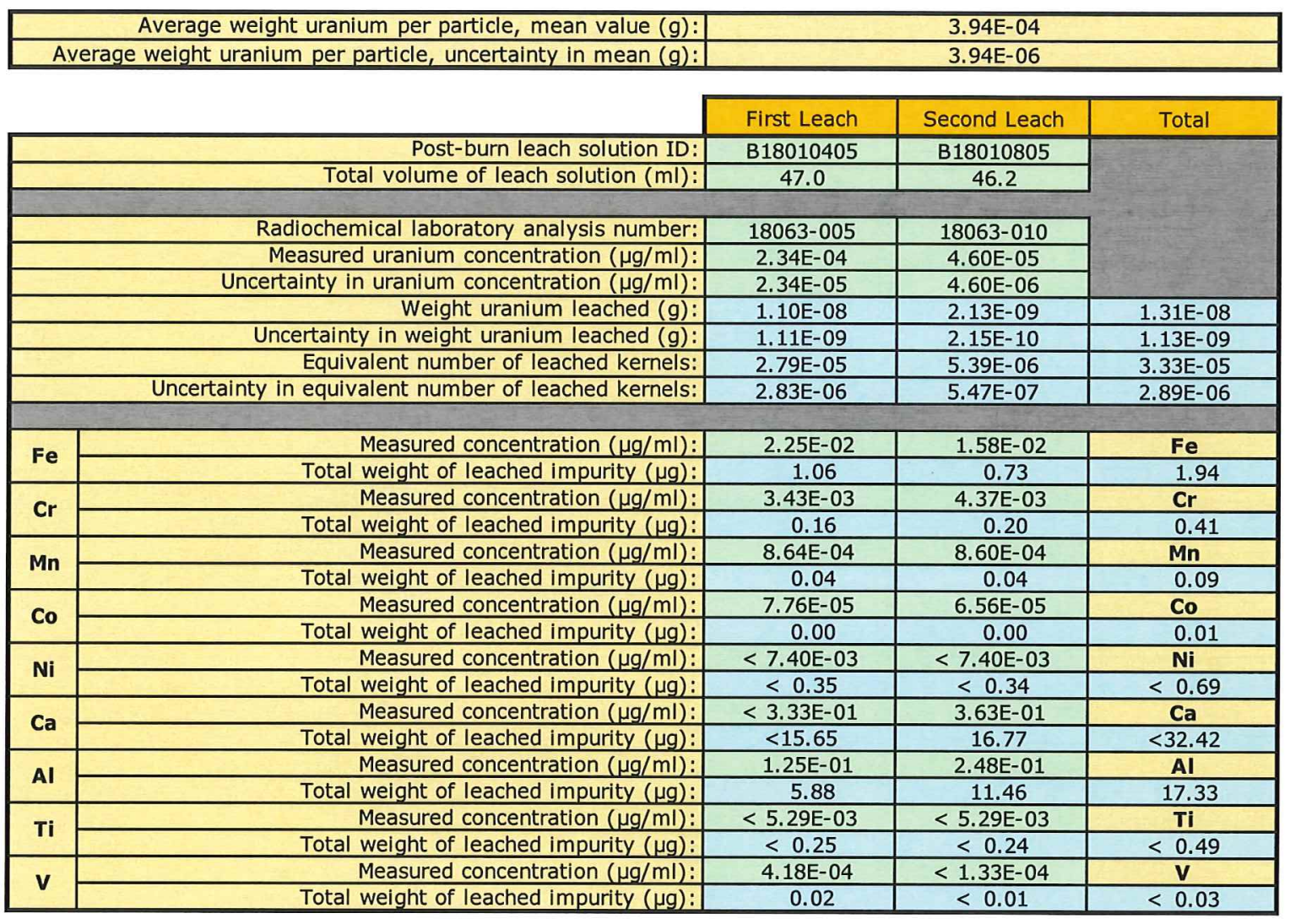

\section{Comments}

FCM checked the data against the Official Results of Analyses report for RMAL18063 on 2/7/2018.

Fied c. montgomery

$2 \cdot 8-2018$ 
Data Report Form DRF-26A: Pre-Bum Leach Uranium and Impurities

\begin{tabular}{|r|r|}
\hline Procedure: & AGR-CHAR-DAM-26 Rev. 3 \\
\hline Operator: & Montgomery/Dyer \\
\hline Compact lot ID: & B\&W 152R-16-14156C and B\&W J52R-16-14156D \\
\hline Compact lot description: & AGR-5/6/7 compacts, 25\% packing fraction \\
\hline Compact ID numbers: & $1233,1254,1287,1291,1821$ \\
\hline DRF filename: & IImc-agr/AGRILeachBurnLeach 14156C\&D-Group 2_DRF26R3.xls \\
\hline
\end{tabular}

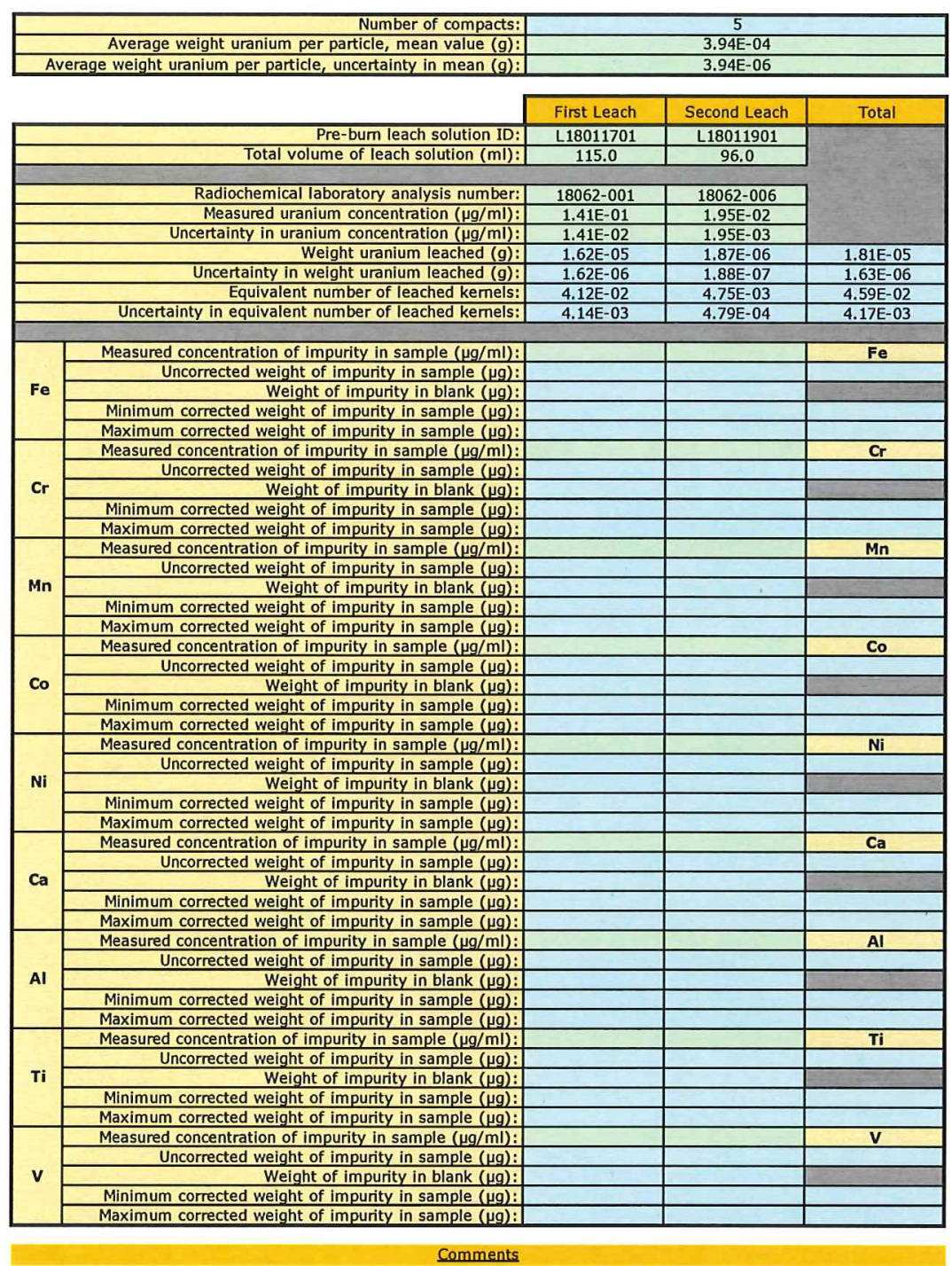

FCM checked the data against the official Results of Analyses report for RMAL18062 on 2/07/2018.

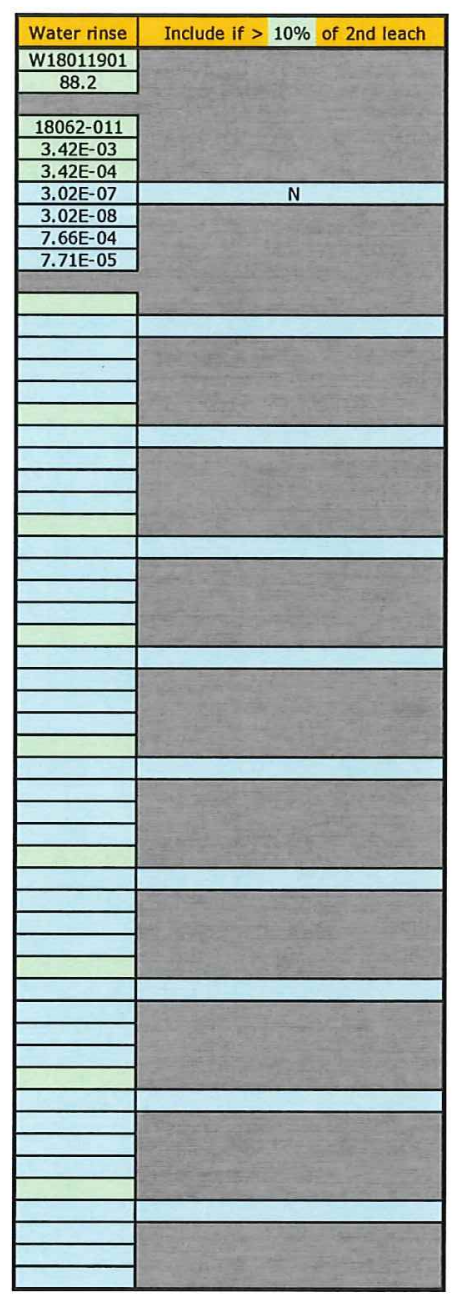

\section{Feed C. Montgomeny $2-8-2018$}


Data Report Form DRF-26A: Pre-Bum Leach Uranium and Impurities

\begin{tabular}{|r|l|}
\hline Procedure: & AGR-CHAR-DAM-26 Rev. 3 \\
\hline Operator: & Montgomery/Dyer \\
\hline Compact lot ID: & B\&W J52R-16-14156C and B\&W J52R-16-14156D \\
\hline Compact lot description: & AGR-5/6/7 compacts, 25\% packing fraction \\
\hline Compact ID numbers: & $1236,1305,1321,1807,1808$ \\
\hline DRF filename: & IImc-agr|AGRILeachBumLeachl14156C\&D-Group 2 DRF26R3.xIs \\
\hline
\end{tabular}

\begin{tabular}{|c|c|c|c|c|}
\hline \multicolumn{2}{|r|}{ Number of compacts: } & \multicolumn{3}{|c|}{5} \\
\hline \multirow{2}{*}{\multicolumn{2}{|c|}{$\begin{array}{l}\text { Average weight uranium per particle, mean value }(g) \text { : } \\
\text { Average weight uranium per particle, uncertainty in mean }(g) \text { : }\end{array}$}} & \\
\hline & & \multicolumn{2}{|r|}{$3.94 \mathrm{E}-06$} & \\
\hline & & First Leach & Second Leach & Total \\
\hline & Pre-bum leach solution ID: & $\mathrm{L} 18011702$ & $\underline{\mathrm{L} 18011902}$ & \\
\hline & Total volume of leach solution $(\mathrm{ml})$ : & 122.0 & 96.0 & \\
\hline & Radiochemical laboratory analysis number: & $18062-002$ & $18062-007$ & \\
\hline & Measured uranium concentration $(\mu \mathrm{g} / \mathrm{ml})$ : & $2.81 E+00$ & $2.58 \mathrm{E}-01$ & \\
\hline & Uncertainty in uranium concentration $(\mathrm{\mu g} / \mathrm{ml})$ : & $2.81 \mathrm{E}-01$ & $2.58 \mathrm{E}-02$ & \\
\hline & Weight uranium leached $(\mathrm{g})$ : & $3,43 \mathrm{E}-04$ & $2.48 \mathrm{E}-05$ & $3.74 \mathrm{E}-04$ \\
\hline & Uncertainty in weight uranium leached $(\mathrm{g})$ : & $3.43 \mathrm{E}-05$ & $2.48 \mathrm{E}-06$ & $3.44 \mathrm{E}-05$ \\
\hline & Equivalent number of leached kemels: & $8.70 \mathrm{E}-01$ & $6.29 \mathrm{E}-02$ & $9.49 \mathrm{E}-01$ \\
\hline & Uncertainty in equivalent number of leached kemels: & $8.76 \mathrm{E}-02$ & $6.33 \mathrm{E}-03$ & $8.79 \mathrm{E}-02$ \\
\hline \multirow{5}{*}{$\mathbf{F e}$} & Measured concentration of impurity in sample $(\mu \mathrm{g} / \mathrm{ml})$ : & & & Fe \\
\hline & Uncorrected weight of impurity in sample $(\mu \mathrm{g})$ : & & & \\
\hline & Weight of impurity in blank $(\mu \mathrm{g})$ : & & & \\
\hline & Minimum corrected weight of impurity in sample $(\mu g)$ : & & & \\
\hline & Maximum corrected weight of impurity in sample $(\mu \mathrm{g})$ : & & & \\
\hline \multirow{5}{*}{$\mathrm{Cr}$} & Measured concentration of impurity in sample $(\mathrm{\mu g} / \mathrm{ml})$ : & & & $\mathrm{Cr}$ \\
\hline & Uncorrected weight of impurity in sample $(\mu \mathrm{g})$ : & & & \\
\hline & Weight of impurity in blank $(\mu \mathrm{g})$ : & & & \\
\hline & Minimum corrected weight of impurity in sample $(\mu g)$ : & & & \\
\hline & Maximum corrected weight of impurity in sample $(\mu g)$ : & & & \\
\hline \multirow{5}{*}{ Mn } & Measured concentration of impurity in sample $(\mu \mathrm{g} / \mathrm{ml})$ : & & & $\mathrm{Mn}$ \\
\hline & Uncorrected weight of impurity in sample $(\mu \mathrm{g})$ : & & & \\
\hline & Weight of impurity in blank $(\mu g)$ : & & & \\
\hline & Minimum corrected weight of impurity in sample $(\mu g)$ : & & & \\
\hline & Maximum corrected weight of impurity in sample $(\mu \mathrm{g})$ : & & & \\
\hline \multirow{5}{*}{ Co } & Measured concentration of impurity in sample $(\mu \mathrm{g} / \mathrm{ml})$ : & & & Co \\
\hline & Uncorrected weight of impurity in sample $(\mu \mathrm{g})$ : & & & \\
\hline & Weight of impurity in blank $(\mu g)$ : & & & \\
\hline & Minimum corrected weight of impurity in sample $(\mu \mathrm{g})$ : & & & \\
\hline & Maximum corrected weight of impurity in sample $(\mu \mathrm{g})$ : & & & \\
\hline \multirow{5}{*}{$\mathbf{N i}$} & Measured concentration of impurity in sample $(\mu \mathrm{g} / \mathrm{ml})$ : & & & $\mathrm{Ni}$ \\
\hline & Uncorrected weight of impurity in sample $(\mu \mathrm{g})$ : & & & \\
\hline & Weight of impurity in blank $(\mu g)$ : & & & \\
\hline & Minimum corrected weight of impurity in sample $(\mu g)$ : & & & \\
\hline & Maximum corrected weight of impurity in sample $(\mu g)$ : & & & \\
\hline \multirow{5}{*}{$\mathrm{Ca}$} & Measured concentration of impurity in sample $(\mu \mathrm{g} / \mathrm{ml})$ : & & & $\mathrm{Ca}$ \\
\hline & Uncorrected weight of impurity in sample $(\mu \mathrm{g})$ : & & & \\
\hline & Weight of impurity in blank $(\mu g)$ : & & & \\
\hline & Minimum corrected weight of impurity in sample $(\mu g)$ : & & & \\
\hline & Maximum corrected weight of impurity in sample $(\mu g)$ : & & & \\
\hline \multirow{5}{*}{ Al } & Measured concentration of impurity in sample $(\mu \mathrm{g} / \mathrm{ml})$ : & & & Al \\
\hline & Uncorrected weight of impurity in sample $(\mu g)$ : & & & \\
\hline & Weight of impurity in blank $(\mu g)$ : & & & \\
\hline & Minimum corrected weight of impurity in sample $(\mu g)$ : & & & \\
\hline & Maximum corrected weight of impurity in sample $(\mu g)$ : & & & \\
\hline \multirow{5}{*}{$\mathrm{Ti}$} & Measured concentration of impurity in sample $(\mu \mathrm{g} / \mathrm{ml})$ : & & & $\mathrm{Ti}$ \\
\hline & Uncorrected weight of impurity in sample $(\mu \mathrm{g})$ : & & & \\
\hline & Weight of impurity in blank $(\mu g): 1$ & & & \\
\hline & Minimum corrected weight of impurity in sample $(\mu g)$ : & & & \\
\hline & Maximum corrected weight of impurity in sample $(\mu g)$ : & & & \\
\hline \multirow{5}{*}{ v } & Measured concentration of impurity in sample $(\mathrm{\mu g} / \mathrm{ml})$ : & & & $\mathbf{v}$ \\
\hline & Uncorrected weight of impurity in sample $(\mu \mathrm{g})$ : & & & \\
\hline & Weight of impurity in blank ( $\mathrm{\mu g})$ : & & & \\
\hline & Minimum corrected weight of impurity in sample $(\mu q)$ : & & & \\
\hline & Maximum corrected weight of impurity in sample $(\mu g)$ : & & & \\
\hline
\end{tabular}

comments

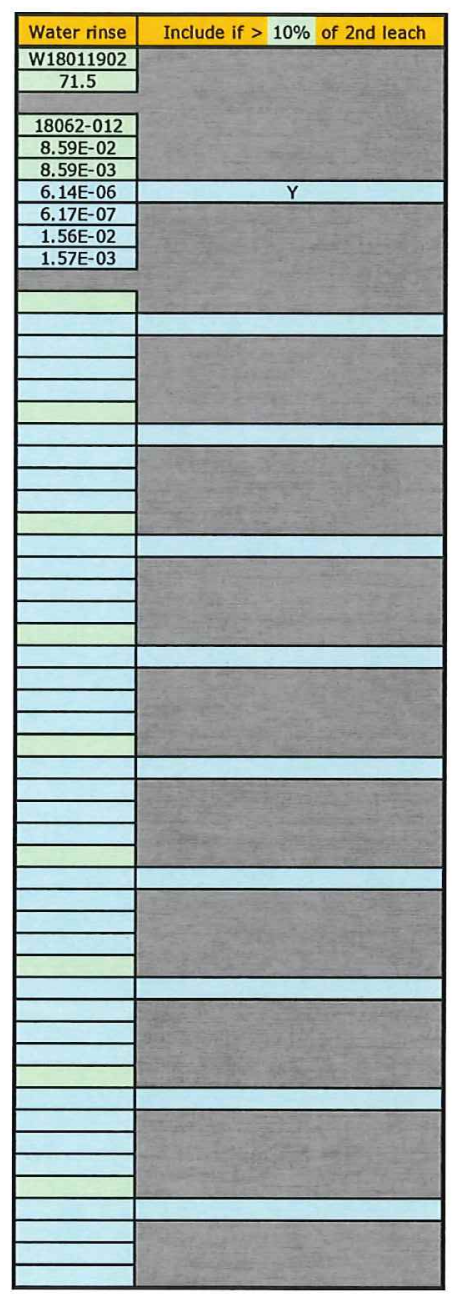

FCM checked the data against the official Results of Analyses report for RMAL18062 on 2/07/2018.

\section{Fued c. Montgomery $\frac{2-8-2018}{\text { Doeratior }}$}


Data Report Form DRF-26A: Pre-Bum Leach Uranium and Impurities

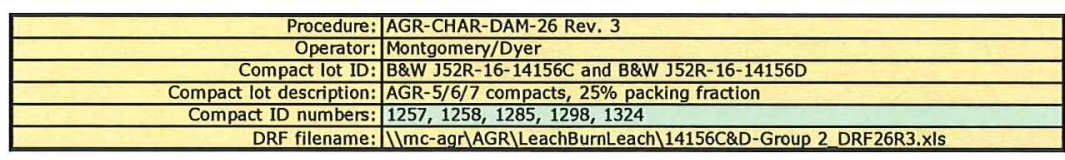

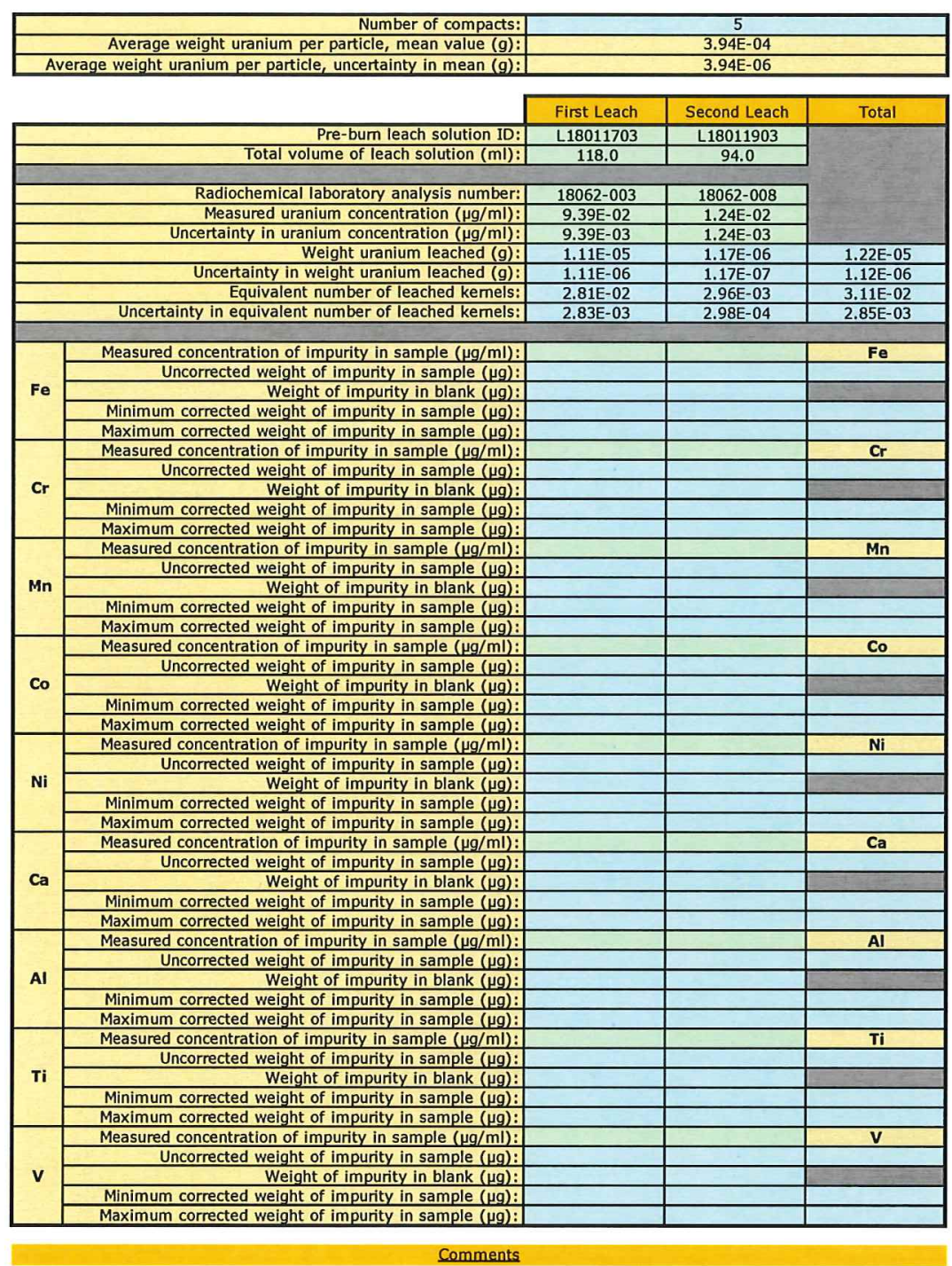

FCM checked the data against the official Results of Analyses report for RMAL18062 on 2/07/2018.

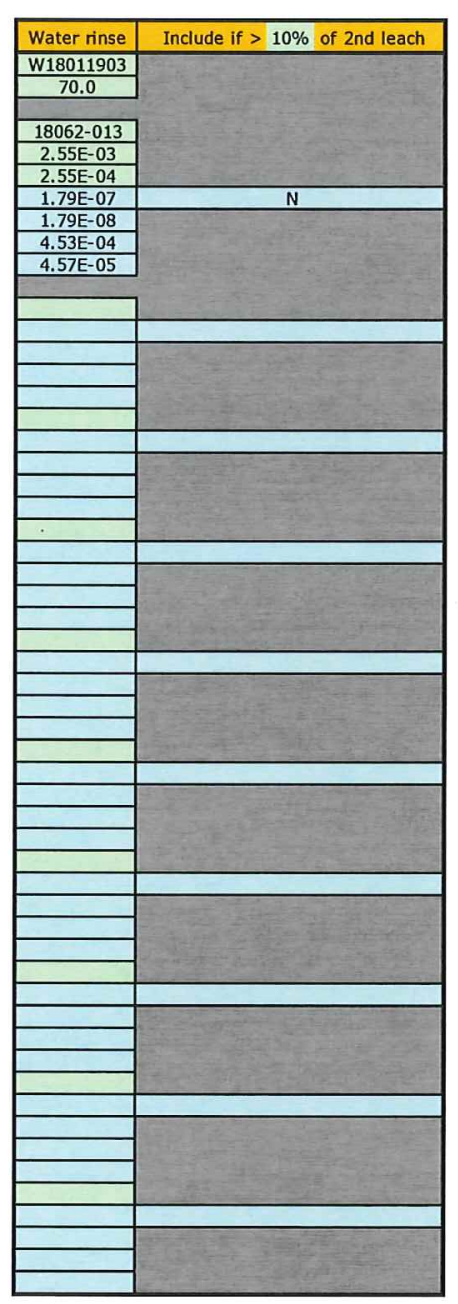

\section{Fued c. Montgomem \\ $2-8-2018$}


Data Report Form DRF-26A: Pre-Bum Leach Uranium and Impurities

\begin{tabular}{|c|c|}
\hline Procedure: & AGR-CHAR-DAM-26 Rev. 3 \\
\hline Operator: & Montgomery/Dyer \\
\hline Compact lot ID: & B\&W J52R-16-14156C and B\&W J52R-16-14156D \\
\hline Compact lot description: & AGR-5/6/7 compacts, $25 \%$ packing fraction \\
\hline Compact ID numbers: & $1277,1279,1314,1812,1828$ \\
\hline DRF filename: & 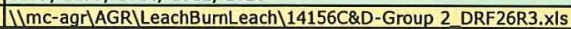 \\
\hline
\end{tabular}
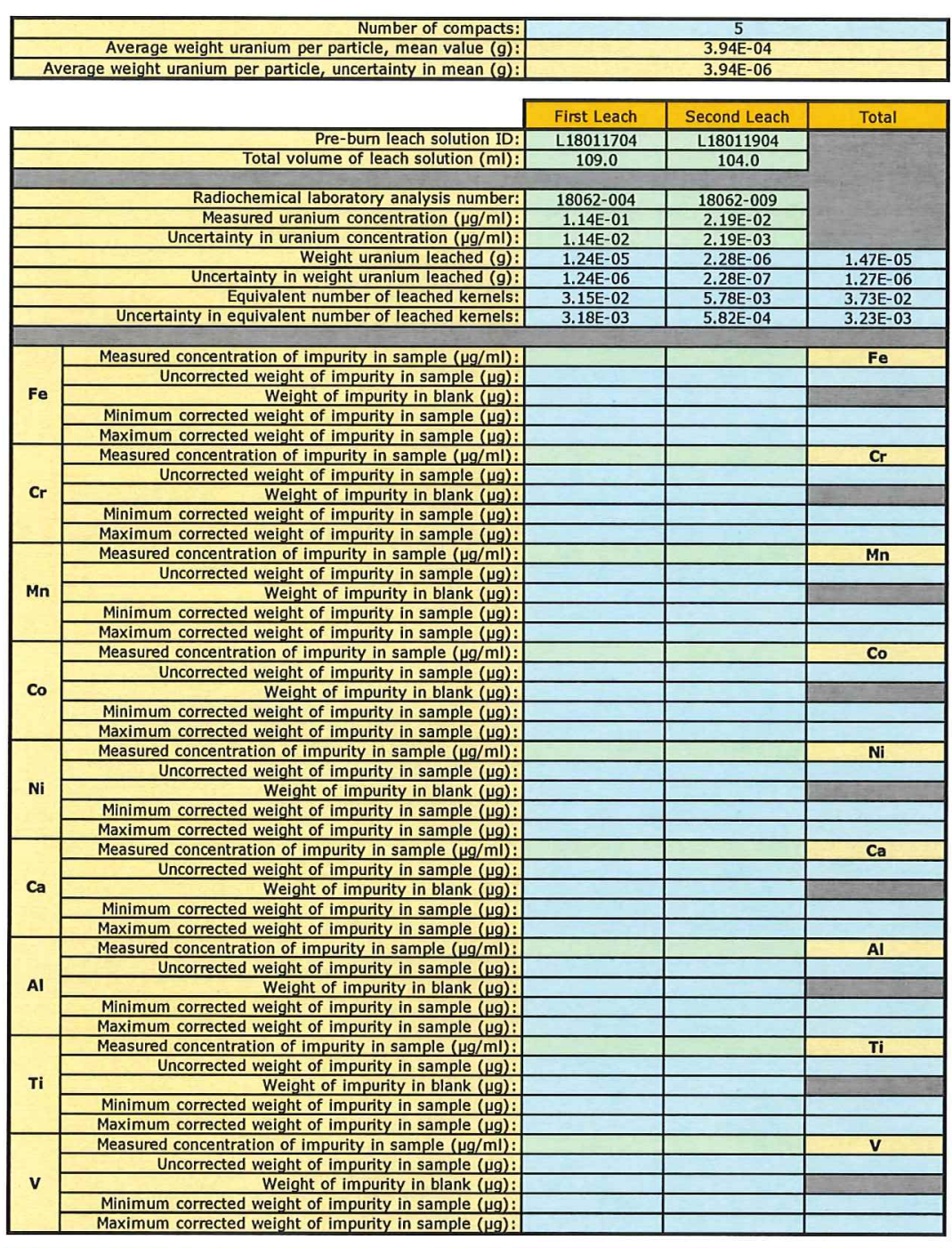

Comments

FCM checked the data against the official Results of Analyses report for RMAL18062 on 2/07/2018.

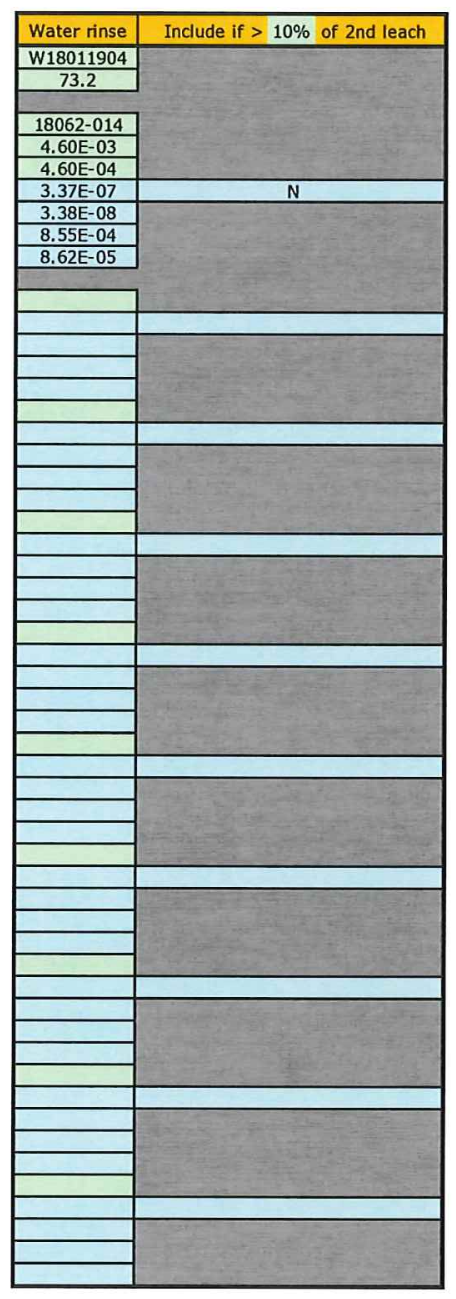

\section{Fred c. Montgomery $\quad 2-8-2018$}




\section{Data Report Form DRF-26A: Pre-Burn Leach Uranium and Impurities}

\begin{tabular}{|r|l|}
\hline Procedure: & AGR-CHAR-DAM-26 Rev. 3 \\
\hline Operator: & Montgomery/Dyer \\
\hline Compact lot ID: & B\&W J52R-16-14156C and B\&W J52R-16-14156D \\
\hline Compact lot description: & AGR-5/6/7 compacts, 25\% packing fraction \\
\hline Compact ID numbers: & Pre-burn leach blank \\
\hline DRF filename: & \Imc-agr\AGR\LeachBurnLeach\14156C\&D-Group 2_DRF26R3.xIs \\
\hline
\end{tabular}

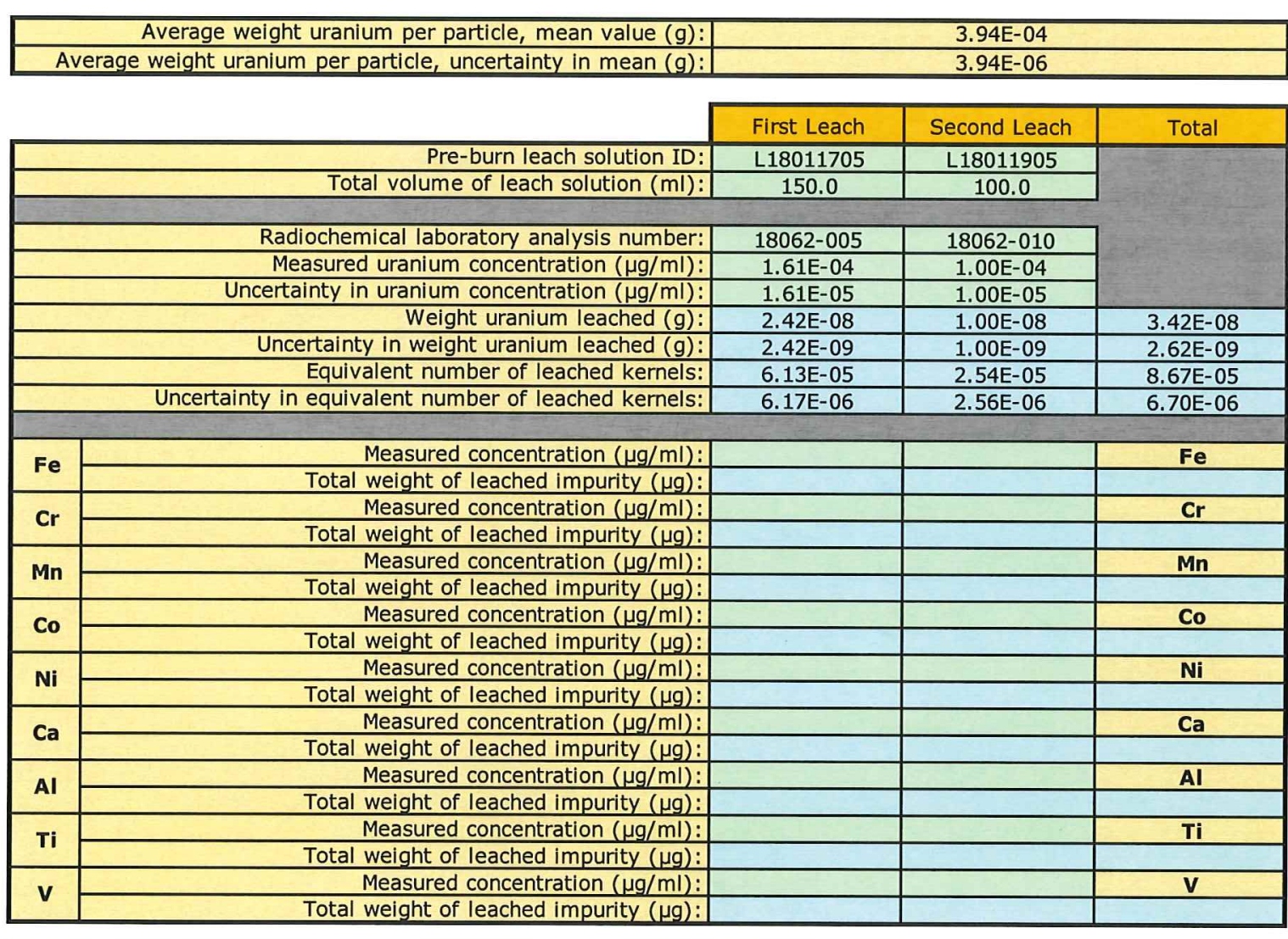

\section{Comments}

FCM checked the data against the official Results of Analyses report for RMAL18062 on 2/07/2018.

Fied C. Montgomeny
$2-8-2018$

Date


Data Report Form DRF-26B: Post-Bum Leach Uranium and Impurities

\begin{tabular}{|r|l|}
\hline Procedure: & AGR-CHAR-DAM-26 Rev, 3 \\
\hline Operator: & Montgomery/Dyer \\
\hline Compact lot ID: & B\&W J52R-16-14156C and B\&W J52R-16-14156D \\
\hline Compact lot description: & AGR-5/6/7 compacts, 25\% packing fraction \\
\hline Compact ID numbers: & $1233,1254,1287,1291,1821$ \\
\hline DRF filename: & |Imc-agr/AGRILeachBurnLeach 14156C\&D-Group 2_DRF26R3.xls \\
\hline
\end{tabular}

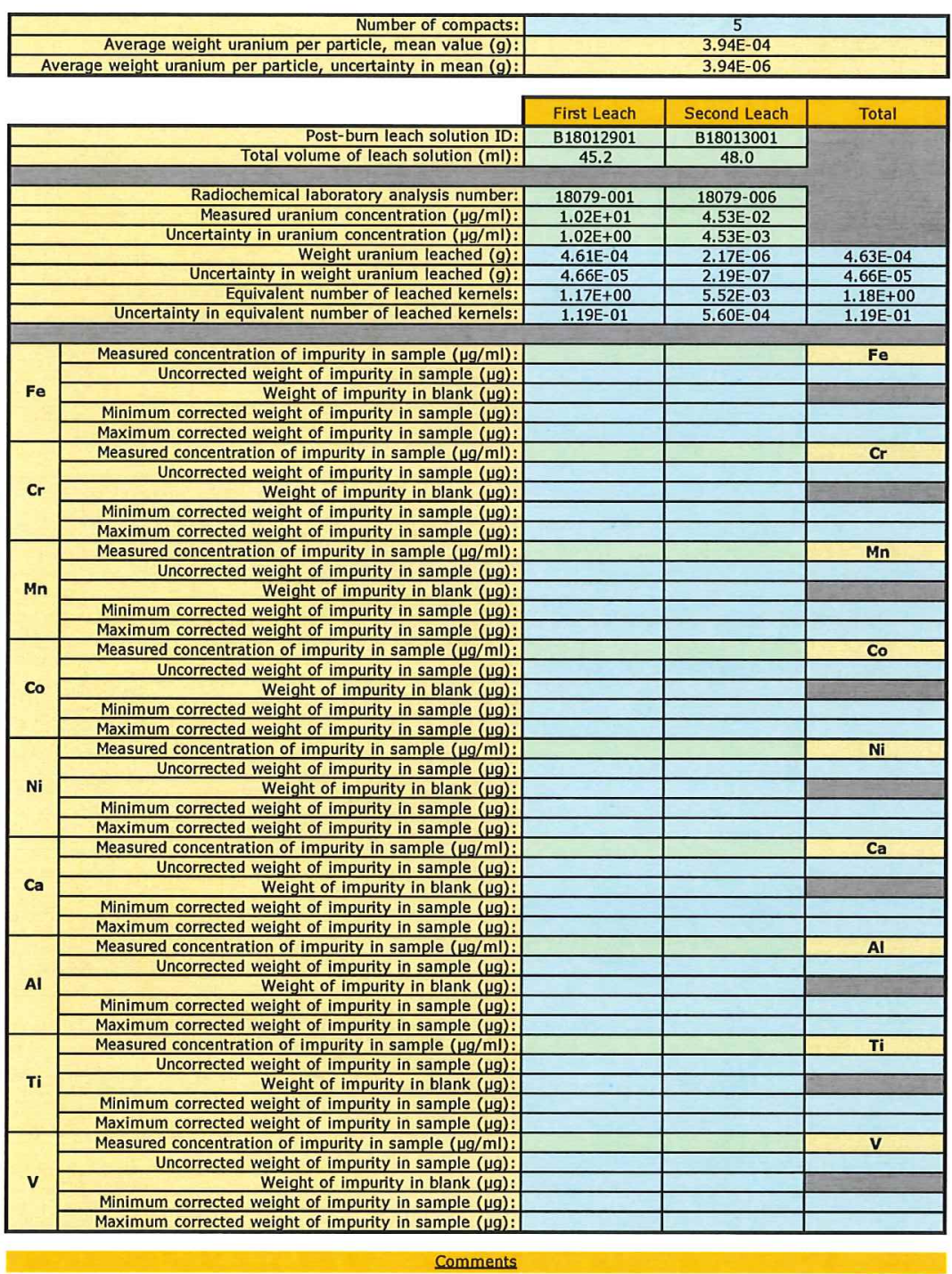

FCM checked the data against the official Results of Analyses report for RMAL18079 on 2/07/2018.

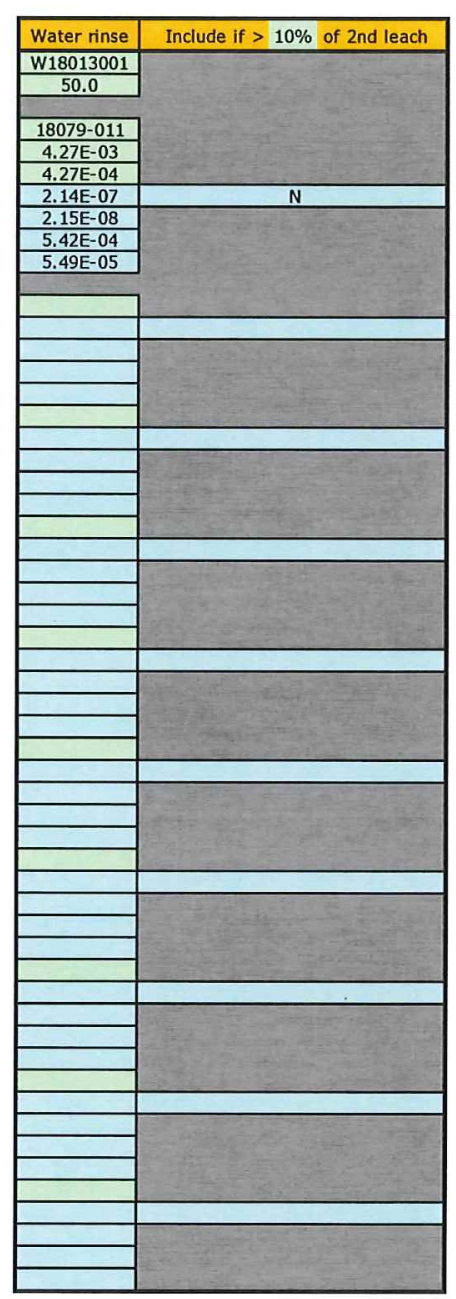

\section{Fued c. Montgomeey}

$2-8-2018$ 
Data Report Form DRF-26B: Post-Bum Leach Uranium and Impurities

\begin{tabular}{|r|l|}
\hline Procedure: & AGR-CHAR-DAM-26 Rev. 3 \\
\hline Operator: & Montgomery/Dyer \\
\hline Compact lot ID: & B\&W J52R-16-14156C and B\&W J52R-16-14156D \\
\hline Compact lot description: & AGR-5/6/7 compacts, 25\% packing fraction \\
\hline Compact ID numbers: & $1236,1305,1321,1807,1808$ \\
\hline DRF filename: & IImC-agr|AGRILeachBurnLeach 14156C\&D-Group 2 DRF26R3,xls \\
\hline
\end{tabular}

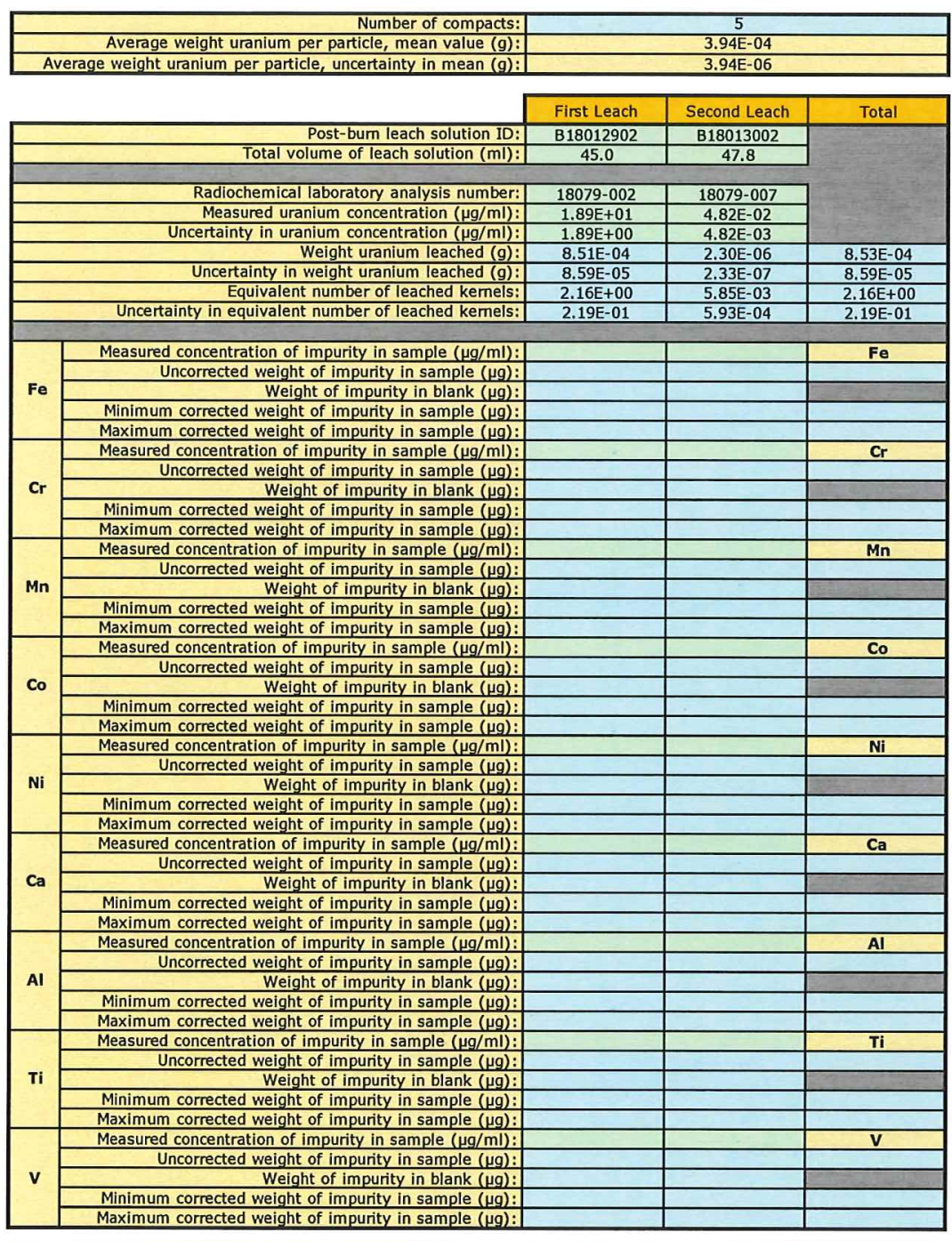

Comments

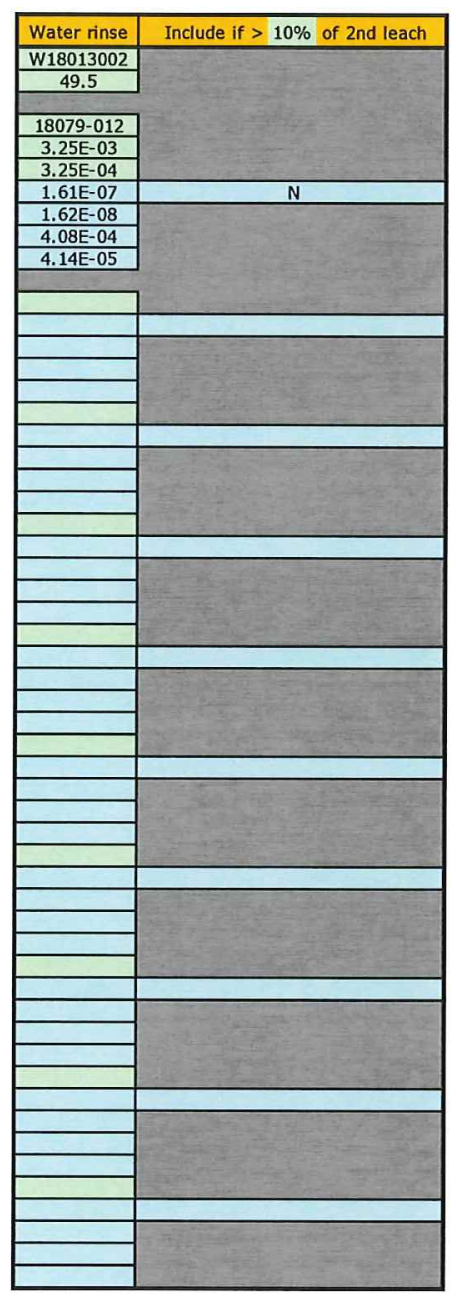

FCM checked the data against the official Results of Analyses report for RMAL18079 on 2/07/2018.

\section{Fied C. Montgomery $\frac{2-8-2018}{\text { opeetior }}$}


Data Report Form DRF-26B: Post-Bum Leach Uranium and Imourities

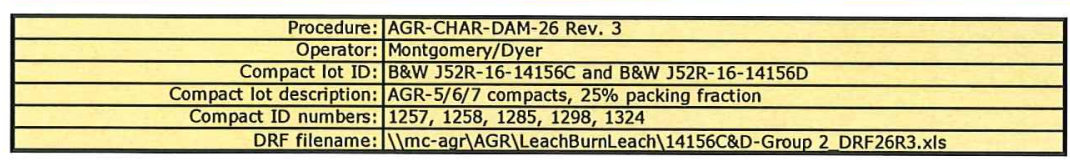

\begin{tabular}{|r|r|}
\hline Number of compacts: & 5 \\
\hline Average weight uranium per particle, mean value $(\mathrm{g}):$ & $3.94 \mathrm{E}-04$ \\
\hline Average weight uranium per particle, uncertainty in mean $(\mathrm{g}):$ & $3.94 \mathrm{E}-06$ \\
\hline
\end{tabular}

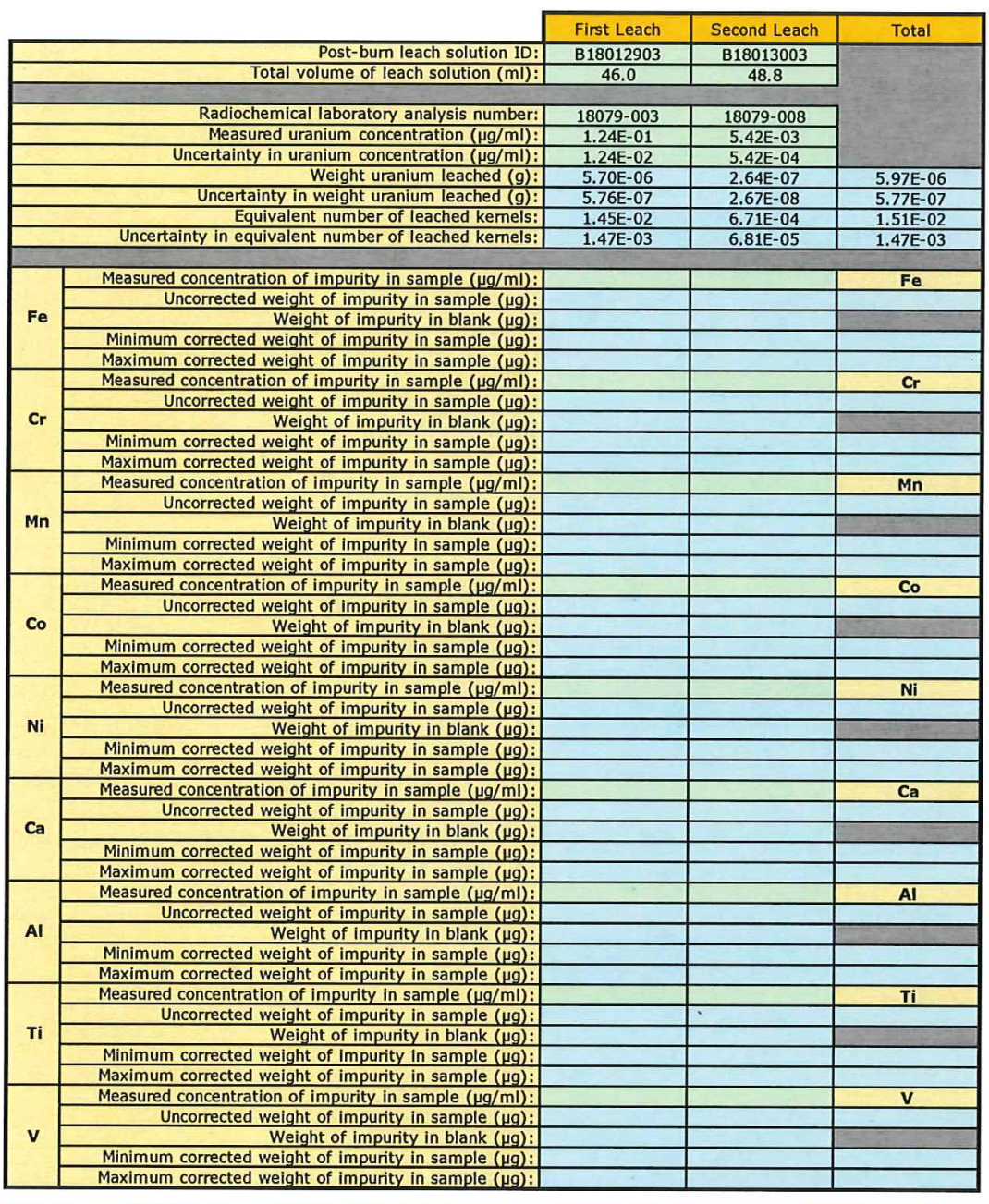

Comments

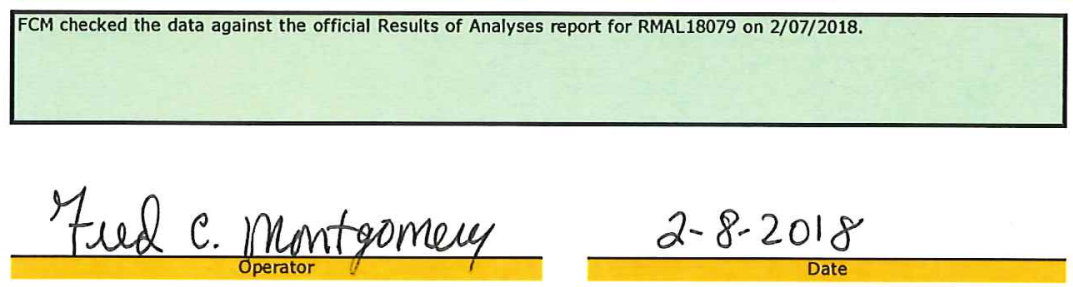

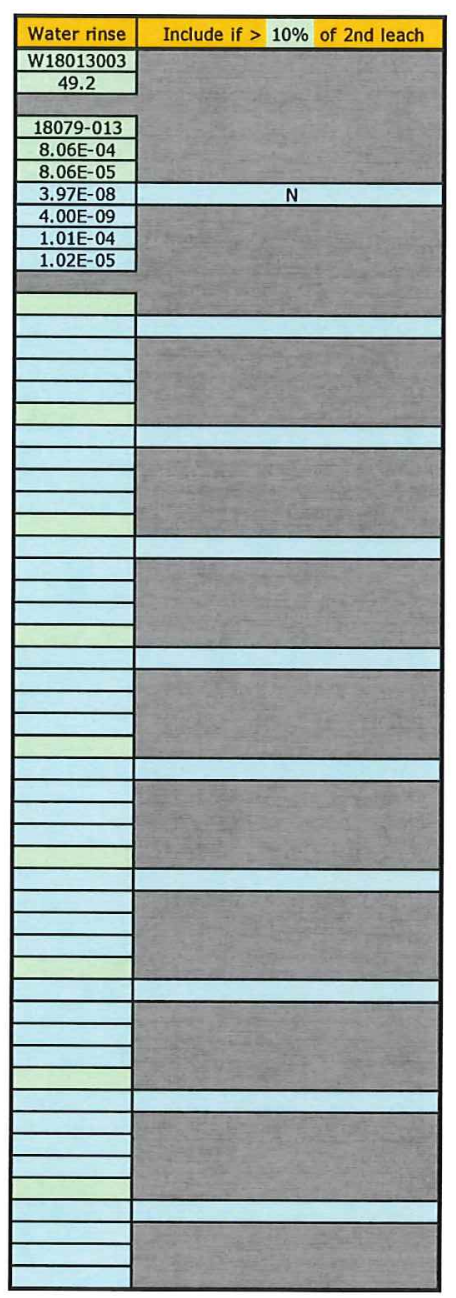


Data Report Form DRF-26B: Post-Bum Leach Uranium and Impurities

\begin{tabular}{|r|l|}
\hline Procedure: & AGR-CHAR-DAM-26 Rev. 3 \\
\hline Operator: & Montgomery/Dyer \\
\hline Compact lot ID: & B\&W J52R-16-14156C and B\&W J52R-16-14156D \\
\hline Compact lot description: & AGR-5/6/7 compacts, 25\% packing fraction \\
\hline Compact ID numbers: & $1277,1279,1314,1812,1828$ \\
\hline DRF filename: & IImC-agr|AGRILeachBumLeach $14156 C \& D-$ Group 2_DRF26R3.xIs \\
\hline
\end{tabular}

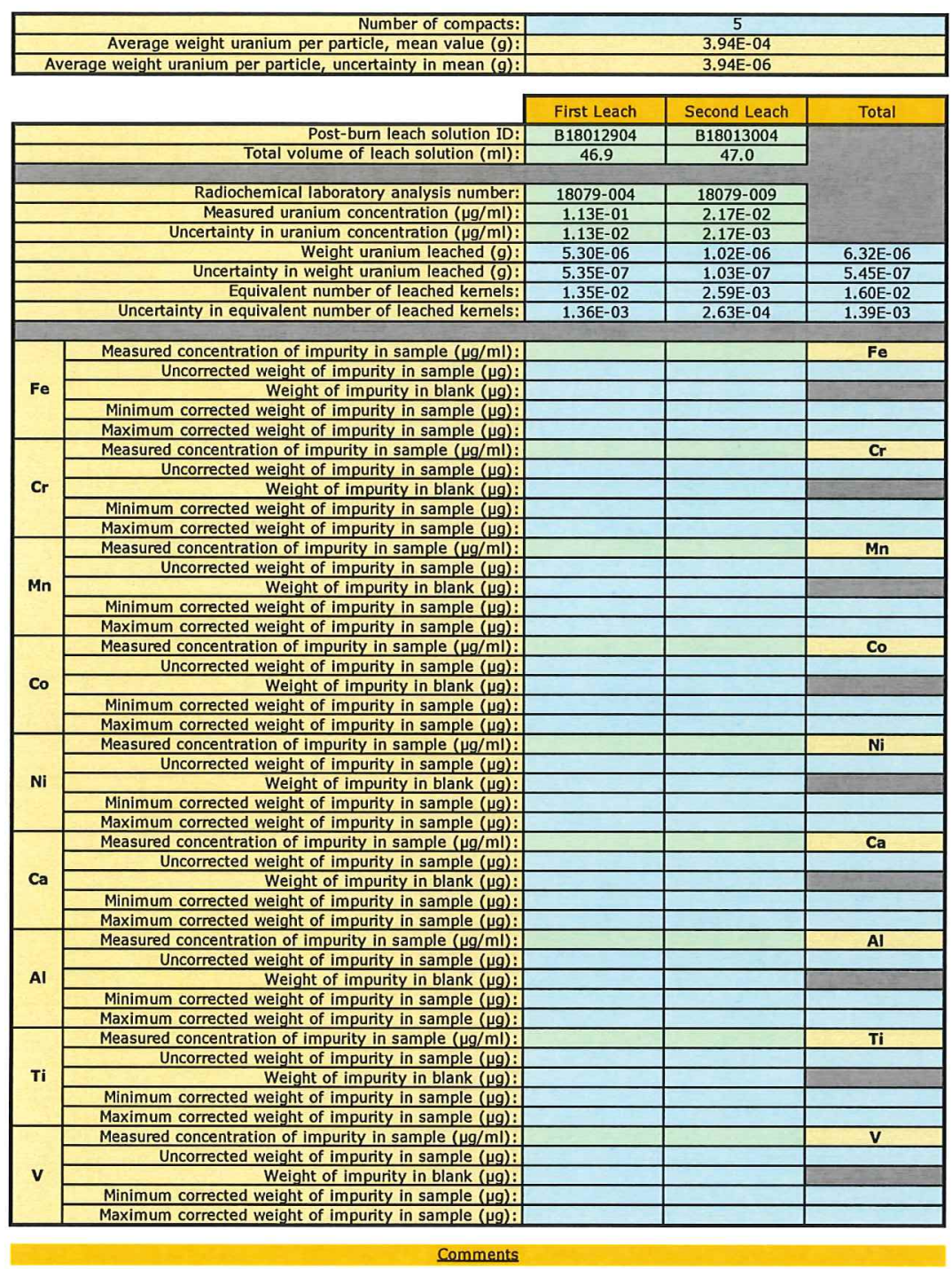

FCM checked the data against the official Results of Analyses report for RMAL18079 on 2/07/2018.

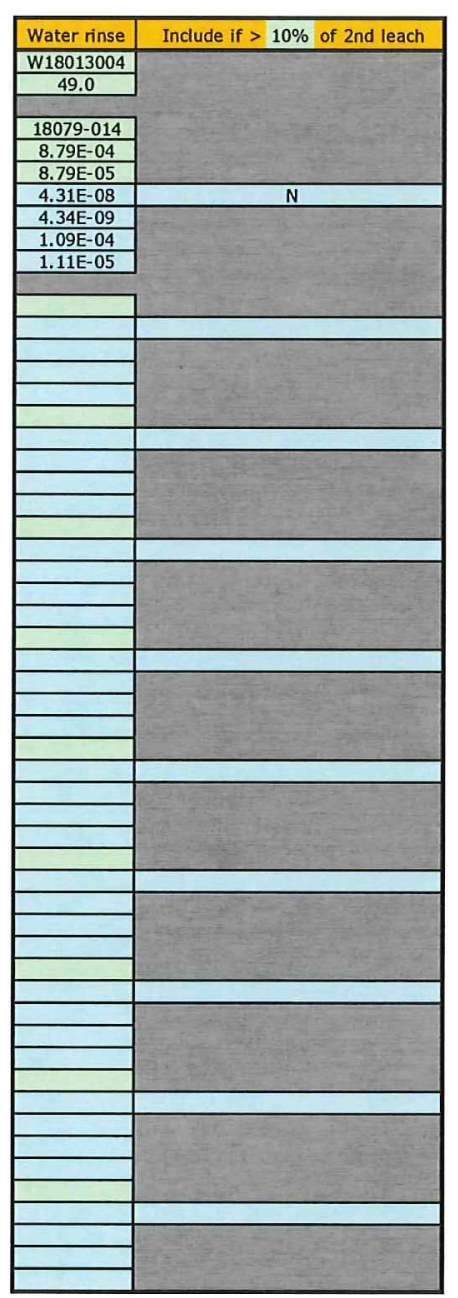

\section{Feed C. Montyomery 2-8-2018}




\section{Data Report Form DRF-26B: Post-Burn Leach Uranium and Impurities}

\begin{tabular}{|r|l|}
\hline Procedure: & AGR-CHAR-DAM-26 Rev. 3 \\
\hline Operator: & Montgomery/Dyer \\
\hline Compact lot ID: & B\&W J52R-16-14156C and B\&W J52R-16-14156D \\
\hline Compact lot description: & AGR-5/6/7 compacts, 25\% packing fraction \\
\hline Compact ID numbers: & Post-burn leach blank \\
\hline DRF filename: & \Imc-agr\AGR\LeachBurnLeach $\backslash 14156 C \& D-G r o u p ~ 2$ DRF26R3.xls \\
\hline
\end{tabular}

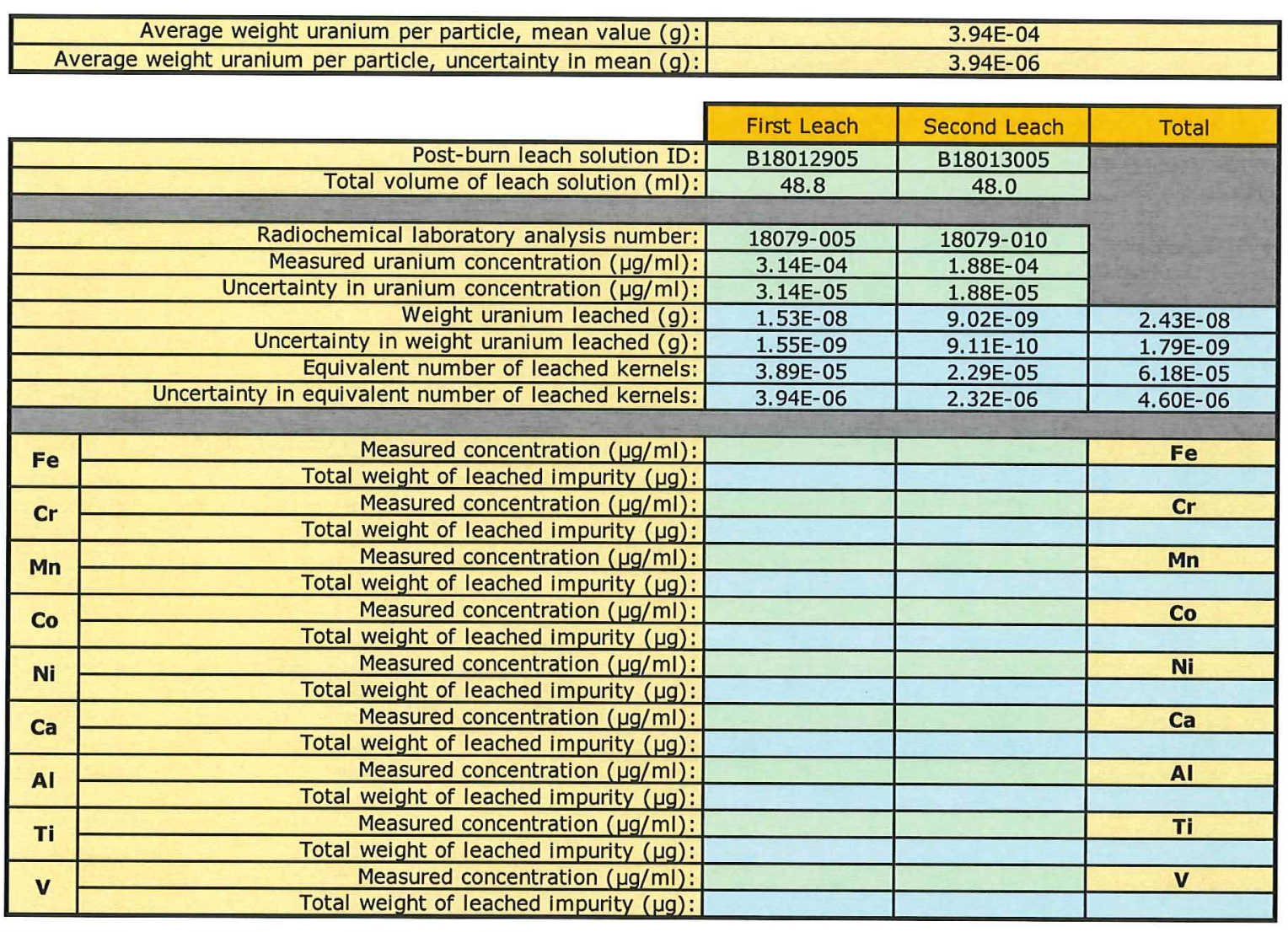

\section{Comments}

FCM checked the data against the official Results of Analyses report for RMAL18079 on 2/07/2018.

$\frac{\text { Fud c. Montgomery }}{\text { Operator }}$
$2-8-2018$

Date 


\section{Data Report Form DRF-26A: Pre-Burn Leach Uranium and Impurities}

\begin{tabular}{|r|l|}
\hline Procedure: & AGR-CHAR-DAM-26 Rev. 3 \\
\hline Operator: & Montgomery \\
\hline Compact lot ID: & BWXT J52R-16-14156D \\
\hline Compact lot description: & AGR-5/6/7 compacts, 25\% packing fraction \\
\hline Compact ID numbers: & $1801,1834,1818,1826,1830$ \\
\hline DRF filename: & 14156 D_PF25-Group 1_DLBL_ICPMS_DRF26R3.xls \\
\hline
\end{tabular}

\begin{tabular}{|c|c|c|c|c|}
\hline & Number of compacts: & & 5 & \\
\hline & Average weight uranium per particle, mean value $(g)$ : & & $3.94 \mathrm{E}-04$ & \\
\hline & rage weight uranium per particle, uncertainty in mean $(g)$ : & & $3.94 \mathrm{E}-06$ & \\
\hline & & First Leach & Second Leach & Total \\
\hline & Pre-burn leach solution ID: & L19021801 & L19022001 & \\
\hline & Total volume of leach solution $(\mathrm{ml}):$ & 143.0 & 131.0 & \\
\hline & RMAL analysis number: & $19145-001$ & $19145-003$ & \\
\hline & Measured uranium concentration $(\mu \mathrm{g} / \mathrm{ml})$ : & $1.03 \mathrm{E}-01$ & $1.18 \mathrm{E}-02$ & \\
\hline & Uncertainty in uranium concentration $(\mu \mathrm{g} / \mathrm{ml}):$ & $1.03 E-02$ & $1.18 \mathrm{E}-03$ & \\
\hline & Weight uranium leached $(\mathrm{g})$ : & $1.48 \mathrm{E}-05$ & $1.54 \mathrm{E}-06$ & $1.63 \mathrm{E}-05$ \\
\hline & Uncertainty in weight uranium leached $(\mathrm{g}):$ & $1.48 \mathrm{E}-06$ & $1.54 \mathrm{E}-07$ & $1.49 \mathrm{E}-06$ \\
\hline & Equivalent number of leached kernels: & $3.75 \mathrm{E}-02$ & $3.91 \mathrm{E}-03$ & $4.14 \mathrm{E}-02$ \\
\hline & Uncertainty in equivalent number of leached kernels: & $3.77 E-03$ & $3.93 \mathrm{E}-04$ & $3.79 \mathrm{E}-03$ \\
\hline & Measured concentration of impurity in sample $(\mu \mathrm{g} / \mathrm{ml})$ : & & & $\mathbf{F e}$ \\
\hline & Uncorrected weight of impurity in sample $(\mu \mathrm{g})$ : & & & \\
\hline $\mathbf{F e}$ & Weight of impurity in blank $(\mu \mathrm{g})$ : & & & \\
\hline & Minimum corrected weight of impurity in sample $(\mu g)$ : & & & \\
\hline & Maximum corrected weight of impurity in sample $(\mu \mathrm{g}):$ & & & \\
\hline & Measured concentration of impurity in sample $(\mu \mathrm{g} / \mathrm{ml}):$ & & & $\mathrm{Cr}$ \\
\hline & Uncorrected weight of impurity in sample $(\mu g)$ : & & & \\
\hline $\mathbf{C r}$ & Weight of impurity in blank $(\mu \mathrm{g})$ : & & & \\
\hline & Minimum corrected weight of impurity in sample $(\mu g):$ & & & \\
\hline & Maximum corrected weight of impurity in sample $(\mu \mathrm{g}):$ & & & \\
\hline & Measured concentration of impurity in sample $(\mu \mathrm{g} / \mathrm{ml})$ : & & & Mn \\
\hline & Uncorrected weight of impurity in sample $(\mu g)$ : & & & \\
\hline Mn & Weight of impurity in blank $(\mu \mathrm{g})$ : & & & \\
\hline & Minimum corrected weight of impurity in sample $(\mu \mathrm{g}):$ & & & \\
\hline & Maximum corrected weight of impurity in sample $(\mu \mathrm{g}):$ & & & \\
\hline & Measured concentration of impurity in sample $(\mu \mathrm{g} / \mathrm{ml}):$ & & & Co \\
\hline & Uncorrected weight of impurity in sample $(\mu g)$ : & & & \\
\hline Co & Weight of impurity in blank $(\mu \mathrm{g})$ : & & & \\
\hline & Minimum corrected weight of impurity in sample $(\mu \mathrm{g})$ : & & & \\
\hline & Maximum corrected weight of impurity in sample $(\mu \mathrm{g})$ : & & & \\
\hline & Measured concentration of impurity in sample $(\mu \mathrm{g} / \mathrm{ml})$ : & & & $\mathrm{Ni}$ \\
\hline & Uncorrected weight of impurity in sample $(\mu \mathrm{g})$ : & & & \\
\hline $\mathbf{N i}$ & Weight of impurity in blank $(\mu \mathrm{g})$ : & & & \\
\hline & Minimum corrected weight of impurity in sample $(\mu \mathrm{g})$ : & & & \\
\hline & Maximum corrected weight of impurity in sample $(\mu \mathrm{g})$ : & & & \\
\hline & Measured concentration of impurity in sample $(\mu \mathrm{g} / \mathrm{ml})$ : & & & $\mathrm{Ca}$ \\
\hline & Uncorrected weight of impurity in sample $(\mu \mathrm{g})$ : & & & \\
\hline Ca & Weight of impurity in blank $(\mu \mathrm{g})$ : & & & \\
\hline & Minimum corrected weight of impurity in sample $(\mu \mathrm{g})$ : & & & \\
\hline & Maximum corrected weight of impurity in sample $(\mu \mathrm{g})$ : & & & \\
\hline & Measured concentration of impurity in sample $(\mu \mathrm{g} / \mathrm{ml})$ : & & & Al \\
\hline & Uncorrected weight of impurity in sample $(\mu \mathrm{g})$ : & & & \\
\hline Al & Weight of impurity in blank $(\mu \mathrm{g})$ : & & & \\
\hline & Minimum corrected weight of impurity in sample $(\mu \mathrm{g})$ : & & & \\
\hline & Maximum corrected weight of impurity in sample $(\mu \mathrm{g})$ : & & & \\
\hline & Measured concentration of impurity in sample $(\mu \mathrm{g} / \mathrm{ml})$ : & & & $\mathbf{T i}$ \\
\hline & Uncorrected weight of impurity in sample $(\mu \mathrm{g})$ : & & & \\
\hline $\mathbf{T i}$ & Weight of impurity in blank $(\mu \mathrm{g})$ : & & & \\
\hline & Minimum corrected weight of impurity in sample $(\mu \mathrm{g})$ : & & & \\
\hline & Maximum corrected weight of impurity in sample $(\mu \mathrm{g})$ : & & & \\
\hline & Measured concentration of impurity in sample $(\mu \mathrm{g} / \mathrm{ml})$ : & & & $\mathbf{V}$ \\
\hline & Uncorrected weight of impurity in sample $(\mu \mathrm{g})$ : & & & \\
\hline v & Weight of impurity in blank $(\mu \mathrm{g})$ : & & & \\
\hline & Minimum corrected weight of impurity in sample $(\mu \mathrm{g})$ : & & & \\
\hline & Maximum corrected weight of impurity in sample $(\mu \mathrm{g})$ : & & & \\
\hline
\end{tabular}

\section{Comments}

Leached in Vessel \#31 (previously used for 14154C-Group 1 Clutch 1).

FCM checked the recorded data against the official Results of Analysis for RMAL19145 on 3/21/2019.

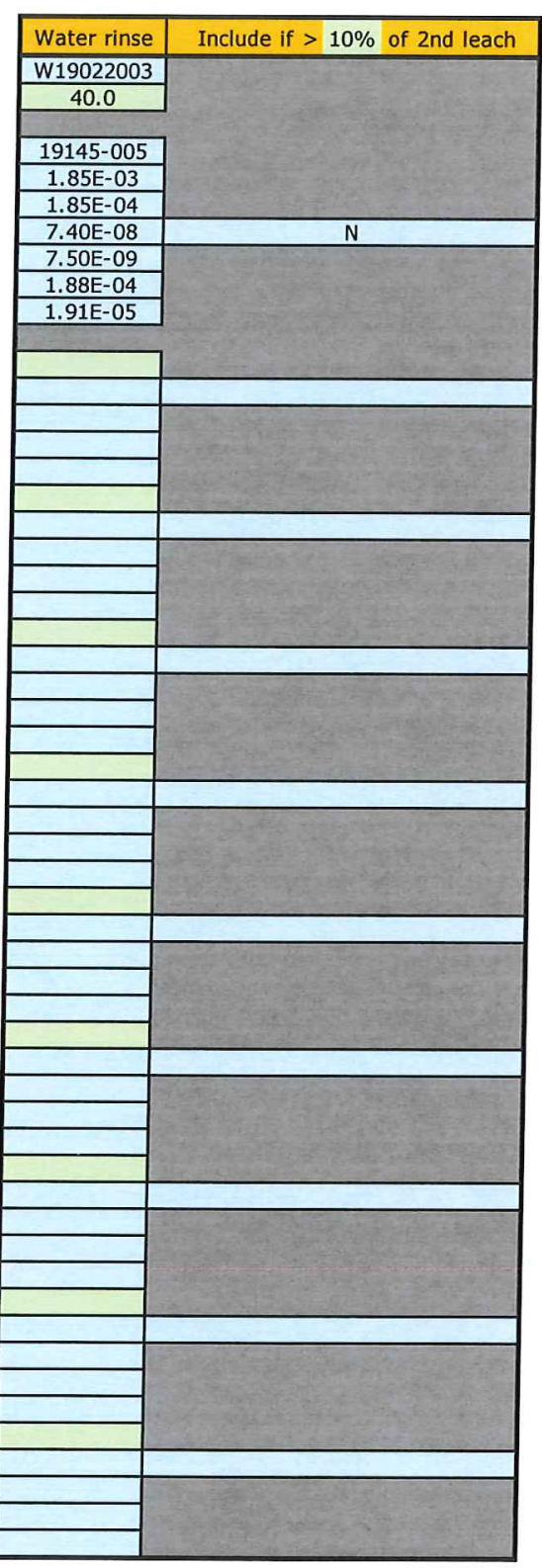

\section{7red c. Montgomery}

Operator
$4-18-2019$

Date 


\section{Data Report Form DRF-26A: Pre-Burn Leach Uranium and Impurities}

\begin{tabular}{|r|l|}
\hline Procedure: & AGR-CHAR-DAM-26 Rev. 3 \\
\hline Operator: & Montgomery \\
\hline Compact lot ID: & BWXT J52R-16-14156D \\
\hline Compact lot description: & AGR-5/6/7 compacts, 25\% packing fraction \\
\hline Compact ID numbers: & $1809,1817,1823,1803,1833$ \\
\hline DRF filename: & 14156 D_PF25-Group 1_DLBL_ICPMS_DRF26R3.xIs \\
\hline
\end{tabular}

\begin{tabular}{|r|c|}
\hline Number of compacts: & 5 \\
\hline Average weight uranium per particle, mean value $(\mathrm{g}):$ & $3.94 \mathrm{E}-04$ \\
\hline Average weight uranium per particle, uncertainty in mean $(\mathrm{g}):$ & $3.94 \mathrm{E}-06$ \\
\hline
\end{tabular}

\begin{tabular}{|c|c|c|c|c|}
\hline & 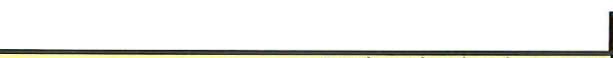 & First Leach & Second Leach & Total \\
\hline & Pre-burn leach solution ID: & L19021802 & L19022002 & \\
\hline & Total volume of leach solution $(\mathrm{ml}):$ & 138.0 & 133.0 & \\
\hline & RMAL analysis number: & $19145-002$ & $19145-004$ & \\
\hline & Measured uranium concentration $(\mu \mathrm{g} / \mathrm{ml})$ : & $1.11 \mathrm{E}-01$ & $1.48 \mathrm{E}-02$ & \\
\hline & Uncertainty in uranium concentration $(\mu \mathrm{g} / \mathrm{ml})$ : & $1.11 \mathrm{E}-02$ & $1.48 \mathrm{E}-03$ & \\
\hline & Weight uranium leached $(\mathrm{g}):$ & $1.53 \mathrm{E}-05$ & $1.97 \mathrm{E}-06$ & $1.73 \mathrm{E}-05$ \\
\hline & Uncertainty in weight uranium leached $(\mathrm{g}):$ & $1.53 \mathrm{E}-06$ & $1.97 \mathrm{E}-07$ & $1.54 \mathrm{E}-06$ \\
\hline & Equivalent number of leached kernels: & $3.88 \mathrm{E}-02$ & $5.00 \mathrm{E}-03$ & $4.38 \mathrm{E}-02$ \\
\hline & Uncertainty in equivalent number of leached kernels: & $3.90 \mathrm{E}-03$ & $5.03 E-04$ & $3.94 \mathrm{E}-03$ \\
\hline \multirow{5}{*}{$\mathrm{Fe}$} & Measured concentration of impurity in sample $(\mu \mathrm{g} / \mathrm{ml})$ : & & & $\mathrm{Fe}$ \\
\hline & Uncorrected weight of impurity in sample $(\mu \mathrm{g}):$ & & & \\
\hline & Weight of impurity in blank $(\mu \mathrm{g})$ : & & & \\
\hline & Minimum corrected weight of impurity in sample $(\mu \mathrm{g}):$ & & & \\
\hline & Maximum corrected weight of impurity in sample $(\mu \mathrm{g})$ : & & & \\
\hline \multirow{5}{*}{$\mathbf{C r}$} & Measured concentration of impurity in sample $(\mu \mathrm{g} / \mathrm{ml})$ : & & & $\mathbf{C r}$ \\
\hline & Uncorrected weight of impurity in sample $(\mu \mathrm{g})$ : & & & \\
\hline & Weight of impurity in blank $(\mu g)$ : & & & \\
\hline & Minimum corrected weight of impurity in sample $(\mu g)$ : & & & \\
\hline & Maximum corrected weight of impurity in sample $(\mu \mathrm{g})$ : & & & \\
\hline \multirow{5}{*}{ Mn } & Measured concentration of impurity in sample $(\mu \mathrm{g} / \mathrm{ml}):$ & & & Mn \\
\hline & Uncorrected weight of impurity in sample $(\mu \mathrm{g})$ : & & & \\
\hline & Weight of impurity in blank $(\mu \mathrm{g})$ : & & & \\
\hline & Minimum corrected weight of impurity in sample $(\mu \mathrm{g})$ : & & & \\
\hline & Maximum corrected weight of impurity in sample $(\mu \mathrm{g})$ : & & & \\
\hline \multirow{5}{*}{ Co } & Measured concentration of impurity in sample $(\mu \mathrm{g} / \mathrm{ml})$ : & & & Co \\
\hline & Uncorrected weight of impurity in sample $(\mu \mathrm{g}):$ & & & \\
\hline & Weight of impurity in blank $(\mu \mathrm{g}):$ & & & \\
\hline & Minimum corrected weight of impurity in sample $(\mu \mathrm{g}):$ & & & \\
\hline & Maximum corrected weight of impurity in sample $(\mu \mathrm{g}):$ & & & \\
\hline \multirow{5}{*}{$\mathbf{N i}$} & Measured concentration of impurity in sample $(\mu \mathrm{g} / \mathrm{ml}):$ & & & $\mathbf{N i}$ \\
\hline & Uncorrected weight of impurity in sample $(\mu \mathrm{g}):$ & & & \\
\hline & Weight of impurity in blank $(\mu \mathrm{g})$ : & & & \\
\hline & Minimum corrected weight of impurity in sample $(\mu \mathrm{g}):$ & & & \\
\hline & Maximum corrected weight of impurity in sample $(\mu \mathrm{g}):$ & & & \\
\hline \multirow{5}{*}{$\mathbf{C a}$} & Measured concentration of impurity in sample $(\mu \mathrm{g} / \mathrm{ml}):$ & & & $\mathrm{Ca}$ \\
\hline & Uncorrected weight of impurity in sample $(\mu \mathrm{g})$ : & & & \\
\hline & Weight of impurity in blank $(\mu \mathrm{g})$ : & & & \\
\hline & Minimum corrected weight of impurity in sample $(\mu \mathrm{g}):$ & & & \\
\hline & Maximum corrected weight of impurity in sample $(\mu \mathrm{g}):$ & & & \\
\hline \multirow{5}{*}{ Al } & Measured concentration of impurity in sample $(\mu \mathrm{g} / \mathrm{ml}):$ & & & Al \\
\hline & Uncorrected weight of impurity in sample $(\mu \mathrm{g})$ : & & & \\
\hline & $\begin{array}{r}\text { Weight of impurity in blank }(\mu \mathrm{g}): \\
\end{array}$ & & & \\
\hline & Minimum corrected weight of impurity in sample $(\mu \mathrm{g}):$ & & & \\
\hline & Maximum corrected weight of impurity in sample $(\mu \mathrm{g})$ : & & & \\
\hline \multirow{5}{*}{$\mathbf{T i}$} & Measured concentration of impurity in sample $(\mu \mathrm{g} / \mathrm{ml})$ : & & & Ti \\
\hline & Uncorrected weight of impurity in sample $(\mu \mathrm{g})$ : & & & \\
\hline & Weight of impurity in blank $(\mu \mathrm{g}):$ & & & \\
\hline & Minimum corrected weight of impurity in sample $(\mu g)$ : & & & \\
\hline & Maximum corrected weight of impurity in sample $(\mu \mathrm{g})$ : & & & \\
\hline \multirow{5}{*}{$\mathbf{v}$} & Measured concentration of impurity in sample $(\mu \mathrm{g} / \mathrm{ml}):$ & & & $\mathbf{V}$ \\
\hline & Uncorrected weight of impurity in sample $(\mu \mathrm{g}):$ & & & \\
\hline & $\begin{array}{r}\text { Weight of impurity in blank }(\mu \mathrm{g}): \\
\end{array}$ & & & \\
\hline & Minimum corrected weight of impurity in sample $(\mu \mathrm{g}):$ & & & \\
\hline & Maximum corrected weight of impurity in sample $(\mu \mathrm{g}):$ & & & \\
\hline
\end{tabular}

comments

Leached in Vessel \#32 (previously used for 14154C-Group 1 Clutch 2).

FCM checked the recorded data against the official Results of Analysis for RMAL19145 on 3/21/2019.

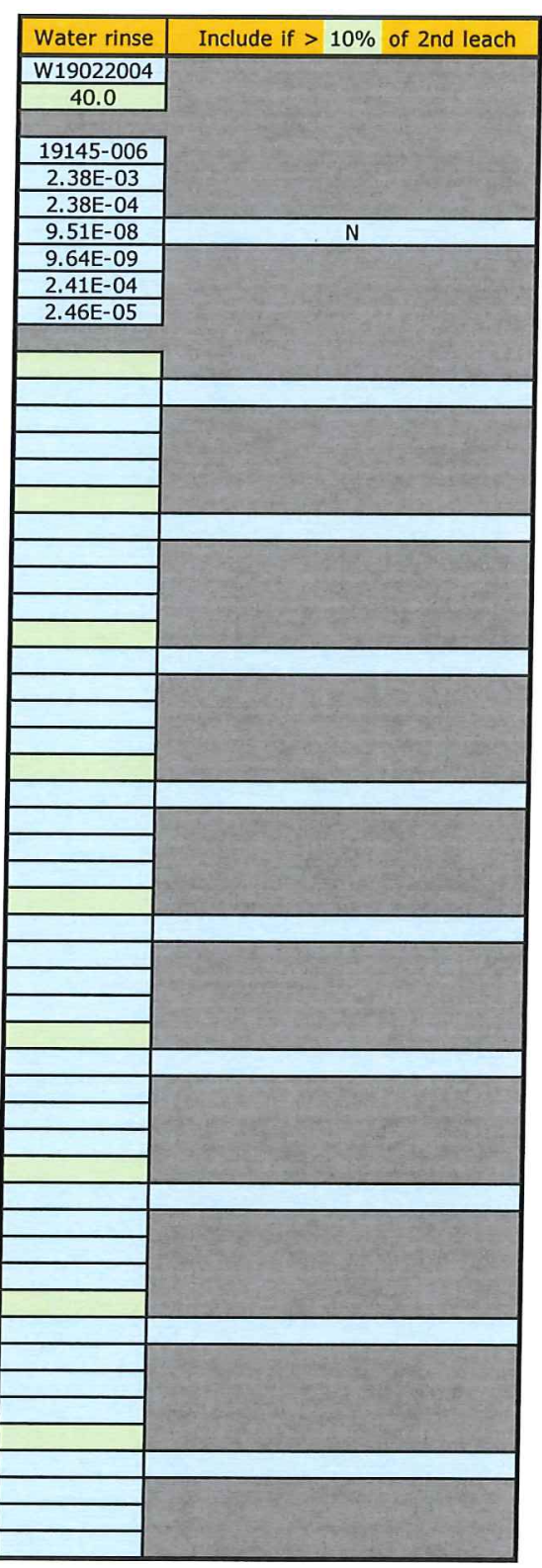

\section{Fied c. montgomey}

Operator
$4-18-2019$ 
Data Report Form DRF-26A: Pre-Burn Leach Uranium and Impurities

\begin{tabular}{|r|l|}
\hline Procedure: & AGR-CHAR-DAM-26 Rev. 3 \\
\hline Operator: & Montgomery \\
\hline Compact lot ID: & BWXT J52R-16-14156D \\
\hline Compact lot description: & AGR-5/6/7 compacts, 25\% packing fraction \\
\hline Compact ID numbers: & $1832,1825,1820,1835,1815$ \\
\hline DRF filename: & $14156 \mathrm{D} \_$PF25-Group 1_DLBL ICPMS_DRF26R3.xIs \\
\hline
\end{tabular}

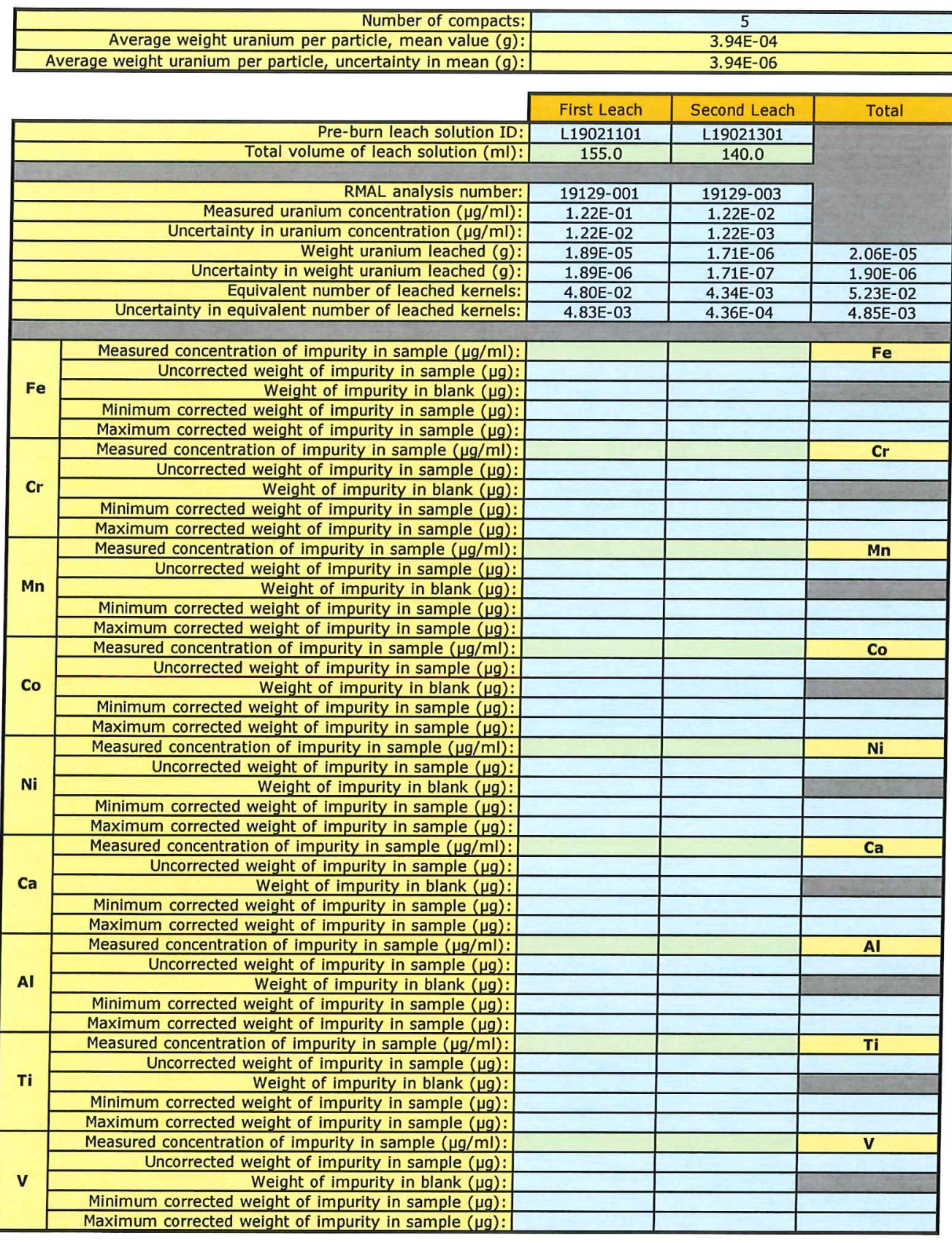

comments

Leached in Vessel \#33 (previously used for 14154C-Group 1 Clutch 3).

FCM checked the recorded data against the official Results of Analysis for RMAL19129 on 3/21/2019.

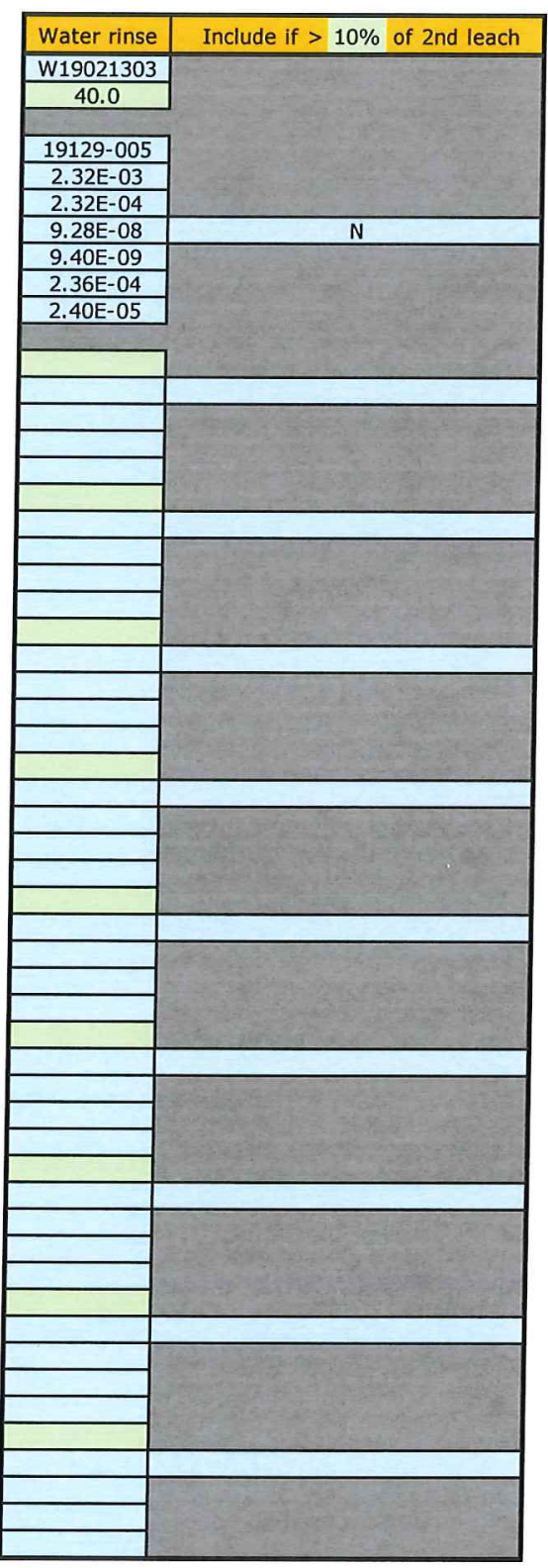

\section{Fied c. Montgomery}

Operato

\section{$4-18-2019$}

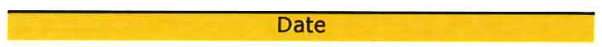


Data Report Form DRF-26A: Pre-Burn Leach Uranium and Impurities

\begin{tabular}{|r|l|}
\hline Procedure: & AGR-CHAR-DAM-26 Rev. 3 \\
\hline Operator: & Montgomery \\
\hline Compact lot ID: & BWXT J52R-16-14156D \\
\hline Compact lot description: & AGR-5/6/7 compacts, 25\% packing fraction \\
\hline Compact ID numbers: & $1816,1813,1822,1827,1814$ \\
\hline DRF filename: & 14156 P PF25-Group 1_DLBL_ICPMS_DRF26R3.xIs \\
\hline
\end{tabular}

\begin{tabular}{|c|c|c|c|c|}
\hline \multicolumn{2}{|r|}{ Number of compacts: } & \multicolumn{3}{|c|}{5} \\
\hline \multirow{2}{*}{\multicolumn{2}{|c|}{$\begin{array}{l}\text { Average weight uranium per particle, mean value }(\mathrm{g}) \text { : } \\
\text { Average weight uranium per particle, uncertainty in mean }(\mathrm{g}) \text { : }\end{array}$}} & \multicolumn{3}{|c|}{ 3.94E-04 } \\
\hline & & \multicolumn{3}{|c|}{$3.94 \mathrm{E}-06$} \\
\hline & First Leach & Second Leach & Total \\
\hline & Pre-burn leach solution ID: & L19021102 & L19021302 & \\
\hline & Total volume of leach solution $(\mathrm{ml})$ : & 156.0 & 140.0 & \\
\hline & RMAL analysis number: & $19129-002$ & $19129-004$ & \\
\hline & Measured uranium concentration $(\mu \mathrm{g} / \mathrm{ml})$ : & $7.76 \mathrm{E}-02$ & $8.80 \mathrm{E}-03$ & \\
\hline & Uncertainty in uranium concentration $(\mu \mathrm{g} / \mathrm{ml})$ : & $7.76 \mathrm{E}-03$ & $8.80 \mathrm{E}-04$ & \\
\hline & Weight uranium leached $(\mathrm{g})$ : & $1.21 \mathrm{E}-05$ & $1.23 \mathrm{E}-06$ & $1.33 \mathrm{E}-05$ \\
\hline & Uncertainty in weight uranium leached $(\mathrm{g})$ : & $1.21 \mathrm{E}-06$ & $1.23 \mathrm{E}-07$ & $1.22 \mathrm{E}-06$ \\
\hline & Equivalent number of leached kernels: & $3.07 E-02$ & $3.13 \mathrm{E}-03$ & $3.39 \mathrm{E}-02$ \\
\hline & Uncertainty in equivalent number of leached kernels: & $3.09 \mathrm{E}-03$ & $3.15 \mathrm{E}-04$ & $3.11 \mathrm{E}-03$ \\
\hline \multirow{5}{*}{$\mathrm{Fe}$} & Measured concentration of impurity in sample $(\mu \mathrm{g} / \mathrm{ml})$ : & & & $\mathrm{Fe}$ \\
\hline & Uncorrected weight of impurity in sample $(\mu \mathrm{g})$ : & & & \\
\hline & Weight of impurity in blank $(\mu \mathrm{g})$ : & & & \\
\hline & Minimum corrected weight of impurity in sample $(\mu \mathrm{g})$ : & & & \\
\hline & Maximum corrected weight of impurity in sample $(\mu \mathrm{g})$ : & & & \\
\hline \multirow{5}{*}{$\mathbf{C r}$} & Measured concentration of impurity in sample $(\mu \mathrm{g} / \mathrm{ml})$ : & & & $\mathrm{Cr}$ \\
\hline & Uncorrected weight of impurity in sample $(\mu \mathrm{g})$ : & & & \\
\hline & Weight of impurity in blank $(\mu \mathrm{g})$ : & & & \\
\hline & Minimum corrected weight of impurity in sample $(\mu g)$ : & & & \\
\hline & Maximum corrected weight of impurity in sample $(\mu \mathrm{g})$ : & & & \\
\hline \multirow{5}{*}{ Mn } & Measured concentration of impurity in sample $(\mu \mathrm{g} / \mathrm{ml})$ : & & & Mn \\
\hline & Uncorrected weight of impurity in sample $(\mu \mathrm{g})$ : & & & \\
\hline & Weight of impurity in blank $(\mu \mathrm{g})$ : & & & \\
\hline & Minimum corrected weight of impurity in sample $(\mu \mathrm{g})$ : & & & \\
\hline & Maximum corrected weight of impurity in sample $(\mu \mathrm{g})$ : & & & \\
\hline \multirow{5}{*}{ Co } & Measured concentration of impurity in sample $(\mu \mathrm{g} / \mathrm{ml})$ : & & & Co \\
\hline & Uncorrected weight of impurity in sample $(\mu \mathrm{g})$ : & & & \\
\hline & Weight of impurity in blank $(\mu \mathrm{g})$ : & & & \\
\hline & Minimum corrected weight of impurity in sample $(\mu \mathrm{g})$ : & & & \\
\hline & Maximum corrected weight of impurity in sample $(\mu \mathrm{g}):$ & & & \\
\hline \multirow{5}{*}{$\mathbf{N i}$} & Measured concentration of impurity in sample $(\mu \mathrm{g} / \mathrm{ml})$ : & & & $\mathrm{Ni}$ \\
\hline & Uncorrected weight of impurity in sample $(\mu \mathrm{g})$ : & & & \\
\hline & Weight of impurity in blank $(\mu \mathrm{g})$ : & & & \\
\hline & Minimum corrected weight of impurity in sample $(\mu \mathrm{g})$ : & & & \\
\hline & Maximum corrected weight of impurity in sample $(\mu \mathrm{g})$ : & & & \\
\hline \multirow{5}{*}{$\mathbf{C a}$} & Measured concentration of impurity in sample $(\mu \mathrm{g} / \mathrm{ml})$ : & & & $\mathbf{C a}$ \\
\hline & Uncorrected weight of impurity in sample $(\mu \mathrm{g})$ : & & & \\
\hline & Weight of impurity in blank $(\mu \mathrm{g})$ : & & & \\
\hline & Minimum corrected weight of impurity in sample $(\mu \mathrm{g}):$ & & & \\
\hline & Maximum corrected weight of impurity in sample $(\mu \mathrm{g})$ : & & & \\
\hline \multirow{5}{*}{ Al } & Measured concentration of impurity in sample $(\mu \mathrm{g} / \mathrm{ml})$ : & & & Al \\
\hline & Uncorrected weight of impurity in sample $(\mu \mathrm{g})$ : & & & \\
\hline & Weight of impurity in blank $(\mu g)$ : & & & \\
\hline & Minimum corrected weight of impurity in sample $(\mu \mathrm{g}):$ & & & \\
\hline & Maximum corrected weight of impurity in sample $(\mu g):$ & & & \\
\hline \multirow{5}{*}{$\mathbf{T i}$} & Measured concentration of impurity in sample $(\mu \mathrm{g} / \mathrm{ml}):$ & & & $\mathbf{T i}$ \\
\hline & Uncorrected weight of impurity in sample $(\mu \mathrm{g})$ : & & & \\
\hline & Weight of impurity in blank $(\mu \mathrm{g}):$ & & & \\
\hline & Minimum corrected weight of impurity in sample $(\mu \mathrm{g}):$ & & & \\
\hline & Maximum corrected weight of impurity in sample $(\mu \mathrm{g}):$ & & & \\
\hline \multirow{5}{*}{$\mathbf{v}$} & Measured concentration of impurity in sample $(\mu \mathrm{g} / \mathrm{ml}):$ & & & $\mathbf{V}$ \\
\hline & Uncorrected weight of impurity in sample $(\mu \mathrm{g})$ : & & & \\
\hline & Weight of impurity in blank $(\mu \mathrm{g})$ : & & & \\
\hline & Minimum corrected weight of impurity in sample $(\mu \mathrm{g})$ : & & & \\
\hline & Maximum corrected weight of impurity in sample $(\mu \mathrm{g}):$ & & & \\
\hline
\end{tabular}

\section{comments}

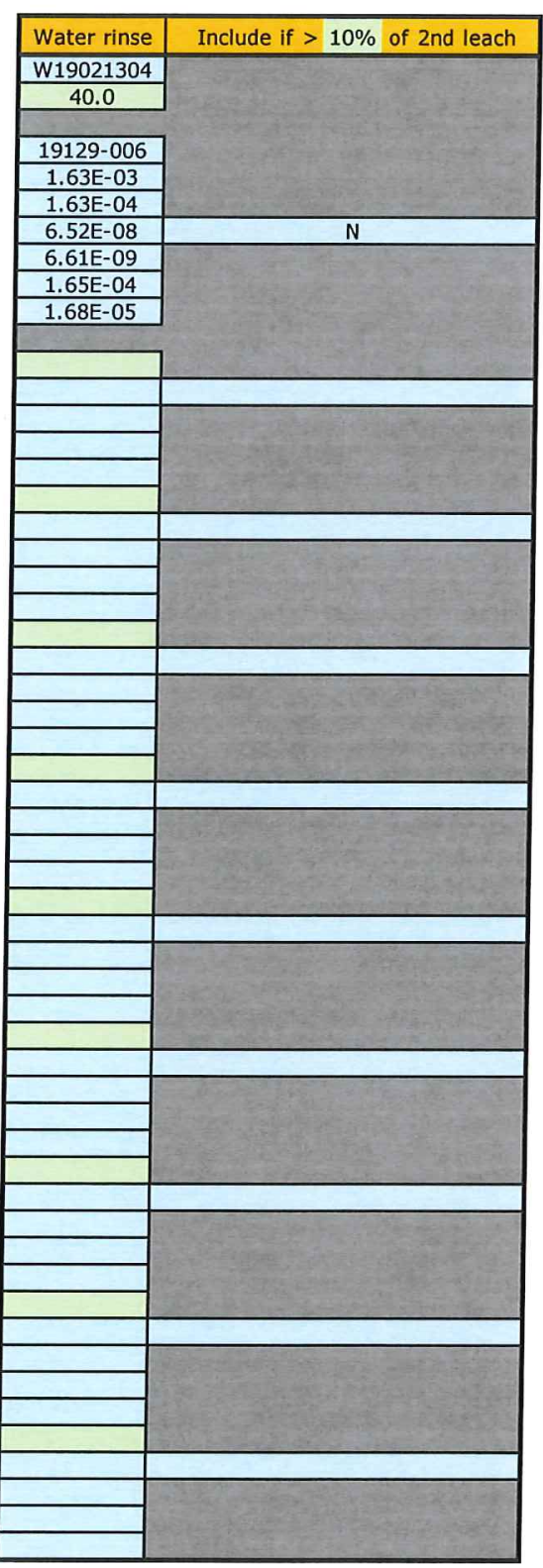

Leached in Vessel \#30 (previously used for 14154C-Group 1 Clutch 4).

FCM checked the recorded data against the official Results of Analysis for RMAL19129 on 3/21/2019.

Fied c. Montyomery

Operator
$4-18-2019$

Date 
Data Report Form DRF-26B: Post-Burn Leach Uranium and Impurities

\begin{tabular}{|r|l|}
\hline Procedure: & AGR-CHAR-DAM-26 Rev. 3 \\
\hline Operator: & Montgomery \\
\hline Compact lot ID: & BWXT J52R-16-14156D \\
\hline Compact lot description: & AGR-5/6/7 compacts, 25\% packing fraction \\
\hline Compact ID numbers: & $1801,1834,1818,1826,1830$ \\
\hline DRF filename: & 14156 D_PF25-Group 1_DLBL_ICPMS_DRF26R3.xIs \\
\hline
\end{tabular}

\begin{tabular}{|r|c|}
\hline Number of compacts: & 5 \\
\hline Average weight uranium per particle, mean value $(\mathrm{g}):$ & $3.94 \mathrm{E}-04$ \\
\hline Average weight uranium per particle, uncertainty in mean $(\mathrm{g}):$ & $3.94 \mathrm{E}-06$ \\
\hline
\end{tabular}

\begin{tabular}{|c|c|c|c|c|}
\hline & 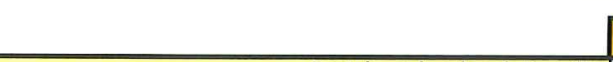 & First Leach & Second Leach & Total \\
\hline & $\begin{array}{c} \\
\end{array}$ & B19022801 & B19030501 & \\
\hline & Total volume of leach solution $(\mathrm{ml})$ : & 56.2 & 68.0 & \\
\hline & RMAL analysis number: & $19192-001$ & $19192-003$ & \\
\hline & Measured uranium concentration $(\mu \mathrm{g} / \mathrm{ml})$ : & $8.73 \mathrm{E}-02$ & $2.44 \mathrm{E}-03$ & \\
\hline & Uncertainty in uranium concentration $(\mu \mathrm{g} / \mathrm{ml})$ : & $8.73 \mathrm{E}-03$ & $2.44 \mathrm{E}-04$ & \\
\hline & Weight uranium leached $(\mathrm{g}):$ & $4.91 \mathrm{E}-06$ & $1.66 \mathrm{E}-07$ & 5.07E-06 \\
\hline & Uncertainty in weight uranium leached $(\mathrm{g})$ : & $4.94 \mathrm{E}-07$ & $1.67 \mathrm{E}-08$ & $4.94 \mathrm{E}-07$ \\
\hline & Equivalent number of leached kernels: & $1.25 \mathrm{E}-02$ & $4.21 \mathrm{E}-04$ & $1.29 \mathrm{E}-02$ \\
\hline & Uncertainty in equivalent number of leached kernels: & $1.26 \mathrm{E}-03$ & $4.25 \mathrm{E}-05$ & $1.26 \mathrm{E}-03$ \\
\hline \multirow{5}{*}{$\mathrm{Fe}$} & Measured concentration of impurity in sample $(\mu \mathrm{g} / \mathrm{ml})$ : & & & Fe \\
\hline & Uncorrected weight of impurity in sample $(\mu \mathrm{g}):$ & & & \\
\hline & Weight of impurity in blank $(\mu \mathrm{g}):$ & & & \\
\hline & Minimum corrected weight of impurity in sample $(\mu \mathrm{g})$ : & & & \\
\hline & Maximum corrected weight of impurity in sample $(\mu \mathrm{g})$ : & & & \\
\hline \multirow{5}{*}{$\mathrm{Cr}$} & Measured concentration of impurity in sample $(\mu \mathrm{g} / \mathrm{ml})$ : & & & $\mathbf{C r}$ \\
\hline & Uncorrected weight of impurity in sample $(\mu \mathrm{g})$ : & & & \\
\hline & Weight of impurity in blank $(\mu \mathrm{g})$ : & & & \\
\hline & Minimum corrected weight of impurity in sample $(\mu g)$ : & & & \\
\hline & Maximum corrected weight of impurity in sample $(\mu g)$ : & & & \\
\hline \multirow{5}{*}{ Mn } & Measured concentration of impurity in sample $(\mu \mathrm{g} / \mathrm{ml})$ : & & & Mn \\
\hline & Uncorrected weight of impurity in sample $(\mu \mathrm{g})$ : & & & \\
\hline & Weight of impurity in blank $(\mu \mathrm{g})$ : & & & \\
\hline & Minimum corrected weight of impurity in sample $(\mu \mathrm{g})$ : & & & \\
\hline & Maximum corrected weight of impurity in sample $(\mu \mathrm{g})$ : & & & \\
\hline \multirow{5}{*}{ Co } & Measured concentration of impurity in sample $(\mu \mathrm{g} / \mathrm{ml})$ : & & & Co \\
\hline & Uncorrected weight of impurity in sample $(\mu \mathrm{g})$ : & & & \\
\hline & Weight of impurity in blank $(\mu g)$ : & & & \\
\hline & Minimum corrected weight of impurity in sample $(\mu \mathrm{g})$ : & & & \\
\hline & Maximum corrected weight of impurity in sample $(\mu \mathrm{g})$ : & & & \\
\hline \multirow{5}{*}{$\mathbf{N i}$} & Measured concentration of impurity in sample $(\mu \mathrm{g} / \mathrm{ml})$ : & & & $\mathrm{Ni}$ \\
\hline & Uncorrected weight of impurity in sample $(\mu \mathrm{g}):$ & & & \\
\hline & Weight of impurity in blank $(\mu \mathrm{g})$ : & & & \\
\hline & Minimum corrected weight of impurity in sample $(\mu \mathrm{g})$ : & & & \\
\hline & Maximum corrected weight of impurity in sample $(\mu \mathrm{g})$ : & & & \\
\hline \multirow{5}{*}{$\mathrm{Ca}$} & Measured concentration of impurity in sample $(\mu \mathrm{g} / \mathrm{ml})$ : & & & $\mathrm{Ca}$ \\
\hline & Uncorrected weight of impurity in sample $(\mu \mathrm{g})$ : & & & \\
\hline & Weight of impurity in blank $(\mu \mathrm{g})$ : & & & \\
\hline & Minimum corrected weight of impurity in sample $(\mu \mathrm{g})$ : & & & \\
\hline & Maximum corrected weight of impurity in sample $(\mu \mathrm{g})$ : & & & \\
\hline \multirow{5}{*}{ Al } & Measured concentration of impurity in sample $(\mu \mathrm{g} / \mathrm{ml})$ : & & & Al \\
\hline & Uncorrected weight of impurity in sample $(\mu \mathrm{g})$ : & & & \\
\hline & Weight of impurity in blank $(\mu \mathrm{g}):$ & & & \\
\hline & Minimum corrected weight of impurity in sample $(\mu \mathrm{g})$ : & & & \\
\hline & Maximum corrected weight of impurity in sample $(\mu \mathrm{g})$ : & & & \\
\hline \multirow{5}{*}{ Ti } & Measured concentration of impurity in sample $(\mu \mathrm{g} / \mathrm{ml})$ : & & & Ti \\
\hline & Uncorrected weight of impurity in sample $(\mu \mathrm{g})$ : & & & \\
\hline & Weight of impurity in blank $(\mu \mathrm{g})$ : & & & \\
\hline & Minimum corrected weight of impurity in sample $(\mu \mathrm{g}):$ & & & \\
\hline & Maximum corrected weight of impurity in sample $(\mu \mathrm{g}):$ & & & \\
\hline \multirow{5}{*}{$\mathbf{v}$} & Measured concentration of impurity in sample $(\mu \mathrm{g} / \mathrm{ml})$ : & & & $\mathbf{v}$ \\
\hline & Uncorrected weight of impurity in sample $(\mu \mathrm{g})$ : & & & \\
\hline & Weight of impurity in blank $(\mu \mathrm{g})$ : & & & \\
\hline & Minimum corrected weight of impurity in sample $(\mu \mathrm{g})$ : & & & \\
\hline & Maximum corrected weight of impurity in sample $(\mu \mathrm{g}):$ : & & & \\
\hline
\end{tabular}

Comments

FCM checked the recorded data against the official Results of Analysis for RMAL19192 on 4/12/2019.

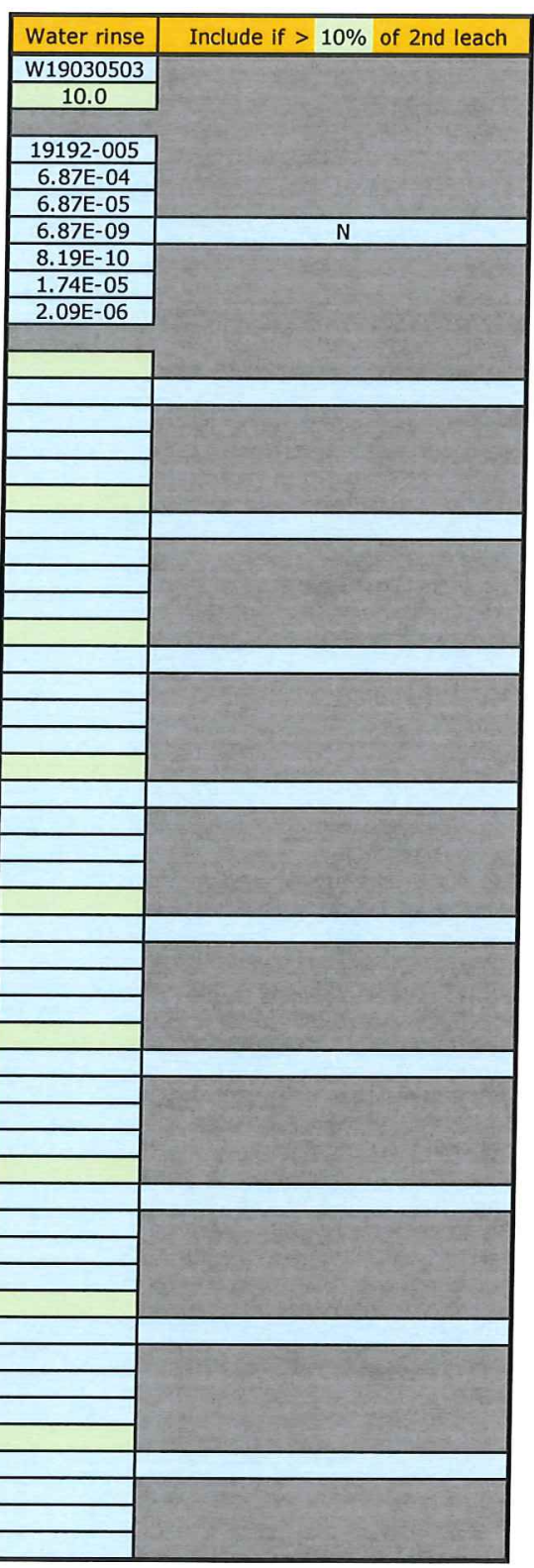


Data Report Form DRF-26B: Post-Burn Leach Uranium and Impurities

\begin{tabular}{|c|c|}
\hline Procedure: & AGR-CHAR-DAM-26 Rev. 3 \\
\hline Operator: & Montgomery \\
\hline Compact lot ID: & BWXT J52R-16-14156D \\
\hline Compact lot description: & AGR-5/6/7 compacts, $25 \%$ packing fraction \\
\hline Compact ID numbers: & $1809,1817,1823,1803,1833$ \\
\hline DRF filename: & 14156D_PF25-Group 1_DLBL_ICPMS_DRF26R3.xls \\
\hline
\end{tabular}

\begin{tabular}{|c|c|c|c|c|}
\hline \multicolumn{2}{|r|}{ Number of compacts: } & \multicolumn{3}{|c|}{5} \\
\hline \multirow{2}{*}{\multicolumn{2}{|c|}{$\begin{array}{l}\text { Average weight uranium per particle, mean value }(\mathrm{g}) \text { : } \\
\text { Average weight uranium per particle, uncertainty in mean }(\mathrm{g}) \text { : }\end{array}$}} & \multicolumn{3}{|c|}{$3.94 \mathrm{E}-04$} \\
\hline & & \multicolumn{3}{|c|}{$3.94 \mathrm{E}-06$} \\
\hline & & First Leach & Second Leach & Total \\
\hline & Post-burn leach solution ID: & B19022802 & B19030502 & \\
\hline & Total volume of leach solution $(\mathrm{ml})$ : & 57.2 & 58.8 & \\
\hline & & & & \\
\hline & RMAL analysis number: & $19192-002$ & 19192-004 & \\
\hline & Measured uranium concentration $(\mu \mathrm{g} / \mathrm{ml}):$ & $8.78 \mathrm{E}-01$ & $7.93 \mathrm{E}-01$ & \\
\hline & Uncertainty in uranium concentration $(\mu \mathrm{g} / \mathrm{ml})$ : & $8.78 \mathrm{E}-02$ & $7.93 \mathrm{E}-02$ & \\
\hline & Weight uranium leached $(\mathrm{g}):$ & $5.02 \mathrm{E}-05$ & $4.66 \mathrm{E}-05$ & $9.69 \mathrm{E}-05$ \\
\hline & Uncertainty in weight uranium leached $(\mathrm{g})$ : & $5.05 \mathrm{E}-06$ & $4.69 \mathrm{E}-06$ & $6.90 \mathrm{E}-06$ \\
\hline & $\begin{aligned} \text { Equivalent number of leached kernels: } \\
\end{aligned}$ & $1.27 E-01$ & $1.18 \mathrm{E}-01$ & $2.46 \mathrm{E}-01$ \\
\hline & Uncertainty in equivalent number of leached kernels: & $1.29 \mathrm{E}-02$ & $1.20 \mathrm{E}-02$ & $1.77 E-02$ \\
\hline \multirow{5}{*}{$\mathbf{F e}$} & Measured concentration of impurity in sample $(\mu \mathrm{g} / \mathrm{ml})$ : & & & $\mathrm{Fe}$ \\
\hline & Uncorrected weight of impurity in sample $(\mu \mathrm{g})$ : & & & \\
\hline & Weight of impurity in blank $(\mu \mathrm{g})$ : & & & \\
\hline & Minimum corrected weight of impurity in sample $(\mu \mathrm{g})$ : & & & \\
\hline & Maximum corrected weight of impurity in sample $(\mu \mathrm{g})$ : & & & \\
\hline \multirow{5}{*}{$\mathbf{C r}$} & Measured concentration of impurity in sample $(\mu \mathrm{g} / \mathrm{ml})$ : & & & $\mathbf{C r}$ \\
\hline & Uncorrected weight of impurity in sample $(\mu \mathrm{g})$ : & & & \\
\hline & Weight of impurity in blank $(\mu g)$ : & & & \\
\hline & Minimum corrected weight of impurity in sample $(\mu \mathrm{g})$ : & & & \\
\hline & Maximum corrected weight of impurity in sample $(\mu g)$ : & & & \\
\hline \multirow{5}{*}{ Mn } & Measured concentration of impurity in sample $(\mu \mathrm{g} / \mathrm{ml}):$ & & & Mn \\
\hline & Uncorrected weight of impurity in sample $(\mu \mathrm{g}):$ & & & \\
\hline & Weight of impurity in blank $(\mu \mathrm{g})$ : & & & \\
\hline & Minimum corrected weight of impurity in sample $(\mu g)$ : & & & \\
\hline & Maximum corrected weight of impurity in sample $(\mu \mathrm{g})$ : & & & \\
\hline \multirow{5}{*}{ Co } & Measured concentration of impurity in sample $(\mu \mathrm{g} / \mathrm{ml})$ : & & & Co \\
\hline & Uncorrected weight of impurity in sample $(\mu \mathrm{g})$ : & & & \\
\hline & Weight of impurity in blank $(\mu \mathrm{g})$ : & & & \\
\hline & Minimum corrected weight of impurity in sample $(\mu \mathrm{g}):$ & & & \\
\hline & Maximum corrected weight of impurity in sample $(\mu g)$ : & & & \\
\hline \multirow{5}{*}{$\mathbf{N i}$} & Measured concentration of impurity in sample $(\mu \mathrm{g} / \mathrm{ml})$ : & & & $\mathbf{N i}$ \\
\hline & Uncorrected weight of impurity in sample $(\mu \mathrm{g})$ : & & & \\
\hline & Weight of impurity in blank $(\mu \mathrm{g})$ : & & & \\
\hline & Minimum corrected weight of impurity in sample $(\mu \mathrm{g}):$ & & & \\
\hline & Maximum corrected weight of impurity in sample $(\mu \mathrm{g}):$ & & & \\
\hline \multirow{5}{*}{$\mathbf{C a}$} & Measured concentration of impurity in sample $(\mu \mathrm{g} / \mathrm{ml})$ : & & & $\mathbf{C a}$ \\
\hline & Uncorrected weight of impurity in sample $(\mu \mathrm{g})$ : & & & \\
\hline & Weight of impurity in blank $(\mu \mathrm{g})$ : & & & \\
\hline & Minimum corrected weight of impurity in sample $(\mu \mathrm{g}):$ & & & \\
\hline & Maximum corrected weight of impurity in sample $(\mu \mathrm{g})$ : & & & \\
\hline \multirow{5}{*}{ Al } & Measured concentration of impurity in sample $(\mu \mathrm{g} / \mathrm{ml})$ : & & & Al \\
\hline & Uncorrected weight of impurity in sample $(\mu \mathrm{g})$ : & & & \\
\hline & Weight of impurity in blank $(\mu \mathrm{g})$ : & & & \\
\hline & Minimum corrected weight of impurity in sample $(\mu \mathrm{g})$ : & & & \\
\hline & Maximum corrected weight of impurity in sample $(\mu \mathrm{g})$ : & & & \\
\hline \multirow{5}{*}{$\mathbf{T i}$} & Measured concentration of impurity in sample $(\mu \mathrm{g} / \mathrm{ml})$ : & & & $\mathrm{Ti}$ \\
\hline & Uncorrected weight of impurity in sample $(\mu \mathrm{g})$ : & & & \\
\hline & Weight of impurity in blank $(\mu \mathrm{g})$ : & & & \\
\hline & Minimum corrected weight of impurity in sample $(\mu \mathrm{g})$ : & & & \\
\hline & Maximum corrected weight of impurity in sample $(\mu \mathrm{g})$ : & & & \\
\hline \multirow{5}{*}{$\mathbf{v}$} & Measured concentration of impurity in sample $(\mu \mathrm{g} / \mathrm{ml})$ : & & & $\mathbf{V}$ \\
\hline & Uncorrected weight of impurity in sample $(\mu \mathrm{g})$ : & & & \\
\hline & Weight of impurity in blank $(\mu \mathrm{g}):$ & & & \\
\hline & Minimum corrected weight of impurity in sample $(\mu \mathrm{g})$ : & & & \\
\hline & Maximum corrected weight of impurity in sample $(\mu \mathrm{g})$ : & & & \\
\hline
\end{tabular}

\section{comments}

FCM checked the recorded data against the official Results of Analysis for RMAL19192 on 4/12/2019.

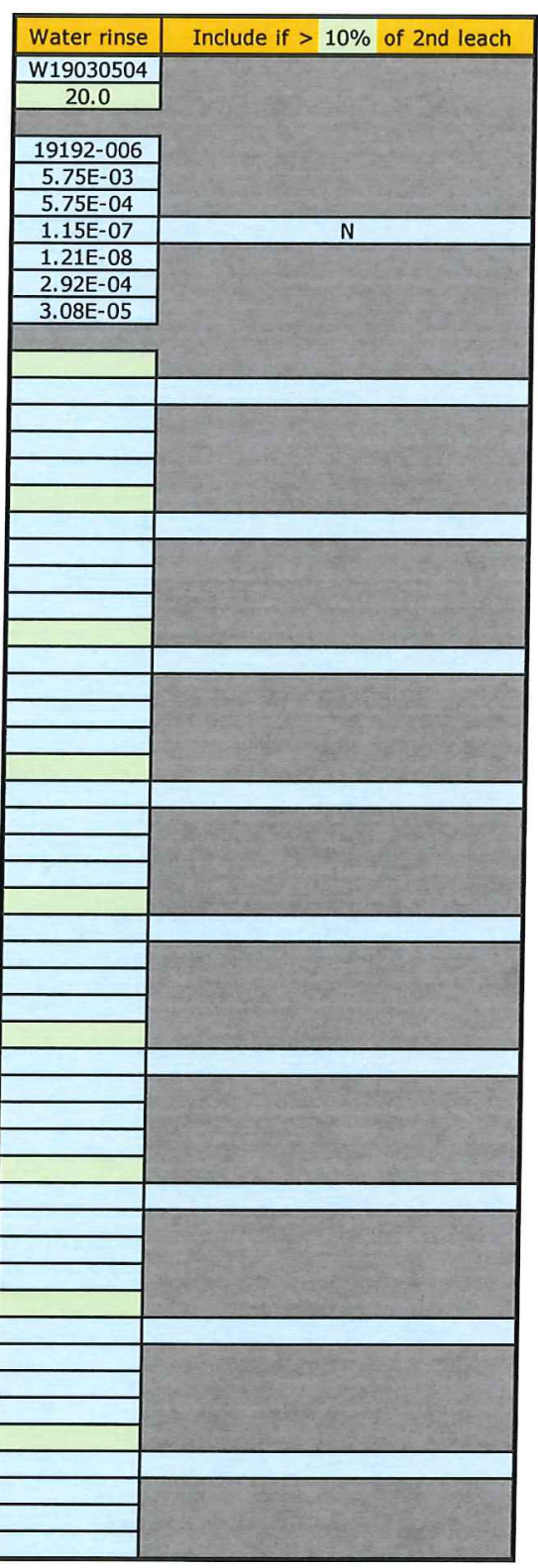


Data Report Form DRF-26B: Post-Burn Leach Uranium and Impurities

\begin{tabular}{|r|l|}
\hline Procedure: & AGR-CHAR-DAM-26 Rev, 3 \\
\hline Operator: & Montgomery \\
\hline Compact lot ID: & BWXT J52R-16-14156D \\
\hline Compact lot description: & AGR-5/6/7 compacts, 25\% packing fraction \\
\hline Compact ID numbers: & $1832,1825,1820,1835,1815$ \\
\hline DRF filename: & $14156 D \_P F 25-$ Group 1_DLBL_ICPMS_DRF26R3.xIs \\
\hline
\end{tabular}

\begin{tabular}{|c|c|c|c|c|}
\hline \multicolumn{2}{|r|}{ Number of compacts: } & \multicolumn{3}{|c|}{5} \\
\hline \multirow{2}{*}{\multicolumn{2}{|c|}{$\begin{array}{l}\text { Average weight uranium per particle, mean value }(g) \text { : } \\
\text { Average weight uranium per particle, uncertainty in mean }(g) \text { : }\end{array}$}} & \multirow{2}{*}{\multicolumn{3}{|c|}{$\begin{array}{l}3.94 \mathrm{E}-04 \\
3.94 \mathrm{E}-06 \\
\end{array}$}} \\
\hline & & & & \\
\hline & First Leach & Second Leach & Total \\
\hline & Post-burn leach solution ID: & B19022101 & B19022501 & \\
\hline & Total volume of leach solution $(\mathrm{ml})$ : & 55.7 & 59.0 & \\
\hline & RMAL analysis number: & $19159-001$ & $19159-003$ & \\
\hline & Measured uranium concentration $(\mu \mathrm{g} / \mathrm{ml})$ : & $8.54 \mathrm{E}-02$ & $2.04 \mathrm{E}-03$ & \\
\hline & Uncertainty in uranium concentration $(\mu \mathrm{g} / \mathrm{ml})$ : & $8.54 \mathrm{E}-03$ & $2.04 \mathrm{E}-04$ & \\
\hline & Weight uranium leached $(g)$ : & $4.76 \mathrm{E}-06$ & $1.20 \mathrm{E}-07$ & $4.88 \mathrm{E}-06$ \\
\hline & Uncertainty in weight uranium leached $(\mathrm{g})$ : & $4.79 \mathrm{E}-07$ & $1.21 \mathrm{E}-08$ & $4.79 \mathrm{E}-07$ \\
\hline & Equivalent number of leached kernels: & $1.21 \mathrm{E}-02$ & $3.05 \mathrm{E}-04$ & $1.24 \mathrm{E}-02$ \\
\hline & Uncertainty in equivalent number of leached kernels: & $1.22 \mathrm{E}-03$ & $3.09 \mathrm{E}-05$ & $1.22 \mathrm{E}-03$ \\
\hline \multirow{5}{*}{$\mathbf{F e}$} & Measured concentration of impurity in sample $(\mu \mathrm{g} / \mathrm{ml})$ : & & & $\mathrm{Fe}$ \\
\hline & Uncorrected weight of impurity in sample $(\mu g)$ : & & & \\
\hline & Weight of impurity in blank $(\mu \mathrm{g})$ : & & & \\
\hline & Minimum corrected weight of impurity in sample $(\mu \mathrm{g})$ : & & & \\
\hline & Maximum corrected weight of impurity in sample $(\mu g)$ : & & & \\
\hline \multirow{5}{*}{$\mathbf{C r}$} & Measured concentration of impurity in sample $(\mu \mathrm{g} / \mathrm{ml})$ : & & & $\mathbf{C r}$ \\
\hline & Uncorrected weight of impurity in sample $(\mu \mathrm{g})$ : & & & \\
\hline & $\begin{array}{c}\text { Weight of impurity in blank }(\mu \mathrm{g}) \text { : } \\
\end{array}$ & & & \\
\hline & Minimum corrected weight of impurity in sample $(\mu \mathrm{g})$ : & & & \\
\hline & Maximum corrected weight of impurity in sample $(\mu \mathrm{g})$ : & & & \\
\hline \multirow{5}{*}{ Mn } & Measured concentration of impurity in sample $(\mu \mathrm{g} / \mathrm{ml})$ : & & & $\mathbf{M n}$ \\
\hline & Uncorrected weight of impurity in sample $(\mu \mathrm{g})$ : & & & \\
\hline & Weight of impurity in blank $(\mu \mathrm{g})$ : & & & \\
\hline & Minimum corrected weight of impurity in sample $(\mu \mathrm{g})$ : & & & \\
\hline & Maximum corrected weight of impurity in sample $(\mu \mathrm{g})$ : & & & \\
\hline \multirow{5}{*}{ Co } & Measured concentration of impurity in sample $(\mu \mathrm{g} / \mathrm{ml})$ : & & & Co \\
\hline & Uncorrected weight of impurity in sample $(\mu \mathrm{g})$ : & & & \\
\hline & Weight of impurity in blank $(\mu \mathrm{g})$ : & & & \\
\hline & Minimum corrected weight of impurity in sample $(\mu \mathrm{g})$ : & & & \\
\hline & Maximum corrected weight of impurity in sample $(\mu \mathrm{g})$ : & & & \\
\hline \multirow{5}{*}{$\mathbf{N i}$} & Measured concentration of impurity in sample $(\mu \mathrm{g} / \mathrm{ml})$ : & & & $\mathbf{N i}$ \\
\hline & Uncorrected weight of impurity in sample $(\mu \mathrm{g})$ : & & & \\
\hline & Weight of impurity in blank $(\mu \mathrm{g})$ : & & & \\
\hline & Minimum corrected weight of impurity in sample $(\mu \mathrm{g})$ : & & & \\
\hline & Maximum corrected weight of impurity in sample $(\mu \mathrm{g})$ : & & & \\
\hline \multirow{5}{*}{$\mathrm{Ca}$} & Measured concentration of impurity in sample $(\mu \mathrm{g} / \mathrm{ml})$ : & & & $\mathbf{C a}$ \\
\hline & Uncorrected weight of impurity in sample $(\mu \mathrm{g})$ : & & & \\
\hline & Weight of impurity in blank $(\mu \mathrm{g})$ : & & & \\
\hline & Minimum corrected weight of impurity in sample $(\mu \mathrm{g})$ : & & & \\
\hline & Maximum corrected weight of impurity in sample $(\mu \mathrm{g})$ : & & & \\
\hline \multirow{5}{*}{ Al } & Measured concentration of impurity in sample $(\mu \mathrm{g} / \mathrm{ml})$ : & & & Al \\
\hline & Uncorrected weight of impurity in sample $(\mu \mathrm{g})$ : & & & \\
\hline & Weight of impurity in blank $(\mu \mathrm{g})$ : & & & \\
\hline & Minimum corrected weight of impurity in sample $(\mu \mathrm{g})$ : & & & \\
\hline & Maximum corrected weight of impurity in sample $(\mu \mathrm{g})$ : & & & \\
\hline \multirow{5}{*}{$\mathrm{Ti}$} & Measured concentration of impurity in sample $(\mu \mathrm{g} / \mathrm{ml})$ : & & & Ti \\
\hline & Uncorrected weight of impurity in sample $(\mu \mathrm{g})$ : & & & \\
\hline & Weight of impurity in blank $(\mu \mathrm{g})$ : & & & \\
\hline & Minimum corrected weight of impurity in sample $(\mu \mathrm{g})$ : & & & \\
\hline & Maximum corrected weight of impurity in sample $(\mu \mathrm{g})$ : & & & \\
\hline \multirow{5}{*}{$\mathbf{v}$} & Measured concentration of impurity in sample $(\mathrm{\mu g} / \mathrm{ml})$ : & & & $\mathbf{v}$ \\
\hline & Uncorrected weight of impurity in sample $(\mu \mathrm{g})$ : & & & \\
\hline & Weight of impurity in blank $(\mu \mathrm{g})$ : & & & \\
\hline & Minimum corrected weight of impurity in sample $(\mu \mathrm{g})$ : & & & \\
\hline & Maximum corrected weight of impurity in sample $(\mu \mathrm{g})$ : & & & \\
\hline
\end{tabular}

Comments

FCM checked the recorded data against the official Results of Analysis for RMAL19159 on 3/26/2019.

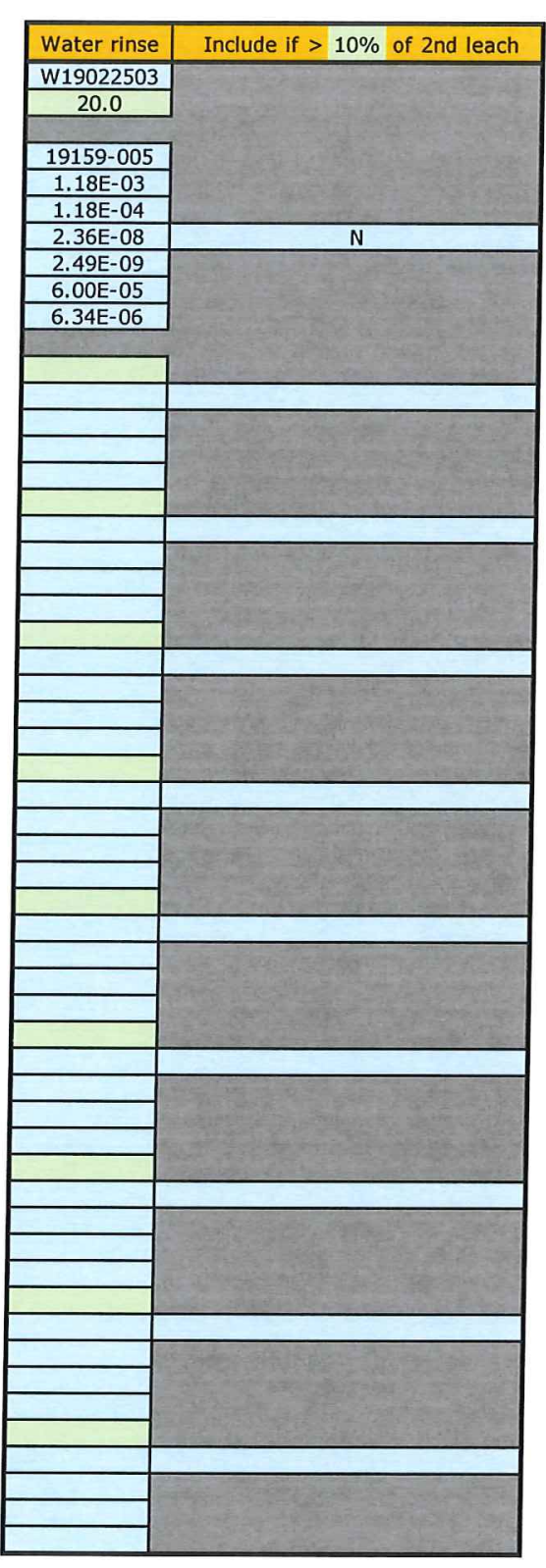


Data Report Form DRF-26B: Post-Burn Leach Uranium and Impurities

\begin{tabular}{|r|l|}
\hline Procedure: & AGR-CHAR-DAM-26 Rev. 3 \\
\hline Operator: & Montgomery \\
\hline Compact lot ID: & BWXT J52R-16-14156D \\
\hline Compact lot description: & AGR-5/6/7 compacts, 25\% packing fraction \\
\hline Compact ID numbers: & $1816,1813,1822,1827,1814$ \\
\hline DRF filename: & $14156 \mathrm{D}$ PF25-Group 1_DLBL_ICPMS_DRF26R3.xIs \\
\hline
\end{tabular}

\begin{tabular}{|r|c|}
\hline Number of compacts: & 5 \\
\hline Average weight uranium per particle, mean value $(\mathrm{g}):$ & $3.94 \mathrm{E}-04$ \\
\hline Average weight uranium per particle, uncertainty in mean $(\mathrm{g}):$ & $3.94 \mathrm{E}-06$ \\
\hline
\end{tabular}

\begin{tabular}{|c|c|c|c|c|}
\hline & First Leach & Second Leach & Total \\
\hline & Post-burn leach solution ID: & B19022102 & B19022502 & \\
\hline & Total volume of leach solution $(\mathrm{ml})$ : & 57.7 & 57.5 & \\
\hline & RMAL analysis number: & $19159-002$ & $19159-004$ & \\
\hline & Measured uranium concentration $(\mathrm{\mu g} / \mathrm{ml})$ : & $8.55 \mathrm{E}-02$ & $2.31 \mathrm{E}-03$ & \\
\hline & Uncertainty in uranium concentration $(\mu \mathrm{g} / \mathrm{ml})$ : & $8.55 \mathrm{E}-03$ & $2.31 \mathrm{E}-04$ & \\
\hline & Weight uranium leached $(\mathrm{g})$ : & $4.93 \mathrm{E}-06$ & $1.33 \mathrm{E}-07$ & $5.06 \mathrm{E}-06$ \\
\hline & Uncertainty in weight uranium leached $(\mathrm{g})$ : & $4.96 \mathrm{E}-07$ & $1.34 \mathrm{E}-08$ & $4.97 \mathrm{E}-07$ \\
\hline & Equivalent number of leached kernels: & $1.25 \mathrm{E}-02$ & $3.37 \mathrm{E}-04$ & $1.29 \mathrm{E}-02$ \\
\hline & Uncertainty in equivalent number of leached kernels: & $1.27 \mathrm{E}-03$ & $3.41 \mathrm{E}-05$ & $1.27 \mathrm{E}-03$ \\
\hline \multirow{5}{*}{$\mathrm{Fe}$} & Measured concentration of impurity in sample $(\mu \mathrm{g} / \mathrm{ml})$ : & & & $\mathrm{Fe}$ \\
\hline & Uncorrected weight of impurity in sample $(\mu \mathrm{g})$ : & & & \\
\hline & Weight of impurity in blank $(\mu g)$ : & & & \\
\hline & Minimum corrected weight of impurity in sample $(\mu \mathrm{g})$ : & & & \\
\hline & Maximum corrected weight of impurity in sample $(\mu \mathrm{g})$ : & & & \\
\hline \multirow{5}{*}{$\mathbf{C r}$} & Measured concentration of impurity in sample $(\mathrm{\mu g} / \mathrm{ml})$ : & & & $\mathbf{C r}$ \\
\hline & Uncorrected weight of impurity in sample $(\mu \mathrm{g})$ : & & & \\
\hline & Weight of impurity in blank $(\mu \mathrm{g})$ : & & & \\
\hline & Minimum corrected weight of impurity in sample $(\mu \mathrm{g})$ : & & & \\
\hline & Maximum corrected weight of impurity in sample $(\mu \mathrm{g})$ : & & & \\
\hline \multirow{5}{*}{ Mn } & Measured concentration of impurity in sample $(\mu \mathrm{g} / \mathrm{ml})$ : & & & $\mathbf{M n}$ \\
\hline & Uncorrected weight of impurity in sample $(\mu \mathrm{g})$ : & & & \\
\hline & Weight of impurity in blank $(\mu \mathrm{g})$ : & & & \\
\hline & Minimum corrected weight of impurity in sample $(\mu \mathrm{g})$ : & & & \\
\hline & Maximum corrected weight of impurity in sample $(\mu \mathrm{g})$ : & & & \\
\hline \multirow{5}{*}{ Co } & Measured concentration of impurity in sample $(\mu \mathrm{g} / \mathrm{ml})$ : & & & Co \\
\hline & Uncorrected weight of impurity in sample $(\mu \mathrm{g})$ : & & & \\
\hline & Weight of impurity in blank $(\mu \mathrm{g})$ : & & & \\
\hline & Minimum corrected weight of impurity in sample $(\mu \mathrm{g})$ : & & & \\
\hline & Maximum corrected weight of impurity in sample $(\mu \mathrm{g})$ : & & & \\
\hline \multirow{5}{*}{$\mathbf{N i}$} & Measured concentration of impurity in sample $(\mu \mathrm{g} / \mathrm{ml})$ : & & & Ni \\
\hline & Uncorrected weight of impurity in sample $(\mu \mathrm{g})$ : & & & \\
\hline & Weight of impurity in blank $(\mu \mathrm{g})$ : & & & \\
\hline & Minimum corrected weight of impurity in sample $(\mu \mathrm{g})$ : & & & \\
\hline & Maximum corrected weight of impurity in sample $(\mu \mathrm{g})$ : & & & \\
\hline \multirow{5}{*}{$\mathbf{C a}$} & Measured concentration of impurity in sample $(\mu \mathrm{g} / \mathrm{ml})$ : & & & $\mathbf{C a}$ \\
\hline & Uncorrected weight of impurity in sample $(\mu \mathrm{g})$ : & & & \\
\hline & Weight of impurity in blank $(\mu \mathrm{g})$ : & & & \\
\hline & Minimum corrected weight of impurity in sample $(\mu \mathrm{g})$ : & & & \\
\hline & Maximum corrected weight of impurity in sample $(\mu \mathrm{g})$ : & & & \\
\hline \multirow{5}{*}{ Al } & Measured concentration of impurity in sample $(\mu \mathrm{g} / \mathrm{ml})$ : & & & Al \\
\hline & Uncorrected weight of impurity in sample $(\mu \mathrm{g})$ : & & & \\
\hline & Weight of impurity in blank $(\mu \mathrm{gg})$ : & & & \\
\hline & Minimum corrected weight of impurity in sample $(\mu \mathrm{g})$ : & & & \\
\hline & Maximum corrected weight of impurity in sample $(\mu \mathrm{g})$ : & & & \\
\hline \multirow{5}{*}{$\mathbf{T i}$} & Measured concentration of impurity in sample $(\mu \mathrm{g} / \mathrm{ml})$ : & & & Ti \\
\hline & Uncorrected weight of impurity in sample $(\mu \mathrm{g})$ : & & & \\
\hline & Weight of impurity in blank $(\mu \mathrm{g})$ : & & & \\
\hline & Minimum corrected weight of impurity in sample $(\mu \mathrm{g})$ : & & & \\
\hline & Maximum corrected weight of impurity in sample $(\mu \mathrm{g})$ : & & & \\
\hline \multirow{5}{*}{$\mathbf{v}$} & Measured concentration of impurity in sample $(\mu \mathrm{g} / \mathrm{ml}):$ & & & $\mathbf{v}$ \\
\hline & Uncorrected weight of impurity in sample $(\mu \mathrm{g})$ : & & & \\
\hline & Weight of impurity in blank $(\mu \mathrm{g})$ : & & & \\
\hline & Minimum corrected weight of impurity in sample $(\mu \mathrm{g})$ : & & & \\
\hline & Maximum corrected weight of impurity in sample $(\mu \mathrm{g}):$ & & & \\
\hline
\end{tabular}

Comments

FCM checked the recorded data against the official Results of Analysis for RMAL19159 on 3/26/2019.

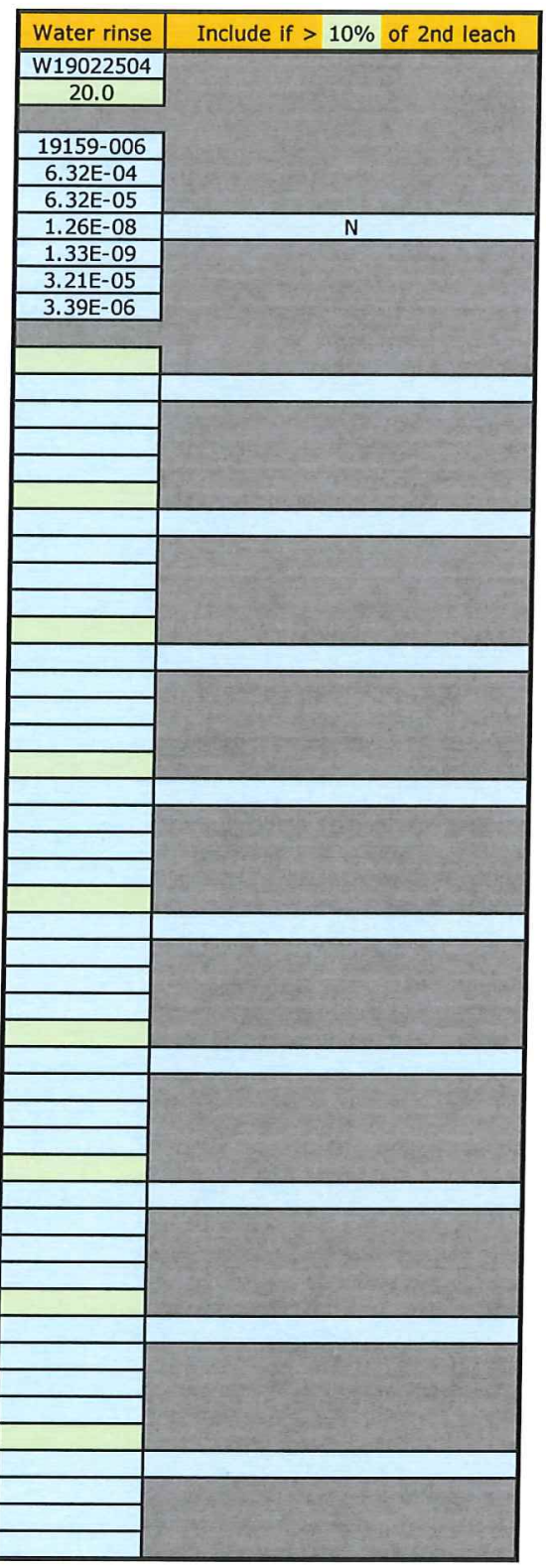

Fred c. Montgomeen Operator

\section{$4-18-2019$}

C-37 

APPENDIX D. REPORT FORMS FOR 40\% PF COMPACT LBL 

Inspection Report Form IRF-B: Summary of Impurites Outside SiC - Maximum Corrected Values

\begin{tabular}{|r|l|}
\hline Procedure: & AGR-CHAR-DAM-26 Rev. 3 \\
\hline Operator: & Montgomery/Dyer \\
\hline Compact lot ID: & BWXT J52R-16-14154C \\
\hline Compact lot description: & AGR-5/6/7 compacts, $40 \%$ packing fraction \\
\hline
\end{tabular}

\begin{tabular}{|c|c|c|c|c|c|c|}
\hline Compact ID numbers: & $\begin{array}{c}1021,1042, \\
1056,1093, \\
1105\end{array}$ & $\begin{array}{c}1004,1016 \\
1018,1085 \\
1101 \\
\end{array}$ & $\begin{array}{c}1006,1057 \\
1068,1078 \\
1107\end{array}$ & $\begin{array}{c}1002,1036 \\
1038,1083 \\
1098\end{array}$ & Mean & $\begin{array}{l}\text { Standard } \\
\text { Deviation }\end{array}$ \\
\hline Number of compacts: & 5 & 5 & 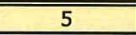 & 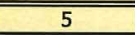 & & \\
\hline \multicolumn{7}{|l|}{ Iron } \\
\hline Pre-burn leach (DRF-26A) $(\mu \mathrm{g})$ : & 102.24 & 114.25 & 122.92 & 119.03 & & \\
\hline Post-burn leach (DRF-26B) $(\mu \mathrm{g})$ : & 117.31 & 117.96 & 155.01 & 114.58 & & \\
\hline Total leached $(\mu \mathrm{g})$ : & 219.55 & 232.21 & 277.93 & 233.61 & & \\
\hline Fe outside SiC ( $\mu \mathrm{g} /$ compact): & 43.91 & 46.44 & 55.59 & 46.72 & 48.16 & 5.11 \\
\hline \multicolumn{7}{|l|}{ Chromium } \\
\hline Pre-burn leach (DRF-26A) $(\mu g)$ : & 1.47 & 1.92 & 3.99 & 2.02 & & \\
\hline Post-burn leach (DRF-26B) $(\mu \mathrm{g})$ : & 1.05 & 0.77 & 0.90 & 0.83 & & \\
\hline Total leached $(\mu \mathrm{g}):$ & 2.52 & 2.69 & 4.89 & 2.85 & & \\
\hline Cr outside SiC ( $\mu \mathrm{g} /$ compact): & 0.50 & 0.54 & 0.98 & 0.57 & 0.65 & 0.22 \\
\hline Manganese & & & & & & \\
\hline Pre-burn leach (DRF-26A) $(\mu \mathrm{g}):$ & 1.29 & 1.42 & 1.31 & 1.42 & & \\
\hline Post-burn leach (DRF-26B) $(\mu \mathrm{g})$ : & 0.45 & 0.31 & 0.33 & 0.37 & & \\
\hline Total leached $(\mu \mathrm{g})$ : & 1.75 & 1.73 & 1.64 & 1.78 & & \\
\hline Mn outside $S i C(\mu \mathrm{g} /$ compact): & 0.35 & 0.35 & 0.33 & 0.36 & 0.345 & 0.013 \\
\hline \multicolumn{7}{|l|}{ Cobalt } \\
\hline Pre-burn leach $(\mathrm{DRF}-26 \mathrm{~A})(\mu \mathrm{g}):$ & 0.03 & 0.06 & 0.04 & 0.04 & & \\
\hline Post-burn leach (DRF-26B) $(\mu g)$ : & 0.05 & 0.06 & 0.08 & 0.05 & & \\
\hline Total leached $(\mu \mathrm{g})$ : & 0.09 & 0.11 & 0.12 & 0.09 & & \\
\hline Co outside SiC ( $\mu \mathrm{g} /$ compact): & 0.017 & 0.023 & 0.025 & 0.018 & 0.021 & 0.004 \\
\hline \multicolumn{7}{|l|}{ Nickel } \\
\hline Pre-burn leach (DRF-26A) $(\mu \mathrm{g}):$ & 2.92 & 5.73 & 4.05 & 8.51 & & \\
\hline Post-burn leach (DRF-26B) $(\mu \mathrm{g}):$ & 2.85 & 2.57 & 3.38 & 2.75 & & \\
\hline Total leached $(\mu g)$ : & 5.77 & 8.30 & 7.43 & 11.25 & & \\
\hline Ni outside SiC ( $\mu \mathrm{g} /$ compact): & 1.15 & 1.66 & 1.49 & 2.25 & 1.64 & 0.46 \\
\hline \multicolumn{7}{|l|}{ Transition Metals } \\
\hline 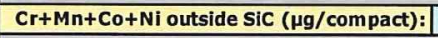 & 2.03 & 2.57 & 2.82 & 3.20 & 2.65 & 0.49 \\
\hline \multicolumn{7}{|l|}{ Calcium } \\
\hline Pre-burn leach (DRF-26A) $(\mu \mathrm{g}):$ & 532.64 & 567.86 & 491.77 & 489.92 & & \\
\hline Post-burn leach (DRF-26B) $(\mu \mathrm{g})$ : & 48.50 & 58.77 & 45.46 & 50.55 & & \\
\hline Total leached $(\mu \mathrm{g}):$ & 581.15 & 626.63 & 537.23 & 540.47 & & \\
\hline Ca outside $\operatorname{SiC}(\mu \mathrm{g} /$ compact $)$ : & 116.23 & 125.33 & 107.45 & 108.09 & 114.27 & 8.38 \\
\hline \multicolumn{7}{|l|}{ Aluminum } \\
\hline Pre-burn leach (DRF-26A) $(\mu \mathrm{g})$ : & 604.67 & 606.05 & 573.87 & 595.01 & & \\
\hline Post-burn leach (DRF-26B) $(\mu \mathrm{g}):$ & 87.93 & 63.66 & 66.78 & 81.06 & & \\
\hline Total leached $(\mu \mathrm{g})$ : & 692.59 & 669.71 & 640.65 & 676.07 & & \\
\hline Al outside SiC $(\mu \mathrm{g} /$ compact): & 138.52 & 133.94 & 128.13 & 135.21 & 133.95 & 4.33 \\
\hline \multicolumn{7}{|l|}{ Titanium } \\
\hline Pre-burn leach (DRF-26A) $(\mu \mathrm{g})$ : & 21.57 & 19.58 & 24.84 & 28.18 & & \\
\hline Post-burn leach (DRF-26B) $(\mu \mathrm{g}):$ & 29.17 & 26.65 & 22.17 & 21.10 & & \\
\hline Total leached $(\mu \mathrm{g}):$ & 50.74 & 46.23 & 47.01 & 49.28 & & \\
\hline Ti outside SiC ( $\mu \mathrm{g} /$ compact): & 10.15 & 9.25 & 9.40 & 9.86 & 9.66 & 0.41 \\
\hline \multicolumn{7}{|l|}{ Vanadium } \\
\hline Pre-burn leach (DRF-26A) $(\mu \mathrm{g}):$ & 15.10 & 16.29 & 15.81 & 16.51 & & \\
\hline Post-burn leach (DRF-26B) $(\mu g)$ : & 13.02 & 11.04 & 11.55 & 11.38 & & \\
\hline Total leached $(\mu \mathrm{g})$ : & 28.13 & 27.33 & 27.36 & 27.90 & & \\
\hline V outside $S i C(\mu \mathrm{g} /$ compact): & 5.63 & 5.47 & 5.47 & 5.58 & 5.54 & 0.08 \\
\hline \multicolumn{7}{|l|}{ Titanium and Vanadium } \\
\hline$T i+V$ outside $\operatorname{SiC}(\mu \mathrm{g} /$ compact): & 15.77 & 14.71 & 14.87 & 15.43 & 15.20 & 0.49 \\
\hline
\end{tabular}

comments

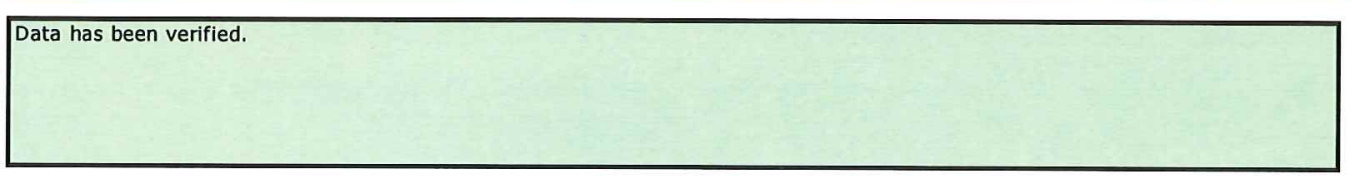

\footnotetext{
Fued c. Montgomeny
}

$\frac{2-8-2018}{\text { Date }}$ 
Procedure: AGR-CHAR-DAM-26 Rev. 3

Operator: Montgomery/Dyer

Compact lot ID: BWXT J52R-16-14154C

Compact lot description: AGR-5/6/7 compacts, $40 \%$ packing fraction

\begin{tabular}{|r|c|c|c|c|c|}
\hline Compact ID numbers: & $\begin{array}{c}1009,1015, \\
1059,1065, \\
1069\end{array}$ & $\begin{array}{c}1013,1026, \\
1029,1066, \\
1071\end{array}$ & $\begin{array}{c}1054,1062, \\
1089,1096, \\
1097\end{array}$ & $\begin{array}{c}1023,1040, \\
1048,1084, \\
1088\end{array}$ & Total \\
\hline \hline Number of compacts: & 5 & 5 & 5 & 5 & 20 \\
\hline Equivalent number of leached kernels: & $2.1 \mathrm{E}+00$ & $3.1 \mathrm{E}+00$ & $2.0 \mathrm{E}+00$ & $2.7 \mathrm{E}+00$ & $1.0 \mathrm{E}+01$ \\
\hline
\end{tabular}

comments

Data has been verified.

Fred c. Montgomery

operator
2.8 .2018

Date 


\begin{tabular}{|r|l|}
\hline Procedure: & AGR-CHAR-DAM-26 Rev. 3 \\
\hline Operator: & Montgomery/Dyer \\
\hline Compact lot ID: & BWXT J52R-16-14154C \\
\hline Compact lot description: & AGR-5/6/7 compacts, 40\% packing fraction \\
\hline
\end{tabular}

\begin{tabular}{|r|c|c|c|c|c|}
\hline Compact ID numbers: & $\begin{array}{c}1021,1042, \\
1056,1093, \\
1105\end{array}$ & $\begin{array}{c}1004,1016, \\
1018,1085, \\
1101\end{array}$ & $\begin{array}{c}1006,1057, \\
1068,1078, \\
1107\end{array}$ & $\begin{array}{c}1002,1036, \\
1038,1083, \\
1098\end{array}$ & Total \\
\hline \hline Number of compacts: & 5 & 5 & 5 & 5 & 20 \\
\hline Equivalent number of leached kernels: & $3.3 \mathrm{E}-02$ & $4.6 \mathrm{E}-02$ & $1.1 \mathrm{E}+00$ & $3.2 \mathrm{E}-02$ & $1.2 \mathrm{E}+00$ \\
\hline
\end{tabular}

\section{Comments}

Data has been verified.

Fud c. numtgomery

Operator
$2-8-2018$

Date 


\begin{tabular}{|r|l|}
\hline Procedure: & AGR-CHAR-DAM-26 Rev. 3 \\
\hline Operator: & Montgomery \\
\hline Compact lot ID: & BWXT J52R-16-14154C \\
\hline Compact lot description: & AGR-5/6/7 compacts, 40\% packing fraction \\
\hline
\end{tabular}

\begin{tabular}{|r|c|c|c|c|c|}
\hline Compact ID numbers: & $\begin{array}{c}1052,1086, \\
104,1034, \\
1007\end{array}$ & $\begin{array}{c}1072,1064, \\
1027,1103, \\
1061\end{array}$ & $\begin{array}{c}1094,1050, \\
1106,1079, \\
1041\end{array}$ & $\begin{array}{c}1031,1080, \\
1076,1092, \\
1051\end{array}$ & Total \\
\hline \hline Number of compacts: & 5 & 5 & 5 & 5 & 20 \\
\hline Equivalent number of leached kernels: & $1.0 \mathrm{E}+00$ & $1.0 \mathrm{E}+00$ & $1.1 \mathrm{E}+00$ & $3.6 \mathrm{E}-02$ & $3.2 \mathrm{E}+00$ \\
\hline
\end{tabular}

Comments

7red c. Mntaomey Operator
$4-18-2019$

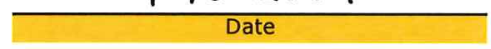




\begin{tabular}{|r|l|}
\hline Procedure: & AGR-CHAR-DAM-26 Rev. 3 \\
\hline Operator: & Montgomery \\
\hline Compact lot ID: & BWXT J52R-16-14155C \\
\hline Compact lot description: & AGR-5/6/7 compacts, $40 \%$ packing fraction \\
\hline
\end{tabular}

\begin{tabular}{|r|c|c|c|c|c|}
\hline Compact ID numbers: & $\begin{array}{c}1167,1137, \\
1162,1129, \\
1136\end{array}$ & $\begin{array}{c}1124,1151, \\
1211,1166, \\
1170\end{array}$ & $\begin{array}{c}1194,1195, \\
1156,1169, \\
1205\end{array}$ & $\begin{array}{c}1126,1140, \\
1184,1203, \\
1191\end{array}$ & Total \\
\hline \hline Number of compacts: & 5 & 5 & 5 & 5 & 20 \\
\hline Equivalent number of leached kernels: & $4.5 \mathrm{E}+00$ & $2.3 \mathrm{E}-01$ & $4.6 \mathrm{E}-02$ & $2.1 \mathrm{E}+00$ & $6.8 \mathrm{E}+00$ \\
\hline
\end{tabular}

Comments

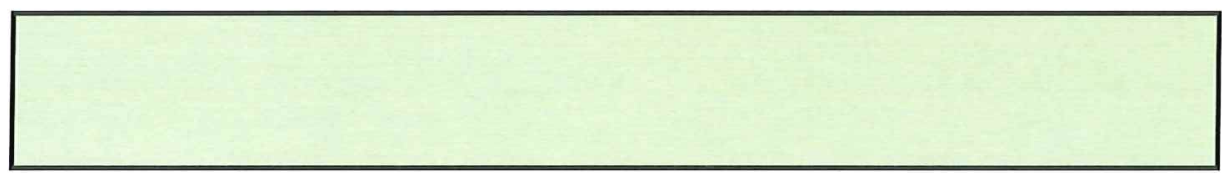

Fied C. Montgomery 
Procedure: AGR-CHAR-DAM-26 Rev. 3

Operator: Montgomery

Compact lot ID: BWXT J52R-16-14155C

Compact lot description: AGR-5/6/7 compacts, $40 \%$ packing fraction

\begin{tabular}{|r|c|c|c|c|c|}
\hline Compact ID numbers: & $\begin{array}{c}1213,1179, \\
128,1112, \\
1123\end{array}$ & $\begin{array}{c}1145,1186, \\
113,1214, \\
1119\end{array}$ & $\begin{array}{c}1148,1159, \\
1127,1190, \\
1189\end{array}$ & $\begin{array}{c}1202,1121, \\
1208,1207, \\
1183\end{array}$ & Total \\
\hline \hline Number of compacts: & 5 & 5 & 5 & 5 & 20 \\
\hline Equivalent number of leached kernels: & $2.0 \mathrm{E}+00$ & $4.3 \mathrm{E}-02$ & $2.1 \mathrm{E}+00$ & $1.1 \mathrm{E}+00$ & $5.2 \mathrm{E}+00$ \\
\hline
\end{tabular}

Comments

Fied C. Mintgomeery
$4-18-2019$ 
Inspection Report Form IRF-D: Summary of Post-Burn Leach Uranium

\begin{tabular}{|r|l|}
\hline Procedure: & AGR-CHAR-DAM-26 Rev. 3 \\
\hline Operator: & Montgomery/Dyer \\
\hline Compact lot ID: & BWXT J52R-16-14154C \\
\hline Compact lot description: & AGR-5/6/7 compacts, $40 \%$ packing fraction \\
\hline
\end{tabular}

\begin{tabular}{|r|c|c|c|c|c|}
\hline Compact ID numbers: & $\begin{array}{c}1009,1015, \\
1059,1065, \\
1069\end{array}$ & $\begin{array}{c}1013,1026, \\
1029,1066, \\
1071\end{array}$ & $\begin{array}{c}1054,1062, \\
1089,1096, \\
1097\end{array}$ & $\begin{array}{c}1023,1040, \\
1048,1084, \\
1088\end{array}$ & Total \\
\hline \hline Number of compacts: & 5 & 5 & 5 & 5 & 20 \\
\hline Equivalent number of leached kernels: & $1.0 \mathrm{E}+00$ & $8.6 \mathrm{E}-02$ & $8.4 \mathrm{E}-01$ & $1.0 \mathrm{E}+00$ & $3.0 \mathrm{E}+00$ \\
\hline
\end{tabular}

\section{Comments}

Data has been verified.

Tued C. Montgonery Operator
$2-8-2018$

Date 


\begin{tabular}{|r|l|}
\hline Procedure: & AGR-CHAR-DAM-26 Rev. 3 \\
\hline Operator: & Montgomery/Dyer \\
\hline Compact lot ID: & BWXT J52R-16-14154C \\
\hline Compact lot description: & AGR-5/6/7 compacts, $40 \%$ packing fraction \\
\hline
\end{tabular}

\begin{tabular}{|r|c|c|c|c|c|}
\hline Compact ID numbers: & $\begin{array}{c}1021,1042, \\
1056,1093, \\
1105\end{array}$ & $\begin{array}{c}1004,1016, \\
1018,1085, \\
1101\end{array}$ & $\begin{array}{c}1006,1057, \\
1068,1078, \\
1107\end{array}$ & $\begin{array}{c}1002,1036, \\
1038,1083, \\
1098\end{array}$ & Total \\
\hline \hline Number of compacts: & 5 & 5 & 5 & 5 & 20 \\
\hline Equivalent number of leached kernels: & $3.8 \mathrm{E}-02$ & $3.2 \mathrm{E}-02$ & $1.1 \mathrm{E}+00$ & $3.5 \mathrm{E}-02$ & $1.2 \mathrm{E}+00$ \\
\hline
\end{tabular}

\section{Comments}

Data has been verified.

Fred C. Mmtgomery

Operator
$2.8-2018$

Date 
Procedure: AGR-CHAR-DAM-26 Rev. 3

perator: Montgomery

Compact lot ID: BWXT J52R-16-14154C

Compact lot description: AGR-5/6/7 compacts, $40 \%$ packing fraction

\begin{tabular}{|r|c|c|c|c|c|}
\hline Compact ID numbers: & $\begin{array}{c}1052,1086, \\
1104,1034, \\
1007\end{array}$ & $\begin{array}{c}1072,1064, \\
1027,1103, \\
1061\end{array}$ & $\begin{array}{c}1094,1050, \\
1106,1079, \\
1041\end{array}$ & $\begin{array}{c}1031,1080, \\
1076,1092, \\
1051\end{array}$ & Total \\
\hline \hline Number of compacts: & 5 & 5 & 5 & 5 & 20 \\
\hline Equivalent number of leached kernels: & $6.0 \mathrm{E}-02$ & $2.1 \mathrm{E}+00$ & $1.1 \mathrm{E}-01$ & $2.1 \mathrm{E}+00$ & $4.4 \mathrm{E}+00$ \\
\hline
\end{tabular}

Comments

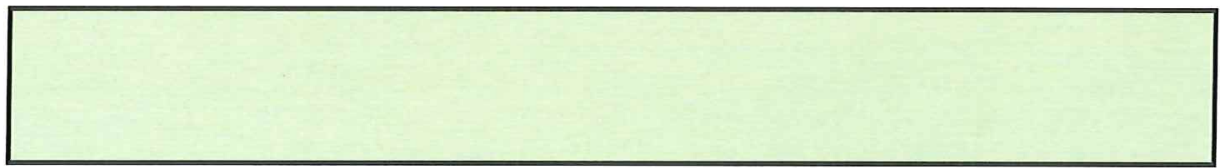

Fied C. Montgomery Operator 


\begin{tabular}{|r|l|}
\hline Procedure: & AGR-CHAR-DAM-26 Rev. 3 \\
\hline Operator: & Montgomery \\
\hline Compact lot ID: & BWXT J52R-16-14155C \\
\hline Compact lot description: & AGR-5/6/7 compacts, 40\% packing fraction \\
\hline
\end{tabular}

\begin{tabular}{|r|c|c|c|c|c|}
\hline Compact ID numbers: & $\begin{array}{c}1167,1137, \\
1162,1129, \\
1136\end{array}$ & $\begin{array}{c}1124,1151,116 r^{\prime} \\
1170,1195,\end{array}$ & $\begin{array}{c}1156,1169, \\
1205\end{array}$ & $\begin{array}{c}1126,1140,1203, \\
1191\end{array}$ & Total \\
\hline \hline Number of compacts: & 5 & 5 & 5 & 5 & 20 \\
\hline Equivalent number of leached kernels: & $1.1 \mathrm{E}+00$ & $1.1 \mathrm{E}+00$ & $2.9 \mathrm{E}+00$ & $3.9 \mathrm{E}-02$ & $5.2 \mathrm{E}+00$ \\
\hline
\end{tabular}

Comments

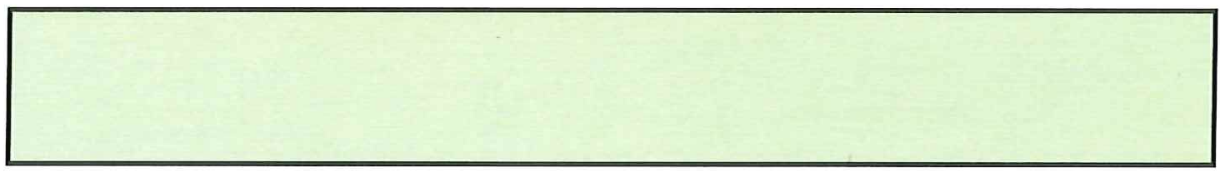

Fred c. montgomery

$4-18-2019$ 
Procedure: AGR-CHAR-DAM-26 Rev. 3

Operator: Montgomery

Compact lot ID: BWXT J52R-16-14155C

Compact lot description: $A G R-5 / 6 / 7$ compacts, $40 \%$ packing fraction

\begin{tabular}{|r|c|c|c|c|c|}
\hline Compact ID numbers: & $\begin{array}{c}1213,1179, \\
1128,1112, \\
1123\end{array}$ & $\begin{array}{c}1145,1186, \\
113,1214, \\
1119\end{array}$ & $\begin{array}{c}1148,1159, \\
1127,1190, \\
1189\end{array}$ & $\begin{array}{c}1202,1121, \\
1208,1207, \\
1183\end{array}$ & Total \\
\hline \hline Number of compacts: & 5 & 5 & 5 & 5 & 20 \\
\hline Equivalent number of leached kernels: & $1.1 \mathrm{E}+00$ & $3.3 \mathrm{E}-02$ & $1.0 \mathrm{E}+00$ & $1.0 \mathrm{E}+00$ & $3.2 \mathrm{E}+00$ \\
\hline
\end{tabular}

Comments

7red c. Montgomery

Operator
$4-18-2019$

Date 
Data Report Form DRF-26A: Pre-Bum Leach Uranlum and Impurities

\begin{tabular}{|r|l|}
\hline Procedure: & AGR-CHAR-DAM-26 Rev. 3 \\
\hline Operator: & Montgomery/Dyer \\
\hline Compact lot ID: & BWXT J52R-16-14154C \\
\hline Compact lot description: & AGR-5/6/7 compacts, 40\% packing fraction \\
\hline Compact ID numbers: & $1009,1015,1059,1065,1069$ \\
\hline DRF filename: & 1ImC-agr/AGRILeachBurnLeach/14154C-Group 1_DRF26R3.xls \\
\hline
\end{tabular}

\begin{tabular}{|r|r|}
\hline Number of compacts: & 5 \\
\hline Average weight uranium per particle, mean value $(g):$ & $3.94 \mathrm{E}-04$ \\
\hline Average weight uranium per particle, uncertainty in mean $(g):$ & $3.94 \mathrm{E}-06$ \\
\hline
\end{tabular}

\begin{tabular}{|c|c|c|c|c|}
\hline & First Leach & Second Leach & Total \\
\hline \multirow{2}{*}{\multicolumn{2}{|c|}{$\begin{array}{cc} & \text { Pre-bum leach solution ID: } \\
\text { Total volume of leach solution }(\mathrm{ml}):\end{array}$}} & L17110801 & L17110901 & \\
\hline & & 156.0 & 91.0 & \\
\hline & Radiochemical laboratory analysis number: & $17812-001$ & $17812-006$ & \\
\hline & Measured uranium concentration $(\mu \mathrm{g} / \mathrm{ml})$ : & $4.93 E+00$ & $5.99 \mathrm{E}-01$ & \\
\hline & Uncertainty in uranium concentration $(\mu \mathrm{g} / \mathrm{ml})$ : & $4.93 \mathrm{E}-01$ & $5.99 \mathrm{E}-02$ & \\
\hline & Weight uranium leached $(\mathrm{g})$ : & $7.69 \mathrm{E}-04$ & $5.45 \mathrm{E}-05$ & $8.36 \mathrm{E}-04$ \\
\hline & Uncertainty in weight uranium leached (g): & $7.70 \mathrm{E}-05$ & $5.46 \mathrm{E}-06$ & $7.72 \mathrm{E}-05$ \\
\hline & Equivalent number of leached kemels: & $1.95 \mathrm{E}+00$ & $1.38 \mathrm{E}-01$ & $2.12 \mathrm{E}+00$ \\
\hline & Uncertainty in equivalent number of leached kernels: & $1.96 \mathrm{E}-01$ & $1.39 \mathrm{E}-02$ & $1.97 \mathrm{E}-01$ \\
\hline \multirow{5}{*}{$\mathbf{F e}$} & Measured concentration of impurity in sample $(\mu \mathrm{g} / \mathrm{ml})$ : & & & $\mathbf{F e}$ \\
\hline & Uncorrected weight of impurity in sample $(\mu \mathrm{g})$ : & & & \\
\hline & Weight of impurity in blank $(\mu g)$ : & & & \\
\hline & Minimum corrected weight of impurity in sample $(\mu \mathrm{g})$ : & & & \\
\hline & Maximum corrected weight of impurity in sample $(\mu g)$ : & & & \\
\hline \multirow{5}{*}{$\mathbf{C r}$} & Measured concentration of impurity in sample $(\mu \mathrm{g} / \mathrm{ml})$ : & & & $\mathbf{C r}_{\mathbf{r}}$ \\
\hline & Uncorrected weight of impurity in sample $(\mu \mathrm{g})$ : & & & \\
\hline & Weight of impurity in blank $(\mu g)$ : & & & \\
\hline & Minimum corrected weight of impurity in sample $(\mu g)$ : & & & \\
\hline & Maximum corrected weight of impurity in sample $(\mu \mathrm{g})$ : & & & \\
\hline \multirow{5}{*}{ Mn } & Measured concentration of impurity in sample $(\mu \mathrm{g} / \mathrm{ml})$ : & & & $\mathrm{Mn}$ \\
\hline & Uncorrected weight of impurity in sample $(\mu \mathrm{g})$ : & & & \\
\hline & Weight of impurity in blank $(\mu \mathrm{g})$ : & & & \\
\hline & Minimum corrected weight of impurity in sample ( $\mu \mathrm{g})$ : & & & \\
\hline & Maximum corrected weight of impurity in sample $(\mu g)$ : & & & \\
\hline \multirow{5}{*}{ Co } & Measured concentration of impurity in sample $(\mu \mathrm{g} / \mathrm{ml})$ : & & & Co \\
\hline & Uncorrected weight of impurity in sample $(\mu \mathrm{g})$ : & & & \\
\hline & Weight of impurity in blank $(\mu g)$ : & & & \\
\hline & Minimum corrected weight of impurity in sample $(\mu \mathrm{g})$ : & & & \\
\hline & Maximum corrected weight of impurity in sample $(\mu g)$ : & & & \\
\hline \multirow{5}{*}{$\mathbf{N i}$} & Measured concentration of impurity in sample $(\mu \mathrm{g} / \mathrm{ml})$ : & & & $\mathrm{Ni}$ \\
\hline & Uncorrected weight of impurity in sample $(\mu \mathrm{g})$ : & & & \\
\hline & Weight of impurity in blank $(\mu g)$ : & & & \\
\hline & Minimum corrected weight of impurity in sample $(\mu g)$ : & & & \\
\hline & Maximum corrected weight of impurity in sample $(\mu \mathrm{g})$ : & & & \\
\hline \multirow{5}{*}{$\mathbf{C a}$} & Measured concentration of impurity in sample $(\mu \mathrm{g} / \mathrm{ml})$ : & & & $\mathbf{C a}$ \\
\hline & Uncorrected weight of impurity in sample $(\mu g)$ : & & & \\
\hline & Weight of impurity in blank $(\mu \mathrm{g})$ : & & & \\
\hline & Minimum corrected weight of impurity in sample $(\mu g)$ : & & & \\
\hline & Maximum corrected weight of impurity in sample $(\mu \mathrm{g})$ : & & & \\
\hline \multirow{5}{*}{ Al } & Measured concentration of impurity in sample $(\mu \mathrm{g} / \mathrm{ml})$ : & & & Al \\
\hline & Uncorrected weight of impurity in sample $(\mu \mathrm{g})$ : & & & \\
\hline & Weight of impurity in blank $(\mu g)$ : & & & \\
\hline & Minimum corrected weight of impurity in sample $(\mu g)$ : & & & \\
\hline & Maximum corrected weight of impurity in sample $(\mu g)$ : & & & \\
\hline \multirow{5}{*}{$\mathbf{T i}$} & Measured concentration of impurity in sample $(\mu \mathrm{g} / \mathrm{ml})$ : & & & $\mathbf{T i}$ \\
\hline & Uncorrected weight of impurity in sample $(\mu \mathrm{g})$ : & & & \\
\hline & Weight of impurity in blank $(\mu g)$ : & & & \\
\hline & Minimum corrected weight of impurity in sample $(\mu \mathrm{g})$ : & & & \\
\hline & Maximum corrected weight of impurity in sample $(\mu g)$ : & & & \\
\hline \multirow{5}{*}{$\mathbf{v}$} & Measured concentration of impurity in sample $(\mu \mathrm{g} / \mathrm{ml})$ : & & & $\mathbf{v}$ \\
\hline & Uncorrected weight of impurity in sample $(\mu \mathrm{g})$ : & & & \\
\hline & Weight of impurity in blank $(\mu \mathrm{g})$ : & & & \\
\hline & Minimum corrected weight of impurity in sample $(\mu \mathrm{g})$ : & & & \\
\hline & Maximum corrected weight of impurity in sample $(\mu g)$ : & & & \\
\hline
\end{tabular}

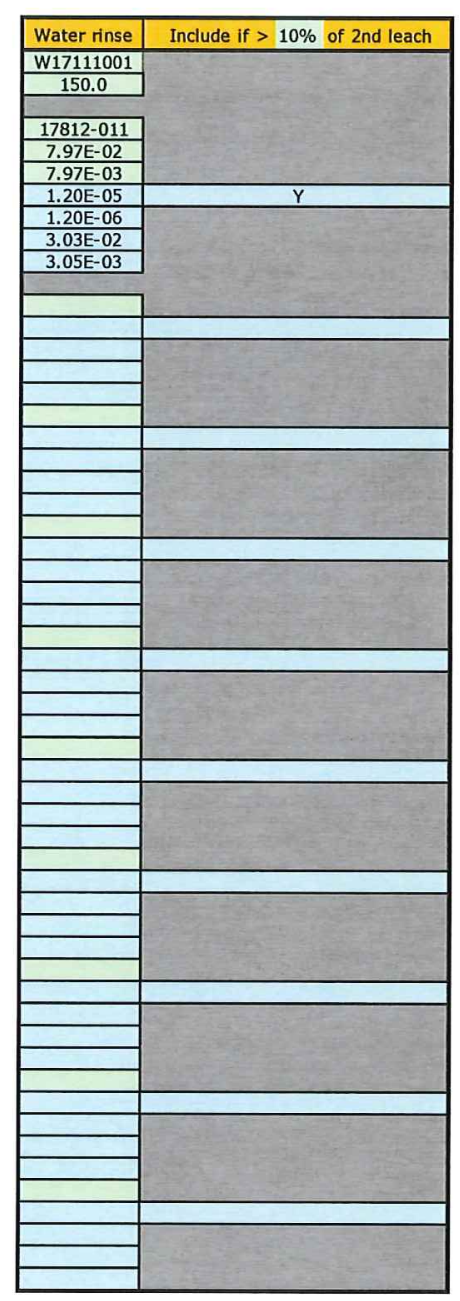

FCM checked the recorded data against the official Results of Analysis for RMAL17812 on 1/31/2018.

\section{Feed C. Montgomery $\quad 2-6-2018$}


Data Report Form DRF-26A: Pre-Bum Leach Uranium and Impurities

\begin{tabular}{|r|l|}
\hline Procedure: & AGR-CHAR-DAM-26 Rev. 3 \\
\hline Operator: & Montgomery/Dyer \\
\hline Compact lot ID: & BWXT J52R-16-14154C \\
\hline Compact lot description: & AGR-5/6/7 compacts, 40\% packing fraction \\
\hline Compact ID numbers: & $1013,1026,1029,1066,1071$ \\
\hline DRF filename: & |Imc-agr/AGRILeachBurnLeach\14154C-Group 1 DRF26R3.x/s \\
\hline
\end{tabular}

\begin{tabular}{|r|c|}
\hline Number of compacts: & 5 \\
\hline Average weight uranium per particle, mean value $(\mathrm{g}):$ & $3.94 \mathrm{E}-04$ \\
\hline Average weight uranium per particle, uncertainty in mean $(\mathrm{g}):$ & $3.94 \mathrm{E}-06$ \\
\hline
\end{tabular}

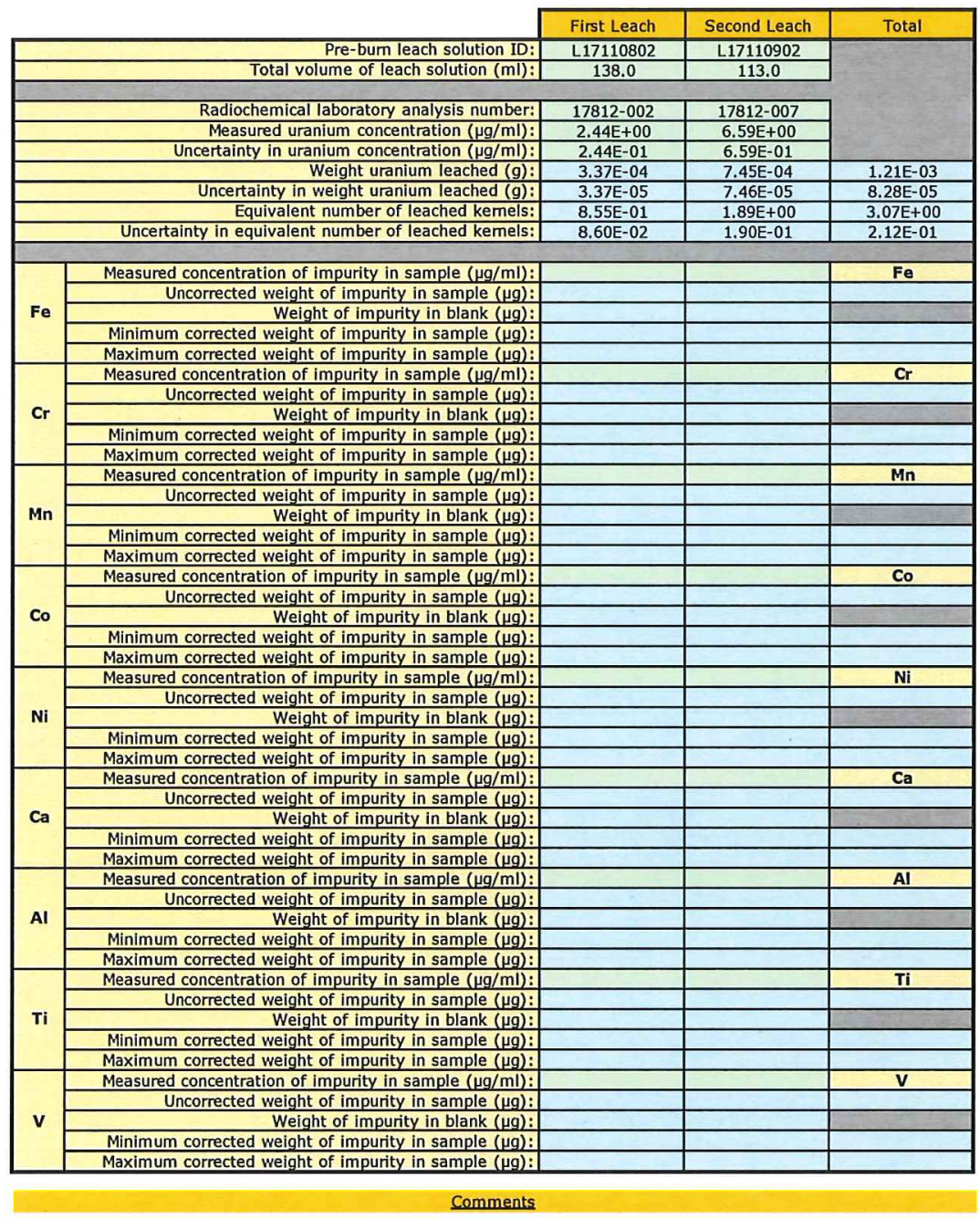

FCM checked the recorded data against the official Results of Analysis for RMAL17812 on 1/31/2018.

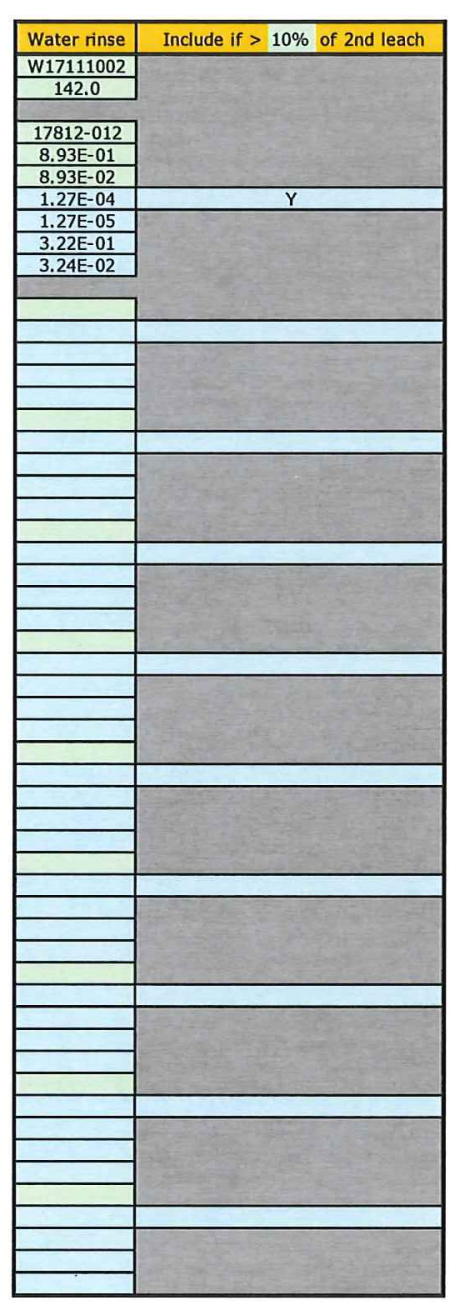

\section{Fied c. Montgomeres $\quad 2-6-2018$}


Data Report Form DRF-26A:-Pre-Bum Leach Uranium and Impurities

\begin{tabular}{|r|l|}
\hline Procedure: & AGR-CHAR-DAM-26 Rev. 3 \\
\hline Operator: & Montgomery/Dyer \\
\hline Compact lot ID: & BWXT J52R-16-14154C \\
\hline Compact lot description: & AGR-5/6/7 compacts, 40\% packing fraction \\
\hline Compact ID numbers: & $1054,1062,1089,1096,1097$ \\
\hline DRF filename: & ImC-agr|AGRILeachBurnLeach\14154C-Group 1 DRF26R3,xls \\
\hline
\end{tabular}

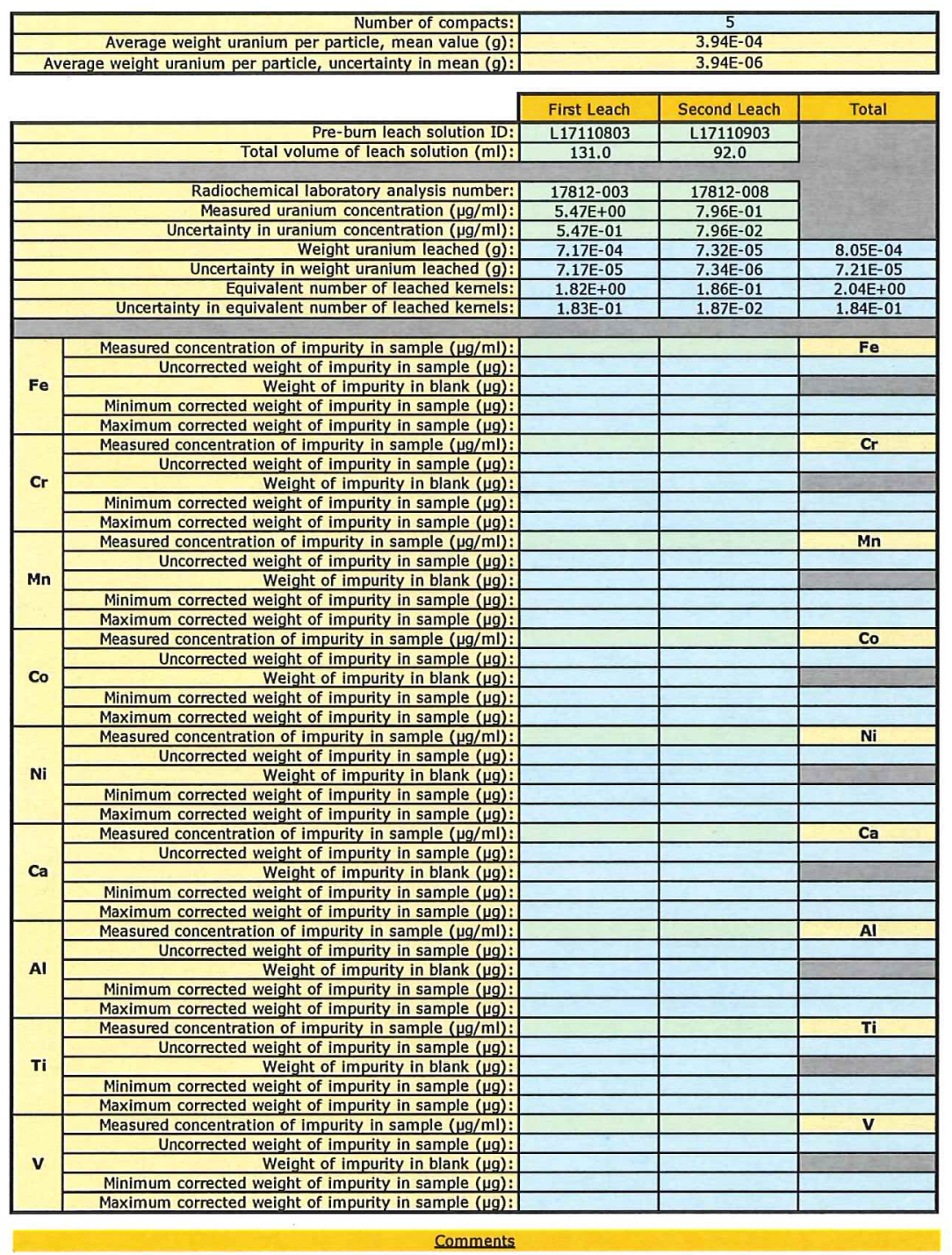

FCM checked the recorded data against the official Results of Analysis for RMAL17812 on 1/31/2018.

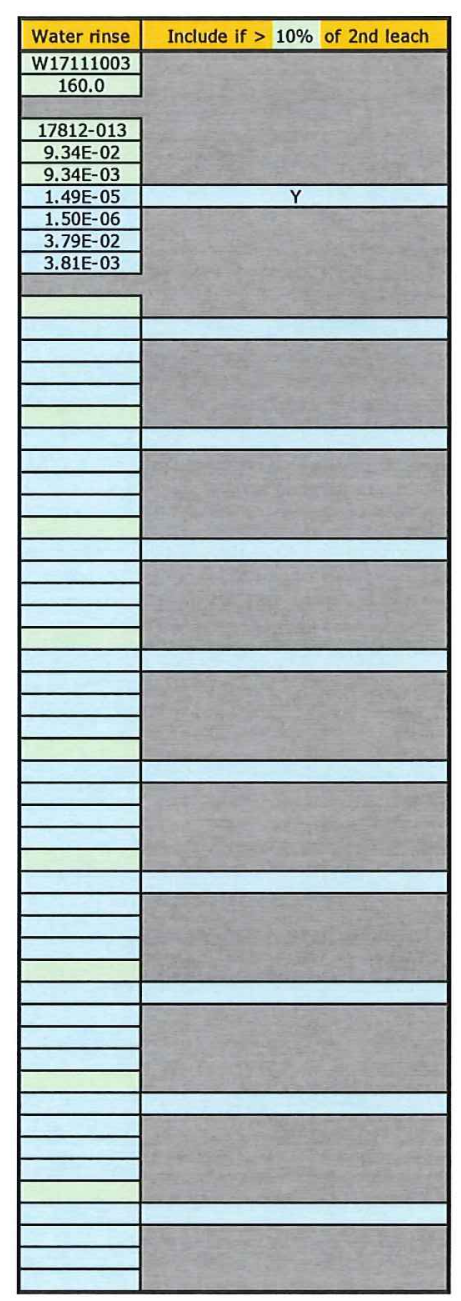


Data Report Form DRF-26A: Pre-Bum Leach Uranium and Impurities

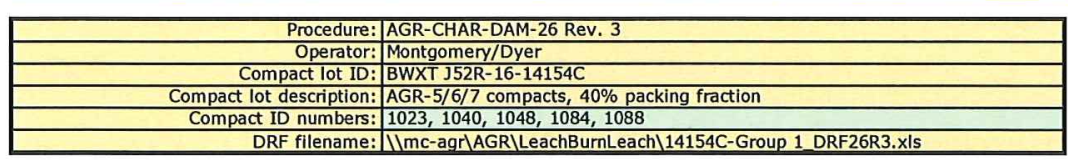

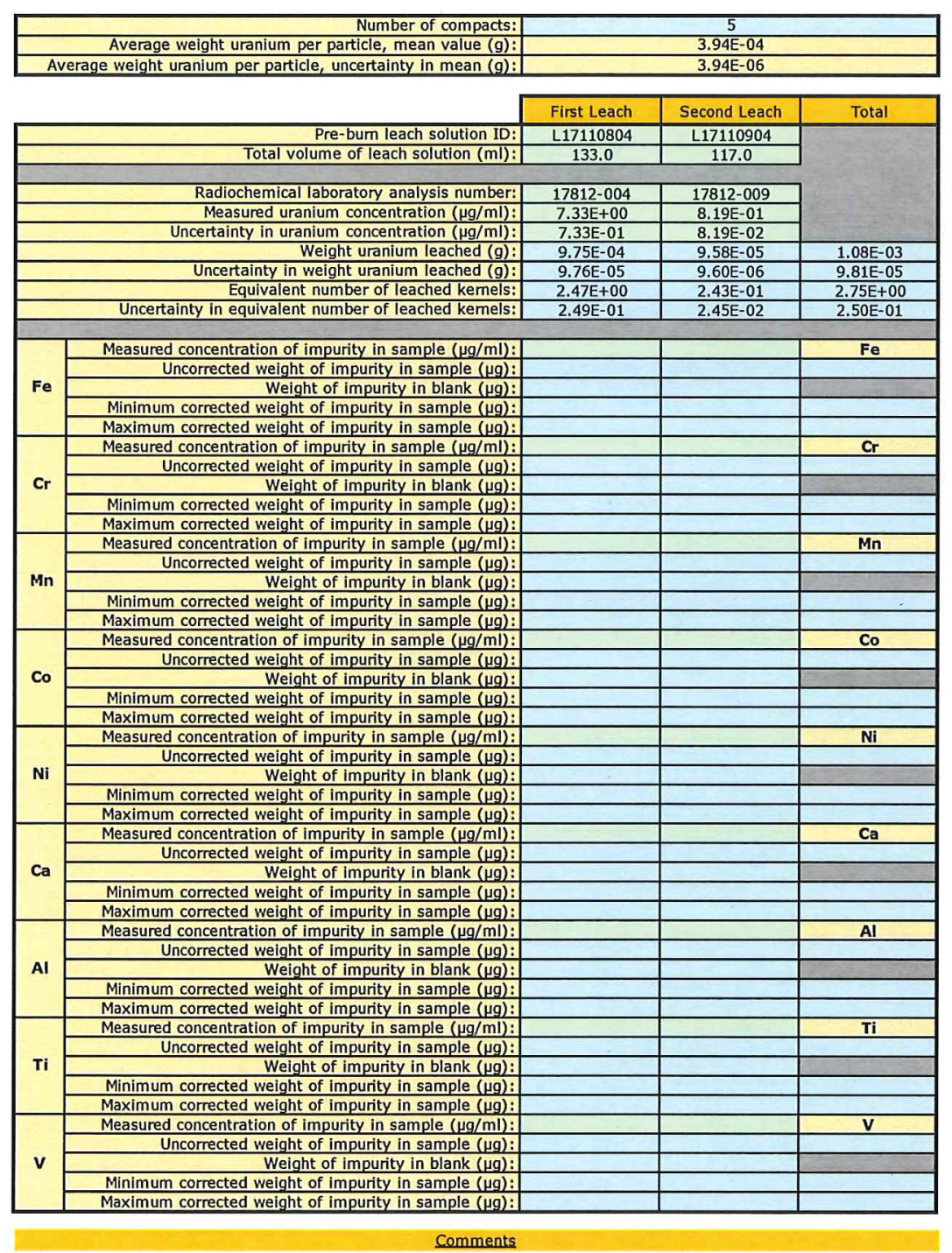

FCM checked the recorded data against the official Results of Analysis for RMAL17812 on 1/31/2018.

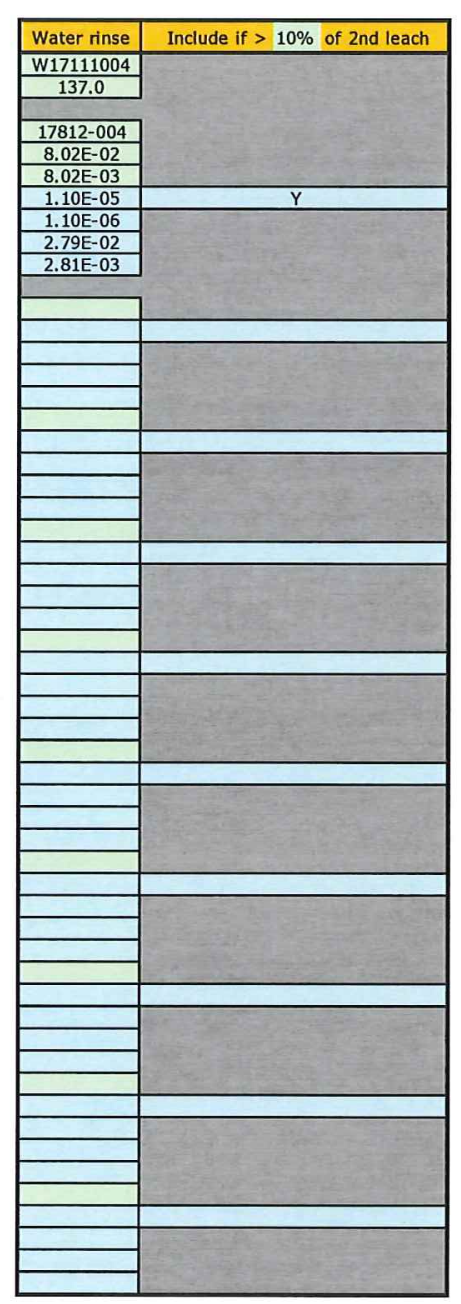


Data Report Form DRF-26A: Pre-Bum Leach Uranium and Impurities

\begin{tabular}{|r|l|}
\hline Procedure: & AGR-CHAR-DAM-26 Rev. 3 \\
\hline Operator: & Montgomery/Dyer \\
\hline Compact lot ID: & BWXT J52R-16-14154C \\
\hline Compact lot description: & AGR-5/6/7 compacts, 40\% packing fraction \\
\hline Compact ID numbers: & Pre-burn leach blank \\
\hline DRF filename: & Memc-agr/AGRILeachBurnLeachl14154C-Group 1_DRF26R3.xls \\
\hline
\end{tabular}

\begin{tabular}{|r|r|}
\hline Average weight uranium per particle, mean value $(g):$ & $3.94 \mathrm{E}-04$ \\
\hline Average weight uranium per particle, uncertainty in mean $(\mathrm{g}):$ & $3.94 \mathrm{E}-06$ \\
\hline
\end{tabular}

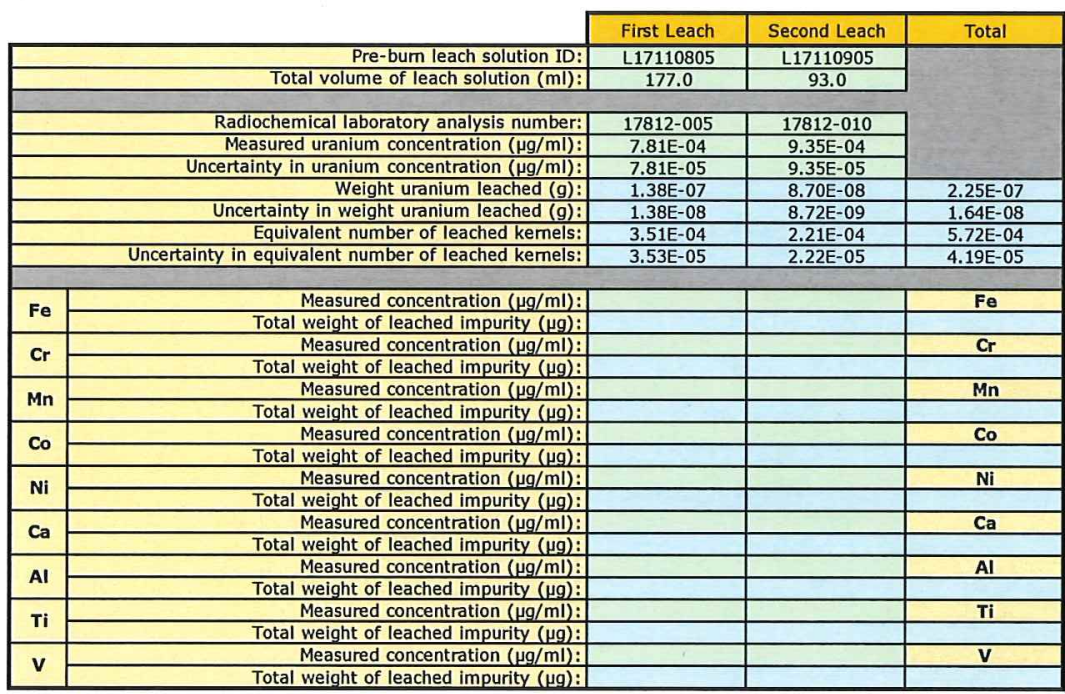

comments

FCM checked the recorded data against the official Results of Analysis for RMAL17812 on 1/31/2018.

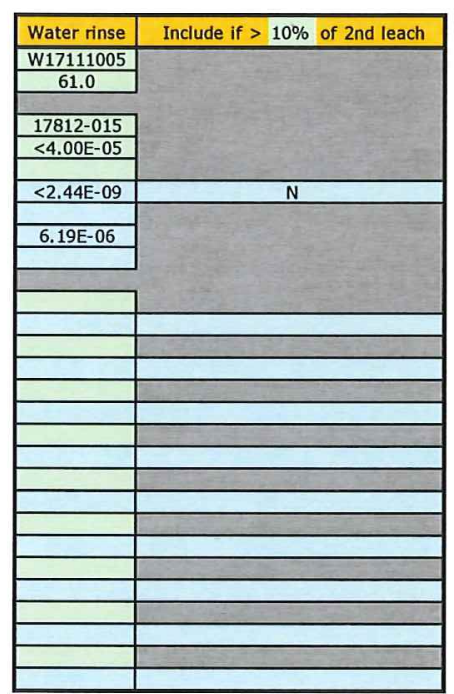

\section{Fred C. Montgomery 2-6-2018}


Data Report Form DRF-26B: Post-Bum Leach Uranium and Impurities

\begin{tabular}{|r|l|}
\hline Procedure: & AGR-CHAR-DAM-26 Rev. 3 \\
\hline Operator: & Montgomery/Dyer \\
\hline Compact lot ID: & BWXT J52R-16-14154C \\
\hline Compact lot description: & AGR-5/6/7 compacts, 40\% packing fraction \\
\hline Compact ID numbers: & $1009,1015,1059,1065,1069$ \\
\hline DRF filename: & IImC-agr/AGR/LeachBurnLeach/14154C-Group 1 DRF26R3,xls \\
\hline
\end{tabular}

\begin{tabular}{|c|c|c|c|c|}
\hline \multirow{3}{*}{\multicolumn{2}{|c|}{$\begin{array}{cc} & \text { Number of compacts: } \\
\text { Average weight uranium per particle, mean value }(\mathrm{g}): & \text { : } \\
\text { Average weight uranium per particle, uncertainty in mean }(\mathrm{g}) & \text { : }\end{array}$}} & \multicolumn{3}{|c|}{$\overline{5}$} \\
\hline & & \multicolumn{3}{|c|}{$3.94 \mathrm{E}-04$} \\
\hline & & \multicolumn{3}{|c|}{$3.94 \mathrm{E}-06$} \\
\hline & & First Leach & Second Leach & Total \\
\hline & Post-bum leach solution ID: & B17112801 & B17113001 & \\
\hline & Total volume of leach solution $(\mathrm{ml}):$ & 48.0 & 50.0 & \\
\hline & Radiochemical laboratory analysis number: & $17858-001$ & $17858-006$ & \\
\hline & Measured uranium concentration $(\mu \mathrm{g} / \mathrm{ml})$ : & $8.45 \mathrm{E}+00$ & $\frac{17000-000}{6.58 \mathrm{E}-02}$ & \\
\hline & Uncertainty in uranium concentration $(\mu \mathrm{g} / \mathrm{ml})$ : & $8.45 \mathrm{E}-01$ & $6.25 \mathrm{E}-03$ & \\
\hline & Weight uranium leached $(\mathrm{g})$ : & $4.06 \mathrm{E}-04$ & $3.29 \mathrm{E}-06$ & $4.09 \mathrm{E}-04$ \\
\hline & Uncertainty in weight uranium leached $(\mathrm{g})$ : & $4.09 \mathrm{E}-05$ & $3.15 E-07$ & $4.09 \mathrm{E}-05$ \\
\hline & Equivalent number of leached kemels: & $1.03 E+00$ & $8.35 \mathrm{E}-03$ & $1.04 \mathrm{E}+00$ \\
\hline & Uncertainty in equivalent number of leached kemels: & $1.04 \mathrm{E}-01$ & $8.05 E-04$ & $1.04 \mathrm{E}-01$ \\
\hline \multirow{5}{*}{$\mathbf{F e}$} & Measured concentration of impurity in sample $(\mu \mathrm{g} / \mathrm{ml})$ : & & & Fe \\
\hline & Uncorrected weight of impurity in sample $(\mu \mathrm{g})$ : & & & \\
\hline & Weight of impurity in blank $(\mu g)$ : & & & \\
\hline & Minimum corrected weight of impurity in sample $(\mu g)$ : & & & \\
\hline & Maximum corrected weight of impurity in sample $(\mu g)$ : & & & \\
\hline \multirow{5}{*}{$\mathrm{Cr}$} & Measured concentration of impurity in sample $(\mu \mathrm{g} / \mathrm{ml})$ : & & & $\mathrm{Cr}_{\mathbf{r}}$ \\
\hline & Uncorrected weight of impurity in sample $(\mu \mathrm{g})$ : & & & \\
\hline & Weight of impurity in blank $(\mu g)$ : & & & \\
\hline & Minimum corrected weight of impurity in sample $(\mu g)$ : & & & \\
\hline & Maximum corrected weight of impurity in sample $(\mu g)$ : & & & \\
\hline \multirow{5}{*}{ Mn } & Measured concentration of impurity in sample $(\mu \mathrm{g} / \mathrm{ml})$ : & & & Mn \\
\hline & Uncorrected weight of impurity in sample $(\mu \mathrm{g})$ : & & & \\
\hline & Weight of impurity in blank $(\mu \mathrm{g})$ : & & & \\
\hline & Minimum corrected weight of impurity in sample $(\mu g)$ : & & & \\
\hline & Maximum corrected weight of impurity in sample $(\mu \mathrm{g})$ : & & & \\
\hline \multirow{5}{*}{ Co } & Measured concentration of impurity in sample $(\mu \mathrm{g} / \mathrm{ml})$ : & & & Co \\
\hline & Uncorrected weight of impurity in sample $(\mu \mathrm{g})$ : & & & \\
\hline & Weight of impurity in blank $(\mu g)$ : & & & \\
\hline & Minimum corrected weight of impurity in sample $(\mu g)$ : & & & \\
\hline & Maximum corrected weight of impurity in sample $(\mu \mathrm{g})$ : & & & \\
\hline \multirow{5}{*}{$\mathrm{Ni}$} & Measured concentration of impurity in sample $(\mu \mathrm{g} / \mathrm{ml})$ : & & & $\mathrm{Ni}$ \\
\hline & Uncorrected weight of impurity in sample $(\mu g)$ : & & & \\
\hline & Weight of impurity in blank $(\mu \mathrm{g})$ : & & & \\
\hline & Minimum corrected weight of impurity in sample $(\mu \mathrm{g})$; & & & \\
\hline & Maximum corrected weight of impurity in sample $(\mu \mathrm{g})$ : & & & \\
\hline \multirow{5}{*}{$\mathrm{Ca}$} & Measured concentration of impurity in sample $(\mu \mathrm{g} / \mathrm{ml})$ : & & & $\mathbf{C a}$ \\
\hline & Uncorrected weight of impurity in sample $(\mu g)$ : & & & \\
\hline & Weight of impurity in blank $(\mu g)$ : & & & \\
\hline & Minimum corrected weight of impurity in sample $(\mu g)$ : & & & \\
\hline & Maximum corrected weight of impurity in sample $(\mu g)$ : & & & \\
\hline \multirow{5}{*}{ Al } & Measured concentration of impurity in sample $(\mathrm{\mu g} / \mathrm{ml})$ : & & & Al \\
\hline & Uncorrected weight of impurity in sample $(\mu g)$ : & & & \\
\hline & Weight of impurity in blank $(\mu g)$ : & & & \\
\hline & Minimum corrected weight of impurity in sample $(\mu g)$ : & & & \\
\hline & Maximum corrected weight of impurity in sample $(\mu g)$ : & & & \\
\hline \multirow{5}{*}{$\mathrm{Ti}$} & Measured concentration of impurity in sample $(\mathrm{\mu g} / \mathrm{ml})$ : & & & $\mathbf{T i}$ \\
\hline & Uncorrected weight of impurity in sample $(\mu \mathrm{g})$ : & & & \\
\hline & Weight of impurity in blank $(\mu g)$ : & & & \\
\hline & Minimum corrected weight of impurity in sample $(\mu g)$ : & & & \\
\hline & Maximum corrected weight of impurity in sample $(\mu g)$ : & & & \\
\hline \multirow{5}{*}{ v } & Measured concentration of impurity in sample $(\mu \mathrm{g} / \mathrm{ml})$ : & & & $\mathbf{v}$ \\
\hline & Uncorrected weight of impurity in sample $(\mu \mathrm{g})$ : & & & \\
\hline & Weight of impurity in blank $(\mu g)$ : & & & \\
\hline & Minimum corrected weight of impurity in sample $(\mu g)$ : & & & \\
\hline & Maximum corrected weight of impurity in sample $(\mu g)$ : & & & \\
\hline
\end{tabular}

FCM checked the recorded data against the official Results of Analysis for RMAL17858 on 1/31/2018.

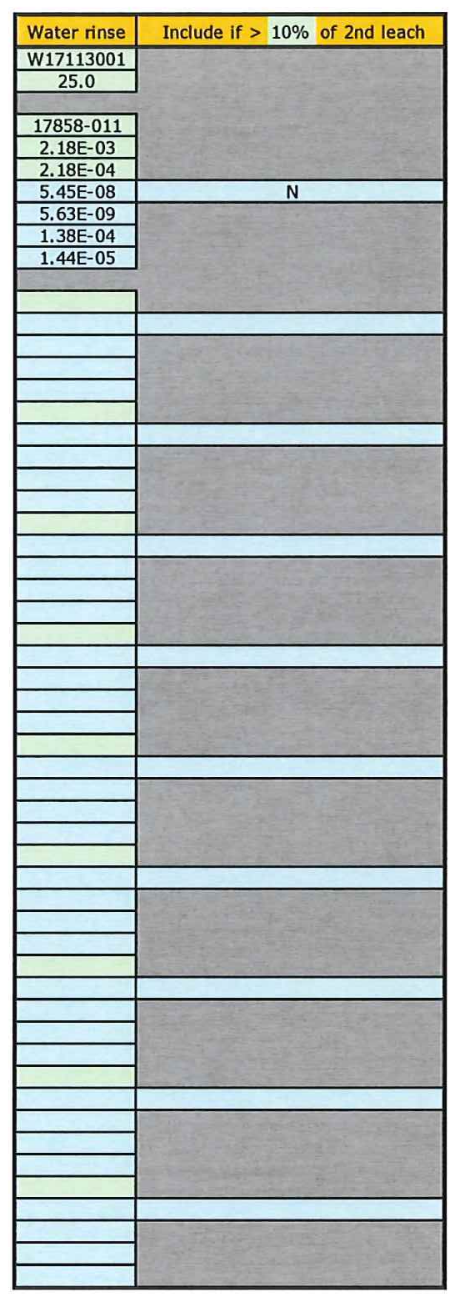

\section{Faed C. Montgomery $\quad 2-6-2018$}


Data Report Form DRF-26B: Post-Bum Leach Uranium and Impurities

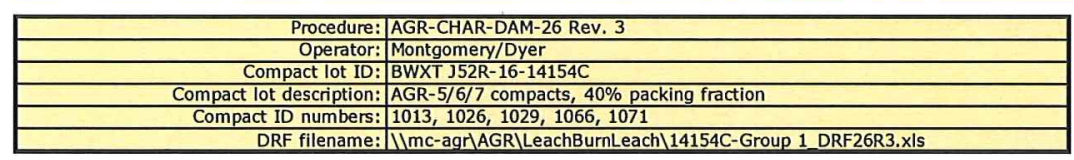

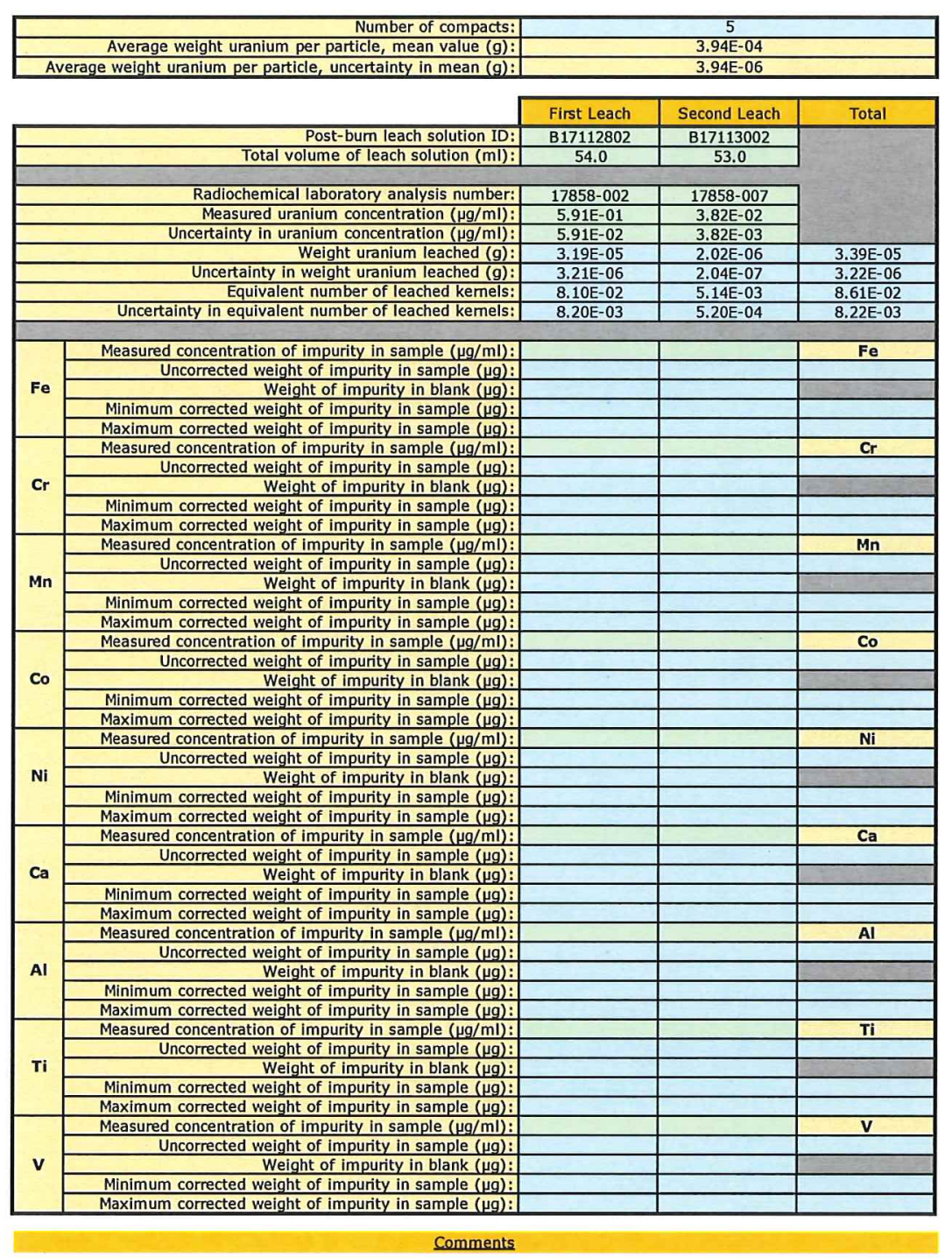

FCM checked the recorded data against the official Results of Analysis for RMAL17858 on 1/31/2018.

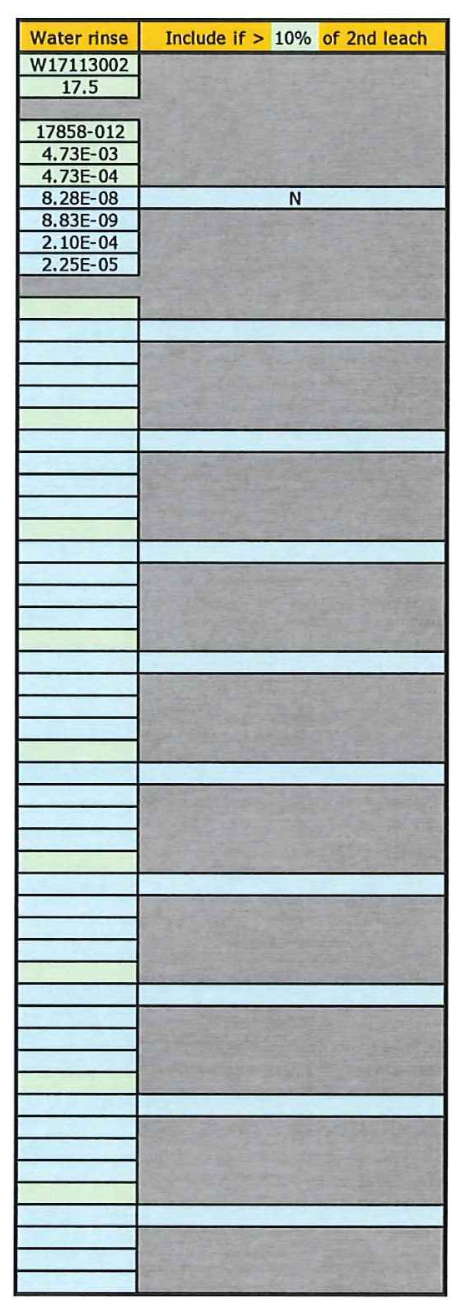

\section{Fied C. Montgomem $\frac{2-6-2018}{\text { operator }}$}


Data Report Form DRF-26B: Post-Bum Leach Uranium and Impurities.

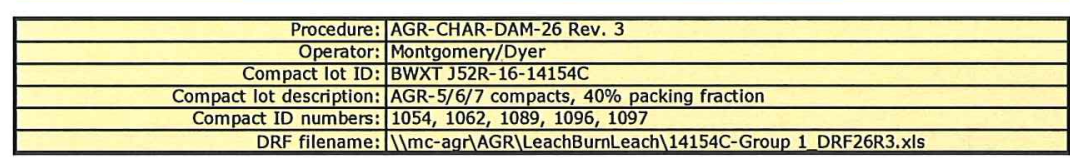

\begin{tabular}{|r|r|}
\hline Number of compacts: & 5 \\
\hline Average weight uranium per particle, mean value $(g):$ & $3.94 \mathrm{E}-04$ \\
\hline Average weight uranium per particle, uncertainty in mean $(\mathrm{g}):$ & $3.94 \mathrm{E}-06$ \\
\hline
\end{tabular}

\begin{tabular}{|c|c|c|c|c|}
\hline & First Leach & Second Leach & Total \\
\hline & Post-bum leach solu & B17112803 & B17113003 & \\
\hline & Total volume of leach solution (ml): & & 47.0 & \\
\hline & Radiochemical laboratory analysis number: & $17858-003$ & & \\
\hline & Measured uranium concentration $(\mathrm{\mu g} / \mathrm{ml})$ : & $6.15 E+00$ & $\frac{1.03 E-01}{1.01}$ & \\
\hline & Uncertainty in uranium concentration $(\mu \mathrm{g} / \mathrm{ml})$ : & $6.15 \mathrm{E}-01$ & $1.03 \mathrm{E}-02$ & \\
\hline & Weight uranium leached $(\mathrm{g})$ & $3.26 \mathrm{E}-04$ & $4.84 \mathrm{E}-06$ & $3.31 \mathrm{E}-04$ \\
\hline & Uncertainty in weight uranium leached $(g)$ : & $3.28 \mathrm{E}-05$ & $\begin{array}{ll}4.04-00 \\
4.89 E-07\end{array}$ & 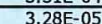 \\
\hline & Equivalent number of leached kemels: & $8.27 \mathrm{E}-01$ & $\begin{array}{ll}4.035-01 \\
1.23 E-02\end{array}$ & $\begin{array}{ll}0.20 \mathrm{~L}-03 \\
8.40 \mathrm{E}-01\end{array}$ \\
\hline & Uncertainty in equivalent number of leached kemels: & $8.38 \mathrm{E}-02$ & $1.25 \mathrm{E}-03$ & $\begin{array}{ll}0.405-01 \\
8.38 E-02\end{array}$ \\
\hline \multirow{5}{*}{$\mathbf{F e}$} & Measured concentration of impurity in sample ( $\mu \mathrm{o} / \mathrm{ml})$ : & & & Fe \\
\hline & Uncorrected weight of impurity in sample $(\mu g)$ : & & & \\
\hline & Weight of impurity in blank $(\mu \mathrm{g})$ : & & & \\
\hline & Minimum corrected weight of impurity in sample $(\mu g)$ : & & & \\
\hline & Maximum corrected weight of impurity in sample $(\mu g)$ : & & & \\
\hline \multirow{5}{*}{$\mathrm{Cr}$} & Measured concentration of impurity in sample $(\mathrm{kg} / \mathrm{ml})$ : & & & $\mathrm{Cr}_{\mathbf{r}}$ \\
\hline & Uncorrected weight of impurity in sample $(\mu g)$ : & & & \\
\hline & Weight of impurity in blank $(\mathrm{yg})$ : & & & \\
\hline & Minimum corrected weight of impurity in sample $(\mu g)$ : & & & \\
\hline & Maximum corrected weight of impurity in sample $(\mathrm{\mu} g)$ : & & & \\
\hline \multirow{5}{*}{ Mn } & Masured concentration of impurity in sample $(\mathrm{ug} / \mathrm{ml})$ : & & & Mn \\
\hline & Uncorrected weight of impurity in sample $(\mu g)$ : & & & \\
\hline & Weight of impurity in blank $(\mu g)$ : & & & \\
\hline & Minimum corrected weight of impurity in sample $(\mu g)$ : & & & \\
\hline & Maximum corrected weight of impurity in sample $(\mu g)$ : & & & \\
\hline \multirow{5}{*}{ co } & Measured concentration of impurity in sample $(\mathrm{\mu g} / \mathrm{ml})$ : & & & co \\
\hline & Uncorrected weight of impurity in sample $(\mu \mathrm{g})$ : & & & \\
\hline & $\begin{array}{l}\text { Weight of impurity in blank }(\mu \mathrm{g}) \text { : } \\
\end{array}$ & & & \\
\hline & Minimum corrected weight of impurity in sample $(\mathrm{\mu g})$ : & & & \\
\hline & Maximum corrected weight of impurity in sample $(\mu g)$ : & & & \\
\hline \multirow{5}{*}{ Ni } & Measured concentration of impurity in sample $(\mathrm{\mu g} / \mathrm{ml})$ : & & & $\mathrm{Ni}$ \\
\hline & Uncorrected weight of impurity in sample $(\mathrm{\mu g})$; & & & \\
\hline & Weight of impurity in blank ( $\mathrm{\mu g})$ : & & & \\
\hline & Minimum corrected weight of impurity in sample $(\mu g)$ : & & & \\
\hline & Maximum corrected weight of impurity in sample $(\mu g)$ : & & & \\
\hline \multirow{5}{*}{$\mathrm{Ca}$} & Measured concentration of impurity in sample $(\mu \mathrm{g} / \mathrm{ml})$ : & & & Ca \\
\hline & Uncorrected weight of impurity in sample $(\mu \mathrm{\mu})$ : & & & \\
\hline & Weight of impurity in blank $(\mu g)$ : & & & \\
\hline & Minimum corrected weight of impurity in sample $(\mu \mathrm{g})$ : & & & \\
\hline & Maximum corrected weight of impurity in sample $(\mu g)$ : & & & \\
\hline \multirow{5}{*}{ Al } & Measured concentration of impurity in sample $(\mathrm{\mu g} / \mathrm{ml})$ : & & & Al \\
\hline & Uncorrected weight of impurity in sample $(\mathrm{\mu g})$ : & & & \\
\hline & Weight of impurity in blank $(\mu g)$ : & & & \\
\hline & Minimum corrected weight of impurity in sample $(\mu \mathrm{g})$ : & & & \\
\hline & Maximum corrected weight of impurity in sample $(\mu g)$ : & & & $T T^{2}$ \\
\hline \multirow{4}{*}{$\mathbf{T i}$} & Measured concentration of impurity in sample $(\mathrm{\mu g} / \mathrm{ml})$ : & & & Ti \\
\hline & Uncorrected weight of impurity in sample $(\mu \mathrm{g})$ : & & & \\
\hline & Minimum corrected weight of impurity in sample $(\mu g)$ : & & & \\
\hline & Maximum corrected weight of impurity in sample $(\mathrm{gg})$ : & & & \\
\hline \multirow{5}{*}{$\mathbf{v}$} & Measured concentration of impurity in sample $(\mathrm{\mu g} / \mathrm{ml})$ : & & & $\mathbf{v}$ \\
\hline & Uncorrected weight of impurity in sample $(\boldsymbol{\mu g})$ : & & & \\
\hline & Weight of impurity in blank $(\mu \mathrm{\mu})$ : & & & \\
\hline & Minimum corrected weight of impurity in $\mathrm{sc}_{\mathrm{C}}$ & & & \\
\hline & Maximum corrected weight of impurity in sample $(\mu \mathrm{g})$ : & & & \\
\hline
\end{tabular}

FCM checked the recorded data against the official Results of Analysis for RMAL17858 on 1/31/2018.

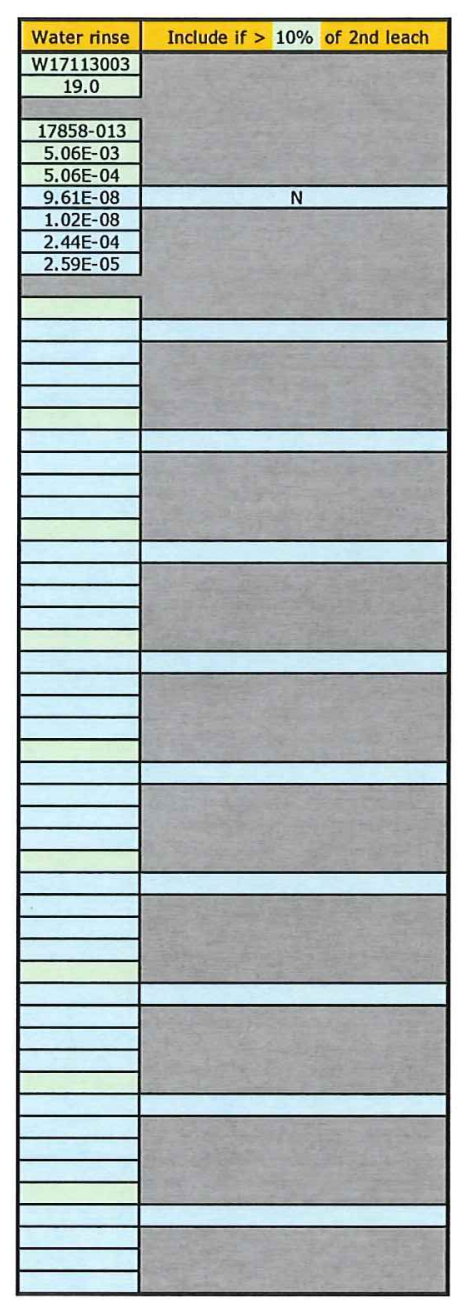
(19)

Fieed c. Montromery $2-6 \cdot 2018$ 
Data Report Form DRF-26B: Post-Bum Leach Uranium and Impurities

\begin{tabular}{|r|l|}
\hline Procedure: & AGR-CHAR-DAM-26 Rev. 3 \\
\hline Operator: & Montgomery/Dyer \\
\hline Compact lot ID: & BWXT J52R-16-14154C \\
\hline Compact lot description: & AGR-5/6/7 compacts, $40 \%$ packing fraction \\
\hline Compact ID numbers: & $1023,1040,1048,1084,1088$ \\
\hline DRF filename: & IImC-agr|AGR/LeachBurnLeach 14154C-Group 1_DRF26R3.xls \\
\hline
\end{tabular}
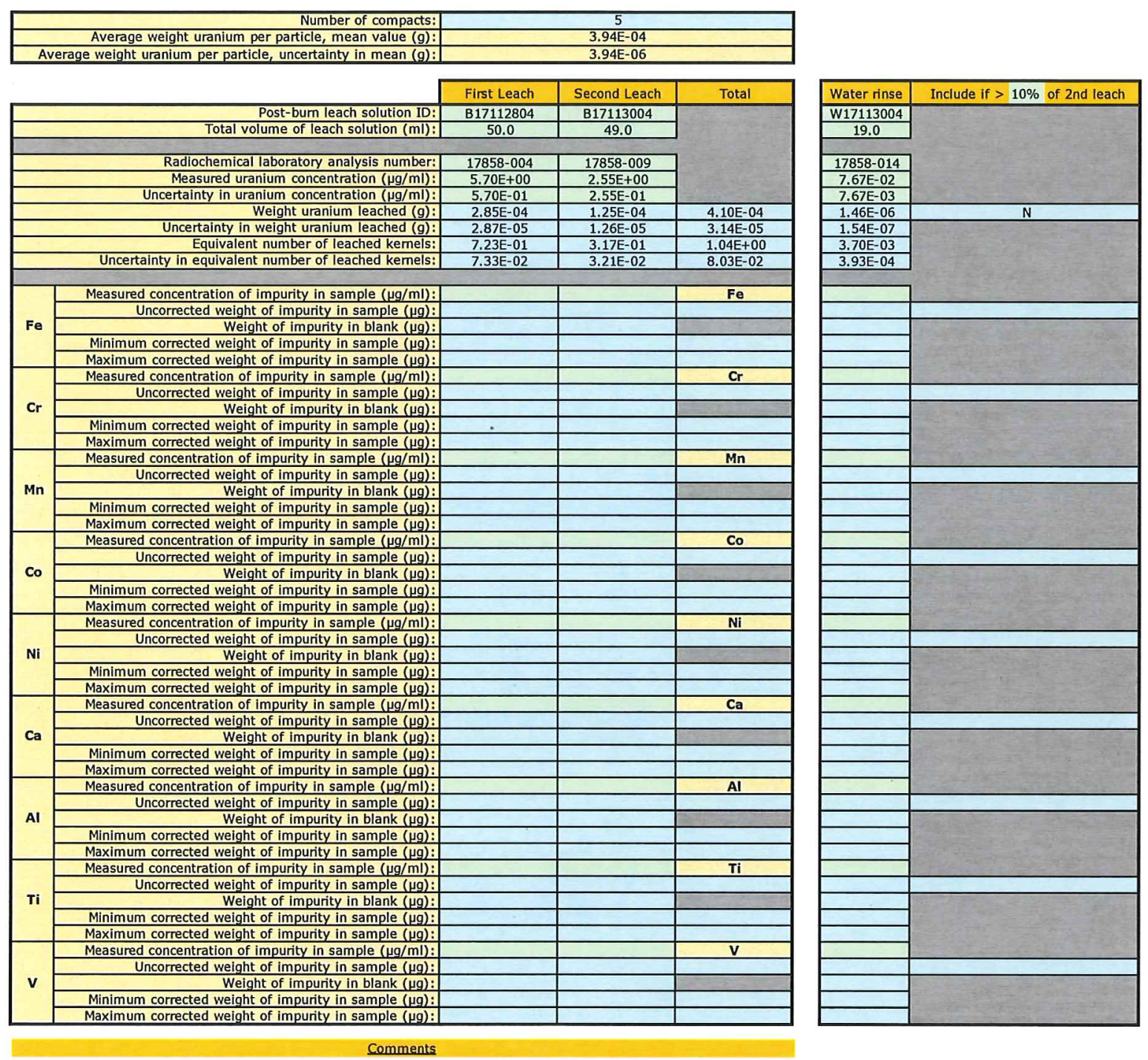

FCM checked the recorded data against the official Results of Analysis for RMAL17858 on 1/31/2018.

\section{Fred C. Montgomery $\frac{2-6-2018}{\text { openator }}$}


Data Report Form DRF-268: Post-Bum Leach Uranium and Impurities
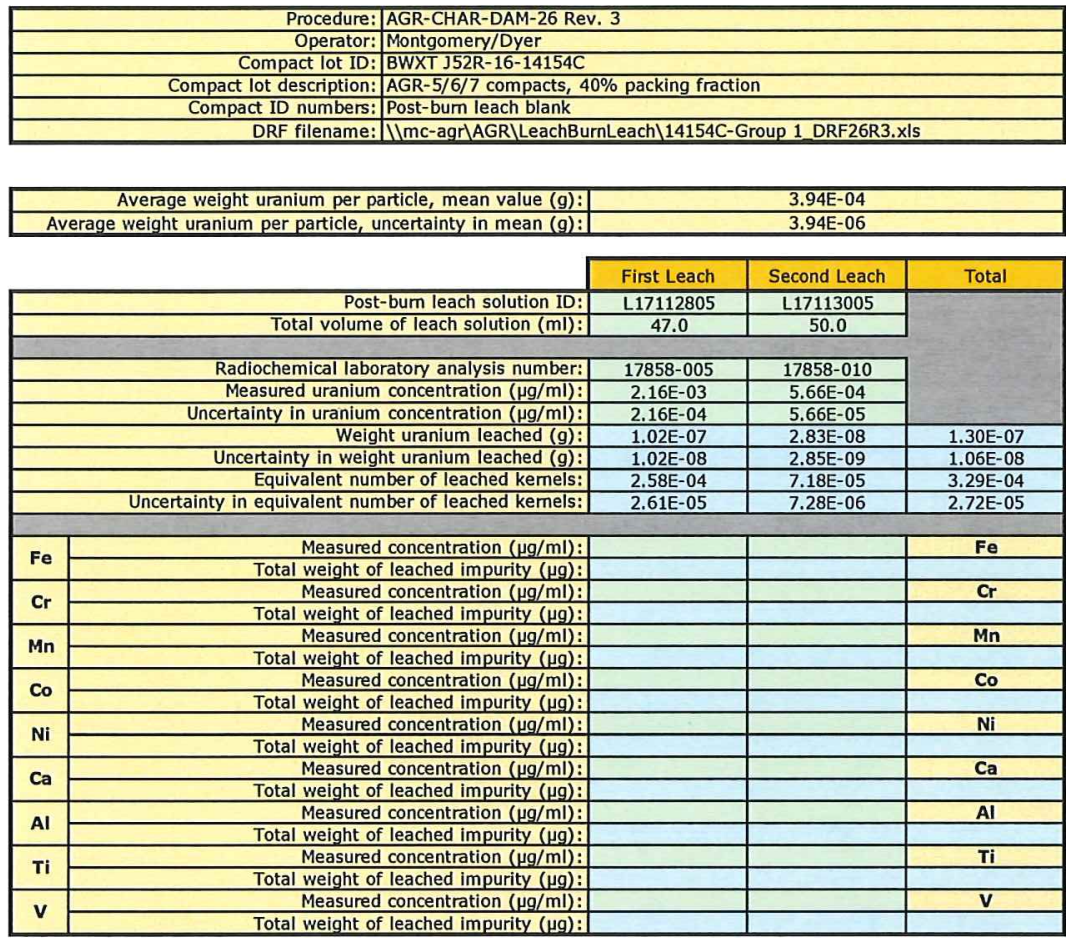

comments

FCM checked the recorded data against the official Results of Analysis for RMAL17858 on 1/31/2018.

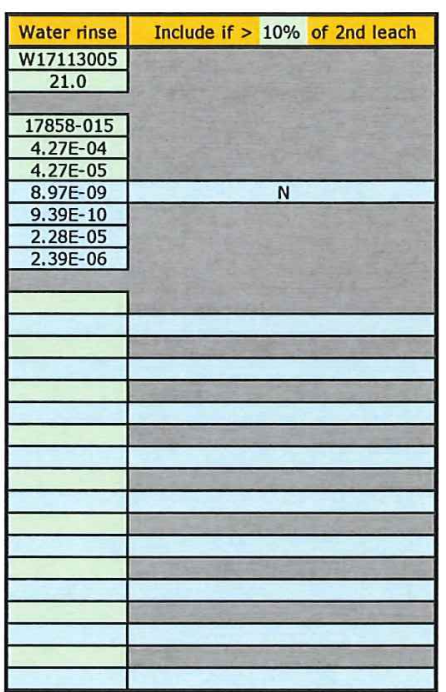

Feed C. Montgomery 
Data Report Form DRF-26A: Pre-Bum Leach Uranium and Impurities

\begin{tabular}{|r|l|}
\hline Procedure: & AGR-CHAR-DAM-26 Rev. 3 \\
\hline Operator: & Montgomery/Dyer \\
\hline Compact lot ID: & BWXT J52R-16-14154C \\
\hline Compact lot description: & AGR-5/6/7 compacts, 40\% packing fraction \\
\hline Compact ID numbers: & $1021,1042,1056,1093,1105$ \\
\hline DRF filename: & 1Imc-agr)AGRILeachBurnLeach 14154C-Group 2 DRF26R3.xls \\
\hline
\end{tabular}

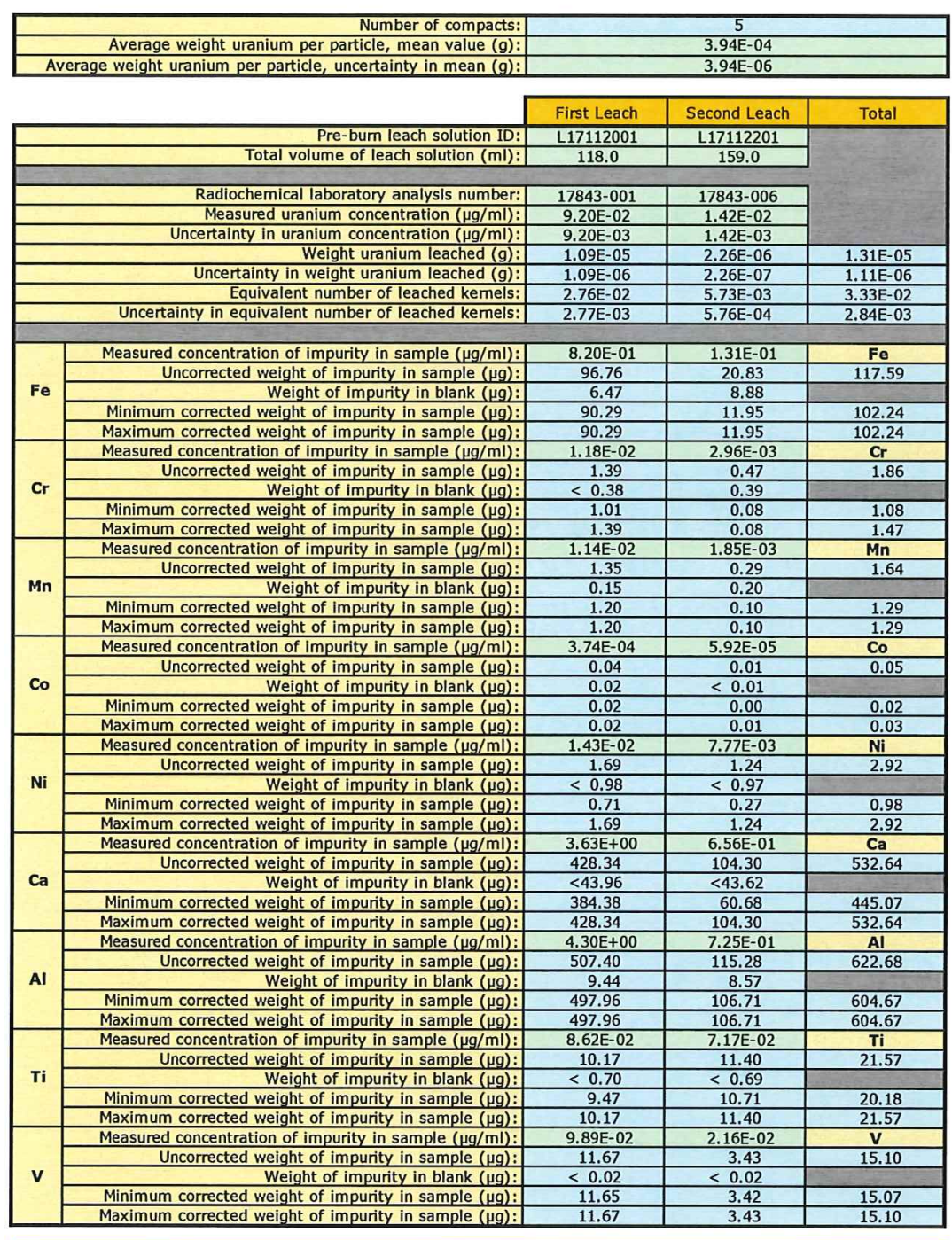

Comments

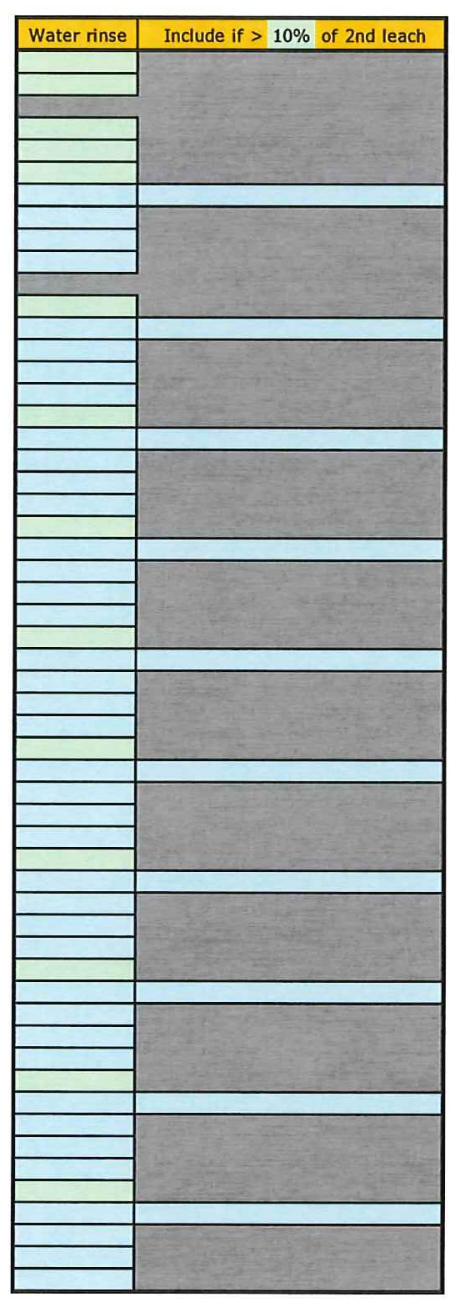

Water rinse not analyzed.

FCM checked the data against the official results of RMAL17843 on 2/5/2018.

\section{Fred C. Montgomery}

$2-8-2018$ 
Data Report Form DRF-26A: Pre-Bum Leach Uranium and Impurities

\begin{tabular}{|r|l|}
\hline Procedure: & AGR-CHAR-DAM-26 Rev. 3 \\
\hline Operator: & Montgomery/Dyer \\
\hline Compact lot ID: & BWXT J52R-16-14154C \\
\hline Compact lot description: & AGR-5/6/7 compacts, 40\% packing fraction \\
\hline Compact ID numbers: & $1004,1016,1018,1085,1101$ \\
\hline DRF filename: & IImC-agr|AGRILeachBurnLeach 14154C-Group 2_DRF26R3.xls \\
\hline
\end{tabular}

\begin{tabular}{|r|r|}
\hline Number of compacts: & 5 \\
\hline Average weight uranium per particle, mean value $(\mathbf{g}):$ & $3.94 \mathrm{E}-04$ \\
\hline Average weight uranium per particle, uncertainty in mean $(\mathrm{g}):$ & $3.94 \mathrm{E}-06$ \\
\hline
\end{tabular}

\begin{tabular}{|c|c|c|c|c|}
\hline & First Leach & Second Leach & Total \\
\hline & Pre-bum leach solution ID: & L17112002 & L17112202 & \\
\hline & Total volume of leach solution $(\mathrm{ml})$ : & 121.0 & 154.0 & \\
\hline & Radiochemical laboratory analysis number: & $17843-002$ & $17843-007$ & \\
\hline & Measured uranium concentration $(\mu \mathrm{g} / \mathrm{ml})$ : & $1.26 \mathrm{E}-01$ & $1.75 \mathrm{E}-02$ & \\
\hline & Uncertainty in uranium concentration $(\mu \mathrm{g} / \mathrm{ml})$ : & $1.26 \mathrm{E}-02$ & $1.75 \mathrm{E}-03$ & \\
\hline & Weight uranium leached $(\mathrm{g})$ : & $1.52 \mathrm{E}-05$ & $2.70 \mathrm{E}-06$ & $1.79 \mathrm{E}-05$ \\
\hline & Uncertainty in weight uranium leached $(\mathrm{g})$ : & $1.53 \mathrm{E}-06$ & $2.70 \mathrm{E}-07$ & $1.55 \mathrm{E}-06$ \\
\hline & Equivalent number of leached kemels: & $3.87 \mathrm{E}-02$ & $6.84 \mathrm{E}-03$ & $4.55 \mathrm{E}-02$ \\
\hline & Uncertainty in equivalent number of leached kemels: & $3.89 \mathrm{E}-03$ & $6.88 \mathrm{E}-04$ & $3.96 \mathrm{E}-03$ \\
\hline \multirow{5}{*}{$\mathbf{F e}$} & Measured concentration of impurity in sample $(\mu \mathrm{g} / \mathrm{ml})$ : & $8.98 \mathrm{E}-01$ & $1.36 \mathrm{E}-01$ & $\mathbf{F e}$ \\
\hline & Uncorrected weight of impurity in sample $(\mu g)$ : & 108.66 & 20.94 & 129.60 \\
\hline & Weight of impurity in blank $(\mu \mathrm{g})$ : & 6.47 & 8.88 & \\
\hline & Minimum corrected weight of impurity in sample $(\mu \mathrm{g})$ : & 102.19 & 12.06 & 114.25 \\
\hline & Maximum corrected weight of impurity in sample $(\mu g)$ : & 102.19 & 12.06 & 114.25 \\
\hline \multirow{5}{*}{$\mathbf{C r}$} & Measured concentration of impurity in sample $(\mu \mathrm{g} / \mathrm{ml})$ : & $1.37 \mathrm{E}-02$ & $4.29 \mathrm{E}-03$ & $\mathrm{Cr}$ \\
\hline & Uncorrected weight of impurity in sample $(\mu \mathrm{g})$ : & 1.66 & 0.66 & 2.32 \\
\hline & Weight of impurity in blank $(\mu \mathrm{g})$ : & $<0.38$ & 0.39 & \\
\hline & Minimum corrected weight of impurity in sample $(\mu \mathrm{g})$ : & 1.27 & 0.27 & 1.54 \\
\hline & Maximum corrected weight of impurity in sample $(\mu \mathrm{g})$ : & 1.66 & 0.27 & 1.92 \\
\hline \multirow{5}{*}{ Mn } & Measured concentration of impurity in sample $(\mu \mathrm{g} / \mathrm{ml})$ : & $1.21 \mathrm{E}-02$ & $1.98 \mathrm{E}-03$ & Mn \\
\hline & Uncorrected weight of impurity in sample $(\mu \mathrm{g})$ : & 1,46 & 0.30 & 1.77 \\
\hline & Weight of impurity in blank $(\mu \mathrm{g})$ : & 0.15 & 0.20 & \\
\hline & Minimum corrected weight of impurity in sample $(\mu \mathrm{g})$ : & 1.31 & 0.11 & 1.42 \\
\hline & Maximum corrected weight of impurity in sample $(\mu \mathrm{g})$ : & 1.31 & 0.11 & 1.42 \\
\hline \multirow{5}{*}{ Co } & Measured concentration of impurity in sample $(\mu \mathrm{g} / \mathrm{ml})$ : & $5.22 \mathrm{E}-04$ & $8.52 \mathrm{E}-05$ & Co \\
\hline & Uncorrected weight of impurity in sample $(\mu \mathrm{g})$ : & 0.06 & 0.01 & 0.08 \\
\hline & Weight of impurity in blank $(\mu \mathrm{g})$ : & 0.02 & $<0.01$ & \\
\hline & Minimum corrected weight of impurity in sample $(\mu g)$ : & 0.04 & 0.00 & 0.05 \\
\hline & Maximum corrected weight of impurity in sample $(\mu g)$ : & 0.04 & 0.01 & 0.06 \\
\hline \multirow{5}{*}{$\mathbf{N i}$} & Measured concentration of impurity in sample $(\mu \mathrm{g} / \mathrm{ml})$ : & $3.39 \mathrm{E}-02$ & $1.06 \mathrm{E}-02$ & $\mathrm{Ni}$ \\
\hline & Uncorrected weight of impurity in sample $(\mu \mathrm{g})$ : & 4.10 & 1.63 & 5.73 \\
\hline & Weight of impurity in blank $(\mu g)$ : & $<0.98$ & $<0.97$ & \\
\hline & Minimum corrected weight of impurity in sample $(\mu g)$ : & 3.13 & 0.66 & 3.79 \\
\hline & Maximum corrected weight of impurity in sample $(\mu \mathrm{g})$ : & 4.10 & 1.63 & 5.73 \\
\hline \multirow{5}{*}{ Ca } & Measured concentration of impurity in sample $(\mu \mathrm{g} / \mathrm{ml})$ : & $3.68 \mathrm{E}+00$ & $7.96 \mathrm{E}-01$ & Ca \\
\hline & Uncorrected weight of impurity in sample $(\mu \mathrm{g})$ : & 445.28 & 122.58 & 567.86 \\
\hline & Weight of impurity in blank $(\mu g)$ : & $<43.96$ & $<43.62$ & \\
\hline & Minimum corrected weight of impurity in sample $(\mu \mathrm{g})$ : & 401.32 & 78.96 & 480.29 \\
\hline & Maximum corrected weight of impurity in sample $(\mu \mathrm{g})$ : & 445.28 & 122.58 & 567.86 \\
\hline \multirow{5}{*}{ Al } & Measured concentration of impurity in sample $(\mu \mathrm{g} / \mathrm{ml})$ : & $4.32 \mathrm{E}+00$ & $6.58 \mathrm{E}-01$ & Al \\
\hline & Uncorrected weight of impurity in sample $(\mu \mathrm{g})$ : & 522.72 & 101.33 & 624.05 \\
\hline & Weight of impurity in blank $(\mu \mathrm{g})$ : & 9.44 & 8.57 & \\
\hline & Minimum corrected weight of impurity in sample $(\mu \mathrm{g})$ : & 513.28 & 92.76 & 606.05 \\
\hline & Maximum corrected weight of impurity in sample $(\mu \mathrm{g})$ : & 513.28 & 92.76 & 606.05 \\
\hline \multirow{5}{*}{$\mathbf{T i}$} & Measured concentration of impurity in sample $(\mu \mathrm{g} / \mathrm{ml})$ : & $8,34 \mathrm{E}-02$ & $6.16 \mathrm{E}-02$ & $\mathrm{Ti}$ \\
\hline & Uncorrected weight of impurity in sample $(\mu \mathrm{g})$ : & 10.09 & 9.49 & 19.58 \\
\hline & Weight of impurity in blank $(\mu \mathrm{g})$ : & $<0.70$ & $<0.69$ & \\
\hline & Minimum corrected weight of impurity in sample $(\mu \mathrm{g})$ : & 9.39 & 8.79 & 18.19 \\
\hline & Maximum corrected weight of impurity in sample $(\mu g)$ : & 10.09 & 9.49 & 19.58 \\
\hline \multirow{5}{*}{ v } & Measured concentration of impurity in sample $(\mu \mathrm{g} / \mathrm{ml})$ : & $1.06 \mathrm{E}-01$ & $2.25 \mathrm{E}-02$ & $\mathbf{v}$ \\
\hline & Uncorrected weight of impurity in sample $(\mu \mathrm{g})$ : & 12.83 & 3.47 & 16.29 \\
\hline & Weight of impurity in blank $(\mu \mathrm{g})$ : & $<0.02$ & $<0.02$ & \\
\hline & Minimum corrected weight of impurity in sample $(\mu \mathrm{g})$ : & 12.81 & 3.45 & 16.26 \\
\hline & Maximum corrected weight of impurity in sample $(\mu \mathrm{g})$ : & 12.83 & 3.47 & 16.29 \\
\hline
\end{tabular}

comments

Water rinse not analyzed.

FCM checked the data against the official results of RMAL17843 on 2/5/2018.

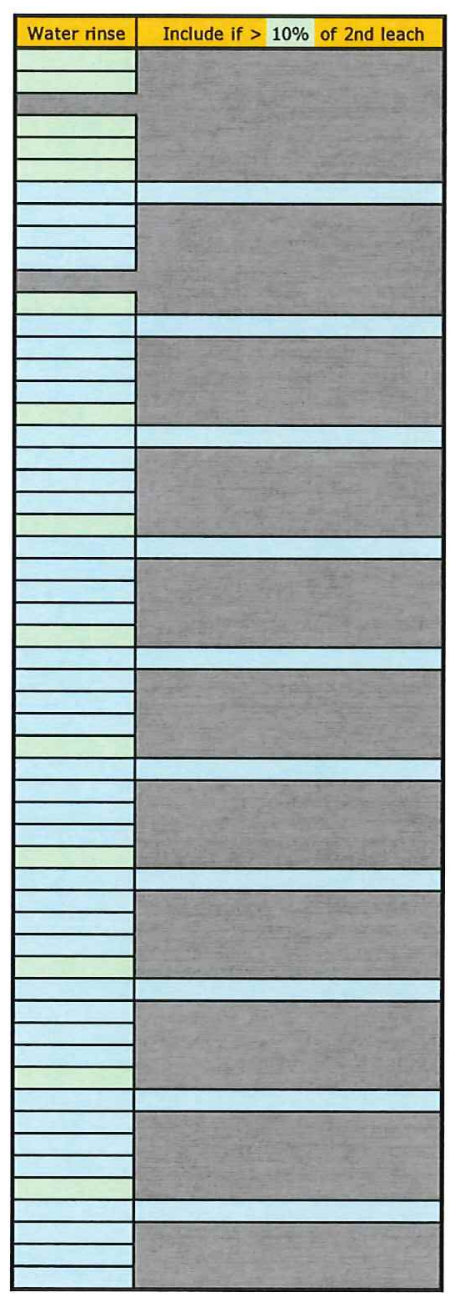


Data Report Form DRF-26A: Pre-Bum Leach Uranium and Impurities

\begin{tabular}{|r|l|}
\hline Procedure: & AGR-CHAR-DAM-26 Rev. 3 \\
\hline Operator: & Montgomery/Dyer \\
\hline Compact lot ID: & BWXT J52R-16-14154C \\
\hline Compact lot description: & AGR-5/6/7 compacts, 40\% packing fraction \\
\hline Compact ID numbers: & $1006,1057,1068,1078,1107$ \\
\hline DRF filename: & IImc-agr|AGRILeachBurnLeach 14154C-Group 2_DRF26R3.xls \\
\hline
\end{tabular}

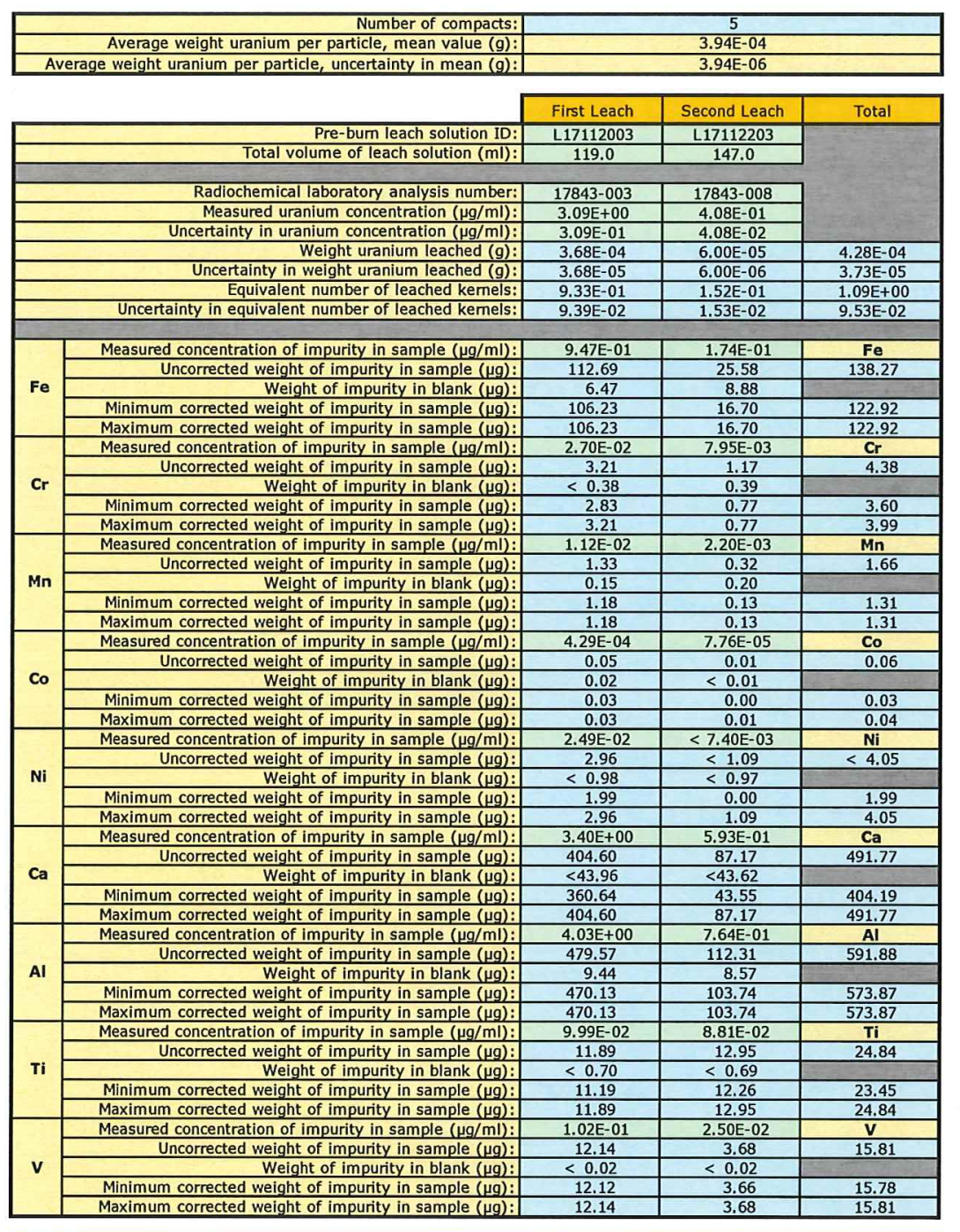

comments

Water rinse not analyzed.

FCM checked the data against the official results of RMAL17843 on 2/5/2018.

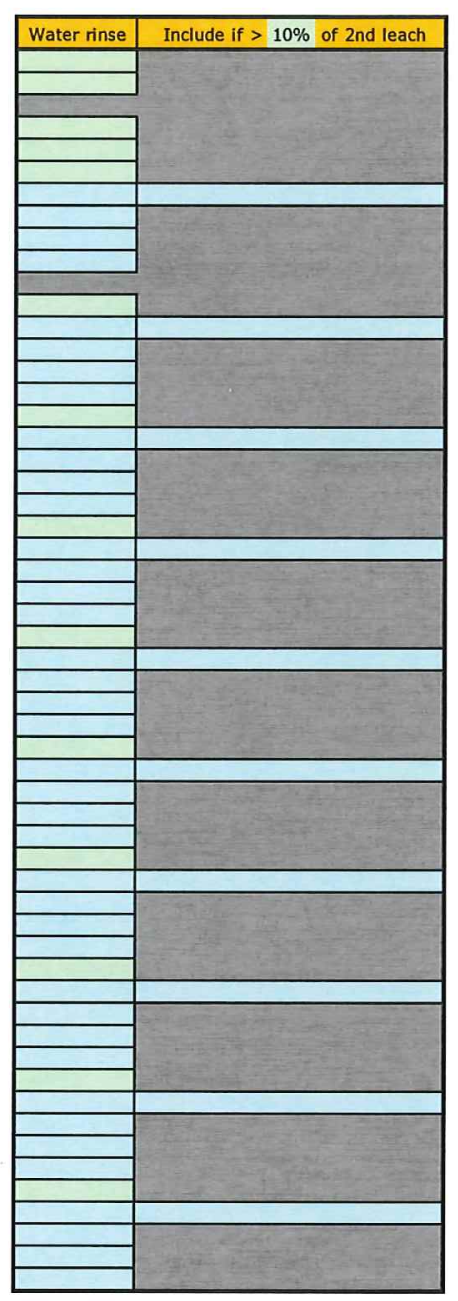


Data Report Form DRF-26A: Pre-Bum Leach Uranium and Impurities

\begin{tabular}{|c|c|}
\hline Procedure: & AGR-CHAR-DAM-26 Rev. 3 \\
\hline Operator: & Montgomery/Dyer \\
\hline Compact lot ID: & BWXT J52R-16-14154C \\
\hline Compact lot description: & AGR- $5 / 6 / 7$ compacts, $40 \%$ packing fraction \\
\hline Compact ID numbers: & $1002,1036,1038,1083,1098$ \\
\hline DRF filename: & IImc-agr|AGR\LeachBurnLeach|14154C-Group 2 DRF26R3.x/s \\
\hline
\end{tabular}

\begin{tabular}{|r|c|}
\hline Number of compacts: & 5 \\
\hline Average weight uranium per particle, mean value $(g):$ & $3.94 \mathrm{E}-04$ \\
\hline Average weight uranium per particle, uncertainty in mean $(g):$ & $3.94 \mathrm{E}-06$ \\
\hline
\end{tabular}

\begin{tabular}{|c|c|c|c|c|}
\hline \multirow{2}{*}{\multicolumn{2}{|c|}{ 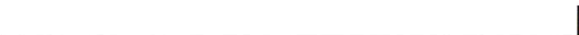 }} & & & \\
\hline & & First Leach & Second Leach & Total \\
\hline \multirow{2}{*}{\multicolumn{2}{|c|}{$\begin{array}{cc} & \text { Pre-burn leach solution ID: } \\
\text { Total volume of leach solution }(\mathrm{ml}):\end{array}$}} & L17112004 & $\underline{L 17112204}$ & \\
\hline & & 116.0 & 140.0 & \\
\hline \multicolumn{2}{|r|}{ Radiochemical laboratory analysis number: } & $17843-004$ & & \\
\hline \multicolumn{2}{|r|}{ Measured uranium concentration $(\mu \mathrm{g} / \mathrm{ml})$ : } & $8.84 \mathrm{E}-02$ & $\frac{17845-009}{1.79 E-02}$ & \\
\hline \multirow{2}{*}{\multicolumn{2}{|c|}{$\begin{array}{r}\text { Uncertainty in uranium concentration }(\mathrm{\mu g} / \mathrm{ml}) \text { : } \\
\text { Weight uranium leached }(\mathrm{g}) \text { : }\end{array}$}} & $8.84 \mathrm{E}-03$ & $1.79 \mathrm{E}-03$ & \\
\hline & & $1.03 \mathrm{E}-05$ & $2.51 \mathrm{E}-06$ & $1.28 \mathrm{E}-05$ \\
\hline \multicolumn{2}{|c|}{ Uncertainty in weight uranium leached $(\mathrm{g})$ : } & $1.03 \mathrm{E}-06$ & $2.51 \mathrm{E}-07$ & $1.06 \mathrm{E}-06$ \\
\hline \multicolumn{2}{|c|}{$\begin{array}{c}\text { Equivalent number of leached kemels: } \\
\end{array}$} & $2.60 \mathrm{E}-02$ & $6.36 \mathrm{E}-03$ & $3.24 \mathrm{E}-02$ \\
\hline \multicolumn{2}{|c|}{ Uncertainty in equivalent number of leached kemels: } & $2.62 E-03$ & $6.40 \mathrm{E}-04$ & $2.70 \mathrm{E}-03$ \\
\hline \multirow{5}{*}{$\mathrm{Fe}$} & Measured concentration of impurity in sample $(\mu \mathrm{g} / \mathrm{ml})$ : & $9.46 \mathrm{E}-01$ & $1.76 \mathrm{E}-01$ & Fe \\
\hline & Uncorrected weight of impurity in sample $(\mu \mathrm{g})$ : & 109.74 & 24.64 & 134.38 \\
\hline & Weight of impurity in blank $(\mu \mathrm{g})$ : & 6.47 & 8.88 & \\
\hline & Minimum corrected weight of impurity in sample $(\mu g)$ : & 103.27 & 15.76 & 119.03 \\
\hline & Maximum corrected weight of impurity in sample $(\mu g)$ : & 103.27 & 15.76 & 119.03 \\
\hline \multirow{5}{*}{$\mathrm{Cr}$} & Measured concentration of impurity in sample $(\mu \mathrm{g} / \mathrm{ml})$ : & $1.39 \mathrm{E}-02$ & $5.73 \mathrm{E}-03$ & $\mathrm{Cr}_{\mathbf{r}}$ \\
\hline & Uncorrected weight of impurity in sample $(\mu \mathrm{g})$ : & 1.61 & 0.80 & 2.41 \\
\hline & Weight of impurity in blank $(\mu \mathrm{g})$ : & $<0.38$ & 0.39 & \\
\hline & Minimum corrected weight of impurity in sample $(\mu \mathrm{g})$ : & 1.23 & 0.41 & 1.64 \\
\hline & Maximum corrected weight of impurity in sample $(\boldsymbol{\mu g})$ : & 1.61 & 0.41 & 2.02 \\
\hline \multirow{5}{*}{ Mn } & Measured concentration of impurity in sample $(\mu \mathrm{g} / \mathrm{ml})$ : & $1.20 \mathrm{E}-02$ & $2.65 \mathrm{E}-03$ & $\mathrm{Mn}$ \\
\hline & Uncorrected weight of impurity in sample $(\mu \mathrm{g})$ : & 1.39 & 0.37 & 1.76 \\
\hline & Weight of impurity in blank $(\mu \mathrm{g})$ : & 0.15 & 0.20 & \\
\hline & Minimum corrected weight of impurity in sample $(\mu \mathrm{g})$ : & 1.24 & 0.17 & 1.42 \\
\hline & Maximum corrected weight of impurity in sample $(\mu g)$ : & 1.24 & 0.17 & 1.42 \\
\hline \multirow{5}{*}{ Co } & Measured concentration of impurity in sample $(\mu \mathrm{g} / \mathrm{ml})$ : & $4.18 \mathrm{E}-04$ & $9.00 \mathrm{E}-05$ & Co \\
\hline & Uncorrected weight of impurity in sample $(\mu \mathrm{g})$ : & 0.05 & 0.01 & 0.06 \\
\hline & Weight of impurity in blank $(\mu \mathrm{g})$ : & 0.02 & $<0.01$ & \\
\hline & Minimum corrected weight of impurity in sample $(\mu \mathrm{g})$ : & 0.03 & 0.00 & 0.03 \\
\hline & Maximum corrected weight of impurity in sample $(\mu \mathrm{gg})$ : & 0.03 & 0.01 & 0.04 \\
\hline \multirow{5}{*}{$\mathbf{N i}$} & Measured concentration of impurity in sample $(\mathrm{\mu g} / \mathrm{ml})$ : & $6.44 \mathrm{E}-02$ & $<7.40 \mathrm{E}-03$ & $\mathrm{Ni}$ \\
\hline & Uncorrected weight of impurity in sample $(\mu \mathrm{g})$ : & 7.47 & $<1.04$ & $<8.51$ \\
\hline & Weight of Impurity in blank $(\mu \mathrm{g})$ : & $<0.98$ & $<0.97$ & \\
\hline & Minimum corrected weight of impurity in sample $(\mu g)$ : & 6.49 & 0.00 & 6.49 \\
\hline & Maximum corrected weight of impurity in sample $(\mu \mathrm{g})$ : & 7.47 & 1.04 & 8.51 \\
\hline \multirow{5}{*}{$\mathbf{C a}$} & Measured concentration of impurity in sample $(\mu \mathrm{g} / \mathrm{ml})$ : & $3.48 \mathrm{E}+00$ & $6.16 \mathrm{E}-01$ & $\mathbf{C a}$ \\
\hline & Uncorrected weight of impurity in sample $(\mu g)$ : & 403.68 & 86.24 & 489.92 \\
\hline & Weight of impurity in blank $(\mu g)$ : & $<43.96$ & $<43.62$ & \\
\hline & Minimum corrected weight of impurity in sample $(\mu q)$ : & 359.72 & 42.62 & 402.34 \\
\hline & Maximum corrected weight of impurity in sample $(\mu g)$ : & 403.68 & 86.24 & 489.92 \\
\hline \multirow{5}{*}{ Al } & Measured concentration of impurity in sample $(\mathrm{\mu g} / \mathrm{ml})$ : & $4.33 \mathrm{E}+00$ & $7.91 \mathrm{E}-01$ & Al \\
\hline & Uncorrected weight of impurity in sample $(\mu \mathrm{g})$ : & 502.28 & 110.74 & 613.02 \\
\hline & Weight of impurity in blank $(\mu \mathrm{g})$ : & 9.44 & 8.57 & \\
\hline & Minimum corrected weight of impurity in sample $(\mu \mathrm{g})$ : & 492.84 & 102.17 & 595.01 \\
\hline & Maximum corrected weight of impurity in sample $(\mu \mathrm{g})$ : & 492.84 & 102.17 & 595.01 \\
\hline \multirow{5}{*}{$\mathbf{T i}$} & Measured concentration of impurity in sample $(\mu \mathrm{g} / \mathrm{ml})$ : & $1.21 \mathrm{E}-01$ & $1.01 \mathrm{E}-01$ & Ti \\
\hline & Uncorrected weight of impurity in sample $(\mu \mathrm{g})$ : & 14.04 & 14.14 & 28.18 \\
\hline & Weight of impurity in blank $(\mu g)$ : & $<0.70$ & $<0.69$ & \\
\hline & Minimum corrected weight of impurity in sample $(\mu g)$ : & 13.34 & 13.45 & 26.78 \\
\hline & Maximum corrected weight of impurity in sample $(\mu g)$ : & 14.04 & 14.14 & 28.18 \\
\hline \multirow{5}{*}{ v } & Measured concentration of impurity in sample $(\mathrm{\mu g} / \mathrm{ml})$ : & $1.10 \mathrm{E}-01$ & $2.68 \mathrm{E}-02$ & $\mathbf{v}$ \\
\hline & Uncorrected weight of impurity in sample $(\mu \mathrm{g})$ : & 12.76 & 3.75 & 16.51 \\
\hline & Weight of impurity in blank $(\mu \mathrm{g})$ : & $<0.02$ & $<0.02$ & \\
\hline & Minimum corrected weight of impurity in sample $(\mu q)$ : & 12.74 & 3.73 & 16.48 \\
\hline & Maximum corrected weight of impurity in sample $(\mu \mathrm{g})$ : & 12.76 & 3.75 & 16.51 \\
\hline
\end{tabular}

comments

Water rinse not analyzed.

FCM checked the data against the official results of RMAL17843 on 2/5/2018.

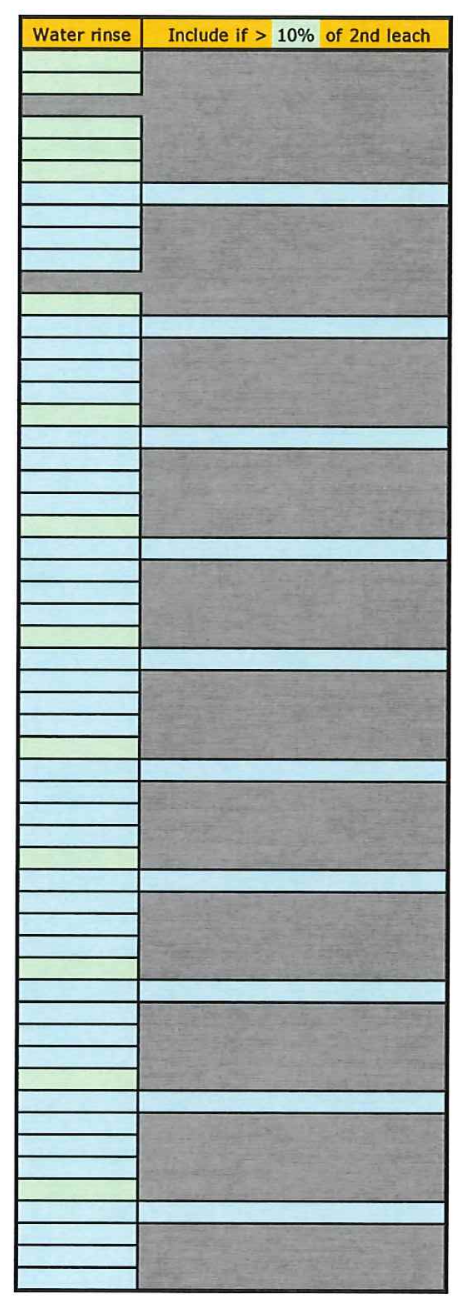

FCM

\section{7 red C. Montgomey $\frac{2.8-2018}{\text { Deferior }}$}



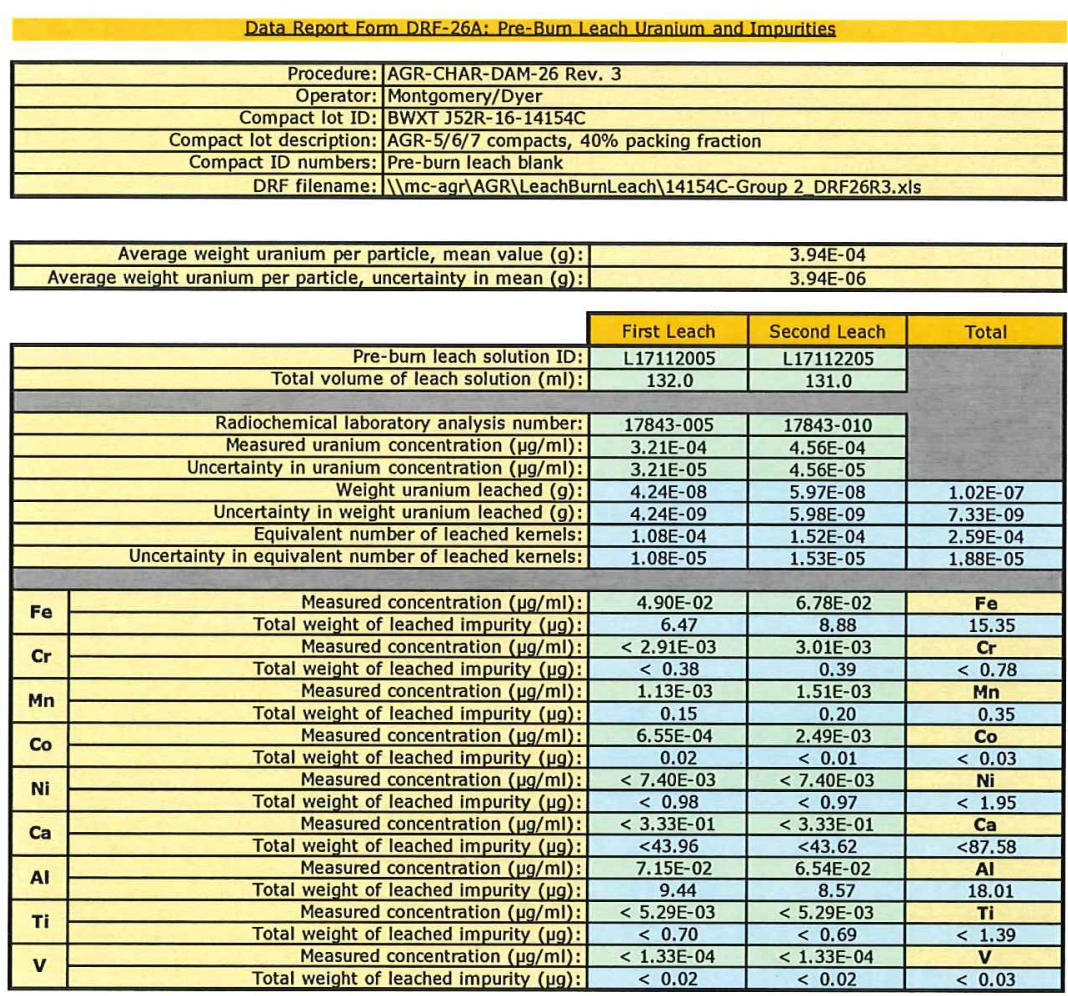

comments

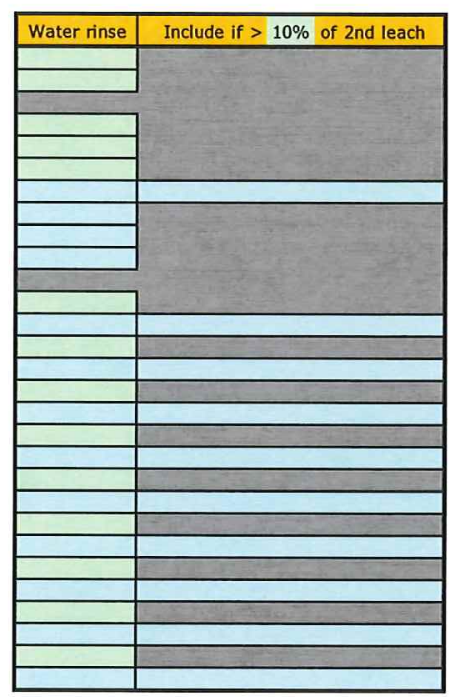

Water rinse not analyzed.

FCM checked the data against the official results of RMAL17843 on 2/5/2018.

Cobalt values for this Blank sample were an artifact of contamination introduced during analysis. Reported values for 1st

and 2 nd leach of $0.09 \mu \mathrm{g}$ and $0.33 \mu \mathrm{g}$, respectively, were replaced with typical values 0.02 and $<0.01$.

\section{Fied C. Montyomery 2-8-2018}


Data Report Form DRF-26B: Post-Bum Leach Uranium and Impurities

\begin{tabular}{|r|l|}
\hline Procedure: & AGR-CHAR-DAM-26 Rev. 3 \\
\hline Operator: & Montgomery/Dyer \\
\hline Compact lot ID: & BWXT J52R-16-14154C \\
\hline Compact lot description: & AGR-5/6/7 compacts, 40\% packing fraction \\
\hline Compact ID numbers: & $1021,1042,1056,1093,1105$ \\
\hline DRF filename: & IImC-agr|AGR/LeachBurnLeach 14154C-Group 2 DRF26R3,xls \\
\hline
\end{tabular}

\begin{tabular}{|r|c|}
\hline Number of compacts: & 5 \\
\hline Average weight uranium per particle, mean value $(g):$ & $3.94 \mathrm{E}-04$ \\
\hline Average weight uranium per particle, uncertainty in mean $(\mathrm{g}):$ & $3.94 \mathrm{E}-06$ \\
\hline
\end{tabular}

\begin{tabular}{|c|c|c|c|c|}
\hline & First Leach & Second Leach & Total \\
\hline & Post-bum leach solution ID: & B17120501 & B17120801 & \\
\hline & Total volume of leach solution (ml): & 47.0 & 50.0 & \\
\hline & Radiochemical laboratory analysis number: & $17875-001$ & $17875-006$ & \\
\hline & Measured uranium concentration $(\mu \mathrm{g} / \mathrm{ml})$ : & $3.10 \mathrm{E}-01$ & $5.72 \mathrm{E}-03$ & \\
\hline & Uncertainty in uranium concentration $(\mu \mathrm{g} / \mathrm{ml})$ : & $3.10 \mathrm{E}-02$ & $5.72 \mathrm{E}-04$ & \\
\hline & Weight uranium leached $(g)$ : & $1.46 \mathrm{E}-05$ & $2.86 \mathrm{E}-07$ & $1.49 \mathrm{E}-05$ \\
\hline & Uncertainty in weight uranium leached $(g)$ : & $1.47 \mathrm{E}-06$ & $2.88 \mathrm{E}-08$ & $1.47 \mathrm{E}-06$ \\
\hline & Equivalent number of leached kemels: & $3.70 \mathrm{E}-02$ & $7.26 \mathrm{E}-04$ & $3.77 \mathrm{E}-02$ \\
\hline & Uncertainty in equivalent number of leached kemels: & $3.75 \mathrm{E}-03$ & $7.36 \mathrm{E}-05$ & $3.75 \mathrm{E}-03$ \\
\hline & Measured concentration of impurity in sample $(\mu \mathrm{og} / \mathrm{ml})$ : & $2.38 \mathrm{E}+00$ & $<1.09 \mathrm{E}-01$ & $\mathrm{~F}$ \\
\hline & Uncorrected weight of impurity in sample $(\mu g)$ : & $\frac{2.00 L T 00}{111.86}$ & $<5.45$ & $<117.31$ \\
\hline $\mathbf{F e}$ & $\begin{array}{l}\text { Weight of impurity in blank }(\mu g) \text { : } \\
\text {. }\end{array}$ & $<5.23$ & $<5.56$ & \\
\hline & Minimum corrected weight of impurity in sample $(\mu q)$ : & 106.63 & 0.00 & 106.63 \\
\hline & Maximum corrected weight of impurity in sample $(\mu g)$; & 111.86 & 5.45 & 117.31 \\
\hline & Measured concentration of impurity in sample $(\mu \mathrm{o} / \mathrm{ml})$ : & $2.18 \mathrm{E}-02$ & $<5.79 \mathrm{E}-04$ & $\mathrm{Cr}$ \\
\hline & Uncorrected weight of impurity in sample $(\mu \mathrm{g})$ : & 1.02 & $<0.03$ & $<1.05$ \\
\hline Cr & Weight of impurity in blank $(\mu \mathrm{g})$ : & $<0.03$ & $<0.03$ & \\
\hline & Minimum corrected weight of impurity in sample $(\mu g)$ : & 1.00 & 0.00 & 1.00 \\
\hline & Maximum corrected weight of impurity in sample $(\mu \mathrm{g})$ : & 1.02 & 0.03 & 1.05 \\
\hline & Measured concentration of impurity in sample $(\mathrm{\mu g} / \mathrm{ml})$ : & $8.36 \mathrm{E}-03$ & $1.23 \mathrm{E}-03$ & Mn \\
\hline & Uncorrected weight of impurity in sample $(\mu g)$ : & 0.39 & 0.06 & 0.45 \\
\hline Mn & Weight of impurity in blank $(\mu g)$ : & $<0.04$ & $<0.05$ & \\
\hline & Minimum corrected weight of impurity in sample $(\mu g)$ : & 0.35 & 0.01 & 0.36 \\
\hline & Maximum corrected weight of impurity in sample $(\mu g)$ : & 0.39 & 0.06 & 0.45 \\
\hline & Measured concentration of impurity in sample $(\mathrm{\mu g} / \mathrm{ml})$ : & $1.41 \mathrm{E}-03$ & $<1.69 \mathrm{E}-04$ & Co \\
\hline & Uncorrected weight of impurity in sample $(\mu \mathrm{g})$ : & 0.07 & $<0.01$ & $<0.07$ \\
\hline co & Weight of impurity in blank $(\mu \mathrm{g})$ : & 0.02 & $<0.01$ & \\
\hline & Minimum corrected weight of impurity in sample $(\mu g)$ : & 0.05 & 0.00 & 0.05 \\
\hline & Maximum corrected weight of impurity in sample $(\mu g)$ : & 0.05 & 0.01 & 0.05 \\
\hline & Measured concentration of impurity in sample $(\mathrm{\mu g} / \mathrm{ml})$ : & $4.43 \mathrm{E}-02$ & $<1.54 \mathrm{E}-02$ & $\mathrm{Ni}$ \\
\hline & Uncorrected weight of impurity in sample $(\mu \mathrm{g})$ : & 2.08 & $<0.77$ & $<2.85$ \\
\hline $\mathbf{N i}$ & Weight of impurity in blank $(\mu \mathrm{g})$ : & $<0.74$ & $<0.79$ & \\
\hline & Minimum corrected weight of impurity in sample $(\mu \mathrm{g})$ : & 1.34 & 0.00 & 1.34 \\
\hline & Maximum corrected weight of impurity in sample $(\mu g)$ : & 2.08 & 0.77 & 2.85 \\
\hline & Measured concentration of impurity in sample $(\mathrm{\mu g} / \mathrm{ml})$ : & $9.87 \mathrm{E}-01$ & $2.30 \mathrm{E}-01$ & $\mathrm{Ca}$ \\
\hline & Uncorrected weight of impurity in sample $(\mu g)$ : & 46.39 & 11.50 & 60.29 \\
\hline ca & Weight of impurity in blank $(\mu \mathrm{g})$ : & 7.58 & 3.27 & \\
\hline & Minimum corrected weight of impurity in sample $(\mu \mathrm{g})$; & 38.81 & 8.23 & 48.50 \\
\hline & Maximum corrected weight of impurity in sample $(\mu g)$ : & 38.81 & 8.23 & 48.50 \\
\hline & Measured concentration of impurity in sample $(\mathrm{\mu g} / \mathrm{ml})$ : & $1.51 \mathrm{E}+00$ & $3.20 \mathrm{E}-01$ & Al \\
\hline & Uncorrected weight of impurity in sample $(\mu \mathrm{g})$ : & 70.97 & 16.00 & 93.42 \\
\hline AI & Weight of impurity in blank $(\mu \mathrm{g})$ : & 1.78 & 2.20 & \\
\hline & Minimum corrected weight of impurity in sample $(\mu g)$ : & 69.19 & 13.80 & 87.93 \\
\hline & Maximum corrected weight of impurity in sample $(\mu \mathrm{g})$ : & 69.19 & 13.80 & 87.93 \\
\hline & Measured concentration of impurity in sample $(\mathrm{\mu g} / \mathrm{ml})$; & $5.44 \mathrm{E}-01$ & $7.20 \mathrm{E}-02$ & Ti \\
\hline & Uncorrected weight of impurity in sample $(\mu \mathrm{g})$ : & 25.57 & 3.60 & 29.17 \\
\hline $\mathbf{T i}$ & Weight of impurity in blank $(\mu \mathrm{g})$ : & $<0.18$ & $<0.19$ & \\
\hline & Minimum corrected weight of impurity in sample $(\mu g)$ : & 25.39 & 3.41 & 28.80 \\
\hline & Maximum corrected weight of impurity in sample $(\mu g)$ : & 25.57 & 3.60 & 29.17 \\
\hline & Measured concentration of impurity in sample $(\mathrm{\mu g} / \mathrm{ml})$ : & $2.73 \mathrm{E}-01$ & $3.87 E-03$ & v \\
\hline & Uncorrected weight of impurity in sample $(\mu \mathrm{g})$ : & 12.83 & 0.19 & 13.02 \\
\hline $\mathbf{v}$ & Weight of impurity in blank $(\mu \mathrm{g})$ : & $<0.04$ & $<0.04$ & \\
\hline & Minimum corrected weight of impurity in sample $(\mu q)$ : & 12.79 & 0.15 & 12.94 \\
\hline & Maximum corrected weight of impurity in sample $(\mu q)$ : & 12.83 & 0.19 & 13.02 \\
\hline
\end{tabular}

comments

FCM checked the data against the of ficial results of RMAL17875 on 2/5/2018.

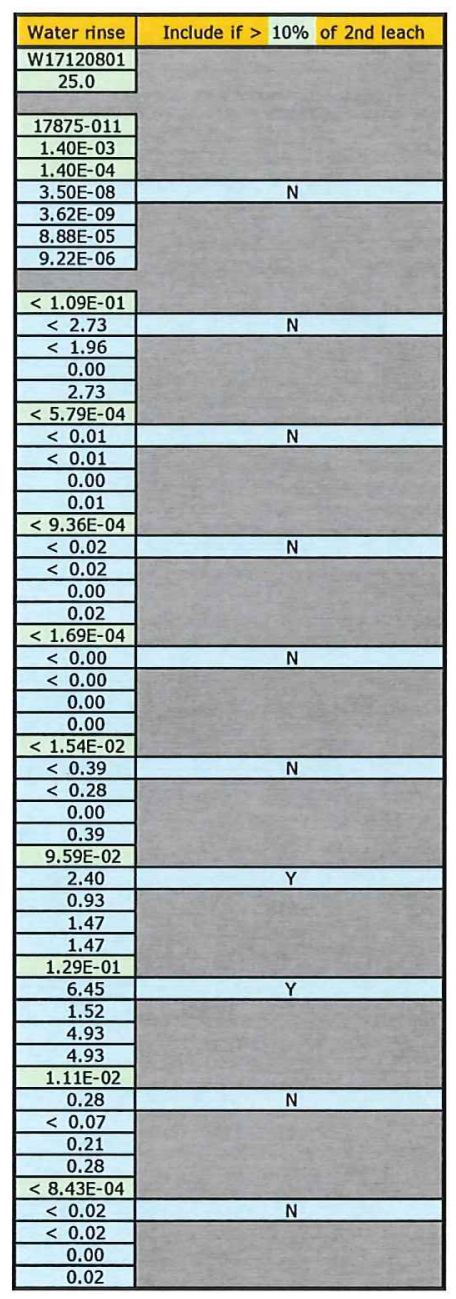

Freed c. Montgomeey

$2-6-2018$ 
Data Report Form DRF-26B: Post-Bum Leach Uranium and Impurities

\begin{tabular}{|r|l|}
\hline Procedure: & AGR-CHAR-DAM-26 Rev, 3 \\
\hline Operator: & Montgomery/Dyer \\
\hline Compact lot ID: & BWXT J52R-16-14154C \\
\hline Compact lot description: & AGR-5/6/7 compacts, 40\% packing fraction \\
\hline Compact ID numbers: & $1004,1016,1018,1085,1101$ \\
\hline DRF filename: & IImC-agr|AGR|LeachBurnLeach 14154C-Group 2_DRF26R3.x|s \\
\hline
\end{tabular}

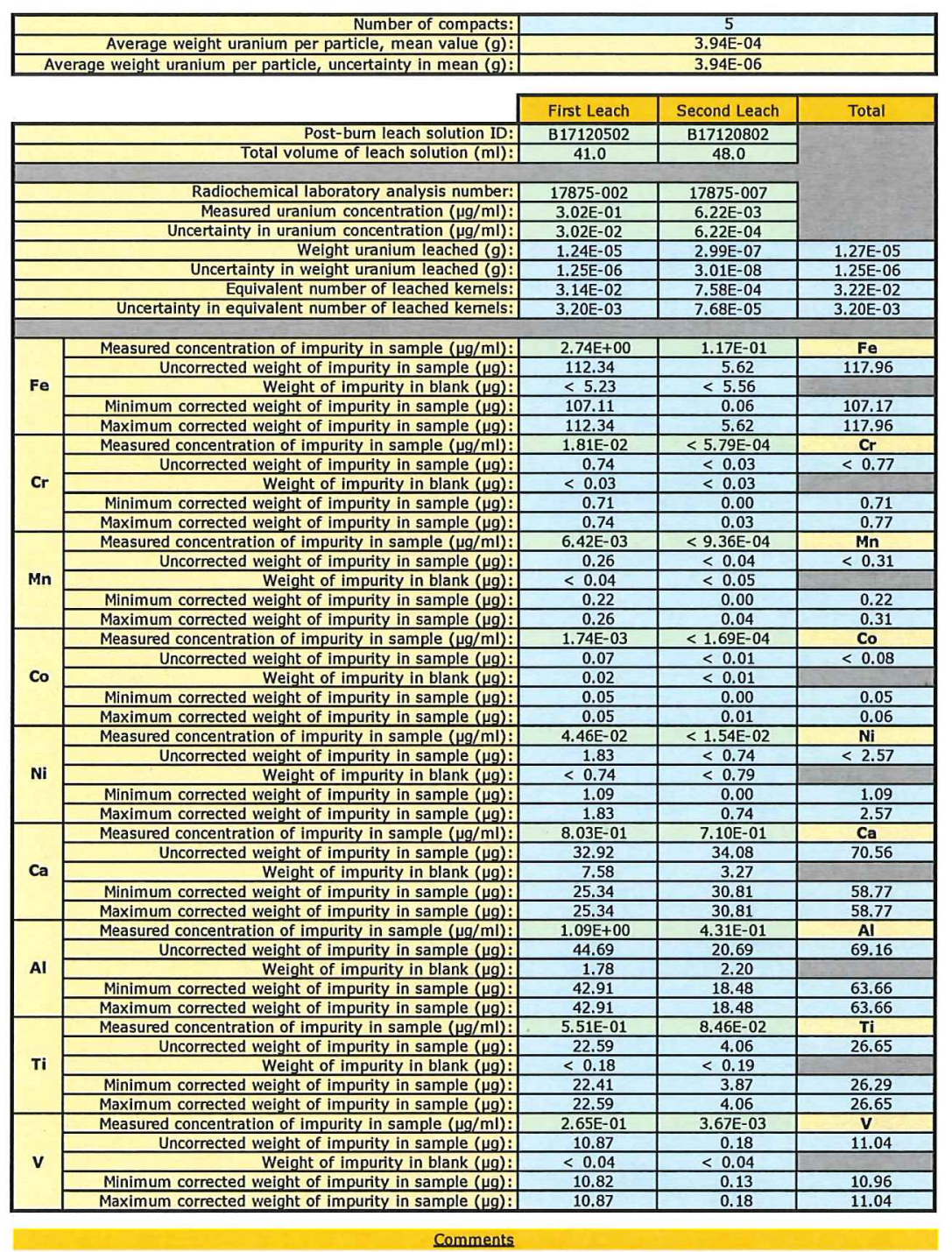

Comments

FCM checked the data against the official results of RMAL17875 on 2/5/2018.

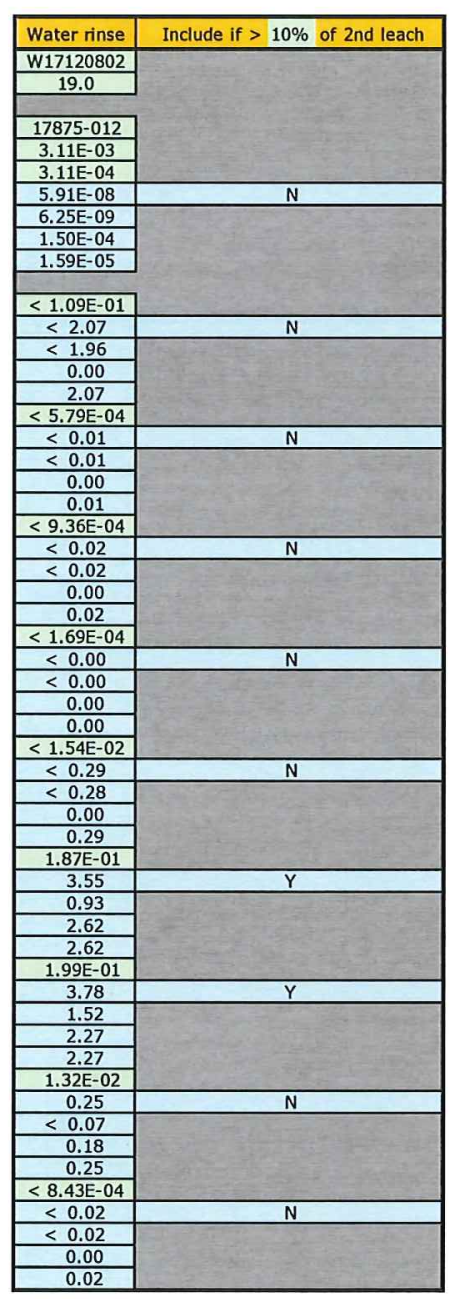

\section{Fuel c. Montyomey}

$2-6-2018$ 
Data Report Form DRF-26B: Post-Bum Leach Uranium and Impurities

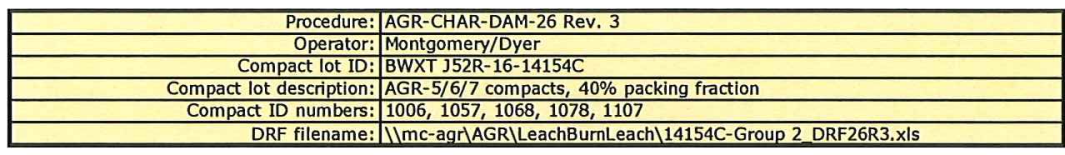

\begin{tabular}{|r|r|}
\hline Number of compacts: & 5 \\
\hline Average weight uranium per particle, mean value $(g):$ & $3.94 \mathrm{E}-04$ \\
\hline Average weight uranium per particle, uncertainty in mean $(\mathrm{g}):$ & $3.94 \mathrm{E}-06$ \\
\hline
\end{tabular}

\begin{tabular}{|c|c|c|c|c|}
\hline & First Leach & Second Leach & Total \\
\hline \multirow{2}{*}{\multicolumn{2}{|c|}{$\begin{array}{cc} & \text { Post-bum leach solution ID: } \\
\text { Total volume of leach solution }(\mathrm{ml}):\end{array}$}} & B17120503 & B17120803 & \\
\hline & & 45.0 & 46.0 & \\
\hline \multicolumn{2}{|r|}{ Radiochemical laboratory analysis number: } & $17875-003$ & $17875-008$ & \\
\hline \multirow{2}{*}{\multicolumn{2}{|c|}{ Measured uranium concentration $(\mu \mathrm{g} / \mathrm{ml})$ : }} & $9.28 \mathrm{E}+00$ & $7.20 \mathrm{E}-02$ & \\
\hline & & $9.28 \mathrm{E}-01$ & $7.20 \mathrm{E}-03$ & \\
\hline \multicolumn{2}{|c|}{$\begin{array}{r}\text { Uncertainty in uranium concentration }(\mu \mathrm{g} / \mathrm{ml}): \\
\text { Weight uranium leached }(\mathrm{g}):\end{array}$} & $4.18 \mathrm{E}-04$ & $3.31 \mathrm{E}-06$ & $4.21 \mathrm{E}-04$ \\
\hline \multicolumn{2}{|c|}{ Uncertainty in weight uranium leached $(\mathrm{g})$ : } & $4.22 \mathrm{E}-05$ & $3.34 \mathrm{E}-07$ & $4.22 \mathrm{E}-05$ \\
\hline \multirow{2}{*}{\multicolumn{2}{|c|}{$\begin{array}{c}\text { Equivalent number of leached kemels: } \\
\text { Uncertainty in equivalent number of leached kernels: }\end{array}$}} & $1.06 E+00$ & $8.41 \mathrm{E}-03$ & $1.07 \mathrm{E}+00$ \\
\hline & & $1.08 \mathrm{E}-01$ & $8.53 \mathrm{E}-04$ & $1.08 \mathrm{E}-01$ \\
\hline \multirow{5}{*}{$\mathbf{F e}$} & Measured concentration of impurity in sample $(\mu \mathrm{g} / \mathrm{ml})$ : & $3.32 E+00$ & $1.22 \mathrm{E}-01$ & $\mathbf{F e}$ \\
\hline & Uncorrected weight of impurity in sample $(\mu \mathrm{g})$ : & 149.40 & 5.61 & 155.01 \\
\hline & Weight of impurity in blank $(\mu g)$ : & $<5.23$ & $<5.56$ & \\
\hline & Minimum corrected weight of impurity in sample $(\mu g)$ : & 144.17 & 0.05 & 144.22 \\
\hline & Maximum corrected weight of impurity in sample $(\mu g)$ : & 149.40 & 5.61 & 155.01 \\
\hline \multirow{5}{*}{$\mathbf{C r}$} & Measured concentration of impurity in sample $(\mu \mathrm{g} / \mathrm{ml})$ : & $1.94 \mathrm{E}-02$ & $<5.79 \mathrm{E}-04$ & $\mathrm{Cr}$ \\
\hline & Uncorrected weight of impurity in sample $(\mu \mathrm{g})$ : & 0.87 & $<0.03$ & $<0.90$ \\
\hline & Weight of impurity in blank $(\mu \mathrm{g})$ : & $<0.03$ & $<0.03$ & \\
\hline & Minimum corrected weight of impurity in sample $(\mu g)$ : & 0.85 & 0.00 & 0.85 \\
\hline & Maximum corrected weight of impurity in sample $(\mu \mathrm{g})$ : & 0.87 & 0.03 & 0.90 \\
\hline \multirow{5}{*}{ Mn } & Measured concentration of impurity in sample $(\mu \mathrm{g} / \mathrm{ml})$ : & $6.30 \mathrm{E}-03$ & $<9.36 \mathrm{E}-04$ & $\mathrm{Mn}$ \\
\hline & Uncorrected weight of impurity in sample $(\mu g)$ : & 0.28 & $<0.04$ & $<0.33$ \\
\hline & $\begin{array}{l}\text { Weight of impurity in blank }(\mu \mathrm{g}) \text { : } \\
\text { W }\end{array}$ & $<0.04$ & $<0.05$ & \\
\hline & Minimum corrected weight of impurity in sample $(\mu g)$ : & 0.24 & 0.00 & 0.24 \\
\hline & Maximum corrected weight of impurity in sample $(\mu g)$ : & 0.28 & 0.04 & 0.33 \\
\hline \multirow{5}{*}{ co } & Measured concentration of impurity in sample $(\mathrm{\mu g} / \mathrm{ml})$ : & $2.12 \mathrm{E}-03$ & $<1.69 \mathrm{E}-04$ & Co \\
\hline & Uncorrected weight of impurity in sample $(\mu g)$ : & 0.10 & $<0.01$ & $<0.10$ \\
\hline & Weight of impurity in blank $(\mu \mathrm{g})$ : & 0.02 & $<0.01$ & \\
\hline & Minimum corrected weight of impurity in sample $(\mu \mathrm{g})$ : & 0.07 & 0.00 & 0.07 \\
\hline & Maximum corrected weight of impurity in sample $(\mu \mathrm{g})$ : & 0.07 & 0.01 & 0.08 \\
\hline \multirow{5}{*}{$\mathbf{N i}$} & Measured concentration of impurity in sample $(\mu \mathrm{g} / \mathrm{ml})$ : & $5.94 \mathrm{E}-02$ & $<1.54 \mathrm{E}-02$ & $\mathrm{Ni}$ \\
\hline & Uncorrected weight of impurity in sample $(\mu \mathrm{g})$ : & 2.67 & $<0.71$ & $<3.38$ \\
\hline & Weight of impurity in blank $(\mu g)$ : & $<0.74$ & $<0.79$ & \\
\hline & Minimum corrected weight of impurity in sample $(\mu g)$ : & 1.93 & 0.00 & 1.93 \\
\hline & Maximum corrected weight of impurity in sample $(\mu g)$ : & 2.67 & 0.71 & 3.38 \\
\hline \multirow{5}{*}{$\mathrm{Ca}$} & Measured concentration of impurity in sample $(\mu \mathrm{g} / \mathrm{ml})$ : & $1.01 \mathrm{E}+00$ & $2.02 \mathrm{E}-01$ & $\mathrm{Ca}$ \\
\hline & Uncorrected weight of impurity in sample $(\mu \mathrm{g})$ : & 45.45 & 9.29 & 57.24 \\
\hline & Weight of impurity in blank $(\mu \mathrm{g})$ : & 7.58 & 3.27 & \\
\hline & Minimum corrected weight of impurity in sample $(\mu g)$ : & 37.87 & 6.02 & 45.46 \\
\hline & Maximum corrected weight of impurity in sample $(\mu \mathrm{g})$ : & 37.87 & 6.02 & 45.46 \\
\hline \multirow{5}{*}{ Al } & Measured concentration of impurity in sample $(\mathrm{\mu g} / \mathrm{ml})$ : & $1.29 \mathrm{E}+00$ & $2.27 \mathrm{E}-01$ & Al \\
\hline & Uncorrected weight of impurity in sample $(\mu \mathrm{g})$ : & 58.05 & 10.44 & 72.27 \\
\hline & Weight of impurity in blank $(\mu g)$ : & 1.78 & 2.20 & \\
\hline & Minimum corrected weight of impurity in sample $(\mu \mathrm{g})$ : & 56.27 & 8.24 & 66.78 \\
\hline & Maximum corrected weight of impurity in sample $(\mu g)$ : & 56.27 & 8.24 & 66.78 \\
\hline \multirow{5}{*}{$\mathrm{Ti}$} & Measured concentration of impurity in sample $(\mu \mathrm{g} / \mathrm{ml})$ : & $4.29 \mathrm{E}-01$ & $6.22 \mathrm{E}-02$ & $\mathrm{Ti}$ \\
\hline & Uncorrected weight of impurity in sample $(\mu g)$ : & 19.31 & 2.86 & 22.17 \\
\hline & Weight of impurity in blank $(\mu g)$ : & $<0.18$ & $<0.19$ & \\
\hline & Minimum corrected weight of impurity in sample $(\mu \mathrm{g})$ : & 19.13 & 2.67 & 21.80 \\
\hline & Maximum corrected weight of impurity in sample $(\mu \mathrm{g})$ : & 19.31 & 2.86 & 22.17 \\
\hline \multirow{5}{*}{ v } & Measured concentration of impurity in sample $(\mu \mathrm{g} / \mathrm{ml})$ : & $2.51 \mathrm{E}-01$ & $5.55 \mathrm{E}-03$ & $\mathbf{v}$ \\
\hline & Uncorrected weight of impurity in sample $(\mu \mathrm{g})$ : & 11.30 & 0.26 & 11.55 \\
\hline & Weight of impurity in blank $(\mu \mathrm{g})$ : & $<0.04$ & $<0.04$ & \\
\hline & Minimum corrected weight of impurity in sample $(\mu g)$ : & 11.25 & 0.21 & 11.47 \\
\hline & Maximum corrected weight of impurity in sample $(\mu \mathrm{g})$ : & 11.30 & 0.26 & 11.55 \\
\hline
\end{tabular}

Comments

FCM checked the data against the official results of RMAL17875 on 2/5/2018.

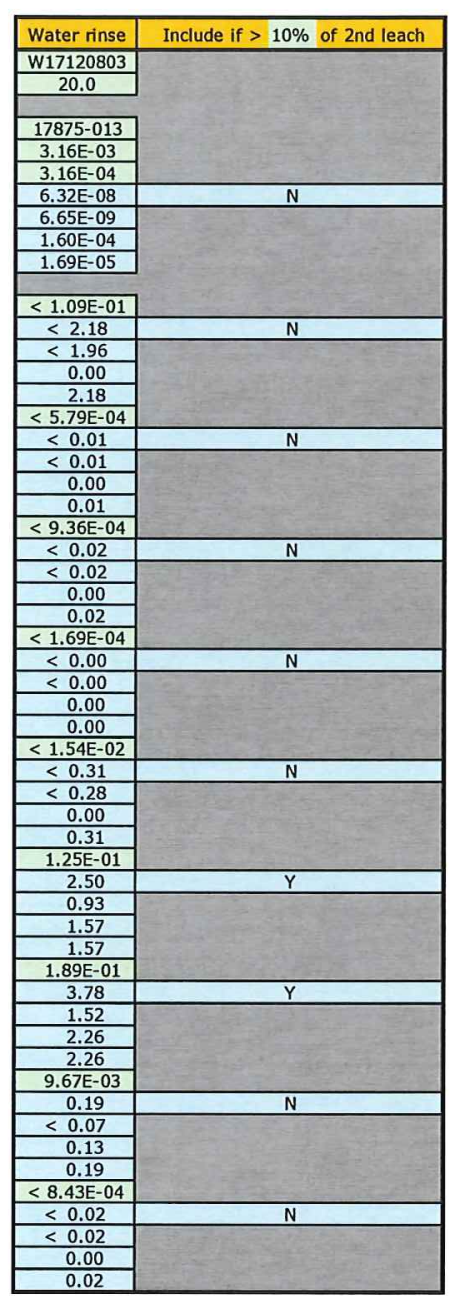

\section{Fued e. Montgomem}

\section{$2-6-2018$}


Data Report Form DRF-26B: Post-Bum Leach Uranium and Impurities

\begin{tabular}{|r|l|}
\hline Procedure: & AGR-CHAR-DAM-26 Rev. 3 \\
\hline Operator: & Montgomery/Dyer \\
\hline Compact lot ID: & BWXT J52R-16-14154C \\
\hline Compact lot description: & AGR-5/6/7 compacts, 40\% packing fraction \\
\hline Compact ID numbers: & $1002,1036,1038,1083,1098$ \\
\hline DRF filename: & IImc-agr|AGR/LeachBurnLeach|14154C-Group 2 DRF26R3.xls \\
\hline
\end{tabular}

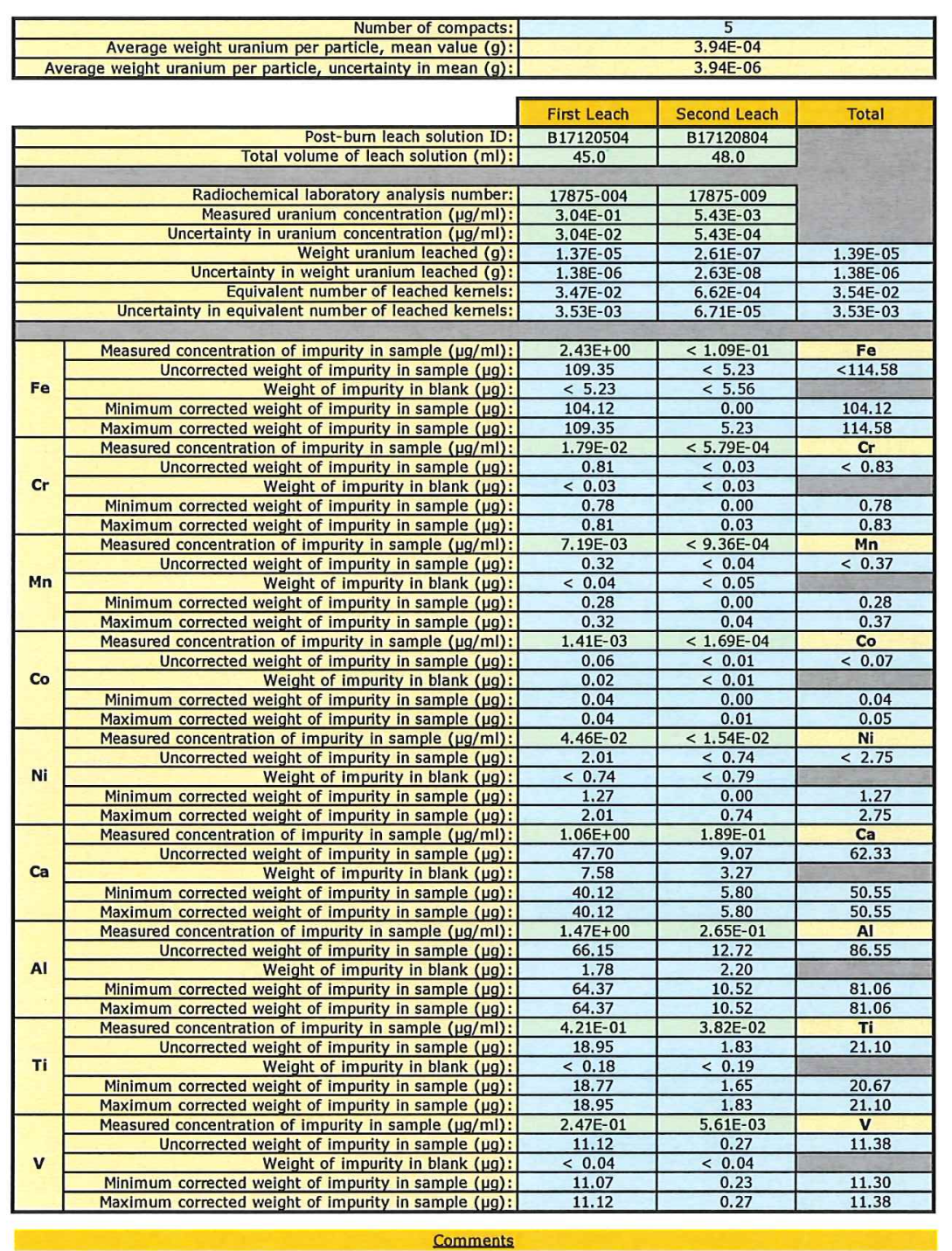

Comments

FCM checked the data against the official results of RMAL17875 on 2/5/2018.

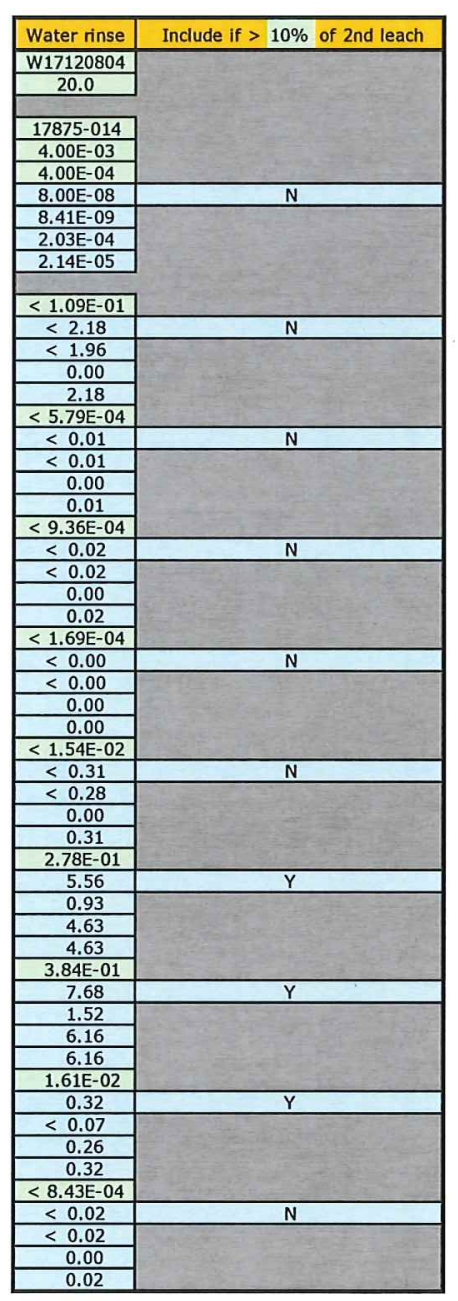

FCM checked the data against the official results of RMAL17875 on $2 / 5 / 2018$

\section{Fied c. Montgomery $\quad 2-6-2018$}


Data Report Form DRF-26B: Post-Bum Leach Uranium and Impurities

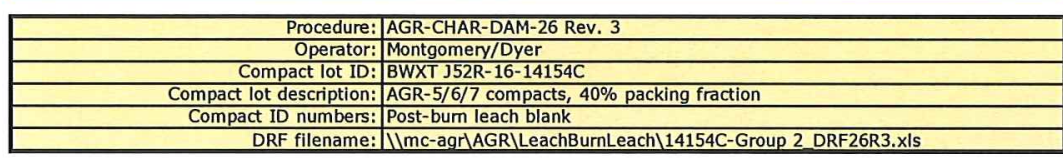

\begin{tabular}{|r|r|}
\hline Average weight uranium per particle, mean value $(\mathrm{g}):$ & $3.94 \mathrm{E}-04$ \\
\hline Average weight uranium per particle, uncertainty in mean $(\mathrm{g}):$ & $3.94 \mathrm{E}-06$ \\
\hline
\end{tabular}

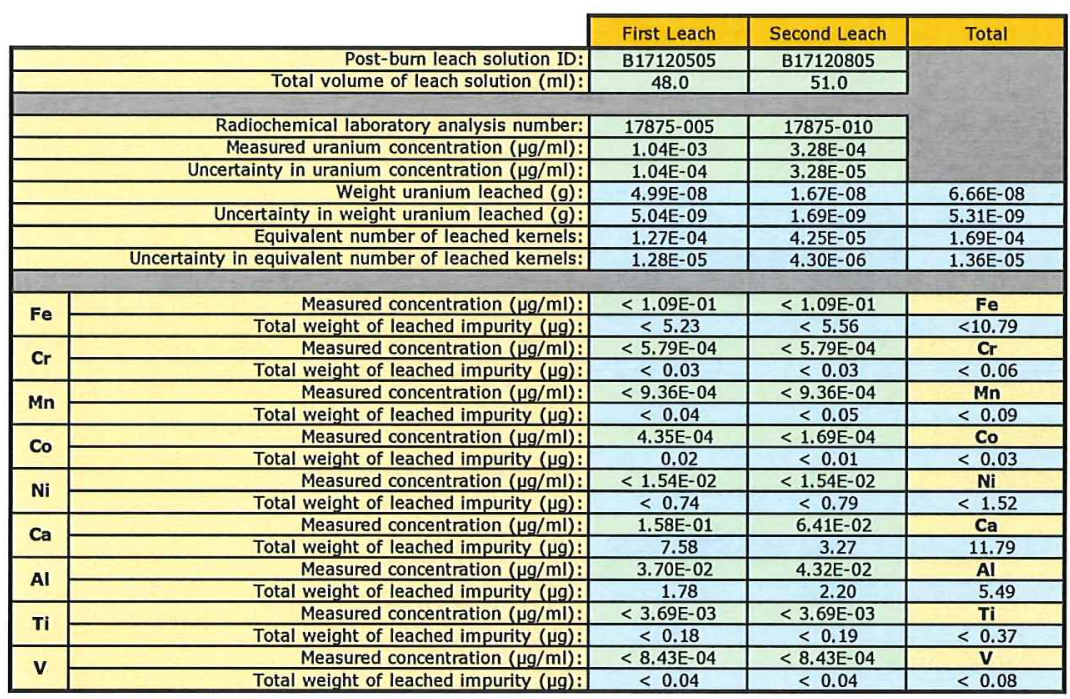

comments

FCM checked the data against the official results of RMAL17875 on 2/5/2018.

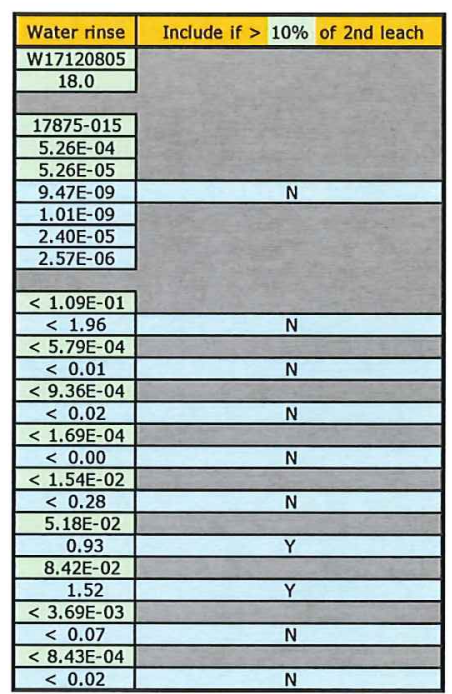

N

\section{Fied c. Montgomery 2-6.2018}


Data Report Form DRF-26A: Pre-Burn Leach Uranium and Impurities

\begin{tabular}{|r|l|}
\hline Procedure: & AGR-CHAR-DAM-26 Rev. 3 \\
\hline Operator: & Montgomery \\
\hline Compact lot ID: & BWXT J52R-16-14154C \\
\hline Compact lot description: & AGR-5/6/7 compacts, 40\% packing fraction \\
\hline Compact ID numbers: & $1052,1086,1104,1034,1007$ \\
\hline DRF filename: & 14154 PPF40-Group 1_DLBL_ICPMS_DRF26R3.xIs \\
\hline
\end{tabular}

\begin{tabular}{|c|c|c|c|c|}
\hline \multirow{3}{*}{\multicolumn{2}{|c|}{$\begin{array}{r}\text { Number of compacts: } \\
\text { Average weight uranium per particle, mean value }(\mathrm{g}): \\
\text { Average weight uranium per particle, uncertainty in mean }(\mathrm{g}):\end{array}$}} & \multicolumn{3}{|c|}{5} \\
\hline & & \multicolumn{3}{|c|}{$3.94 \mathrm{E}-04$} \\
\hline & & \multicolumn{3}{|c|}{$3.94 \mathrm{E}-06$} \\
\hline & & First Leach & Second Leach & Total \\
\hline & Pre-burn leach solution ID: & L19010701 & L19010901 & \\
\hline & Total volume of leach solution $(\mathrm{ml})$ : & 158.0 & 183.0 & \\
\hline & RMAL analysis number: & $19049-001$ & $19049-005$ & \\
\hline & Measured uranium concentration $(\mu \mathrm{g} / \mathrm{ml})$ : & $2.56 \mathrm{E}+00$ & $7.98 \mathrm{E}-03$ & \\
\hline & Uncertainty in uranium concentration $(\mu \mathrm{g} / \mathrm{ml})$ : & $2.56 \mathrm{E}-01$ & $7.98 \mathrm{E}-04$ & \\
\hline & Weight uranium leached $(\mathrm{g})$ : & $4.04 \mathrm{E}-04$ & $1.46 \mathrm{E}-06$ & $4.06 \mathrm{E}-04$ \\
\hline & Uncertainty in weight uranium leached $(\mathrm{g})$ : & $4.05 \mathrm{E}-05$ & $1.46 \mathrm{E}-07$ & $4.05 \mathrm{E}-05$ \\
\hline & Equivalent number of leached kernels: & $1.03 \mathrm{E}+00$ & $3.71 \mathrm{E}-03$ & $1.03 \mathrm{E}+00$ \\
\hline & Uncertainty in equivalent number of leached kernels: & $1.03 \mathrm{E}-01$ & $3.73 \mathrm{E}-04$ & $1.03 \mathrm{E}-01$ \\
\hline \multirow{5}{*}{$\mathbf{F e}$} & Measured concentration of impurity in sample $(\mu \mathrm{g} / \mathrm{ml})$ : & & & $\mathbf{F e}$ \\
\hline & Uncorrected weight of impurity in sample $(\mu \mathrm{g})$ : & & & \\
\hline & Weight of impurity in blank $(\mu \mathrm{g})$ : & & & \\
\hline & Minimum corrected weight of impurity in sample $(\mu \mathrm{g})$ : & & & \\
\hline & Maximum corrected weight of impurity in sample $(\mu \mathrm{g})$ : & & & \\
\hline \multirow{5}{*}{$\mathbf{C r}$} & Measured concentration of impurity in sample $(\mu \mathrm{g} / \mathrm{ml})$ : & & & Cr \\
\hline & Uncorrected weight of impurity in sample $(\mu \mathrm{g})$ : & & & \\
\hline & Weight of impurity in blank $(\mu \mathrm{g})$ : & & & \\
\hline & Minimum corrected weight of impurity in sample $(\mu \mathrm{g})$ : & & & \\
\hline & Maximum corrected weight of impurity in sample $(\mu \mathrm{g})$ : & & & \\
\hline \multirow{5}{*}{ Mn } & Measured concentration of impurity in sample $(\mu \mathrm{g} / \mathrm{ml})$ : & & & Mn \\
\hline & Uncorrected weight of impurity in sample $(\mu \mathrm{g})$ : & & & \\
\hline & Weight of impurity in blank $(\mu \mathrm{g})$ : & & & \\
\hline & Minimum corrected weight of impurity in sample $(\mu \mathrm{g})$ : & & & \\
\hline & Maximum corrected weight of impurity in sample $(\mu \mathrm{g})$ : & & & \\
\hline \multirow{5}{*}{ Co } & Measured concentration of impurity in sample $(\mu \mathrm{g} / \mathrm{ml})$ : & & & Co \\
\hline & Uncorrected weight of impurity in sample $(\mu \mathrm{g})$ : & & & \\
\hline & Weight of impurity in blank $(\mu \mathrm{g})$ : & & & \\
\hline & Minimum corrected weight of impurity in sample $(\mu \mathrm{g})$ : & & & \\
\hline & Maximum corrected weight of impurity in sample $(\mu \mathrm{g})$ : & & & \\
\hline \multirow{5}{*}{$\mathbf{N i}$} & Measured concentration of impurity in sample $(\mu \mathrm{g} / \mathrm{ml})$ : & & & $\mathrm{Ni}$ \\
\hline & Uncorrected weight of impurity in sample $(\mu \mathrm{g})$ : & & & \\
\hline & Weight of impurity in blank $(\mu \mathrm{g})$ : & & & \\
\hline & Minimum corrected weight of impurity in sample $(\mu \mathrm{g})$ : & & & \\
\hline & Maximum corrected weight of impurity in sample $(\mu \mathrm{g})$ : & & & \\
\hline \multirow{5}{*}{$\mathbf{C a}$} & Measured concentration of impurity in sample $(\mu \mathrm{g} / \mathrm{ml})$ : & & & $\mathrm{Ca}$ \\
\hline & Uncorrected weight of impurity in sample $(\mu \mathrm{g})$ : & & & \\
\hline & Weight of impurity in blank $(\mu \mathrm{g})$ : & & & \\
\hline & Minimum corrected weight of impurity in sample $(\mu \mathrm{g})$ : & & & \\
\hline & Maximum corrected weight of impurity in sample $(\mu \mathrm{g})$ : & & & \\
\hline \multirow{5}{*}{ Al } & Measured concentration of impurity in sample $(\mathrm{\mu g} / \mathrm{ml})$ : & & & Al \\
\hline & Uncorrected weight of impurity in sample $(\mu \mathrm{g})$ : & & & \\
\hline & Weight of impurity in blank $(\mu g)$ : & & & \\
\hline & Minimum corrected weight of impurity in sample $(\mu \mathrm{g})$ : & & & \\
\hline & Maximum corrected weight of impurity in sample $(\mu g)$ : & & & \\
\hline \multirow{5}{*}{$\mathbf{T i}$} & Measured concentration of impurity in sample $(\mu \mathrm{g} / \mathrm{ml})$ : & & & Ti \\
\hline & Uncorrected weight of impurity in sample $(\mu \mathrm{g})$ : & & & \\
\hline & Weight of impurity in blank $(\mu \mathrm{g})$ : & & & \\
\hline & Minimum corrected weight of impurity in sample $(\mu \mathrm{g})$ : & & & \\
\hline & Maximum corrected weight of impurity in sample $(\mu \mathrm{g})$ : & & & \\
\hline \multirow{5}{*}{$\mathbf{v}$} & Measured concentration of impurity in sample $(\mu \mathrm{g} / \mathrm{ml})$ : & & & $\mathbf{v}$ \\
\hline & Uncorrected weight of impurity in sample $(\mu \mathrm{g})$ : & & & \\
\hline & Weight of impurity in blank $(\mu \mathrm{g})$ : & & & \\
\hline & Minimum corrected weight of impurity in sample $(\mu \mathrm{g}):$ & & & \\
\hline & Maximum corrected weight of impurity in sample $(\mu \mathrm{g})$ : & & & \\
\hline
\end{tabular}

\section{Comments}

Leached in Vessel \#31 (previously used for 14155D-Group 2 Clutch 5).

FCM checked the recorded data against the official Results of Analysis for RMAL19049 on 3/26/2019.

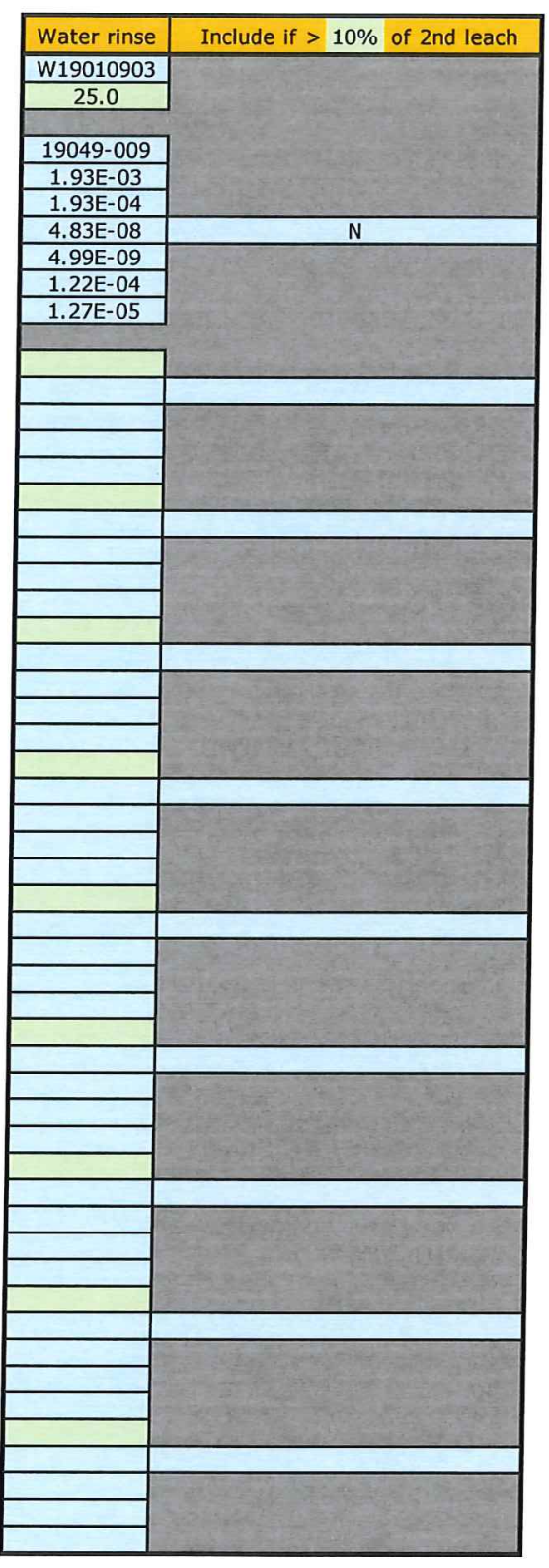




\section{Data Report Form DRF-26A: Pre-Burn Leach Uranium and Impurities}

\begin{tabular}{|r|l|}
\hline Procedure: & AGR-CHAR-DAM-26 Rev. 3 \\
\hline Operator: & Montgomery \\
\hline Compact lot ID: & BWXT J52R-16-14154C \\
\hline Compact lot description: & AGR-5/6/7 compacts, 40\% packing fraction \\
\hline Compact ID numbers: & $1072,1064,1027,1103,1061$ \\
\hline DRF filename: & 14154 C_PF40-Group 1_DLBL_ICPMS_DRF26R3.xIs \\
\hline
\end{tabular}

\begin{tabular}{|r|c|}
\hline Number of compacts: & 5 \\
\hline Average weight uranium per particle, mean value $(\mathrm{g}):$ & $3.94 \mathrm{E}-04$ \\
\hline Average weight uranium per particle, uncertainty in mean $(\mathrm{g}):$ & $3.94 \mathrm{E}-06$ \\
\hline
\end{tabular}

\begin{tabular}{|c|c|c|c|c|}
\hline & First Leach & Second Leach & Total \\
\hline & Pre-burn leach solution ID: & L19010702 & L19010802 & \\
\hline & Total volume of leach solution (ml): & 146.0 & 183.0 & \\
\hline & RMAL analysis number: & $19049-002$ & 19049-006 & \\
\hline & Measured uranium concentration $(\mu \mathrm{g} / \mathrm{ml})$ : & $2.63 E+00$ & $1.03 \mathrm{E}-01$ & \\
\hline & Uncertainty in uranium concentration $(\mu \mathrm{g} / \mathrm{ml})$ : & $2.63 \mathrm{E}-01$ & $1.03 \mathrm{E}-02$ & \\
\hline & Weight uranium leached $(\mathrm{g})$ : & $3.84 \mathrm{E}-04$ & $1.88 \mathrm{E}-05$ & $4.03 \mathrm{E}-04$ \\
\hline & Uncertainty in weight uranium leached $(\mathrm{g})$ : & $3.84 \mathrm{E}-05$ & $1.89 \mathrm{E}-06$ & $3.85 \mathrm{E}-05$ \\
\hline & Equivalent number of leached kernels: & $9.75 \mathrm{E}-01$ & $4.78 \mathrm{E}-02$ & $1.02 \mathrm{E}+00$ \\
\hline & Uncertainty in equivalent number of leached kernels: & $9.80 \mathrm{E}-02$ & $4.81 \mathrm{E}-03$ & $9.82 \mathrm{E}-02$ \\
\hline \multirow{5}{*}{$\mathbf{F e}$} & Measured concentration of impurity in sample $(\mu \mathrm{g} / \mathrm{ml})$ : & & & $\mathbf{F e}$ \\
\hline & Uncorrected weight of impurity in sample $(\mu \mathrm{g})$ : & & & \\
\hline & Weight of impurity in blank $(\mu g)$ : & & & \\
\hline & Minimum corrected weight of impurity in sample $(\mu \mathrm{g})$ : & & & \\
\hline & Maximum corrected weight of impurity in sample $(\mu \mathrm{g})$ : & & & \\
\hline \multirow{5}{*}{$\mathbf{C r}$} & Measured concentration of impurity in sample $(\mathrm{\mu g} / \mathrm{ml})$ : & & & $\mathbf{C r}$ \\
\hline & Uncorrected weight of impurity in sample $(\mu \mathrm{g})$ : & & & \\
\hline & Weight of impurity in blank $(\mu \mathrm{g})$ : & & & \\
\hline & Minimum corrected weight of impurity in sample $(\mu \mathrm{g})$ : & & & \\
\hline & Maximum corrected weight of impurity in sample $(\mu \mathrm{g})$ : & & & \\
\hline \multirow{5}{*}{ Mn } & Measured concentration of impurity in sample $(\mu \mathrm{g} / \mathrm{ml})$ : & & & $\mathbf{M n}$ \\
\hline & Uncorrected weight of impurity in sample $(\mu g)$ : & & & \\
\hline & Weight of impurity in blank $(\mu \mathrm{g})$ : & & & \\
\hline & Minimum corrected weight of impurity in sample $(\mu \mathrm{g})$ : & & & \\
\hline & Maximum corrected weight of impurity in sample $(\mu \mathrm{g})$ : & & & \\
\hline \multirow{5}{*}{ Co } & Measured concentration of impurity in sample $(\mu \mathrm{g} / \mathrm{ml})$ : & & & Co \\
\hline & Uncorrected weight of impurity in sample $(\mu \mathrm{g})$ : & & & \\
\hline & Weight of impurity in blank $(\mu \mathrm{g})$ : & & & \\
\hline & Minimum corrected weight of impurity in sample $(\mu \mathrm{g})$ : & & & \\
\hline & Maximum corrected weight of impurity in sample $(\mu \mathrm{g})$ : & & & \\
\hline \multirow{5}{*}{$\mathbf{N i}$} & Measured concentration of impurity in sample $(\mu \mathrm{g} / \mathrm{ml})$ : & & & $\mathrm{Ni}$ \\
\hline & Uncorrected weight of impurity in sample $(\mu \mathrm{g})$ : & & & \\
\hline & Weight of impurity in blank $(\mu \mathrm{g})$ : & & & \\
\hline & Minimum corrected weight of impurity in sample $(\mu \mathrm{g})$ : & & & \\
\hline & Maximum corrected weight of impurity in sample $(\mu \mathrm{g})$ : & & & \\
\hline \multirow{5}{*}{ Ca } & Measured concentration of impurity in sample $(\mu \mathrm{g} / \mathrm{ml})$ : & & & $\mathbf{C a}$ \\
\hline & Uncorrected weight of impurity in sample $(\mu \mathrm{g})$ : & & & \\
\hline & Weight of impurity in blank $(\mu \mathrm{g})$ : & & & \\
\hline & Minimum corrected weight of impurity in sample $(\mu \mathrm{g}):$ & & & \\
\hline & Maximum corrected weight of impurity in sample $(\mu \mathrm{g})$ : & & & \\
\hline \multirow{5}{*}{ Al } & Measured concentration of impurity in sample $(\mu \mathrm{g} / \mathrm{ml})$ : & & & Al \\
\hline & Uncorrected weight of impurity in sample $(\mu \mathrm{g})$ : & & & \\
\hline & Weight of impurity in blank $(\mu \mathrm{g})$ : & & & \\
\hline & Minimum corrected weight of impurity in sample $(\mu \mathrm{g})$ : & & & \\
\hline & Maximum corrected weight of impurity in sample $(\mu \mathrm{g})$ : & & & \\
\hline \multirow{5}{*}{$\mathbf{T i}$} & Measured concentration of impurity in sample $(\mu \mathrm{g} / \mathrm{ml})$ : & & & Ti \\
\hline & Uncorrected weight of impurity in sample $(\mu \mathrm{g})$ : & & & \\
\hline & Weight of impurity in blank $(\mu \mathrm{g})$ : & & & \\
\hline & Minimum corrected weight of impurity in sample $(\mu \mathrm{g}):$ & & & \\
\hline & Maximum corrected weight of impurity in sample $(\mu \mathrm{g})$ : & & & \\
\hline \multirow{5}{*}{ v } & Measured concentration of impurity in sample $(\mu \mathrm{g} / \mathrm{ml})$ : & & & $\mathbf{v}$ \\
\hline & Uncorrected weight of impurity in sample $(\mu \mathrm{g})$ : & & & \\
\hline & Weight of impurity in blank $(\mu \mathrm{g})$ : & & & \\
\hline & Minimum corrected weight of impurity in sample $(\mu \mathrm{g})$ : & & & \\
\hline & Maximum corrected weight of impurity in sample $(\mu g): 1$ & & & \\
\hline
\end{tabular}

comments

Leached in Vessel \#32 (previously used for 14155D-Group 2 Clutch 6).

FCM checked the recorded data against the official Results of Analysis for RMAL19049 on 3/26/2019.

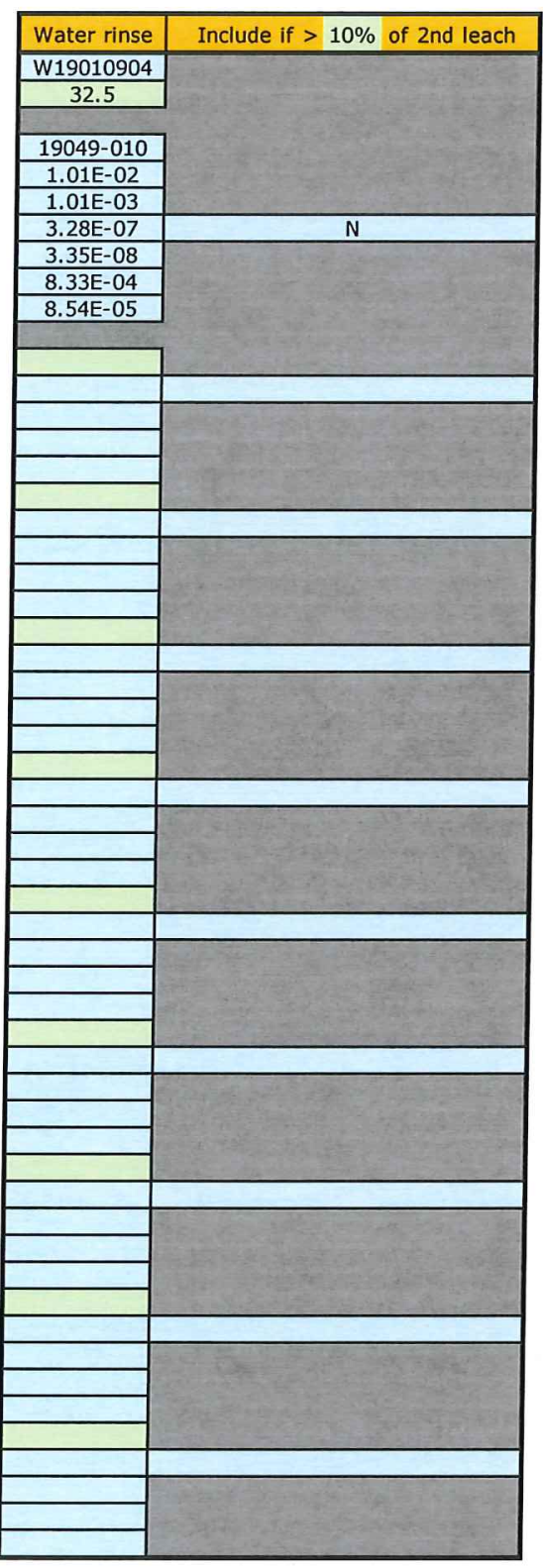


Data Report Form DRF-26A: Pre-Burn Leach Uranium and Impurities

\begin{tabular}{|r|l|}
\hline Procedure: & AGR-CHAR-DAM-26 Rev. 3 \\
\hline Operator: & Montgomery \\
\hline Compact lot ID: & BWXT J52R-16-14154C \\
\hline Compact lot description: & AGR-5/6/7 compacts, $40 \%$ packing fraction \\
\hline Compact ID numbers: & $1094,1050,1106,1079,1041$ \\
\hline DRF filename: & 14154 C_PF 40 -Group 1_DLBL_ICPMS_DRF26R3.xIs \\
\hline
\end{tabular}

\begin{tabular}{|c|c|c|c|c|}
\hline \multicolumn{2}{|r|}{ Number of compacts: } & \multicolumn{3}{|c|}{5} \\
\hline \multirow{2}{*}{\multicolumn{2}{|c|}{$\begin{array}{l}\text { Average weight uranium per particle, mean value }(g) \text { : } \\
\text { Average weight uranium per particle, uncertainty in mean }(g) \text { : }\end{array}$}} & \multicolumn{3}{|c|}{$\frac{3.94 \mathrm{E}-04}{3.94 \mathrm{E}-06}$} \\
\hline & & \multicolumn{3}{|c|}{$3.94 \mathrm{E}-06$} \\
\hline & First Leach & Second Leach & Total \\
\hline & Pre-burn leach solution ID: & L19011001 & L19011401 & \\
\hline & Total volume of leach solution $(\mathrm{ml})$ : & 170.0 & 179.0 & \\
\hline & RMAL analysis number: & $19049-003$ & & \\
\hline & Measured uranium concentration $(\mu \mathrm{g} / \mathrm{ml})$ : & $2.37 \mathrm{E}+00$ & $\frac{19049-007}{1.04 \mathrm{E}-01}$ & \\
\hline & Uncertainty in uranium concentration $(\mu \mathrm{g} / \mathrm{ml})$ : & $2.37 \mathrm{E}-01$ & $1.04 \mathrm{E}-02$ & \\
\hline & Weight uranium leached $(g)$ : & $4.03 \mathrm{E}-04$ & $1.86 \mathrm{E}-05$ & $4.22 \mathrm{E}-04$ \\
\hline & Uncertainty in weight uranium leached $(\mathrm{g})$ : & $4.03 \mathrm{E}-05$ & $1.86 \mathrm{E}-06$ & $4.04 \mathrm{E}-05$ \\
\hline & Equivalent number of leached kernels: & $1.02 \mathrm{E}+00$ & $4.72 \mathrm{E}-02$ & $1.07 \mathrm{E}+00$ \\
\hline & Uncertainty in equivalent number of leached kernels: & $1.03 E-01$ & $4.75 E-03$ & $1.03 \mathrm{E}-01$ \\
\hline \multirow{5}{*}{$\mathbf{F e}$} & Measured concentration of impurity in sample $(\mu \mathrm{g} / \mathrm{ml})$ : & & & $\mathbf{F e}$ \\
\hline & Uncorrected weight of impurity in sample $(\mu \mathrm{g})$ : & & & $\mathrm{re}$ \\
\hline & Weight of impurity in blank $(\mu \mathrm{g})$ : & & & \\
\hline & Minimum corrected weight of impurity in sample $(\mu \mathrm{g})$ : & & & \\
\hline & Maximum corrected weight of impurity in sample $(\mu \mathrm{g})$ : & & & \\
\hline \multirow{5}{*}{ Cr } & Measured concentration of impurity in sample $(\mu \mathrm{g} / \mathrm{ml})$ : & & & Cr \\
\hline & Uncorrected weight of impurity in sample $(\mu \mathrm{g})$ : & & & \\
\hline & Weight of impurity in blank $(\mu \mathrm{g})$ : & & & \\
\hline & Minimum corrected weight of impurity in sample $(\mu \mathrm{g})$ : & & & \\
\hline & Maximum corrected weight of impurity in sample $(\mu \mathrm{g})$ : & & & \\
\hline \multirow{5}{*}{ Mn } & Measured concentration of impurity in sample $(\mu \mathrm{g} / \mathrm{ml})$ : & & & Mn \\
\hline & Uncorrected weight of impurity in sample $(\mu \mathrm{g})$ : & & & \\
\hline & Weight of impurity in blank $(\mu \mathrm{g})$ : & & & \\
\hline & Minimum corrected weight of impurity in sample $(\mu \mathrm{g})$ : & & & \\
\hline & Maximum corrected weight of impurity in sample $(\mu \mathrm{g})$ : & & & \\
\hline \multirow{5}{*}{ Co } & Measured concentration of impurity in sample $(\mu \mathrm{g} / \mathrm{ml})$ : & & & Co \\
\hline & Uncorrected weight of impurity in sample $(\mu \mathrm{g})$ : & & & \\
\hline & Weight of impurity in blank $(\mu \mathrm{g})$ : & & & \\
\hline & Minimum corrected weight of impurity in sample $(\mu \mathrm{g})$ : & & & \\
\hline & Maximum corrected weight of impurity in sample $(\mu \mathrm{g})$ : & & & \\
\hline \multirow{5}{*}{$\mathbf{N i}$} & Measured concentration of impurity in sample $(\mu \mathrm{g} / \mathrm{ml})$ : & & & $\mathrm{Ni}$ \\
\hline & Uncorrected weight of impurity in sample $(\mu \mathrm{g})$ : & & & \\
\hline & Weight of impurity in blank $(\mu \mathrm{g})$ : & & & \\
\hline & Minimum corrected weight of impurity in sample $(\mu \mathrm{g})$ : & & & \\
\hline & Maximum corrected weight of impurity in sample $(\mu \mathrm{g})$ : & & & \\
\hline \multirow{5}{*}{$\mathbf{C a}$} & Measured concentration of impurity in sample $(\mu \mathrm{g} / \mathrm{ml})$ : & & & $\mathrm{Ca}$ \\
\hline & Uncorrected weight of impurity in sample $(\mu \mathrm{g})$ : & & & \\
\hline & Weight of impurity in blank $(\mu \mathrm{g})$ : & & & \\
\hline & Minimum corrected weight of impurity in sample $(\mu \mathrm{g})$ : & & & \\
\hline & Maximum corrected weight of impurity in sample $(\mu \mathrm{g})$ : & & & \\
\hline \multirow{5}{*}{ Al } & Measured concentration of impurity in sample $(\mu \mathrm{g} / \mathrm{ml})$ : & & & Al \\
\hline & Uncorrected weight of impurity in sample $(\mu g)$ : & & & \\
\hline & Weight of impurity in blank $(\mu \mathrm{g})$ : & & & \\
\hline & Minimum corrected weight of impurity in sample $(\mu \mathrm{g})$ : & & & \\
\hline & Maximum corrected weight of impurity in sample $(\mu \mathrm{g})$ : & & & \\
\hline \multirow{4}{*}{$\mathbf{T i}$} & $\begin{array}{r}\text { Measured concentration of impurity in sample }(\mu \mathrm{g} / \mathrm{ml}): \\
\text { Uncorrected weight of impurity in sample }(\mu \mathrm{g}):\end{array}$ & & & Ti \\
\hline & Weight of impurity in blank $(\mu \mathrm{g}):$ & & & \\
\hline & Minimum corrected weight of impurity in sample $(\mu \mathrm{g})$ : & & & \\
\hline & Maximum corrected weight of impurity in sample $(\mu g)$ : & & & \\
\hline \multirow{5}{*}{$\mathbf{v}$} & Measured concentration of impurity in sample $(\mu \mathrm{g} / \mathrm{ml}):$ & & & $\mathbf{v}$ \\
\hline & Uncorrected weight of impurity in sample $(\mu \mathrm{g})$ : & & & \\
\hline & Weight of impurity in blank $(\mu \mathrm{g}):$ & & & \\
\hline & Minimum corrected weight of impurity in sample $(\mu \mathrm{g})$ : & & & \\
\hline & Maximum corrected weight of impurity in sample $(\mu \mathrm{g})$ : & & & \\
\hline
\end{tabular}

\section{comments}

Leached in Vessel \#33 (previously used for 14155D-Group 2 Clutch 7).

FCM checked the recorded data against the official Results of Analysis for RMAL19049 on 3/26/2019.

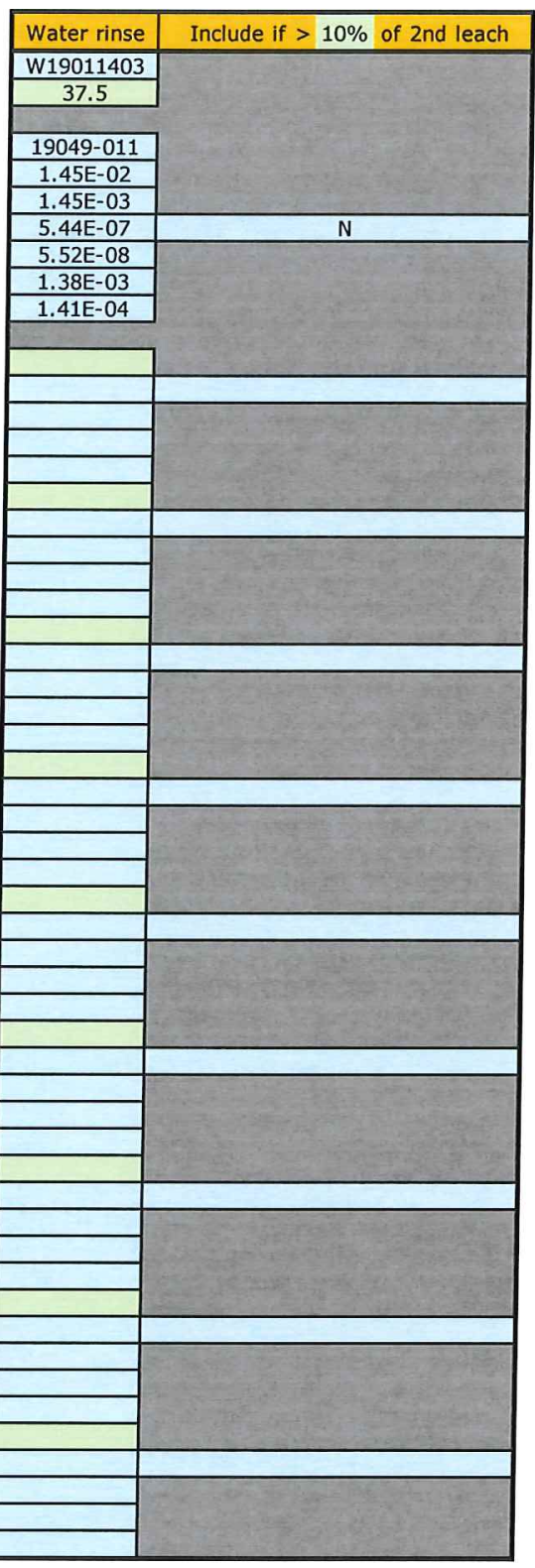

\section{Fied C. Montgomery}

$4-18-2019$

Date


Data Report Form DRF-26A: Pre-Burn Leach Uranium and Impurities

\begin{tabular}{|r|l|}
\hline Procedure: & AGR-CHAR-DAM-26 Rev. 3 \\
\hline Operator: & Montgomery \\
\hline Compact lot ID: & BWXT J52R-16-14154C \\
\hline Compact lot description: & AGR-5/6/7 compacts, 40\% packing fraction \\
\hline Compact ID numbers: & $1031,1080,1076,1092,1051$ \\
\hline DRF filename: & $14154 C$ PF40-Group 1_DLBL_ICPMS_DRF26R3.xIs \\
\hline
\end{tabular}

\begin{tabular}{|c|c|c|c|c|}
\hline \multirow{3}{*}{\multicolumn{2}{|c|}{$\begin{aligned} & \text { Number of compacts: } \\
& \text { Average weight uranium per particle, mean value }(\mathrm{g}): \\
& \text { Average weight uranium per particle, uncertainty in mean }(\mathrm{g}):\end{aligned}$}} & \multicolumn{3}{|c|}{5} \\
\hline & & \multirow{2}{*}{\multicolumn{3}{|c|}{$\begin{array}{l}3.94 \mathrm{E}-04 \\
3.94 \mathrm{E}-06 \\
\end{array}$}} \\
\hline & & & & \\
\hline & & First Leach & Second Leach & Total \\
\hline & Pre-burn leach solution ID: & L19011002 & L19011402 & \\
\hline & Total volume of leach solution $(\mathrm{ml})$ : & 168.0 & 181.0 & \\
\hline & RMAL analysis number: & $19049-004$ & & \\
\hline & Measured uranium concentration $(\mu \mathrm{g} / \mathrm{ml})$ : & $7.30 \mathrm{E}-02$ & $\frac{19049-008}{1.09 E-02}$ & \\
\hline & Uncertainty in uranium concentration $(\mu \mathrm{g} / \mathrm{ml})$ : & $7.30 \mathrm{E}-03$ & $1.09 \mathrm{E}-03$ & \\
\hline & Weight uranium leached $(\mathrm{g})$ : & $1.23 E-05$ & $1.97 \mathrm{E}-06$ & $1.42 \mathrm{E}-05$ \\
\hline & Uncertainty in weight uranium leached $(\mathrm{g})$ : & $1.23 \mathrm{E}-06$ & $1.97 \mathrm{E}-07$ & $1.24 \mathrm{E}-06$ \\
\hline & Equivalent number of leached kernels: & $3.11 \mathrm{E}-02$ & $5.01 \mathrm{E}-03$ & $3.61 \mathrm{E}-02$ \\
\hline & Uncertainty in equivalent number of leached kernels: & $3.13 \mathrm{E}-03$ & $5.04 \mathrm{E}-04$ & $3.18 \mathrm{E}-03$ \\
\hline \multirow{5}{*}{$\mathbf{F e}$} & Measured concentration of impurity in sample $(\mu \mathrm{g} / \mathrm{ml})$ : & & & $\mathrm{Fe}$ \\
\hline & Uncorrected weight of impurity in sample $(\mu \mathrm{g})$ : & & & \\
\hline & Weight of impurity in blank $(\mu \mathrm{g})$ : & & & \\
\hline & Minimum corrected weight of impurity in sample $(\mu \mathrm{g})$ : & & & \\
\hline & Maximum corrected weight of impurity in sample $(\mu \mathrm{g})$ : & & & \\
\hline \multirow{5}{*}{$\mathbf{C r}$} & Measured concentration of impurity in sample $(\mu \mathrm{g} / \mathrm{ml})$ : & & & $\mathbf{C r}$ \\
\hline & Uncorrected weight of impurity in sample $(\mu \mathrm{g})$ : & & & \\
\hline & Weight of impurity in blank $(\mu \mathrm{g})$ : & & & \\
\hline & Minimum corrected weight of impurity in sample $(\mu \mathrm{g})$ : & & & \\
\hline & Maximum corrected weight of impurity in sample $(\mu \mathrm{g})$ : & & & \\
\hline \multirow{5}{*}{$\mathbf{M n}$} & Measured concentration of impurity in sample $(\mu \mathrm{g} / \mathrm{ml})$ : & & & Mn \\
\hline & Uncorrected weight of impurity in sample $(\mu \mathrm{g})$ : & & & \\
\hline & Weight of impurity in blank $(\mu \mathrm{g})$ : & & & \\
\hline & Minimum corrected weight of impurity in sample $(\mu \mathrm{g})$ : & & & \\
\hline & Maximum corrected weight of impurity in sample $(\mu \mathrm{g})$ : & & & \\
\hline \multirow{5}{*}{ Co } & Measured concentration of impurity in sample $(\mu \mathrm{g} / \mathrm{ml})$ : & & & Co \\
\hline & Uncorrected weight of impurity in sample $(\mu \mathrm{g})$ : & & & \\
\hline & Weight of impurity in blank $(\mu \mathrm{g})$ : & & & \\
\hline & Minimum corrected weight of impurity in sample $(\mu \mathrm{g})$ : & & & \\
\hline & Maximum corrected weight of impurity in sample $(\mu \mathrm{g})$ : & & & \\
\hline \multirow{5}{*}{$\mathbf{N i}$} & Measured concentration of impurity in sample $(\mu \mathrm{g} / \mathrm{ml})$ : & & & $\mathbf{N i}$ \\
\hline & Uncorrected weight of impurity in sample $(\mu \mathrm{g})$ : & & & \\
\hline & Weight of impurity in blank $(\mu \mathrm{g})$ : & & & \\
\hline & Minimum corrected weight of impurity in sample $(\mu \mathrm{g})$ : & & & \\
\hline & Maximum corrected weight of impurity in sample $(\mu \mathrm{g})$ : & & & \\
\hline \multirow{5}{*}{$\mathrm{Ca}$} & Measured concentration of impurity in sample $(\mu \mathrm{g} / \mathrm{ml})$ : & & & $\mathbf{C a}$ \\
\hline & Uncorrected weight of impurity in sample $(\mu \mathrm{g})$ : & & & \\
\hline & Weight of impurity in blank $(\mu \mathrm{g})$ : & & & \\
\hline & Minimum corrected weight of impurity in sample $(\mu \mathrm{g})$ : & & & \\
\hline & Maximum corrected weight of impurity in sample $(\mu \mathrm{g})$ : & & & \\
\hline \multirow{5}{*}{ Al } & Measured concentration of impurity in sample $(\mu \mathrm{g} / \mathrm{ml})$ : & & & Al \\
\hline & Uncorrected weight of impurity in sample $(\mu \mathrm{g})$ : & & & \\
\hline & Weight of impurity in blank $(\mu \mathrm{g})$ : & & & \\
\hline & Minimum corrected weight of impurity in sample $(\mu \mathrm{g})$ : & & & \\
\hline & Maximum corrected weight of impurity in sample $(\mu \mathrm{g})$ : & & & \\
\hline \multirow{5}{*}{$\mathbf{T i}$} & Measured concentration of impurity in sample $(\mu \mathrm{g} / \mathrm{ml})$ : & & & $\mathrm{Ti}$ \\
\hline & Uncorrected weight of impurity in sample $(\mu \mathrm{g})$ : & & & \\
\hline & Weight of impurity in blank $(\mu \mathrm{g}):$ & & & \\
\hline & Minimum corrected weight of impurity in sample $(\mu \mathrm{g})$ : & & & \\
\hline & Maximum corrected weight of impurity in sample $(\mu \mathrm{g})$ : & & & \\
\hline \multirow{5}{*}{$\mathbf{v}$} & Measured concentration of impurity in sample $(\mu \mathrm{g} / \mathrm{ml})$ : & & & $\mathbf{v}$ \\
\hline & Uncorrected weight of impurity in sample $(\mu \mathrm{g})$ : & & & \\
\hline & Weight of impurity in blank $(\mu \mathrm{g})$ : & & & \\
\hline & Minimum corrected weight of impurity in sample $(\mu \mathrm{g})$ : & & & \\
\hline & Maximum corrected weight of impurity in sample $(\mu \mathrm{g})$ : & & & \\
\hline
\end{tabular}

\section{Comments}

Leached in Vessel \#30 (previously used for 14155D-Group 2 Clutch 8).

FCM checked the recorded data against the official Results of Analysis for RMAL19049 on 3/26/2019.

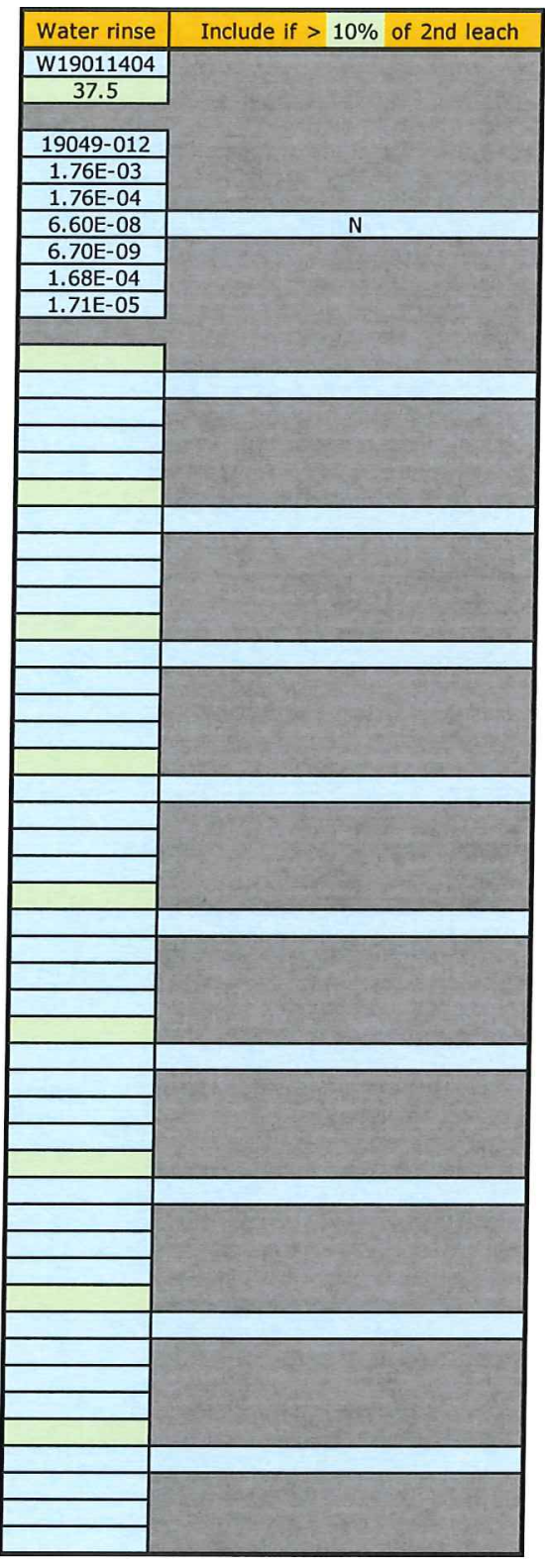

\section{Fred C. Montgomery}

$4-18-2019$

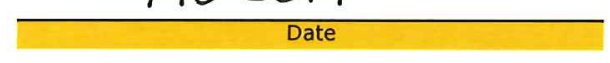


Data Report Form DRF-26B: Post-Burn Leach Uranium and Impurities

\begin{tabular}{|c|c|}
\hline Procedure: & AGR-CHAR-DAM-26 Rev. 3 \\
\hline Operator: & Montgomery \\
\hline Compact lot ID: & BWXT J52R-16-14154C \\
\hline Compact lot description: & AGR- $5 / 6 / 7$ compacts, $40 \%$ packing fraction \\
\hline Compact ID numbers: & $1052,1086,1104,1034,1007$ \\
\hline DRF filename: & 14154C_PF40-Group 1_DLBL_ICPMS_DRF26R3.xIs \\
\hline
\end{tabular}

\begin{aligned} \hline & Number of compacts: \\ \hline Average weight uranium per particle, mean value $(g): & \end{aligned}$ Average weight uranium per particle, uncertainty in mean $(g)$ :

\begin{tabular}{|c|c|c|c|c|}
\hline \multicolumn{2}{|r|}{ Number of compacts: } & \multicolumn{3}{|c|}{5} \\
\hline & Average weight uranium per particle, mean value $(\mathrm{g})$ : & \multirow{2}{*}{\multicolumn{3}{|c|}{$\begin{array}{l}3.94 \mathrm{E}-04 \\
3.94 \mathrm{E}-06 \\
\end{array}$}} \\
\hline \multicolumn{2}{|r|}{ Average weight uranium per particle, uncertainty in mean $(g)$ : } & & & \\
\hline & & First Leach & Second Leach & Total \\
\hline & Post-burn leach solution ID: & B19011701 & B19012301 & \\
\hline & Total volume of leach solution $(\mathrm{ml})$ : & 59.0 & 64.8 & \\
\hline & RMAL analysis number: & $19090-001$ & $19090-005$ & \\
\hline & Measured uranium concentration $(\mu \mathrm{g} / \mathrm{ml})$ : & $2.73 \mathrm{E}-01$ & $1.18 \mathrm{E}-01$ & \\
\hline & Uncertainty in uranium concentration $(\mu \mathrm{g} / \mathrm{ml})$ : & $2.73 E-02$ & $1.18 \mathrm{E}-02$ & \\
\hline & Weight uranium leached $(\mathrm{g})$ : & $1.61 \mathrm{E}-05$ & $7.65 \mathrm{E}-06$ & $2.38 \mathrm{E}-05$ \\
\hline & Uncertainty in weight uranium leached (g): & $1.62 \mathrm{E}-06$ & $7.68 \mathrm{E}-07$ & $1.79 \mathrm{E}-06$ \\
\hline & Equivalent number of leached kernels: & $4.09 \mathrm{E}-02$ & $1.94 \mathrm{E}-02$ & $6.03 \mathrm{E}-02$ \\
\hline & Uncertainty in equivalent number of leached kernels: & 4.13E-03 & $1.96 \mathrm{E}-03$ & $4.59 \mathrm{E}-03$ \\
\hline \multirow{5}{*}{$\mathbf{F e}$} & Measured concentration of impurity in sample $(\mu \mathrm{g} / \mathrm{ml})$ : & & & $\mathbf{F e}$ \\
\hline & Uncorrected weight of impurity in sample $(\mu \mathrm{g})$ : & & & \\
\hline & Weight of impurity in blank $(\mu \mathrm{g})$ : & & & \\
\hline & Minimum corrected weight of impurity in sample $(\mu \mathrm{g})$ : & & & \\
\hline & Maximum corrected weight of impurity in sample $(\mu \mathrm{g})$ : & & & \\
\hline \multirow{5}{*}{$\mathrm{Cr}$} & Measured concentration of impurity in sample $(\mu \mathrm{g} / \mathrm{ml})$ : & & & $\mathbf{C r}$ \\
\hline & Uncorrected weight of impurity in sample $(\mu \mathrm{g})$ : & & & \\
\hline & Weight of impurity in blank $(\mu \mathrm{g})$ : & & & \\
\hline & Minimum corrected weight of impurity in sample $(\mu \mathrm{g})$ : & & & \\
\hline & Maximum corrected weight of impurity in sample $(\mu \mathrm{g})$ : & & & \\
\hline \multirow{5}{*}{ Mn } & Measured concentration of impurity in sample $(\mu \mathrm{g} / \mathrm{ml})$ : & & & Mn \\
\hline & Uncorrected weight of impurity in sample $(\mu \mathrm{g})$ : & & & \\
\hline & Weight of impurity in blank $(\mu \mathrm{g})$ : & & & \\
\hline & Minimum corrected weight of impurity in sample $(\mu g)$ : & & & \\
\hline & Maximum corrected weight of impurity in sample $(\mu \mathrm{g})$ : & & & \\
\hline \multirow{5}{*}{ Co } & Measured concentration of impurity in sample $(\mu \mathrm{g} / \mathrm{ml})$ : & & & Co \\
\hline & Uncorrected weight of impurity in sample $(\mu \mathrm{g})$ : & & & \\
\hline & Weight of impurity in blank $(\mu \mathrm{g})$ : & & & \\
\hline & Minimum corrected weight of impurity in sample $(\mu \mathrm{g})$ : & & & \\
\hline & Maximum corrected weight of impurity in sample $(\mu \mathrm{g})$ : & & & \\
\hline \multirow{5}{*}{$\mathbf{N i}$} & Measured concentration of impurity in sample $(\mu \mathrm{g} / \mathrm{ml})$ : & & & $\mathrm{Ni}$ \\
\hline & Uncorrected weight of impurity in sample $(\mu \mathrm{g})$ : & & & \\
\hline & Weight of impurity in blank $(\mu \mathrm{g})$ : & & & \\
\hline & Minimum corrected weight of impurity in sample $(\mu \mathrm{g})$ : & & & \\
\hline & Maximum corrected weight of impurity in sample $(\mu \mathrm{g})$ : & & & \\
\hline \multirow{4}{*}{ Ca } & Measured concentration of impurity in sample $(\mu \mathrm{g} / \mathrm{ml})$ : & & & Ca \\
\hline & $\begin{array}{r}\text { Uncorrected weight of impurity in sample }(\mu \mathrm{g}) \text { : } \\
\text { Weight of impurity in blank }(\mu \mathrm{g}) \text { : }\end{array}$ & & & \\
\hline & Minimum corrected weight of impurity in sample $(\mu \mathrm{g})$ : & & & \\
\hline & Maximum corrected weight of impurity in sample $(\mu \mathrm{g})$ : & & & \\
\hline \multirow{5}{*}{ Al } & Measured concentration of impurity in sample $(\mathrm{\mu g} / \mathrm{ml})$ : & & & Al \\
\hline & Uncorrected weight of impurity in sample $(\mu \mathrm{g})$ : & & & \\
\hline & Weight of impurity in blank $(\mu \mathrm{g})$ : & & & \\
\hline & Minimum corrected weight of impurity in sample $(\mu \mathrm{g})$ : & & & \\
\hline & Maximum corrected weight of impurity in sample $(\mu \mathrm{g})$ : & & & \\
\hline \multirow{5}{*}{$\mathbf{T i}$} & Measured concentration of impurity in sample $(\mu \mathrm{g} / \mathrm{ml})$ : & & & $\mathrm{Ti}$ \\
\hline & Uncorrected weight of impurity in sample $(\mu \mathrm{g})$ : & & & \\
\hline & Weight of impurity in blank $(\mu \mathrm{g})$ : & & & \\
\hline & Minimum corrected weight of impurity in sample $(\mu \mathrm{g})$ : & & & \\
\hline & Maximum corrected weight of impurity in sample $(\mu \mathrm{g})$ : & & & \\
\hline \multirow{5}{*}{$\mathbf{v}$} & Measured concentration of impurity in sample $(\mu \mathrm{g} / \mathrm{ml})$ : & & & $\mathbf{v}$ \\
\hline & Uncorrected weight of impurity in sample $(\mu \mathrm{g})$ : & & & \\
\hline & Weight of impurity in blank $(\mu \mathrm{g})$ : & & & \\
\hline & Minimum corrected weight of impurity in sample $(\mu \mathrm{g})$ : & & & \\
\hline & Maximum corrected weight of impurity in sample $(\mu \mathrm{g})$ : & & & \\
\hline
\end{tabular}

Comments

FCM checked the recorded data against the official Results of Analysis for RMAL19090 on 4/04/2019.

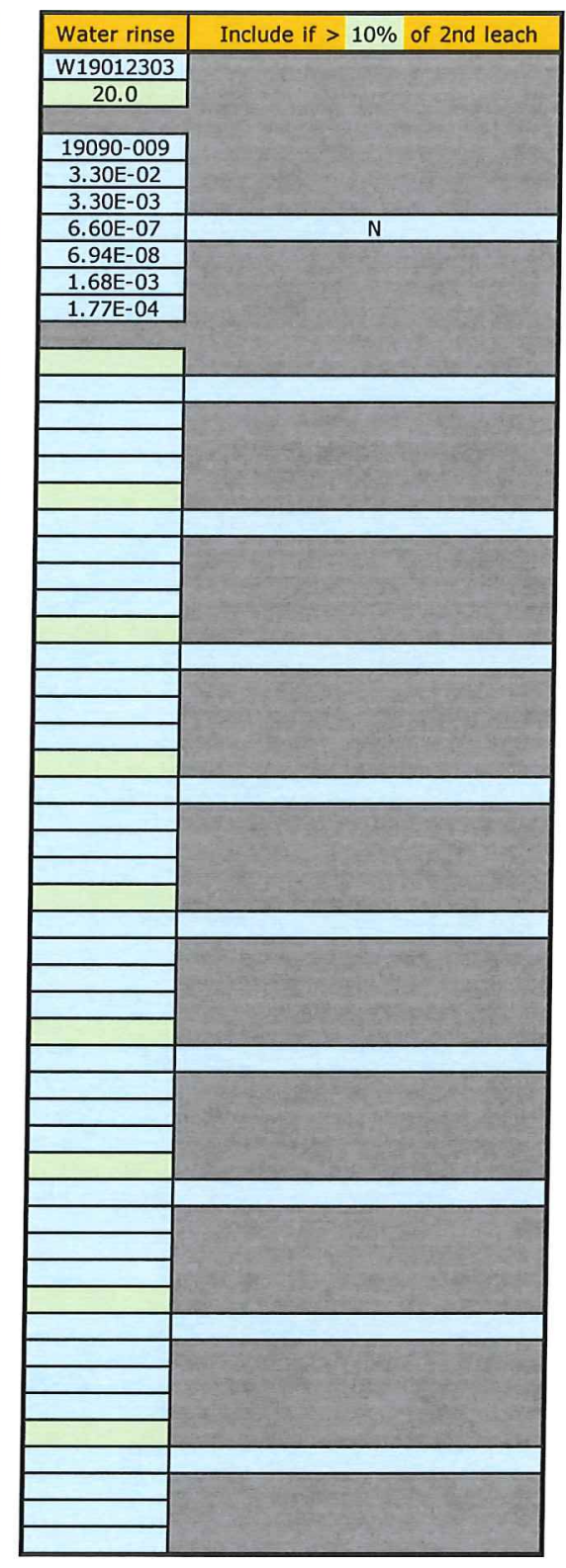

5 $3.94 \mathrm{E}-04$ $3.94 \mathrm{E}-06$

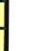

Fied C. Montgomery

Operator
ㄱ. 
Data Report Form DRF-26B: Post-Burn Leach Uranium and Impurities

\begin{tabular}{|r|l|}
\hline Procedure: & AGR-CHAR-DAM-26 Rev. 3 \\
\hline Operator: & Montgomery \\
\hline Compact lot ID: & BWXT J52R-16-14154C \\
\hline Compact lot description: & AGR-5/6/7 compacts, 40\% packing fraction \\
\hline Compact ID numbers: & $1072,1064,1027,1103,1061$ \\
\hline DRF filename: & 14154 C_PF40-Group 1_DLBL_ICPMS_DRF26R3.xIs \\
\hline
\end{tabular}

\begin{tabular}{|r|c|}
\hline Number of compacts: & 5 \\
\hline Average weight uranium per particle, mean value $(\mathrm{g}):$ & $3.94 \mathrm{E}-04$ \\
\hline Average weight uranium per particle, uncertainty in mean $(\mathrm{g}):$ & $3.94 \mathrm{E}-06$ \\
\hline
\end{tabular}

\begin{tabular}{|c|c|c|c|c|}
\hline & First Leach & Second Leach & Total \\
\hline & Post-burn leach solution ID: & B19011702 & B19012302 & \\
\hline & Total volume of leach solution (ml): & 61.8 & 63.2 & \\
\hline & RMAL analysis number: & $19090-002$ & $19090-006$ & \\
\hline & Measured uranium concentration $(\mu \mathrm{g} / \mathrm{ml})$ : & $1.32 \mathrm{E}+01$ & $7.50 \mathrm{E}-02$ & \\
\hline & Uncertainty in uranium concentration $(\mu \mathrm{g} / \mathrm{ml})$ : & $1.32 \mathrm{E}+00$ & $7.50 \mathrm{E}-03$ & \\
\hline & Weight uranium leached $(\mathrm{g})$ : & $8.16 \mathrm{E}-04$ & $4.74 \mathrm{E}-06$ & $8.21 \mathrm{E}-04$ \\
\hline & Uncertainty in weight uranium leached $(\mathrm{g})$ : & $8.20 \mathrm{E}-05$ & $4.77 \mathrm{E}-07$ & $8.20 \mathrm{E}-05$ \\
\hline & Equivalent number of leached kernels: & $2.07 E+00$ & $1.20 \mathrm{E}-02$ & $2.08 \mathrm{E}+00$ \\
\hline & Uncertainty in equivalent number of leached kernels: & $2.09 \mathrm{E}-01$ & $1.22 \mathrm{E}-03$ & $2.09 \mathrm{E}-01$ \\
\hline \multirow{5}{*}{$\mathbf{F e}$} & & & & \\
\hline & Measured concentration of impurity in sample $(\mu \mathrm{g} / \mathrm{ml})$ : & & & $\mathrm{Fe}$ \\
\hline & $\begin{array}{r}\text { Uncorrected weight of impurity in sample }(\mu \mathrm{g}) \text { : } \\
\text { Weight of impurity in blank }(\mu \mathrm{g}) \text { : }\end{array}$ & & & \\
\hline & $\begin{array}{l}\text { Weight of impurity in blank }(\mu \mathrm{g}) \text { : } \\
\text { Minimum corrected weight of impurity in sample }(\mu \mathrm{g}) \text { : }\end{array}$ & & & \\
\hline & & & & \\
\hline \multirow{5}{*}{$\mathrm{Cr}$} & Measured concentration of impurity in sample $(\mu \mathrm{g} / \mathrm{ml})$ : & & & $\mathrm{Cr}$ \\
\hline & Uncorrected weight of impurity in sample $(\mu \mathrm{g})$ : & & & \\
\hline & Weight of impurity in blank $(\mu \mathrm{g})$ : & & & \\
\hline & Minimum corrected weight of impurity in sample $(\mu \mathrm{g})$ : & & & \\
\hline & Maximum corrected weight of impurity in sample $(\mu \mathrm{g})$ : & & & \\
\hline \multirow{5}{*}{ Mn } & Measured concentration of impurity in sample $(\mu \mathrm{g} / \mathrm{ml})$ : & & & Mn \\
\hline & Uncorrected weight of impurity in sample $(\mu \mathrm{g})$ : & & & \\
\hline & Weight of impurity in blank $(\mu g)$ : & & & \\
\hline & Minimum corrected weight of impurity in sample $(\mu \mathrm{g})$ : & & & \\
\hline & Maximum corrected weight of impurity in sample $(\mu \mathrm{g})$ : & & & \\
\hline \multirow{5}{*}{ Co } & Measured concentration of impurity in sample $(\mu \mathrm{g} / \mathrm{ml})$ : & & & Co \\
\hline & Uncorrected weight of impurity in sample $(\mu \mathrm{g})$ : & & & \\
\hline & Weight of impurity in blank $(\mu \mathrm{g})$ : & & & \\
\hline & Minimum corrected weight of impurity in sample $(\mu \mathrm{g})$ : & & & \\
\hline & Maximum corrected weight of impurity in sample $(\mu \mathrm{g})$ : & & & \\
\hline \multirow{5}{*}{$\mathbf{N i}$} & Measured concentration of impurity in sample $(\mu \mathrm{g} / \mathrm{ml})$ : & & & $\mathrm{Ni}$ \\
\hline & Uncorrected weight of impurity in sample $(\mu \mathrm{g})$ : & & & \\
\hline & Weight of impurity in blank $(\mu \mathrm{g})$ : & & & \\
\hline & Minimum corrected weight of impurity in sample $(\mu \mathrm{g})$ : & & & \\
\hline & Maximum corrected weight of impurity in sample $(\mu \mathrm{g})$ : & & & \\
\hline \multirow{5}{*}{$\mathrm{Ca}$} & Measured concentration of impurity in sample $(\mu \mathrm{g} / \mathrm{ml})$ : & & & $\mathrm{Ca}$ \\
\hline & Uncorrected weight of impurity in sample $(\mu \mathrm{g})$ : & & & \\
\hline & Weight of impurity in blank $(\mu \mathrm{g})$ : & & & \\
\hline & Minimum corrected weight of impurity in sample $(\mu \mathrm{g})$ : & & & \\
\hline & Maximum corrected weight of impurity in sample $(\mu \mathrm{g})$ : & & & \\
\hline \multirow{5}{*}{ Al } & Measured concentration of impurity in sample $(\mu \mathrm{g} / \mathrm{ml})$ : & & & Al \\
\hline & Uncorrected weight of impurity in sample $(\mu \mathrm{g})$ : & & & \\
\hline & Weight of impurity in blank $(\mathrm{\mu g})$ : & & & \\
\hline & Minimum corrected weight of impurity in sample $(\mu \mathrm{g}):$ & & & \\
\hline & Maximum corrected weight of impurity in sample $(\mu \mathrm{g})$ : & & & \\
\hline \multirow{5}{*}{$\mathbf{T i}$} & Measured concentration of impurity in sample $(\mu \mathrm{g} / \mathrm{ml})$ : & & & $\mathrm{Ti}$ \\
\hline & Uncorrected weight of impurity in sample $(\mu \mathrm{g})$ : & & & \\
\hline & Weight of impurity in blank $(\mu \mathrm{g})$ : & & & \\
\hline & Minimum corrected weight of impurity in sample $(\mu \mathrm{g})$ : & & & \\
\hline & Maximum corrected weight of impurity in sample $(\mu \mathrm{g})$ : & & & \\
\hline \multirow{5}{*}{$\mathbf{v}$} & Measured concentration of impurity in sample $(\mu \mathrm{g} / \mathrm{ml})$ : & & & $\mathbf{v}$ \\
\hline & Uncorrected weight of impurity in sample $(\mu \mathrm{g})$ : & & & \\
\hline & Weight of impurity in blank $(\mu \mathrm{g}):$ & & & \\
\hline & Minimum corrected weight of impurity in sample $(\mu \mathrm{g})$ : & & & \\
\hline & Maximum corrected weight of impurity in sample $(\mu \mathrm{g}): 1$ & & & \\
\hline
\end{tabular}

Comments

FCM checked the recorded data against the official Results of Analysis for RMAL19090 on 4/04/2019.

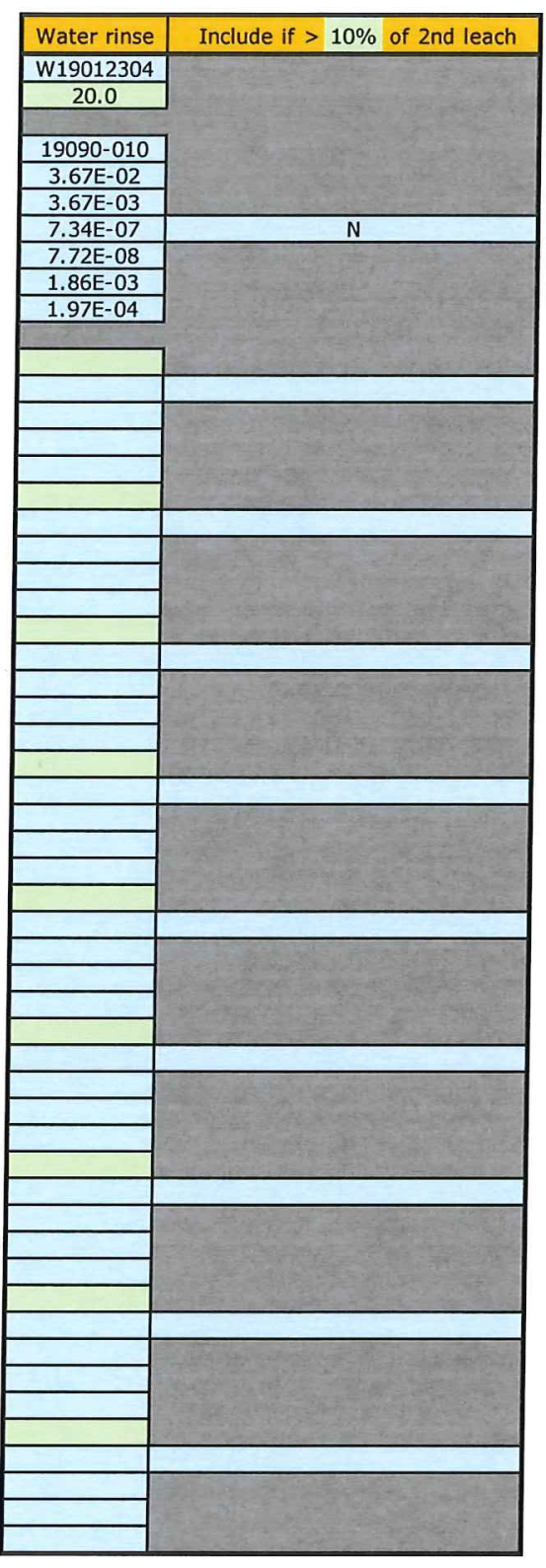




\section{Data Report Form DRF-26B: Post-Burn Leach Uranium and Impurities}

\begin{tabular}{|r|l|}
\hline Procedure: & AGR-CHAR-DAM-26 Rev. 3 \\
\hline Operator: & Montgomery \\
\hline Compact lot ID: & BWXT J52R-16-14154C \\
\hline Compact lot description: & AGR-5/6/7 compacts, 40\% packing fraction \\
\hline Compact ID numbers: & $1094,1050,1106,1079,1041$ \\
\hline DRF filename: & $14154 C$ PF 40-Group 1_DLBL ICPMS_DRF26R3.xIs \\
\hline
\end{tabular}

\begin{tabular}{|r|c|}
\hline Number of compacts: & 5 \\
\hline Average weight uranium per particle, mean value $(\mathrm{g}):$ & $3.94 \mathrm{E}-04$ \\
\hline Average weight uranium per particle, uncertainty in mean $(\mathrm{g}):$ & $3.94 \mathrm{E}-06$ \\
\hline
\end{tabular}

\begin{tabular}{|c|c|c|c|c|}
\hline & First Leach & Second Leach & Total \\
\hline \multirow{2}{*}{\multicolumn{2}{|c|}{$\begin{array}{cc}\text { Post-burn leach solution ID: } & \text { Total volume of leach solution }(\mathrm{ml}): \\
\end{array}$}} & B19012401 & B19012801 & \\
\hline & & 61.3 & 63.3 & \\
\hline \multirow{2}{*}{\multicolumn{2}{|c|}{$\begin{array}{cc}\text { RMAL analysis number: } & \text { Measured uranium concentration }(\mu \mathrm{g} / \mathrm{ml}) \text { : } \\
\text { M } & \text { Mencis }\end{array}$}} & $19090-003$ & $19090-007$ & \\
\hline \multirow{2}{*}{\multicolumn{2}{|c|}{$\begin{array}{c}\text { Measured uranium concentration }(\mu \mathrm{g} / \mathrm{ml}): \\
\text { Uncertainty in uranium concentration }(\mu \mathrm{g} / \mathrm{ml}):\end{array}$}} & $5.13 \mathrm{E}-01$ & $1.98 \mathrm{E}-01$ & \\
\hline & & $5.13 \mathrm{E}-02$ & $1.98 \mathrm{E}-02$ & \\
\hline \multicolumn{2}{|c|}{ Weight uranium leached $(\mathrm{g}):$} & $3.14 \mathrm{E}-05$ & $1.25 \mathrm{E}-05$ & $4.40 \mathrm{E}-05$ \\
\hline \multirow{2}{*}{\multicolumn{2}{|c|}{$\begin{array}{r}\text { Uncertainty in weight uranium leached }(\mathrm{g}): \\
\text { Equivalent number of leached kernels: }\end{array}$}} & $3.16 \mathrm{E}-06$ & $1.26 \mathrm{E}-06$ & $3.40 \mathrm{E}-06$ \\
\hline & & $7.98 \mathrm{E}-02$ & $3.18 \mathrm{E}-02$ & $1.12 \mathrm{E}-01$ \\
\hline \multicolumn{2}{|c|}{ Uncertainty in equivalent number of leached kernels: } & $8.07 E-03$ & $3.21 \mathrm{E}-03$ & $8.71 \mathrm{E}-03$ \\
\hline \multirow{5}{*}{$\mathbf{F e}$} & Measured concentration of impurity in sample $(\mu \mathrm{g} / \mathrm{ml})$ : & & & Fo \\
\hline & Uncorrected weight of impurity in sample $(\mu \mathrm{g})$ : & & & $\mathrm{Fe}$ \\
\hline & Weight of impurity in blank $(\mu \mathrm{g})$ : & & & \\
\hline & Minimum corrected weight of impurity in sample $(\mu \mathrm{g})$ : & & & \\
\hline & Maximum corrected weight of impurity in sample $(\mu \mathrm{g})$ : & & & \\
\hline \multirow{5}{*}{$\mathrm{Cr}$} & Measured concentration of impurity in sample $(\mathrm{\mu g} / \mathrm{ml})$ : & & & $\mathrm{Cr}_{\mathbf{r}}$ \\
\hline & Uncorrected weight of impurity in sample $(\mu \mathrm{g})$ : & & & \\
\hline & Weight of impurity in blank $(\mu \mathrm{g})$ : & & & \\
\hline & Minimum corrected weight of impurity in sample $(\mu \mathrm{g})$ : & & & \\
\hline & Maximum corrected weight of impurity in sample $(\mu \mathrm{g})$ : & & & \\
\hline \multirow{5}{*}{ Mn } & Measured concentration of impurity in sample $(\mu \mathrm{g} / \mathrm{ml})$ : & & & Mn \\
\hline & Uncorrected weight of impurity in sample $(\mu \mathrm{g})$ : & & & \\
\hline & Weight of impurity in blank $(\mu \mathrm{g})$ : & & & \\
\hline & Minimum corrected weight of impurity in sample $(\mu \mathrm{g})$ : & & & \\
\hline & Maximum corrected weight of impurity in sample $(\mu \mathrm{g})$ : & & & \\
\hline \multirow{5}{*}{ co } & Measured concentration of impurity in sample $(\mu \mathrm{g} / \mathrm{ml})$ : & & & Co \\
\hline & Uncorrected weight of impurity in sample $(\mu g)$ : & & & \\
\hline & Weight of impurity in blank $(\mu \mathrm{g})$ : & & & \\
\hline & Minimum corrected weight of impurity in sample $(\mu \mathrm{g})$ : & & & \\
\hline & Maximum corrected weight of impurity in sample $(\mu \mathrm{g})$ : & & & \\
\hline \multirow{5}{*}{$\mathbf{N i}$} & Measured concentration of impurity in sample $(\mu \mathrm{g} / \mathrm{ml})$ : & & & $\mathrm{Ni}$ \\
\hline & Uncorrected weight of impurity in sample $(\mu \mathrm{g})$ : & & & \\
\hline & Weight of impurity in blank $(\mu \mathrm{g})$ : & & & \\
\hline & Minimum corrected weight of impurity in sample $(\mu \mathrm{g})$ : & & & \\
\hline & Maximum corrected weight of impurity in sample $(\mu \mathrm{gg})$ : & & & \\
\hline \multirow{5}{*}{ Ca } & Measured concentration of impurity in sample $(\mu \mathrm{g} / \mathrm{ml})$ : & & & $\mathbf{C a}$ \\
\hline & Uncorrected weight of impurity in sample $(\mu \mathrm{g})$ : & & & \\
\hline & Weight of impurity in blank $(\mu \mathrm{gg})$ : & & & \\
\hline & Minimum corrected weight of impurity in sample $(\mu \mathrm{g})$ : & & & \\
\hline & Maximum corrected weight of impurity in sample $(\mu \mathrm{g})$ : & & & \\
\hline \multirow{5}{*}{ Al } & Measured concentration of impurity in sample $(\mu \mathrm{g} / \mathrm{ml})$ : & & & Al \\
\hline & Uncorrected weight of impurity in sample $(\mu g)$ : & & & \\
\hline & Weight of impurity in blank $(\mu \mathrm{g})$ : & & & \\
\hline & Minimum corrected weight of impurity in sample $(\mu \mathrm{g})$ : & & & \\
\hline & Maximum corrected weight of impurity in sample $(\mu \mathrm{g})$ : & & & \\
\hline \multirow{5}{*}{$\mathrm{Ti}$} & Measured concentration of impurity in sample $(\mu \mathrm{g} / \mathrm{ml})$ : & & & Ti \\
\hline & Uncorrected weight of impurity in sample $(\mu \mathrm{g})$ : & & & \\
\hline & Weight of impurity in blank $(\mu \mathrm{g})$ : & & & \\
\hline & Minimum corrected weight of impurity in sample $(\mu \mathrm{g})$ : & & & \\
\hline & Maximum corrected weight of impurity in sample $(\mu \mathrm{g})$ : & & & \\
\hline \multirow{5}{*}{$\mathbf{v}$} & Measured concentration of impurity in sample $(\mu \mathrm{g} / \mathrm{ml})$ : & & & $\mathbf{v}$ \\
\hline & Uncorrected weight of impurity in sample $(\mu \mathrm{g})$ : & & & \\
\hline & Weight of impurity in blank $(\mu \mathrm{g})$ : & & & \\
\hline & Minimum corrected weight of impurity in sample $(\mu \mathrm{g})$ : & & & \\
\hline & Maximum corrected weight of impurity in sample $(\mu \mathrm{g}): 1$ & & & \\
\hline
\end{tabular}

\section{Comments}

FCM checked the recorded data against the official Results of Analysis for RMAL19090 on 4/04/2019.

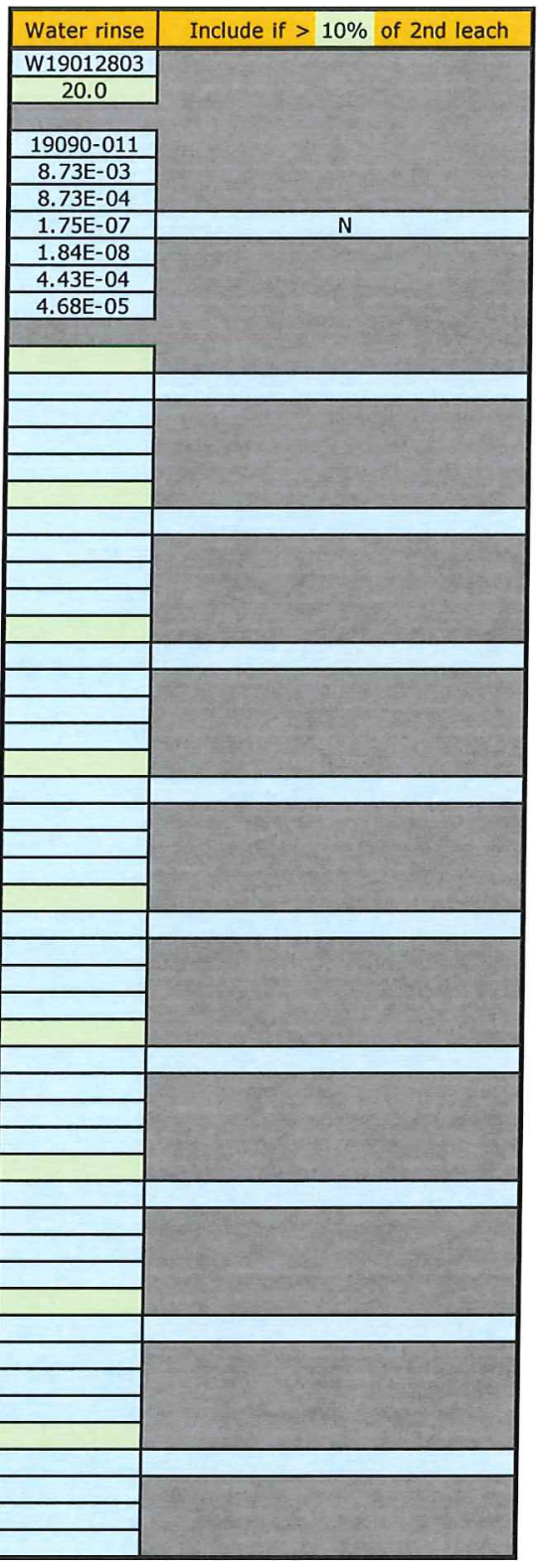

Fud c. Montgomery

Operator
$4-18-2019$

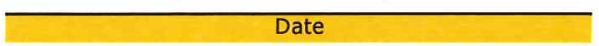


Data Report Form DRF-26B: Post-Burn Leach Uranium and Impurities

\begin{tabular}{|r|l|}
\hline Procedure: & AGR-CHAR-DAM-26 Rev. 3 \\
\hline Operator: & Montgomery \\
\hline Compact lot ID: & BWXT J52R-16-14154C \\
\hline Compact lot description: & AGR-5/6/7 compacts, 40\% packing fraction \\
\hline Compact ID numbers: & $1031,1080,1076,1092,1051$ \\
\hline DRF filename: & $14154 C$ PF40-Group 1_DLBL_ICPMS_DRF26R3.xIs \\
\hline
\end{tabular}

\begin{tabular}{|c|c|c|c|c|}
\hline & Number of compacts: & & 5 & \\
\hline & Average weight uranium per particle, mean value $(g)$ : & & $3.94 \mathrm{E}-04$ & \\
\hline & erage weight uranium per particle, uncertainty in mean $(\mathrm{g})$ : & & $3.94 \mathrm{E}-06$ & \\
\hline & & First Leach & Second Leach & Total \\
\hline & Post-burn leach solution ID: & B19012402 & $\mathrm{B} 19012802$ & \\
\hline & Total volume of leach solution $(\mathrm{ml})$ : & 61.0 & 64.0 & \\
\hline & RMAL analysis number: & 19090-004 & $19090-008$ & \\
\hline & Measured uranium concentration $(\mu \mathrm{g} / \mathrm{ml})$ : & $1.34 \mathrm{E}+01$ & $2.41 \mathrm{E}-01$ & \\
\hline & Uncertainty in uranium concentration $(\mu \mathrm{g} / \mathrm{ml})$ : & $1.34 \mathrm{E}+00$ & $2.41 \mathrm{E}-02$ & \\
\hline & Weight uranium leached $(\mathrm{g})$ : & $8.17 \mathrm{E}-04$ & $1.54 \mathrm{E}-05$ & $8.33 \mathrm{E}-04$ \\
\hline & Uncertainty in weight uranium leached $(\mathrm{g})$ : & $8.22 \mathrm{E}-05$ & $1.55 \mathrm{E}-06$ & $8.22 \mathrm{E}-05$ \\
\hline & Equivalent number of leached kernels: & $2.07 E+00$ & $3.91 \mathrm{E}-02$ & $2.11 E+00$ \\
\hline & Uncertainty in equivalent number of leached kernels: & $2.10 \mathrm{E}-01$ & $3.95 \mathrm{E}-03$ & $2.10 \mathrm{E}-01$ \\
\hline & & & & \\
\hline & $\frac{\text { Measured concentration of impurity in sample }(\mu \mathrm{g} / \mathrm{ml}) \text { : }}{\text { Uncorrected weight of impurity in sample }(\mu \mathrm{q})}$ & & & $\mathbf{F e}$ \\
\hline $\mathbf{F e}$ & $\begin{array}{r}\text { Uncorrected weight of impurity in sample }(\mu \mathrm{g}) \text { : } \\
\text { Weight of impurity in blank }(\mu \mathrm{g}) \text { : }\end{array}$ & & & \\
\hline & Minimum corrected weight of impurity in sample $(\mu \mathrm{g})$ : & & & \\
\hline & Maximum corrected weight of impurity in sample $(\mu \mathrm{g})$ : & & & \\
\hline & Measured concentration of impurity in sample $(\mu \mathrm{g} / \mathrm{ml})$ : & & & $\mathbf{C r}$ \\
\hline & Uncorrected weight of impurity in sample $(\mu \mathrm{g})$ : & & & \\
\hline Cr & Weight of impurity in blank $(\mu \mathrm{g})$ : & & & \\
\hline & Minimum corrected weight of impurity in sample $(\mu g)$ : & & & \\
\hline & Maximum corrected weight of impurity in sample $(\mu \mathrm{g})$ : & & & \\
\hline & Measured concentration of impurity in sample $(\mu \mathrm{g} / \mathrm{ml})$ : & & & Mn \\
\hline & Uncorrected weight of impurity in sample $(\mu \mathrm{g})$ : & & & \\
\hline $\mathbf{M n}$ & Weight of impurity in blank $(\mu \mathrm{g})$ : & & & \\
\hline & Minimum corrected weight of impurity in sample $(\mu \mathrm{g})$ : & & & \\
\hline & $\begin{array}{l}\text { Maximum corrected weight of impurity in sample }(\mu \mathrm{g}) \text { : } \\
\text { Measured concentration of impurity in sample }(\mu \mathrm{g} / \mathrm{ml}) \text { : }\end{array}$ & & & \\
\hline & $\frac{\text { Measured concentration of impurity in sample }(\mu \mathrm{g} / \mathrm{ml}) \text { : }}{\text { Uncorrected weight of impurity in sample }(\mu \mathrm{g}):}$ & & & Co \\
\hline Co & $\begin{array}{r}\text { Uncorrected weight of impurity in sample }(\mu \mathrm{g}) \text { : } \\
\text { Weight of impurity in blank }(\mu g) \text { : }\end{array}$ & & & \\
\hline & $\begin{array}{l}\text { Weight of Impurity in blank }(\mu \mathrm{g}) \text { : } \\
\text { Minimum corrected weight of impurity in sample }(\mu \mathrm{g}) \text { : }\end{array}$ & & & \\
\hline & Maximum corrected weight of impurity in sample $(\mu \mathrm{g})$ : & & & \\
\hline & Measured concentration of impurity in sample $(\mu \mathrm{g} / \mathrm{ml})$ : & & & $\mathrm{Ni}$ \\
\hline & Uncorrected weight of impurity in sample $(\mu \mathrm{g})$ : & & & \\
\hline $\mathbf{N i}$ & Weight of impurity in blank $(\mu \mathrm{g})$ : & & & \\
\hline & Minimum corrected weight of impurity in sample $(\mu \mathrm{g})$ : & & & \\
\hline & Maximum corrected weight of impurity in sample $(\mu \mathrm{g})$ : & & & \\
\hline & Measured concentration of impurity in sample $(\mu \mathrm{g} / \mathrm{ml})$ : & & & $\mathbf{C a}$ \\
\hline & Uncorrected weight of impurity in sample $(\mu \mathrm{g})$ : & & & \\
\hline $\mathrm{Ca}$ & Weight of impurity in blank $(\mu \mathrm{g})$ : & & & \\
\hline & Minimum corrected weight of impurity in sample $(\mu \mathrm{g})$ : & & & \\
\hline & Maximum corrected weight of impurity in sample $(\mu \mathrm{g})$ : & & & \\
\hline & Measured concentration of impurity in sample $(\mu \mathrm{g} / \mathrm{ml})$ : & & & Al \\
\hline & Uncorrected weight of impurity in sample $(\mu \mathrm{g})$ : & & & \\
\hline Al & Weight of impurity in blank $(\mu \mathrm{g})$ : & & & \\
\hline & Minimum corrected weight of impurity in sample $(\mu \mathrm{g})$ : & & & \\
\hline & Maximum corrected weight of impurity in sample $(\mu \mathrm{g})$ : & & & \\
\hline & Measured concentration of impurity in sample $(\mu \mathrm{g} / \mathrm{ml}):$ & & & Ti \\
\hline & Uncorrected weight of impurity in sample $(\mu \mathrm{g})$ : & & & \\
\hline $\mathbf{T i}$ & Weight of impurity in blank $(\mu \mathrm{g})$ : & & & \\
\hline & Minimum corrected weight of impurity in sample $(\mu \mathrm{g})$ : & & & \\
\hline & Maximum corrected weight of impurity in sample $(\mu \mathrm{g})$ : & & & \\
\hline & Measured concentration of impurity in sample $(\mu \mathrm{g} / \mathrm{ml})$ : & & & $\mathbf{v}$ \\
\hline & Uncorrected weight of impurity in sample $(\mu \mathrm{g})$ : & & & \\
\hline v & Weight of impurity in blank $(\mu g)$ : & & & \\
\hline & Minimum corrected weight of impurity in sample $(\mu \mathrm{g})$ : & & & \\
\hline & Maximum corrected weight of impurity in sample $(\mu \mathrm{g}):$ & & & \\
\hline
\end{tabular}

comments

FCM checked the recorded data against the official Results of Analysis for RMAL19090 on 4/04/2019.

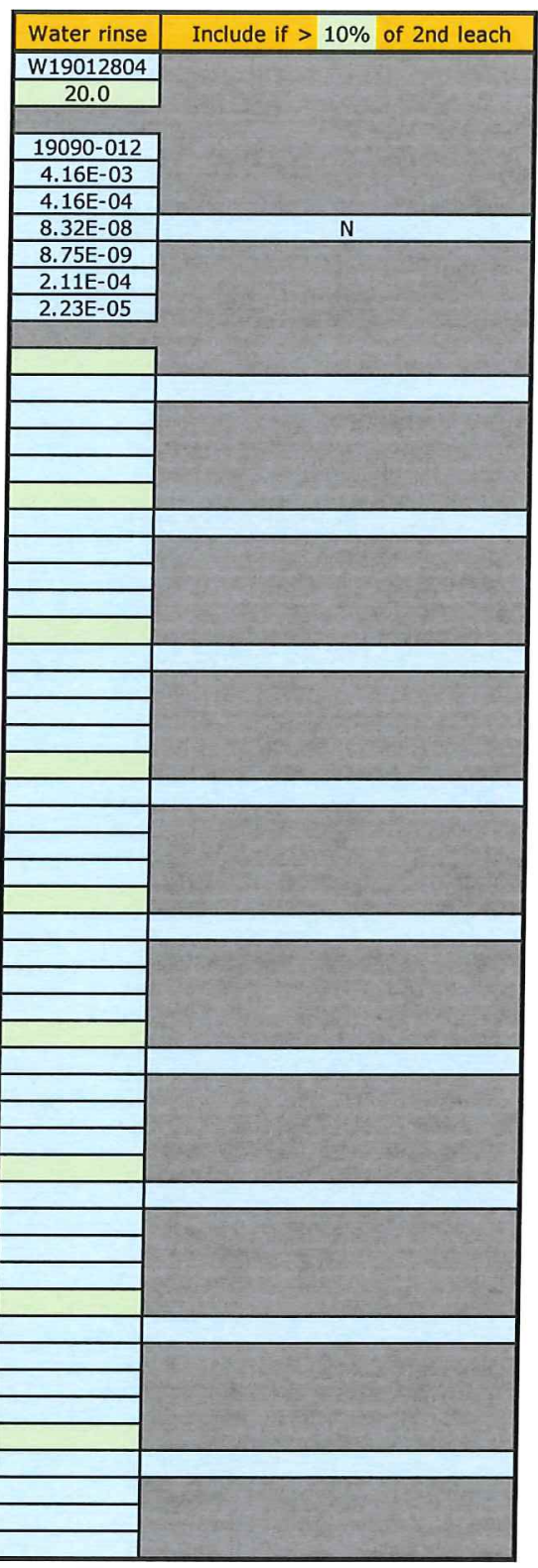


Data Report Form DRF-26A: Pre-Burn Leach Uranium and Impurities

\begin{tabular}{|r|l|}
\hline Procedure: & AGR-CHAR-DAM-26 Rev. 3 \\
\hline Operator: & Montgomery \\
\hline Compact lot ID: & BWXT J52R-16-14155C \\
\hline Compact lot description: & AGR-5/6/7 compacts, 40\% packing fraction \\
\hline Compact ID numbers: & $1167,1137,1162,1129,1136$ \\
\hline DRF filename: & 14155 CPPF40-Group 1_DLBL_ICPMS_DRF26R3.xIs \\
\hline
\end{tabular}

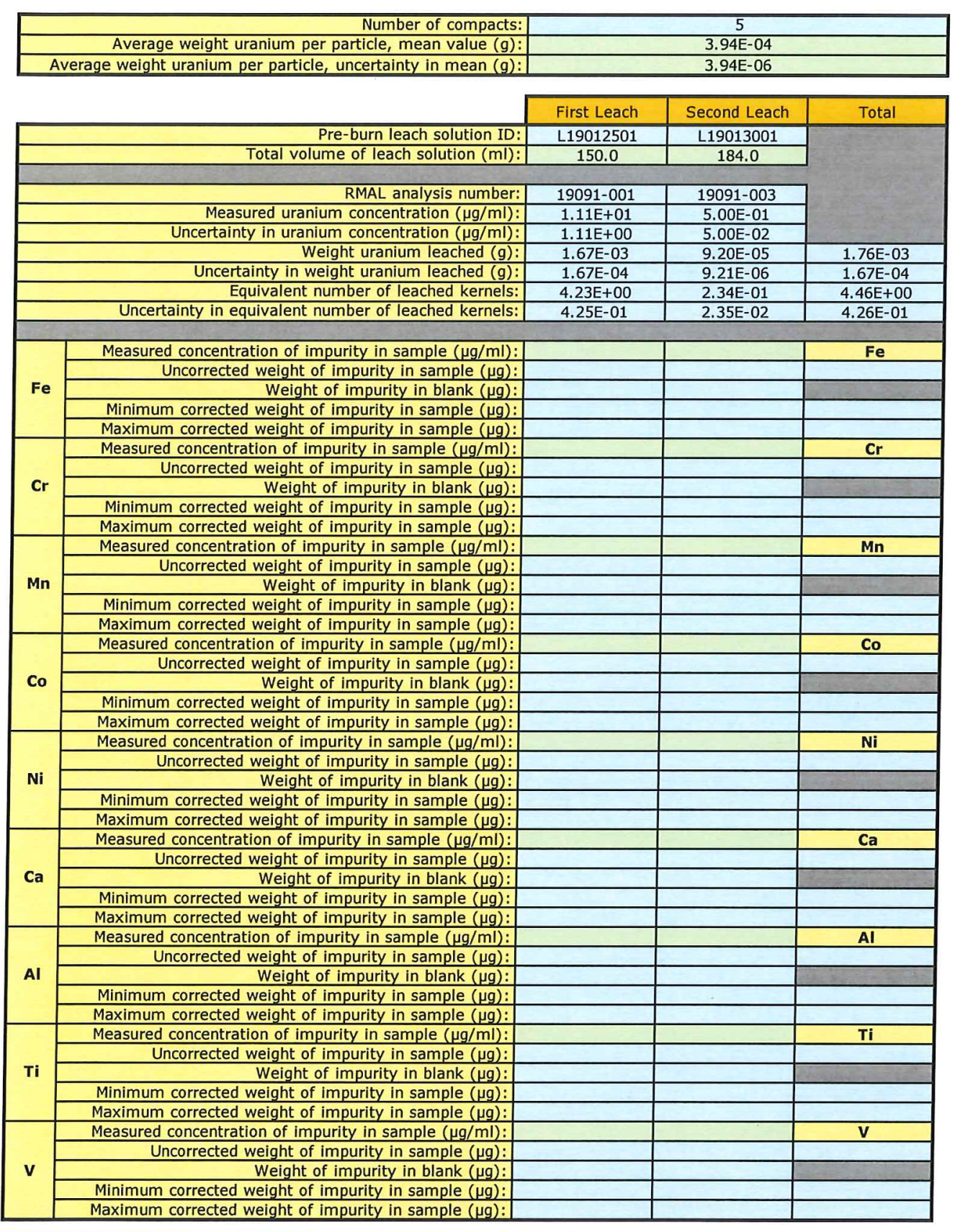

comments

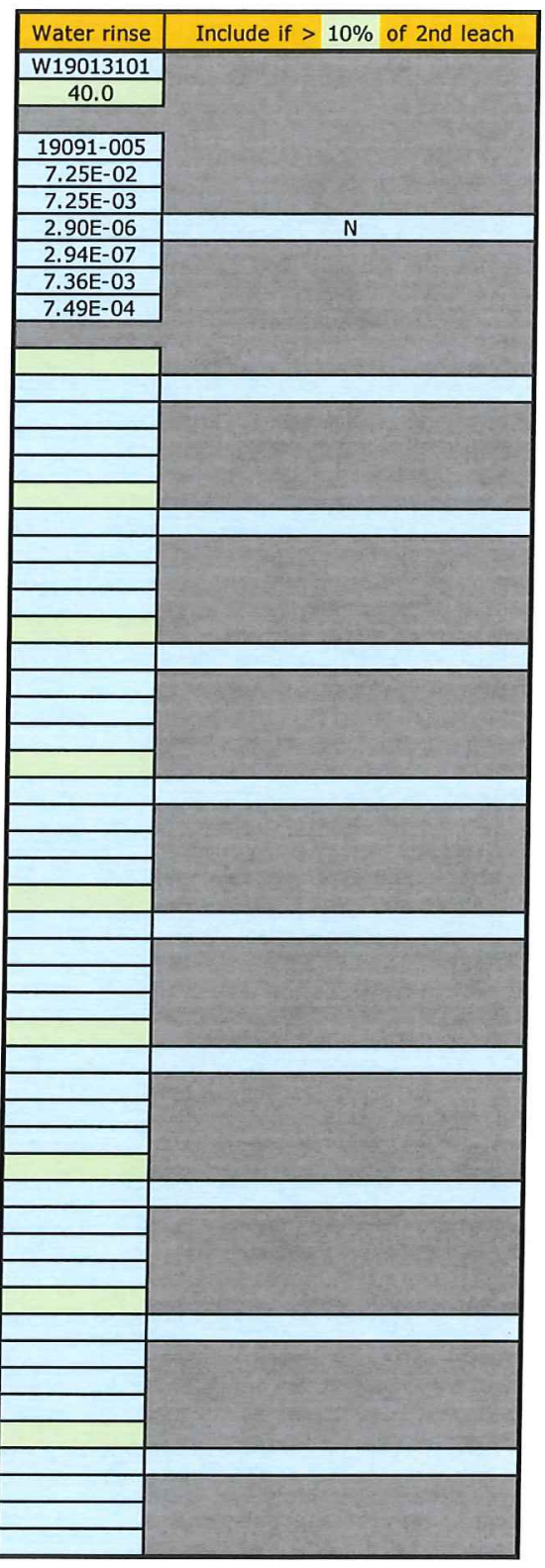

Leached in Vessel RB\#2 (previously used for 11035 overcoated particles-Group 1 Clutch 1).

FCM checked the recorded data against the official Results of Analysis for RMAL19091 on 3/21/2019.

Poured 1st acid rinse from centrifuge tube 2A (L19013002) into the Rig \#1 graduated cylinder (L19013001) instead of

into the Rig \#2 graduated cylinder. This does not impact data because L19013002 concentration was order of magitude

lower than L19013001.

\section{Feed c. Montgomeyy $\frac{4-18-2019}{\text { Doerator }}$}




\section{Data Report Form DRF-26A: Pre-Burn Leach Uranium and Impurities}

\begin{tabular}{|r|l|}
\hline Procedure: & AGR-CHAR-DAM-26 Rev. 3 \\
\hline Operator: & Montgomery \\
\hline Compact lot ID: & BWXT J52R-16-14155C \\
\hline Compact lot description: & AGR-5/6/7 compacts, $40 \%$ packing fraction \\
\hline Compact ID numbers: & $1124,1151,1211,1166,1170$ \\
\hline DRF filename: & $14155 C$ PF 40-Group 1_DLBL ICPMS DRF26R3.xIs \\
\hline
\end{tabular}

\begin{tabular}{r|}
\hline Number of compacts: \\
\hline Average weight uranium per particle, mean value $(g)$ :
\end{tabular}

Average weight uranium per particle, uncertainty in mean $(g)$ :

\begin{tabular}{|c|c|c|c|c|}
\hline & First Leach & Second Leach & \multirow[t]{2}{*}{ Total } \\
\hline & Pre-burn leach solution ID: & L19012502 & L19013002 & \\
\hline \multirow{2}{*}{\multicolumn{4}{|c|}{ Total volume of leach solution $(\mathrm{ml})$ : }} & \\
\hline & & & & \\
\hline & $\begin{array}{r}\text { RMAL analysis number: } \\
\text { Measured uranium concentration }(\mu \mathrm{g} / \mathrm{ml}):\end{array}$ & $\frac{19091-002}{5-2501}$ & $19091-004$ & \\
\hline & $\begin{array}{l}\text { Measured uranium concentration }(\mu \mathrm{g} / \mathrm{ml}) \text { : } \\
\text { Uncertainty in uranium concentration }(\mu \mathrm{g} / \mathrm{ml}) \text { : }\end{array}$ & $\frac{5.26 \mathrm{E}-01}{5.26 \mathrm{E}-02}$ & $\frac{6.25 \mathrm{E}-02}{6.25 \mathrm{E}-03}$ & \\
\hline & Weight uranium leached $(\mathrm{g})$ : & $7.94 \mathrm{E}-05$ & $\begin{array}{l}6.25 \mathrm{E}-03 \\
1.04 \mathrm{E}-05 \\
\end{array}$ & $8.99 \mathrm{E}-05$ \\
\hline & Uncertainty in weight uranium leached $(\mathrm{g})$ : & $7.95 \mathrm{E}-06$ & $1.04 \mathrm{E}-06$ & $8.02 \mathrm{E}-06$ \\
\hline & Equivalent number of leached kernels: & $2.02 \mathrm{E}-01$ & $2.65 \mathrm{E}-02$ & $2.28 \mathrm{E}-01$ \\
\hline & Uncertainty in equivalent number of leached kernels: & $2.03 \mathrm{E}-02$ & $2.66 \mathrm{E}-03$ & $2.05 \mathrm{E}-02$ \\
\hline \multirow{5}{*}{$\mathbf{F e}$} & Measured concentration of impurity in sample $(\mu \mathrm{g} / \mathrm{ml})$ : & & & $\mathrm{Fe}$ \\
\hline & Uncorrected weight of impurity in sample $(\mu g)$ : & & & \\
\hline & Weight of impurity in blank $(\mu \mathrm{g})$ : & & & \\
\hline & Minimum corrected weight of impurity in sample $(\mu \mathrm{g})$ : & & & \\
\hline & Maximum corrected weight of impurity in sample $(\mu \mathrm{g})$ : & & & \\
\hline \multirow{5}{*}{$\mathrm{Cr}$} & Measured concentration of impurity in sample $(\mu \mathrm{g} / \mathrm{ml})$ : & & & $\mathrm{Cr}$ \\
\hline & Uncorrected weight of impurity in sample $(\mu \mathrm{g})$ : & & & \\
\hline & Weight of impurity in blank $(\mu \mathrm{g})$ : & & & \\
\hline & Minimum corrected weight of impurity in sample $(\mu \mathrm{g})$ : & & & \\
\hline & Maximum corrected weight of impurity in sample $(\mu \mathrm{g})$ : & & & \\
\hline \multirow{5}{*}{ Mn } & Measured concentration of impurity in sample $(\mu \mathrm{g} / \mathrm{ml})$ : & & & Mn \\
\hline & Uncorrected weight of impurity in sample $(\mu \mathrm{g})$ : & & & \\
\hline & Weight of impurity in blank $(\mu \mathrm{g})$ : & & & \\
\hline & Minimum corrected weight of impurity in sample $(\mu \mathrm{g})$ : & & & \\
\hline & Maximum corrected weight of impurity in sample $(\mu g)$ : & & & \\
\hline \multirow{5}{*}{ Co } & Measured concentration of impurity in sample $(\mu \mathrm{g} / \mathrm{ml})$; & & & Co \\
\hline & Uncorrected weight of impurity in sample $(\mu \mathrm{g})$ : & & & \\
\hline & Weight of impurity in blank $(\mu \mathrm{g})$ : & & & \\
\hline & Minimum corrected weight of impurity in sample $(\mu \mathrm{g})$ : & & & \\
\hline & Maximum corrected weight of impurity in sample $(\mu g)$ : & & & \\
\hline \multirow{5}{*}{$\mathbf{N i}$} & Measured concentration of impurity in sample $(\mu \mathrm{g} / \mathrm{ml})$ : & & & $\mathbf{N i}$ \\
\hline & Uncorrected weight of impurity in sample $(\mu \mathrm{g})$ : & & & \\
\hline & Weight of impurity in blank $(\mu \mathrm{g})$ : & & & \\
\hline & Minimum corrected weight of impurity in sample $(\mu \mathrm{g})$ : & & & \\
\hline & Maximum corrected weight of impurity in sample $(\mu \mathrm{g})$ : & & & \\
\hline \multirow{5}{*}{ Ca } & Measured concentration of impurity in sample $(\mu \mathrm{g} / \mathrm{ml})$ : & & & $\mathbf{C a}$ \\
\hline & Uncorrected weight of impurity in sample $(\mu \mathrm{g})$ : & & & \\
\hline & Weight of impurity in blank $(\mu \mathrm{g})$ : & & & \\
\hline & Minimum corrected weight of impurity in sample $(\mu \mathrm{g})$ : & & & \\
\hline & Maximum corrected weight of impurity in sample $(\mu \mathrm{g})$ : & & & \\
\hline \multirow{5}{*}{ Al } & Measured concentration of impurity in sample $(\mu \mathrm{g} / \mathrm{ml})$ : & & & Al \\
\hline & Uncorrected weight of impurity in sample $(\mu \mathrm{g})$ : & & & \\
\hline & Weight of impurity in blank $(\mu \mathrm{g})$ : & & & \\
\hline & Minimum corrected weight of impurity in sample $(\mu \mathrm{g})$ : & & & \\
\hline & Maximum corrected weight of impurity in sample $(\mu \mathrm{g})$ : & & & \\
\hline \multirow{5}{*}{$\mathbf{T i}$} & Measured concentration of impurity in sample $(\mu \mathrm{g} / \mathrm{ml})$ : & & & Ti \\
\hline & Uncorrected weight of impurity in sample $(\mu \mathrm{g})$ : & & & \\
\hline & Weight of impurity in blank $(\mu \mathrm{g})$ : & & & \\
\hline & Minimum corrected weight of impurity in sample $(\mu \mathrm{g})$ : & & & \\
\hline & Maximum corrected weight of impurity in sample $(\mu \mathrm{g})$ : & & & \\
\hline \multirow{5}{*}{$\mathbf{v}$} & Measured concentration of impurity in sample $(\mu \mathrm{g} / \mathrm{ml})$ : & & & $\mathbf{v}$ \\
\hline & Uncorrected weight of impurity in sample $(\mu g)$ : & & & \\
\hline & Weight of impurity in blank $(\mu \mathrm{g})$ : & & & \\
\hline & Minimum corrected weight of impurity in sample $(\mu \mathrm{g}):$ & & & \\
\hline & Maximum corrected weight of impurity in sample $(\mu \mathrm{g}):$ : & & & \\
\hline
\end{tabular}

Comments

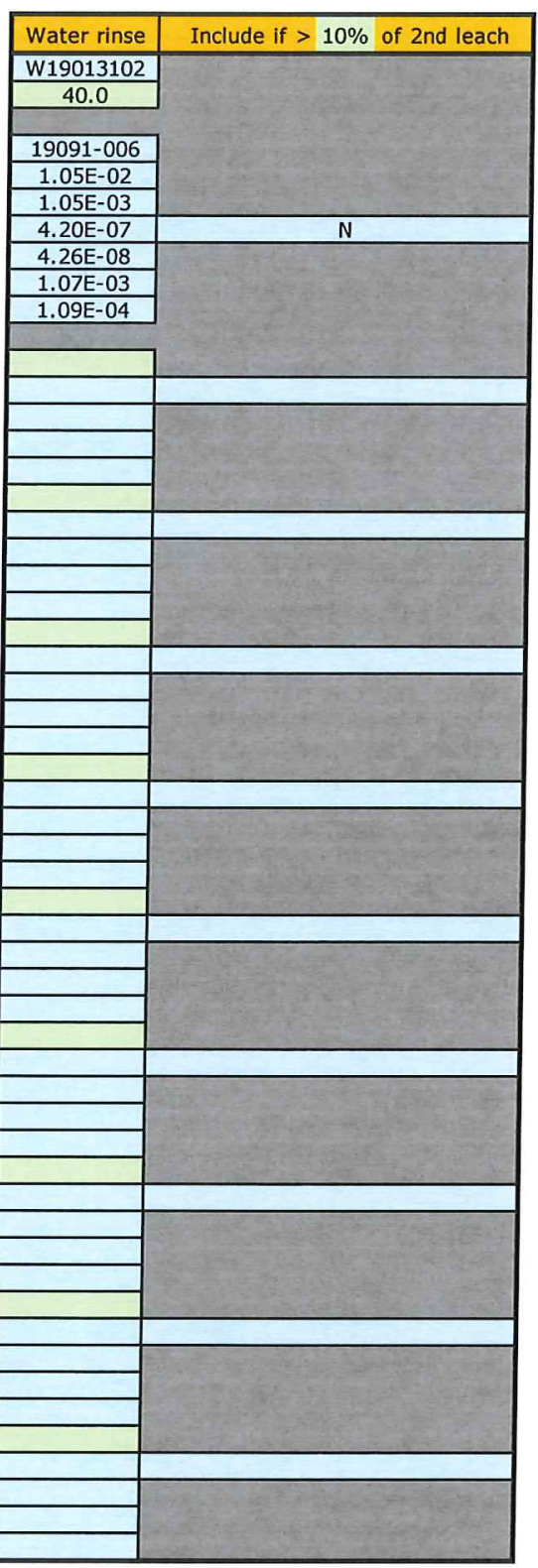

Leached in Vessel RB\#3 (previously used for 11035 overcoated particles-Group 1 Clutch 2).

FCM checked the recorded data against the official Results of Analysis for RMAL19091 on 3/21/2019.

Poured 1st acid rinse from centrifuge tube 2A (L19013002) into the Rig \#1 graduated cylinder (L19013001) instead of

into the Rig \#2 graduated cylinder. This does not impact data because rinse represents small fracton of L19013002

uranium.

\section{Feed c. montgomery}


Data Report Form DRF-26A: Pre-Burn Leach Uranium and Impurities

\begin{tabular}{|r|l|}
\hline Procedure: & AGR-CHAR-DAM-26 Rev. 3 \\
\hline Operator: & Montgomery \\
\hline Compact lot ID: & BWXT J52R-16-14155C \\
\hline Compact lot description: & AGR-5/6/7 compacts, 40\% packing fraction \\
\hline Compact ID numbers: & $1194,1195,1156,1169,1205$ \\
\hline DRF filename: & 14155 CPF40-Group 1_DLBL_ICPMS_DRF26R3.xIs \\
\hline
\end{tabular}

\begin{tabular}{|r|r|}
\hline Number of compacts: & 5 \\
\hline Average weight uranium per particle, mean value $(g):$ & $3.94 \mathrm{E}-04$ \\
\hline Average weight uranium per particle, uncertainty in mean $(\mathrm{g}):$ & $3.94 \mathrm{E}-06$ \\
\hline
\end{tabular}

\begin{tabular}{|c|c|c|c|c|}
\hline & First Leach & Second Leach & Total \\
\hline \multirow{2}{*}{\multicolumn{2}{|c|}{\begin{tabular}{rr|} 
& Pre-burn leach solution ID: \\
Total volume of leach solution $(\mathrm{ml}):$
\end{tabular}}} & L19020101 & L19020401 & \\
\hline & & 154.0 & 139.0 & \\
\hline \multicolumn{2}{|r|}{ RMAL analysis number: } & $19121-001$ & 19121-003 & \\
\hline \multirow{2}{*}{\multicolumn{2}{|c|}{$\begin{array}{c}\text { Measured uranium concentration }(\mu \mathrm{g} / \mathrm{ml}) \text { : } \\
\text { Uncertainty in uranium concentration }(\mu \mathrm{g} / \mathrm{ml}) \text { : }\end{array}$}} & $1.06 \mathrm{E}-01$ & $1.43 \mathrm{E}-02$ & \\
\hline & & $1.06 \mathrm{E}-02$ & $1.43 \mathrm{E}-03$ & \\
\hline \multicolumn{2}{|c|}{$\begin{array}{ll} & \text { Weight uranium leached }(\mathrm{g}) \text { : }\end{array}$} & $1.63 \mathrm{E}-05$ & $1.98 \mathrm{E}-06$ & $1.83 \mathrm{E}-05$ \\
\hline \multirow{2}{*}{\multicolumn{2}{|c|}{$\begin{array}{r}\text { Uncertainty in weight uranium leached }(\mathrm{g}) \text { : } \\
\text { Equivalent number of leached kernels: }\end{array}$}} & $1.63 \mathrm{E}-06$ & $1.99 \mathrm{E}-07$ & $1.64 \mathrm{E}-06$ \\
\hline & & $4.14 \mathrm{E}-02$ & $5.03 \mathrm{E}-03$ & $4.64 \mathrm{E}-02$ \\
\hline \multicolumn{2}{|c|}{ Uncertainty in equivalent number of leached kernels: } & $4.16 \mathrm{E}-03$ & $5.06 \mathrm{E}-04$ & $4.20 \mathrm{E}-03$ \\
\hline \multirow{5}{*}{$\mathbf{F e}$} & Measured concentration of impurity in sample $(\mu \mathrm{g} / \mathrm{ml})$ : & & & $\mathbf{F e}$ \\
\hline & Uncorrected weight of impurity in sample $(\mu \mathrm{g})$ : & & & \\
\hline & Weight of impurity in blank $(\mu \mathrm{g})$ : & & & \\
\hline & Minimum corrected weight of impurity in sample $(\mu \mathrm{g})$ : & & & \\
\hline & Maximum corrected weight of impurity in sample $(\mu \mathrm{g})$ : & & & \\
\hline \multirow{5}{*}{$\mathrm{Cr}$} & Measured concentration of impurity in sample $(\mu \mathrm{g} / \mathrm{ml})$ : & & & $\mathbf{C r}$ \\
\hline & Uncorrected weight of impurity in sample $(\mu \mathrm{g})$ : & & & \\
\hline & Weight of impurity in blank $(\mu \mathrm{g})$ : & & & \\
\hline & Minimum corrected weight of impurity in sample $(\mu g)$ : & & & \\
\hline & Maximum corrected weight of impurity in sample $(\mu g)$ : & & & \\
\hline \multirow{5}{*}{ Mn } & Measured concentration of impurity in sample $(\mu \mathrm{g} / \mathrm{ml})$ : & & & Mn \\
\hline & Uncorrected weight of impurity in sample $(\mu \mathrm{g})$ : & & & \\
\hline & Weight of impurity in blank $(\mu \mathrm{g})$ : & & & \\
\hline & Minimum corrected weight of impurity in sample $(\mu \mathrm{g})$ : & & & \\
\hline & Maximum corrected weight of impurity in sample $(\mu \mathrm{g})$ : & & & \\
\hline \multirow{5}{*}{ Co } & Measured concentration of impurity in sample $(\mu \mathrm{g} / \mathrm{ml})$ : & & & Co \\
\hline & Uncorrected weight of impurity in sample $(\mu \mathrm{g})$ : & & & \\
\hline & Weight of impurity in blank $(\mu \mathrm{g})$ : & & & \\
\hline & Minimum corrected weight of impurity in sample $(\mu \mathrm{g})$ : & & & \\
\hline & Maximum corrected weight of impurity in sample $(\mu \mathrm{g})$ : & & & \\
\hline \multirow{5}{*}{$\mathbf{N i}$} & Measured concentration of impurity in sample $(\mu \mathrm{g} / \mathrm{ml})$ : & & & $\mathrm{Ni}$ \\
\hline & Uncorrected weight of impurity in sample $(\mu \mathrm{g})$ : & & & \\
\hline & Weight of impurity in blank $(\mu \mathrm{g})$ : & & & \\
\hline & Minimum corrected weight of impurity in sample $(\mu \mathrm{g})$ : & & & \\
\hline & Maximum corrected weight of impurity in sample $(\mu g)$ : & & & \\
\hline \multirow{5}{*}{ Ca } & Measured concentration of impurity in sample $(\mu \mathrm{g} / \mathrm{ml})$ : & & & $\mathrm{Ca}$ \\
\hline & Uncorrected weight of impurity in sample $(\mu \mathrm{g})$ : & & & \\
\hline & Weight of impurity in blank $(\mu g)$ : & & & \\
\hline & Minimum corrected weight of impurity in sample $(\mu \mathrm{g})$ : & & & \\
\hline & Maximum corrected weight of impurity in sample $(\mu \mathrm{g})$ : & & & \\
\hline \multirow{5}{*}{ Al } & Measured concentration of impurity in sample $(\mu \mathrm{g} / \mathrm{ml})$ : & & & Al \\
\hline & Uncorrected weight of impurity in sample $(\mu \mathrm{g})$ : & & & \\
\hline & Weight of impurity in blank $(\mu \mathrm{g})$ : & & & \\
\hline & Minimum corrected weight of impurity in sample $(\mu g)$ : & & & \\
\hline & Maximum corrected weight of impurity in sample $(\mu \mathrm{g}):$ & & & \\
\hline \multirow{5}{*}{$\mathrm{Ti}$} & Measured concentration of impurity in sample $(\mu \mathrm{g} / \mathrm{ml})$ : & & & $\mathrm{Ti}$ \\
\hline & Uncorrected weight of impurity in sample $(\mu \mathrm{g})$ : & & & \\
\hline & Weight of impurity in blank $(\mu \mathrm{g}):$ & & & \\
\hline & Minimum corrected weight of impurity in sample $(\mu \mathrm{g})$ : & & & \\
\hline & Maximum corrected weight of impurity in sample $(\mu g)$ : & & & \\
\hline \multirow{5}{*}{$\mathbf{v}$} & Measured concentration of impurity in sample $(\mu \mathrm{g} / \mathrm{ml}):$ & & & $\mathbf{v}$ \\
\hline & Uncorrected weight of impurity in sample $(\mu \mathrm{g})$ : & & & \\
\hline & Weight of impurity in blank $(\mu \mathrm{g})$ : & & & \\
\hline & Minimum corrected weight of impurity in sample $(\mu \mathrm{g})$ : & & & \\
\hline & Maximum corrected weight of impurity in sample $(\mu g)$ : & & & \\
\hline
\end{tabular}

\section{comments}

Leached in Vessel RB\#11 (previously used for 11035 overcoated particles-Group 1 Clutch 3).

FCM checked the recorded data against the official Results of Analysis for RMAL19091 on 3/21/2019.

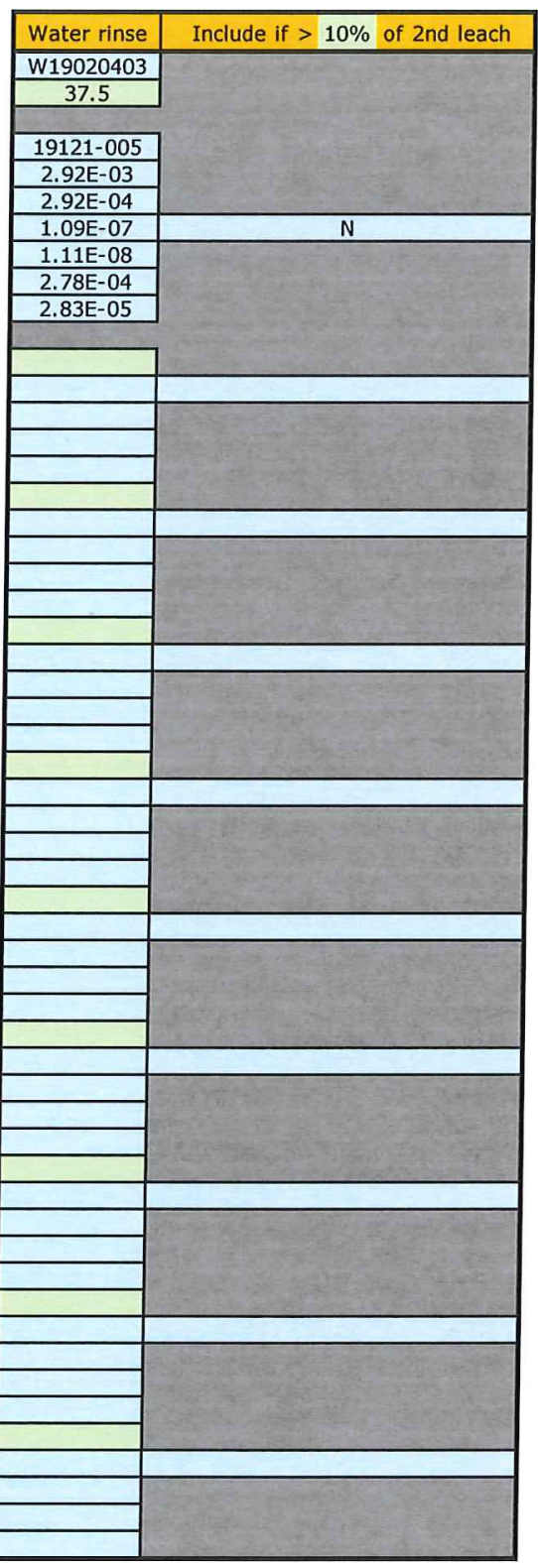

\section{Fed c. montgomery}

$4-18-2019$

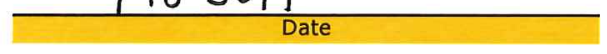




\section{Data Report Form DRF-26A: Pre-Burn Leach Uranium and Impurities}

\begin{tabular}{|r|l|}
\hline Procedure: & AGR-CHAR-DAM-26 Rev. 3 \\
\hline Operator: & Montgomery \\
\hline Compact lot ID: & BWXT J52R-16-14155C \\
\hline Compact lot description: & AGR-5/6/7 compacts, 40\% packing fraction \\
\hline Compact ID numbers: & $1126,1140,1184,1203,1191$ \\
\hline DRF filename: & $14155 C$ PF 40-Group 1_DLBL_ICPMS_DRF26R3.xIs \\
\hline
\end{tabular}

\begin{tabular}{|r|c|}
\hline Number of compacts: & 5 \\
\hline Average weight uranium per particle, mean value $(\mathrm{g}):$ & $3.94 \mathrm{E}-04$ \\
\hline Average weight uranium per particle, uncertainty in mean $(\mathrm{g}):$ & $3.94 \mathrm{E}-06$ \\
\hline
\end{tabular}

\begin{tabular}{|c|c|c|c|c|}
\hline & First Leach & Second Leach & \multirow[t]{2}{*}{ Total } \\
\hline \multirow{2}{*}{\multicolumn{2}{|c|}{$\begin{array}{l}\text { Pre-burn leach solution ID: } \\
\text { Total volume of leach solution (ml): }\end{array}$}} & L19020102 & L19020402 & \\
\hline & & 151.0 & 137.0 & \\
\hline \multicolumn{2}{|r|}{ RMAL analysis number: } & & & \\
\hline \multicolumn{2}{|r|}{ Measured uranium concentration $(\mu \mathrm{g} / \mathrm{ml})$ : } & $\frac{19121-002}{5.15 E+00}$ & $\frac{19121-004}{2.91 \mathrm{E}-01}$ & \\
\hline \multicolumn{2}{|r|}{ Uncertainty in uranium concentration $(\mu \mathrm{g} / \mathrm{ml})$ : } & $5.15 \mathrm{E}-01$ & $\frac{2.91 \mathrm{E}-01}{2.91 \mathrm{E}-02}$ & \\
\hline & Weight uranium leached $(\mathrm{g})$ : & $7.78 \mathrm{E}-04$ & $3.99 \mathrm{E}-05$ & $8.18 \mathrm{E}-04$ \\
\hline \multicolumn{2}{|r|}{ Uncertainty in weight uranium leached $(\mathrm{g})$ : } & $7.79 \mathrm{E}-05$ & $3.99 \mathrm{E}-06$ & $7.80 \mathrm{E}-05$ \\
\hline \multirow{2}{*}{\multicolumn{2}{|c|}{$\begin{array}{c}\text { Equivalent number of leached kernels: } \\
\text { Uncertainty in equivalent number of leached kernels: }\end{array}$}} & $1.97 \mathrm{E}+00$ & $1.01 \mathrm{E}-01$ & $2.08 \mathrm{E}+00$ \\
\hline & & $1.99 \mathrm{E}-01$ & $1.02 \mathrm{E}-02$ & $1.99 \mathrm{E}-01$ \\
\hline \multirow{5}{*}{$\mathbf{F e}$} & Measured concentration of impurity in sample $(\mu \mathrm{g} / \mathrm{ml})$ : & & & $\mathrm{Fe}$ \\
\hline & Uncorrected weight of impurity in sample $(\mu g)$ : & & & \\
\hline & Weight of impurity in blank $(\mu \mathrm{g})$ : & & & \\
\hline & Minimum corrected weight of impurity in sample $(\mu \mathrm{g})$ : & & & \\
\hline & Maximum corrected weight of impurity in sample $(\mu \mathrm{g})$ : & & & \\
\hline \multirow{5}{*}{$\mathrm{Cr}$} & Measured concentration of impurity in sample $(\mu \mathrm{g} / \mathrm{ml})$ : & & & $\mathrm{Cr}$ \\
\hline & Uncorrected weight of impurity in sample $(\mu \mathrm{g})$ : & & & \\
\hline & Weight of impurity in blank $(\mu \mathrm{g})$ : & & & \\
\hline & Minimum corrected weight of impurity in sample $(\mu \mathrm{g})$ : & & & \\
\hline & Maximum corrected weight of impurity in sample $(\mu \mathrm{g})$ : & & & \\
\hline \multirow{5}{*}{ Mn } & Measured concentration of impurity in sample $(\mu \mathrm{g} / \mathrm{ml})$ : & & & Mn \\
\hline & Uncorrected weight of impurity in sample $(\mu \mathrm{g})$ : & & & \\
\hline & Weight of impurity in blank $(\mu \mathrm{g})$ : & & & \\
\hline & Minimum corrected weight of impurity in sample $(\mu \mathrm{g})$ : & & & \\
\hline & Maximum corrected weight of impurity in sample $(\mu \mathrm{g})$ : & & & \\
\hline \multirow{5}{*}{ Co } & Measured concentration of impurity in sample $(\mu \mathrm{g} / \mathrm{ml})$ : & & & Co \\
\hline & Uncorrected weight of impurity in sample $(\mu \mathrm{g})$ : & & & \\
\hline & Weight of impurity in blank $(\mu \mathrm{g})$ : & & & \\
\hline & Minimum corrected weight of impurity in sample $(\mu \mathrm{g})$ : & & & \\
\hline & Maximum corrected weight of impurity in sample $(\mu \mathrm{g})$ : & & & \\
\hline \multirow{5}{*}{$\mathbf{N i}$} & Measured concentration of impurity in sample $(\mu \mathrm{g} / \mathrm{ml})$ : & & & $\mathrm{Ni}$ \\
\hline & Uncorrected weight of impurity in sample $(\mu \mathrm{g})$ : & & & \\
\hline & Weight of impurity in blank $(\mu \mathrm{g})$ : & & & \\
\hline & Minimum corrected weight of impurity in sample $(\mu \mathrm{g})$ : & & & \\
\hline & Maximum corrected weight of impurity in sample $(\mu \mathrm{g})$ : & & & \\
\hline \multirow{5}{*}{ Ca } & Measured concentration of impurity in sample $(\mu \mathrm{g} / \mathrm{ml})$ : & & & $\mathrm{Ca}$ \\
\hline & Uncorrected weight of impurity in sample $(\mu \mathrm{g})$ : & & & \\
\hline & Weight of impurity in blank $(\mu \mathrm{g})$ : & & & \\
\hline & Minimum corrected weight of impurity in sample $(\mu \mathrm{g})$ : & & & \\
\hline & Maximum corrected weight of impurity in sample $(\mu \mathrm{g})$ : & & & \\
\hline \multirow{5}{*}{ AI } & Measured concentration of impurity in sample $(\mu \mathrm{g} / \mathrm{ml})$ : & & & Al \\
\hline & Uncorrected weight of impurity in sample $(\mu \mathrm{g})$ : & & & \\
\hline & Weight of impurity in blank $(\mu \mathrm{g})$ : & & & \\
\hline & Minimum corrected weight of impurity in sample $(\mu \mathrm{g})$ : & & & \\
\hline & Maximum corrected weight of impurity in sample $(\mu \mathrm{g})$ : & & & \\
\hline \multirow{5}{*}{ Ti } & Measured concentration of impurity in sample $(\mu \mathrm{g} / \mathrm{ml})$ : & & & Ti \\
\hline & Uncorrected weight of impurity in sample $(\mu \mathrm{g})$ : & & & \\
\hline & Weight of impurity in blank $(\mu \mathrm{g})$ : & & & \\
\hline & Minimum corrected weight of impurity in sample $(\mu \mathrm{g})$ : & & & \\
\hline & Maximum corrected weight of impurity in sample $(\mu \mathrm{g})$ : & & & \\
\hline \multirow{5}{*}{$\mathbf{v}$} & Measured concentration of impurity in sample $(\mu \mathrm{g} / \mathrm{ml})$ : & & & $\mathbf{v}$ \\
\hline & Uncorrected weight of impurity in sample $(\mu \mathrm{g})$ : & & & \\
\hline & Weight of impurity in blank $(\mu \mathrm{g})$ : & & & \\
\hline & Minimum corrected weight of impurity in sample $(\mu \mathrm{g}):$ & & & \\
\hline & Maximum corrected weight of impurity in sample $(\mu \mathrm{g})$ : & & & \\
\hline
\end{tabular}

comments

eached in Vessel FB\#2 (previously used for 11035 overcoated particles-Group 1 Clutch 2).

FCM checked the recorded data against the official Results of Analysis for RMAL19091 on 3/21/2019.

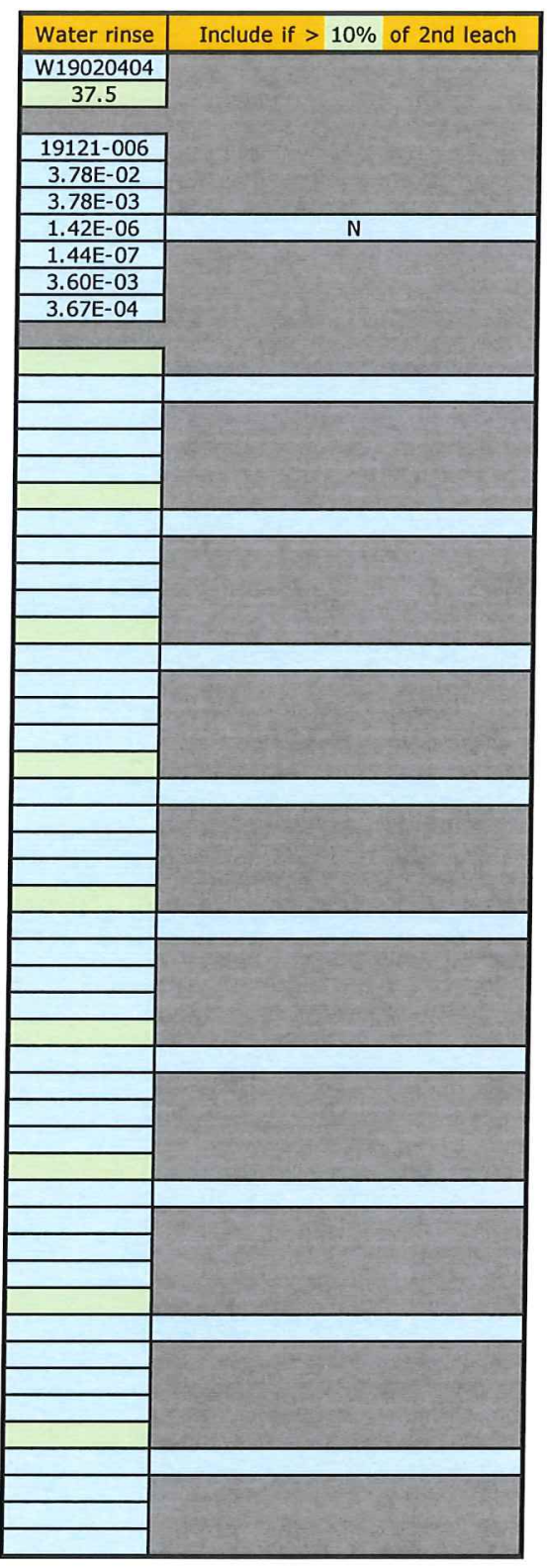

Feed C. montgomery

Operator
$4-18-2019$

Date 
Data Report Form DRF-26B: Post-Burn Leach Uranium and Impurities

\begin{tabular}{|r|l|}
\hline Procedure: & AGR-CHAR-DAM-26 Rev. 3 \\
\hline Operator: & Montgomery \\
\hline Compact lot ID: & BWXT J52R-16-14155C \\
\hline Compact lot description: & AGR-5/6/7 compacts, 40\% packing fraction \\
\hline Compact ID numbers: & $1167,1137,1162,1129,1136$ \\
\hline DRF filename: & 14155 C_PF40-Group 1_DLBL_ICPMS_DRF26R3.xIs \\
\hline
\end{tabular}

\begin{tabular}{|c|c|c|c|c|}
\hline \multicolumn{2}{|r|}{$\begin{array}{ll} & \text { Number of compacts: } \\
\end{array}$} & \multicolumn{3}{|c|}{5} \\
\hline \multirow{2}{*}{\multicolumn{2}{|c|}{$\begin{array}{l}\text { Average weight uranium per particle, mean value }(\mathrm{g}) \text { : } \\
\text { Average weight uranium per particle, uncertainty in mean }(\mathrm{g}) \text { : }\end{array}$}} & \multicolumn{3}{|c|}{$3.94 \mathrm{E}-04$} \\
\hline & & \multicolumn{3}{|c|}{$3.94 \mathrm{E}-06$} \\
\hline & First Leach & Second Leach & Total \\
\hline & Post-burn leach solution ID: & B19020601 & B19020801 & \\
\hline & Total volume of leach solution $(\mathrm{ml})$ : & 55.5 & 59.8 & \\
\hline & & & & \\
\hline & RMAL analysis number: & $19109-001$ & $19109-003$ & \\
\hline & Measured uranium concentration $(\mu \mathrm{g} / \mathrm{ml})$ : & $8.02 \mathrm{E}+00$ & $2.16 \mathrm{E}-02$ & \\
\hline & Uncertainty in uranium concentration $(\mu \mathrm{g} / \mathrm{ml}):$ & $8.02 \mathrm{E}-01$ & $2.16 \mathrm{E}-03$ & \\
\hline & Weight uranium leached $(\mathrm{g})$ : & $4.45 \mathrm{E}-04$ & $1.29 E-06$ & $4.46 \mathrm{E}-04$ \\
\hline & Uncertainty in weight uranium leached $(\mathrm{g})$ : & $4.48 \mathrm{E}-05$ & $1.30 \mathrm{E}-07$ & $4.48 \mathrm{E}-05$ \\
\hline & Equivalent number of leached kernels: & $1.13 \mathrm{E}+00$ & $3.28 \mathrm{E}-03$ & $1.13 E+00$ \\
\hline & Uncertainty in equivalent number of leached kernels: & $1.14 \mathrm{E}-01$ & $3.31 \mathrm{E}-04$ & $1.14 \mathrm{E}-01$ \\
\hline \multirow{5}{*}{$\mathbf{F e}$} & Measured concentration of impurity in sample $(\mu \mathrm{g} / \mathrm{ml})$ : & & & $\mathrm{Fe}$ \\
\hline & Uncorrected weight of impurity in sample $(\mu \mathrm{g})$ : & & & \\
\hline & Weight of impurity in blank $(\mu \mathrm{g})$ : & & & \\
\hline & Minimum corrected weight of impurity in sample $(\mu \mathrm{g})$ : & & & \\
\hline & Maximum corrected weight of impurity in sample $(\mu \mathrm{g})$ : & & & \\
\hline \multirow{5}{*}{$\mathrm{Cr}$} & Measured concentration of impurity in sample $(\mu \mathrm{g} / \mathrm{ml})$ : & & & $\mathrm{Cr}$ \\
\hline & Uncorrected weight of impurity in sample $(\mu \mathrm{g})$ : & & & \\
\hline & Weight of impurity in blank $(\mu \mathrm{g})$ : & & & \\
\hline & Minimum corrected weight of impurity in sample $(\mu \mathrm{g})$ : & & & \\
\hline & Maximum corrected weight of impurity in sample $(\mu \mathrm{g}):$ & & & \\
\hline \multirow{5}{*}{ Mn } & Measured concentration of impurity in sample $(\mu \mathrm{g} / \mathrm{ml})$ : & & & Mn \\
\hline & Uncorrected weight of impurity in sample $(\mu \mathrm{g})$ : & & & \\
\hline & Weight of impurity in blank $(\mu \mathrm{g}):$ & & & \\
\hline & Minimum corrected weight of impurity in sample $(\mu \mathrm{g})$ : & & & \\
\hline & Maximum corrected weight of impurity in sample $(\mu \mathrm{g})$ : & & & \\
\hline \multirow{5}{*}{ Co } & Measured concentration of impurity in sample $(\mu \mathrm{g} / \mathrm{ml})$ : & & & Co \\
\hline & Uncorrected weight of impurity in sample $(\mu \mathrm{g})$ : & & & \\
\hline & Weight of impurity in blank $(\mu \mathrm{g}):$ & & & \\
\hline & Minimum corrected weight of impurity in sample $(\mu \mathrm{g})$ : & & & \\
\hline & Maximum corrected weight of impurity in sample $(\mu g)$ : & & & \\
\hline \multirow{5}{*}{$\mathrm{Ni}$} & Measured concentration of impurity in sample $(\mu \mathrm{g} / \mathrm{ml})$ : & & & $\mathrm{Ni}$ \\
\hline & Uncorrected weight of impurity in sample $(\mu \mathrm{g})$ : & & & \\
\hline & Weight of impurity in blank $(\mu \mathrm{g})$ : & & & \\
\hline & Minimum corrected weight of impurity in sample $(\mu \mathrm{g}):$ & & & \\
\hline & Maximum corrected weight of impurity in sample $(\mu g)$ : & & & \\
\hline \multirow{5}{*}{$\mathbf{C a}$} & Measured concentration of impurity in sample $(\mu \mathrm{g} / \mathrm{ml})$ : & & & $\mathrm{Ca}$ \\
\hline & Uncorrected weight of impurity in sample $(\mu \mathrm{g})$ : & & & \\
\hline & Weight of impurity in blank $(\mu \mathrm{g})$ : & & & \\
\hline & Minimum corrected weight of impurity in sample $(\mu \mathrm{g})$ : & & & \\
\hline & Maximum corrected weight of impurity in sample $(\mu \mathrm{g}):$ & & & \\
\hline \multirow{5}{*}{ Al } & Measured concentration of impurity in sample $(\mu \mathrm{g} / \mathrm{ml})$ : & & & $\overline{A l}$ \\
\hline & Uncorrected weight of impurity in sample $(\mu \mathrm{g})$ : & & & \\
\hline & Weight of impurity in blank $(\mu \mathrm{g}):$ & & & \\
\hline & Minimum corrected weight of impurity in sample $(\mu \mathrm{g})$ : & & & \\
\hline & Maximum corrected weight of impurity in sample $(\mu \mathrm{g})$ : & & & \\
\hline \multirow{5}{*}{$\mathbf{T i}$} & Measured concentration of impurity in sample $(\mu \mathrm{g} / \mathrm{ml})$ : & & & $\mathbf{T i}$ \\
\hline & Uncorrected weight of impurity in sample $(\mu \mathrm{g})$ : & & & \\
\hline & Weight of impurity in blank $(\mu g)$ : & & & \\
\hline & Minimum corrected weight of impurity in sample $(\mu \mathrm{g})$ : & & & \\
\hline & Maximum corrected weight of impurity in sample $(\mu \mathrm{g})$ : & & & \\
\hline \multirow{5}{*}{$\mathbf{v}$} & Measured concentration of impurity in sample $(\mu \mathrm{g} / \mathrm{ml})$ : & & & $\mathbf{V}$ \\
\hline & Uncorrected weight of impurity in sample $(\mu \mathrm{g})$ : & & & \\
\hline & Weight of impurity in blank $(\mu \mathrm{g})$ : & & & \\
\hline & Minimum corrected weight of impurity in sample $(\mu \mathrm{g}):$ & & & \\
\hline & Maximum corrected weight of impurity in sample $(\mu \mathrm{g})$ : & & & \\
\hline
\end{tabular}

\section{Comments}

FCM checked the recorded data against the official Results of Analysis for RMAL19109 on 4/12/2019.

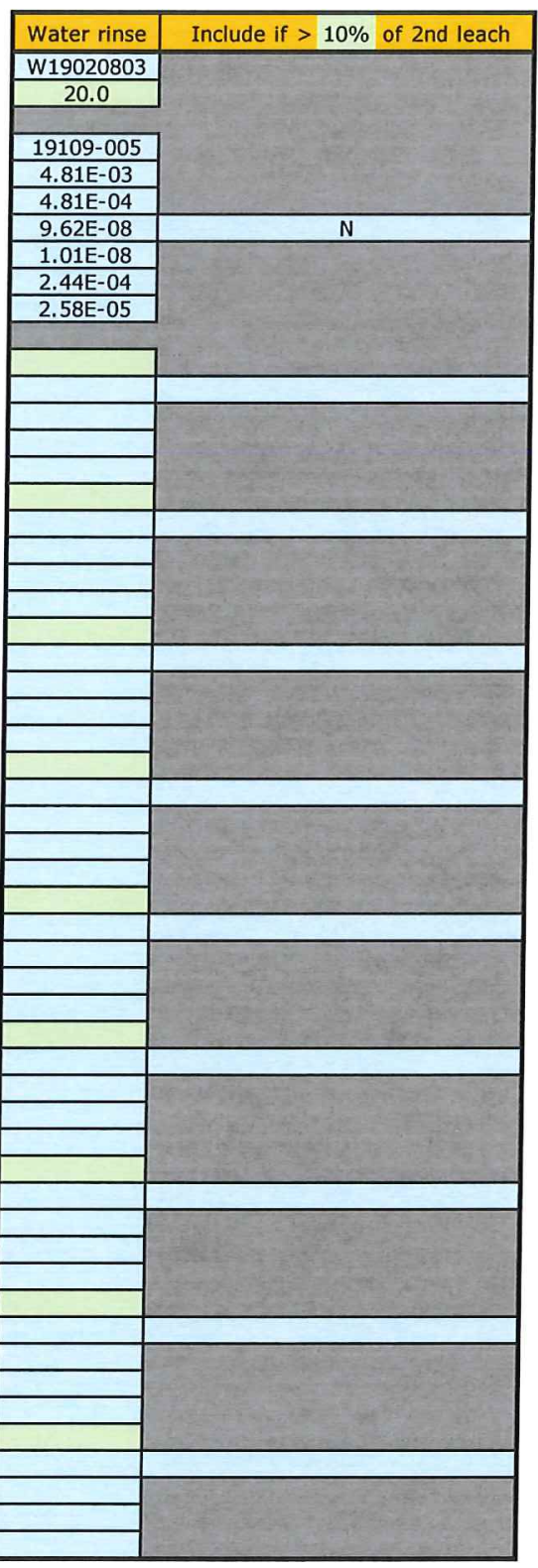

\section{Fred C. Montgomery}

Operator

\section{$4-18-2019$}

Date 
Data Report Form DRF-26B: Post-Burn Leach Uranium and Impurities

\begin{tabular}{|r|l|}
\hline Procedure: & AGR-CHAR-DAM-26 Rev. 3 \\
\hline Operator: & Montgomery \\
\hline Compact lot ID: & BWXT J52R-16-14155C \\
\hline Compact lot description: & AGR-5/6/7 compacts, 40\% packing fraction \\
\hline Compact ID numbers: & $1124,1151,1211,1166,1170$ \\
\hline DRF filename: & $14155 C$ PF40-Group 1_DLBL_ICPMS_DRF26R3.xIs \\
\hline
\end{tabular}

\begin{tabular}{|r|c|}
\hline Number of compacts: & 5 \\
\hline Average weight uranium per particle, mean value $(\mathrm{g}):$ & $3.94 \mathrm{E}-04$ \\
\hline Average weight uranium per particle, uncertainty in mean $(\mathrm{g}):$ & $3.94 \mathrm{E}-06$ \\
\hline
\end{tabular}

\begin{tabular}{|c|c|c|c|c|}
\hline & First Leach & Second Leach & Total \\
\hline \multirow{2}{*}{\multicolumn{2}{|c|}{$\begin{array}{cc} & \text { Post-burn leach solution ID: } \\
\text { Total volume of leach solution }(\mathrm{ml}):\end{array}$}} & B19020602 & B19020802 & \\
\hline & & 57.5 & 59.8 & \\
\hline \multicolumn{2}{|c|}{ RMAL analysis number: } & $19109-002$ & 19109-004 & \\
\hline \multirow{2}{*}{\multicolumn{2}{|c|}{$\begin{array}{cc}\text { Measured uranium concentration }(\mu \mathrm{g} / \mathrm{ml}): \\
\text { Uncertainty in uranium concentration }(\mu \mathrm{g} / \mathrm{ml}):\end{array}$}} & $7.84 \mathrm{E}+00$ & $2.82 \mathrm{E}-02$ & \\
\hline & & $7.84 \mathrm{E}-01$ & $2.82 \mathrm{E}-03$ & \\
\hline \multicolumn{2}{|c|}{ Weight uranium leached $(\mathrm{g})$ : } & $4.51 \mathrm{E}-04$ & $1.69 \mathrm{E}-06$ & $4.52 \mathrm{E}-04$ \\
\hline \multirow{2}{*}{\multicolumn{2}{|c|}{$\begin{array}{r}\text { Uncertainty in weight uranium leached }(\mathrm{g}): \\
\text { Equivalent number of leached kernels: }\end{array}$}} & $4.54 \mathrm{E}-05$ & $1.70 \mathrm{E}-07$ & $4.54 \mathrm{E}-05$ \\
\hline & & $1.14 \mathrm{E}+00$ & $4.28 \mathrm{E}-03$ & $1.15 \mathrm{E}+00$ \\
\hline \multicolumn{2}{|c|}{ Uncertainty in equivalent number of leached kernels: } & $1.16 \mathrm{E}-01$ & $4.33 \mathrm{E}-04$ & $1.16 \mathrm{E}-01$ \\
\hline \multirow{5}{*}{$\mathbf{F e}$} & Measured concentration of impurity in sample $(\mu \mathrm{g} / \mathrm{ml})$ : & & & $\mathrm{Fe}$ \\
\hline & Uncorrected weight of impurity in sample $(\mu \mathrm{g})$ : & & & \\
\hline & Weight of impurity in blank $(\mu \mathrm{g})$ : & & & \\
\hline & Minimum corrected weight of impurity in sample $(\mu \mathrm{g})$ : & & & \\
\hline & Maximum corrected weight of impurity in sample $(\mu \mathrm{g})$ : & & & \\
\hline \multirow{5}{*}{$\mathbf{C r}$} & Measured concentration of impurity in sample $(\mu \mathrm{g} / \mathrm{ml})$ : & & & $\mathbf{C r}$ \\
\hline & Uncorrected weight of impurity in sample $(\mu \mathrm{g})$ : & & & \\
\hline & Weight of impurity in blank $(\mu \mathrm{g})$ : & & & \\
\hline & Minimum corrected weight of impurity in sample $(\mu \mathrm{g})$ : & & & \\
\hline & Maximum corrected weight of impurity in sample $(\mu \mathrm{g})$ : & & & \\
\hline \multirow{5}{*}{ Mn } & Measured concentration of impurity in sample $(\mu \mathrm{g} / \mathrm{ml})$ : & & & Mn \\
\hline & Uncorrected weight of impurity in sample $(\mu \mathrm{g})$ : & & & \\
\hline & Weight of impurity in blank $(\mu \mathrm{g})$ : & & & \\
\hline & Minimum corrected weight of impurity in sample $(\mu g)$ : & & & \\
\hline & Maximum corrected weight of impurity in sample $(\mu \mathrm{g})$ : & & & \\
\hline \multirow{5}{*}{ Co } & Measured concentration of impurity in sample $(\mu \mathrm{g} / \mathrm{ml})$ : & & & Co \\
\hline & Uncorrected weight of impurity in sample $(\mu \mathrm{g})$ : & & & \\
\hline & Weight of impurity in blank $(\mu \mathrm{g})$ : & & & \\
\hline & Minimum corrected weight of impurity in sample $(\mu \mathrm{g})$ : & & & \\
\hline & Maximum corrected weight of impurity in sample $(\mu \mathrm{g})$ : & & & \\
\hline \multirow{5}{*}{$\mathbf{N i}$} & Measured concentration of impurity in sample $(\mu \mathrm{g} / \mathrm{ml})$ : & & & $\mathrm{Ni}$ \\
\hline & Uncorrected weight of impurity in sample $(\mu \mathrm{g})$ : & & & \\
\hline & Weight of impurity in blank $(\mu \mathrm{g})$ : & & & \\
\hline & Minimum corrected weight of impurity in sample $(\mu \mathrm{g})$ : & & & \\
\hline & Maximum corrected weight of impurity in sample $(\mu \mathrm{g})$ : & & & \\
\hline \multirow{5}{*}{ Ca } & Measured concentration of impurity in sample $(\mu \mathrm{g} / \mathrm{ml})$ : & & & $\mathrm{Ca}$ \\
\hline & Uncorrected weight of impurity in sample $(\mu \mathrm{g})$ : & & & \\
\hline & Weight of impurity in blank $(\mu \mathrm{g}):$ & & & \\
\hline & Minimum corrected weight of impurity in sample $(\mu \mathrm{g})$ : & & & \\
\hline & Maximum corrected weight of impurity in sample $(\mu \mathrm{g})$ : & & & \\
\hline \multirow{5}{*}{ Al } & Measured concentration of impurity in sample $(\mu \mathrm{g} / \mathrm{ml})$ : & & & Al \\
\hline & Uncorrected weight of impurity in sample $(\mu \mathrm{g})$ : & & & \\
\hline & Weight of impurity in blank $(\mu g)$ : & & & \\
\hline & Minimum corrected weight of impurity in sample $(\mu \mathrm{g})$ : & & & \\
\hline & Maximum corrected weight of impurity in sample $(\mu \mathrm{g})$ : & & & \\
\hline \multirow{5}{*}{$\mathbf{T i}$} & Measured concentration of impurity in sample $(\mu \mathrm{g} / \mathrm{ml})$ : & & & $\mathbf{T i}$ \\
\hline & Uncorrected weight of impurity in sample $(\mu \mathrm{g})$ : & & & \\
\hline & Weight of impurity in blank $(\mu \mathrm{g})$ : & & & \\
\hline & Minimum corrected weight of impurity in sample $(\mu \mathrm{g})$ : & & & \\
\hline & Maximum corrected weight of impurity in sample $(\mu \mathrm{g})$ : & & & \\
\hline \multirow{5}{*}{$\mathbf{v}$} & Measured concentration of impurity in sample $(\mu \mathrm{g} / \mathrm{ml}):$ & & & $\mathbf{v}$ \\
\hline & Uncorrected weight of impurity in sample $(\mu \mathrm{g})$ : & & & \\
\hline & Weight of impurity in blank $(\mu \mathrm{g})$ : & & & \\
\hline & Minimum corrected weight of impurity in sample $(\mu \mathrm{g})$ : & & & \\
\hline & Maximum corrected weight of impurity in sample $(\mu \mathrm{g}):$ & & & \\
\hline
\end{tabular}

Comments

FCM checked the recorded data against the official Results of Analysis for RMAL19109 on 4/12/2019.

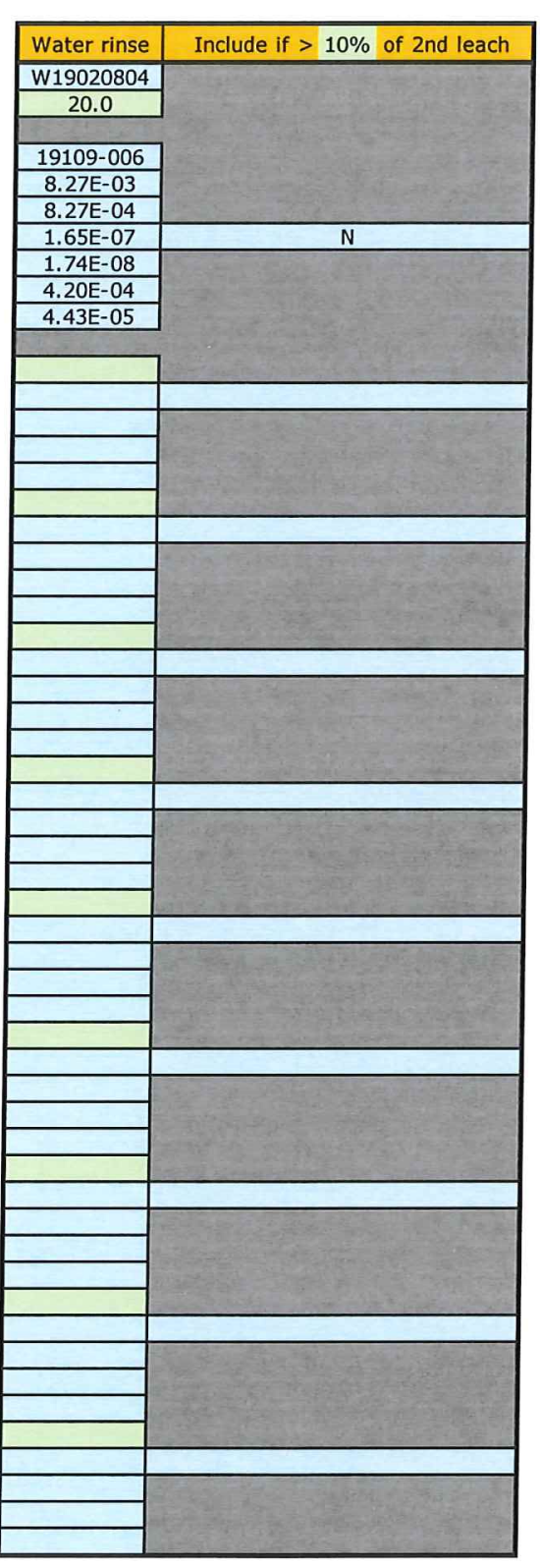


Data Report Form DRF-26B: Post-Burn Leach Uranium and Impurities

\begin{tabular}{|r|l|}
\hline Procedure: & AGR-CHAR-DAM-26 Rev. 3 \\
\hline Operator: & Montgomery \\
\hline Compact lot ID: & BWXT J52R-16-14155C \\
\hline Compact lot description: & AGR-5/6/7 compacts, 40\% packing fraction \\
\hline Compact ID numbers: & $1194,1195,1156,1169,1205$ \\
\hline DRF filename: & 14155 C_PF40-Group 1_DLBL_ICPMS_DRF26R3.xls \\
\hline
\end{tabular}

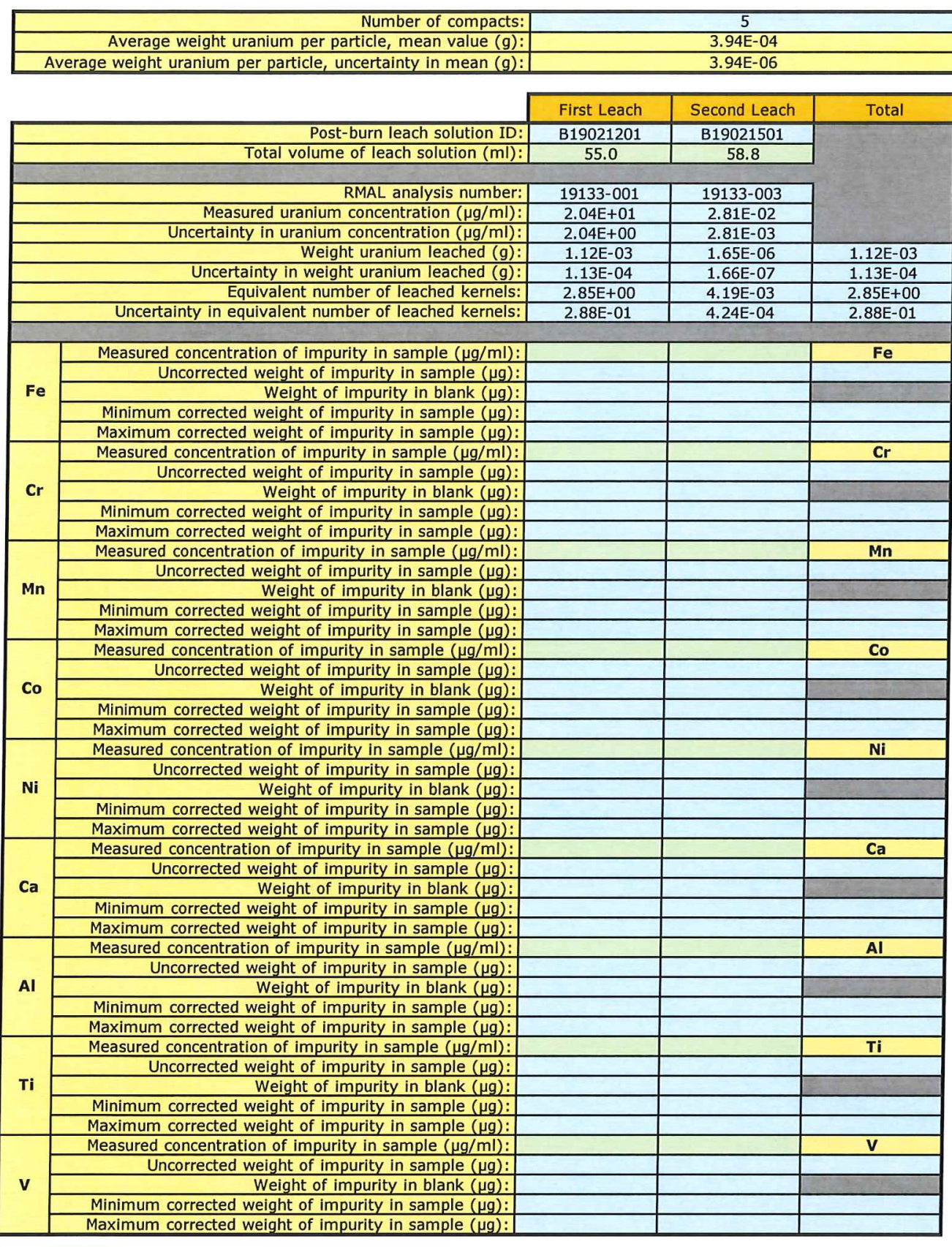

comments

Recorded data checked by FCM against the official Results of Analyses Report for RMAL19133 on 3/21/2019.

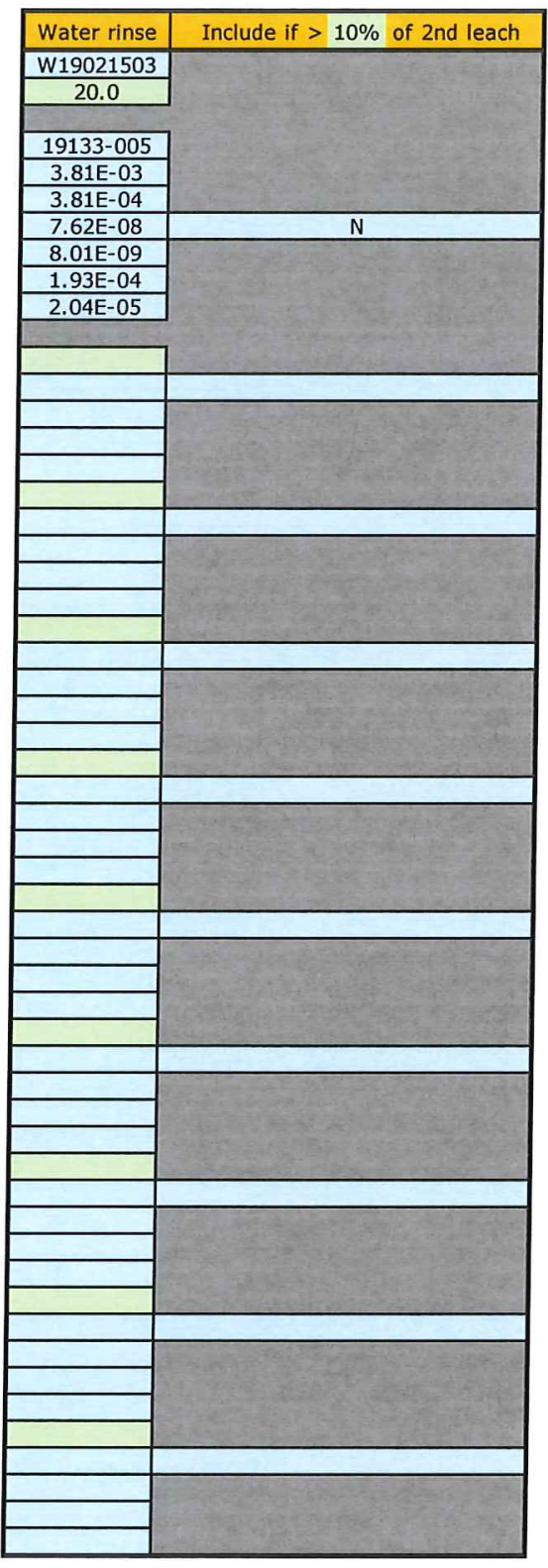

Recorded data checked by FCM against the official Results of Analyses Report for RMAL19133 on 3/21/2019.

\section{Zed c. Montyomery}

$4-18-2019$ 


\section{Data Report Form DRF-26B: Post-Burn Leach Uranium and Impurities}

\begin{tabular}{|r|l|}
\hline Procedure: & AGR-CHAR-DAM-26 Rev. 3 \\
\hline Operator: & Montgomery \\
\hline Compact lot ID: & BWXT J52R-16-14155C \\
\hline Compact lot description: & AGR-5/6/7 compacts, 40\% packing fraction \\
\hline Compact ID numbers: & $1126,1140,1184,1203,1191$ \\
\hline DRF filename: & 14155 C PF 40 -Group 1_DLBL_ICPMS_DRF26R3.xIs \\
\hline
\end{tabular}

\begin{tabular}{|r|c|}
\hline Number of compacts: & 5 \\
\hline Average weight uranium per particle, mean value $(\mathrm{g}):$ & $3.94 \mathrm{E}-04$ \\
\hline Average weight uranium per particle, uncertainty in mean $(\mathrm{g}):$ & $3.94 \mathrm{E}-06$ \\
\hline
\end{tabular}

\begin{tabular}{|c|c|c|c|c|}
\hline & First Leach & Second Leach & Total \\
\hline \multirow{2}{*}{\multicolumn{2}{|c|}{$\begin{array}{cc}\text { Post-burn leach solution ID: } & \text { Total volume of leach solution }(\mathrm{ml}): \\
\end{array}$}} & B19021202 & B19021502 & \\
\hline & & 56.7 & 57.5 & \\
\hline \multicolumn{2}{|c|}{ RMAL analysis number: } & $19133-002$ & $19133-004$ & \\
\hline \multirow{2}{*}{\multicolumn{2}{|c|}{$\begin{array}{c}\text { Measured uranium concentration }(\mu \mathrm{g} / \mathrm{ml}): \\
\text { Uncertainty in uranium concentration }(\mu \mathrm{g} / \mathrm{ml}):\end{array}$}} & $2.66 \mathrm{E}-01$ & $1.68 \mathrm{E}-03$ & \\
\hline & & $2.66 \mathrm{E}-02$ & $1.68 \mathrm{E}-04$ & \\
\hline \multicolumn{2}{|r|}{ Weight uranium leached $(g):$} & $1.51 \mathrm{E}-05$ & $9.66 \mathrm{E}-08$ & $1.52 \mathrm{E}-05$ \\
\hline \multirow{2}{*}{\multicolumn{2}{|c|}{$\begin{array}{r}\text { Uncertainty in weight uranium leached }(\mathrm{g}): \\
\text { Equivalent number of leached kernels: }\end{array}$}} & $1.52 \mathrm{E}-06$ & $9.72 \mathrm{E}-09$ & $1.52 \mathrm{E}-06$ \\
\hline & & $3.83 \mathrm{E}-02$ & $2.45 \mathrm{E}-04$ & $3.85 \mathrm{E}-02$ \\
\hline \multicolumn{2}{|c|}{ Uncertainty in equivalent number of leached kernels: } & $3.87 E-03$ & $2.48 \mathrm{E}-05$ & $3.87 E-03$ \\
\hline \multirow{5}{*}{$\mathrm{Fe}$} & Measured concentration of impurity in sample $(\mu \mathrm{g} / \mathrm{ml})$ : & & & $\mathrm{Fe}$ \\
\hline & Uncorrected weight of impurity in sample $(\mu \mathrm{g})$ : & & & \\
\hline & Weight of impurity in blank $(\mu \mathrm{g})$ : & & & \\
\hline & Minimum corrected weight of impurity in sample $(\mu g)$ : & & & \\
\hline & Maximum corrected weight of impurity in sample $(\mu \mathrm{g})$ : & & & \\
\hline \multirow{5}{*}{$\mathrm{Cr}$} & Measured concentration of impurity in sample $(\mathrm{\mu g} / \mathrm{ml})$ : & & & $\mathrm{Cr}$ \\
\hline & Uncorrected weight of impurity in sample $(\mu \mathrm{g})$ : & & & \\
\hline & Weight of impurity in blank $(\mu \mathrm{g})$ : & & & \\
\hline & Minimum corrected weight of impurity in sample $(\mu \mathrm{g})$ : & & & \\
\hline & Maximum corrected weight of impurity in sample $(\mu \mathrm{g})$ : & & & \\
\hline \multirow{5}{*}{ Mn } & Measured concentration of impurity in sample $(\mu \mathrm{g} / \mathrm{ml})$ : & & & Mn \\
\hline & Uncorrected weight of impurity in sample $(\mu \mathrm{g})$ : & & & \\
\hline & Weight of impurity in blank $(\mu \mathrm{g})$ : & & & \\
\hline & Minimum corrected weight of impurity in sample $(\mu \mathrm{g})$ : & & & \\
\hline & Maximum corrected weight of impurity in sample $(\mu g)$ : & & & \\
\hline \multirow{5}{*}{ Co } & Measured concentration of impurity in sample $(\mu \mathrm{g} / \mathrm{ml})$ : & & & Co \\
\hline & Uncorrected weight of impurity in sample $(\mu \mathrm{g})$ : & & & \\
\hline & Weight of impurity in blank $(\mu \mathrm{g})$ : & & & \\
\hline & Minimum corrected weight of impurity in sample $(\mu \mathrm{g})$ : & & & \\
\hline & Maximum corrected weight of impurity in sample $(\mu \mathrm{g})$ : & & & \\
\hline \multirow{5}{*}{$\mathbf{N i}$} & Measured concentration of impurity in sample $(\mu \mathrm{g} / \mathrm{ml})$ : & & & $\mathrm{Ni}$ \\
\hline & Uncorrected weight of impurity in sample $(\mu \mathrm{g})$ : & & & \\
\hline & Weight of impurity in blank $(\mu \mathrm{g})$ : & & & \\
\hline & Minimum corrected weight of impurity in sample $(\mu \mathrm{g})$ : & & & \\
\hline & Maximum corrected weight of impurity in sample $(\mu \mathrm{g})$ : & & & \\
\hline \multirow{5}{*}{ Ca } & Measured concentration of impurity in sample $(\mu \mathrm{g} / \mathrm{ml})$ : & & & $\mathrm{Ca}$ \\
\hline & Uncorrected weight of impurity in sample $(\mu \mathrm{g})$ : & & & \\
\hline & Weight of impurity in blank $(\mu \mathrm{g})$ : & & & \\
\hline & Minimum corrected weight of impurity in sample $(\mu \mathrm{g})$ : & & & \\
\hline & Maximum corrected weight of impurity in sample $(\mu \mathrm{g})$ : & & & \\
\hline \multirow{5}{*}{ Al } & Measured concentration of impurity in sample $(\mu \mathrm{g} / \mathrm{ml})$ : & & & Al \\
\hline & Uncorrected weight of impurity in sample $(\mu \mathrm{g})$ : & & & \\
\hline & Weight of impurity in blank $(\mu \mathrm{g}):$ & & & \\
\hline & Minimum corrected weight of impurity in sample $(\mu \mathrm{g})$ : & & & \\
\hline & Maximum corrected weight of impurity in sample $(\mu \mathrm{g})$ : & & & \\
\hline \multirow{5}{*}{$\mathbf{T i}$} & Measured concentration of impurity in sample $(\mu \mathrm{g} / \mathrm{ml})$ : & & & $\mathrm{Ti}$ \\
\hline & Uncorrected weight of impurity in sample $(\mu \mathrm{g})$ : & & & \\
\hline & Weight of impurity in blank $(\mu g)$ : & & & \\
\hline & Minimum corrected weight of impurity in sample $(\mu \mathrm{g})$ : & & & \\
\hline & Maximum corrected weight of impurity in sample $(\mu \mathrm{g})$ : & & & \\
\hline \multirow{5}{*}{ v } & Measured concentration of impurity in sample $(\mu \mathrm{g} / \mathrm{ml})$ : & & & $\mathbf{v}$ \\
\hline & Uncorrected weight of impurity in sample $(\mu \mathrm{g})$ : & & & \\
\hline & Weight of impurity in blank $(\mu \mathrm{g})$ : & & & \\
\hline & Minimum corrected weight of impurity in sample $(\mu \mathrm{g})$ : & & & \\
\hline & Maximum corrected weight of impurity in sample $(\mu \mathrm{g}):$ & & & \\
\hline
\end{tabular}

\section{Comments}

Recorded data checked by FCM against the official Results of Analyses Report for RMAL19133 on 3/21/2019.

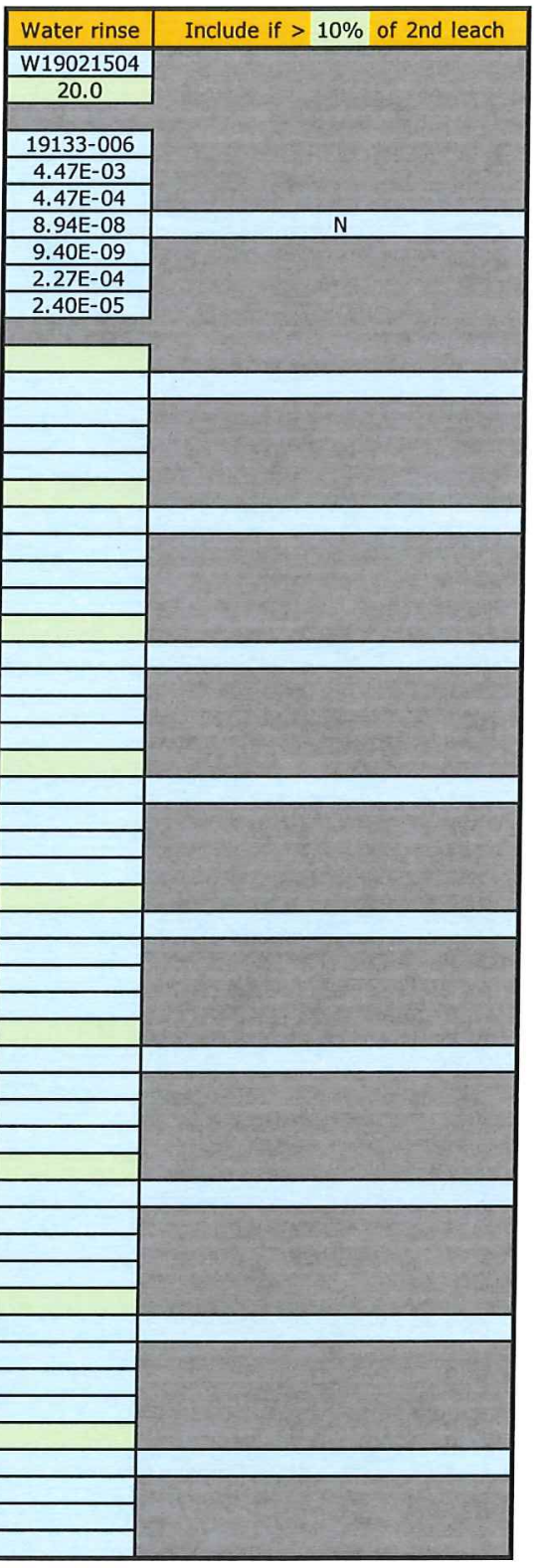


Data Report Form DRF-26A: Pre-Burn Leach Uranium and Impurities

\begin{tabular}{|r|l|}
\hline Procedure: & AGR-CHAR-DAM-26 Rev. 3 \\
\hline Operator: & Montgomery \\
\hline Compact lot ID: & BWXT J52R-16-14155C \\
\hline Compact lot description: & AGR-5/6/7 compacts, $40 \%$ packing fraction \\
\hline Compact ID numbers: & $1213,1179,1128,1112,1123$ \\
\hline DRF filename: & $14155 C$ PF40-Group 2 DLBL ICPMS DRF26R3.xIs \\
\hline
\end{tabular}

\begin{tabular}{|c|c|c|c|c|}
\hline \multicolumn{2}{|r|}{ Number of compacts: } & \multicolumn{3}{|c|}{5} \\
\hline \multicolumn{2}{|r|}{ Average weight uranium per particle, mean value $(\mathrm{g}):$} & \multicolumn{3}{|c|}{$3.94 \mathrm{E}-04$} \\
\hline \multicolumn{2}{|r|}{ Average weight uranium per particle, uncertainty in mean $(\mathrm{g})$ : } & \multicolumn{3}{|c|}{$3.94 \mathrm{E}-06$} \\
\hline & & First Leach & Second Leach & Total \\
\hline & Pre-burn leach solution ID: & L19030401 & L19030601 & \\
\hline & Total volume of leach solution $(\mathrm{ml})$ : & 161.0 & 142.0 & \\
\hline & RMAL analysis number: & $19191-001$ & $19191-003$ & \\
\hline & Measured uranium concentration $(\mu \mathrm{g} / \mathrm{ml})$ : & $4.67 E+00$ & $2.31 \mathrm{E}-01$ & \\
\hline & Uncertainty in uranium concentration $(\mu \mathrm{g} / \mathrm{ml})$ : & $4.67 \mathrm{E}-01$ & $2.31 \mathrm{E}-02$ & \\
\hline & Weight uranium leached $(\mathrm{g}):$ & $7.52 \mathrm{E}-04$ & $3.28 \mathrm{E}-05$ & $7.85 \mathrm{E}-04$ \\
\hline & Uncertainty in weight uranium leached $(\mathrm{g})$ : & $7.52 \mathrm{E}-05$ & $3.28 \mathrm{E}-06$ & $7.53 \mathrm{E}-05$ \\
\hline & Equivalent number of leached kernels: & $1.91 \mathrm{E}+00$ & $8.33 \mathrm{E}-02$ & $1.99 \mathrm{E}+00$ \\
\hline & Uncertainty in equivalent number of leached kernels: & $1.92 \mathrm{E}-01$ & $8.38 \mathrm{E}-03$ & $1.92 \mathrm{E}-01$ \\
\hline \multirow{5}{*}{$\mathbf{F e}$} & Measured concentration of impurity in sample $(\mu \mathrm{g} / \mathrm{ml})$ : & & & $\mathrm{Fe}$ \\
\hline & Uncorrected weight of impurity in sample $(\mu \mathrm{g}):$ & & & \\
\hline & Weight of impurity in blank $(\mu \mathrm{g})$ : & & & \\
\hline & Minimum corrected weight of impurity in sample $(\mu \mathrm{g})$ : & & & \\
\hline & Maximum corrected weight of impurity in sample $(\mu \mathrm{g})$ : & & & \\
\hline \multirow{5}{*}{ Cr } & Measured concentration of impurity in sample $(\mu \mathrm{g} / \mathrm{ml})$ : & & & $\mathbf{C r}$ \\
\hline & Uncorrected weight of impurity in sample $(\mu \mathrm{g})$ : & & & \\
\hline & Weight of impurity in blank $(\mu \mathrm{g})$ : & & & \\
\hline & Minimum corrected weight of impurity in sample $(\mu \mathrm{g})$ : & & & \\
\hline & Maximum corrected weight of impurity in sample $(\mu g)$ : & & & \\
\hline \multirow{5}{*}{ Mn } & Measured concentration of impurity in sample $(\mu \mathrm{g} / \mathrm{ml})$ : & & & Mn \\
\hline & Uncorrected weight of impurity in sample $(\mu \mathrm{g})$ : & & & \\
\hline & Weight of impurity in blank $(\mu \mathrm{g})$ : & & & \\
\hline & Minimum corrected weight of impurity in sample $(\mu \mathrm{g})$ : & & & \\
\hline & Maximum corrected weight of impurity in sample $(\mu \mathrm{g})$ : & & & \\
\hline \multirow{5}{*}{ Co } & Measured concentration of impurity in sample $(\mu \mathrm{g} / \mathrm{ml})$ : & & & Co \\
\hline & Uncorrected weight of impurity in sample $(\mu \mathrm{g})$ : & & & \\
\hline & Weight of impurity in blank $(\mu \mathrm{g})$ : & & & \\
\hline & Minimum corrected weight of impurity in sample $(\mu \mathrm{g})$ : & & & \\
\hline & Maximum corrected weight of impurity in sample $(\mu g)$ : & & & \\
\hline \multirow{5}{*}{$\mathbf{N i}$} & Measured concentration of impurity in sample $(\mu \mathrm{g} / \mathrm{ml})$ : & & & $\mathbf{N i}$ \\
\hline & Uncorrected weight of impurity in sample $(\mu \mathrm{g})$ : & & & \\
\hline & Weight of impurity in blank $(\mu \mathrm{g})$ : & & & \\
\hline & Minimum corrected weight of impurity in sample $(\mu \mathrm{g})$ : & & & \\
\hline & Maximum corrected weight of impurity in sample $(\mu \mathrm{g})$ : & & & \\
\hline \multirow{5}{*}{$\mathbf{C a}$} & Measured concentration of impurity in sample $(\mu \mathrm{g} / \mathrm{ml})$ : & & & $\mathrm{Ca}$ \\
\hline & Uncorrected weight of impurity in sample $(\mu \mathrm{g})$ : & & & \\
\hline & Weight of impurity in blank $(\mu \mathrm{g})$ : & & & \\
\hline & Minimum corrected weight of impurity in sample $(\mu \mathrm{g})$ : & & & \\
\hline & Maximum corrected weight of impurity in sample $(\mu \mathrm{g})$ : & & & \\
\hline \multirow{5}{*}{ Al } & Measured concentration of impurity in sample $(\mu \mathrm{g} / \mathrm{ml})$ : & & & $\mathbf{A l}$ \\
\hline & Uncorrected weight of impurity in sample $(\mu \mathrm{g})$ : & & & \\
\hline & Weight of impurity in blank $(\mu \mathrm{g})$ : & & & \\
\hline & Minimum corrected weight of impurity in sample $(\mu \mathrm{g}):$ & & & \\
\hline & Maximum corrected weight of impurity in sample $(\mu \mathrm{g}):$ & & & \\
\hline \multirow{5}{*}{ Ti } & Measured concentration of impurity in sample $(\mu \mathrm{g} / \mathrm{ml})$ : & & & $\mathbf{T i}$ \\
\hline & Uncorrected weight of impurity in sample $(\mu \mathrm{g})$ : & & & \\
\hline & Weight of impurity in blank $(\mu \mathrm{g})$ : & & & \\
\hline & Minimum corrected weight of impurity in sample $(\mu \mathrm{g})$ : & & & \\
\hline & Maximum corrected weight of impurity in sample $(\mu \mathrm{g})$ : & & & \\
\hline \multirow{5}{*}{$\mathbf{V}$} & Measured concentration of impurity in sample $(\mu \mathrm{g} / \mathrm{ml})$ : & & & $\mathbf{V}$ \\
\hline & Uncorrected weight of impurity in sample $(\mu \mathrm{g})$ : & & & \\
\hline & Weight of impurity in blank $(\mu \mathrm{g})$ : & & & \\
\hline & Minimum corrected weight of impurity in sample $(\mu \mathrm{g})$ : & & & \\
\hline & Maximum corrected weight of impurity in sample $(\mu \mathrm{g})$ : & & & \\
\hline
\end{tabular}

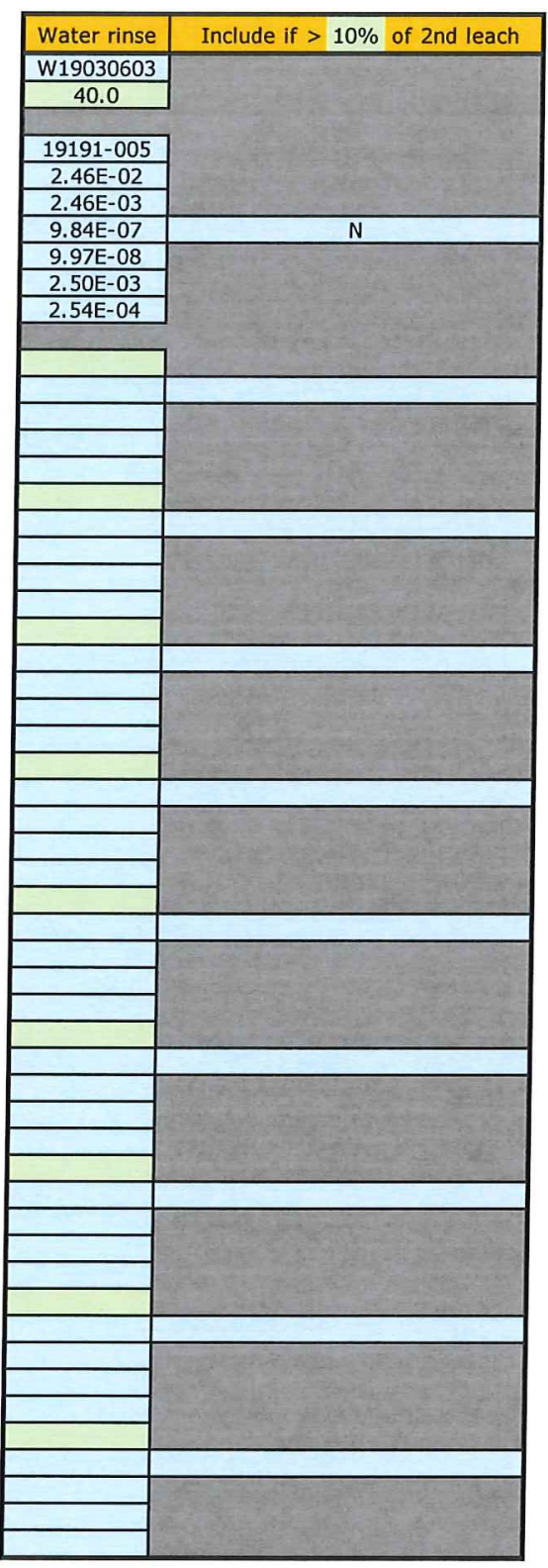

comments

Leached in Vessel \#41 (previously unused).

FCM checked the recorded data against the official Results of Analysis for RMAL19191 on 4/12/2019.

Fred c. Montgomery

Operator
$4-18-2019$

$\longrightarrow$ Date 
Data Report Form DRF-26A: Pre-Burn Leach Uranium and Impurities

\begin{tabular}{|r|l|}
\hline Procedure: & AGR-CHAR-DAM-26 Rev. 3 \\
\hline Operator: & Montgomery \\
\hline Compact lot ID: & BWXT J52R-16-14155C \\
\hline Compact lot description: & AGR-5/6/7 compacts, 40\% packing fraction \\
\hline Compact ID numbers: & $1145,1186,1113,1214,1119$ \\
\hline DRF filename: & 14155 _PF 40 -Group 2_DLBL_ICPMS_DRF26R3.xIs \\
\hline
\end{tabular}

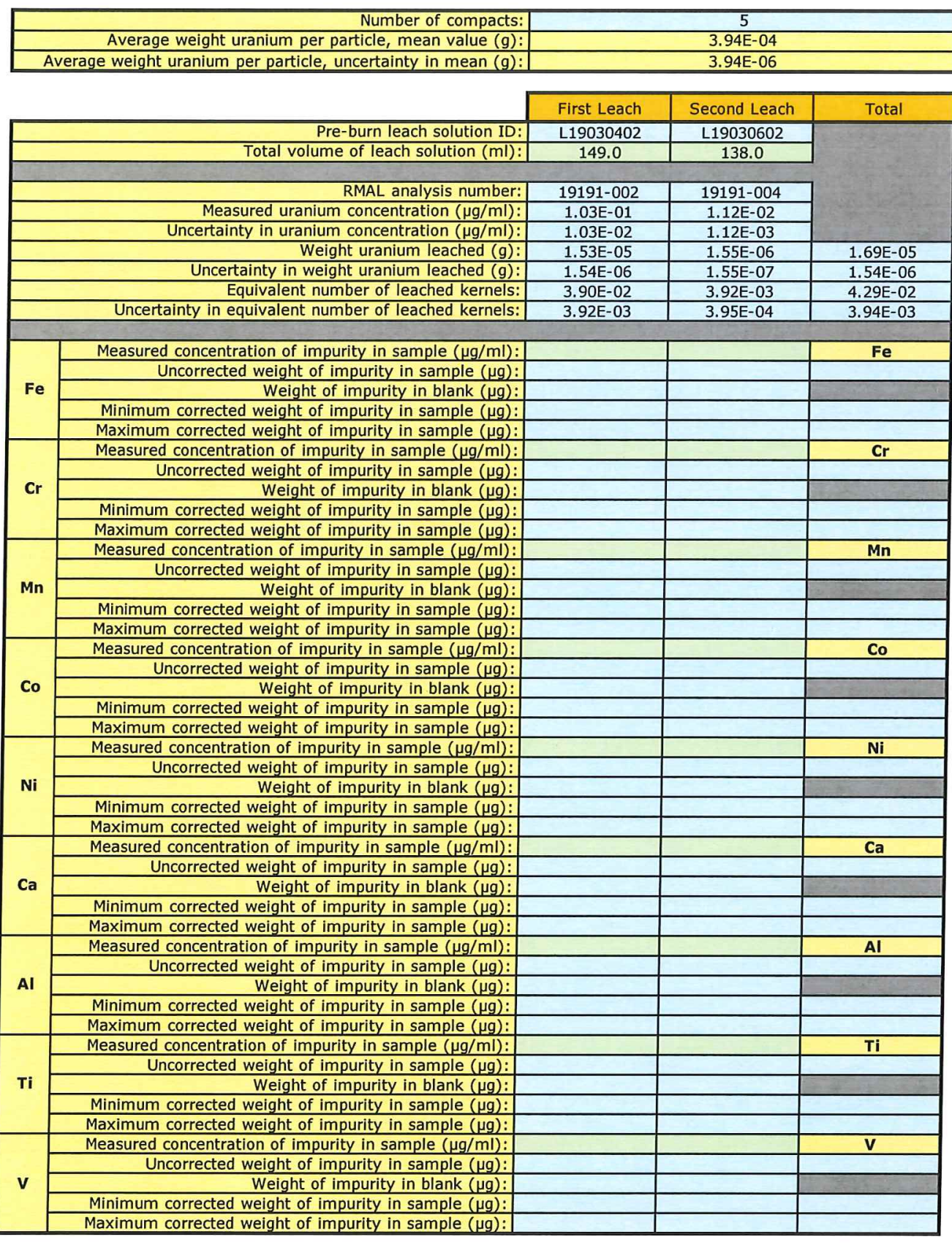

Comments

Leached in Vessel \#42 (previously unused).

FCM checked the recorded data against the official Results of Analysis for RMAL19191 on 4/12/2019.

Feed c. Montgomery

Operator
$4-18-2019$

Date

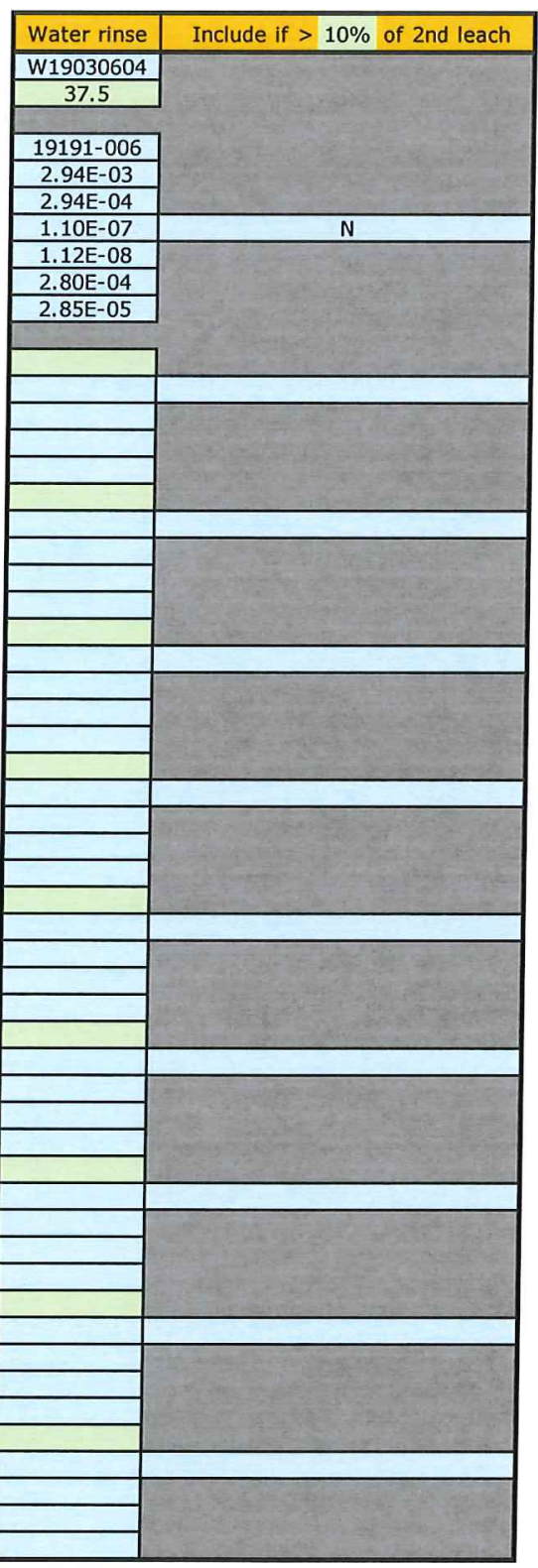


Data Report Form DRF-26A: Pre-Burn Leach Uranium and Impurities

\begin{tabular}{|r|l|}
\hline Procedure: & AGR-CHAR-DAM-26 Rev. 3 \\
\hline Operator: & Montgomery \\
\hline Compact lot ID: & BWXT J52R-16-14155C \\
\hline Compact lot description: & AGR-5/6/7 compacts, 40\% packing fraction \\
\hline Compact ID numbers: & $1148,1159,1127,1190,1189$ \\
\hline DRF filename: & 14155 CPF40-Group 2_DLBL_ICPMS_DRF26R3.xls \\
\hline
\end{tabular}

\begin{tabular}{|r|r|}
\hline Number of compacts: & 5 \\
\hline Average weight uranium per particle, mean value $(\mathrm{g}):$ & $3.94 \mathrm{E}-04$ \\
\hline Average weight uranium per particle, uncertainty in mean $(\mathrm{g}):$ & $3.94 \mathrm{E}-06$ \\
\hline
\end{tabular}

\begin{tabular}{|c|c|c|c|c|}
\hline & First Leach & Second Leach & Total \\
\hline \multirow{2}{*}{\multicolumn{2}{|c|}{$\begin{array}{cc} & \text { Pre-burn leach solution ID: } \\
\text { Total volume of leach solution }(\mathrm{ml}):\end{array}$}} & L19031101 & L19031301 & \\
\hline & & 149.0 & 138.0 & \\
\hline \multirow{2}{*}{\multicolumn{2}{|c|}{ RMAL analysis number: }} & & & \\
\hline & & 19205-001 & 19205-003 & \\
\hline \multirow{2}{*}{\multicolumn{2}{|c|}{ 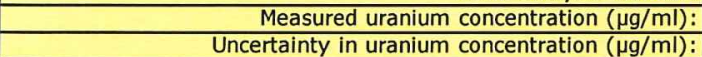 }} & $5.24 \mathrm{E}+00$ & $3.85 \mathrm{E}-01$ & \\
\hline & & $5.24 \mathrm{E}-01$ & $3.85 \mathrm{E}-02$ & \\
\hline \multicolumn{2}{|r|}{ Weight uranium leached $(\mathrm{g})$ : } & $7.81 \mathrm{E}-04$ & $5.31 \mathrm{E}-05$ & $8.34 \mathrm{E}-04$ \\
\hline \multicolumn{2}{|c|}{ Uncertainty in weight uranium leached $(\mathrm{g})$ : } & $7.82 \mathrm{E}-05$ & $5.32 \mathrm{E}-06$ & $7.83 \mathrm{E}-05$ \\
\hline \multirow{2}{*}{\multicolumn{2}{|c|}{$\begin{array}{c}\text { Equivalent number of leached kernels: } \\
\text { Uncertainty in equivalent number of leached kernels: }\end{array}$}} & $1.98 \mathrm{E}+00$ & $1.35 \mathrm{E}-01$ & $2.12 \mathrm{E}+00$ \\
\hline & & $1.99 \mathrm{E}-01$ & $1.36 \mathrm{E}-02$ & $2.00 \mathrm{E}-01$ \\
\hline \multirow{5}{*}{$\mathbf{F e}$} & Measured concentration of impurity in sample $(\mu \mathrm{g} / \mathrm{ml})$ : & & & $\mathrm{Fe}$ \\
\hline & Uncorrected weight of impurity in sample $(\mu \mathrm{g})$ : & & & \\
\hline & Weight of impurity in blank $(\mu \mathrm{g})$ : & & & \\
\hline & Minimum corrected weight of impurity in sample $(\mu \mathrm{g})$ : & & & \\
\hline & Maximum corrected weight of impurity in sample $(\mu \mathrm{g})$ : & & & \\
\hline \multirow{5}{*}{$\mathrm{Cr}$} & Measured concentration of impurity in sample $(\mu \mathrm{g} / \mathrm{ml})$ : & & & $\mathbf{C r}$ \\
\hline & Uncorrected weight of impurity in sample $(\mu \mathrm{g})$ : & & & \\
\hline & Weight of impurity in blank $(\mu g)$ : & & & \\
\hline & Minimum corrected weight of impurity in sample $(\mu \mathrm{g})$ : & & & \\
\hline & Maximum corrected weight of impurity in sample $(\mu \mathrm{g})$ : & & & \\
\hline \multirow{5}{*}{ Mn } & Measured concentration of impurity in sample $(\mu \mathrm{g} / \mathrm{ml})$ : & & & Mn \\
\hline & Uncorrected weight of impurity in sample $(\mu \mathrm{g})$ : & & & \\
\hline & Weight of impurity in blank $(\mu \mathrm{g})$ : & & & \\
\hline & Minimum corrected weight of impurity in sample $(\mu g)$ : & & & \\
\hline & Maximum corrected weight of impurity in sample $(\mu \mathrm{g})$ : & & & \\
\hline \multirow{5}{*}{ Co } & Measured concentration of impurity in sample $(\mu \mathrm{g} / \mathrm{ml})$ : & & & Co \\
\hline & Uncorrected weight of impurity in sample $(\mu g)$ : & & & \\
\hline & Weight of impurity in blank $(\mu \mathrm{g})$ : & & & \\
\hline & Minimum corrected weight of impurity in sample $(\mu \mathrm{g})$ : & & & \\
\hline & Maximum corrected weight of impurity in sample $(\mu \mathrm{g})$ : & & & \\
\hline \multirow{5}{*}{$\mathbf{N i}$} & Measured concentration of impurity in sample $(\mu \mathrm{g} / \mathrm{ml})$ : & & & $\mathbf{N i}$ \\
\hline & Uncorrected weight of impurity in sample $(\mu \mathrm{g})$ : & & & \\
\hline & Weight of impurity in blank $(\mu \mathrm{g})$ : & & & \\
\hline & Minimum corrected weight of impurity in sample $(\mu \mathrm{g})$ : & & & \\
\hline & Maximum corrected weight of impurity in sample $(\mu \mathrm{g})$ : & & & \\
\hline \multirow{5}{*}{ Ca } & Measured concentration of impurity in sample $(\mu \mathrm{g} / \mathrm{ml})$ : & & & $\mathrm{Ca}$ \\
\hline & Uncorrected weight of impurity in sample $(\mu \mathrm{g})$ : & & & \\
\hline & Weight of impurity in blank $(\mu \mathrm{g})$ : & & & \\
\hline & Minimum corrected weight of impurity in sample $(\mu \mathrm{g})$ : & & & \\
\hline & Maximum corrected weight of impurity in sample $(\mu \mathrm{g})$ : & & & \\
\hline \multirow{5}{*}{ Al } & Measured concentration of impurity in sample $(\mu \mathrm{g} / \mathrm{ml})$ : & & & Al \\
\hline & Uncorrected weight of impurity in sample $(\mu \mathrm{g})$ : & & & \\
\hline & Weight of impurity in blank $(\mu \mathrm{g})$ : & & & \\
\hline & Minimum corrected weight of impurity in sample $(\mu \mathrm{g})$ : & & & \\
\hline & Maximum corrected weight of impurity in sample $(\mu \mathrm{g})$ : & & & \\
\hline \multirow{5}{*}{$\mathrm{Ti}$} & Measured concentration of impurity in sample $(\mu \mathrm{g} / \mathrm{ml})$ : & & & $\mathrm{Ti}$ \\
\hline & Uncorrected weight of impurity in sample $(\mu g)$ : & & & \\
\hline & Weight of impurity in blank $(\mu \mathrm{g}):$ & & & \\
\hline & Minimum corrected weight of impurity in sample $(\mu \mathrm{g})$ : & & & \\
\hline & Maximum corrected weight of impurity in sample $(\mu \mathrm{g})$ : & & & \\
\hline \multirow{5}{*}{$\mathbf{v}$} & Measured concentration of impurity in sample $(\mu \mathrm{g} / \mathrm{ml})$ : & & & $\mathbf{v}$ \\
\hline & Uncorrected weight of impurity in sample $(\mu \mathrm{g})$ : & & & \\
\hline & Weight of impurity in blank $(\mu \mathrm{g})$ : & & & \\
\hline & Minimum corrected weight of impurity in sample $(\mu \mathrm{g})$ : & & & \\
\hline & Maximum corrected weight of impurity in sample $(\mu \mathrm{g})$ : & & & \\
\hline
\end{tabular}

\section{Comments}

Leached in Vessel \#43 (previously unused).

FCM checked the recorded data against the official Results of Analysis for RMAL19205 on 4/12/2019.

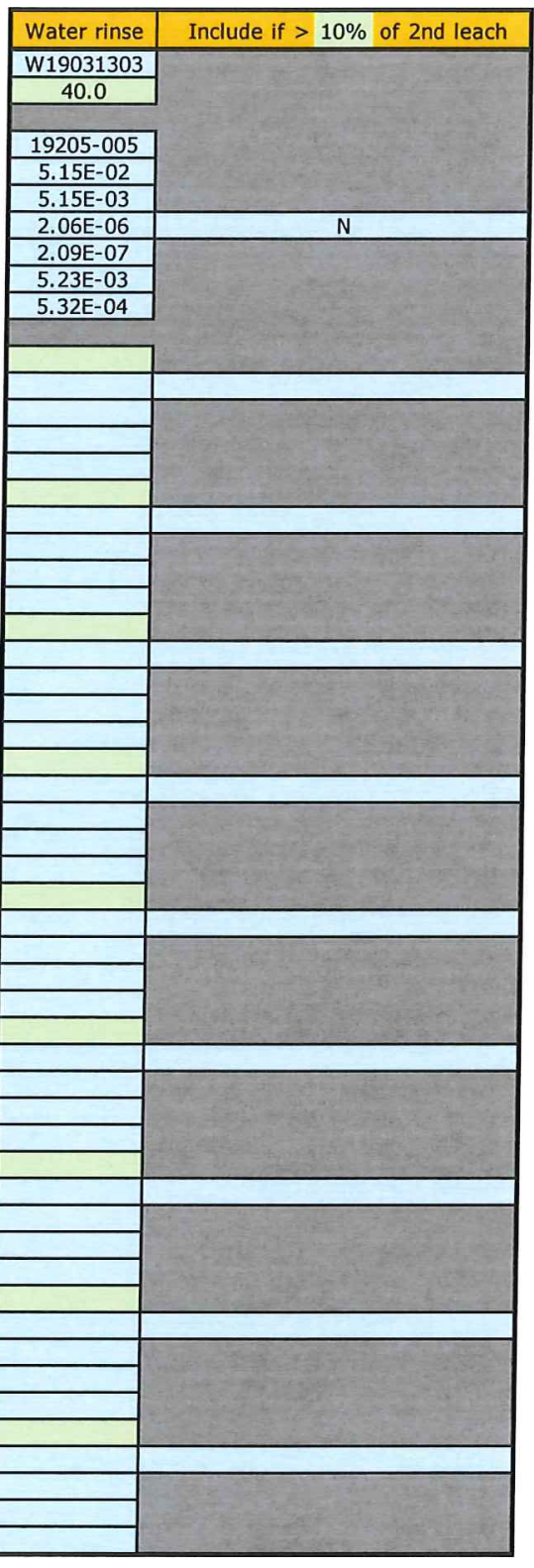

\section{Freel c. Montgomery \\ Operator}

$4-18-2019$

Date 
Data Report Form DRF-26A: Pre-Burn Leach Uranium and Impurities

\begin{tabular}{|r|l|}
\hline Procedure: & AGR-CHAR-DAM-26 Rev. 3 \\
\hline Operator: & Montgomery \\
\hline Compact lot ID: & BWXT J52R-16-14155C \\
\hline Compact lot description: & AGR-5/6/7 compacts, $40 \%$ packing fraction \\
\hline Compact ID numbers: & $1202,1121,1208,1207,1183$ \\
\hline DRF filename: & $14155 C$ PF40-Group 2 DLBL ICPMS DRF26R3.xIs \\
\hline
\end{tabular}

\begin{tabular}{|c|c|c|c|c|}
\hline \multirow{3}{*}{\multicolumn{2}{|c|}{$\begin{aligned} & \text { Number of compacts: } \\
& \text { Average weight uranium per particle, mean value }(\mathrm{g}): \text { Average weight uranium per particle, uncertainty in mean }(\mathrm{g}): \\
&\end{aligned}$}} & \multirow{2}{*}{\multicolumn{3}{|c|}{$\begin{array}{c}5 \\
3.94 E-04\end{array}$}} \\
\hline & & & & \\
\hline & & \multicolumn{3}{|c|}{$3.94 \mathrm{E}-06$} \\
\hline & & First Leach & Second Leach & Total \\
\hline & Pre-burn leach solution ID: & L19031102 & L19031302 & \\
\hline & Total volume of leach solution $(\mathrm{ml})$ : & 141.0 & 126.0 & \\
\hline & RMAL analysis number: & $19205-002$ & $19205-004$ & \\
\hline & Measured uranium concentration $(\mu \mathrm{g} / \mathrm{ml})$ : & $2.79 \mathrm{E}+00$ & $1.82 \mathrm{E}-01$ & \\
\hline & Uncertainty in uranium concentration $(\mu \mathrm{g} / \mathrm{ml})$ : & $2.79 \mathrm{E}-01$ & $1.82 \mathrm{E}-02$ & \\
\hline & Weight uranium leached $(\mathrm{g})$ : & $3.93 \mathrm{E}-04$ & $2.29 \mathrm{E}-05$ & $4.16 \mathrm{E}-04$ \\
\hline & Uncertainty in weight uranium leached $(\mathrm{g})$ : & $3.94 \mathrm{E}-05$ & $2.30 \mathrm{E}-06$ & $3.94 \mathrm{E}-05$ \\
\hline & Equivalent number of leached kernels: & $9.98 \mathrm{E}-01$ & $5.82 \mathrm{E}-02$ & $1.06 \mathrm{E}+00$ \\
\hline & Uncertainty in equivalent number of leached kernels: & $1.00 \mathrm{E}-01$ & $5.86 \mathrm{E}-03$ & $1.01 \mathrm{E}-01$ \\
\hline \multirow{5}{*}{$\mathbf{F e}$} & Measured concentration of impurity in sample $(\mu \mathrm{g} / \mathrm{ml})$ : & & & $\mathbf{F e}$ \\
\hline & Uncorrected weight of impurity in sample $(\mu \mathrm{g})$ : & & & \\
\hline & Weight of impurity in blank $(\mu \mathrm{g})$ : & & & \\
\hline & Minimum corrected weight of impurity in sample $(\mu \mathrm{g})$ : & & & \\
\hline & Maximum corrected weight of impurity in sample $(\mu \mathrm{g})$ : & & & \\
\hline \multirow{4}{*}{$\mathrm{Cr}$} & Measured concentration of impurity in sample $(\mu \mathrm{g} / \mathrm{ml})$ : & & & $\mathbf{C r}$ \\
\hline & Uncorrected weight of impurity in sample $(\mu \mathrm{g})$ : & & & \\
\hline & Weight of impurity in blank $(\mu \mathrm{g})$ : & & & \\
\hline & $\begin{array}{l}\text { Minimum corrected weight of impurity in sample }(\mu \mathrm{g}) \text { : } \\
\text { Maximum corrected weight of impurity in sample }(\mu \mathrm{q} \text { : }\end{array}$ & & & \\
\hline \multirow{5}{*}{ Mn } & Maximum corrected weight of impurity in sample $(\mu \mathrm{g})$ : & & & \\
\hline & $\frac{\text { Measured concentration of impurity in sample }(\mu \mathrm{g} / \mathrm{ml}) \text { : }}{\text { Uncorrected weight of impurity in sample }(\mu \mathrm{g})}$ & & & Mn \\
\hline & Weight of impurity in blank $(\mu \mathrm{g})$ : & & & \\
\hline & Minimum corrected weight of impurity in sample $(\mu \mathrm{g})$ : & & & \\
\hline & Maximum corrected weight of impurity in sample $(\mu g)$ : & & & \\
\hline \multirow{4}{*}{ Co } & Measured concentration of impurity in sample $(\mu \mathrm{g} / \mathrm{ml})$ : & & & Co \\
\hline & Uncorrected weight of impurity in sample $(\mu \mathrm{g})$ : & & & \\
\hline & Weight of impurity in blank $(\mu \mathrm{g})$ : & & & \\
\hline & Minimum corrected weight of impurity in sample $(\mu \mathrm{g})$ : & & & \\
\hline \multirow{5}{*}{$\mathbf{N i}$} & Maximum corrected weight of impurity in sample $(\mu \mathrm{g})$ : & & & \\
\hline & $\begin{array}{c}\text { Measured concentration of impurity in sample }(\mu \mathrm{g} / \mathrm{ml}) \text { : } \\
\text { Uncorrected weight of impurity in sample }(\mu \mathrm{g}) \text { : }\end{array}$ & & & $\mathrm{Ni}$ \\
\hline & $\begin{array}{r}\text { Weight of impurity in blank }(\mu g) \text { : } \\
\text { Wected }\end{array}$ & & & \\
\hline & Minimum corrected weight of impurity in sample $(\mu g)$ : & & & \\
\hline & Maximum corrected weight of impurity in sample $(\mu \mathrm{g})$ : & & & \\
\hline \multirow{5}{*}{$\mathrm{Ca}$} & Measured concentration of impurity in sample $(\mu \mathrm{g} / \mathrm{ml})$ : & & & $\mathrm{Ca}$ \\
\hline & Uncorrected weight of impurity in sample $(\mu \mathrm{g})$ : & & & \\
\hline & Weight of impurity in blank $(\mu \mathrm{g})$ : & & & \\
\hline & Minimum corrected weight of impurity in sample $(\mu \mathrm{g})$ : & & & \\
\hline & Maximum corrected weight of impurity in sample $(\mu \mathrm{g})$ : & & & \\
\hline \multirow{5}{*}{ Al } & Measured concentration of impurity in sample $(\mu \mathrm{g} / \mathrm{ml})$; & & & Al \\
\hline & Uncorrected weight of impurity in sample $(\mu \mathrm{g})$ : & & & \\
\hline & Weight of impurity in blank $(\mu \mathrm{g})$ : & & & \\
\hline & Minimum corrected weight of impurity in sample $(\mu \mathrm{g})$ : & & & \\
\hline & Maximum corrected weight of impurity in sample $(\mu \mathrm{g})$ : & & & \\
\hline \multirow{5}{*}{$\mathbf{T i}$} & Measured concentration of impurity in sample $(\mu \mathrm{g} / \mathrm{ml})$ : & & & Ti \\
\hline & Uncorrected weight of impurity in sample $(\mu \mathrm{g})$ : & & & \\
\hline & Weight of impurity in blank $(\mu \mathrm{g})$ : & & & \\
\hline & Minimum corrected weight of impurity in sample $(\mu \mathrm{g})$ : & & & \\
\hline & Maximum corrected weight of impurity in sample $(\mu \mathrm{g})$ : & & & \\
\hline \multirow{5}{*}{ v } & Measured concentration of impurity in sample $(\mu \mathrm{g} / \mathrm{ml})$ : & & & $\mathbf{v}$ \\
\hline & Uncorrected weight of impurity in sample $(\mu \mathrm{g})$ : & & & \\
\hline & Weight of impurity in blank $(\mu \mathrm{g})$ : & & & \\
\hline & Minimum corrected weight of impurity in sample $(\mu \mathrm{g})$ : & & & \\
\hline & Maximum corrected weight of impurity in sample $(\mu \mathrm{g})$ : & & & \\
\hline
\end{tabular}

\section{Comments}

Leached in Vessel \#44 (previously unused).

FCM checked the recorded data against the official Results of Analysis for RMAL19205 on 4/12/2019.

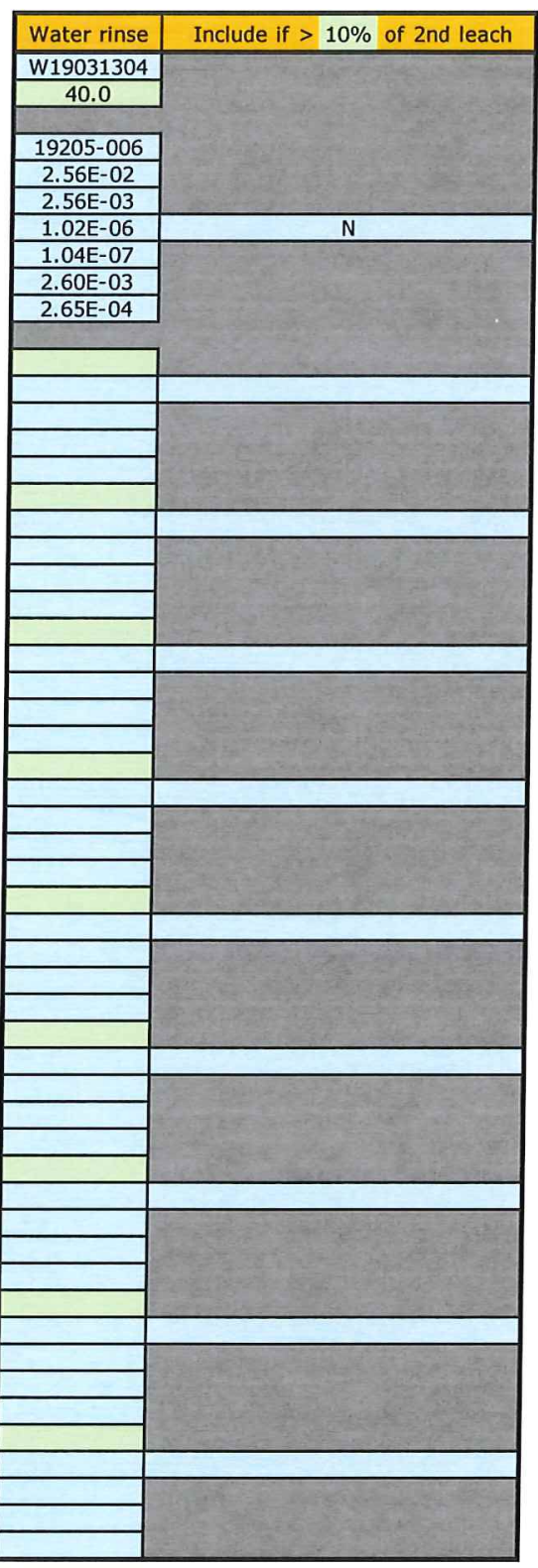

\section{Fied c. Montgomen}

$4-18-2019$

Date 


\section{Data Report Form DRF-26B: Post-Burn Leach Uranium and Impurities}

\begin{tabular}{|r|l|}
\hline Procedure: & AGR-CHAR-DAM-26 Rev. 3 \\
\hline Operator: & Montgomery \\
\hline Compact lot ID: & BWXT J52R-16-14155C \\
\hline Compact lot description: & AGR-5/6/7 compacts, 40\% packing fraction \\
\hline Compact ID numbers: & $1213,1179,1128,1112,1123$ \\
\hline DRF filename: & 14155 C PF40-Group 2 DLBL ICPMS DRF26R3.xIs \\
\hline
\end{tabular}

\begin{tabular}{|c|c|c|c|c|}
\hline \multicolumn{2}{|r|}{ 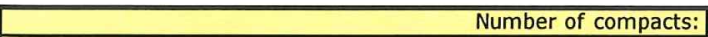 } & \multicolumn{3}{|c|}{5} \\
\hline \multirow{2}{*}{\multicolumn{2}{|c|}{$\begin{array}{l}\text { Average weight uranium per particle, mean value }(\mathrm{g}) \text { : } \\
\text { Average weight uranium per particle, uncertainty in mean }(\mathrm{g}) \text { : }\end{array}$}} & \multirow{2}{*}{\multicolumn{3}{|c|}{$\frac{3.94 \mathrm{E}-04}{3.94 \mathrm{E}-06}$}} \\
\hline & & \multicolumn{2}{|r|}{$3.94 \mathrm{E}-06$} & \\
\hline \multicolumn{2}{|r|}{ (a) } & First Leach & Second Leach & Total \\
\hline & Post-burn leach solution ID: & B19031801 & B19031901 & \\
\hline & Total volume of leach solution $(\mathrm{ml})$ : & 56.8 & 58.0 & \\
\hline & RMAL analysis number: & $19214-001$ & $19214-003$ & \\
\hline & Measured uranium concentration $(\mu \mathrm{g} / \mathrm{ml})$ : & $7.61 \mathrm{E}+00$ & $3.08 \mathrm{E}-02$ & \\
\hline & Uncertainty in uranium concentration $(\mu \mathrm{g} / \mathrm{ml})$ : & $7.61 \mathrm{E}-01$ & $3.08 \mathrm{E}-03$ & \\
\hline & Weight uranium leached $(g)$ : & $4.32 \mathrm{E}-04$ & $1.79 \mathrm{E}-06$ & $4.34 \mathrm{E}-04$ \\
\hline & Uncertainty in weight uranium leached $(\mathrm{g})$ : & $4.35 \mathrm{E}-05$ & $1.80 \mathrm{E}-07$ & $4.35 \mathrm{E}-05$ \\
\hline & Equivalent number of leached kernels: & $1.10 \mathrm{E}+00$ & $4.53 \mathrm{E}-03$ & $1.10 \mathrm{E}+00$ \\
\hline & Uncertainty in equivalent number of leached kernels: & $1.11 \mathrm{E}-01$ & $4.58 \mathrm{E}-04$ & $1.11 \mathrm{E}-01$ \\
\hline \multirow{5}{*}{$\mathbf{F e}$} & Measured concentration of impurity in sample $(\mu \mathrm{g} / \mathrm{ml})$ : & & & $\mathrm{Fe}$ \\
\hline & Uncorrected weight of impurity in sample $(\mu \mathrm{g})$ : & & & \\
\hline & Weight of impurity in blank $(\mu \mathrm{g})$ : & & & \\
\hline & Minimum corrected weight of impurity in sample $(\mu \mathrm{g})$ : & & & \\
\hline & Maximum corrected weight of impurity in sample $(\mu \mathrm{g})$ : & & & \\
\hline \multirow{5}{*}{$\mathbf{C r}$} & Measured concentration of impurity in sample $(\mu \mathrm{g} / \mathrm{ml})$ : & & & $\mathrm{Cr}$ \\
\hline & Uncorrected weight of impurity in sample $(\mu \mathrm{g})$ : & & & \\
\hline & Weight of impurity in blank $(\mu \mathrm{g})$ : & & & \\
\hline & Minimum corrected weight of impurity in sample $(\mu \mathrm{g})$ : & & & \\
\hline & Maximum corrected weight of impurity in sample $(\mu \mathrm{g})$ : & & & \\
\hline \multirow{5}{*}{ Mn } & Measured concentration of impurity in sample $(\mu \mathrm{g} / \mathrm{ml})$ : & & & Mn \\
\hline & Uncorrected weight of impurity in sample $(\mu \mathrm{g})$ : & & & \\
\hline & Weight of impurity in blank $(\mu \mathrm{g})$ : & & & \\
\hline & Minimum corrected weight of impurity in sample $(\mu \mathrm{g})$ : & & & \\
\hline & Maximum corrected weight of impurity in sample $(\mu \mathrm{g})$ : & & & \\
\hline \multirow{5}{*}{ Co } & Measured concentration of impurity in sample $(\mu \mathrm{g} / \mathrm{ml})$ : & & & Co \\
\hline & Uncorrected weight of impurity in sample $(\mu \mathrm{g})$ : & & & \\
\hline & Weight of impurity in blank $(\mu \mathrm{g})$ : & & & \\
\hline & Minimum corrected weight of impurity in sample $(\mu \mathrm{g})$ : & & & \\
\hline & Maximum corrected weight of impurity in sample $(\mu \mathrm{g})$ : & & & \\
\hline \multirow{5}{*}{$\mathbf{N i}$} & Measured concentration of impurity in sample $(\mu \mathrm{g} / \mathrm{ml})$ : & & & $\mathrm{Ni}$ \\
\hline & Uncorrected weight of impurity in sample $(\mu \mathrm{g})$ : & & & \\
\hline & Weight of impurity in blank $(\mu \mathrm{g})$ : & & & \\
\hline & Minimum corrected weight of impurity in sample $(\mu g)$ : & & & \\
\hline & Maximum corrected weight of impurity in sample $(\mu \mathrm{g})$ : & & & \\
\hline \multirow{5}{*}{$\mathrm{Ca}$} & Measured concentration of impurity in sample $(\mu \mathrm{g} / \mathrm{ml})$ : & & & $\mathbf{C a}$ \\
\hline & Uncorrected weight of impurity in sample $(\mu \mathrm{g})$ : & & & \\
\hline & Weight of impurity in blank $(\mu \mathrm{g})$ : & & & \\
\hline & Minimum corrected weight of impurity in sample $(\mu \mathrm{g}):$ & & & \\
\hline & Maximum corrected weight of impurity in sample $(\mu g)$ : & & & \\
\hline \multirow{5}{*}{ Al } & Measured concentration of impurity in sample $(\mu \mathrm{g} / \mathrm{ml})$ : & & & $\overline{\mathrm{Al}}$ \\
\hline & Uncorrected weight of impurity in sample $(\mu \mathrm{g})$ : & & & \\
\hline & Weight of impurity in blank $(\mu \mathrm{g})$ : & & & \\
\hline & Minimum corrected weight of impurity in sample $(\mu \mathrm{g})$ : & & & \\
\hline & Maximum corrected weight of impurity in sample $(\mu \mathrm{g})$ : & & & \\
\hline \multirow{5}{*}{$\mathbf{T i}$} & Measured concentration of impurity in sample $(\mu \mathrm{g} / \mathrm{ml})$ : & & & $\mathbf{T i}$ \\
\hline & Uncorrected weight of impurity in sample $(\mu \mathrm{g})$ : & & & \\
\hline & Weight of impurity in blank $(\mu \mathrm{g})$ : & & & \\
\hline & Minimum corrected weight of impurity in sample $(\mu \mathrm{g})$ : & & & \\
\hline & Maximum corrected weight of impurity in sample $(\mu \mathrm{g})$ : & & & \\
\hline \multirow{5}{*}{$\mathbf{v}$} & Measured concentration of impurity in sample $(\mu \mathrm{g} / \mathrm{ml})$ : & & & $\mathbf{v}$ \\
\hline & Uncorrected weight of impurity in sample $(\mu \mathrm{g})$ : & & & \\
\hline & Weight of impurity in blank $(\mu \mathrm{g})$ : & & & \\
\hline & Minimum corrected weight of impurity in sample $(\mu \mathrm{g})$ : & & & \\
\hline & Maximum corrected weight of impurity in sample $(\mu \mathrm{g})$ : & & & \\
\hline
\end{tabular}

\section{Comments}

FCM checked the recorded data against the official Results of Analysis for RMAL19214 on 4/12/2019.

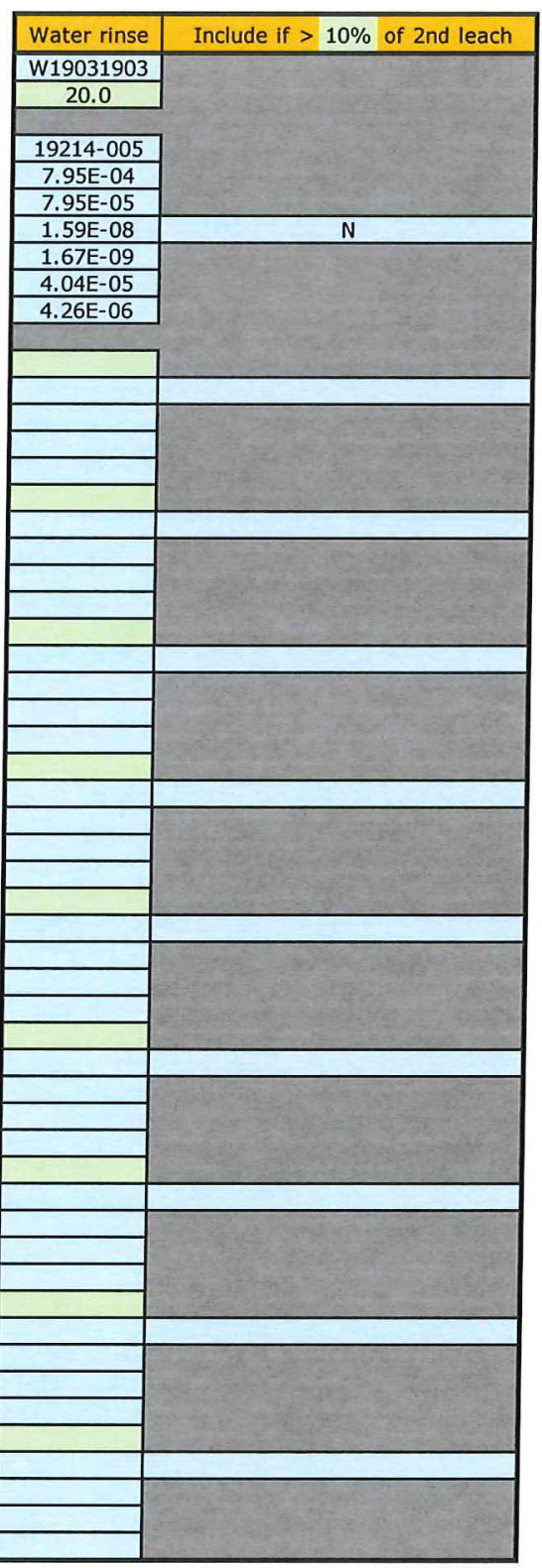

\section{Fred c. Montgomem $\frac{4-18-2019}{\text { Doprator }}$}


Data Report Form DRF-26B: Post-Burn Leach Uranium and Impurities

\begin{tabular}{|r|l|}
\hline Procedure: & AGR-CHAR-DAM-26 Rev. 3 \\
\hline Operator: & Montgomery \\
\hline Compact lot ID: & BWXT J52R-16-14155C \\
\hline Compact lot description: & AGR-5/6/7 compacts, 40\% packing fraction \\
\hline Compact ID numbers: & $1145,1186,1113,1214,1119$ \\
\hline DRF filename: & 14155 CPF40-Group 2_DLBL_ICPMS_DRF26R3.xIs \\
\hline
\end{tabular}

\begin{tabular}{r|}
\hline \\
\hline Number of compacts: \\
\hline Average weight uranium per particle, mean value $(g)$ :
\end{tabular} Average weight uranium per particle, uncertainty in mean $(g)$ :

\begin{tabular}{|c|c|c|c|c|}
\hline & \multirow{2}{*}{ 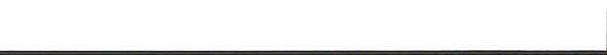 } & & & \\
\hline & & First Leach & Second Leach & Total \\
\hline & Post-burn leach solution ID: & B19031802 & B19031902 & \\
\hline & Total volume of leach solution $(\mathrm{ml})$ : & 55.3 & 58.8 & \\
\hline & RMAL analysis number: & $19214-002$ & $19214-004$ & \\
\hline & Measured uranium concentration $(\mu \mathrm{g} / \mathrm{ml})$ : & $2.30 \mathrm{E}-01$ & $6.40 \mathrm{E}-03$ & \\
\hline & Uncertainty in uranium concentration $(\mu \mathrm{g} / \mathrm{ml})$ : & $2.30 \mathrm{E}-02$ & $6.40 \mathrm{E}-04$ & \\
\hline & Weight uranium leached $(g)$ : & $1.27 \mathrm{E}-05$ & $3.76 \mathrm{E}-07$ & $1.31 \mathrm{E}-05$ \\
\hline & Uncertainty in weight uranium leached $(\mathrm{g})$ : & $1.28 \mathrm{E}-06$ & $3.79 \mathrm{E}-08$ & $1.28 \mathrm{E}-06$ \\
\hline & Equivalent number of leached kernels: & $3.23 \mathrm{E}-02$ & $9.55 \mathrm{E}-04$ & $3.32 \mathrm{E}-02$ \\
\hline & Uncertainty in equivalent number of leached kernels: & $3.27 \mathrm{E}-03$ & $9.66 \mathrm{E}-05$ & $3.27 \mathrm{E}-03$ \\
\hline \multirow{5}{*}{$\mathbf{F e}$} & Measured concentration of impurity in sample $(\mu \mathrm{g} / \mathrm{ml})$ : & & & $\mathbf{F e}$ \\
\hline & Uncorrected weight of impurity in sample $(\mu \mathrm{g})$ : & & & \\
\hline & Weight of impurity in blank $(\mu \mathrm{g})$ : & & & \\
\hline & Minimum corrected weight of impurity in sample $(\mu g)$ : & & & \\
\hline & Maximum corrected weight of impurity in sample $(\mu \mathrm{g})$ : & & & \\
\hline \multirow{5}{*}{$\mathrm{cr}$} & Measured concentration of impurity in sample $(\mu \mathrm{g} / \mathrm{ml})$ : & & & $\mathrm{Cr}$ \\
\hline & Uncorrected weight of impurity in sample $(\mu \mathrm{g})$ : & & & \\
\hline & Weight of impurity in blank $(\mu \mathrm{g})$ : & & & \\
\hline & Minimum corrected weight of impurity in sample $(\mu \mathrm{g})$ : & & & \\
\hline & Maximum corrected weight of impurity in sample $(\mu \mathrm{g})$ : & & & \\
\hline \multirow{5}{*}{ Mn } & Measured concentration of impurity in sample $(\mu \mathrm{g} / \mathrm{ml})$ : & & & Mn \\
\hline & Uncorrected weight of impurity in sample $(\mu \mathrm{g})$ : & & & \\
\hline & Weight of impurity in blank $(\mu \mathrm{g})$ : & & & \\
\hline & Minimum corrected weight of impurity in sample $(\mu \mathrm{g})$ : & & & \\
\hline & Maximum corrected weight of impurity in sample $(\mu \mathrm{g})$ : & & & \\
\hline \multirow{5}{*}{ co } & Measured concentration of impurity in sample $(\mu \mathrm{g} / \mathrm{ml})$ : & & & Co \\
\hline & Uncorrected weight of impurity in sample $(\mu \mathrm{g})$ : & & & \\
\hline & Weight of impurity in blank $(\mu \mathrm{g})$ : & & & \\
\hline & Minimum corrected weight of impurity in sample $(\mu g)$ : & & & \\
\hline & Maximum corrected weight of impurity in sample $(\mu \mathrm{g})$ : & & & \\
\hline \multirow{5}{*}{$\mathrm{Ni}$} & Measured concentration of impurity in sample $(\mu \mathrm{g} / \mathrm{ml})$ : & & & $\mathrm{Ni}$ \\
\hline & Uncorrected weight of impurity in sample $(\mu g)$ : & & & \\
\hline & Weight of impurity in blank $(\mu \mathrm{g})$ : & & & 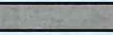 \\
\hline & Minimum corrected weight of impurity in sample $(\mu \mathrm{g})$ : & & & \\
\hline & Maximum corrected weight of impurity in sample $(\mu \mathrm{g})$ : & & & \\
\hline \multirow{5}{*}{$\mathbf{C a}$} & Measured concentration of impurity in sample $(\mu \mathrm{g} / \mathrm{ml})$ : & & & $\mathbf{C a}$ \\
\hline & Uncorrected weight of impurity in sample $(\mu \mathrm{g})$ : & & & \\
\hline & Weight of impurity in blank $(\mu \mathrm{g})$ : & & & \\
\hline & Minimum corrected weight of impurity in sample $(\mu g)$ : & & & \\
\hline & Maximum corrected weight of impurity in sample $(\mu g)$ : & & & \\
\hline \multirow{5}{*}{ Al } & Measured concentration of impurity in sample $(\mu \mathrm{g} / \mathrm{ml})$ : & & & Al \\
\hline & Uncorrected weight of impurity in sample $(\mu \mathrm{g})$ : & & & \\
\hline & Weight of impurity in blank $(\mu g)$ : & & & \\
\hline & Minimum corrected weight of impurity in sample $(\mu \mathrm{g})$ : & & & \\
\hline & Maximum corrected weight of impurity in sample $(\mu g)$ : & & & \\
\hline \multirow{5}{*}{$\mathbf{T i}$} & Measured concentration of impurity in sample $(\mu \mathrm{g} / \mathrm{ml})$ : & & & Ti \\
\hline & Uncorrected weight of impurity in sample $(\mu \mathrm{g})$ : & & & \\
\hline & Weight of impurity in blank $(\mu \mathrm{g})$ : & & & \\
\hline & Minimum corrected weight of impurity in sample $(\mu \mathrm{g})$ : & & & \\
\hline & Maximum corrected weight of impurity in sample $(\mu g)$ : & & & \\
\hline \multirow{5}{*}{$\mathbf{v}$} & Measured concentration of impurity in sample $(\mu \mathrm{g} / \mathrm{ml})$ : & & & $\mathbf{v}$ \\
\hline & Uncorrected weight of impurity in sample $(\mu \mathrm{g})$ : & & & \\
\hline & Weight of impurity in blank $(\mu \mathrm{g})$ : & & & \\
\hline & Minimum corrected weight of impurity in sample $(\mu \mathrm{g})$ : & & & \\
\hline & Maximum corrected weight of impurity in sample $(\mu g):$ & & & \\
\hline
\end{tabular}

comments

FCM checked the recorded data against the official Results of Analysis for RMAL19214 on 4/12/2019.

5 $3.94 \mathrm{E}-04$

$3.94 \mathrm{E}-06$

\section{2}

$6.40 \mathrm{E}-04$

$3.76 \mathrm{E}-07$

$2 \mathrm{E}-02$

$r$

(1)

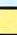

$+$

Maximum corrected weight of impurity in sample $(\mu \mathrm{g})$ :

$+2$

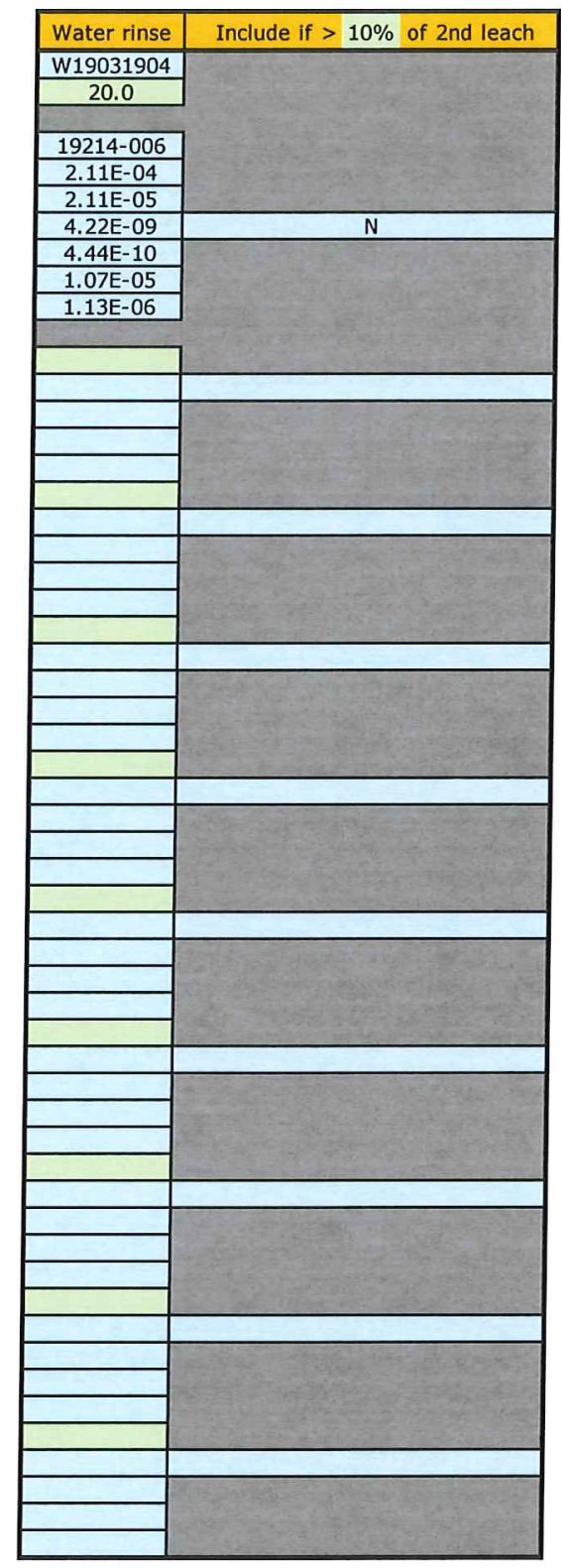

\section{Fied c. Montgomery 4-18-2019


Data Report Form DRF-26B: Post-Burn Leach Uranium and Impurities

\begin{tabular}{|r|l|}
\hline Procedure: & AGR-CHAR-DAM-26 Rev. 3 \\
\hline Operator: & Montgomery \\
\hline Compact lot ID: & BWXT J52R-16-14155C \\
\hline Compact lot description: & AGR-5/6/7 compacts, 40\% packing fraction \\
\hline Compact ID numbers: & $1148,1159,1127,1190,1189$ \\
\hline DRF filename: & 14155 C_PF 40 -Group 2_DLBL_ICPMS_DRF26R3.xIs \\
\hline
\end{tabular}

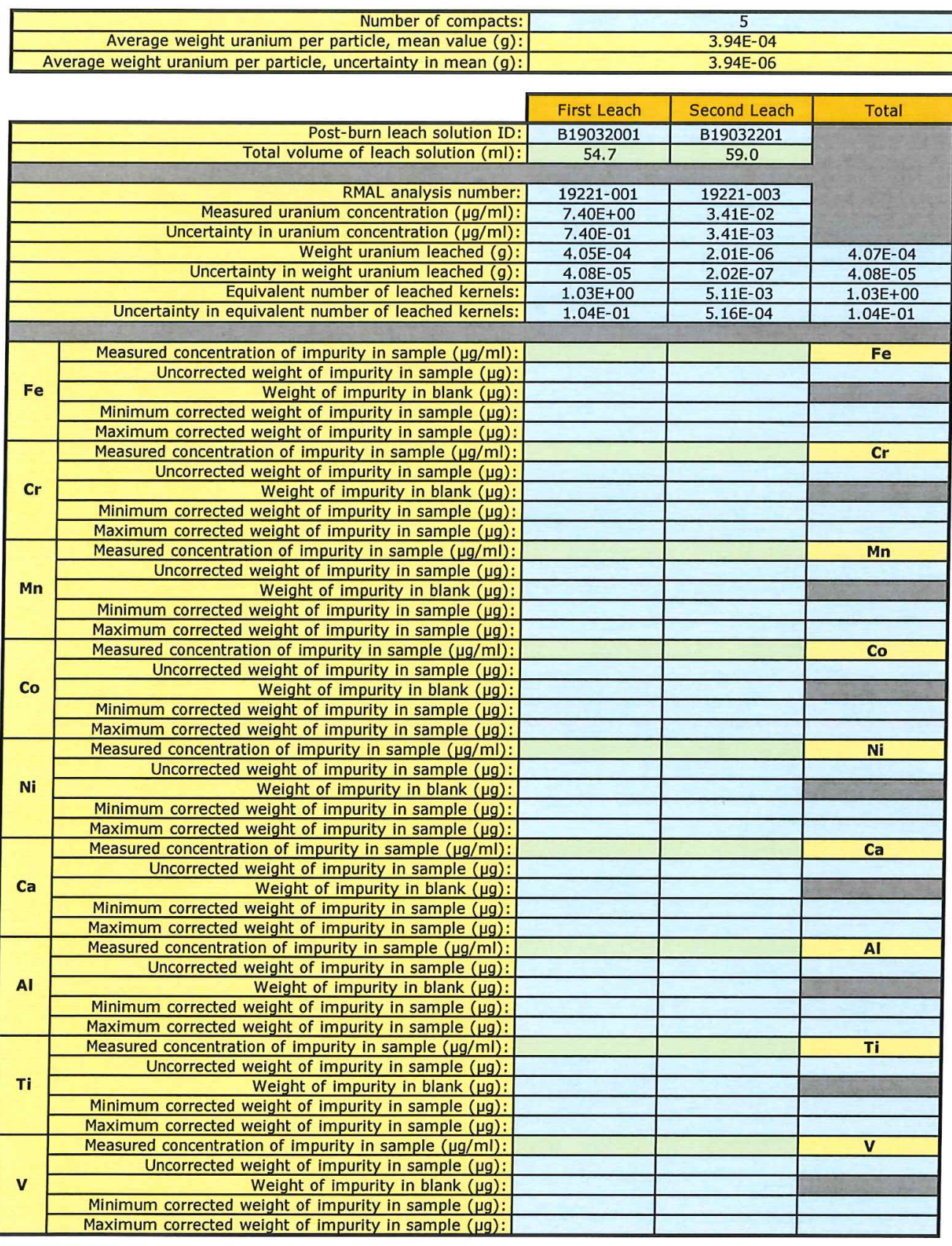

comments

FCM checked the recorded data against the official Results of Analysis for RMAL19221 on 4/12/2019.

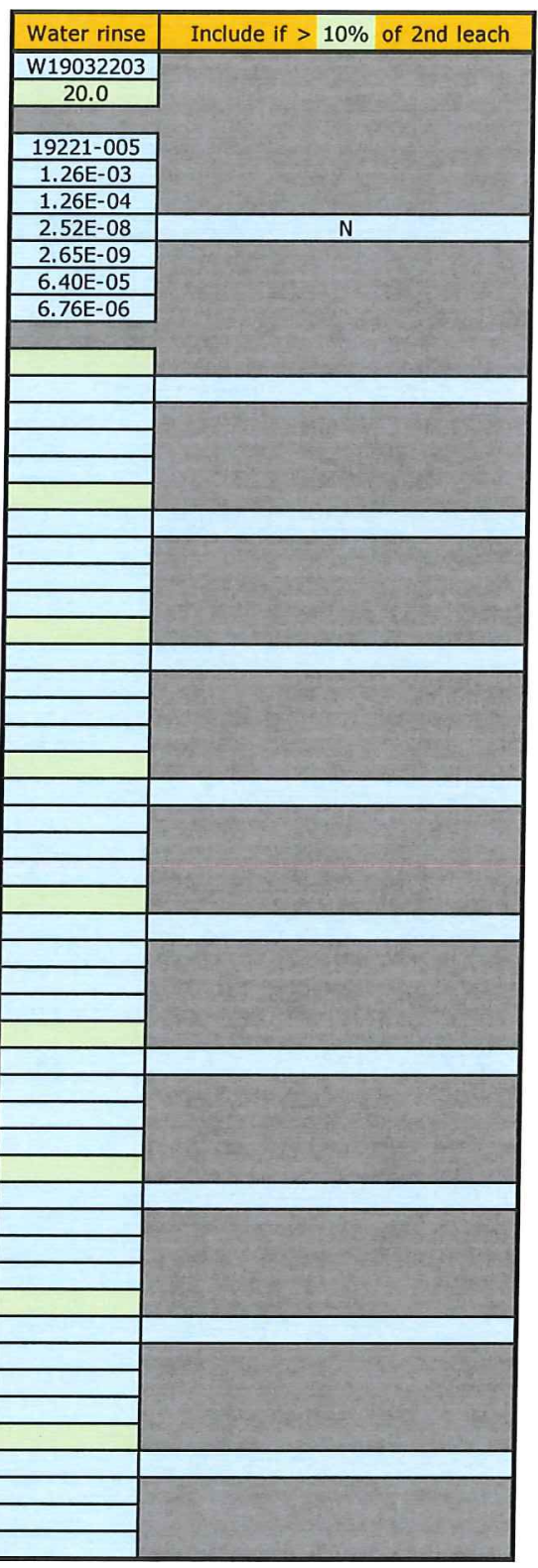


Data Report Form DRF-26B: Post-Burn Leach Uranium and Impurities

\begin{tabular}{|r|l|}
\hline Procedure: & AGR-CHAR-DAM-26 Rev. 3 \\
\hline Operator: & Montgomery \\
\hline Compact lot ID: & BWXT J52R-16-14155C \\
\hline Compact lot description: & AGR-5/6/7 compacts, $40 \%$ packing fraction \\
\hline Compact ID numbers: & $1202,1121,1208,1207,1183$ \\
\hline DRF filename: & 14155 C_PF40-Group 2_DLBL_ICPMS_DRF26R3.xIs \\
\hline
\end{tabular}

\begin{tabular}{|r|c|}
\hline Number of compacts: & 5 \\
\hline Average weight uranium per particle, mean value $(\mathrm{g}):$ & $3.94 \mathrm{E}-04$ \\
\hline Average weight uranium per particle, uncertainty in mean $(\mathrm{g}):$ & $3.94 \mathrm{E}-06$ \\
\hline
\end{tabular}

\begin{tabular}{|c|c|c|c|c|}
\hline & & & \\
\hline & & First Leach & Second Leach & Total \\
\hline & Post-burn leach solution ID: & B19032002 & B19032202 & \\
\hline & Total volume of leach solution $(\mathrm{ml})$ : & 56.5 & 58.7 & \\
\hline & RMAL analysis number: & & & \\
\hline & $\begin{array}{r}\text { R MAL analysis number: } \\
\text { Measured uranium concentration }(\mu \mathrm{g} / \mathrm{ml}) \text { : }\end{array}$ & $\frac{19221-002}{7.23 E+00}$ & $\frac{19221-004}{3.28 \mathrm{E}-02}$ & \\
\hline & Uncertainty in uranium concentration $(\mu \mathrm{g} / \mathrm{ml})$ : & $7.23 \mathrm{E}-01$ & $\frac{3.28 \mathrm{~L}-03}{3.03}$ & \\
\hline & Weight uranium leached $(\mathrm{g})$ : & $4.08 \mathrm{E}-04$ & $1.93 \mathrm{E}-06$ & $4.10 \mathrm{E}-04$ \\
\hline & Uncertainty in weight uranium leached $(\mathrm{g})$ : & $4.11 \mathrm{E}-05$ & $1.94 \mathrm{E}-07$ & $4.11 \mathrm{E}-05$ \\
\hline & Equivalent number of leached kernels: & $1.04 \mathrm{E}+00$ & $4.89 \mathrm{E}-03$ & $1.04 \mathrm{E}+00$ \\
\hline & Uncertainty in equivalent number of leached kernels: & $1.05 \mathrm{E}-01$ & $4.94 \mathrm{E}-04$ & $1.05 \mathrm{E}-01$ \\
\hline \multirow{5}{*}{$\mathbf{F e}$} & Measured concentration of impurity in sample $(\mu \mathrm{g} / \mathrm{ml})$ : & & & $\mathbf{F e}$ \\
\hline & Uncorrected weight of impurity in sample $(\mu \mathrm{g})$ : & & & \\
\hline & Weight of impurity in blank $(\mu \mathrm{g})$ : & & & \\
\hline & Minimum corrected weight of impurity in sample $(\mu \mathrm{g})$ : & & & \\
\hline & Maximum corrected weight of impurity in sample $(\mu \mathrm{g})$ : & & & \\
\hline \multirow{5}{*}{$\mathbf{C r}$} & Measured concentration of impurity in sample $(\mu \mathrm{g} / \mathrm{ml})$ : & & & $\mathbf{C r}$ \\
\hline & Uncorrected weight of impurity in sample $(\mu \mathrm{g})$ : & & & \\
\hline & Weight of impurity in blank $(\mu \mathrm{g})$ : & & & \\
\hline & Minimum corrected weight of impurity in sample $(\mu \mathrm{g})$ : & & & \\
\hline & Maximum corrected weight of impurity in sample $(\mu \mathrm{g})$ : & & & \\
\hline \multirow{5}{*}{ Mn } & Measured concentration of impurity in sample $(\mu \mathrm{g} / \mathrm{ml})$ : & & & Mn \\
\hline & Uncorrected weight of impurity in sample $(\mu \mathrm{g})$ : & & & \\
\hline & Weight of impurity in blank $(\mu \mathrm{g})$ : & & & \\
\hline & Minimum corrected weight of impurity in sample $(\mu \mathrm{g})$ : & & & \\
\hline & Maximum corrected weight of impurity in sample $(\mu \mathrm{g})$ : & & & \\
\hline \multirow{5}{*}{ co } & Measured concentration of impurity in sample $(\mu \mathrm{g} / \mathrm{ml})$ : & & & Co \\
\hline & Uncorrected weight of impurity in sample $(\mu \mathrm{g})$ : & & & \\
\hline & Weight of impurity in blank $(\mu \mathrm{g})$ : & & & \\
\hline & Minimum corrected weight of impurity in sample $(\mu \mathrm{g})$ : & & & \\
\hline & Maximum corrected weight of impurity in sample $(\mu \mathrm{g})$ : & & & \\
\hline \multirow{5}{*}{$\mathbf{N i}$} & Measured concentration of impurity in sample $(\mu \mathrm{g} / \mathrm{ml})$ : & & & $\mathbf{N i}$ \\
\hline & Uncorrected weight of impurity in sample $(\mu \mathrm{g})$ : & & & \\
\hline & Weight of impurity in blank $(\mu \mathrm{g})$ : & & & \\
\hline & Minimum corrected weight of impurity in sample $(\mu \mathrm{g})$ : & & & \\
\hline & Maximum corrected weight of impurity in sample $(\mu \mathrm{g})$ : & & & \\
\hline \multirow{5}{*}{$\mathbf{C a}$} & Measured concentration of impurity in sample $(\mu \mathrm{g} / \mathrm{ml})$ : & & & $\mathrm{Ca}$ \\
\hline & Uncorrected weight of impurity in sample $(\mu \mathrm{g})$ : & & & \\
\hline & Weight of impurity in blank $(\mu \mathrm{g})$ : & & & \\
\hline & Minimum corrected weight of impurity in sample $(\mu \mathrm{g})$ : & & & \\
\hline & Maximum corrected weight of impurity in sample $(\mu \mathrm{g})$ : & & & \\
\hline \multirow{5}{*}{ AI } & Measured concentration of impurity in sample $(\mu \mathrm{g} / \mathrm{ml})$ : & & & Al \\
\hline & Uncorrected weight of impurity in sample $(\mu g)$ : & & & \\
\hline & Weight of impurity in blank $(\mu \mathrm{g})$ : & & & \\
\hline & Minimum corrected weight of impurity in sample $(\mu \mathrm{g})$ : & & & \\
\hline & Maximum corrected weight of impurity in sample $(\mu \mathrm{g})$ : & & & \\
\hline \multirow{5}{*}{$\mathrm{Ti}$} & Measured concentration of impurity in sample $(\mu \mathrm{g} / \mathrm{ml})$ : & & & Ti \\
\hline & Uncorrected weight of impurity in sample $(\mu \mathrm{g})$ : & & & \\
\hline & Weight of impurity in blank $(\mu \mathrm{g}):$ & & & \\
\hline & Minimum corrected weight of impurity in sample $(\mu \mathrm{g})$ : & & & \\
\hline & Maximum corrected weight of impurity in sample $(\mu \mathrm{g}):$ & & & \\
\hline \multirow{5}{*}{$\mathbf{v}$} & Measured concentration of impurity in sample $(\mu \mathrm{g} / \mathrm{ml})$ : & & & $\mathbf{v}$ \\
\hline & Uncorrected weight of impurity in sample $(\mu \mathrm{g})$ : & & & \\
\hline & Weight of impurity in blank $(\mu \mathrm{g})$ : & & & \\
\hline & Minimum corrected weight of impurity in sample $(\mu \mathrm{g})$ : & & & \\
\hline & Maximum corrected weight of impurity in sample $(\mu \mathrm{g}): 1$ & & & \\
\hline
\end{tabular}

\section{comments}

FCM checked the recorded data against the official Results of Analysis for RMAL19221 on 4/12/2019.

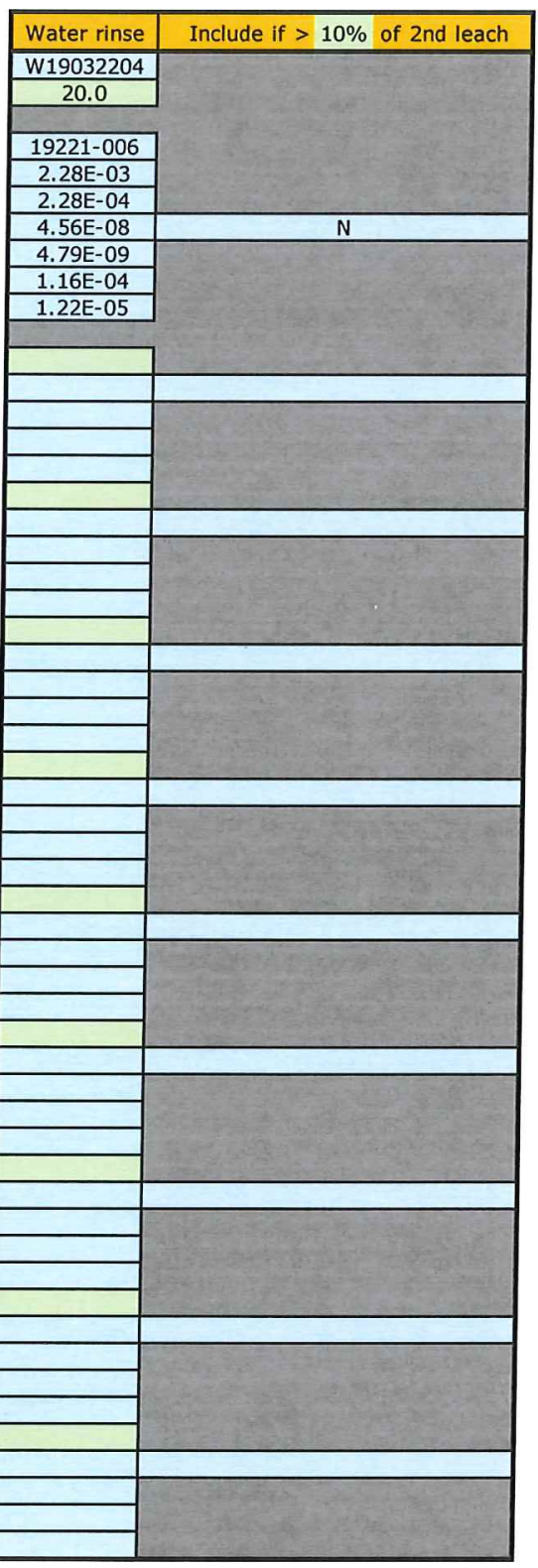



APPENDIX E. REPORT FORMS FOR 40\% PF COMPACT BL 

Procedure: AGR-CHAR-DAM-26 Rev. 3

Operator: Montgomer

Compact lot ID: BWXT J52R-16-14154D

Compact lot description: AGR-5/6/7 compacts, $40 \%$ packing fraction

\begin{tabular}{|r|c|c|c|c|c|}
\hline Compact ID numbers: & $\begin{array}{c}1504,1538, \\
1524,1514, \\
1507\end{array}$ & $\begin{array}{c}1526,1515, \\
1541,1530, \\
1528\end{array}$ & $\begin{array}{c}1539,1527, \\
1512,1513, \\
1517\end{array}$ & $\begin{array}{c}1520,1528, \\
1511,1500, \\
1506\end{array}$ & Total \\
\hline \hline Number of compacts: & 5 & 5 & 5 & 5 & 20 \\
\hline Equivalent number of leached kernels: & $3.3 \mathrm{E}+00$ & $1.2 \mathrm{E}-01$ & $2.2 \mathrm{E}+00$ & $2.2 \mathrm{E}+00$ & $7.9 \mathrm{E}+00$ \\
\hline
\end{tabular}

Comments

No deconsolidation or pre-burn leach was performed. Compacts subjected to burn-leach.

Fred C. Mnontgomeey Operator
$4-18-2019$ 
Inspection Report Form IRF-D: Summary of Post-Burn Leach Uranium

Procedure: AGR-CHAR-DAM-26 Rev. 3

Operator: Montgomery

Compact lot ID: 1 BWXT J52R-16-14154D

Compact lot description: $A G R-5 / 6 / 7$ compacts, $40 \%$ packing fraction

\begin{tabular}{|r|c|c|c|c|c|}
\hline Compact ID numbers: & $\begin{array}{c}1508,1510, \\
1501,1533, \\
1519\end{array}$ & $\begin{array}{c}1503,1518, \\
1505,1534, \\
1521\end{array}$ & $\begin{array}{c}1537,1535, \\
1540,1502, \\
1509\end{array}$ & $\begin{array}{c}1522,1531, \\
1543,1532, \\
1525\end{array}$ & Total \\
\hline \hline Number of compacts: & 5 & 5 & 5 & 5 & 20 \\
\hline Equivalent number of leached kernels: & $2.8 \mathrm{E}+00$ & $3.3 \mathrm{E}+00$ & $7.0 \mathrm{E}-02$ & $1.1 \mathrm{E}+00$ & $7.2 \mathrm{E}+00$ \\
\hline
\end{tabular}

Comments

No deconsolidation or pre-burn leach was performed. Compacts subjected to burn-leach.

(

Fred C. Montgomery Operator
$4-18-2019$ 


\begin{tabular}{|r|l|}
\hline Procedure: & AGR-CHAR-DAM-26 Rev. 3 \\
\hline Operator: & Montgomery \\
\hline Compact lot ID: & BWXT J52R-16-14155D \\
\hline Compact lot description: & AGR-5/6/7 compacts, 40\% packing fraction \\
\hline
\end{tabular}

\begin{tabular}{|r|c|c|c|c|c|}
\hline Compact ID numbers: & $\begin{array}{c}1659,1648, \\
1670,1655, \\
1662\end{array}$ & $\begin{array}{c}1673,1666, \\
1656,1675, \\
1668\end{array}$ & $\begin{array}{c}1669,1657, \\
1661,1649, \\
1650\end{array}$ & $\begin{array}{c}1663,1654, \\
1646,1643, \\
1667\end{array}$ & Total \\
\hline \hline Number of compacts: & 5 & 5 & 5 & 5 & 20 \\
\hline Equivalent number of leached kernels: & $2.2 \mathrm{E}+00$ & $1.5 \mathrm{E}+00$ & $1.3 \mathrm{E}+00$ & $2.1 \mathrm{E}+00$ & $7.1 \mathrm{E}+00$ \\
\hline
\end{tabular}

Comments

No deconsolidation or pre-burn leach was performed. Compacts subjected to burn-leach.

\section{Feed c. Montgomery




\begin{tabular}{|r|l|}
\hline Procedure: & AGR-CHAR-DAM-26 Rev. 3 \\
\hline Operator: & Montgomery \\
\hline Compact lot ID: & BWXT J52R-16-14155D \\
\hline Compact lot description: & AGR-5/6/7 compacts, 40\% packing fraction \\
\hline
\end{tabular}

\begin{tabular}{|r|c|c|c|c|c|}
\hline Compact ID numbers: & $\begin{array}{c}1658,1674, \\
1671,1653^{\prime} \\
1640\end{array}$ & $\begin{array}{c}1652,1641, \\
1644,1642^{\prime}, \\
1665\end{array}$ & $\begin{array}{c}1645,1651,1677,1664, \\
1672\end{array}$ & $\begin{array}{c}1679,1647,1678_{,} \\
1660\end{array}$ & Total \\
\hline \hline Number of compacts: & 5 & 5 & 5 & 5 & 20 \\
\hline Equivalent number of leached kernels: & $1.0 \mathrm{E}+00$ & $1.5 \mathrm{E}+00$ & $2.9 \mathrm{E}+00$ & $8.4 \mathrm{E}-02$ & $5.5 \mathrm{E}+00$ \\
\hline
\end{tabular}

Comments

No deconsolidation or pre-burn leach was performed. Compacts subjected to burn-leach.

Fred C. Montgomery 
Data Report Form DRF-26B: Post-Burn Leach Uranium and Impurities

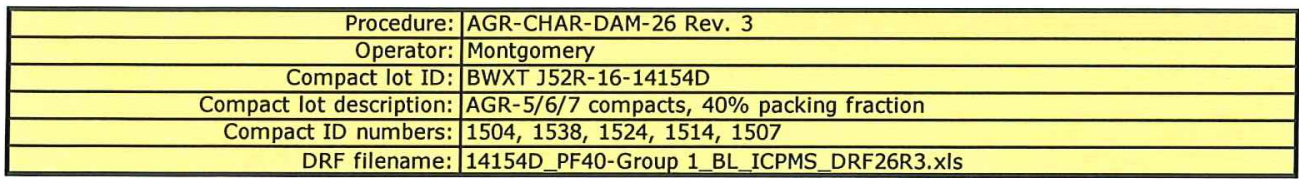

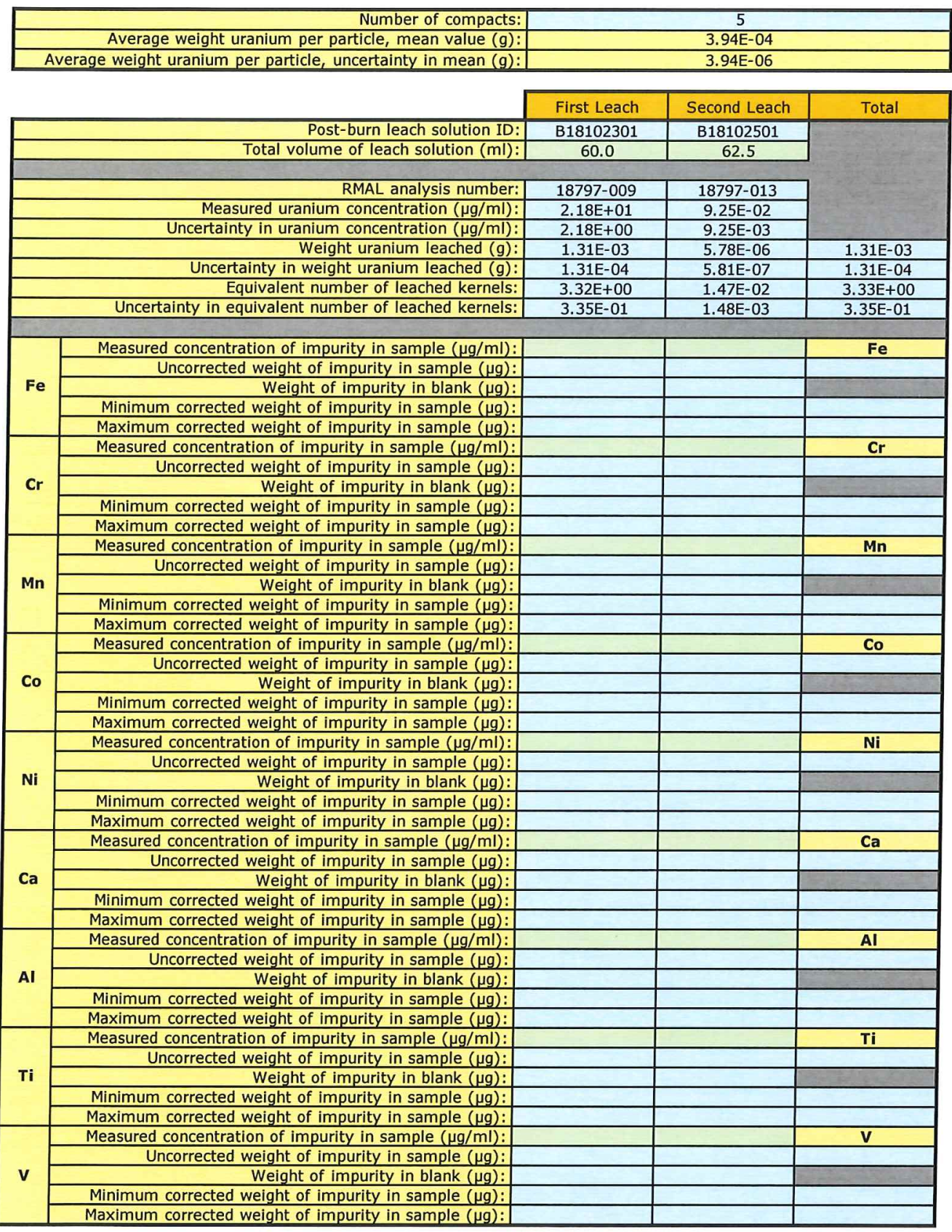

Comments

eached in Vessel RB\#2 (previously leached and analyzed as Blank 1 before use)

FCM checked the recorded data against the official Results of Analysis for RMAL18797 on 3/21/2019.

Shown is the result of the second ICPMS analyses of B18102301.

The first analysis results were rejected based on IDMS analysis.

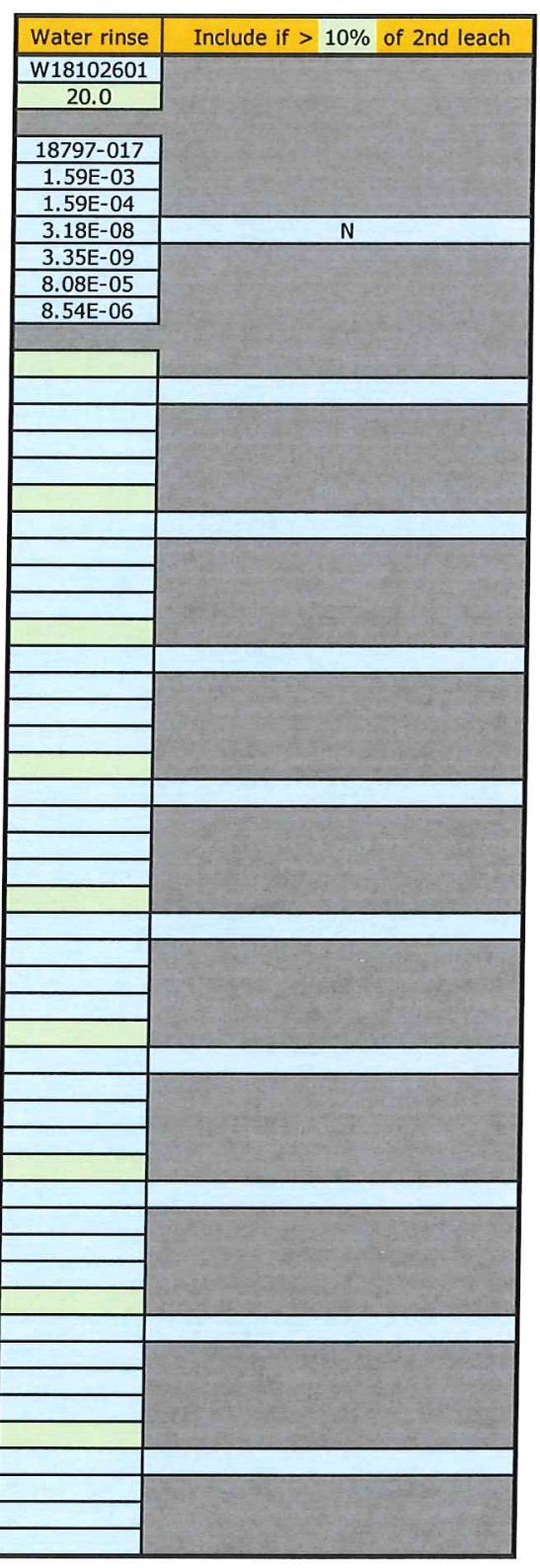


Data Report Form DRF-26B: Post-Burn Leach Uranium and Impurities

\begin{tabular}{|r|l|}
\hline Procedure: & AGR-CHAR-DAM-26 Rev. 3 \\
\hline Operator: & Montgomery \\
\hline Compact lot ID: & BWXT J52R-16-14154D \\
\hline Compact lot description: & AGR-5/6/7 compacts, 40\% packing fraction \\
\hline Compact ID numbers: & $1504,1538,1524,1514,1507$ \\
\hline DRF filename: & 14154 D_PF40-Group 1_BL_ICPMS_DRF26R3.xls \\
\hline
\end{tabular}

\begin{tabular}{|r|c|}
\hline Number of compacts: & 5 \\
\hline Average weight uranium per particle, mean value $(\mathrm{g}):$ & $3.94 \mathrm{E}-04$ \\
\hline Average weight uranium per particle, uncertainty in mean $(\mathrm{g}):$ & $3.94 \mathrm{E}-06$ \\
\hline
\end{tabular}

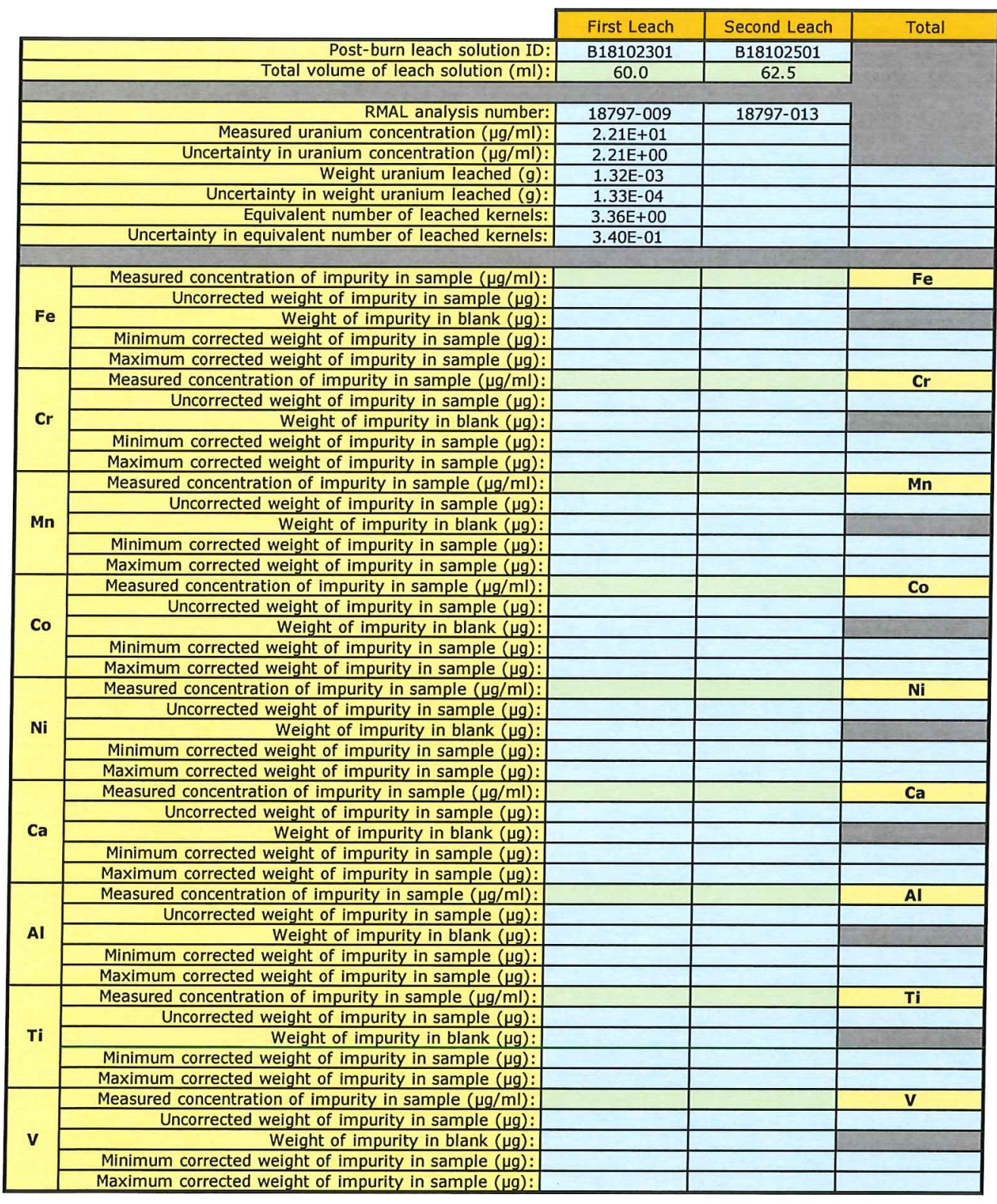

\section{Comments}

Leached in Vessel RB\#2 (previously leached and analyzed as Blank 1 before use).

FCM checked the recorded data against the official Results of Analysis for RMAL18797 on 3/21/2019.

Shown is the result of the first ICPMS analysis of B18102301.

The first analysis results were rejected based on IDMS analysis.

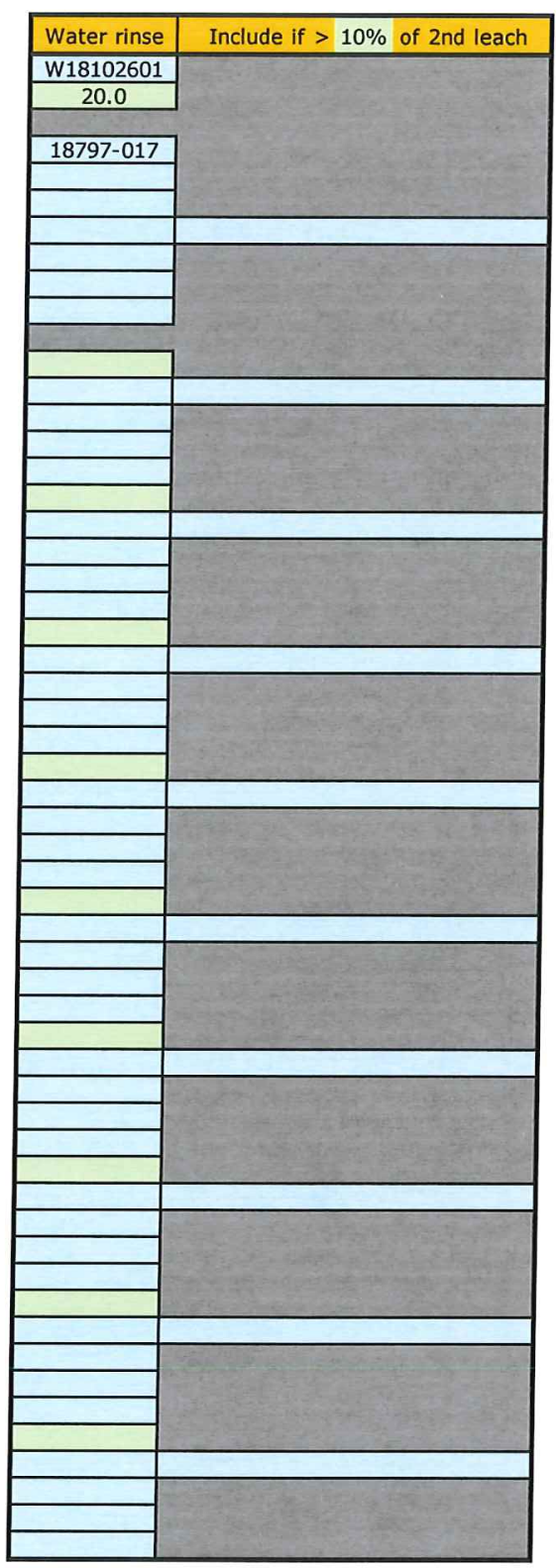

\section{Fred c. montgomery}

$4-18-2019$

Date 
Data Report Form DRF-26B: Post-Burn Leach Uranium and Impurities

\begin{tabular}{|r|r|}
\hline Procedure: & AGR-CHAR-DAM-26 Rev. 3 \\
\hline Operator: & Montgomery \\
\hline Compact lot ID: & BWXT J52R-16-14154D \\
\hline Compact lot description: & AGR-5/6/7 compacts, 40\% packing fraction \\
\hline Compact ID numbers: & $1504,1538,1524,1514,1507$ \\
\hline DRF filename: & $14154 \mathrm{D} \_$PF40-Group 1_BL_ICPMS_DRF26R3.xIs \\
\hline
\end{tabular}

\begin{tabular}{|c|c|c|c|c|}
\hline \multicolumn{2}{|r|}{ Number of compacts: } & \multicolumn{3}{|c|}{5} \\
\hline \multirow{2}{*}{\multicolumn{2}{|c|}{$\begin{array}{l}\text { Average weight uranium per particle, mean value }(\mathrm{g}) \text { : } \\
\text { Average weight uranium per particle, uncertainty in mean }(\mathrm{g}) \text { : }\end{array}$}} & \multicolumn{3}{|c|}{$3.94 \mathrm{E}-04$} \\
\hline & & \multicolumn{3}{|c|}{$3.94 \mathrm{E}-06$} \\
\hline & First Leach & Second Leach & Total \\
\hline & Post-burn leach solution ID: & $\mathrm{B} 18102301$ & B18102501 & \\
\hline & Total volume of leach solution (ml): & 60.0 & 62.5 & \\
\hline & RMAL analysis number: & $18797-009$ & $18797-013$ & \\
\hline & Measured uranium concentration $(\mu \mathrm{g} / \mathrm{ml})$ : & $2.12 \mathrm{E}+01$ & & \\
\hline & Uncertainty in uranium concentration $(\mu \mathrm{g} / \mathrm{ml})$ : & $1.06 \mathrm{E}+00$ & & \\
\hline & Weight uranium leached $(\mathrm{g})$ : & $1.27 \mathrm{E}-03$ & & \\
\hline & Uncertainty in weight uranium leached $(\mathrm{g})$ : & $6.50 \mathrm{E}-05$ & & \\
\hline & Equivalent number of leached kernels: & $3.22 \mathrm{E}+00$ & & \\
\hline & Uncertainty in equivalent number of leached kernels: & $1.68 \mathrm{E}-01$ & & \\
\hline \multirow{5}{*}{$\mathbf{F e}$} & Measured concentration of impurity in sample $(\mu \mathrm{o} / \mathrm{mll}$ : & & & \\
\hline & Uncorrected weight of impurity in sample $(\mu \mathrm{g})$ : & & & $\mathrm{Fe}$ \\
\hline & Weight of impurity in blank $(\mu \mathrm{g})$ : & & & \\
\hline & Minimum corrected weight of impurity in sample $(\mu \mathrm{g})$ : & & & \\
\hline & Maximum corrected weight of impurity in sample $(\mu \mathrm{g})$ : & & & \\
\hline \multirow{5}{*}{ Cr } & Measured concentration of impurity in sample $(\mu \mathrm{g} / \mathrm{ml})$ : & & & $\mathbf{C r}$ \\
\hline & Uncorrected weight of impurity in sample $(\mu \mathrm{g})$ : & & & \\
\hline & Weight of impurity in blank $(\mu \mathrm{g})$ : & & & \\
\hline & Minimum corrected weight of impurity in sample $(\mu \mathrm{g})$ : & & & \\
\hline & Maximum corrected weight of impurity in sample $(\mu \mathrm{g})$ : & & & \\
\hline \multirow{5}{*}{ Mn } & Measured concentration of impurity in sample $(\mu \mathrm{g} / \mathrm{ml})$ : & & & Mn \\
\hline & Uncorrected weight of impurity in sample $(\mu \mathrm{g})$ : & & & \\
\hline & Weight of impurity in blank $(\mu \mathrm{g})$ : & & & \\
\hline & Minimum corrected weight of impurity in sample $(\mu \mathrm{g})$ : & & & \\
\hline & Maximum corrected weight of impurity in sample $(\mu \mathrm{g})$ : & & & \\
\hline \multirow{4}{*}{ Co } & Measured concentration of impurity in sample $(\mu \mathrm{g} / \mathrm{ml})$ : & & & Co \\
\hline & $\begin{aligned} \text { Uncorrected weight of impurity in sample }(\mu \mathrm{g}) \text { : } & \text { Weight of impurity in blank }(\mu \mathrm{g}) \text { : }\end{aligned}$ & & & \\
\hline & Minimum corrected weight of impurity in sample $(\mu g)$ : & & & \\
\hline & Maximum corrected weight of impurity in sample $(\mu \mathrm{g})$ : & & & \\
\hline \multirow{5}{*}{$\mathbf{N i}$} & Measured concentration of impurity in sample $(\mu \mathrm{g} / \mathrm{ml})$ : & & & $\mathbf{N i}$ \\
\hline & Uncorrected weight of impurity in sample $(\mu \mathrm{g})$ : & & & \\
\hline & Weight of impurity in blank $(\mu \mathrm{g})$ : & & & \\
\hline & Minimum corrected weight of impurity in sample $(\mu g)$ : & & & \\
\hline & Maximum corrected weight of impurity in sample $(\mu \mathrm{g})$ : & & & \\
\hline \multirow{5}{*}{$\mathbf{C a}$} & Measured concentration of impurity in sample $(\mu \mathrm{g} / \mathrm{ml})$ : & & & $\mathbf{C a}$ \\
\hline & Uncorrected weight of impurity in sample $(\mu \mathrm{g})$ : & & & \\
\hline & Weight of impurity in blank $(\mu \mathrm{g})$ : & & & \\
\hline & Minimum corrected weight of impurity in sample $(\mu \mathrm{g})$ : & & & \\
\hline & Maximum corrected weight of impurity in sample $(\mu \mathrm{g})$ : & & & \\
\hline \multirow{4}{*}{ Al } & Measured concentration of impurity in sample $(\mu \mathrm{g} / \mathrm{ml})$ : & & & Al \\
\hline & Uncorrected weight of impurity in sample $(\mu \mathrm{g})$ : & & & \\
\hline & $\begin{array}{r}\text { Weight of impurity in blank }(\mu \mathrm{g}) \text { : } \\
\text { Minimum corrected weight of impurity in sample }(\mu \mathrm{g}):\end{array}$ & & & \\
\hline & Maximum corrected weight of impurity in sample $(\mu \mathrm{g})$ : & & & \\
\hline \multirow{5}{*}{$\mathbf{T i}$} & Measured concentration of impurity in sample $(\mu \mathrm{g} / \mathrm{ml})$ : & & & Ti \\
\hline & Uncorrected weight of impurity in sample $(\mu \mathrm{g})$ : & & & \\
\hline & Weight of impurity in blank $(\mu \mathrm{g})$ : & & & \\
\hline & Minimum corrected weight of impurity in sample $(\mu \mathrm{g})$ : & & & \\
\hline & Maximum corrected weight of impurity in sample $(\mu \mathrm{g})$ : & & & \\
\hline \multirow{5}{*}{ v } & Measured concentration of impurity in sample $(\mu \mathrm{g} / \mathrm{ml})$ : & & & $\mathbf{v}$ \\
\hline & Uncorrected weight of impurity in sample $(\mu \mathrm{g})$ : & & & \\
\hline & Weight of impurity in blank $(\mu \mathrm{g})$ : & & & \\
\hline & Minimum corrected weight of impurity in sample $(\mu g)$ : & & & \\
\hline & Maximum corrected weight of impurity in sample $(\mu \mathrm{g})$ : & & & \\
\hline
\end{tabular}

comments

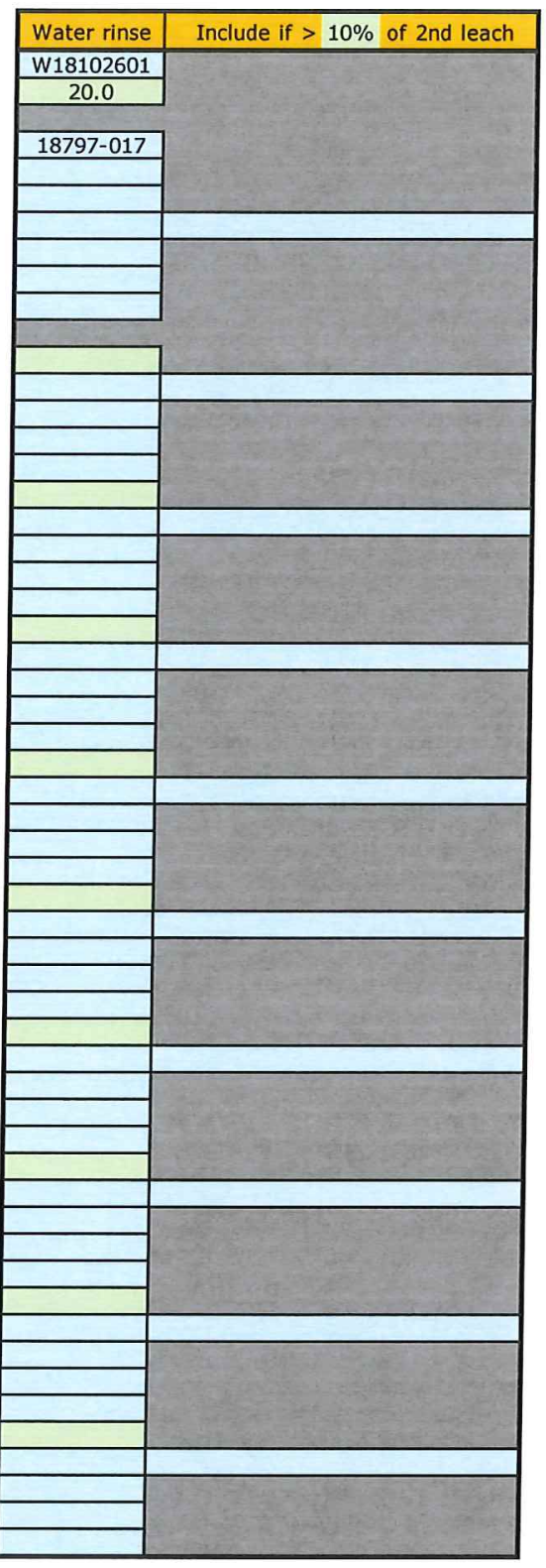

Leached in Vessel RB\#2 (previously leached and analyzed as Blank 1 before use).

FCM checked the recorded data against the official Results of Analysis for RMAL18797 on 3/21/2019.

Shown is the result of the isotope dilution mass spectrometry analysis of B18102301.

\section{Fied c. Montgomery}

$4-18-2019$

$\frac{4-18-2019}{\text { Date }}$ 


\section{Data Report Form DRF-26B: Post-Burn Leach Uranium and Impurities}

\begin{tabular}{|c|c|}
\hline Procedure: & AGR-CHAR-DAM-26 Rev. 3 \\
\hline Operator: & Montgomery \\
\hline Compact lot ID: & BWXT J52R-16-14154D \\
\hline Compact lot description: & AGR- $5 / 6 / 7$ compacts, $40 \%$ packing fraction \\
\hline Compact ID numbers: & $1526,1515,1541,1530,1528$ \\
\hline DRF filename: & 14154D_PF40-Group 1_BL_ICPMS_DRF26R3.xIs \\
\hline
\end{tabular}

\begin{tabular}{|r|r|}
\hline Number of compacts: & 5 \\
\hline Average weight uranium per particle, mean value $(\mathrm{g}):$ & $3.94 \mathrm{E}-04$ \\
\hline Average weight uranium per particle, uncertainty in mean $(\mathrm{g}):$ & $3.94 \mathrm{E}-06$ \\
\hline
\end{tabular}

\begin{tabular}{|c|c|c|c|c|}
\hline & First Leach & Second Leach & Total \\
\hline & Post-burn leach solution ID: & B18102302 & B18102502 & \\
\hline & Total volume of leach solution $(\mathrm{ml})$ : & 59.5 & 62.8 & \\
\hline & RMAL analysis number: & $18797-010$ & $18797-014$ & \\
\hline & Measured uranium concentration $(\mu \mathrm{g} / \mathrm{ml})$ : & $7.86 \mathrm{E}-01$ & $5.76 \mathrm{E}-03$ & \\
\hline & Uncertainty in uranium concentration $(\mu \mathrm{g} / \mathrm{ml})$ : & $7.86 \mathrm{E}-02$ & $5.76 \mathrm{E}-04$ & \\
\hline & Weight uranium leached $(\mathrm{g}):$ & $4.68 \mathrm{E}-05$ & $3.62 \mathrm{E}-07$ & $4.71 \mathrm{E}-05$ \\
\hline & Uncertainty in weight uranium leached $(\mathrm{g})$ : & $4.70 \mathrm{E}-06$ & $3.63 \mathrm{E}-08$ & $4.70 \mathrm{E}-06$ \\
\hline & Equivalent number of leached kernels: & $1.19 \mathrm{E}-01$ & $9.18 \mathrm{E}-04$ & $1.20 \mathrm{E}-01$ \\
\hline & Uncertainty in equivalent number of leached kernels: & $1.20 \mathrm{E}-02$ & 9.27E-05 & $1.20 \mathrm{E}-02$ \\
\hline \multirow{5}{*}{$\mathrm{Fe}$} & Measured concentration of impurity in sample $(\mu \mathrm{g} / \mathrm{ml})$ : & & & $\mathrm{Fe}$ \\
\hline & Uncorrected weight of impurity in sample $(\mu \mathrm{g})$ : & & & \\
\hline & Weight of impurity in blank $(\mu \mathrm{g})$ : & & & \\
\hline & Minimum corrected weight of impurity in sample $(\mu \mathrm{g})$ : & & & \\
\hline & Maximum corrected weight of impurity in sample $(\mu \mathrm{g})$ : & & & \\
\hline \multirow{5}{*}{$\mathbf{C r}$} & Measured concentration of impurity in sample $(\mu \mathrm{g} / \mathrm{ml})$ : & & & $\mathbf{C r}$ \\
\hline & Uncorrected weight of impurity in sample $(\mu \mathrm{g})$ : & & & \\
\hline & Weight of impurity in blank $(\mu \mathrm{g})$ : & & & \\
\hline & Minimum corrected weight of impurity in sample $(\mu \mathrm{g}):$ & & & \\
\hline & Maximum corrected weight of impurity in sample $(\mu \mathrm{g})$ : & & & \\
\hline \multirow{5}{*}{ Mn } & Measured concentration of impurity in sample $(\mu \mathrm{g} / \mathrm{ml})$ : & & & Mn \\
\hline & Uncorrected weight of impurity in sample $(\mu \mathrm{g})$ : & & & \\
\hline & Weight of impurity in blank $(\mu \mathrm{g})$ : & & & \\
\hline & Minimum corrected weight of impurity in sample $(\mu \mathrm{g}):$ & & & \\
\hline & Maximum corrected weight of impurity in sample $(\mu \mathrm{g})$ : & & & \\
\hline \multirow{5}{*}{ Co } & Measured concentration of impurity in sample $(\mu \mathrm{g} / \mathrm{ml})$ : & & & Co \\
\hline & Uncorrected weight of impurity in sample $(\mu \mathrm{g})$ : & & & \\
\hline & Weight of impurity in blank $(\mu \mathrm{g})$ : & & & \\
\hline & Minimum corrected weight of impurity in sample $(\mu \mathrm{g}):$ & & & \\
\hline & Maximum corrected weight of impurity in sample $(\mu \mathrm{g}):$ & & & \\
\hline \multirow{5}{*}{$\mathbf{N i}$} & Measured concentration of impurity in sample $(\mu \mathrm{g} / \mathrm{ml}):$ & & & $\mathrm{Ni}$ \\
\hline & Uncorrected weight of impurity in sample $(\mu \mathrm{g}):$ & & & \\
\hline & Weight of impurity in blank $(\mu \mathrm{g})$ : & & & \\
\hline & Minimum corrected weight of impurity in sample $(\mu \mathrm{g}):$ & & & \\
\hline & Maximum corrected weight of impurity in sample $(\mu g)$ : & & & \\
\hline \multirow{5}{*}{$\mathbf{C a}$} & Measured concentration of impurity in sample $(\mu \mathrm{g} / \mathrm{ml}):$ & & & $\mathbf{C a}$ \\
\hline & Uncorrected weight of impurity in sample $(\mu \mathrm{g}):$ & & & \\
\hline & Weight of impurity in blank $(\mu \mathrm{g})$ : & & & \\
\hline & Minimum corrected weight of impurity in sample $(\mu \mathrm{g}):$ & & & \\
\hline & Maximum corrected weight of impurity in sample $(\mu \mathrm{g})$ : & & & \\
\hline \multirow{5}{*}{ Al } & Measured concentration of impurity in sample $(\mu \mathrm{g} / \mathrm{ml})$ : & & & Al \\
\hline & Uncorrected weight of impurity in sample $(\mu \mathrm{g})$ : & & & \\
\hline & Weight of impurity in blank $(\mu \mathrm{g})$ : & & & \\
\hline & Minimum corrected weight of impurity in sample $(\mu \mathrm{g}):$ & & & \\
\hline & Maximum corrected weight of impurity in sample $(\mu \mathrm{g}):$ & & & \\
\hline \multirow{5}{*}{$\mathbf{T i}$} & Measured concentration of impurity in sample $(\mu \mathrm{g} / \mathrm{ml})$ : & & & Ti \\
\hline & Uncorrected weight of impurity in sample $(\mu \mathrm{g})$ : & & & \\
\hline & Weight of impurity in blank $(\mu \mathrm{g})$ : & & & \\
\hline & Minimum corrected weight of impurity in sample $(\mu \mathrm{g}):$ & & & \\
\hline & Maximum corrected weight of impurity in sample $(\mu \mathrm{g})$ : & & & \\
\hline \multirow{5}{*}{$\mathbf{v}$} & Measured concentration of impurity in sample $(\mu \mathrm{g} / \mathrm{ml})$ : & & & $\mathbf{V}$ \\
\hline & Uncorrected weight of impurity in sample $(\mu \mathrm{g})$ : & & & \\
\hline & Weight of impurity in blank $(\mu \mathrm{g})$ : & & & \\
\hline & Minimum corrected weight of impurity in sample $(\mu \mathrm{g}):$ & & & \\
\hline & Maximum corrected weight of impurity in sample $(\mu \mathrm{g})$ : & & & \\
\hline
\end{tabular}

\section{Comments}

Leached in Vessel RB\#3 (previously leached and analyzed as Blank 2 before use).

FCM checked the recorded data against the official Results of Analysis for RMAL18797 on 3/21/2019.

Shown is the result of the second ICPMS analyses of B18102302.

The first analysis results were rejected based on IDMS analysis.

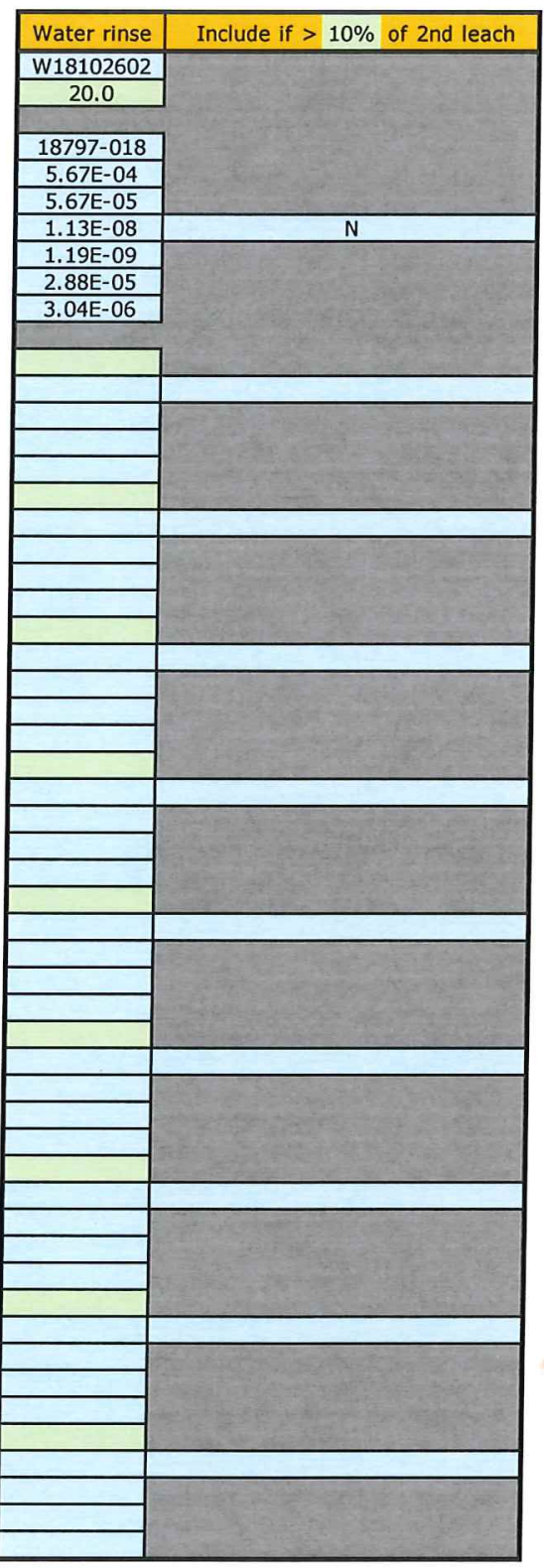

\section{Fred c. Montgomery


Data Report Form DRF-26B: Post-Burn Leach Uranium and Impurities

\begin{tabular}{|r|l|}
\hline Procedure: & AGR-CHAR-DAM-26 Rev. 3 \\
\hline Operator: & Montgomery \\
\hline Compact lot ID: & BWXT J52R-16-14154D \\
\hline Compact lot description: & AGR-5/6/7 compacts, 40\% packing fraction \\
\hline Compact ID numbers: & $1526,1515,1541,1530,1528$ \\
\hline DRF filename: & $14154 D \_P F 40-G r o u p 1$ BL_ICPMS_DRF26R3.xIs \\
\hline
\end{tabular}

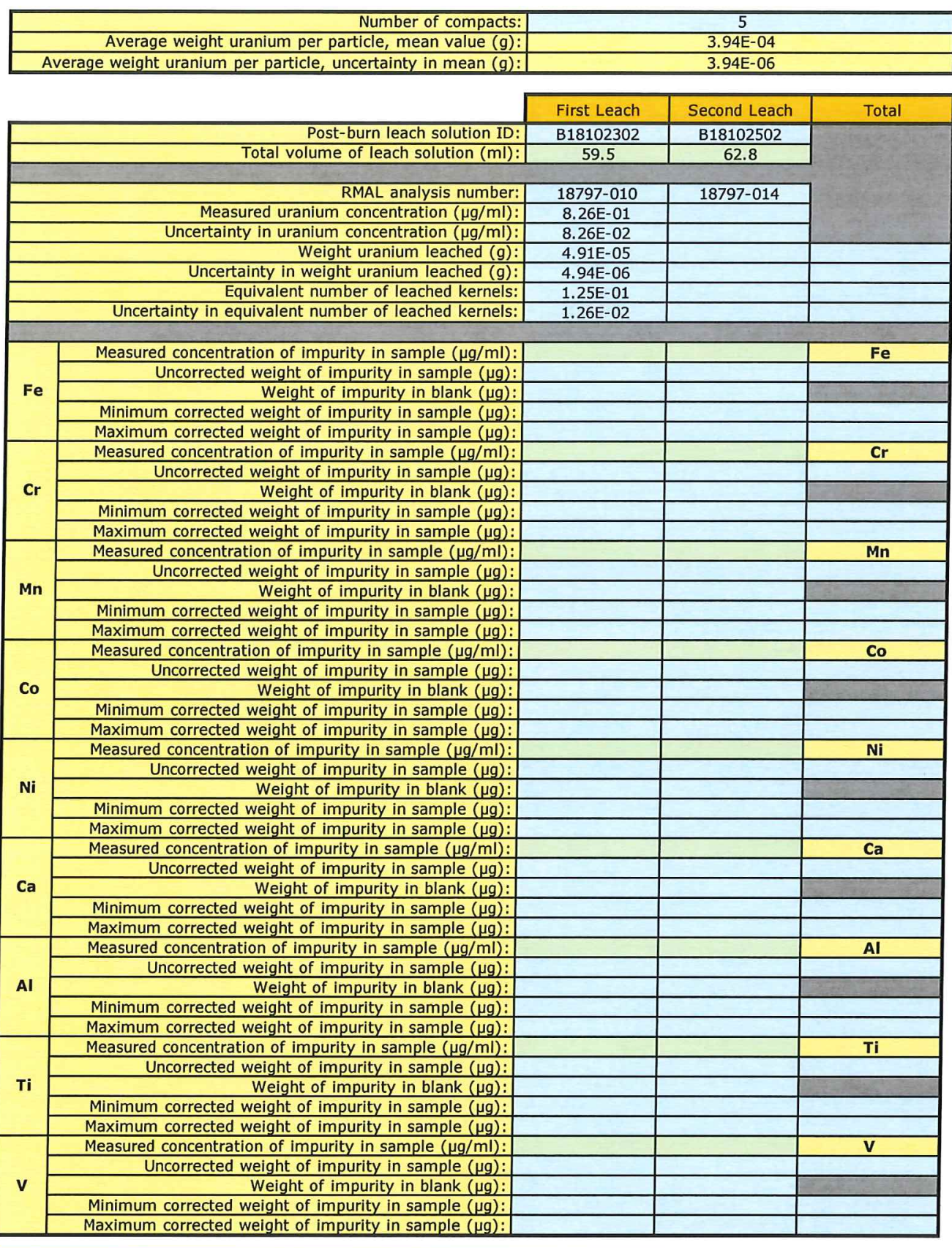

comments

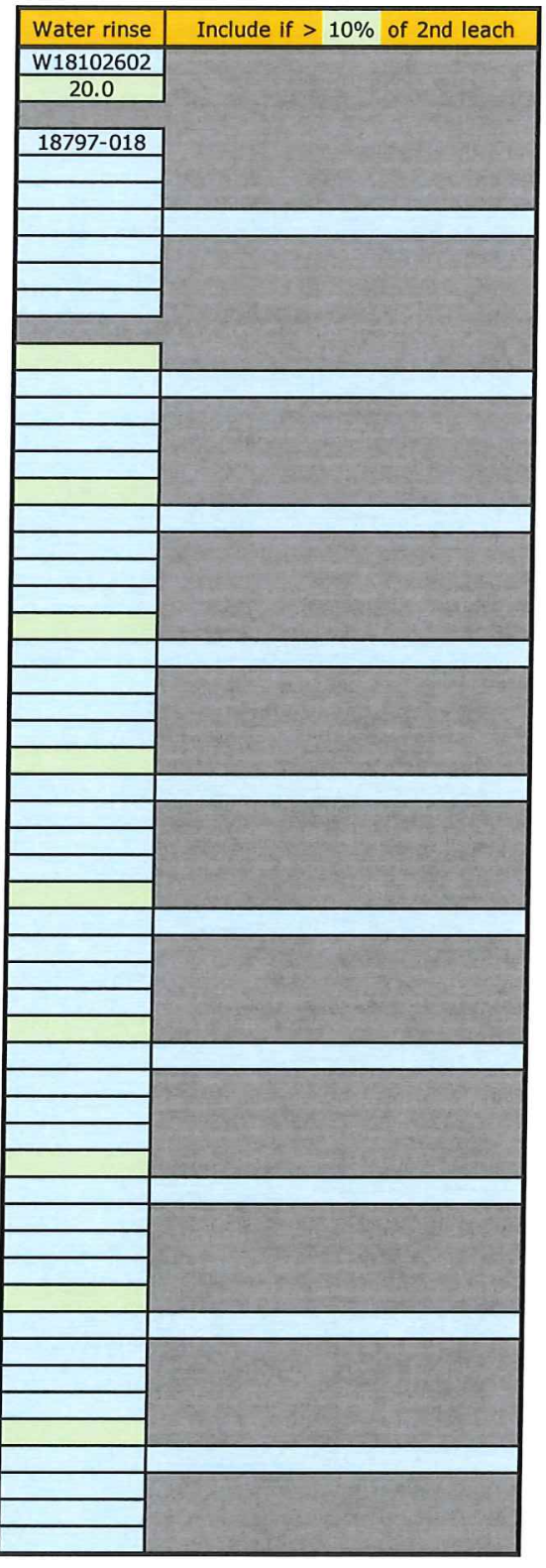

Leached in Vessel RB\#3 (previously leached and analyzed as Blank 2 before use).

FCM checked the recorded data against the official Results of Analysis for RMAL18797 on 3/21/2019.

Shown is the result of the first ICPMS analyses of B18102302.

The first analysis results were rejected based on IDMS analysis.

\section{Fied e. mentgomers}

\section{$4-18-2019$}


Data Report Form DRF-26B: Post-Burn Leach Uranium and Impurities

\begin{tabular}{|r|l|}
\hline Procedure: & AGR-CHAR-DAM-26 Rev. 3 \\
\hline Operator: & Montgomery \\
\hline Compact lot ID: & BWXT J52R-16-14154D \\
\hline Compact lot description: & AGR-5/6/7 compacts, 40\% packing fraction \\
\hline Compact ID numbers: & $1539,1527,1512,1513,1517$ \\
\hline DRF filename: & $14154 \mathrm{D} \_$PF40-Group 1_BL_ICPMS_DRF26R3.xIs \\
\hline
\end{tabular}

\begin{tabular}{|c|c|c|c|c|}
\hline & Number of compacts: & & $\overline{5}$ & \\
\hline & Average weight uranium per particle, mean value $(\mathrm{g})$ : & & $3.94 \mathrm{E}-04$ & \\
\hline & rage weight uranium per particle, uncertainty in mean $(\mathrm{g})$ : & & $3.94 \mathrm{E}-06$ & \\
\hline & & First Leach & Second Leach & Total \\
\hline & Post-burn leach solution ID: & B18102303 & B18102503 & \\
\hline & Total volume of leach solution $(\mathrm{ml})$ : & 59.5 & 62.2 & \\
\hline & RMAL analysis number: & $18797-011$ & $18797-015$ & \\
\hline & Measured uranium concentration $(\mu \mathrm{g} / \mathrm{ml})$ : & $1.45 \mathrm{E}+01$ & $\frac{10 / 97-013}{7.32 E-02}$ & \\
\hline & Uncertainty in uranium concentration $(\mu \mathrm{g} / \mathrm{ml})$ : & $1.45 \mathrm{E}+00$ & $7.32 \mathrm{E}-03$ & \\
\hline & Weight uranium leached $(g)$ : & $8.65 \mathrm{E}-04$ & $4.55 \mathrm{E}-06$ & $8.69 \mathrm{E}-04$ \\
\hline & Uncertainty in weight uranium leached $(\mathrm{g})$ : & $8.70 \mathrm{E}-05$ & $4.58 \mathrm{E}-07$ & $8.70 \mathrm{E}-05$ \\
\hline & Equivalent number of leached kernels: & $2.19 E+00$ & $1.16 \mathrm{E}-02$ & $2.21 \mathrm{E}+00$ \\
\hline & Uncertainty in equivalent number of leached kernels: & $2.22 \mathrm{E}-01$ & $1.17 \mathrm{E}-03$ & $2.22 \mathrm{E}-01$ \\
\hline & Measured concentration of impurity in sample $(\mu \mathrm{g} / \mathrm{ml})$ : & & & $\overline{F e}$ \\
\hline & Uncorrected weight of impurity in sample $(\mu \mathrm{g})$ : & & & \\
\hline $\mathbf{F e}$ & Weight of impurity in blank $(\mu \mathrm{g})$ : & & & \\
\hline & Minimum corrected weight of impurity in sample $(\mu \mathrm{g})$ : & & & \\
\hline & Maximum corrected weight of impurity in sample $(\mu \mathrm{g})$ : & & & \\
\hline & Measured concentration of impurity in sample $(\mu \mathrm{g} / \mathrm{ml})$ & & & $\mathbf{C r}$ \\
\hline & Uncorrected weight of impurity in sample $(\mu \mathrm{g})$ & & & \\
\hline $\mathrm{Cr}$ & Weight of impurity in blank $(\mu \mathrm{g})$ & & & \\
\hline & Minimum corrected weight of impurity in sample $(\mu \mathrm{g})$ : & & & \\
\hline & Maximum corrected weight of impurity in sample $(\mu g)$ : & & & \\
\hline & Measured concentration of impurity in sample $(\mu \mathrm{g} / \mathrm{ml})$ : & & & Mn \\
\hline & Uncorrected weight of impurity in sample $(\mu \mathrm{g})$ : & & & \\
\hline $\mathbf{M n}$ & Weight of impurity in blank $(\mu \mathrm{g})$ : & & & \\
\hline & Minimum corrected weight of impurity in sample $(\mu \mathrm{g})$ : & & & \\
\hline & Maximum corrected weight of impurity in sample $(\mu \mathrm{g})$ : & & & \\
\hline & Measured concentration of impurity in sample $(\mu \mathrm{g} / \mathrm{ml})$ : & & & Co \\
\hline & Uncorrected weight of impurity in sample $(\mu \mathrm{g})$ : & & & \\
\hline Co & Weight of impurity in blank $(\mu \mathrm{g})$ : & & & \\
\hline & Minimum corrected weight of impurity in sample $(\mu \mathrm{g})$ : & & & \\
\hline & Maximum corrected weight of impurity in sample $(\mu \mathrm{g})$ : & & & \\
\hline & Measured concentration of impurity in sample $(\mu \mathrm{g} / \mathrm{ml})$ : & & & $\mathrm{Ni}$ \\
\hline & Uncorrected weight of impurity in sample $(\mu g)$ : & & & \\
\hline $\mathbf{N i}$ & Weight of impurity in blank $(\mu \mathrm{g})$ : & & & \\
\hline & Minimum corrected weight of impurity in sample $(\mu \mathrm{g})$ : & & & \\
\hline & Maximum corrected weight of impurity in sample $(\mu \mathrm{g})$ : & & & \\
\hline & Measured concentration of impurity in sample $(\mu \mathrm{g} / \mathrm{ml}):$ & & & $\mathbf{C a}$ \\
\hline $\mathrm{Ca}$ & Uncorrected weight of impurity in sample $(\mu \mathrm{g})$ : & & & \\
\hline Ca & Weight of impurity in blank $(\mu \mathrm{g})$ : & & & \\
\hline & Minimum corrected weight of impurity in sample $(\mu \mathrm{g})$ : & & & \\
\hline & Maximum corrected weight of impurity in sample $(\mu \mathrm{g})$ : & & & \\
\hline & Measured concentration of impurity in sample $(\mu \mathrm{g} / \mathrm{ml})$ : & & & Al \\
\hline Al & $\begin{array}{l}\text { Uncorrected weight of impurity in sample }(\mu \mathrm{g}) \text { : } \\
\text { Weight of impurity in blank }(\mu \mathrm{g}) \text { : }\end{array}$ & & & \\
\hline & $\begin{array}{r}\text { Weight of impurity in blank }(\mu \mathrm{g}) \text { : } \\
\text { Minimum corrected weight of impurity in sample }(\mu \mathrm{g}) \text { : }\end{array}$ & & & \\
\hline & $\begin{array}{l}\text { Minimum corrected weight of impurity in sample }(\mu \mathrm{g}) \text { : } \\
\text { Maximum corrected weight of impurity in sample }(\mu \mathrm{g}) \text { : }\end{array}$ & & & \\
\hline & $\begin{array}{l}\text { Maximum corrected weight of impurity in sample }(\mu \mathrm{g}) \text { : } \\
\text { Measured concentration of impurity in sample }(\mu \mathrm{g} / \mathrm{ml}) \text { : }\end{array}$ & & & $\mathrm{Ti}$ \\
\hline & Uncorrected weight of impurity in sample $(\mu \mathrm{g})$ : & & & \\
\hline Ti & Weight of impurity in blank $(\mu \mathrm{g})$ : & & & \\
\hline & Minimum corrected weight of impurity in sample $(\mu \mathrm{g})$ : & & & \\
\hline & Maximum corrected weight of impurity in sample $(\mu \mathrm{g})$ : & & & \\
\hline & Measured concentration of impurity in sample $(\mu \mathrm{g} / \mathrm{ml})$ : & & & $\mathbf{v}$ \\
\hline & Uncorrected weight of impurity in sample $(\mu \mathrm{g})$ : & & & \\
\hline $\mathbf{v}$ & Weight of impurity in blank $(\mu \mathrm{g})$ : & & & \\
\hline & $\begin{array}{l}\text { Minimum corrected weight of impurity in sample }(\mu g) \text { : } \\
\text { Maximum corrected weight of impurity in sample }(\mu g) \text { : }\end{array}$ & & & \\
\hline & Maximum corrected weight of impurity in sample $(\mu \mathrm{g})$ : & & & \\
\hline
\end{tabular}

comments

Leached in Vessel RB\#11 (previously leached and analyzed as Blank 3 before use).

FCM checked the recorded data against the official Results of Analysis for RMAL18797 on 3/21/2019.

Shown is the result of the second ICPMS analyses of B18102303.

The first analysis results were rejected based on IDMS analysis.

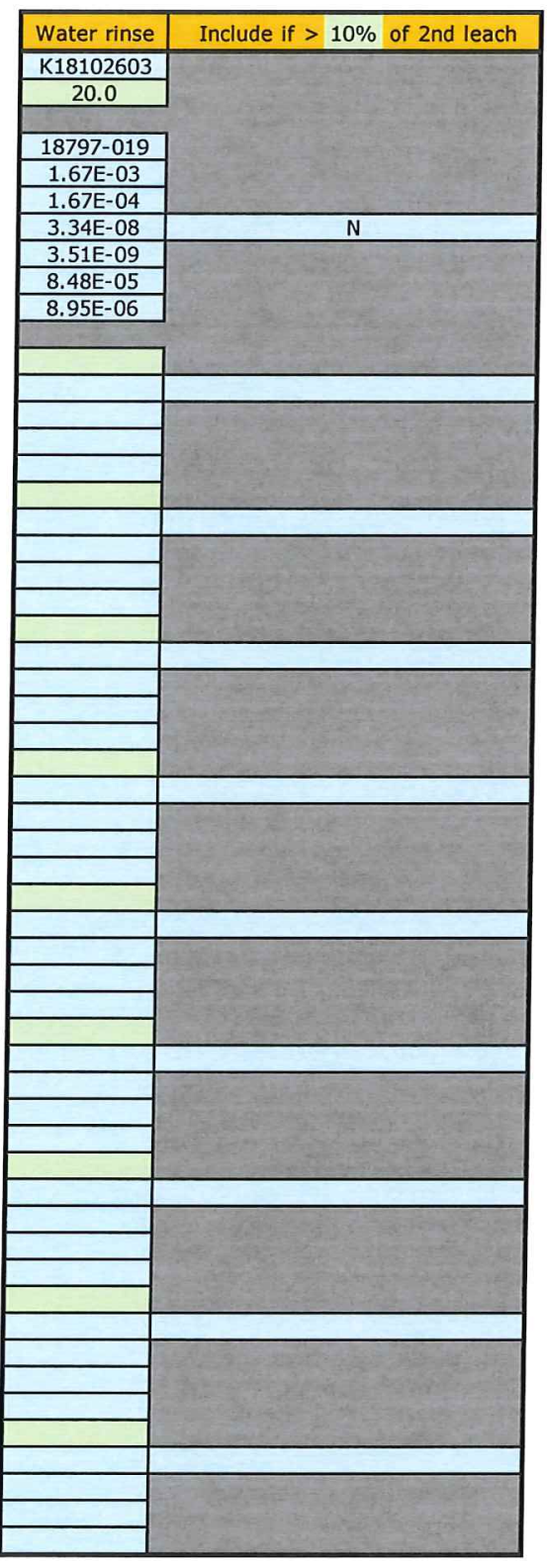


Data Report Form DRF-26B: Post-Burn Leach Uranium and Impurities

\begin{tabular}{|r|l|}
\hline Procedure: & AGR-CHAR-DAM-26 Rev. 3 \\
\hline Operator: & Montgomery \\
\hline Compact lot ID: & BWXT J52R-16-14154D \\
\hline Compact lot description: & AGR-5/6/7 compacts, 40\% packing fraction \\
\hline Compact ID numbers: & $1539,1527,1512,1513,1517$ \\
\hline DRF filename: & $14154 D \_$PF 40-Group 1 BL_ICPMS_DRF26R3.xIs \\
\hline
\end{tabular}

\begin{tabular}{|c|c|c|c|c|}
\hline \multicolumn{2}{|c|}{$\begin{array}{ll} & \text { Number of compacts: } \\
\end{array}$} & \multicolumn{3}{|c|}{5} \\
\hline \multirow{2}{*}{\multicolumn{2}{|c|}{$\begin{array}{r}\text { Average weight uranium per particle, mean value }(\mathrm{g}): \\
\text { Average weight uranium per particle, uncertainty in mean }(\mathrm{g}):\end{array}$}} & \multicolumn{3}{|c|}{$\begin{array}{l}3.94 \mathrm{E}-04 \\
3.94 \mathrm{~F}-06\end{array}$} \\
\hline & & & $3.94 \mathrm{E}-06$ & \\
\hline & & First Leach & Second Leach & Total \\
\hline & Post-burn leach solution ID: & B18102303 & B18102503 & \\
\hline & Total volume of leach solution $(\mathrm{ml})$ : & 59.5 & 62.2 & \\
\hline & RMAL analysis number: & $18797-011$ & $18797-015$ & \\
\hline & Measured uranium concentration $(\mu \mathrm{g} / \mathrm{ml})$ : & $1.57 \mathrm{E}+01$ & & \\
\hline & Uncertainty in uranium concentration $(\mu \mathrm{g} / \mathrm{ml})$ : & $1.57 \mathrm{E}+00$ & & \\
\hline & Weight uranium leached $(\mathrm{g})$ : & $9.31 \mathrm{E}-04$ & & \\
\hline & Uncertainty in weight uranium leached $(\mathrm{g})$ : & $9.37 \mathrm{E}-05$ & & \\
\hline & Equivalent number of leached kernels: & $2.36 \mathrm{E}+00$ & & \\
\hline & Uncertainty in equivalent number of leached kernels: & $2.39 \mathrm{E}-01$ & & \\
\hline \multirow{5}{*}{$\mathrm{Fe}$} & Measured concentration of impurity in sample $(\mu \mathrm{g} / \mathrm{ml})$ : & & & $\mathrm{Fe}$ \\
\hline & Uncorrected weight of impurity in sample $(\mu \mathrm{g})$ : & & & \\
\hline & Weight of impurity in blank $(\mu g)$ : & & & \\
\hline & Minimum corrected weight of impurity in sample $(\mu \mathrm{g})$ : & & & \\
\hline & Maximum corrected weight of impurity in sample $(\mu \mathrm{g})$ : & & & \\
\hline \multirow{5}{*}{ Cr } & Measured concentration of impurity in sample $(\mu \mathrm{g} / \mathrm{ml})$ : & & & $\mathbf{C r}$ \\
\hline & Uncorrected weight of impurity in sample $(\mu \mathrm{g})$ : & & & \\
\hline & Weight of impurity in blank $(\mu \mathrm{g})$ : & & & \\
\hline & Minimum corrected weight of impurity in sample $(\mu \mathrm{g})$ : & & & \\
\hline & Maximum corrected weight of impurity in sample $(\mu \mathrm{g})$ : & & & \\
\hline \multirow{5}{*}{ Mn } & Measured concentration of impurity in sample $(\mu \mathrm{g} / \mathrm{ml})$ : & & & Mn \\
\hline & Uncorrected weight of impurity in sample $(\mu \mathrm{g})$ : & & & \\
\hline & Weight of impurity in blank $(\mu \mathrm{g})$ : & & & \\
\hline & Minimum corrected weight of impurity in sample $(\mu g)$ : & & & \\
\hline & Maximum corrected weight of impurity in sample $(\mu g)$ : & & & \\
\hline \multirow{5}{*}{ Co } & Measured concentration of impurity in sample $(\mu \mathrm{g} / \mathrm{ml})$ : & & & Co \\
\hline & Uncorrected weight of impurity in sample $(\mu \mathrm{g})$ : & & & \\
\hline & Weight of impurity in blank $(\mu \mathrm{g})$ : & & & \\
\hline & Minimum corrected weight of impurity in sample $(\mu \mathrm{g})$ : & & & \\
\hline & Maximum corrected weight of impurity in sample $(\mu \mathrm{g})$ : & & & \\
\hline \multirow{5}{*}{$\mathbf{N i}$} & Measured concentration of impurity in sample $(\mu \mathrm{g} / \mathrm{ml})$ : & & & $\mathbf{N i}$ \\
\hline & Uncorrected weight of impurity in sample $(\mu \mathrm{g})$ : & & & \\
\hline & Weight of impurity in blank $(\mu \mathrm{g})$ : & & & \\
\hline & Minimum corrected weight of impurity in sample $(\mu \mathrm{g})$ : & & & \\
\hline & Maximum corrected weight of impurity in sample $(\mu g)$ : & & & \\
\hline \multirow{5}{*}{$\mathbf{C a}$} & Measured concentration of impurity in sample $(\mu \mathrm{g} / \mathrm{ml})$ : & & & $\mathbf{C a}$ \\
\hline & Uncorrected weight of impurity in sample $(\mu \mathrm{g})$ : & & & \\
\hline & Weight of impurity in blank $(\mu \mathrm{g})$ : & & & \\
\hline & Minimum corrected weight of impurity in sample $(\mu \mathrm{g})$ : & & & \\
\hline & Maximum corrected weight of impurity in sample $(\mu \mathrm{g}):$ & & & \\
\hline \multirow{5}{*}{ Al } & Measured concentration of impurity in sample $(\mu \mathrm{g} / \mathrm{ml})$ : & & & Al \\
\hline & Uncorrected weight of impurity in sample $(\mu \mathrm{g})$ : & & & \\
\hline & Weight of impurity in blank $(\mu \mathrm{g})$ : & & & \\
\hline & Minimum corrected weight of impurity in sample $(\mu \mathrm{g})$ : & & & \\
\hline & Maximum corrected weight of impurity in sample $(\mu \mathrm{g})$ : & & & \\
\hline \multirow{5}{*}{$\mathbf{T i}$} & Measured concentration of impurity in sample $(\mu \mathrm{g} / \mathrm{ml})$ : & & & $\mathbf{T i}$ \\
\hline & Uncorrected weight of impurity in sample $(\mu \mathrm{g})$ : & & & \\
\hline & Weight of impurity in blank $(\mu \mathrm{g})$ : & & & \\
\hline & Minimum corrected weight of impurity in sample $(\mu \mathrm{g})$ : & & & \\
\hline & Maximum corrected weight of impurity in sample $(\mu \mathrm{g})$ : & & & \\
\hline \multirow{5}{*}{$\mathbf{v}$} & Measured concentration of impurity in sample $(\mu \mathrm{g} / \mathrm{ml})$ : & & & $\mathbf{V}$ \\
\hline & Uncorrected weight of impurity in sample $(\mu \mathrm{g})$ : & & & \\
\hline & Weight of impurity in blank $(\mu \mathrm{g})$ : & & & \\
\hline & Minimum corrected weight of impurity in sample $(\mu \mathrm{g}):$ & & & \\
\hline & Maximum corrected weight of impurity in sample $(\mu \mathrm{g})$ : & & & \\
\hline
\end{tabular}

Comments

Leached in Vessel RB\#11 (previously leached and analyzed as Blank 3 before use).

FCM checked the recorded data against the official Results of Analysis for RMAL18797 on 3/21/2019.

Shown is the result of the first ICPMS analyses of B18102303.

The first analysis results were rejected based on IDMS analysis.

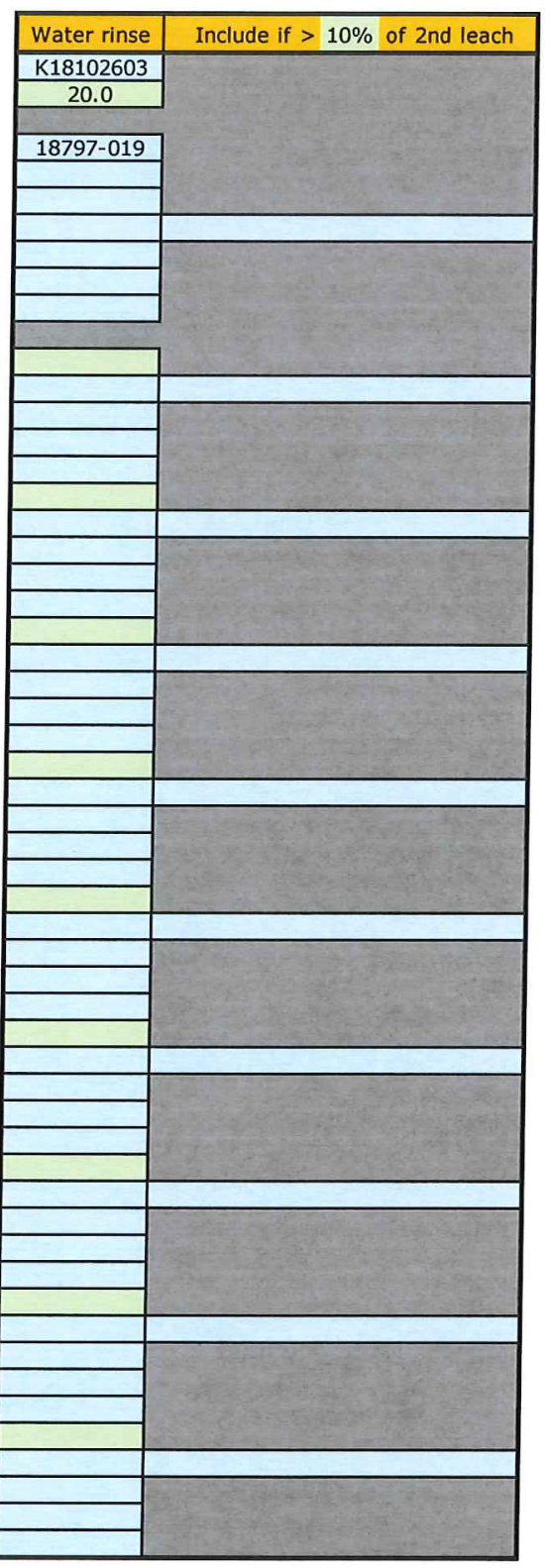

\section{Fied c. Montgomery} Operator
$4-18-2019$

Date 
Data Report Form DRF-26B: Post-Burn Leach Uranium and Impurities

\begin{tabular}{|c|c|}
\hline Procedure: & AGR-CHAR-DAM-26 Rev. 3 \\
\hline Operator: & Montgomery \\
\hline Compact lot ID: & BWXT J52R-16-14154D \\
\hline Compact lot description: & AGR-5/6/7 compacts, $40 \%$ packing fraction \\
\hline Compact ID numbers: & $1520,1528,1511,1500,1506$ \\
\hline DRF filename: & 14154D_PF40-Group 1_BL_ICPMS_DRF26R3.xIs \\
\hline
\end{tabular}

\begin{tabular}{|r|c|}
\hline Number of compacts: & 5 \\
\hline Average weight uranium per particle, mean value $(\mathrm{g}):$ & $3.94 \mathrm{E}-04$ \\
\hline Average weight uranium per particle, uncertainty in mean $(\mathrm{g}):$ & $3.94 \mathrm{E}-06$ \\
\hline
\end{tabular}

\begin{tabular}{|c|c|c|c|c|}
\hline & & & \\
\hline & & First Leach & Second Leach & Total \\
\hline & Post-burn leach solution ID: & B18102304 & B18102504 & \\
\hline & Total volume of leach solution $(\mathrm{ml})$ : & 61.0 & 64.0 & \\
\hline & RMAL analysis number: & $18797-012$ & $18797-016$ & \\
\hline & Measured uranium concentration $(\mu \mathrm{g} / \mathrm{ml})$ : & $1.44 E+01$ & $7.88 \mathrm{E}-02$ & \\
\hline & Uncertainty in uranium concentration $(\mu \mathrm{g} / \mathrm{ml})$ : & $1.44 \mathrm{E}+00$ & $7.88 \mathrm{E}-03$ & \\
\hline & Weight uranium leached $(\mathrm{g})$ : & $8.76 \mathrm{E}-04$ & $5.05 E-06$ & $8.81 \mathrm{E}-04$ \\
\hline & Uncertainty in weight uranium leached (g): & $8.81 \mathrm{E}-05$ & $5.07 \mathrm{E}-07$ & $8.81 \mathrm{E}-05$ \\
\hline & Equivalent number of leached kernels: & $2.22 \mathrm{E}+00$ & $1.28 \mathrm{E}-02$ & $2.24 \mathrm{E}+00$ \\
\hline & Uncertainty in equivalent number of leached kernels: & $2.25 \mathrm{E}-01$ & $1.29 \mathrm{E}-03$ & $2.25 \mathrm{E}-01$ \\
\hline \multirow{5}{*}{$\mathrm{Fe}$} & Measured concentration of impurity in sample $(\mu \mathrm{g} / \mathrm{ml})$ : & & & $\mathrm{Fe}$ \\
\hline & Uncorrected weight of impurity in sample $(\mu \mathrm{g})$ : & & & \\
\hline & Weight of impurity in blank $(\mu \mathrm{g})$ : & & & \\
\hline & Minimum corrected weight of impurity in sample $(\mu g)$ : & & & \\
\hline & Maximum corrected weight of impurity in sample $(\mu g)$ : & & & \\
\hline \multirow{5}{*}{$\mathrm{Cr}$} & Measured concentration of impurity in sample $(\mu \mathrm{g} / \mathrm{ml}):$ & & & $\mathrm{Cr}$ \\
\hline & Uncorrected weight of impurity in sample $(\mu \mathrm{g})$ : & & & \\
\hline & Weight of impurity in blank $(\mu \mathrm{g}):$ & & & \\
\hline & Minimum corrected weight of impurity in sample $(\mu \mathrm{g})$ : & & & \\
\hline & Maximum corrected weight of impurity in sample $(\mu \mathrm{g})$ : & & & \\
\hline \multirow{5}{*}{ Mn } & Measured concentration of impurity in sample $(\mu \mathrm{g} / \mathrm{ml})$ : & & & Mn \\
\hline & Uncorrected weight of impurity in sample $(\mu \mathrm{g})$ : & & & \\
\hline & Weight of impurity in blank $(\mu \mathrm{g})$ : & & & \\
\hline & Minimum corrected weight of impurity in sample $(\mu \mathrm{g})$ : & & & \\
\hline & Maximum corrected weight of impurity in sample $(\mu \mathrm{g})$ : & & & \\
\hline \multirow{5}{*}{ co } & Measured concentration of impurity in sample $(\mu \mathrm{g} / \mathrm{ml})$ : & & & Co \\
\hline & Uncorrected weight of impurity in sample $(\mu \mathrm{g})$ : & & & \\
\hline & Weight of impurity in blank $(\mu \mathrm{g})$ : & & & \\
\hline & Minimum corrected weight of impurity in sample $(\mu \mathrm{g})$ : & & & \\
\hline & Maximum corrected weight of impurity in sample $(\mu \mathrm{g}):$ & & & \\
\hline \multirow{5}{*}{$\mathbf{N i}$} & Measured concentration of impurity in sample $(\mu \mathrm{g} / \mathrm{ml})$ : & & & $\mathrm{Ni}$ \\
\hline & Uncorrected weight of impurity in sample $(\mu \mathrm{g})$ : & & & \\
\hline & Weight of impurity in blank $(\mu \mathrm{g}):$ & & & \\
\hline & Minimum corrected weight of impurity in sample $(\mu \mathrm{g}):$ & & & \\
\hline & Maximum corrected weight of impurity in sample $(\mu \mathrm{g})$ : & & & \\
\hline \multirow{5}{*}{ Ca } & Measured concentration of impurity in sample $(\mu \mathrm{g} / \mathrm{ml})$ : & & & $\mathrm{Ca}$ \\
\hline & Uncorrected weight of impurity in sample $(\mu \mathrm{g})$ : & & & \\
\hline & Weight of impurity in blank $(\mu \mathrm{g})$ : & & & \\
\hline & Minimum corrected weight of impurity in sample $(\mu \mathrm{g})$ : & & & \\
\hline & Maximum corrected weight of impurity in sample $(\mu \mathrm{g})$ : & & & \\
\hline \multirow{5}{*}{ Al } & Measured concentration of impurity in sample $(\mathrm{\mu g} / \mathrm{ml})$ : & & & $\overline{A l}$ \\
\hline & Uncorrected weight of impurity in sample $(\mu \mathrm{g})$ : & & & \\
\hline & Weight of impurity in blank $(\mu \mathrm{g})$ : & & & \\
\hline & Minimum corrected weight of impurity in sample $(\mu \mathrm{g})$ : & & & \\
\hline & Maximum corrected weight of impurity in sample $(\mu \mathrm{g}):$ & & & \\
\hline \multirow{5}{*}{$\mathbf{T i}$} & Measured concentration of impurity in sample $(\mu \mathrm{g} / \mathrm{ml})$ : & & & $\mathrm{Ti}$ \\
\hline & Uncorrected weight of impurity in sample $(\mu \mathrm{g})$ : & & & \\
\hline & Weight of impurity in blank $(\mu \mathrm{g})$ : & & & \\
\hline & Minimum corrected weight of impurity in sample $(\mu \mathrm{g})$ : & & & \\
\hline & Maximum corrected weight of impurity in sample $(\mu \mathrm{g}):$ & & & \\
\hline \multirow{5}{*}{$\mathbf{v}$} & Measured concentration of impurity in sample $(\mu \mathrm{g} / \mathrm{ml})$ : & & & $\mathbf{V}$ \\
\hline & Uncorrected weight of impurity in sample $(\mu \mathrm{g})$ : & & & \\
\hline & Weight of impurity in blank $(\mu \mathrm{g}):$ & & & \\
\hline & Minimum corrected weight of impurity in sample $(\mu \mathrm{g})$ : & & & \\
\hline & Maximum corrected weight of impurity in sample $(\mu \mathrm{g}):$ : & & & \\
\hline
\end{tabular}

\section{Comments}

Leached in Vessel FB\#2 (previously leached and analyzed as Blank 4 before use).

FCM checked the recorded data against the official Results of Analysis for RMAL18797 on 3/21/2019.

Shown is the result of the second ICPMS analyses of B18102304.

The first analysis results were rejected based on IDMS analysis.

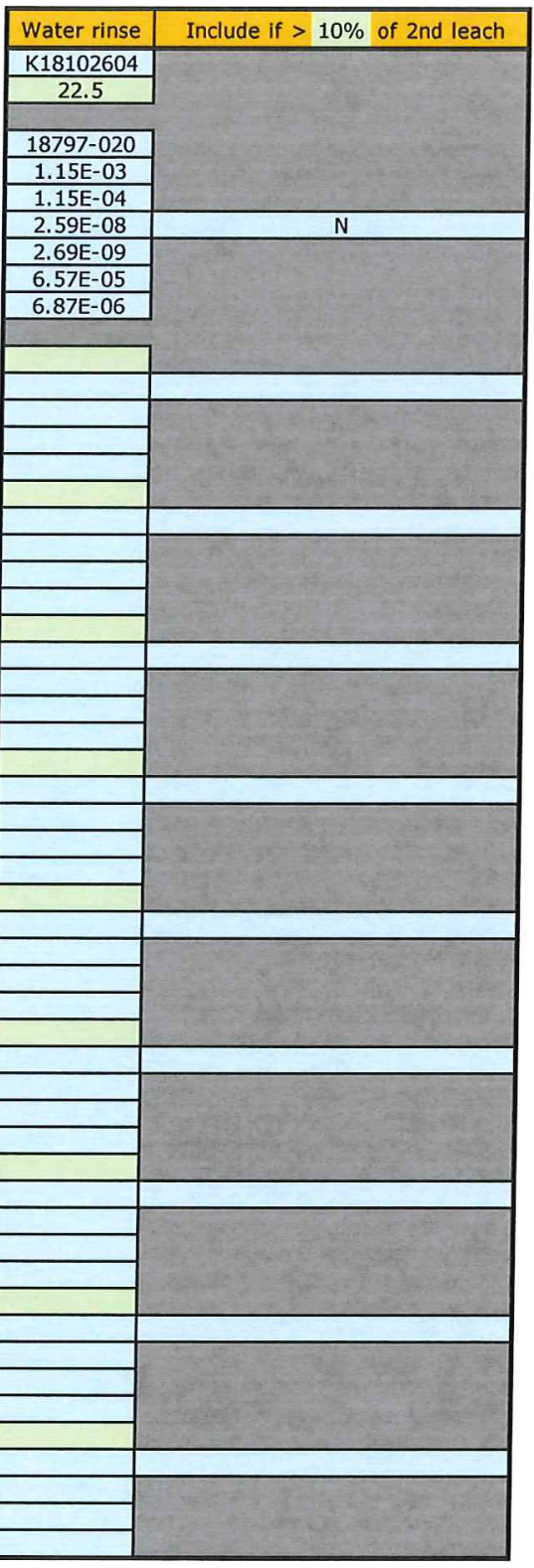

\section{Fred c. Mnntgomery}

$4-18-2019$

Date 
Data Report Form DRF-26B: Post-Burn Leach Uranium and Impurities

\begin{tabular}{|r|l|}
\hline Procedure: & AGR-CHAR-DAM-26 Rev. 3 \\
\hline Operator: & Montgomery \\
\hline Compact lot ID: & BWXT J52R-16-14154D \\
\hline Compact lot description: & AGR-5/6/7 compacts, 40\% packing fraction \\
\hline Compact ID numbers: & $1520,1528,1511,1500,1506$ \\
\hline DRF filename: & $14154 \mathrm{D} \_$PF40-Group 1_BL_ICPMS_DRF26R3.xIs \\
\hline
\end{tabular}

\begin{tabular}{|c|c|c|c|c|}
\hline \multirow{3}{*}{\multicolumn{2}{|c|}{\begin{tabular}{|cc} 
& Number of compacts: \\
Average weight uranium per particle, mean value $(\mathrm{g}):$ \\
Average weight uranium per particle, uncertainty in mean $(\mathrm{g})$ :
\end{tabular}}} & \multirow{2}{*}{\multicolumn{3}{|c|}{$\begin{array}{c}5 \\
3.94 \mathrm{E}-04\end{array}$}} \\
\hline & & & & \\
\hline & & \multicolumn{3}{|c|}{$3.94 \mathrm{E}-06$} \\
\hline & & First Leach & Second Leach & Total \\
\hline & Post-burn leach solution ID: & B18102304 & B18102504 & \\
\hline & Total volume of leach solution $(\mathrm{ml})$ : & 61.0 & 64.0 & \\
\hline & RMAL analysis number: & $18797-012$ & $18797-016$ & \\
\hline & Measured uranium concentration $(\mu \mathrm{g} / \mathrm{ml})$ : & $1.44 \mathrm{E}+01$ & & \\
\hline & Uncertainty in uranium concentration $(\mu \mathrm{g} / \mathrm{ml})$ : & $1.44 E+00$ & & \\
\hline & Weight uranium leached $(g)$ : & $8.78 \mathrm{E}-04$ & & \\
\hline & Uncertainty in weight uranium leached $(\mathrm{g})$ : & $8.83 \mathrm{E}-05$ & & \\
\hline & Equivalent number of leached kernels: & $2.23 E+00$ & & \\
\hline & Uncertainty in equivalent number of leached kernels: & $2.25 \mathrm{E}-01$ & & \\
\hline \multirow{5}{*}{$\mathbf{F e}$} & Measured concentration of impurity in sample $(\mu \mathrm{g} / \mathrm{ml})$; & & & $\mathbf{F e}$ \\
\hline & Uncorrected weight of impurity in sample $(\mu g)$ : & & & \\
\hline & Weight of impurity in blank $(\mu \mathrm{g})$ : & & & \\
\hline & Minimum corrected weight of impurity in sample $(\mu \mathrm{g})$ : & & & \\
\hline & Maximum corrected weight of impurity in sample $(\mu \mathrm{g})$ : & & & \\
\hline \multirow{5}{*}{$\mathrm{Cr}$} & Measured concentration of impurity in sample $(\mu \mathrm{g} / \mathrm{ml})$ : & & & Cr \\
\hline & Uncorrected weight of impurity in sample $(\mu \mathrm{g})$ : & & & \\
\hline & Weight of impurity in blank $(\mu \mathrm{g})$ : & & & \\
\hline & Minimum corrected weight of impurity in sample $(\mu \mathrm{g})$ : & & & \\
\hline & Maximum corrected weight of impurity in sample $(\mu \mathrm{g})$ : & & & \\
\hline \multirow{5}{*}{ Mn } & Measured concentration of impurity in sample $(\mu \mathrm{g} / \mathrm{ml})$ : & & & Mn \\
\hline & Uncorrected weight of impurity in sample $(\mu \mathrm{g})$ : & & & \\
\hline & Weight of impurity in blank $(\mu \mathrm{g})$ : & & & \\
\hline & Minimum corrected weight of impurity in sample $(\mu \mathrm{g})$ : & & & \\
\hline & Maximum corrected weight of impurity in sample $(\mu g)$ : & & & \\
\hline \multirow{5}{*}{ Co } & Measured concentration of impurity in sample $(\mu \mathrm{g} / \mathrm{ml})$ : & & & Co \\
\hline & Uncorrected weight of impurity in sample $(\mu \mathrm{g})$ : & & & \\
\hline & Weight of impurity in blank $(\mu \mathrm{g})$ : & & & \\
\hline & Minimum corrected weight of impurity in sample $(\mu \mathrm{g})$ : & & & \\
\hline & Maximum corrected weight of impurity in sample $(\mu \mathrm{g})$ : & & & \\
\hline \multirow{5}{*}{$\mathbf{N i}$} & Measured concentration of impurity in sample $(\mu \mathrm{g} / \mathrm{ml})$ : & & & $\mathbf{N i}$ \\
\hline & Uncorrected weight of impurity in sample $(\mu g)$ : & & & \\
\hline & Weight of impurity in blank $(\mu g)$ : & & & \\
\hline & Minimum corrected weight of impurity in sample $(\mu \mathrm{g})$ : & & & \\
\hline & Maximum corrected weight of impurity in sample $(\mu \mathrm{g})$ : & & & \\
\hline \multirow{4}{*}{$\mathrm{Ca}$} & Measured concentration of impurity in sample $(\mu \mathrm{g} / \mathrm{ml})$ : & & & $\mathrm{Ca}$ \\
\hline & Uncorrected weight of impurity in sample $(\mu \mathrm{g})$ : & & & \\
\hline & Weight of impurity in blank $(\mu \mathrm{g})$ : & & & \\
\hline & Minimum corrected weight of impurity in sample $(\mu \mathrm{g})$ : & & & \\
\hline \multirow{5}{*}{ Al } & $\begin{array}{l}\text { Maximum corrected weight of impurity in sample }(\mu \mathrm{g}) \\
\text { Measured concentration of impurity in sample }(\mu \mathrm{gl} / \mathrm{ml})\end{array}$ & & & \\
\hline & $\begin{array}{r}\text { Measured concentration of impurity in sample }(\mu \mathrm{g} / \mathrm{ml}) \text { : } \\
\text { Uncorrected weight of impurity in sample }(\mu \mathrm{g}) \text { : }\end{array}$ & & & Al \\
\hline & Weight of impurity in blank $(\mu \mathrm{g})$ : & & & \\
\hline & Minimum corrected weight of impurity in sample $(\mu \mathrm{g})$ : & & & \\
\hline & Maximum corrected weight of impurity in sample $(\mu \mathrm{g})$ : & & & \\
\hline \multirow{5}{*}{$\mathbf{T i}$} & Measured concentration of impurity in sample $(\mu \mathrm{g} / \mathrm{ml})$ : & & & Ti \\
\hline & Uncorrected weight of impurity in sample $(\mu \mathrm{g})$ : & & & \\
\hline & Weight of impurity in blank $(\mu \mathrm{g})$ : & & & \\
\hline & Minimum corrected weight of impurity in sample $(\mu \mathrm{g})$ : & & & \\
\hline & Maximum corrected weight of impurity in sample $(\mu \mathrm{g})$ : & & & \\
\hline \multirow{5}{*}{$\mathbf{v}$} & Measured concentration of impurity in sample $(\mu \mathrm{g} / \mathrm{ml})$ : & & & $\mathbf{v}$ \\
\hline & Uncorrected weight of impurity in sample $(\mu \mathrm{g})$ : & & & \\
\hline & Weight of impurity in blank $(\mu \mathrm{g}):$ & & & \\
\hline & Minimum corrected weight of impurity in sample $(\mu \mathrm{g}):$ & & & \\
\hline & Maximum corrected weight of impurity in sample $(\mu \mathrm{g}$ & & & \\
\hline
\end{tabular}

comments

Leached in Vessel FB\#2 (previously leached and analyzed as Blank 4 before use)

FCM checked the recorded data against the official Results of Analysis for RMAL18797 on 3/21/2019.

Shown is the result of the first ICPMS analyses of B18102304.

The first analysis results were rejected based on IDMS analysis.

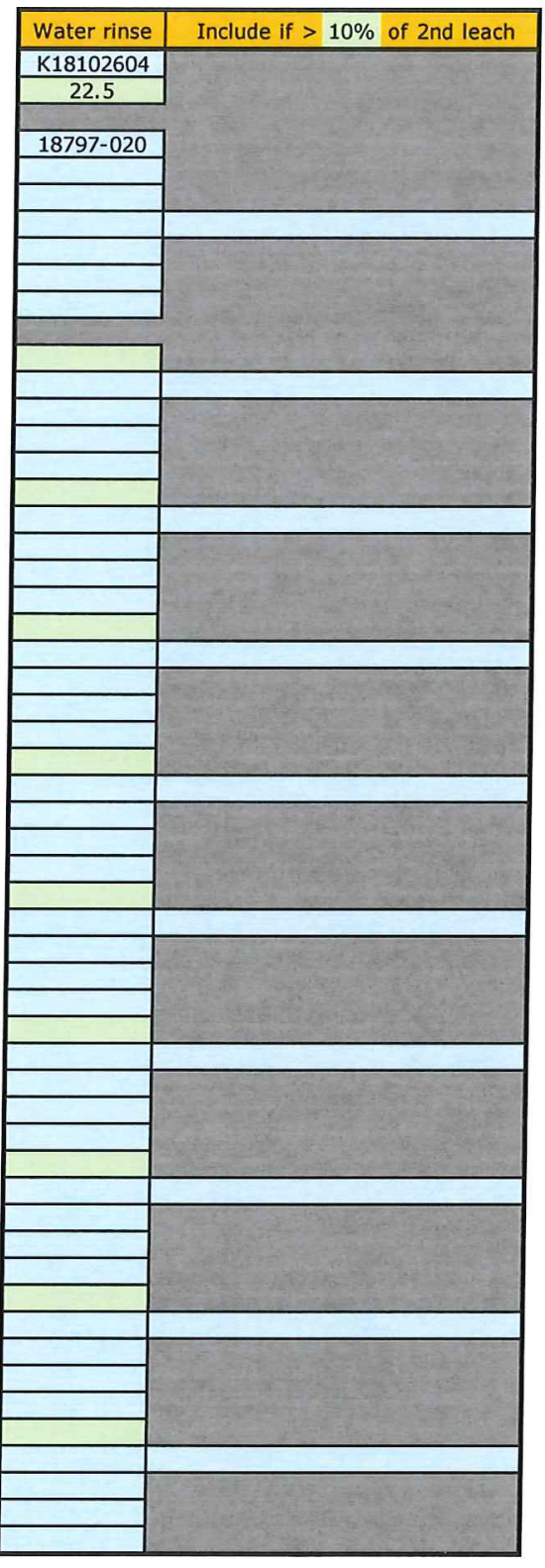

\section{Feed c. Montgomery}

$4-18-2019$

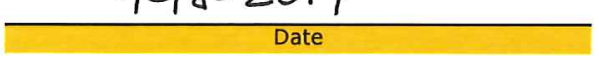




\section{Data Report Form DRF-26B: Post-Burn Leach Uranium and Impuritie}

\begin{tabular}{|r|l|}
\hline Procedure: & AGR-CHAR-DAM-26 Rev, 3 \\
\hline Operator: & Montgomery \\
\hline Compact lot ID: & BWXT J52R-16-14154D \\
\hline Compact lot description: & AGR-5/6/7 compacts, 40\% packing fraction \\
\hline Compact ID numbers: & Blank 1 \\
\hline DRF filename: & 14154D_PF40-Group 1_BL_ICPMS_DRF26R3.xIs \\
\hline
\end{tabular}

Average weight uranium per particle, mean value $(g)$ : Average weight uranium per particle uncertainty in mean $(g):$ $3.94 \mathrm{E}-04$ $3.94 \mathrm{E}-06$

\begin{tabular}{|c|c|c|c|c|}
\hline & First Leach & Second Leach & Total \\
\hline \multicolumn{2}{|c|}{ Post-burn leach solution ID: } & L18100901 & & \\
\hline & Total volume of leach solution $(\mathrm{ml})$ : & 92.5 & & \\
\hline \multicolumn{2}{|c|}{ RMAL analysis number: } & $18797-001$ & & \\
\hline \multicolumn{2}{|c|}{ Measured uranium concentration $(\mu \mathrm{g} / \mathrm{ml})$ : } & $2.96 \mathrm{E}-03$ & & \\
\hline \multicolumn{2}{|c|}{ Uncertainty in uranium concentration $(\mu \mathrm{g} / \mathrm{ml})$ : } & $2.96 \mathrm{E}-04$ & & \\
\hline \multicolumn{2}{|c|}{ Weight uranium leached $(\mathrm{g}):$} & $2.74 \mathrm{E}-07$ & & \\
\hline \multicolumn{2}{|c|}{ Uncertainty in weight uranium leached $(\mathrm{g}):$} & $2.75 \mathrm{E}-08$ & & \\
\hline \multicolumn{2}{|c|}{$\begin{array}{c}\text { Equivalent number of leached kernels: } \\
\end{array}$} & $6.95 \mathrm{E}-04$ & & \\
\hline \multicolumn{2}{|c|}{ Uncertainty in equivalent number of leached kernels: } & $7.01 \mathrm{E}-05$ & & \\
\hline \multirow{2}{*}{$\mathbf{F e}$} & Measured concentration $(\mu \mathrm{g} / \mathrm{ml})$ : & & & Fe \\
\hline & Total weight of leached impurity $(\mu \mathrm{g})$ : & & & \\
\hline \multirow{2}{*}{$\mathrm{Cr}$} & Measured concentration $(\mu \mathrm{g} / \mathrm{ml})$ : & & & $\mathbf{C r}$ \\
\hline & Total weight of leached impurity $(\mu \mathrm{g})$ : & & & \\
\hline \multirow{2}{*}{ Mn } & Measured concentration $(\mu \mathrm{g} / \mathrm{ml})$ : & & & Mn \\
\hline & Total weight of leached impurity $(\mu \mathrm{g})$ : & & & \\
\hline \multirow{2}{*}{ Co } & Measured concentration $(\mu \mathrm{g} / \mathrm{ml})$ : & & & Co \\
\hline & Total weight of leached impurity $(\mu \mathrm{g})$ : & & & \\
\hline \multirow{2}{*}{$\mathbf{N i}$} & Measured concentration $(\mu \mathrm{g} / \mathrm{ml})$ : & & & $\mathrm{Ni}$ \\
\hline & Total weight of leached impurity $(\mu \mathrm{g})$ : & & & \\
\hline \multirow{2}{*}{$\mathrm{Ca}$} & Measured concentration $(\mu \mathrm{g} / \mathrm{ml})$ : & & & $\mathbf{C a}$ \\
\hline & Total weight of leached impurity $(\mu \mathrm{g})$ : & & & \\
\hline \multirow{2}{*}{ Al } & Measured concentration $(\mu \mathrm{g} / \mathrm{ml})$ : & & & Al \\
\hline & Total weight of leached impurity $(\mu \mathrm{g})$ : & & & \\
\hline \multirow{2}{*}{$\mathrm{Ti}$} & Measured concentration $(\mu \mathrm{g} / \mathrm{ml})$ : & & & $\mathrm{Ti}$ \\
\hline & Total weight of leached impurity $(\mu \mathrm{g})$ : & & & \\
\hline \multirow{2}{*}{$\mathbf{v}$} & Measured concentration $(\mu \mathrm{g} / \mathrm{ml})$ : & & & $\mathbf{v}$ \\
\hline & Total weight of leached impurity $(\mu \mathrm{g})$ : & & & \\
\hline
\end{tabular}

\section{Comments}

Blank 1 was obtained on Vessel RB\#2 before it was used for burn-leach of 14154D-Group 1 Clutch 1 FCM checked the recorded data against the official Results of Analysis for RMAL18797 on 3/21/2019.

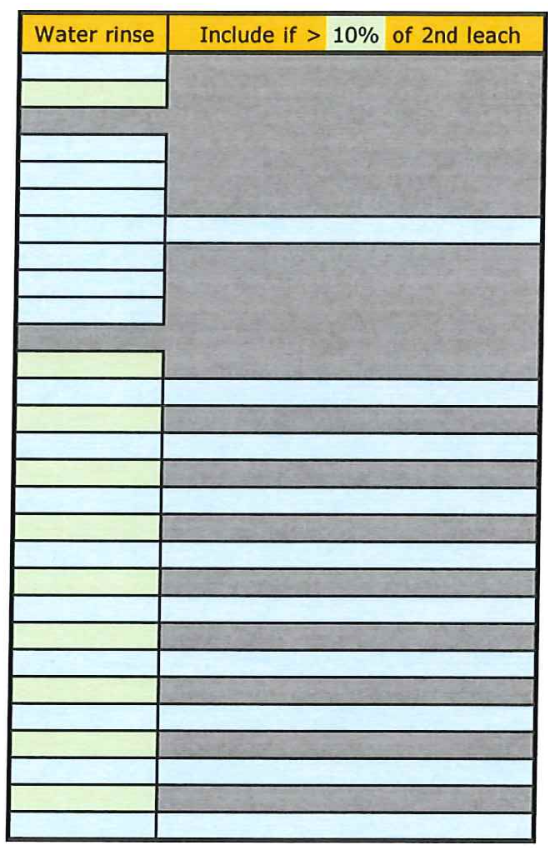

Fred C. Montgomery

$4-18-2019$ 


\section{Data Report Form DRF-26B: Post-Burn Leach Uranium and Impurities}

\begin{tabular}{|r|l|}
\hline Procedure: & AGR-CHAR-DAM-26 Rev. 3 \\
\hline Operator: & Montgomery \\
\hline Compact lot ID: & BWXT J52R-16-14154D \\
\hline Compact lot description: & AGR-5/6/7 compacts, 40\% packing fraction \\
\hline Compact ID numbers: & Blank 2 \\
\hline DRF filename: & 14154D_PF40-Group 1_BL_ICPMS_DRF26R3.xIs \\
\hline
\end{tabular}

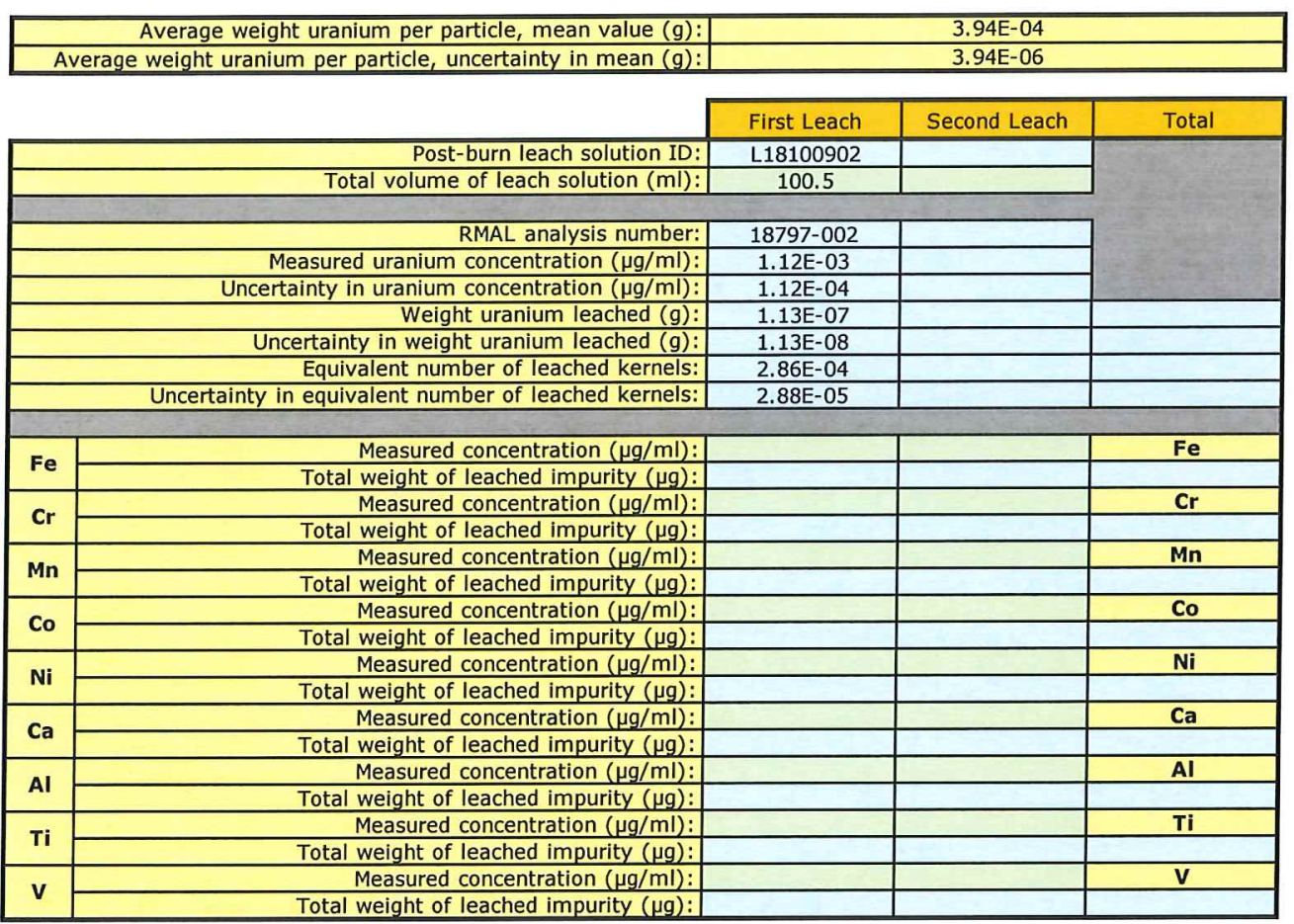

\section{Comments}

Feed C. Montgomens Operator
$4-18-2019$

Date

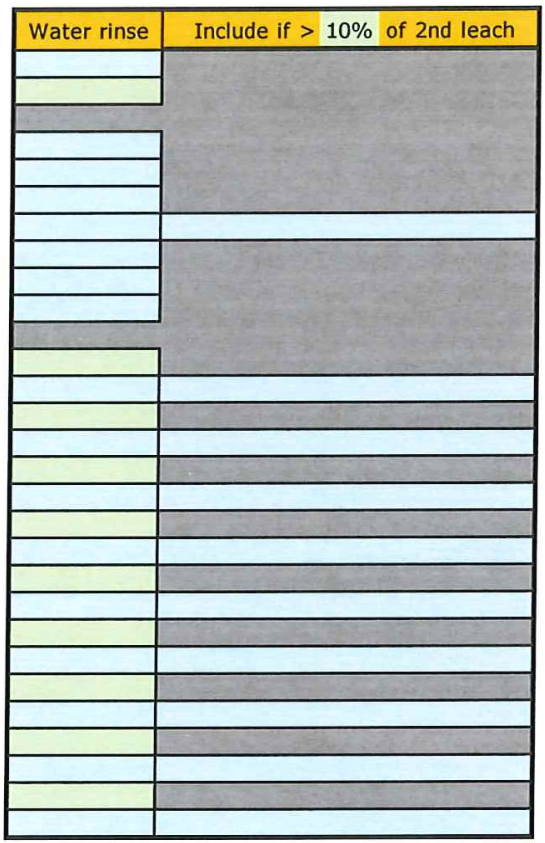


Data Report Form DRF-26B: Post-Burn Leach Uranium and Impurities

\begin{tabular}{|r|l|}
\hline Procedure: & AGR-CHAR-DAM-26 Rev. 3 \\
\hline Operator: & Montgomery \\
\hline Compact lot ID: & BWXT J52R-16-14154D \\
\hline Compact lot description: & AGR-5/6/7 compacts, 40\% packing fraction \\
\hline Compact ID numbers: & Blank 3 \\
\hline DRF filename: & 14154 D_PF40-Group 1_BL_ICPMS_DRF26R3.x/s \\
\hline
\end{tabular}

\begin{tabular}{|r|r|}
\hline Average weight uranium per particle, mean value $(\mathrm{g}):$ & $3.94 \mathrm{E}-04$ \\
\hline Average weight uranium per particle, uncertainty in mean $(\mathrm{g}):$ & $3.94 \mathrm{E}-06$ \\
\hline
\end{tabular}

\begin{tabular}{|c|c|c|c|c|}
\hline & 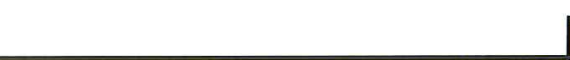 & First Leach & Second Leach & Total \\
\hline & Post-burn leach solution ID: & L18100903 & & \\
\hline & Total volume of leach solution (ml): & 92.0 & & \\
\hline & RMAL analysis number: & $18797-003$ & & \\
\hline & Measured uranium concentration $(\mu \mathrm{g} / \mathrm{ml})$ : & $3.87 \mathrm{E}-03$ & & \\
\hline & Uncertainty in uranium concentration $(\mu \mathrm{g} / \mathrm{ml})$ : & $3.87 \mathrm{E}-04$ & & \\
\hline & Weight uranium leached $(\mathrm{g}):$ & $3.56 \mathrm{E}-07$ & & \\
\hline & Uncertainty in weight uranium leached $(\mathrm{g})$ : & $3.57 E-08$ & & \\
\hline & Equivalent number of leached kernels: & $9.05 \mathrm{E}-04$ & & \\
\hline & Uncertainty in equivalent number of leached kernels: & $9.11 \mathrm{E}-05$ & & \\
\hline \multirow{2}{*}{$\mathbf{F e}$} & Measured concentration $(\mu \mathrm{g} / \mathrm{ml})$ : & & & $\mathrm{Fe}$ \\
\hline & Total weight of leached impurity $(\mu \mathrm{g}):$ & & & \\
\hline \multirow{2}{*}{$\mathbf{C r}$} & Measured concentration $(\mu \mathrm{g} / \mathrm{ml}):$ & & & $\mathbf{C r}$ \\
\hline & Total weight of leached impurity $(\mu \mathrm{g})$ : & & & \\
\hline \multirow{2}{*}{ Mn } & Measured concentration $(\mu \mathrm{g} / \mathrm{ml})$ : & & & Mn \\
\hline & Total weight of leached impurity $(\mu \mathrm{g})$ : & & & \\
\hline \multirow{2}{*}{ Co } & Measured concentration $(\mu \mathrm{g} / \mathrm{ml})$ : & & & Co \\
\hline & Total weight of leached impurity $(\mu \mathrm{g})$ : & & & \\
\hline \multirow{2}{*}{$\mathbf{N i}$} & Measured concentration $(\mu \mathrm{g} / \mathrm{ml})$ : & & & $\mathrm{Ni}$ \\
\hline & Total weight of leached impurity $(\mu \mathrm{g})$ : & & & \\
\hline \multirow{2}{*}{$\mathrm{Ca}$} & Measured concentration $(\mu \mathrm{g} / \mathrm{ml})$ : & & & $\mathbf{C a}$ \\
\hline & Total weight of leached impurity $(\mu g)$ : & & & \\
\hline \multirow{2}{*}{ Al } & Measured concentration $(\mu \mathrm{g} / \mathrm{ml})$ : & & & Al \\
\hline & Total weight of leached impurity $(\mu \mathrm{g})$ : & & & \\
\hline \multirow{2}{*}{ Ti } & Measured concentration $(\mu \mathrm{g} / \mathrm{ml})$ : & & & $\mathrm{Ti}$ \\
\hline & Total weight of leached impurity $(\mu \mathrm{g})$ : & & & \\
\hline \multirow{2}{*}{$\mathbf{v}$} & Measured concentration $(\mu \mathrm{g} / \mathrm{ml})$ : & & & $\mathbf{V}$ \\
\hline & Total weight of leached impurity $(\mu \mathrm{g})$ : & & & \\
\hline
\end{tabular}

\section{Comments}

Blank 3 was obtained on Vessel RB\#11 before it was used for burn-leach of 14154D-Group 1 Clutch 3 . FCM checked the recorded data against the official Results of Analysis for RMAL18797 on 3/21/2019.

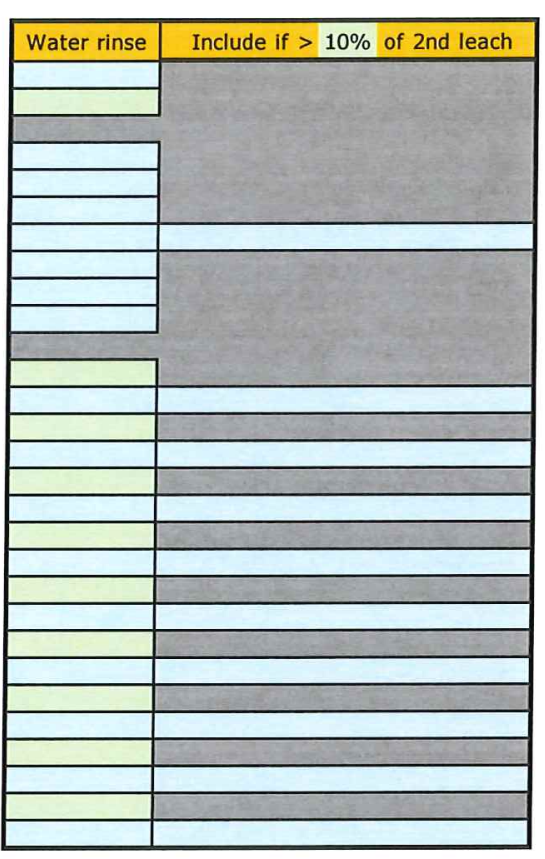

Fred C. Montgomery Operator
$4-18-2019$

Date 
Data Report Form DRF-26B: Post-Burn Leach Uranium and Impurities

\begin{tabular}{|r|l|}
\hline Procedure: & AGR-CHAR-DAM-26 Rev. 3 \\
\hline Operator: & Montgomery \\
\hline Compact lot ID: & BWXT J52R-16-14154D \\
\hline Compact lot description: & AGR-5/6/7 compacts, 40\% packing fraction \\
\hline Compact ID numbers: & Blank 4 \\
\hline DRF filename: & 14154D_PF40-Group 1_BL_ICPMS_DRF26R3.xIs \\
\hline
\end{tabular}

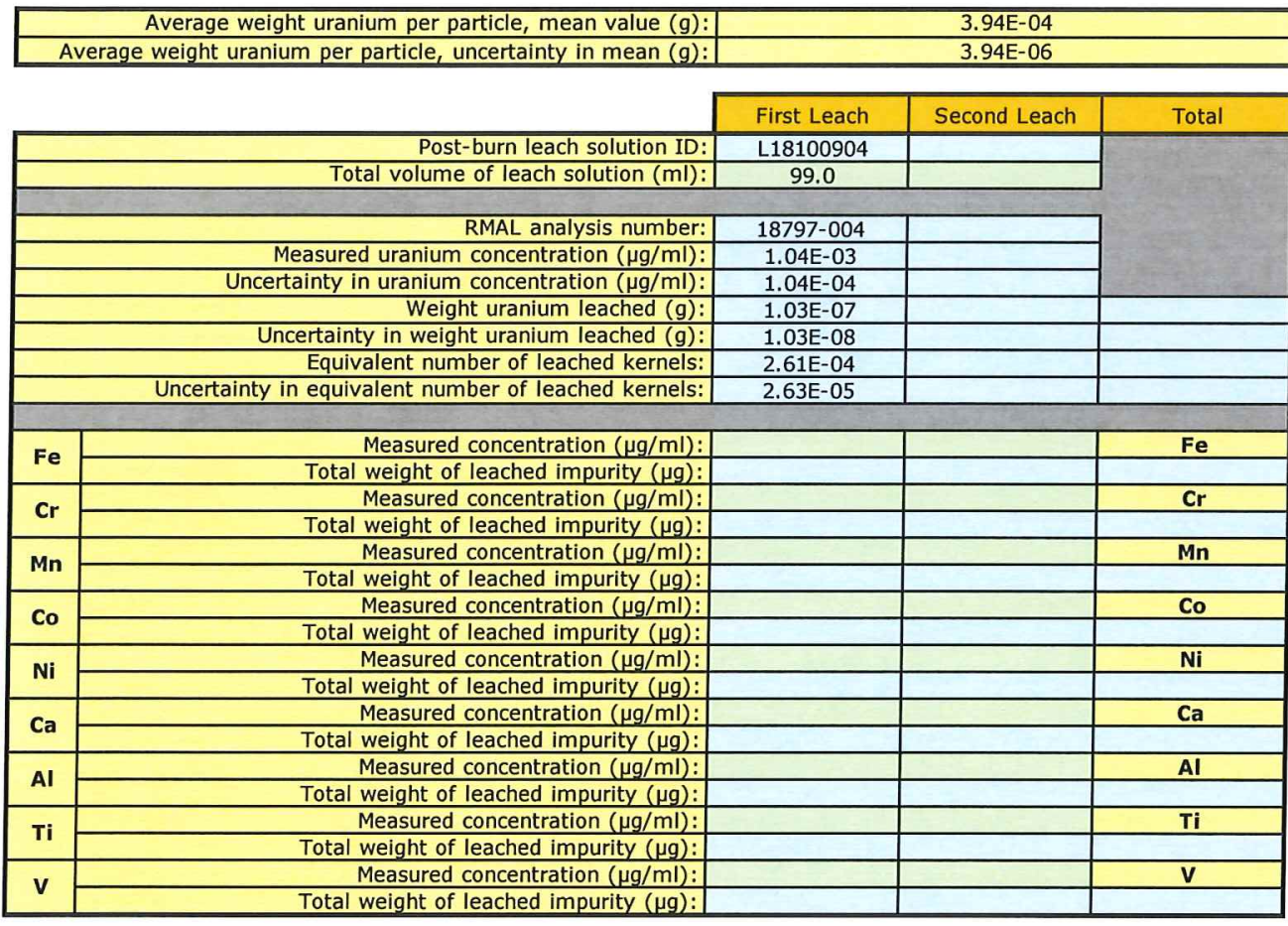

\section{Comments}

Blank 4 was obtained on Vessel FB\#2 before it was used for burn-leach of 14154D-Group 1 Clutch 4. FCM checked the recorded data against the official Results of Analysis for RMAL18797 on 3/21/2019.

\section{Fied c. Montgomery}

\section{$4-18-2019$}

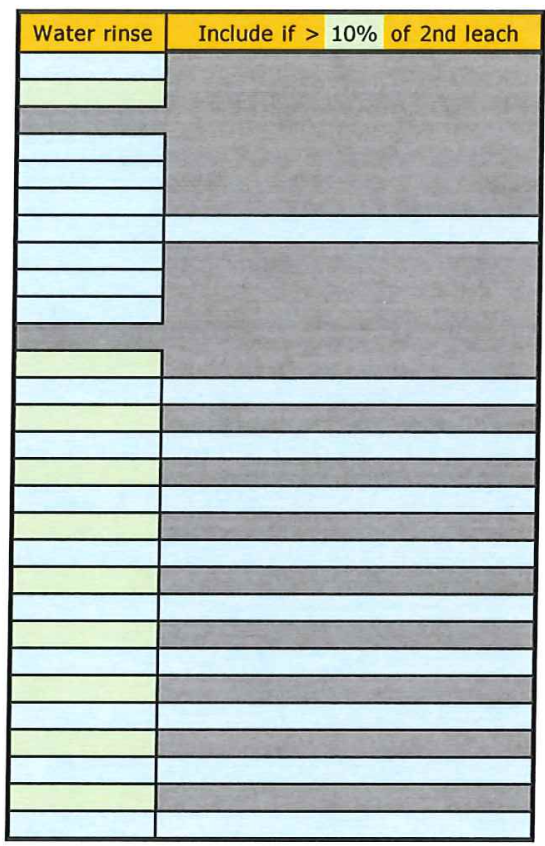




\section{Data Report Form DRF-26B: Post-Burn Leach Uranium and Impurities}

Procedure: AGR-CHAR-DAM-26 Rev. 3

Operator: Montgomery

Compact lot ID: BWXT J52R-16-14154D

Compact lot description: AGR-5/6/7 compacts, $40 \%$ packing fraction

Compact ID numbers: $1508,1510,1501,1533,1519$

DRF filename: 14154D_PF40-Group 2_BL_ICPMS_DRF26R3.xIs

Number of compacts:

Average weight uranium per particle, mean value $(g)$

Average weight uranium per particle, uncertainty in mean (g)

\begin{tabular}{|c|c|c|c|c|}
\hline & First Leach & Second Leach & Total \\
\hline & Post-burn leach solution ID: & B18111501 & B18111901 & \\
\hline & Total volume of leach solution $(\mathrm{ml})$ : & 56.8 & 62.5 & \\
\hline & RMAL analysis number: & $18877-001$ & $18877-005$ & \\
\hline & Measured uranium concentration $(\mu \mathrm{g} / \mathrm{ml})$ : & $1.90 \mathrm{E}+01$ & $7.19 \mathrm{E}-02$ & \\
\hline & Uncertainty in uranium concentration $(\mu \mathrm{g} / \mathrm{ml})$ : & $1.90 \mathrm{E}+00$ & $7.19 \mathrm{E}-03$ & \\
\hline & Weight uranium leached $(\mathrm{g})$ : & $1.08 \mathrm{E}-03$ & $4.49 \mathrm{E}-06$ & $1.08 \mathrm{E}-03$ \\
\hline & Uncertainty in weight uranium leached $(\mathrm{g})$ : & $1.09 \mathrm{E}-04$ & $4.52 \mathrm{E}-07$ & $1.09 \mathrm{E}-04$ \\
\hline & Equivalent number of leached kernels: & $2.74 E+00$ & $1.14 \mathrm{E}-02$ & $2.75 \mathrm{E}+00$ \\
\hline & Uncertainty in equivalent number of leached kernels: & $2.77 \mathrm{E}-01$ & $1.15 \mathrm{E}-03$ & $2.77 \mathrm{E}-01$ \\
\hline \multirow{5}{*}{$\mathrm{Fe}$} & Measured concentration of impurity in sample $(\mu \mathrm{g} / \mathrm{ml})$ : & & & $\mathbf{F e}$ \\
\hline & Uncorrected weight of impurity in sample $(\mu \mathrm{g})$ : & & & \\
\hline & Weight of impurity in blank $(\mu \mathrm{g})$ : & & & \\
\hline & Minimum corrected weight of impurity in sample $(\mu \mathrm{g})$ : & & & \\
\hline & Maximum corrected weight of impurity in sample $(\mu g)$ : & & & \\
\hline \multirow{5}{*}{$\mathbf{C r}$} & Measured concentration of impurity in sample $(\mu \mathrm{g} / \mathrm{ml})$ : & & & $\mathbf{C r}$ \\
\hline & Uncorrected weight of impurity in sample $(\mu \mathrm{g})$ : & & & \\
\hline & Weight of impurity in blank $(\mu \mathrm{g})$ : & & & \\
\hline & Minimum corrected weight of impurity in sample $(\mu \mathrm{g})$ : & & & \\
\hline & Maximum corrected weight of impurity in sample $(\mu \mathrm{g})$ : & & & \\
\hline \multirow{5}{*}{ Mn } & Measured concentration of impurity in sample $(\mu \mathrm{g} / \mathrm{ml})$ : & & & Mn \\
\hline & Uncorrected weight of impurity in sample $(\mu g)$ : & & & \\
\hline & Weight of impurity in blank $(\mu g)$ : & & & \\
\hline & Minimum corrected weight of impurity in sample $(\mu \mathrm{g})$ : & & & \\
\hline & Maximum corrected weight of impurity in sample $(\mu g)$ : & & & \\
\hline \multirow{5}{*}{ Co } & Measured concentration of impurity in sample $(\mu \mathrm{g} / \mathrm{ml})$ : & & & Co \\
\hline & Uncorrected weight of impurity in sample $(\mu \mathrm{g})$ : & & & \\
\hline & Weight of impurity in blank $(\mu g)$ : & & & \\
\hline & Minimum corrected weight of impurity in sample $(\mu \mathrm{g})$ : & & & \\
\hline & Maximum corrected weight of impurity in sample $(\mu \mathrm{g})$ : & & & \\
\hline \multirow{5}{*}{$\mathbf{N i}$} & Measured concentration of impurity in sample $(\mu \mathrm{g} / \mathrm{ml})$ : & & & $\mathrm{Ni}$ \\
\hline & Uncorrected weight of impurity in sample $(\mu \mathrm{g})$ : & & & \\
\hline & Weight of impurity in blank $(\mu \mathrm{g})$ : & & & \\
\hline & Minimum corrected weight of impurity in sample $(\mu \mathrm{g}):$ & & & \\
\hline & Maximum corrected weight of impurity in sample $(\mu g)$ : & & & \\
\hline \multirow{5}{*}{ Ca } & Measured concentration of impurity in sample $(\mu \mathrm{g} / \mathrm{ml})$ : & & & $\mathbf{C a}$ \\
\hline & Uncorrected weight of impurity in sample $(\mu \mathrm{g})$ : & & & \\
\hline & Weight of impurity in blank $(\mu \mathrm{g})$ : & & & \\
\hline & Minimum corrected weight of impurity in sample $(\mu g)$ : & & & \\
\hline & Maximum corrected weight of impurity in sample $(\mu g)$ : & & & \\
\hline \multirow{5}{*}{ Al } & Measured concentration of impurity in sample $(\mu \mathrm{g} / \mathrm{ml})$ : & & & Al \\
\hline & Uncorrected weight of impurity in sample $(\mu \mathrm{g})$ : & & & \\
\hline & Weight of impurity in blank $(\mu \mathrm{g})$ : & & & \\
\hline & Minimum corrected weight of impurity in sample $(\mu \mathrm{g})$ : & & & \\
\hline & Maximum corrected weight of impurity in sample $(\mu \mathrm{g})$ : & & & \\
\hline \multirow{5}{*}{$\mathbf{T i}$} & Measured concentration of impurity in sample $(\mu \mathrm{g} / \mathrm{ml})$ : & & & $\mathbf{T i}$ \\
\hline & Uncorrected weight of impurity in sample $(\mu \mathrm{g})$ : & & & \\
\hline & Weight of impurity in blank $(\mu g)$ : & & & \\
\hline & Minimum corrected weight of impurity in sample $(\mu \mathrm{g})$ : & & & \\
\hline & Maximum corrected weight of impurity in sample $(\mu \mathrm{g})$ : & & & \\
\hline \multirow{5}{*}{$\mathbf{v}$} & Measured concentration of impurity in sample $(\mu \mathrm{g} / \mathrm{ml})$ : & & & $\mathbf{v}$ \\
\hline & Uncorrected weight of impurity in sample $(\mu \mathrm{g})$ : & & & \\
\hline & Weight of impurity in blank $(\mu \mathrm{g})$ : & & & \\
\hline & Minimum corrected weight of impurity in sample $(\mu \mathrm{g})$ : & & & \\
\hline & Maximum corrected weight of impurity in sample $(\mu \mathrm{g}):$ & & & \\
\hline
\end{tabular}

\begin{tabular}{|l|l|}
\hline Water rinse & Include if $>10 \%$ of 2 nd leach \\
\hline
\end{tabular} W18111905 22.5

$18877-009$

$2.08 \mathrm{E}-03$

$2.08 \mathrm{E}-04$

4.67E-08

$4.86 \mathrm{E}-09$

$1.19 \mathrm{E}-04$

$1.24 \mathrm{E}-05$

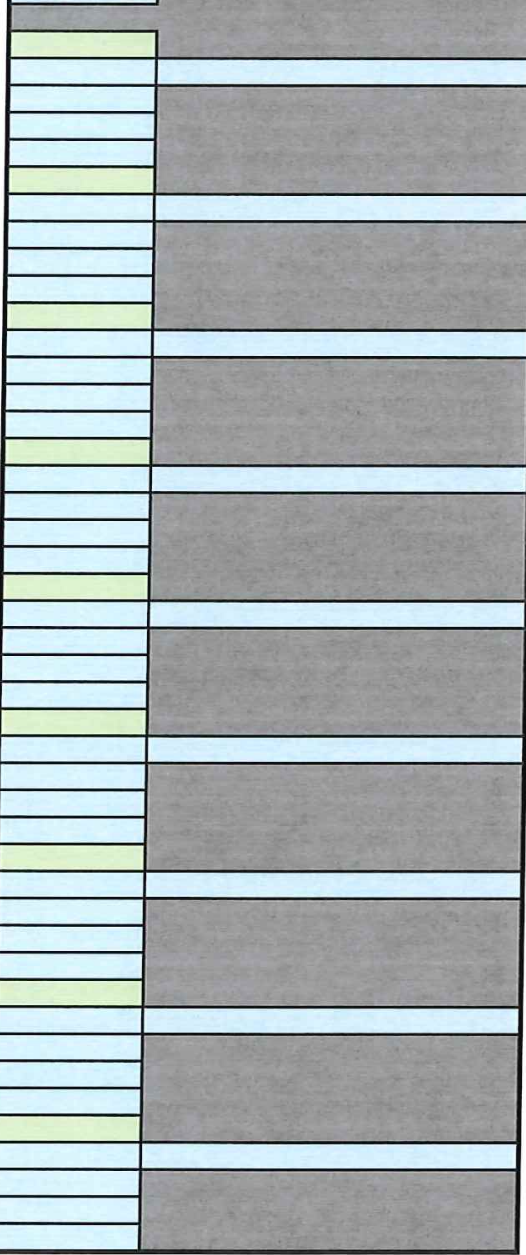

Comments

Leached in Vessel \#31 (previously unused).

FCM checked the recorded data against the official Results of Analysis for RMAL18877 on 3/21/2019.

Shown is the result of the second ICPMS analyses of B18111501.

The first analysis results were rejected based on IDMS analysis.

\section{Fied c. Montgomeey}

\section{$4-18-2019$}


Data Report Form DRF-26B: Post-Burn Leach Uranium and Impurities

\begin{tabular}{|r|l|}
\hline Procedure: & AGR-CHAR-DAM-26 Rev. 3 \\
\hline Operator: & Montgomery \\
\hline Compact lot ID: & BWXT J52R-16-14154D \\
\hline Compact lot description: & AGR-5/6/7 compacts, 40\% packing fraction \\
\hline Compact ID numbers: & $1508,1510,1501,1533,1519$ \\
\hline DRF filename: & $14154 D \_P F 40-G r o u p 2$ BL_ICPMS_DRF26R3.xIs \\
\hline
\end{tabular}

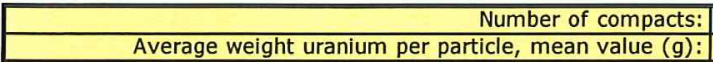
Average weight uranium per particle, uncertainty in mean (g):

\begin{tabular}{|c|c|c|c|c|}
\hline & First Leach & Second Leach & Total \\
\hline \multirow{2}{*}{\multicolumn{2}{|c|}{$\begin{array}{rr}\text { Post-burn leach solution ID: } \\
\text { Total volume of leach solution }(\mathrm{ml}):\end{array}$}} & B18111501 & B18111901 & \\
\hline & & 56.8 & 62.5 & \\
\hline \multicolumn{2}{|c|}{ RMAL analysis number: } & $18877-001$ & $18877-005$ & \\
\hline \multirow{2}{*}{\multicolumn{2}{|c|}{$\begin{array}{c}\text { Measured uranium concentration }(\mu \mathrm{g} / \mathrm{ml}): \\
\text { Uncertainty in uranium concentration }(\mu \mathrm{g} / \mathrm{ml}):\end{array}$}} & $2.45 \mathrm{E}+01$ & & \\
\hline & & $2.45 \mathrm{E}+00$ & & \\
\hline \multicolumn{2}{|c|}{ Weight uranium leached $(g):$} & $1.39 \mathrm{E}-03$ & & \\
\hline \multirow{2}{*}{\multicolumn{2}{|c|}{$\begin{array}{r}\text { Uncertainty in weight uranium leached }(\mathrm{g}): \\
\text { Equivalent number of leached kernels: }\end{array}$}} & $1.40 \mathrm{E}-04$ & & \\
\hline & & $3.53 \mathrm{E}+00$ & & \\
\hline \multicolumn{2}{|c|}{ Uncertainty in equivalent number of leached kernels: } & $3.57 \mathrm{E}-01$ & & \\
\hline \multirow{5}{*}{$\mathbf{F e}$} & Measured concentration of impurity in sample $(\mu \mathrm{g} / \mathrm{ml})$ : & & & Fe \\
\hline & Uncorrected weight of impurity in sample $(\mu g)$ : & & & \\
\hline & Weight of impurity in blank $(\mu \mathrm{g})$ : & & & \\
\hline & Minimum corrected weight of impurity in sample $(\mu \mathrm{g})$ : & & & \\
\hline & Maximum corrected weight of impurity in sample $(\mu \mathrm{g})$ : & & & \\
\hline \multirow{5}{*}{$\mathrm{Cr}$} & Measured concentration of impurity in sample $(\mu \mathrm{g} / \mathrm{ml})$ : & & & $\mathrm{Cr}$ \\
\hline & Uncorrected weight of impurity in sample $(\mu \mathrm{g})$ : & & & \\
\hline & Weight of impurity in blank $(\mu \mathrm{g})$ : & & & \\
\hline & Minimum corrected weight of impurity in sample $(\mu \mathrm{g})$ : & & & \\
\hline & Maximum corrected weight of impurity in sample $(\mu g)$ : & & & \\
\hline \multirow{5}{*}{ Mn } & Measured concentration of impurity in sample $(\mu \mathrm{g} / \mathrm{ml})$ : & & & Mn \\
\hline & Uncorrected weight of impurity in sample $(\mu \mathrm{g})$ : & & & \\
\hline & Weight of impurity in blank $(\mu \mathrm{g})$ : & & & \\
\hline & Minimum corrected weight of impurity in sample $(\mu \mathrm{g})$ : & & & \\
\hline & Maximum corrected weight of impurity in sample $(\mu g)$ : & & & \\
\hline \multirow{5}{*}{ Co } & Measured concentration of impurity in sample $(\mu \mathrm{g} / \mathrm{ml})$ : & & & Co \\
\hline & Uncorrected weight of impurity in sample $(\mu \mathrm{g})$ : & & & \\
\hline & Weight of impurity in blank $(\mu g)$ : & & & \\
\hline & Minimum corrected weight of impurity in sample $(\mu \mathrm{g})$ : & & & \\
\hline & Maximum corrected weight of impurity in sample $(\mu \mathrm{g})$ : & & & \\
\hline \multirow{5}{*}{$\mathbf{N i}$} & Measured concentration of impurity in sample $(\mu \mathrm{g} / \mathrm{ml})$ : & & & $\mathrm{Ni}$ \\
\hline & Uncorrected weight of impurity in sample $(\mu \mathrm{g})$ : & & & \\
\hline & Weight of impurity in blank $(\mu \mathrm{g})$ : & & & \\
\hline & Minimum corrected weight of impurity in sample $(\mu \mathrm{g}):$ & & & \\
\hline & Maximum corrected weight of impurity in sample $(\mu \mathrm{g})$ : & & & \\
\hline \multirow{5}{*}{ Ca } & Measured concentration of impurity in sample $(\mathrm{\mu g} / \mathrm{ml})$ : & & & $\mathbf{C a}$ \\
\hline & Uncorrected weight of impurity in sample $(\mu \mathrm{g})$ : & & & \\
\hline & Weight of impurity in blank $(\mu g)$ : & & & \\
\hline & Minimum corrected weight of impurity in sample $(\mu \mathrm{g})$ : & & & \\
\hline & Maximum corrected weight of impurity in sample $(\mu g)$ : & & & \\
\hline \multirow{5}{*}{ Al } & Measured concentration of impurity in sample $(\mu \mathrm{g} / \mathrm{ml})$ : & & & Al \\
\hline & Uncorrected weight of impurity in sample $(\mu g)$ : & & & \\
\hline & Weight of impurity in blank $(\mu \mathrm{g})$ : & & & \\
\hline & Minimum corrected weight of impurity in sample $(\mu \mathrm{g}):$ & & & \\
\hline & Maximum corrected weight of impurity in sample $(\mu \mathrm{g}):$ & & & \\
\hline \multirow{5}{*}{$\mathrm{Ti}$} & Measured concentration of impurity in sample $(\mu \mathrm{g} / \mathrm{ml})$ : & & & $T i$ \\
\hline & Uncorrected weight of impurity in sample $(\mu \mathrm{g})$ : & & & \\
\hline & Weight of impurity in blank $(\mu \mathrm{g})$ : & & & \\
\hline & Minimum corrected weight of impurity in sample $(\mu \mathrm{g})$ : & & & \\
\hline & Maximum corrected weight of impurity in sample $(\mu \mathrm{g})$ : & & & \\
\hline \multirow{5}{*}{$\mathbf{v}$} & Measured concentration of impurity in sample $(\mu \mathrm{g} / \mathrm{ml})$ : & & & $\mathbf{v}$ \\
\hline & Uncorrected weight of impurity in sample $(\mu \mathrm{g})$ : & & & \\
\hline & Weight of impurity in blank $(\mu \mathrm{g})$ : & & & \\
\hline & Minimum corrected weight of impurity in sample $(\mu \mathrm{g}):$ & & & \\
\hline & Maximum corrected weight of impurity in sample $(\mu \mathrm{g}):$ & & & \\
\hline
\end{tabular}

Comments

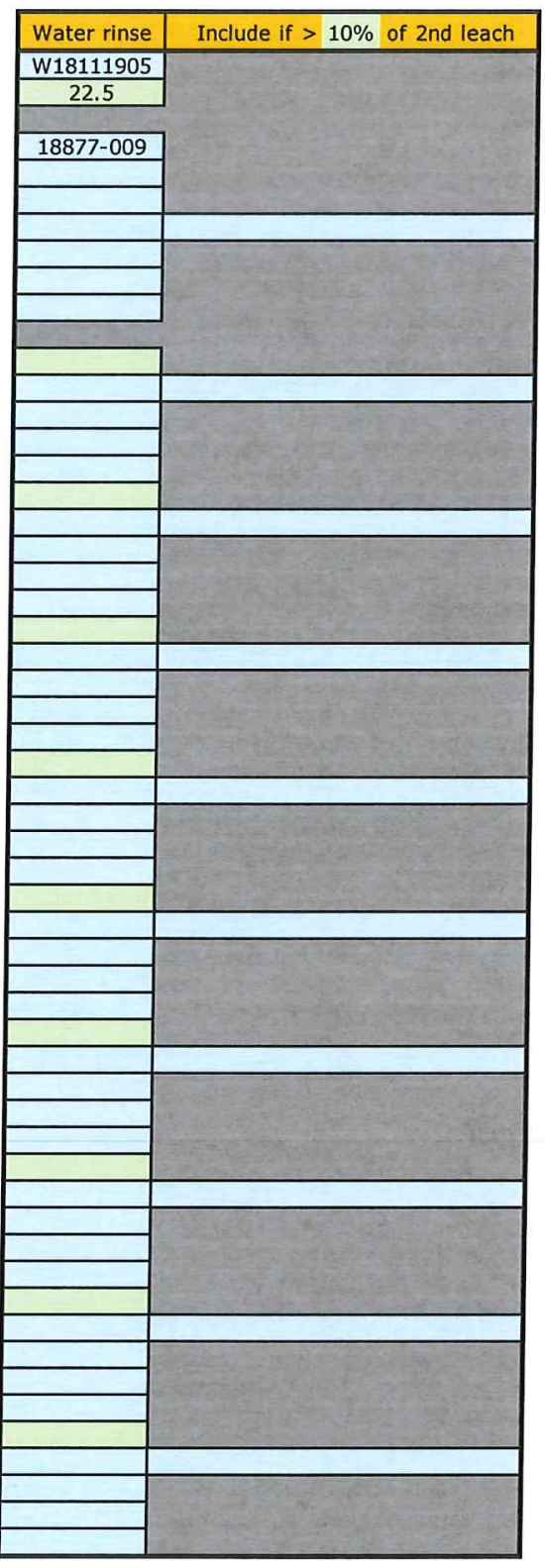

Leached in Vessel \#31 (previously unused).

FCM checked the recorded data against the official Results of Analysis for RMAL18877 on 3/21/2019.

Shown is the result of the first ICPMS analysis of B18111501.

The first analysis results were rejected based on IDMS analysis.

\section{Fed c. Mont gomeny $\frac{4-18-2019}{\text { operator }}$}


Data Report Form DRF-26B: Post-Burn Leach Uranium and Impurities

\begin{tabular}{|r|l|}
\hline Procedure: & AGR-CHAR-DAM-26 Rev. 3 \\
\hline Operator: & Montgomery \\
\hline Compact lot ID: & BWXT J52R-16-14154D \\
\hline Compact lot description: & AGR-5/6/7 compacts, 40\% packing fraction \\
\hline Compact ID numbers: & $1508,1510,1501,1533,1519$ \\
\hline DRF filename: & $14154 D \_P F 40-$ Group 2_BL_ICPMS_DRF26R3.xIs \\
\hline
\end{tabular}

\begin{tabular}{|c|c|c|c|c|}
\hline \multirow{3}{*}{\multicolumn{2}{|c|}{ 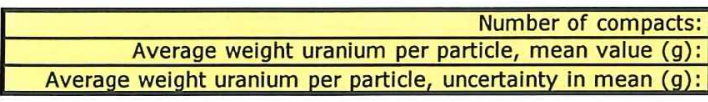 }} & \multirow{2}{*}{\multicolumn{3}{|c|}{$\begin{array}{c}5 \\
3.94 \mathrm{E}-04 \\
\end{array}$}} \\
\hline & & & & \\
\hline & & \multicolumn{3}{|c|}{$3.94 \mathrm{E}-06$} \\
\hline & & First Leach & Second Leach & Total \\
\hline & Post-burn leach solution ID: & B18111501 & B18111901 & \\
\hline & Total volume of leach solution $(\mathrm{ml})$ : & 56.8 & 62.5 & \\
\hline & RMAL analysis number: & $18877-001$ & $18877-005$ & \\
\hline & Measured uranium concentration $(\mu \mathrm{g} / \mathrm{ml})$ : & $1.93 \mathrm{E}+01$ & & \\
\hline & Uncertainty in uranium concentration $(\mu \mathrm{g} / \mathrm{ml})$ : & $9.64 \mathrm{E}-01$ & & \\
\hline & Weight uranium leached $(g)$ : & $1.10 \mathrm{E}-03$ & & \\
\hline & Uncertainty in weight uranium leached $(\mathrm{g})$ : & $5.62 \mathrm{E}-05$ & & \\
\hline & Equivalent number of leached kernels: & $2.78 \mathrm{E}+00$ & & \\
\hline & Uncertainty in equivalent number of leached kernels: & $1.45 \mathrm{E}-01$ & & \\
\hline \multirow{5}{*}{$\mathbf{F e}$} & Measured concentration of impurity in sample $(\mu \mathrm{g} / \mathrm{ml})$ : & & & $\mathrm{Fe}$ \\
\hline & Uncorrected weight of impurity in sample $(\mu \mathrm{g})$ : & & & \\
\hline & Weight of impurity in blank $(\mu \mathrm{g})$ : & & & \\
\hline & Minimum corrected weight of impurity in sample $(\mu \mathrm{g})$ : & & & \\
\hline & Maximum corrected weight of impurity in sample $(\mu g)$ : & & & \\
\hline \multirow{5}{*}{ Cr } & Measured concentration of impurity in sample $(\mu \mathrm{g} / \mathrm{ml})$ : & & & $\mathrm{Cr}$ \\
\hline & Uncorrected weight of impurity in sample $(\mu \mathrm{g})$ : & & & \\
\hline & Weight of impurity in blank $(\mu \mathrm{g})$ : & & & \\
\hline & Minimum corrected weight of impurity in sample $(\mu g)$ : & & & \\
\hline & Maximum corrected weight of impurity in sample $(\mu g)$ : & & & \\
\hline \multirow{5}{*}{ Mn } & Measured concentration of impurity in sample $(\mu \mathrm{g} / \mathrm{ml})$ : & & & Mn \\
\hline & Uncorrected weight of impurity in sample $(\mu \mathrm{g})$ : & & & \\
\hline & Weight of impurity in blank $(\mu \mathrm{g})$ : & & & \\
\hline & Minimum corrected weight of impurity in sample $(\mu \mathrm{g})$ : & & & \\
\hline & Maximum corrected weight of impurity in sample $(\mu \mathrm{g})$ : & & & \\
\hline \multirow{5}{*}{ co } & Measured concentration of impurity in sample $(\mu \mathrm{g} / \mathrm{ml})$ : & & & Co \\
\hline & Uncorrected weight of impurity in sample $(\mu \mathrm{g})$ : & & & \\
\hline & Weight of impurity in blank $(\mu \mathrm{g})$ : & & & \\
\hline & Minimum corrected weight of impurity in sample $(\mu \mathrm{g})$ : & & & \\
\hline & Maximum corrected weight of impurity in sample $(\mu \mathrm{g})$ : & & & \\
\hline \multirow{4}{*}{$\mathrm{Ni}$} & Measured concentration of impurity in sample $(\mu \mathrm{g} / \mathrm{ml})$ : & & & $\mathbf{N i}$ \\
\hline & Uncorrected weight of impurity in sample $(\mu \mathrm{g})$ : & & & \\
\hline & $\begin{array}{c}\text { Weight of impurity in blank }(\mu \mathrm{g}) \text { : } \\
\text { Minimum corrected weight of impurity in sample }(\mu \mathrm{g}):\end{array}$ & & & \\
\hline & Maximum corrected weight of impurity in sample $(\mu \mathrm{g})$ : & & & \\
\hline \multirow{5}{*}{$\mathrm{Ca}$} & Measured concentration of impurity in sample $(\mu \mathrm{g} / \mathrm{ml})$ : & & & $\mathbf{C a}$ \\
\hline & Uncorrected weight of impurity in sample $(\mu \mathrm{g})$ : & & & \\
\hline & Weight of impurity in blank $(\mu \mathrm{g})$ : & & & \\
\hline & Minimum corrected weight of impurity in sample $(\mu g)$ : & & & \\
\hline & Maximum corrected weight of impurity in sample $(\mu \mathrm{g})$ : & & & \\
\hline \multirow{5}{*}{ Al } & Measured concentration of impurity in sample $(\mu \mathrm{g} / \mathrm{ml})$ : & & & Al \\
\hline & Uncorrected weight of impurity in sample $(\mu \mathrm{g})$ : & & & \\
\hline & Weight of impurity in blank $(\mu \mathrm{g})$ : & & & \\
\hline & Minimum corrected weight of impurity in sample $(\mu \mathrm{g})$ : & & & \\
\hline & Maximum corrected weight of impurity in sample $(\mu \mathrm{g})$ : & & & \\
\hline \multirow{4}{*}{$\mathrm{Ti}$} & Measured concentration of impurity in sample $(\mu \mathrm{g} / \mathrm{ml})$ : & & & $\mathrm{Ti}$ \\
\hline & Uncorrected weight of impurity in sample $(\mu \mathrm{g})$ : & & & \\
\hline & $\begin{array}{c}\text { Weight of impurity in blank }(\mu \mathrm{g}) \text { : } \\
\text { Minimum corrected weiaht of impurity in sample }(\mu a) \text {. }\end{array}$ & & & \\
\hline & $\begin{array}{l}\text { Minimum corrected weight of impurity in sample }(\mu \mathrm{g}) \text { : } \\
\text { Maximum corrected weight of impurity in sample }(\mu \mathrm{g}) \text { : }\end{array}$ & & & \\
\hline \multirow{5}{*}{$\mathbf{v}$} & $\begin{array}{l}\text { Maximum corrected weight of Impurity in sample }(\mu \mathrm{g}) \text { : } \\
\text { Measured concentration of impurity in sample }(\mu \mathrm{g} / \mathrm{ml}) \text { : }\end{array}$ & & & $\mathbf{v}$ \\
\hline & Uncorrected weight of impurity in sample $(\mu \mathrm{g})$ : & & & \\
\hline & Weight of impurity in blank $(\mu \mathrm{g})$ : & & & \\
\hline & Minimum corrected weight of impurity in sample $(\mu \mathrm{g})$ : & & & \\
\hline & Maximum corrected weight of impurity in sample $(\mu g):$ & & & \\
\hline
\end{tabular}

comments

Leached in Vessel \#31 (previously unused).

FCM checked the recorded data against the official Results of Analysis for RMAL18877 on 3/21/2019.

Shown is the result of the isotope dilution mass spectrometry analysis of B18111501.

\section{Feed C. Montgomery}

\section{$4-18-2019$}

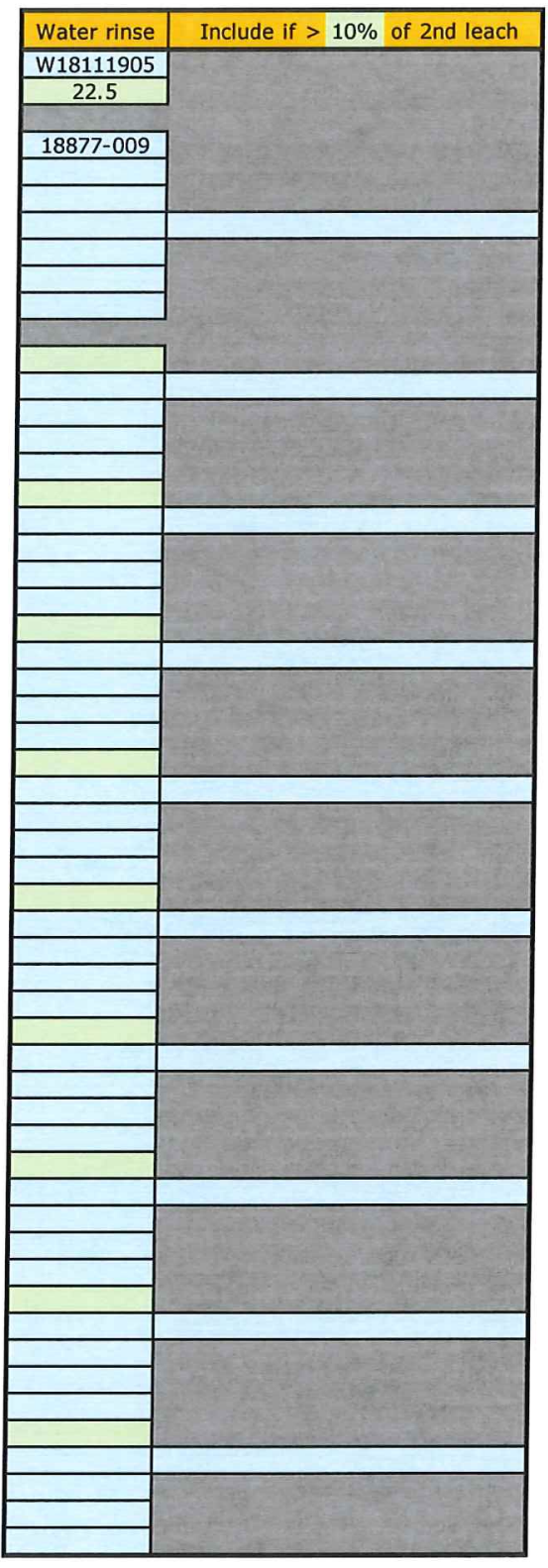


Data Report Form DRF-26B: Post-Burn Leach Uranium and Impurities

\begin{tabular}{|r|l|}
\hline Procedure: & AGR-CHAR-DAM-26 Rev. 3 \\
\hline Operator: & Montgomery \\
\hline Compact lot ID: & BWXT J52R-16-14154D \\
\hline Compact lot description: & AGR-5/6/7 compacts, 40\% packing fraction \\
\hline Compact ID numbers: & $1503,1518,1505,1534,1521$ \\
\hline DRF filename: & 14154 D PF40-Group 2 BL_ICPMS_DRF26R3.xIs \\
\hline
\end{tabular}

\begin{tabular}{|c|c|c|c|c|}
\hline \multicolumn{2}{|r|}{$\begin{array}{ll} & \text { Number of compacts: } \\
\end{array}$} & \multicolumn{3}{|c|}{5} \\
\hline \multirow{2}{*}{\multicolumn{2}{|c|}{$\begin{array}{l}\text { Average weight uranium per particle, mean value }(\mathrm{g}) \text { : } \\
\text { Average weight uranium per particle, uncertainty in mean }(\mathrm{g}):\end{array}$}} & \multicolumn{3}{|c|}{$3.94 \mathrm{E}-04$} \\
\hline & & \multicolumn{3}{|c|}{$3.94 \mathrm{E}-06$} \\
\hline & & First Leach & Second Leach & Total \\
\hline & Post-burn leach solution ID: & B18111502 & B18111902 & \\
\hline & Total volume of leach solution $(\mathrm{ml})$ : & 57.4 & 60.3 & \\
\hline & RMAL analysis number: & $18877-002$ & $18877-006$ & \\
\hline & Measured uranium concentration $(\mu \mathrm{g} / \mathrm{ml})$ : & $2.25 \mathrm{E}+01$ & $1.00 \mathrm{E}-01$ & \\
\hline & Uncertainty in uranium concentration $(\mu \mathrm{g} / \mathrm{ml})$ : & $2.25 \mathrm{E}+00$ & $1.00 \mathrm{E}-02$ & \\
\hline & Weight uranium leached $(\mathrm{g})$ : & $1.29 E-03$ & $6.05 \mathrm{E}-06$ & $1.30 \mathrm{E}-03$ \\
\hline & Uncertainty in weight uranium leached $(\mathrm{g})$ : & $1.30 \mathrm{E}-04$ & $6.08 \mathrm{E}-07$ & $1.30 \mathrm{E}-04$ \\
\hline & Equivalent number of leached kernels: & $3.28 \mathrm{E}+00$ & $1.53 \mathrm{E}-02$ & $3.29 \mathrm{E}+00$ \\
\hline & Uncertainty in equivalent number of leached kernels: & $3.31 \mathrm{E}-01$ & $1.55 \mathrm{E}-03$ & $3.31 \mathrm{E}-01$ \\
\hline \multirow{5}{*}{$\mathrm{Fe}$} & Measured concentration of impurity in sample $(\mu \mathrm{g} / \mathrm{ml})$ : & & & $\mathrm{Fe}$ \\
\hline & Uncorrected weight of impurity in sample $(\mu g)$ : & & & \\
\hline & Weight of impurity in blank $(\mu \mathrm{g})$ : & & & \\
\hline & Minimum corrected weight of impurity in sample $(\mu \mathrm{g})$ : & & & \\
\hline & Maximum corrected weight of impurity in sample $(\mu \mathrm{g})$ : & & & \\
\hline \multirow{5}{*}{$\mathbf{C r}$} & Measured concentration of impurity in sample $(\mu \mathrm{g} / \mathrm{ml})$ : & & & $\mathrm{Cr}$ \\
\hline & Uncorrected weight of impurity in sample $(\mu \mathrm{g})$ : & & & \\
\hline & Weight of impurity in blank $(\mu \mathrm{g})$ : & & & \\
\hline & Minimum corrected weight of impurity in sample $(\mu g)$ : & & & \\
\hline & Maximum corrected weight of impurity in sample $(\mu \mathrm{g})$ : & & & \\
\hline \multirow{5}{*}{ Mn } & Measured concentration of impurity in sample $(\mu \mathrm{g} / \mathrm{ml})$ : & & & Mn \\
\hline & Uncorrected weight of impurity in sample $(\mu \mathrm{g}):$ & & & \\
\hline & Weight of impurity in blank $(\mu \mathrm{g})$ : & & & \\
\hline & Minimum corrected weight of impurity in sample $(\mu \mathrm{g}):$ & & & \\
\hline & Maximum corrected weight of impurity in sample $(\mu \mathrm{g})$ : & & & \\
\hline \multirow{5}{*}{ Co } & Measured concentration of impurity in sample $(\mu \mathrm{g} / \mathrm{ml})$ : & & & Co \\
\hline & Uncorrected weight of impurity in sample $(\mu \mathrm{g})$ : & & & \\
\hline & Weight of impurity in blank $(\mu \mathrm{g}):$ & & & \\
\hline & Minimum corrected weight of impurity in sample $(\mu \mathrm{g})$ : & & & \\
\hline & Maximum corrected weight of impurity in sample $(\mu \mathrm{g})$ : & & & \\
\hline \multirow{5}{*}{$\mathbf{N i}$} & Measured concentration of impurity in sample $(\mu \mathrm{g} / \mathrm{ml})$ : & & & $\mathrm{Ni}$ \\
\hline & Uncorrected weight of impurity in sample $(\mu \mathrm{g})$ : & & & \\
\hline & Weight of impurity in blank $(\mu \mathrm{g})$ : & & & \\
\hline & Minimum corrected weight of impurity in sample $(\mu \mathrm{g})$ : & & & \\
\hline & Maximum corrected weight of impurity in sample $(\mu \mathrm{g})$ : & & & \\
\hline \multirow{5}{*}{$\mathrm{Ca}$} & Measured concentration of impurity in sample $(\mu \mathrm{g} / \mathrm{ml})$ : & & & $\mathrm{Ca}$ \\
\hline & Uncorrected weight of impurity in sample $(\mu \mathrm{g}):$ & & & \\
\hline & Weight of impurity in blank $(\mu \mathrm{g})$ : & & & \\
\hline & Minimum corrected weight of impurity in sample $(\mu \mathrm{g})$ : & & & \\
\hline & Maximum corrected weight of impurity in sample $(\mu \mathrm{g})$ : & & & \\
\hline \multirow{5}{*}{ Al } & Measured concentration of impurity in sample $(\mu \mathrm{g} / \mathrm{ml})$ : & & & Al \\
\hline & Uncorrected weight of impurity in sample $(\mu \mathrm{g})$ : & & & \\
\hline & Weight of impurity in blank $(\mu \mathrm{g})$ : & & & \\
\hline & Minimum corrected weight of impurity in sample $(\mu \mathrm{g})$ : & & & \\
\hline & Maximum corrected weight of impurity in sample $(\mu \mathrm{g})$ : & & & \\
\hline \multirow{5}{*}{$\mathbf{T i}$} & Measured concentration of impurity in sample $(\mu \mathrm{g} / \mathrm{ml})$ : & & & $\mathbf{T i}$ \\
\hline & Uncorrected weight of impurity in sample $(\mu \mathrm{g})$ : & & & \\
\hline & Weight of impurity in blank $(\mu \mathrm{g})$ : & & & \\
\hline & Minimum corrected weight of impurity in sample $(\mu \mathrm{g})$ : & & & \\
\hline & Maximum corrected weight of impurity in sample $(\mu \mathrm{g})$ : & & & \\
\hline \multirow{5}{*}{$\mathbf{v}$} & Measured concentration of impurity in sample $(\mu \mathrm{g} / \mathrm{ml})$ : & & & $\mathbf{v}$ \\
\hline & Uncorrected weight of impurity in sample $(\mu g)$ : & & & \\
\hline & Weight of impurity in blank $(\mu \mathrm{g})$ : & & & \\
\hline & Minimum corrected weight of impurity in sample $(\mu \mathrm{g})$ : & & & \\
\hline & Maximum corrected weight of impurity in sample $(\mu \mathrm{g})$ : & & & \\
\hline
\end{tabular}

Comments

Leached in Vessel \#32 (previously unused).

FCM checked the recorded data against the official Results of Analysis for RMAL18877 on 3/21/2019.

Shown is the result of the second ICPMS analyses of B18111502.

The first analysis results were rejected based on IDMS analysis.

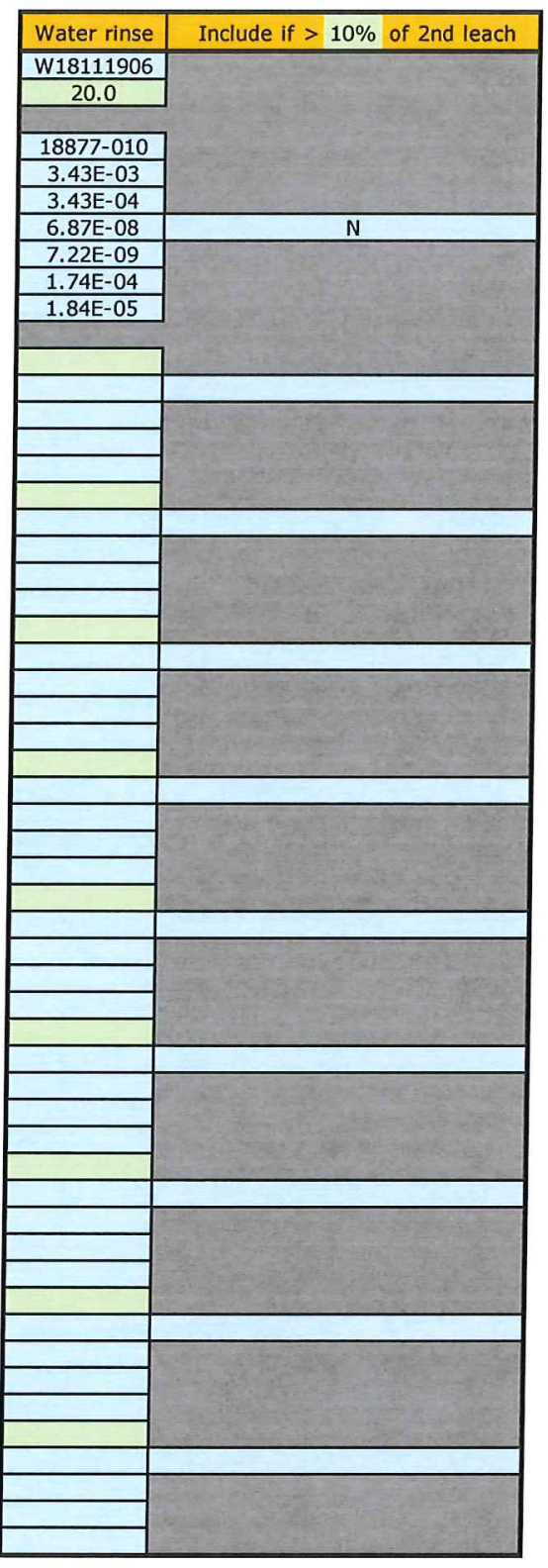

\section{Fied C. Montgomery}

\section{$4-18-2019$}


Data Report Form DRF-26B: Post-Burn Leach Uranium and Impurities

\begin{tabular}{|r|l|}
\hline Procedure: & AGR-CHAR-DAM-26 Rev. 3 \\
\hline Operator: & Montgomery \\
\hline Compact lot ID: & BWXT J52R-16-14154D \\
\hline Compact lot description: & AGR-5/6/7 compacts, 40\% packing fraction \\
\hline Compact ID numbers: & $1503,1518,1505,1534,1521$ \\
\hline DRF filename: & 14154 D_PF40-Group 2 BL_ICPMS_DRF26R3.xls \\
\hline
\end{tabular}

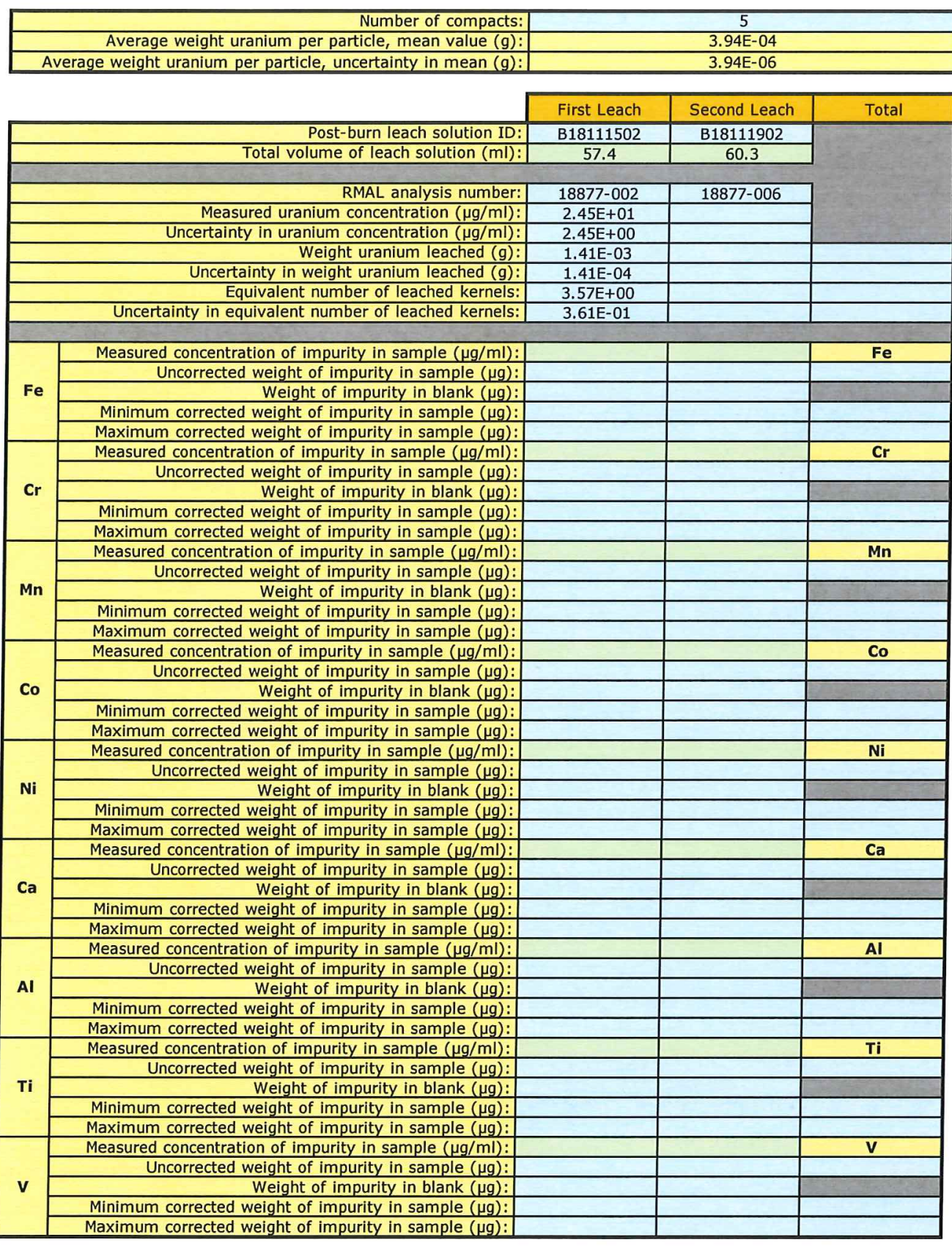

comments

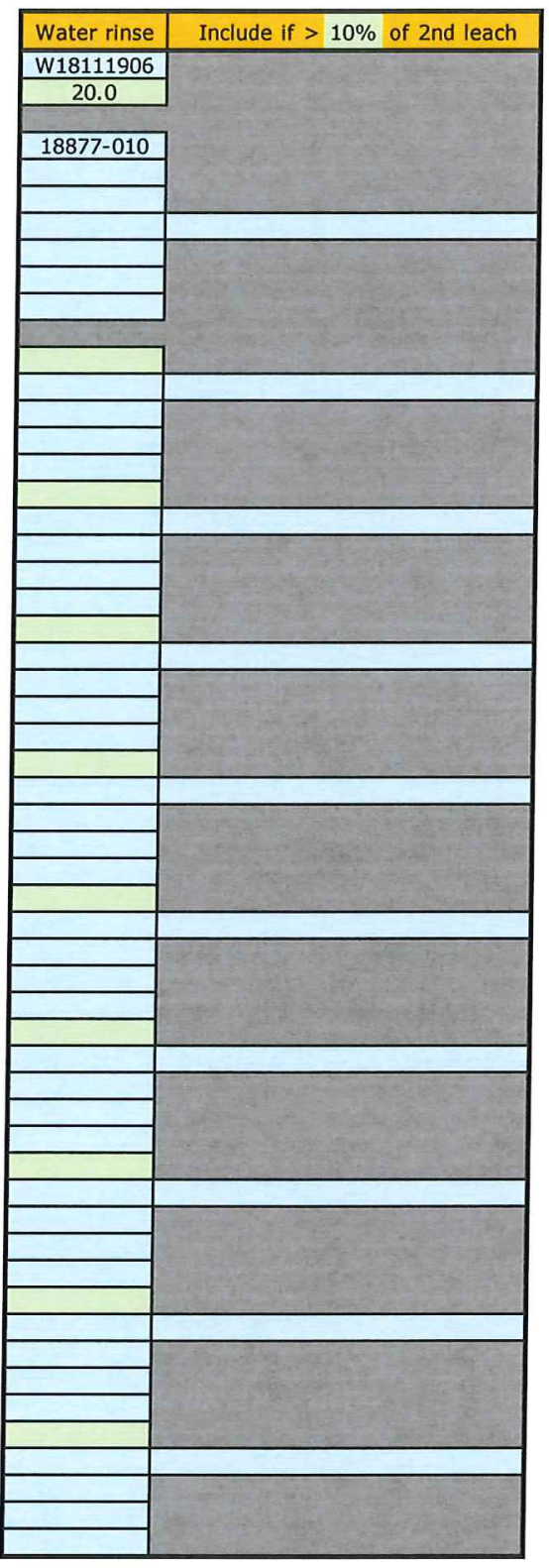

eached in Vessel \#32 (previously unused).

FCM checked the recorded data against the official Results of Analysis for RMAL18877 on 3/21/2019.

Shown is the result of the first ICPMS analysis of B18111502.

The first analysis results were rejected based on IDMS analysis.

\section{7ied C. Montgomeny $\frac{4-18-2019}{\text { Date }}$}




\section{Data Report Form DRF-26B: Post-Burn Leach Uranium and Impurities}

\begin{tabular}{|r|l|}
\hline Procedure: & AGR-CHAR-DAM-26 Rev. 3 \\
\hline Operator: & Montgomery \\
\hline Compact lot ID: & BWXT J52R-16-14154D \\
\hline Compact lot description: & AGR-5/6/7 compacts, 40\% packing fraction \\
\hline Compact ID numbers: & $1503,1518,1505,1534,1521$ \\
\hline DRF filename: & $14154 D \_$PF40-Group 2 BL_ICPMS_DRF26R3.xIs \\
\hline
\end{tabular}

\begin{tabular}{|r|c|}
\hline Number of compacts: & 5 \\
\hline Average weight uranium per particle, mean value $(\mathrm{g}):$ & $3.94 \mathrm{E}-04$ \\
\hline Average weight uranium per particle, uncertainty in mean $(\mathrm{g}):$ & $3.94 \mathrm{E}-06$ \\
\hline
\end{tabular}

\begin{tabular}{|c|c|c|c|c|}
\hline & First Leach & Second Leach & \multirow[t]{2}{*}{ Total } \\
\hline & Post-burn leach solution ID: & B18111502 & B18111902 & \\
\hline & Total volume of leach solution $(\mathrm{ml})$ : & 57.4 & 60.3 & \\
\hline & RMAL analysis number: & $18877-002$ & $18877-006$ & \\
\hline & Measured uranium concentration $(\mu \mathrm{g} / \mathrm{ml})$ : & $2.28 \mathrm{E}+01$ & & \\
\hline & Uncertainty in uranium concentration $(\mathrm{\mu g} / \mathrm{ml})$ : & $1.14 \mathrm{E}+00$ & & \\
\hline & Weight uranium leached $(\mathrm{g})$ : & $1.31 \mathrm{E}-03$ & & \\
\hline & Uncertainty in weight uranium leached $(\mathrm{g})$ : & $6.71 \mathrm{E}-05$ & & \\
\hline & Equivalent number of leached kernels: & $3.32 \mathrm{E}+00$ & & \\
\hline & Uncertainty in equivalent number of leached kernels: & $1.74 \mathrm{E}-01$ & & \\
\hline \multirow{5}{*}{$\mathbf{F e}$} & Measured concentration of impurity in sample $(\mu \mathrm{g} / \mathrm{ml})$ : & & & $\mathbf{F e}$ \\
\hline & Uncorrected weight of impurity in sample $(\mu \mathrm{g})$ : & & & \\
\hline & Weight of impurity in blank $(\mu \mathrm{g})$ : & & & \\
\hline & Minimum corrected weight of impurity in sample $(\mu \mathrm{g})$ : & & & \\
\hline & Maximum corrected weight of impurity in sample $(\mu \mathrm{g})$ : & & & \\
\hline \multirow{5}{*}{$\mathbf{C r}$} & Measured concentration of impurity in sample $(\mu \mathrm{g} / \mathrm{ml})$ : & & & $\mathrm{Cr}_{\mathbf{r}}$ \\
\hline & Uncorrected weight of impurity in sample $(\mu \mathrm{g})$ : & & & \\
\hline & Weight of impurity in blank $(\mu \mathrm{g})$ : & & & \\
\hline & Minimum corrected weight of impurity in sample $(\mu \mathrm{g})$ : & & & \\
\hline & Maximum corrected weight of impurity in sample $(\mu g)$ : & & & \\
\hline \multirow{5}{*}{ Mn } & Measured concentration of impurity in sample $(\mu \mathrm{g} / \mathrm{ml})$ : & & & Mn \\
\hline & Uncorrected weight of impurity in sample $(\mu \mathrm{g})$ : & & & \\
\hline & Weight of impurity in blank $(\mu \mathrm{g})$ : & & & \\
\hline & Minimum corrected weight of impurity in sample $(\mu \mathrm{g})$ : & & & \\
\hline & Maximum corrected weight of impurity in sample $(\mu \mathrm{g})$ : & & & \\
\hline \multirow{5}{*}{ Co } & Measured concentration of impurity in sample $(\mu \mathrm{g} / \mathrm{ml})$ : & & & Co \\
\hline & Uncorrected weight of impurity in sample $(\mu \mathrm{g})$ : & & & \\
\hline & Weight of impurity in blank $(\mu \mathrm{g})$ : & & & 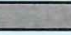 \\
\hline & Minimum corrected weight of impurity in sample $(\mu \mathrm{g})$ : & & & \\
\hline & Maximum corrected weight of impurity in sample $(\mu \mathrm{g})$ : & & & \\
\hline \multirow{5}{*}{$\mathbf{N i}$} & Measured concentration of impurity in sample $(\mu \mathrm{g} / \mathrm{ml})$ : & & & $\mathrm{Ni}$ \\
\hline & Uncorrected weight of impurity in sample $(\mu \mathrm{g})$ : & & & \\
\hline & Weight of impurity in blank $(\mu \mathrm{g})$ : & & & \\
\hline & Minimum corrected weight of impurity in sample $(\mu \mathrm{g})$ : & & & \\
\hline & Maximum corrected weight of impurity in sample $(\mu \mathrm{g})$ : & & & \\
\hline \multirow{5}{*}{ Ca } & Measured concentration of impurity in sample $(\mu \mathrm{g} / \mathrm{ml})$ : & & & $\mathrm{Ca}$ \\
\hline & Uncorrected weight of impurity in sample $(\mu \mathrm{g})$ : & & & \\
\hline & Weight of impurity in blank $(\mu \mathrm{g})$ : & & & \\
\hline & Minimum corrected weight of impurity in sample $(\mu \mathrm{g})$ : & & & \\
\hline & Maximum corrected weight of impurity in sample $(\mu \mathrm{g})$ : & & & \\
\hline \multirow{5}{*}{ Al } & Measured concentration of impurity in sample $(\mu \mathrm{g} / \mathrm{ml})$ : & & & Al \\
\hline & Uncorrected weight of impurity in sample $(\mu \mathrm{g})$ : & & & \\
\hline & Weight of impurity in blank $(\mu \mathrm{g})$ : & & & \\
\hline & Minimum corrected weight of impurity in sample $(\mu \mathrm{g})$ : & & & \\
\hline & Maximum corrected weight of impurity in sample $(\mu g)$ : & & & \\
\hline \multirow{5}{*}{$\mathbf{T i}$} & Measured concentration of impurity in sample $(\mu \mathrm{g} / \mathrm{ml})$ : & & & Ti \\
\hline & Uncorrected weight of impurity in sample $(\mu \mathrm{g})$ : & & & \\
\hline & Weight of impurity in blank $(\mu \mathrm{gg})$ : & & & \\
\hline & Minimum corrected weight of impurity in sample $(\mu \mathrm{g})$ : & & & \\
\hline & Maximum corrected weight of impurity in sample $(\mu \mathrm{g})$ : & & & \\
\hline \multirow{5}{*}{$\mathbf{v}$} & Measured concentration of impurity in sample $(\mu \mathrm{g} / \mathrm{ml})$ : & & & $\mathbf{v}$ \\
\hline & Uncorrected weight of impurity in sample $(\mu \mathrm{g})$ : & & & \\
\hline & Weight of impurity in blank $(\mu g)$ : & & & \\
\hline & Minimum corrected weight of impurity in sample $(\mu \mathrm{g})$ : & & & \\
\hline & Maximum corrected weight of impurity in sample $(\mu \mathrm{g})$ : & & & \\
\hline
\end{tabular}

\section{Comments}

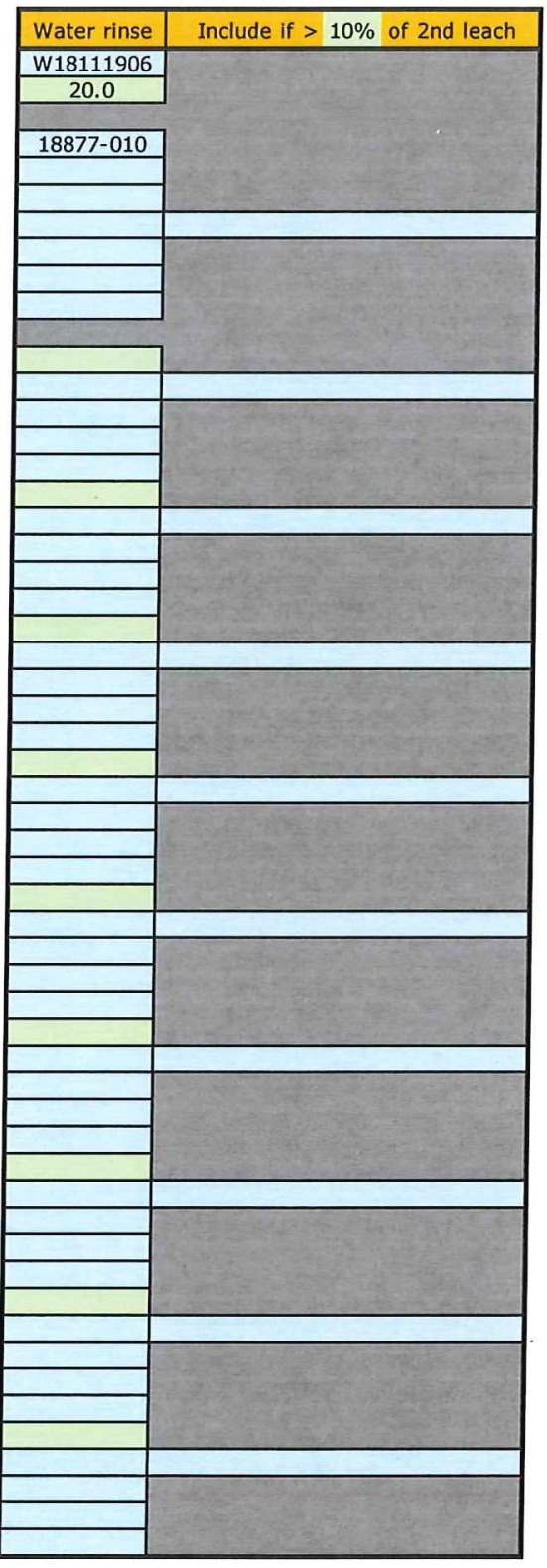

Leached in Vessel \#32 (previously unused).

FCM checked the recorded data against the official Results of Analysis for RMAL18877 on 3/21/2019.

Shown is the result of the isotope dilution mass spectrometry analysis of B18111502.

\section{Fied C. Montgomuy}

$4-18-2019$ 


\section{Data Report Form DRF-26B: Post-Burn Leach Uranium and Impurities}

\begin{tabular}{|r|l|}
\hline Procedure: & AGR-CHAR-DAM-26 Rev. 3 \\
\hline Operator: & Montgomery \\
\hline Compact lot ID: & BWXT J52R-16-14154D \\
\hline Compact lot description: & AGR-5/6/7 compacts, 40\% packing fraction \\
\hline Compact ID numbers: & $1537,1535,1540,1502,1509$ \\
\hline DRF filename: & $14154 D \_P F 40-G r o u p 2$ BL_ICPMS_DRF26R3.xls \\
\hline
\end{tabular}

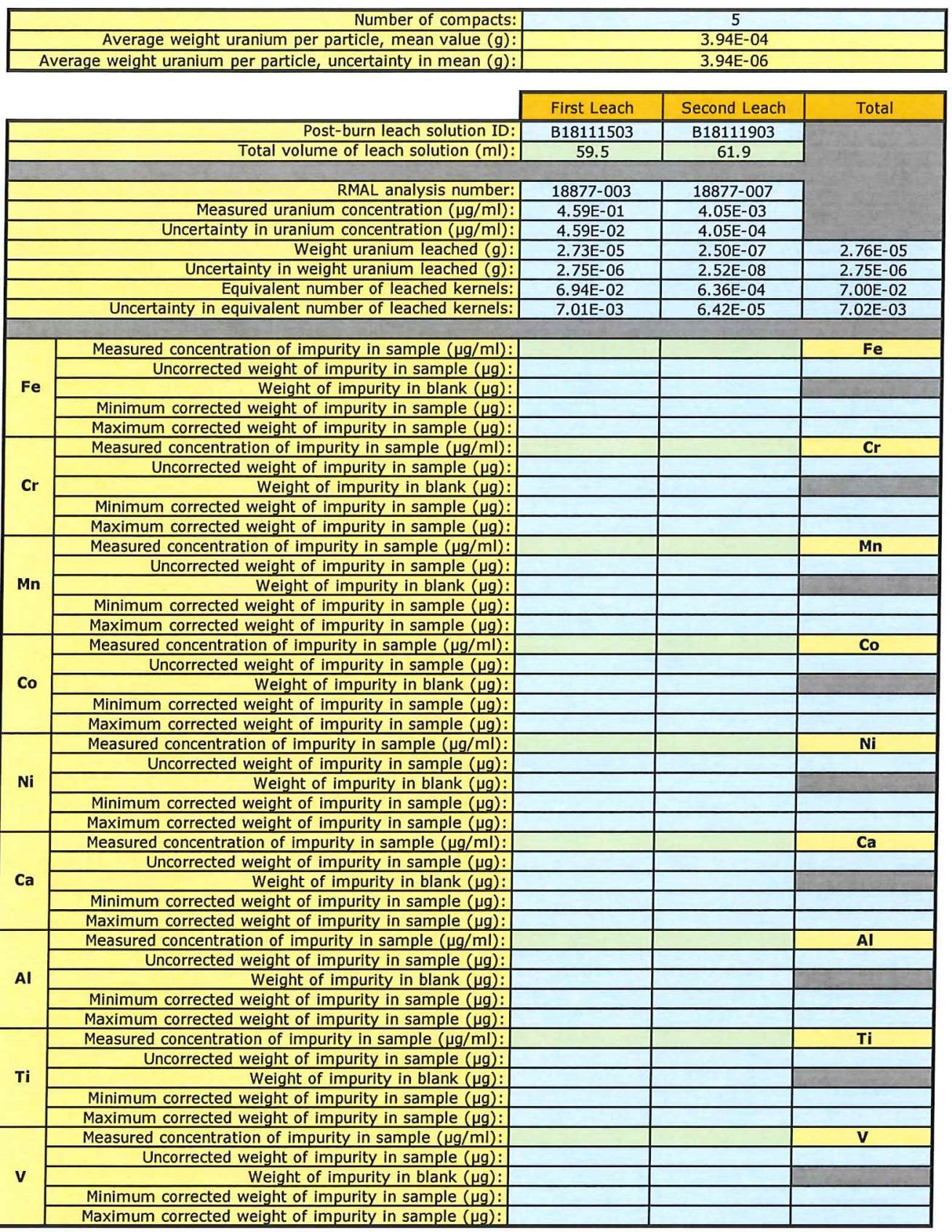

\section{comments}

Leached in Vessel \#33 (previously unused).

FCM checked the recorded data against the official Results of Analysis for RMAL18877 on 3/21/2019.

Shown is the result of the second ICPMS analyses of B18111503.

The first analysis results were rejected based on IDMS analysis.

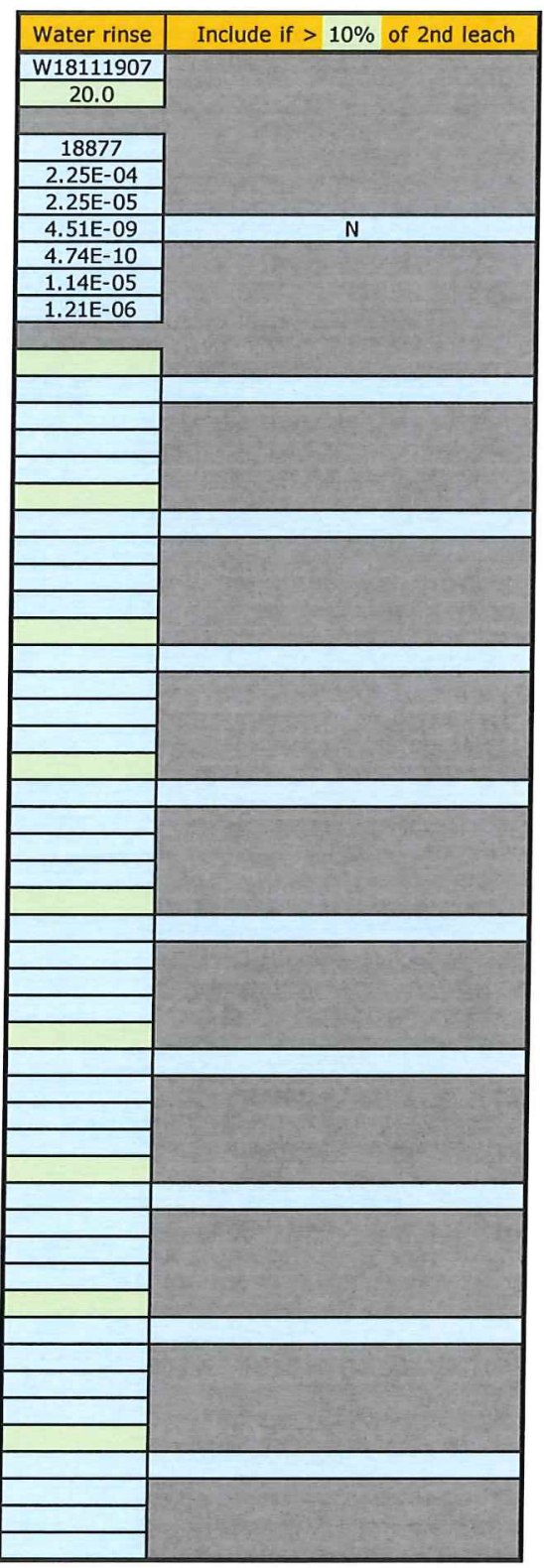

\section{Fied C. Montgomeny}

\section{$4-18-2019$}


Data Report Form DRF-26B: Post-Burn Leach Uranium and Impurities

\begin{tabular}{|r|l|}
\hline Procedure: & AGR-CHAR-DAM-26 Rev. 3 \\
\hline Operator: & Montgomery \\
\hline Compact lot ID: & BWXT J52R-16-14154D \\
\hline Compact lot description: & AGR-5/6/7 compacts, 40\% packing fraction \\
\hline Compact ID numbers: & $1537,1535,1540,1502,1509$ \\
\hline DRF filename: & $14154 \mathrm{D}$ PPF40-Group 2_BL_ICPMS_DRF26R3.xls \\
\hline
\end{tabular}

\begin{tabular}{r|}
\hline Number of compacts: \\
\hline Average weight uranium per particle, mean value $(g)$ :
\end{tabular} Average weight uranium per particle, uncertainty in mean $(g)$ :

\begin{tabular}{|c|c|c|c|c|}
\hline & 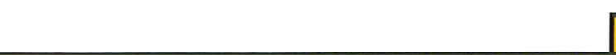 & First Leach & Second Leach & Total \\
\hline & Post-burn leach solution ID: & B18111503 & B18111903 & \\
\hline & Total volume of leach solution $(\mathrm{ml}):$ & 59.5 & 61.9 & \\
\hline & RMAL analysis number: & $18877-003$ & $18877-007$ & \\
\hline & Measured uranium concentration $(\mu \mathrm{g} / \mathrm{ml})$ : & $5.45 \mathrm{E}-01$ & & \\
\hline & Uncertainty in uranium concentration $(\mu \mathrm{g} / \mathrm{ml})$ : & $5.45 \mathrm{E}-02$ & & \\
\hline & Weight uranium leached $(\mathrm{g}):$ & $3.24 \mathrm{E}-05$ & & \\
\hline & Uncertainty in weight uranium leached $(\mathrm{g})$ : & $3.26 \mathrm{E}-06$ & & \\
\hline & Equivalent number of leached kernels: & $8.23 E-02$ & & \\
\hline & Uncertainty in equivalent number of leached kernels: & $8.32 \mathrm{E}-03$ & & \\
\hline \multirow{5}{*}{$\mathrm{Fe}$} & Measured concentration of impurity in sample $(\mu \mathrm{g} / \mathrm{ml})$ : & & & Fe \\
\hline & Uncorrected weight of impurity in sample $(\mu \mathrm{g})$ : & & & \\
\hline & Weight of impurity in blank $(\mu \mathrm{g})$ : & & & \\
\hline & Minimum corrected weight of impurity in sample $(\mu g)$ : & & & \\
\hline & Maximum corrected weight of impurity in sample $(\mu \mathrm{g}):$ & & & \\
\hline \multirow{5}{*}{$\mathbf{C r}$} & Measured concentration of impurity in sample $(\mu \mathrm{g} / \mathrm{ml})$ : & & & $\mathbf{C r}$ \\
\hline & Uncorrected weight of impurity in sample $(\mu \mathrm{g})$ : & & & \\
\hline & Weight of impurity in blank $(\mu \mathrm{g})$ : & & & \\
\hline & Minimum corrected weight of impurity in sample $(\mu \mathrm{g})$ : & & & \\
\hline & Maximum corrected weight of impurity in sample $(\mu g)$ : & & & \\
\hline \multirow{5}{*}{ Mn } & Measured concentration of impurity in sample $(\mu \mathrm{g} / \mathrm{ml})$ : & & & Mn \\
\hline & Uncorrected weight of impurity in sample $(\mu \mathrm{g})$ : & & & \\
\hline & Weight of impurity in blank $(\mu g)$ : & & & \\
\hline & Minimum corrected weight of impurity in sample $(\mu \mathrm{g}):$ & & & \\
\hline & Maximum corrected weight of impurity in sample $(\mu \mathrm{g})$ : & & & \\
\hline \multirow{5}{*}{ Co } & Measured concentration of impurity in sample $(\mu \mathrm{g} / \mathrm{ml})$ : & & & Co \\
\hline & Uncorrected weight of impurity in sample $(\mu \mathrm{g})$ : & & & \\
\hline & Weight of impurity in blank $(\mu \mathrm{g})$ : & & & \\
\hline & Minimum corrected weight of impurity in sample $(\mu \mathrm{g})$ : & & & \\
\hline & Maximum corrected weight of impurity in sample $(\mu \mathrm{g}):$ & & & \\
\hline \multirow{5}{*}{$\mathbf{N i}$} & Measured concentration of impurity in sample $(\mu \mathrm{g} / \mathrm{ml})$ : & & & $\mathrm{Ni}$ \\
\hline & Uncorrected weight of impurity in sample $(\mu \mathrm{g})$ : & & & \\
\hline & Weight of impurity in blank $(\mu \mathrm{g})$ : & & & \\
\hline & Minimum corrected weight of impurity in sample $(\mu \mathrm{g})$ : & & & \\
\hline & Maximum corrected weight of impurity in sample $(\mu \mathrm{g})$ : & & & \\
\hline \multirow{5}{*}{$\mathbf{C a}$} & Measured concentration of impurity in sample $(\mu \mathrm{g} / \mathrm{ml})$ : & & & $\mathbf{C a}$ \\
\hline & Uncorrected weight of impurity in sample $(\mu \mathrm{g})$ : & & & \\
\hline & Weight of impurity in blank $(\mu \mathrm{g})$ : & & & \\
\hline & Minimum corrected weight of impurity in sample $(\mu \mathrm{g})$ : & & & \\
\hline & Maximum corrected weight of impurity in sample $(\mu \mathrm{g})$ : & & & \\
\hline \multirow{5}{*}{ Al } & Measured concentration of impurity in sample $(\mu \mathrm{g} / \mathrm{ml})$ : & & & Al \\
\hline & Uncorrected weight of impurity in sample $(\mu \mathrm{g})$ : & & & \\
\hline & Weight of impurity in blank $(\mu \mathrm{g})$ : & & & \\
\hline & Minimum corrected weight of impurity in sample $(\mu \mathrm{g})$ : & & & \\
\hline & Maximum corrected weight of impurity in sample $(\mu \mathrm{g})$ : & & & \\
\hline \multirow{5}{*}{$\mathbf{T i}$} & Measured concentration of impurity in sample $(\mu \mathrm{g} / \mathrm{ml})$ : & & & Ti \\
\hline & Uncorrected weight of impurity in sample $(\mu \mathrm{g})$ : & & & \\
\hline & Weight of impurity in blank $(\mu \mathrm{g})$ : & & & \\
\hline & Minimum corrected weight of impurity in sample $(\mu \mathrm{g})$ : & & & \\
\hline & Maximum corrected weight of impurity in sample $(\mu \mathrm{g})$ : & & & \\
\hline \multirow{5}{*}{$\mathbf{v}$} & Measured concentration of impurity in sample $(\mu \mathrm{g} / \mathrm{ml}):$ & & & $\mathbf{V}$ \\
\hline & Uncorrected weight of impurity in sample $(\mu \mathrm{g}):$ & & & \\
\hline & Weight of impurity in blank $(\mu \mathrm{g}):$ & & & \\
\hline & Minimum corrected weight of impurity in sample $(\mu \mathrm{g})$ : & & & \\
\hline & Maximum corrected weight of impurity in sample $(\mu \mathrm{g}):$ & & & \\
\hline
\end{tabular}

\section{Comments}

Leached in Vessel \#33 (previously unused).

FCM checked the recorded data against the official Results of Analysis for RMAL18877 on 3/21/2019.

Shown is the result of the first ICPMS analysis of B18111503.

The first analysis results were rejected based on IDMS analysis

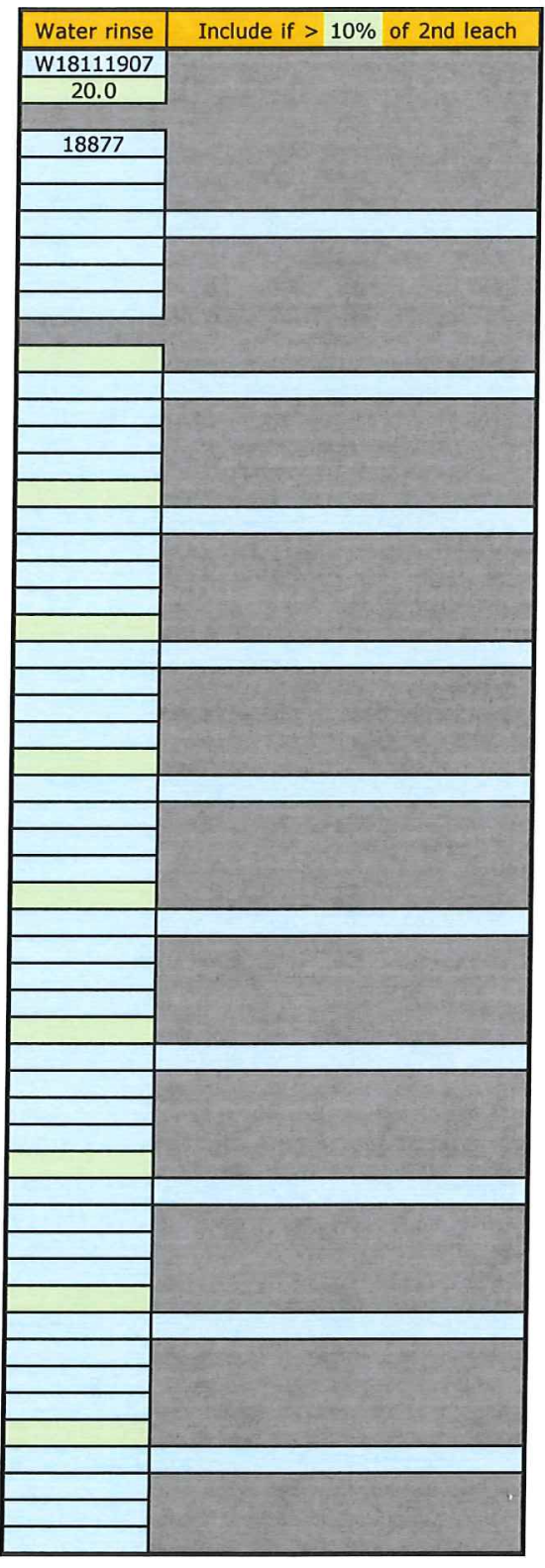

\section{Fued c. Montgomey} Operator

\section{$4-18-2019$}

Date 


\section{Data Report Form DRF-26B: Post-Burn Leach Uranium and Impurities}

\begin{tabular}{|r|l|}
\hline Procedure: & AGR-CHAR-DAM-26 Rev. 3 \\
\hline Operator: & Montgomery \\
\hline Compact lot ID: & BWXT J52R-16-14154D \\
\hline Compact lot description: & AGR-5/6/7 compacts, 40\% packing fraction \\
\hline Compact ID numbers: & $1522,1531,1543,1532,1525$ \\
\hline DRF filename: & $14154 D \_P F 40-G r o u p 2$ BL_ICPMS_DRF26R3.xIs \\
\hline
\end{tabular}

\begin{tabular}{|r|c|}
\hline Number of compacts: & 5 \\
\hline Average weight uranium per particle, mean value $(\mathrm{g}):$ & $3.94 \mathrm{E}-04$ \\
\hline Average weight uranium per particle, uncertainty in mean $(\mathrm{g}):$ & $3.94 \mathrm{E}-06$ \\
\hline
\end{tabular}

\begin{tabular}{|c|c|c|c|c|}
\hline & & & & \\
\hline & & First Leach & Second Leach & Total \\
\hline & Post-burn leach solution ID: & B18111504 & B18111904 & \\
\hline & Total volume of leach solution $(\mathrm{ml})$ : & 59.3 & 62.3 & \\
\hline & RMAL analysis number: & $18877-004$ & $18877-008$ & \\
\hline & Measured uranium concentration $(\mu \mathrm{g} / \mathrm{ml})$ : & $7.44 E+00$ & $4.19 \mathrm{E}-02$ & \\
\hline & Uncertainty in uranium concentration $(\mu \mathrm{g} / \mathrm{ml})$ : & $7.44 \mathrm{E}-01$ & $4.19 \mathrm{E}-03$ & \\
\hline & Weight uranium leached $(\mathrm{g})$ : & $4.41 \mathrm{E}-04$ & $2.61 \mathrm{E}-06$ & $4.44 \mathrm{E}-04$ \\
\hline & Uncertainty in weight uranium leached $(\mathrm{g})$ : & $4.44 \mathrm{E}-05$ & $2.63 \mathrm{E}-07$ & $4.44 \mathrm{E}-05$ \\
\hline & Equivalent number of leached kernels: & $1.12 \mathrm{E}+00$ & $6.63 \mathrm{E}-03$ & $1.13 \mathrm{E}+00$ \\
\hline & Uncertainty in equivalent number of leached kernels: & $1.13 \mathrm{E}-01$ & $6.70 \mathrm{E}-04$ & $1.13 \mathrm{E}-01$ \\
\hline \multirow{5}{*}{ Fe } & Measured concentration of impurity in sample $(\mu \mathrm{g} / \mathrm{ml})$ : & & & $\mathrm{Fe}$ \\
\hline & Uncorrected weight of impurity in sample $(\mu \mathrm{g})$ : & & & \\
\hline & Weight of impurity in blank $(\mu \mathrm{g})$ : & & & \\
\hline & Minimum corrected weight of impurity in sample $(\mu \mathrm{g})$ : & & & \\
\hline & Maximum corrected weight of impurity in sample $(\mu \mathrm{g})$ : & & & \\
\hline \multirow{5}{*}{$\mathrm{Cr}$} & Measured concentration of impurity in sample $(\mu \mathrm{g} / \mathrm{ml})$ : & & & $\mathrm{Cr}$ \\
\hline & Uncorrected weight of impurity in sample $(\mu \mathrm{g})$ : & & & \\
\hline & Weight of impurity in blank $(\mu \mathrm{g})$ : & & & \\
\hline & Minimum corrected weight of impurity in sample $(\mu \mathrm{g})$ : & & & \\
\hline & Maximum corrected weight of impurity in sample $(\mu \mathrm{g})$ : & & & \\
\hline \multirow{5}{*}{ Mn } & Measured concentration of impurity in sample $(\mu \mathrm{g} / \mathrm{ml})$ : & & & Mn \\
\hline & Uncorrected weight of impurity in sample $(\mu \mathrm{g})$ : & & & \\
\hline & Weight of impurity in blank $(\mu \mathrm{g})$ : & & & \\
\hline & Minimum corrected weight of impurity in sample $(\mu g)$ : & & & \\
\hline & Maximum corrected weight of impurity in sample $(\mu \mathrm{g})$ : & & & \\
\hline \multirow{5}{*}{ Co } & Measured concentration of impurity in sample $(\mu \mathrm{g} / \mathrm{ml})$ : & & & Co \\
\hline & Uncorrected weight of impurity in sample $(\mu \mathrm{g})$ : & & & \\
\hline & Weight of impurity in blank $(\mu \mathrm{g})$ : & & & \\
\hline & Minimum corrected weight of impurity in sample $(\mu \mathrm{g})$ : & & & \\
\hline & Maximum corrected weight of impurity in sample $(\mu \mathrm{g})$ : & & & \\
\hline \multirow{5}{*}{$\mathbf{N i}$} & Measured concentration of impurity in sample $(\mu \mathrm{g} / \mathrm{ml})$ : & & & $\mathrm{Ni}$ \\
\hline & Uncorrected weight of impurity in sample $(\mu \mathrm{g})$ : & & & \\
\hline & Weight of impurity in blank $(\mu \mathrm{g})$ : & & & \\
\hline & Minimum corrected weight of impurity in sample $(\mu \mathrm{g})$ : & & & \\
\hline & Maximum corrected weight of impurity in sample $(\mu g)$ : & & & \\
\hline \multirow{5}{*}{$\mathbf{C a}$} & Measured concentration of impurity in sample $(\mu \mathrm{g} / \mathrm{ml})$ : & & & $\mathrm{Ca}$ \\
\hline & Uncorrected weight of impurity in sample $(\mu \mathrm{g})$ : & & & \\
\hline & Weight of impurity in blank $(\mu g)$ : & & & \\
\hline & Minimum corrected weight of impurity in sample $(\mu \mathrm{g})$ : & & & \\
\hline & Maximum corrected weight of impurity in sample $(\mu \mathrm{g})$ : & & & \\
\hline \multirow{5}{*}{ Al } & Measured concentration of impurity in sample $(\mu \mathrm{g} / \mathrm{ml})$ : & & & Al \\
\hline & Uncorrected weight of impurity in sample $(\mu \mathrm{g})$ : & & & \\
\hline & Weight of impurity in blank $(\mu g)$ : & & & \\
\hline & Minimum corrected weight of impurity in sample $(\mu \mathrm{g})$ : & & & \\
\hline & Maximum corrected weight of impurity in sample $(\mu \mathrm{g}):$ & & & \\
\hline \multirow{5}{*}{$\mathbf{T i}$} & Measured concentration of impurity in sample $(\mu \mathrm{g} / \mathrm{ml})$ : & & & $\mathbf{T i}$ \\
\hline & Uncorrected weight of impurity in sample $(\mu \mathrm{g})$ : & & & \\
\hline & Weight of impurity in blank $(\mu \mathrm{g})$ : & & & \\
\hline & Minimum corrected weight of impurity in sample $(\mu \mathrm{g})$ : & & & \\
\hline & Maximum corrected weight of impurity in sample $(\mu g)$ : & & & \\
\hline \multirow{5}{*}{$\mathbf{v}$} & Measured concentration of impurity in sample $(\mu \mathrm{g} / \mathrm{ml})$ : & & & $\mathbf{V}$ \\
\hline & Uncorrected weight of impurity in sample $(\mu \mathrm{g})$ : & & & \\
\hline & Weight of impurity in blank $(\mu \mathrm{g}):$ & & & \\
\hline & Minimum corrected weight of impurity in sample $(\mu \mathrm{g})$ : & & & \\
\hline & Maximum corrected weight of impurity in sample $(\mu \mathrm{g}): 1$ & & & \\
\hline
\end{tabular}

\section{Comments}

Leached in Vessel \#30 (previously unused).

FCM checked the recorded data against the official Results of Analysis for RMAL18877 on 3/21/2019.

Shown is the result of the second ICPMS analyses of B18111504.

The first analysis results were rejected based on IDMS analysis.

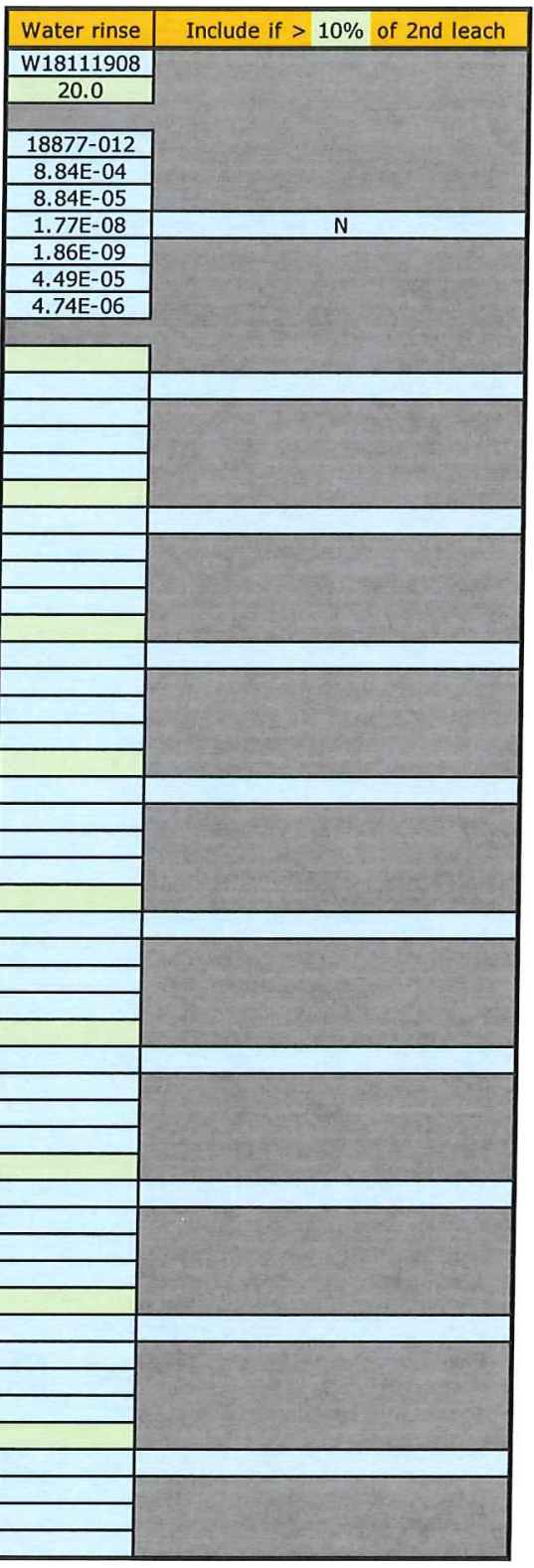

\section{Feed C. Montgomeens}

\section{$4-18-2019$}

Date 
Data Report Form DRF-26B: Post-Burn Leach Uranium and Impurities

\begin{tabular}{|r|l|}
\hline Procedure: & AGR-CHAR-DAM-26 Rev. 3 \\
\hline Operator: & Montgomery \\
\hline Compact lot ID: & BWXT J52R-16-14154D \\
\hline Compact lot description: & AGR-5/6/7 compacts, 40\% packing fraction \\
\hline Compact ID numbers: & $1522,1531,1543,1532,1525$ \\
\hline DRF filename: & 14154 D_PF40-Group 2_BL_ICPMS_DRF26R3,xIs \\
\hline
\end{tabular}

\begin{tabular}{|r|c|}
\hline Number of compacts: & 5 \\
\hline Average weight uranium per particle, mean value $(\mathrm{g}):$ & $3.94 \mathrm{E}-04$ \\
\hline Average weight uranium per particle, uncertainty in mean $(\mathrm{g}):$ & $3.94 \mathrm{E}-06$ \\
\hline
\end{tabular}

\begin{tabular}{|c|c|c|c|c|}
\hline & First Leach & Second Leach & Total \\
\hline & Post-burn leach solution ID: & B18111504 & B18111904 & \\
\hline & Total volume of leach solution $(\mathrm{ml})$ : & 59.3 & 62.3 & \\
\hline & RMAL analysis number: & $18877-004$ & $18877-008$ & \\
\hline & Measured uranium concentration $(\mu \mathrm{g} / \mathrm{ml})$ : & $8.57 E+00$ & & \\
\hline & Uncertainty in uranium concentration $(\mu \mathrm{g} / \mathrm{ml})$ : & $8.57 \mathrm{E}-01$ & & \\
\hline & Weight uranium leached $(g)$ : & $5.08 \mathrm{E}-04$ & & \\
\hline & Uncertainty in weight uranium leached $(\mathrm{g})$ : & $5.11 \mathrm{E}-05$ & & \\
\hline & Equivalent number of leached kernels: & $1.29 \mathrm{E}+00$ & & \\
\hline & Uncertainty in equivalent number of leached kernels: & $1.30 \mathrm{E}-01$ & & \\
\hline \multirow{5}{*}{$\mathbf{F e}$} & Measured concentration of impurity in sample $(\mu \mathrm{g} / \mathrm{ml})$ : & & & $\mathrm{Fe}$ \\
\hline & Uncorrected weight of impurity in sample $(\mu \mathrm{g})$ : & & & $\mathrm{Fe}$ \\
\hline & Weight of impurity in blank $(\mu \mathrm{g})$ : & & & \\
\hline & Minimum corrected weight of impurity in sample $(\mu \mathrm{g})$ : & & & \\
\hline & Maximum corrected weight of impurity in sample $(\mu \mathrm{g})$ : & & & \\
\hline \multirow{5}{*}{$\mathbf{C r}$} & Measured concentration of impurity in sample $(\mu \mathrm{g} / \mathrm{ml})$ : & & & $\mathbf{C r}$ \\
\hline & Uncorrected weight of impurity in sample $(\mu \mathrm{g})$ : & & & \\
\hline & Weight of impurity in blank $(\mu \mathrm{g})$ : & & & \\
\hline & Minimum corrected weight of impurity in sample $(\mu \mathrm{g})$ : & & & \\
\hline & Maximum corrected weight of impurity in sample $(\mu g)$ : & & & \\
\hline \multirow{5}{*}{ Mn } & Measured concentration of impurity in sample $(\mu \mathrm{g} / \mathrm{ml})$ : & & & $\mathbf{M n}$ \\
\hline & Uncorrected weight of impurity in sample $(\mu \mathrm{g})$ : & & & \\
\hline & Weight of impurity in blank $(\mu \mathrm{g})$ : & & & \\
\hline & Minimum corrected weight of impurity in sample $(\mu \mathrm{g})$ : & & & \\
\hline & Maximum corrected weight of impurity in sample $(\mu \mathrm{g})$ : & & & \\
\hline \multirow{5}{*}{ Co } & Measured concentration of impurity in sample $(\mu \mathrm{g} / \mathrm{ml})$ : & & & Co \\
\hline & Uncorrected weight of impurity in sample $(\mu \mathrm{g})$ : & & & \\
\hline & Weight of impurity in blank $(\mu \mathrm{g})$ : & & & \\
\hline & Minimum corrected weight of impurity in sample $(\mu \mathrm{g})$ : & & & \\
\hline & Maximum corrected weight of impurity in sample $(\mu \mathrm{g})$ : & & & \\
\hline \multirow{5}{*}{$\mathbf{N i}$} & Measured concentration of impurity in sample $(\mu \mathrm{g} / \mathrm{ml})$ : & & & $\mathbf{N i}$ \\
\hline & Uncorrected weight of impurity in sample $(\mu \mathrm{g})$ : & & & \\
\hline & Weight of impurity in blank $(\mu g)$ : & & & \\
\hline & Minimum corrected weight of impurity in sample $(\mu \mathrm{g})$ : & & & \\
\hline & Maximum corrected weight of impurity in sample $(\mu \mathrm{g})$ : & & & \\
\hline \multirow{5}{*}{$\mathrm{Ca}$} & Measured concentration of impurity in sample $(\mu \mathrm{g} / \mathrm{ml})$ : & & & $\mathbf{C a}$ \\
\hline & Uncorrected weight of impurity in sample $(\mu \mathrm{g})$ : & & & \\
\hline & Weight of impurity in blank $(\mu \mathrm{g})$ : & & & \\
\hline & Minimum corrected weight of impurity in sample $(\mu \mathrm{g})$ : & & & \\
\hline & Maximum corrected weight of impurity in sample $(\mu \mathrm{g})$ : & & & \\
\hline \multirow{5}{*}{ Al } & Measured concentration of impurity in sample $(\mu \mathrm{g} / \mathrm{ml})$ : & & & Al \\
\hline & Uncorrected weight of impurity in sample $(\mu \mathrm{g})$ : & & & \\
\hline & Weight of impurity in blank $(\mu \mathrm{g})$ : & & & \\
\hline & Minimum corrected weight of impurity in sample $(\mu \mathrm{g})$ : & & & \\
\hline & Maximum corrected weight of impurity in sample $(\mu \mathrm{g})$ : & & & \\
\hline \multirow{5}{*}{$\mathbf{T i}$} & Measured concentration of impurity in sample $(\mu \mathrm{g} / \mathrm{ml})$ : & & & $\mathbf{T i}$ \\
\hline & Uncorrected weight of impurity in sample $(\mu g)$ : & & & \\
\hline & Weight of impurity in blank $(\mu \mathrm{g})$ : & & & \\
\hline & Minimum corrected weight of impurity in sample $(\mu g)$ : & & & \\
\hline & Maximum corrected weight of impurity in sample $(\mu \mathrm{g})$ : & & & \\
\hline \multirow{5}{*}{$\mathbf{v}$} & Measured concentration of impurity in sample $(\mu \mathrm{g} / \mathrm{ml})$ : & & & $\mathbf{v}$ \\
\hline & Uncorrected weight of impurity in sample $(\mu \mathrm{g})$ : & & & \\
\hline & Weight of impurity in blank $(\mu \mathrm{g})$ : & & & \\
\hline & Minimum corrected weight of impurity in sample $(\mu \mathrm{g})$ : & & & \\
\hline & Maximum corrected weight of impurity in sample $(\mu \mathrm{g})$ : & & & \\
\hline
\end{tabular}

comments

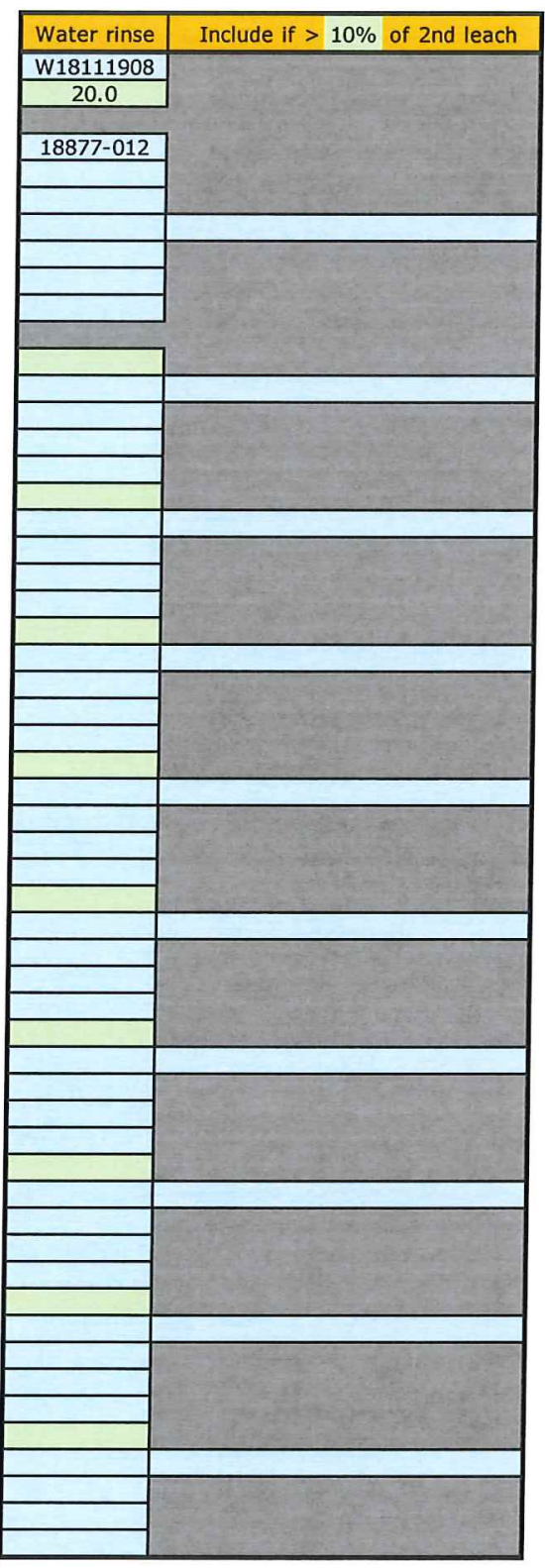

Leached in Vessel \#30 (previously unused).

FCM checked the recorded data against the official Results of Analysis for RMAL18877 on 3/21/2019.

Shown is the result of the first ICPMS analysis of B18111504.

The first analysis results were rejected based on IDMS analysis.

\section{Feed C. Montgomery}

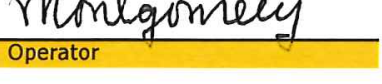

$$
4-18-2019
$$




\section{Data Report Form DRF-26B: Post-Burn Leach Uranium and Impurities}

\begin{tabular}{|r|l|}
\hline Procedure: & AGR-CHAR-DAM-26 Rev. 3 \\
\hline Operator: & Montgomery \\
\hline Compact lot ID: & BWXT J52R-16-14155D \\
\hline Compact lot description: & AGR-5/6/7 compacts, 40\% packing fraction \\
\hline Compact ID numbers: & $1659,1648,1670,1655,1662$ \\
\hline DRF filename: & 14155 D PF40-Group 1 BL_ICPMS_DRF26R3.xls \\
\hline
\end{tabular}

\begin{tabular}{r|}
\hline \\
Number of compacts: \\
\hline Average weight uranium per particle, mean value $(g):$
\end{tabular}

Average weight uranium per particle, uncertainty in mean $(g)$

\begin{tabular}{|c|c|c|c|c|}
\hline & 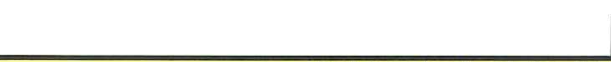 & First Leach & Second Leach & Total \\
\hline & Post-burn leach solution ID: & B18112801 & B18113001 & \\
\hline & Total volume of leach solution $(\mathrm{ml})$ : & 59.5 & 61.5 & \\
\hline & RMAL analysis number: & $18892-001$ & $18892-005$ & \\
\hline & Measured uranium concentration $(\mu \mathrm{g} / \mathrm{ml})$ : & $1.46 \mathrm{E}+01$ & $4.83 \mathrm{E}-02$ & \\
\hline & Uncertainty in uranium concentration $(\mu \mathrm{g} / \mathrm{ml})$ : & $1.46 \mathrm{E}+00$ & $4.83 E-03$ & \\
\hline & Weight uranium leached $(\mathrm{g})$ : & $8.69 \mathrm{E}-04$ & $2.97 \mathrm{E}-06$ & $8.72 \mathrm{E}-04$ \\
\hline & Uncertainty in weight uranium leached $(\mathrm{g})$ : & $8.74 \mathrm{E}-05$ & $2.99 E-07$ & $8.74 \mathrm{E}-05$ \\
\hline & Equivalent number of leached kernels: & $2.20 \mathrm{E}+00$ & $7.54 \mathrm{E}-03$ & $2.21 \mathrm{E}+00$ \\
\hline & Uncertainty in equivalent number of leached kernels: & $2.23 \mathrm{E}-01$ & $7.62 \mathrm{E}-04$ & $2.23 \mathrm{E}-01$ \\
\hline \multirow{5}{*}{$\mathrm{Fe}$} & Measured concentration of impurity in sample $(\mu \mathrm{g} / \mathrm{ml})$ : & & & $\mathrm{Fe}$ \\
\hline & Uncorrected weight of impurity in sample $(\mu \mathrm{g})$ : & & & \\
\hline & Weight of impurity in blank $(\mu \mathrm{g})$ : & & & \\
\hline & Minimum corrected weight of impurity in sample $(\mu \mathrm{g})$ : & & & \\
\hline & Maximum corrected weight of impurity in sample $(\mu \mathrm{g})$ : & & & \\
\hline \multirow{5}{*}{$\mathbf{C r}$} & Measured concentration of impurity in sample $(\mu \mathrm{g} / \mathrm{ml})$ : & & & $\mathrm{Cr}$ \\
\hline & Uncorrected weight of impurity in sample $(\mu \mathrm{g}):$ & & & \\
\hline & Weight of impurity in blank $(\mu \mathrm{g})$ : & & & \\
\hline & Minimum corrected weight of impurity in sample $(\mu \mathrm{g})$ : & & & \\
\hline & Maximum corrected weight of impurity in sample $(\mu \mathrm{g})$ : & & & \\
\hline \multirow{5}{*}{ Mn } & Measured concentration of impurity in sample $(\mu \mathrm{g} / \mathrm{ml})$ : & & & Mn \\
\hline & Uncorrected weight of impurity in sample $(\mu \mathrm{g}):$ & & & \\
\hline & Weight of impurity in blank $(\mu \mathrm{g})$ : & & & \\
\hline & Minimum corrected weight of impurity in sample $(\mu \mathrm{g}):$ & & & \\
\hline & Maximum corrected weight of impurity in sample $(\mu \mathrm{g})$ : & & & \\
\hline \multirow{5}{*}{ Co } & Measured concentration of impurity in sample $(\mu \mathrm{g} / \mathrm{ml})$ : & & & Co \\
\hline & Uncorrected weight of impurity in sample $(\mu \mathrm{g})$ : & & & \\
\hline & Weight of impurity in blank $(\mu \mathrm{g}):$ & & & \\
\hline & Minimum corrected weight of impurity in sample $(\mu \mathrm{g})$ : & & & \\
\hline & Maximum corrected weight of impurity in sample $(\mu \mathrm{g})$ : & & & \\
\hline \multirow{5}{*}{$\mathbf{N i}$} & Measured concentration of impurity in sample $(\mu \mathrm{g} / \mathrm{ml})$ : & & & $\mathbf{N i}$ \\
\hline & Uncorrected weight of impurity in sample $(\mu \mathrm{g}):$ & & & \\
\hline & Weight of impurity in blank $(\mu \mathrm{g})$ : & & & \\
\hline & Minimum corrected weight of impurity in sample $(\mu \mathrm{g}):$ & & & \\
\hline & Maximum corrected weight of impurity in sample $(\mu \mathrm{g})$ : & & & \\
\hline \multirow{5}{*}{$\mathbf{C a}$} & Measured concentration of impurity in sample $(\mu \mathrm{g} / \mathrm{ml})$ : & & & $\mathbf{C a}$ \\
\hline & Uncorrected weight of impurity in sample $(\mu \mathrm{g})$ : & & & \\
\hline & Weight of impurity in blank $(\mu \mathrm{g})$ : & & & \\
\hline & Minimum corrected weight of impurity in sample $(\mu \mathrm{g})$ : & & & \\
\hline & Maximum corrected weight of impurity in sample $(\mu \mathrm{g})$ : & & & \\
\hline \multirow{5}{*}{ Al } & Measured concentration of impurity in sample $(\mu \mathrm{g} / \mathrm{ml})$ : & & & Al \\
\hline & Uncorrected weight of impurity in sample $(\mu \mathrm{g})$ : & & & \\
\hline & Weight of impurity in blank $(\mu \mathrm{g})$ : & & & \\
\hline & Minimum corrected weight of impurity in sample $(\mu \mathrm{g})$ : & & & \\
\hline & Maximum corrected weight of impurity in sample $(\mu \mathrm{g})$ : & & & \\
\hline \multirow{5}{*}{$\mathbf{T i}$} & Measured concentration of impurity in sample $(\mu \mathrm{g} / \mathrm{ml})$ : & & & $\mathbf{T i}$ \\
\hline & Uncorrected weight of impurity in sample $(\mu \mathrm{g})$ : & & & \\
\hline & Weight of impurity in blank $(\mu \mathrm{g})$ : & & & \\
\hline & Minimum corrected weight of impurity in sample $(\mu \mathrm{g})$ : & & & \\
\hline & Maximum corrected weight of impurity in sample $(\mu \mathrm{g})$ : & & & \\
\hline \multirow{5}{*}{$\mathbf{v}$} & Measured concentration of impurity in sample $(\mu \mathrm{g} / \mathrm{ml})$ : & & & $\mathbf{V}$ \\
\hline & Uncorrected weight of impurity in sample $(\mu \mathrm{g})$ : & & & \\
\hline & Weight of impurity in blank $(\mu \mathrm{g})$ : & & & \\
\hline & Minimum corrected weight of impurity in sample $(\mu \mathrm{g})$ : & & & \\
\hline & Maximum corrected weight of impurity in sample $(\mu \mathrm{g}):$ & & & \\
\hline
\end{tabular}

Comments

Leached in Vessel RB\#2 (previously used for 14154D-Group 1 Clutch 1).

FCM checked the recorded data against the official Results of Analysis for RMAL18892 on 3/21/2019.

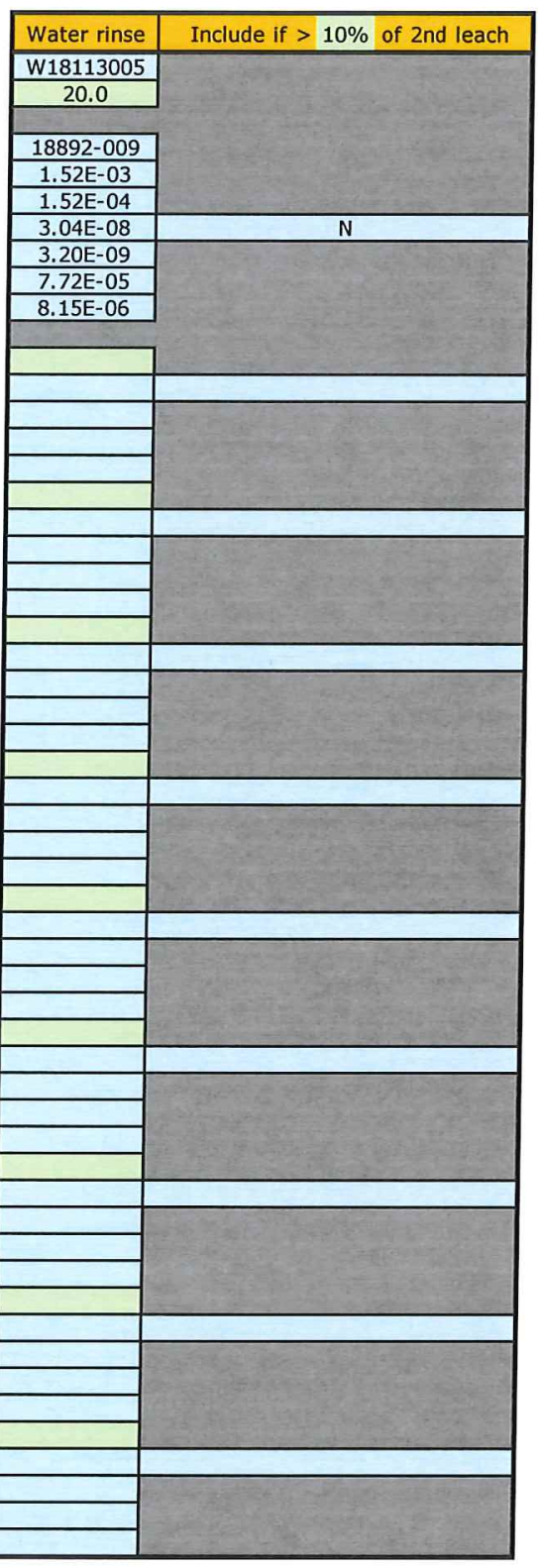

Fied c. Montgomey

Operator 
Data Report Form DRF-26B: Post-Burn Leach Uranium and Impurities

\begin{tabular}{|r|l|}
\hline Procedure: & AGR-CHAR-DAM-26 Rev. 3 \\
\hline Operator: & Montgomery \\
\hline Compact lot ID: & BWXT J52R-16-14155D \\
\hline Compact lot description: & AGR-5/6/7 compacts, 40\% packing fraction \\
\hline Compact ID numbers: & $1673,1666,1656,1675,1668$ \\
\hline DRF filename: & $14155 D$ PF40-Group 1_BL_ICPMS_DRF26R3.xls \\
\hline
\end{tabular}

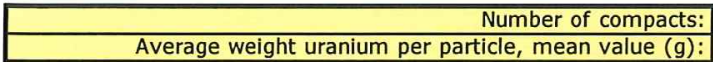
Average weight uranium per particle, uncertainty in mean (g):

\begin{tabular}{|c|c|c|c|c|}
\hline & First Leach & Second Leach & Total \\
\hline & Post-burn leach solution ID: & B18112802 & B18113002 & \\
\hline & Total volume of leach solution $(\mathrm{ml})$ : & 59.0 & 63.8 & \\
\hline & & & & \\
\hline & $\begin{array}{r}\text { RMAL analysis number: } \\
\text { Measured uranium concentration }(\mu \mathrm{g} / \mathrm{ml}) \text { : }\end{array}$ & $\frac{18892-002}{9.75 E+00}$ & $\frac{18892-006}{3.82 E-02}$ & \\
\hline & Uncertainty in uranium concentration $(\mu \mathrm{g} / \mathrm{ml})$ : & $9.75 \mathrm{E}-01$ & $\frac{3.02-02}{3.82 \mathrm{E}-03}$ & \\
\hline & Weight uranium leached $(\mathrm{g})$ : & $5.75 \mathrm{E}-04$ & $2.44 \mathrm{E}-06$ & $5.78 \mathrm{E}-04$ \\
\hline & Uncertainty in weight uranium leached $(\mathrm{g})$ : & $5.79 \mathrm{E}-05$ & $2.45 \mathrm{E}-07$ & $5.79 \mathrm{E}-05$ \\
\hline & Equivalent number of leached kernels: & $1.46 \mathrm{E}+00$ & $6.19 \mathrm{E}-03$ & $1.47 \mathrm{E}+00$ \\
\hline & Uncertainty in equivalent number of leached kernels: & $1.48 \mathrm{E}-01$ & $6.25 \mathrm{E}-04$ & $1.48 \mathrm{E}-01$ \\
\hline \multirow{5}{*}{$\mathrm{Fe}$} & Measured concentration of impurity in sample $(\mu \mathrm{g} / \mathrm{ml})$ : & & & $\mathbf{F e}$ \\
\hline & Uncorrected weight of impurity in sample $(\mu \mathrm{g})$ : & & & \\
\hline & Weight of impurity in blank $(\mu \mathrm{g})$ : & & & \\
\hline & Minimum corrected weight of impurity in sample $(\mu \mathrm{g})$ : & & & \\
\hline & Maximum corrected weight of impurity in sample $(\mu \mathrm{g})$ : & & & \\
\hline \multirow{5}{*}{$\mathrm{Cr}$} & Measured concentration of impurity in sample $(\mu \mathrm{g} / \mathrm{ml})$ : & & & $\mathrm{Cr}$ \\
\hline & Uncorrected weight of impurity in sample $(\mu \mathrm{g})$ : & & & \\
\hline & Weight of impurity in blank $(\mu \mathrm{g})$ : & & & \\
\hline & Minimum corrected weight of impurity in sample $(\mu \mathrm{g})$ : & & & \\
\hline & Maximum corrected weight of impurity in sample $(\mu \mathrm{g})$ : & & & \\
\hline \multirow{5}{*}{ Mn } & Measured concentration of impurity in sample $(\mu \mathrm{g} / \mathrm{ml})$ : & & & Mn \\
\hline & Uncorrected weight of impurity in sample $(\mu \mathrm{g})$ : & & & \\
\hline & Weight of impurity in blank $(\mu g)$ : & & & \\
\hline & Minimum corrected weight of impurity in sample $(\mu \mathrm{g})$ : & & & \\
\hline & Maximum corrected weight of impurity in sample $(\mu \mathrm{g})$ : & & & \\
\hline \multirow{5}{*}{ Co } & Measured concentration of impurity in sample $(\mu \mathrm{g} / \mathrm{ml})$ : & & & Co \\
\hline & Uncorrected weight of impurity in sample $(\mu \mathrm{g})$ : & & & \\
\hline & Weight of impurity in blank $(\mu \mathrm{g})$ : & & & \\
\hline & Minimum corrected weight of impurity in sample $(\mu g)$ : & & & \\
\hline & Maximum corrected weight of impurity in sample $(\mu g)$ : & & & \\
\hline \multirow{5}{*}{$\mathrm{Ni}$} & Measured concentration of impurity in sample $(\mu \mathrm{g} / \mathrm{ml})$ : & & & $\mathrm{Ni}$ \\
\hline & Uncorrected weight of impurity in sample $(\mu \mathrm{g})$ : & & & \\
\hline & Weight of impurity in blank $(\mu \mathrm{g})$ : & & & \\
\hline & Minimum corrected weight of impurity in sample $(\mu g)$ : & & & \\
\hline & Maximum corrected weight of impurity in sample $(\mu g)$ : & & & \\
\hline \multirow{5}{*}{$\mathbf{C a}$} & Measured concentration of impurity in sample $(\mu \mathrm{g} / \mathrm{ml})$ : & & & $\mathbf{C a}$ \\
\hline & Uncorrected weight of impurity in sample $(\mu \mathrm{g})$ : & & & \\
\hline & Weight of impurity in blank $(\mathrm{\mu g})$ : & & & \\
\hline & Minimum corrected weight of impurity in sample $(\mu \mathrm{g})$ : & & & \\
\hline & Maximum corrected weight of impurity in sample $(\mu \mathrm{g})$ : & & & \\
\hline \multirow{5}{*}{ Al } & Measured concentration of impurity in sample $(\mu \mathrm{g} / \mathrm{ml})$ : & & & $\mathbf{A l}$ \\
\hline & Uncorrected weight of impurity in sample $(\mu \mathrm{g})$ : & & & \\
\hline & Weight of impurity in blank $(\mu \mathrm{g})$ : & & & \\
\hline & Minimum corrected weight of impurity in sample $(\mu \mathrm{g})$ : & & & \\
\hline & Maximum corrected weight of impurity in sample $(\mu \mathrm{g}):$ & & & \\
\hline \multirow{5}{*}{$\mathrm{Ti}$} & Measured concentration of impurity in sample $(\mu \mathrm{g} / \mathrm{ml})$ : & & & Ti \\
\hline & Uncorrected weight of impurity in sample $(\mu \mathrm{g})$ : & & & \\
\hline & Weight of impurity in blank $(\mu \mathrm{g}):$ & & & \\
\hline & Minimum corrected weight of impurity in sample $(\mu \mathrm{g})$ : & & & \\
\hline & Maximum corrected weight of impurity in sample $(\mu \mathrm{g})$ : & & & \\
\hline \multirow{5}{*}{$\mathbf{v}$} & Measured concentration of impurity in sample $(\mu \mathrm{g} / \mathrm{ml})$ : & & & $\mathbf{v}$ \\
\hline & Uncorrected weight of impurity in sample $(\mu \mathrm{g})$ : & & & \\
\hline & Weight of impurity in blank $(\mu \mathrm{g})$ : & & & \\
\hline & Minimum corrected weight of impurity in sample $(\mu \mathrm{g})$ : & & & \\
\hline & Maximum corrected weight of impurity in sample $(\mu \mathrm{g}):$ & & & \\
\hline
\end{tabular}

\section{comments}

Leached in Vessel RB\#3 (previously used for 14154D-Group 1 Clutch 2).

FCM checked the recorded data against the official Results of Analysis for RMAL18892 on 3/21/2019.

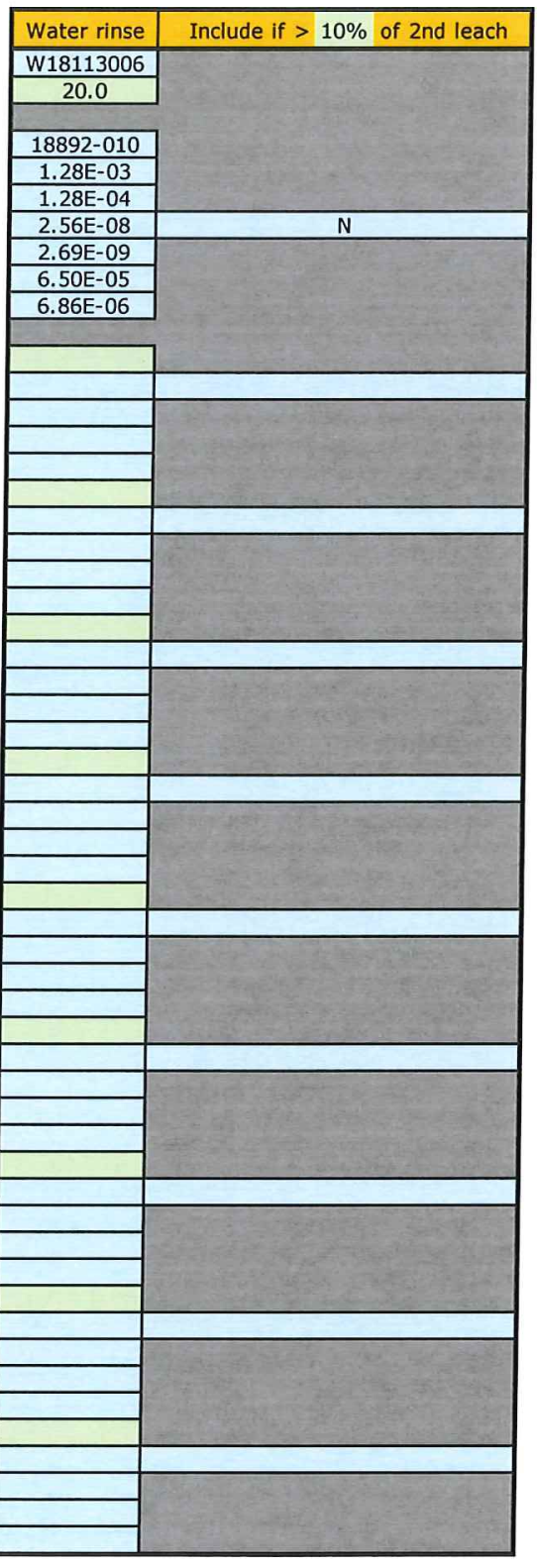

Tred c. Montgomery

Operator
$4-18-2019$

Date 
Data Report Form DRF-26B: Post-Burn Leach Uranium and Impurities

\begin{tabular}{|r|l|}
\hline Procedure: & AGR-CHAR-DAM-26 Rev. 3 \\
\hline Operator: & Montgomery \\
\hline Compact lot ID: & BWXT J52R-16-14155D \\
\hline Compact lot description: & AGR-5/6/7 compacts, 40\% packing fraction \\
\hline Compact ID numbers: & $1669,1657,1661,1649,1650$ \\
\hline DRF filename: & 14155 D_PF40-Group 1_BL_ICPMS_DRF26R3.xls \\
\hline
\end{tabular}

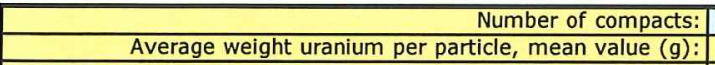
Average weight uranium per particle, uncertainty in mean $(g)$ :

\begin{tabular}{|c|c|c|c|c|}
\hline & First Leach & Second Leach & Total \\
\hline & Post-burn leach solution ID: & $\mathrm{B} 18112803$ & B18113003 & \\
\hline & Total volume of leach solution $(\mathrm{ml})$ : & 60.3 & 63.0 & \\
\hline & RMAL analysis number: & $18892-003$ & 18892-007 & \\
\hline & Measured uranium concentration $(\mu \mathrm{g} / \mathrm{ml})$ : & $8.20 \mathrm{E}+00$ & $3.49 \mathrm{E}-02$ & \\
\hline & Uncertainty in uranium concentration $(\mu \mathrm{g} / \mathrm{ml})$ : & $8.20 \mathrm{E}-01$ & $3.49 \mathrm{E}-03$ & \\
\hline & Weight uranium leached $(\mathrm{g})$ : & $4.94 \mathrm{E}-04$ & $2.20 \mathrm{E}-06$ & $4.97 \mathrm{E}-04$ \\
\hline & Uncertainty in weight uranium leached $(\mathrm{g})$ : & $4.97 \mathrm{E}-05$ & $2.21 \mathrm{E}-07$ & $4.97 \mathrm{E}-05$ \\
\hline & Equivalent number of leached kernels: & $1.25 \mathrm{E}+00$ & $5.58 \mathrm{E}-03$ & $1.26 \mathrm{E}+00$ \\
\hline & Uncertainty in equivalent number of leached kernels: & $1.27 \mathrm{E}-01$ & $5.64 \mathrm{E}-04$ & $1.27 \mathrm{E}-01$ \\
\hline \multirow{5}{*}{$\mathbf{F e}$} & Measured concentration of impurity in sample $(\mu \mathrm{g} / \mathrm{ml})$ : & & & $\mathbf{F e}$ \\
\hline & Uncorrected weight of impurity in sample $(\mu \mathrm{g})$ : & & & \\
\hline & Weight of impurity in blank $(\mu g)$ : & & & \\
\hline & Minimum corrected weight of impurity in sample $(\mu \mathrm{g})$ : & & & \\
\hline & Maximum corrected weight of impurity in sample $(\mu \mathrm{g})$ : & & & \\
\hline \multirow{5}{*}{$\mathrm{Cr}$} & Measured concentration of impurity in sample $(\mathrm{\mu g} / \mathrm{ml})$ : & & & $\mathbf{C r}$ \\
\hline & Uncorrected weight of impurity in sample $(\mu \mathrm{g})$ : & & & \\
\hline & Weight of impurity in blank $(\mu \mathrm{g})$ : & & & \\
\hline & Minimum corrected weight of impurity in sample $(\mu \mathrm{g})$ : & & & \\
\hline & Maximum corrected weight of impurity in sample $(\mu \mathrm{g})$ : & & & \\
\hline \multirow{5}{*}{ Mn } & Measured concentration of impurity in sample $(\mu \mathrm{g} / \mathrm{ml})$ : & & & Mn \\
\hline & Uncorrected weight of impurity in sample $(\mu \mathrm{g})$ : & & & \\
\hline & Weight of impurity in blank $(\mu g)$ : & & & \\
\hline & Minimum corrected weight of impurity in sample $(\mu \mathrm{g})$ : & & & \\
\hline & Maximum corrected weight of impurity in sample $(\mu g)$ : & & & \\
\hline \multirow{5}{*}{ Co } & Measured concentration of impurity in sample $(\mu \mathrm{g} / \mathrm{ml})$ : & & & Co \\
\hline & Uncorrected weight of impurity in sample $(\mu \mathrm{g})$ : & & & \\
\hline & Weight of impurity in blank $(\mu \mathrm{g})$ : & & & \\
\hline & Minimum corrected weight of impurity in sample $(\mu \mathrm{g})$ : & & & \\
\hline & Maximum corrected weight of impurity in sample $(\mu \mathrm{g})$ : & & & \\
\hline \multirow{5}{*}{$\mathbf{N i}$} & Measured concentration of impurity in sample $(\mathrm{\mu g} / \mathrm{ml})$ : & & & $\mathrm{Ni}$ \\
\hline & Uncorrected weight of impurity in sample $(\mu \mathrm{g})$ : & & & \\
\hline & $\begin{array}{r}\text { Weight of impurity in blank }(\mu g): \\
\end{array}$ & & & \\
\hline & Minimum corrected weight of impurity in sample $(\mu \mathrm{g})$ : & & & \\
\hline & Maximum corrected weight of impurity in sample $(\mu g)$ : & & & \\
\hline \multirow{5}{*}{ Ca } & Measured concentration of impurity in sample $(\mu \mathrm{g} / \mathrm{ml})$ : & & & $\mathrm{Ca}$ \\
\hline & Uncorrected weight of impurity in sample $(\mu \mathrm{g})$ : & & & \\
\hline & Weight of impurity in blank $(\mu \mathrm{gg}):$ & & & \\
\hline & Minimum corrected weight of impurity in sample $(\mu \mathrm{g})$ : & & & \\
\hline & Maximum corrected weight of impurity in sample $(\mu g)$ : & & & \\
\hline \multirow{5}{*}{ Al } & Measured concentration of impurity in sample $(\mu \mathrm{g} / \mathrm{ml})$ : & & & Al \\
\hline & Uncorrected weight of impurity in sample $(\mu \mathrm{g})$ : & & & \\
\hline & Weight of impurity in blank $(\mu \mathrm{g})$ : & & & \\
\hline & Minimum corrected weight of impurity in sample $(\mu \mathrm{g})$ : & & & \\
\hline & Maximum corrected weight of impurity in sample $(\mu \mathrm{g})$ : & & & \\
\hline \multirow{5}{*}{$\mathbf{T i}$} & Measured concentration of impurity in sample $(\mu \mathrm{g} / \mathrm{ml})$ : & & & Ti \\
\hline & Uncorrected weight of impurity in sample $(\mu \mathrm{g})$ : & & & \\
\hline & Weight of impurity in blank $(\mu \mathrm{g}):$ & & & \\
\hline & Minimum corrected weight of impurity in sample $(\mu \mathrm{g})$ : & & & \\
\hline & Maximum corrected weight of impurity in sample $(\mu \mathrm{g})$ : & & & \\
\hline \multirow{5}{*}{$\mathbf{v}$} & Measured concentration of impurity in sample $(\mu \mathrm{g} / \mathrm{ml})$ : & & & $\mathbf{v}$ \\
\hline & Uncorrected weight of impurity in sample $(\mu \mathrm{g})$ : & & & \\
\hline & Weight of impurity in blank $(\mu \mathrm{g})$ : & & & \\
\hline & Minimum corrected weight of impurity in sample $(\mu \mathrm{g})$ : & & & \\
\hline & Maximum corrected weight of impurity in sample $(\mu \mathrm{g}): 1$ & & & \\
\hline
\end{tabular}

\section{Comments}

Leached in Vessel RB\#11 (previously used for 14154D-Group 1 Clutch 3).

FCM checked the recorded data against the official Results of Analysis for RMAL18892 on 3/21/2019.
5

$3.94 \mathrm{E}-04$

\section{3}

8892-007

$3.49 \mathrm{E}-03$

2.20E-06

\begin{tabular}{l}
$4.925 \mathrm{E}+00$ \\
\hline $1.25 \mathrm{E}+00$
\end{tabular}

$1.27 \mathrm{E}-01$

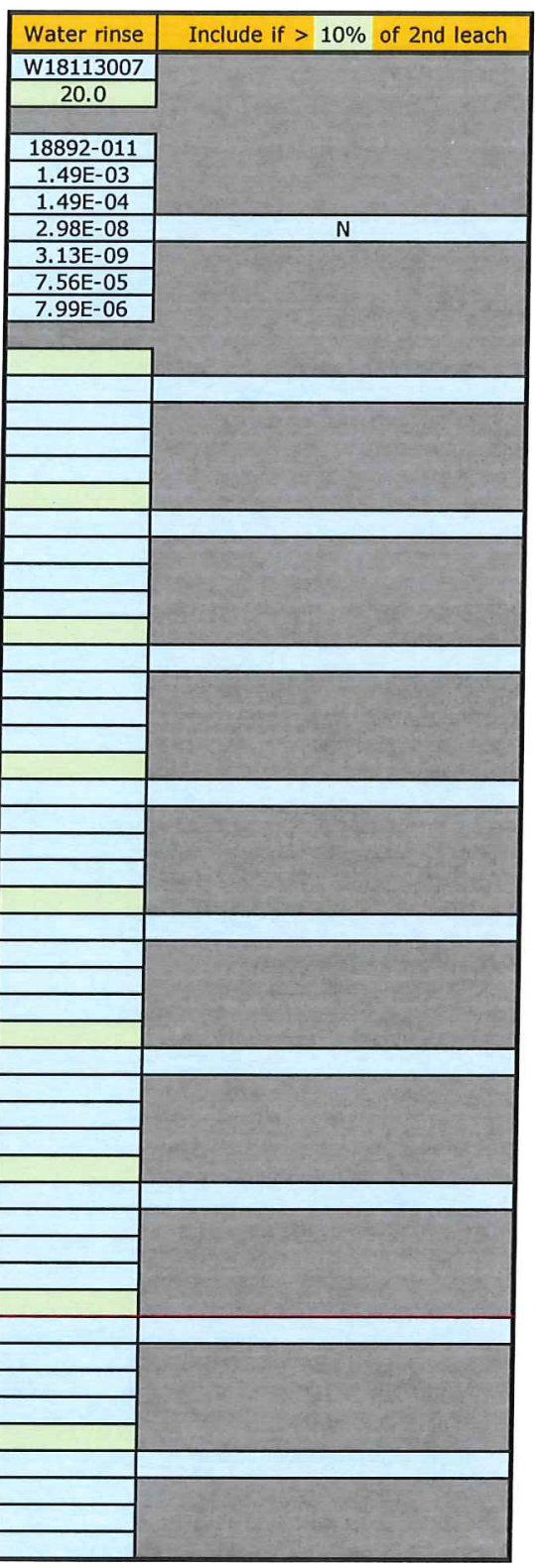

7ied c. Montgomey$$
\text { . }
$$ 


\section{Data Report Form DRF-26B: Post-Burn Leach Uranium and Impurities}

\begin{tabular}{|r|l|}
\hline Procedure: & AGR-CHAR-DAM-26 Rev. 3 \\
\hline Operator: & Montgomery \\
\hline Compact lot ID: & BWXT J52R-16-14155D \\
\hline Compact lot description: & AGR-5/6/7 compacts, 40\% packing fraction \\
\hline Compact ID numbers: & $1663,1654,1646,1643,1667$ \\
\hline DRF filename: & 14155 D PF40-Group 1 BL_ICPMS_DRF26R3.xls \\
\hline
\end{tabular}

\begin{tabular}{|r|c|}
\hline Number of compacts: & 5 \\
\hline Average weight uranium per particle, mean value $(\mathrm{g}):$ & $3.94 \mathrm{E}-04$ \\
\hline Average weight uranium per particle, uncertainty in mean $(\mathrm{g}):$ & $3.94 \mathrm{E}-06$ \\
\hline
\end{tabular}

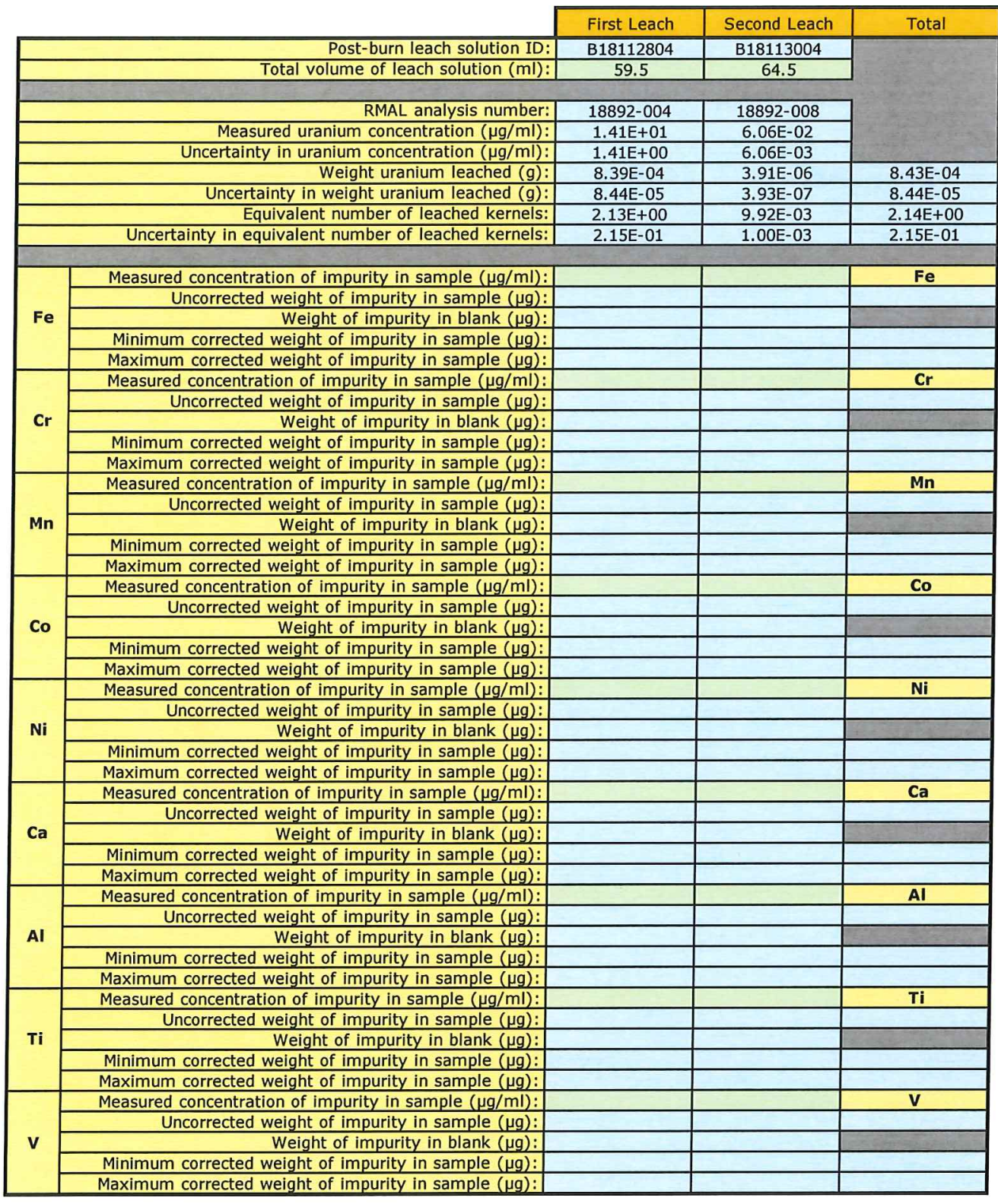

\section{Comments}

Leached in Vessel FB\#2 (previously used for 14154D-Group 1 Clutch 4).

FCM checked the recorded data against the official Results of Analysis for RMAL18892 on 3/21/2019.

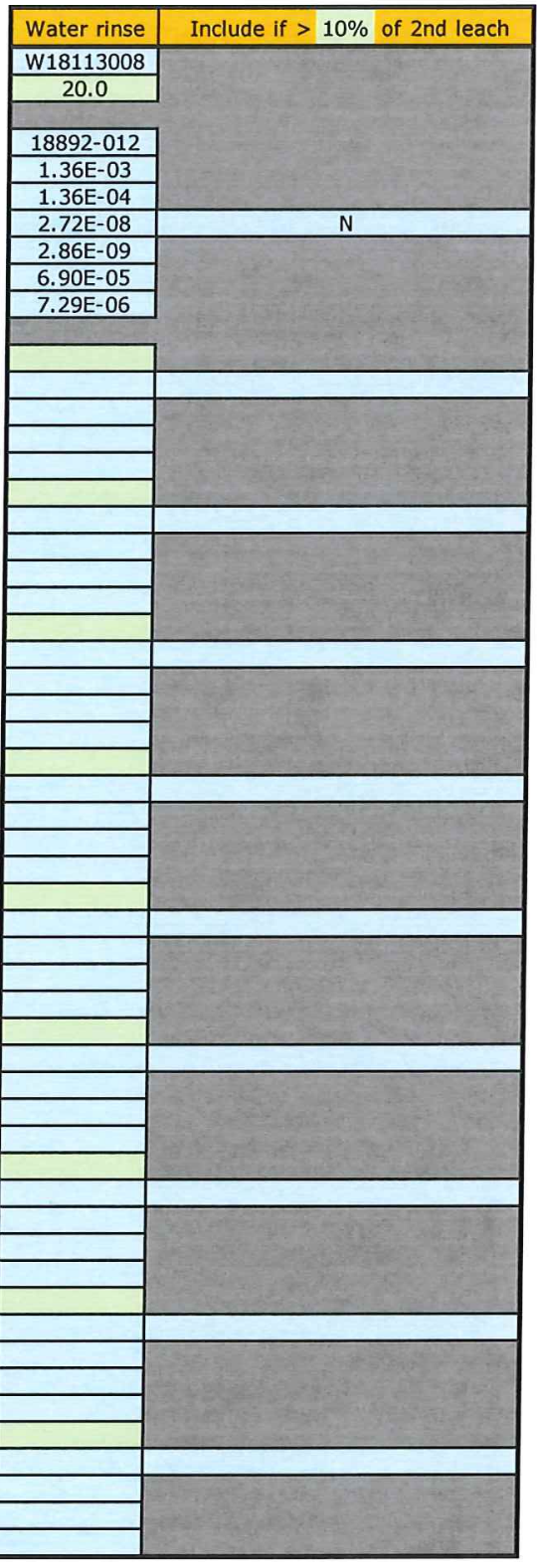

Feed c. montgomery

\section{heed c. Mortyomery}

$4-18-2019$

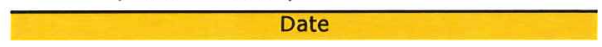


Data Report Form DRF-26B: Post-Burn Leach Uranium and Impurities

\begin{tabular}{|r|l|}
\hline Procedure: & AGR-CHAR-DAM-26 Rev. 3 \\
\hline Operator: & Montgomery \\
\hline Compact lot ID: & BWXT J52R-16-14155D \\
\hline Compact lot description: & AGR-5/6/7 compacts, 40\% packing fraction \\
\hline Compact ID numbers: & $1658,1674,1671,1653,1640$ \\
\hline DRF filename: & 14155 D_PF40-Group 2_BL_ICPMS_DRF26R3.xls \\
\hline
\end{tabular}

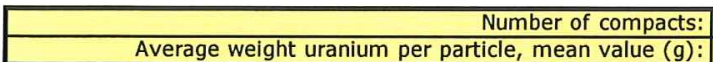

Average weight uranium per particle, uncertainty in mean $(g)$ :

\begin{tabular}{|c|c|c|c|c|}
\hline & First Leach & Second Leach & Total \\
\hline & Post-burn leach solution ID: & B18120603 & B18121101 & \\
\hline & Total volume of leach solution $(\mathrm{ml})$ : & 60.0 & 65.0 & \\
\hline & RMAL analysis number: & $18909-001$ & $18909-005$ & \\
\hline & Measured uranium concentration $(\mu \mathrm{g} / \mathrm{ml})$ : & $6.62 \mathrm{E}+00$ & $3.17 \mathrm{E}-02$ & \\
\hline & Uncertainty in uranium concentration $(\mu \mathrm{g} / \mathrm{ml})$ : & $6.62 \mathrm{E}-01$ & $3.17 \mathrm{E}-03$ & \\
\hline & Weight uranium leached $(\mathrm{g})$ : & $3.97 \mathrm{E}-04$ & $2.06 \mathrm{E}-06$ & $3.99 \mathrm{E}-04$ \\
\hline & Uncertainty in weight uranium leached $(\mathrm{g})$ : & $4.00 \mathrm{E}-05$ & $2.07 \mathrm{E}-07$ & $4.00 \mathrm{E}-05$ \\
\hline & Equivalent number of leached kernels: & $1.01 \mathrm{E}+00$ & $5.23 \mathrm{E}-03$ & $1.01 \mathrm{E}+00$ \\
\hline & Uncertainty in equivalent number of leached kernels: & $1.02 \mathrm{E}-01$ & $5.28 \mathrm{E}-04$ & $1.02 \mathrm{E}-01$ \\
\hline \multirow{5}{*}{$\mathrm{Fe}$} & Measured concentration of impurity in sample $(\mu \mathrm{g} / \mathrm{ml})$ : & & & $\overline{\mathrm{Fe}}$ \\
\hline & Uncorrected weight of impurity in sample $(\mu \mathrm{g})$ : & & & \\
\hline & Weight of impurity in blank $(\mu \mathrm{g})$ : & & & \\
\hline & Minimum corrected weight of impurity in sample $(\mu \mathrm{g})$ : & & & \\
\hline & Maximum corrected weight of impurity in sample $(\mu \mathrm{g})$ : & & & \\
\hline \multirow{5}{*}{$\mathrm{Cr}$} & Measured concentration of impurity in sample $(\mu \mathrm{g} / \mathrm{ml})$ : & & & $\mathrm{Cr}$ \\
\hline & Uncorrected weight of impurity in sample $(\mu \mathrm{g})$ : & & & \\
\hline & Weight of impurity in blank $(\mu g)$ : & & & \\
\hline & Minimum corrected weight of impurity in sample $(\mu \mathrm{g})$ : & & & \\
\hline & Maximum corrected weight of impurity in sample $(\mu \mathrm{g})$ : & & & \\
\hline \multirow{5}{*}{ Mn } & Measured concentration of impurity in sample $(\mu \mathrm{g} / \mathrm{ml})$ : & & & Mn \\
\hline & Uncorrected weight of impurity in sample $(\mu \mathrm{g})$ : & & & \\
\hline & Weight of impurity in blank $(\mu \mathrm{g})$ : & & & \\
\hline & Minimum corrected weight of impurity in sample $(\mu \mathrm{g})$ : & & & \\
\hline & Maximum corrected weight of impurity in sample $(\mu \mathrm{g})$ : & & & \\
\hline \multirow{5}{*}{ Co } & Measured concentration of impurity in sample $(\mu \mathrm{g} / \mathrm{ml})$ : & & & Co \\
\hline & Uncorrected weight of impurity in sample $(\mu \mathrm{g})$ : & & & \\
\hline & Weight of impurity in blank $(\mu \mathrm{g})$ : & & & \\
\hline & Minimum corrected weight of impurity in sample $(\mu \mathrm{g})$ : & & & \\
\hline & Maximum corrected weight of impurity in sample $(\mu \mathrm{g})$ : & & & \\
\hline \multirow{5}{*}{$\mathbf{N i}$} & Measured concentration of impurity in sample $(\mu \mathrm{g} / \mathrm{ml})$ : & & & $\mathrm{Ni}$ \\
\hline & Uncorrected weight of impurity in sample $(\mu \mathrm{g})$ : & & & \\
\hline & $\begin{array}{r}\text { Weight of impurity in blank }(\mu \mathrm{g}) \text { : } \\
\text {. }\end{array}$ & & & \\
\hline & Minimum corrected weight of impurity in sample $(\mu \mathrm{g})$ : & & & \\
\hline & Maximum corrected weight of impurity in sample $(\mu g)$ : & & & \\
\hline \multirow{5}{*}{$\mathrm{Ca}$} & Measured concentration of impurity in sample $(\mu \mathrm{g} / \mathrm{ml})$ : & & & $\mathbf{C a}$ \\
\hline & Uncorrected weight of impurity in sample $(\mu \mathrm{g})$ : & & & \\
\hline & Weight of impurity in blank $(\mu \mathrm{g})$ : & & & \\
\hline & Minimum corrected weight of impurity in sample $(\mu \mathrm{g})$ : & & & \\
\hline & Maximum corrected weight of impurity in sample $(\mu \mathrm{g})$ : & & & \\
\hline \multirow{5}{*}{ AI } & Measured concentration of impurity in sample $(\mu \mathrm{g} / \mathrm{ml})$ : & & & Al \\
\hline & Uncorrected weight of impurity in sample $(\mu \mathrm{g})$ : & & & \\
\hline & Weight of impurity in blank $(\mu \mathrm{g})$ : & & & \\
\hline & Minimum corrected weight of impurity in sample $(\mu \mathrm{g})$ : & & & \\
\hline & Maximum corrected weight of impurity in sample $(\mu \mathrm{g})$ : & & & \\
\hline \multirow{5}{*}{ Ti } & Measured concentration of impurity in sample $(\mu \mathrm{g} / \mathrm{ml})$ : & & & $\mathrm{Ti}$ \\
\hline & Uncorrected weight of impurity in sample $(\mu g)$ : & & & \\
\hline & Weight of impurity in blank $(\mu \mathrm{g})$ : & & & \\
\hline & Minimum corrected weight of impurity in sample $(\mu g)$ : & & & \\
\hline & Maximum corrected weight of impurity in sample $(\mu g)$ : & & & \\
\hline \multirow{5}{*}{$\mathbf{v}$} & Measured concentration of impurity in sample $(\mathrm{\mu g} / \mathrm{ml})$ : & & & $\mathbf{v}$ \\
\hline & Uncorrected weight of impurity in sample $(\mu \mathrm{g}):$ & & & \\
\hline & Weight of impurity in blank $(\mu \mathrm{g})$ : & & & \\
\hline & Minimum corrected weight of impurity in sample $(\mu \mathrm{g})$ : & & & \\
\hline & Maximum corrected weight of impurity in sample $(\mu \mathrm{g}): 1$ & & & \\
\hline
\end{tabular}

comments

Leached in Vessel \#31 (previously used for 14154D-Group 2 Clutch 5).

FCM checked the recorded data against the official Results of Analysis for RMAL18909 on 3/21/2019.

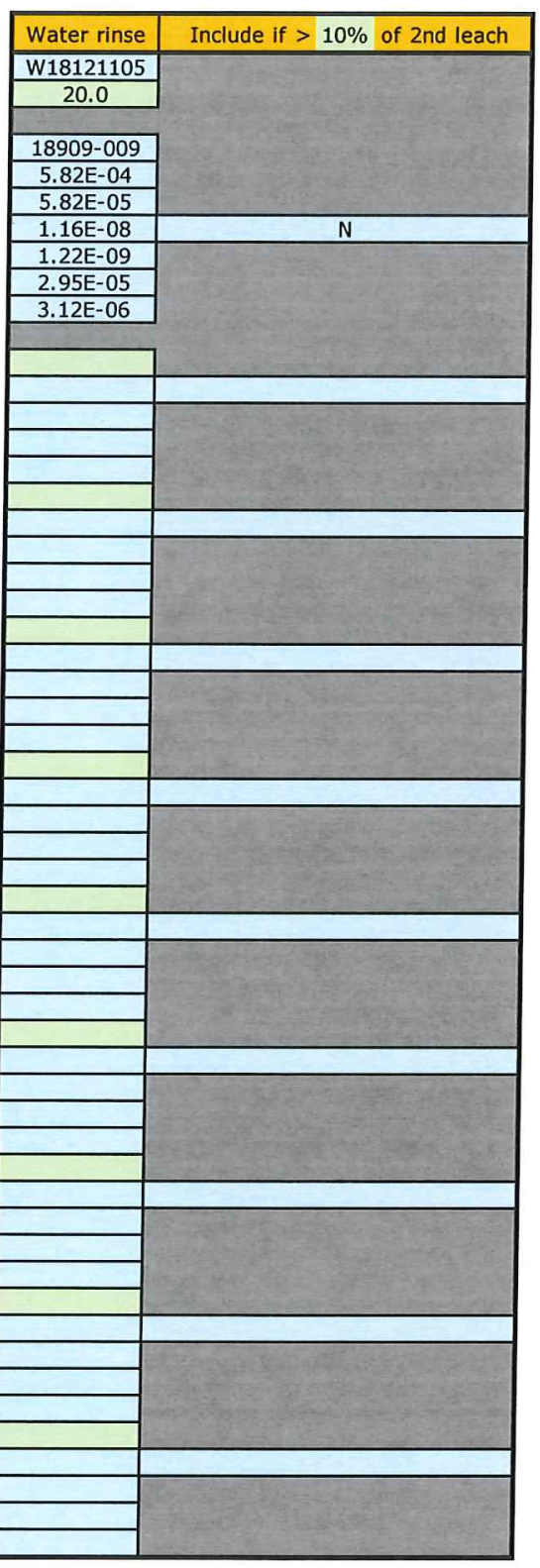

Fred C. Montgomery

Operator
$4-18.2019$

Date 
Data Report Form DRF-26B: Post-Burn Leach Uranium and Impurities

\begin{tabular}{|r|l|}
\hline Procedure: & AGR-CHAR-DAM-26 Rev, 3 \\
\hline Operator: & Montgomery \\
\hline Compact lot ID: & BWXT J52R-16-14155D \\
\hline Compact lot description: & AGR-5/6/7 compacts, 40\% packing fraction \\
\hline Compact ID numbers: & $1652,1641,1644,1642,1665$ \\
\hline DRF filename: & 14155 D_PF40-Group 2_BL_ICPMS_DRF26R3.x/s \\
\hline
\end{tabular}

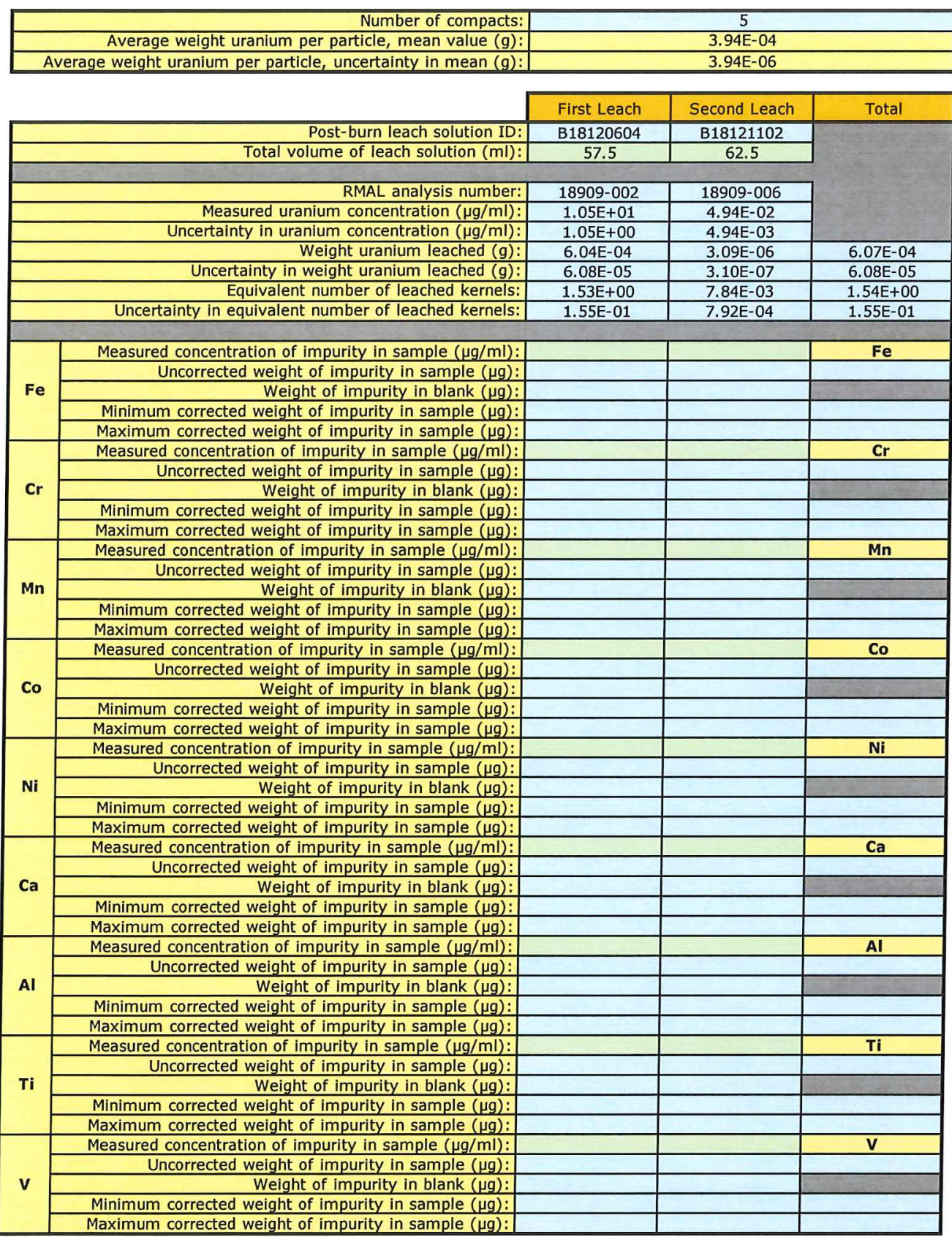

\section{Comments}

Leached in Vessel \#32 (previously used for 14154D-Group 2 Clutch 6).

FCM checked the recorded data against the official Results of Analysis for RMAL18909 on 3/21/2019.

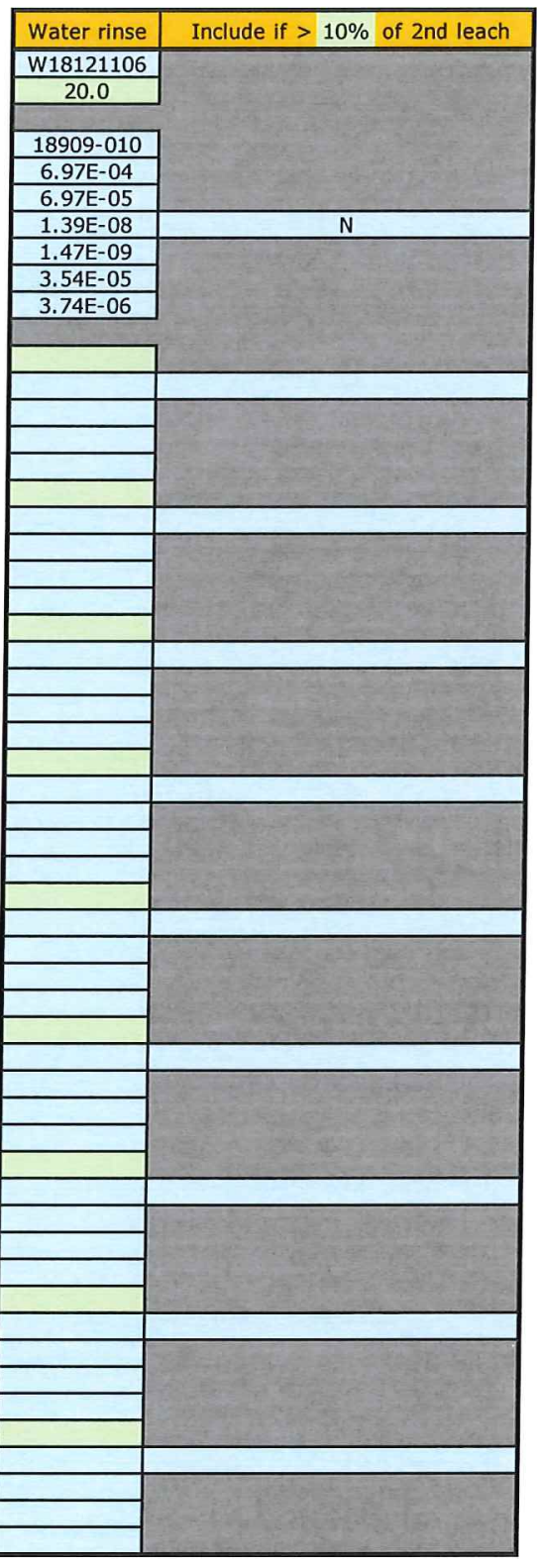

\section{Fred c. Montgomeey}

Operator
$4-18-2019$

Date 
Data Report Form DRF-26B: Post-Burn Leach Uranium and Impurities

\begin{tabular}{|r|l|}
\hline Procedure: & AGR-CHAR-DAM-26 Rev. 3 \\
\hline Operator: & Montgomery \\
\hline Compact lot ID: & BWXT J52R-16-14155D \\
\hline Compact lot description: & AGR-5/6/7 compacts, 40\% packing fraction \\
\hline Compact ID numbers: & $1645,1651,1677,1664,1672$ \\
\hline DRF filename: & 14155 D_PF40-Group 2_BL_ICPMS_DRF26R3.xls \\
\hline
\end{tabular}

\begin{tabular}{|r|c|}
\hline Number of compacts: & 5 \\
\hline Average weight uranium per particle, mean value $(\mathrm{g}):$ & $3.94 \mathrm{E}-04$ \\
\hline Average weight uranium per particle, uncertainty in mean $(\mathrm{g}):$ & $3.94 \mathrm{E}-06$ \\
\hline
\end{tabular}

\begin{tabular}{|c|c|c|c|c|}
\hline & \\
\hline & & First Leach & Second Leach & Total \\
\hline \multicolumn{2}{|r|}{ Post-burn leach solution ID: } & B18120605 & B18121103 & \\
\hline \multicolumn{2}{|r|}{ Total volume of leach solution $(\mathrm{ml}):$} & 59.0 & 63.5 & \\
\hline \multicolumn{2}{|r|}{ RMAL analysis number: } & $18909-003$ & $18909-007$ & \\
\hline \multicolumn{2}{|c|}{ Measured uranium concentration $(\mu \mathrm{g} / \mathrm{ml}):$} & $1.93 \mathrm{E}+01$ & $9.18 \mathrm{E}-02$ & \\
\hline \multicolumn{2}{|c|}{ Uncertainty in uranium concentration $(\mu \mathrm{g} / \mathrm{ml})$ : } & $1.93 \mathrm{E}+00$ & $9.18 \mathrm{E}-03$ & \\
\hline \multicolumn{2}{|c|}{ Weight uranium leached $(g):$} & $1.14 \mathrm{E}-03$ & $5.83 \mathrm{E}-06$ & $1.14 \mathrm{E}-03$ \\
\hline \multicolumn{2}{|c|}{ Uncertainty in weight uranium leached $(\mathrm{g}):$} & $1.15 \mathrm{E}-04$ & $5.86 \mathrm{E}-07$ & $1.15 \mathrm{E}-04$ \\
\hline \multicolumn{2}{|c|}{ Equivalent number of leached kernels: } & $2.89 \mathrm{E}+00$ & $1.48 \mathrm{E}-02$ & $2.90 E+00$ \\
\hline \multicolumn{2}{|c|}{ Uncertainty in equivalent number of leached kernels: } & $2.92 \mathrm{E}-01$ & $1.49 \mathrm{E}-03$ & $2.92 \mathrm{E}-01$ \\
\hline \multirow{6}{*}{$\mathrm{Fe}$} & & & & \\
\hline & Measured concentration of impurity in sample $(\mu \mathrm{g} / \mathrm{ml})$ : & & & $\mathrm{Fe}$ \\
\hline & Uncorrected weight of impurity in sample $(\mu g)$ : & & & \\
\hline & Weight of impurity in blank $(\mu \mathrm{g}):$ & & & \\
\hline & Minimum corrected weight of impurity in sample $(\mu \mathrm{g}):$ & & & \\
\hline & Maximum corrected weight of impurity in sample $(\mu \mathrm{g})$ : & & & \\
\hline \multirow{5}{*}{$\mathbf{C r}$} & Measured concentration of impurity in sample $(\mu \mathrm{g} / \mathrm{ml})$ : & & & $\mathbf{C r}$ \\
\hline & Uncorrected weight of impurity in sample $(\mu \mathrm{g})$ : & & & \\
\hline & Weight of impurity in blank $(\mu \mathrm{g})$ : & & & \\
\hline & Minimum corrected weight of impurity in sample $(\mu \mathrm{g})$ : & & & \\
\hline & Maximum corrected weight of impurity in sample $(\mu \mathrm{g})$ : & & & \\
\hline \multirow{5}{*}{ Mn } & Measured concentration of impurity in sample $(\mu \mathrm{g} / \mathrm{ml})$ : & & & Mn \\
\hline & Uncorrected weight of impurity in sample $(\mu \mathrm{g})$ : & & & \\
\hline & Weight of impurity in blank $(\mu \mathrm{g})$ : & & & \\
\hline & Minimum corrected weight of impurity in sample $(\mu \mathrm{g})$ : & & & \\
\hline & Maximum corrected weight of impurity in sample $(\mu \mathrm{g})$ : & & & \\
\hline \multirow{5}{*}{ Co } & Measured concentration of impurity in sample $(\mu \mathrm{g} / \mathrm{ml})$ : & & & Co \\
\hline & Uncorrected weight of impurity in sample $(\mu \mathrm{g})$ : & & & \\
\hline & Weight of impurity in blank $(\mu \mathrm{g})$ : & & & \\
\hline & Minimum corrected weight of impurity in sample $(\mu \mathrm{g})$ : & & & \\
\hline & Maximum corrected weight of impurity in sample $(\mu \mathrm{g}):$ & & & \\
\hline \multirow{5}{*}{$\mathrm{Ni}$} & Measured concentration of impurity in sample $(\mu \mathrm{g} / \mathrm{ml})$ : & & & $\mathbf{N i}$ \\
\hline & Uncorrected weight of impurity in sample $(\mu \mathrm{g})$ : & & & \\
\hline & Weight of impurity in blank $(\mu \mathrm{g})$ : & & & \\
\hline & Minimum corrected weight of impurity in sample $(\mu \mathrm{g})$ : & & & \\
\hline & Maximum corrected weight of impurity in sample $(\mu \mathrm{g})$ : & & & \\
\hline \multirow{5}{*}{$\mathbf{C a}$} & Measured concentration of impurity in sample $(\mu \mathrm{g} / \mathrm{ml})$ : & & & $\mathbf{C a}$ \\
\hline & Uncorrected weight of impurity in sample $(\mu \mathrm{g})$ : & & & \\
\hline & Weight of impurity in blank $(\mu \mathrm{g}):$ & & & \\
\hline & Minimum corrected weight of impurity in sample $(\mu \mathrm{g})$ : & & & \\
\hline & Maximum corrected weight of impurity in sample $(\mu \mathrm{g})$ : & & & \\
\hline \multirow{5}{*}{ Al } & Measured concentration of impurity in sample $(\mu \mathrm{g} / \mathrm{ml})$ : & & & Al \\
\hline & Uncorrected weight of impurity in sample $(\mu \mathrm{g})$ : & & & \\
\hline & Weight of impurity in blank $(\mu g):$ & & & \\
\hline & Minimum corrected weight of impurity in sample $(\mu \mathrm{g})$ : & & & \\
\hline & Maximum corrected weight of impurity in sample $(\mu \mathrm{g})$ : & & & \\
\hline & Measured concentration of impurity in sample $(\mu \mathrm{g} / \mathrm{ml})$ : & & & $\mathrm{Ti}$ \\
\hline & Uncorrected weight of impurity in sample $(\mu \mathrm{g})$ : & & & \\
\hline $\mathbf{T i}$ & Weight of impurity in blank $(\mu \mathrm{g}):$ & & & \\
\hline & Minimum corrected weight of impurity in sample $(\mu \mathrm{g})$ : & & & \\
\hline & Maximum corrected weight of impurity in sample $(\mu \mathrm{g}):$ & & & \\
\hline & Measured concentration of impurity in sample $(\mu \mathrm{g} / \mathrm{ml})$ : & & & $\mathbf{v}$ \\
\hline & Uncorrected weight of impurity in sample $(\mu \mathrm{g})$ : & & & \\
\hline $\mathbf{v}$ & Weight of impurity in blank $(\mu \mathrm{g})$ : & & & \\
\hline & Minimum corrected weight of impurity in sample $(\mu g)$ : & & & \\
\hline & Maximum corrected weight of impurity in sample $(\mu \mathrm{g})$ : & & & \\
\hline
\end{tabular}

\section{Comments}

Leached in Vessel \#33 (previously used for 14154D-Group 2 Clutch 7).

FCM checked the recorded data against the official Results of Analysis for RMAL18909 on 3/21/2019.

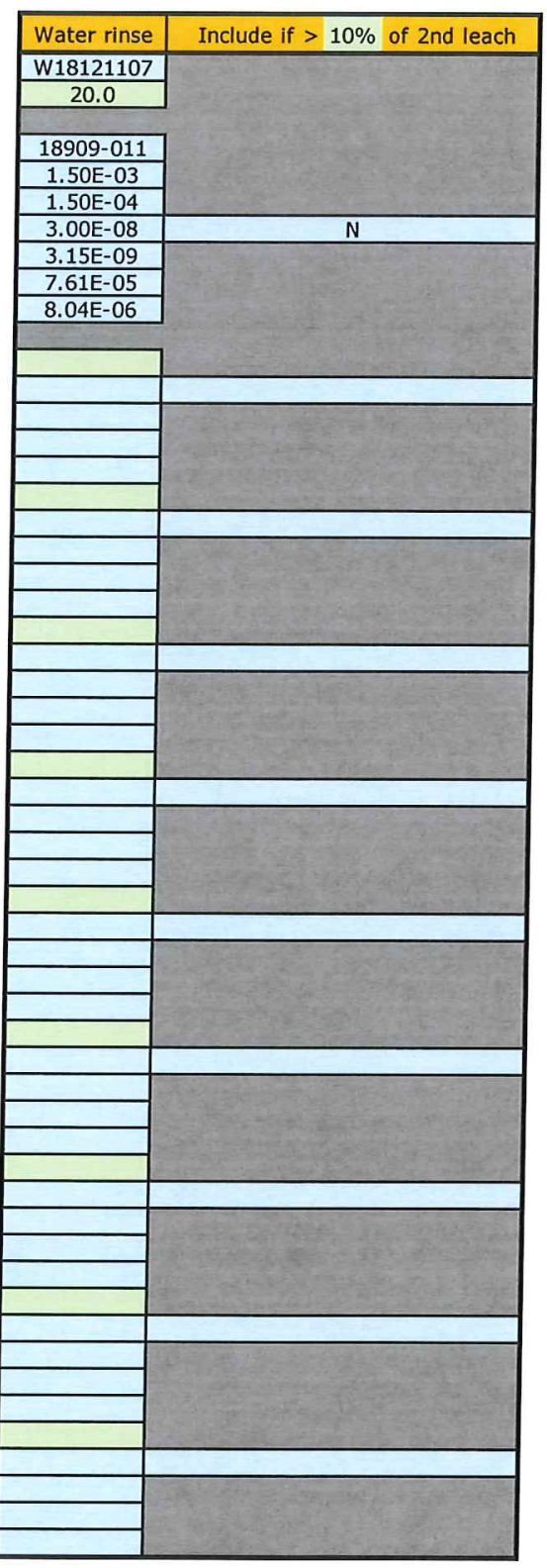

Fred c. montgomery Operator
$4-18-2019$

Date 
Data Report Form DRF-26B: Post-Burn Leach Uranium and Impurities

\begin{tabular}{|r|l|}
\hline Procedure: & AGR-CHAR-DAM-26 Rev. 3 \\
\hline Operator: & Montgomery \\
\hline Compact lot ID: & BWXT J52R-16-14155D \\
\hline Compact lot description: & AGR-5/6/7 compacts, 40\% packing fraction \\
\hline Compact ID numbers: & $1679,1647,1676,1678,1660$ \\
\hline DRF filename: & 14155 D_PF40-Group 2_BL_ICPMS_DRF26R3.xls \\
\hline
\end{tabular}

\begin{tabular}{|c|c|c|c|c|}
\hline \multicolumn{2}{|r|}{ 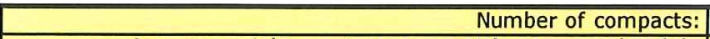 } & \multicolumn{3}{|c|}{5} \\
\hline \multirow{2}{*}{\multicolumn{2}{|c|}{$\begin{array}{r}\text { Average weight uranium per particle, mean value }(g): \\
\text { Average weight uranium per particle, uncertainty in mean }(g):\end{array}$}} & \multicolumn{3}{|c|}{$3.94 \mathrm{E}-04$} \\
\hline & & \multicolumn{3}{|c|}{$3.94 \mathrm{E}-06$} \\
\hline & & First Leach & Second Leach & Total \\
\hline & Post-burn leach solution ID: & B18120606 & B18121104 & \\
\hline & Total volume of leach solution $(\mathrm{ml})$ : & 59.5 & 65.0 & \\
\hline & RMAL analysis number: & $18909-004$ & & \\
\hline & Measured uranium concentration $(\mu \mathrm{g} / \mathrm{ml})$ : & $5.51 \mathrm{E}-01$ & $4.81 \mathrm{E}-03$ & \\
\hline & Uncertainty in uranium concentration $(\mu \mathrm{g} / \mathrm{ml})$ : & $5.51 \mathrm{E}-02$ & $4.81 \mathrm{E}-04$ & \\
\hline & Weight uranium leached $(g):$ & $3.28 \mathrm{E}-05$ & $3.13 \mathrm{E}-07$ & $3.31 \mathrm{E}-05$ \\
\hline & Uncertainty in weight uranium leached $(\mathrm{g}):$ & $3.30 \mathrm{E}-06$ & $3.14 \mathrm{E}-08$ & $3.30 \mathrm{E}-06$ \\
\hline & Equivalent number of leached kernels: & $8.32 \mathrm{E}-02$ & $7.94 \mathrm{E}-04$ & $8.40 \mathrm{E}-02$ \\
\hline & Uncertainty in equivalent number of leached kernels: & $8.41 \mathrm{E}-03$ & $8.01 \mathrm{E}-05$ & $8.41 \mathrm{E}-03$ \\
\hline \multirow{5}{*}{$\mathrm{Fe}$} & Measured concentration of impurity in sample $(\mu \mathrm{g} / \mathrm{ml})$ : & & & $\mathrm{Fe}$ \\
\hline & Uncorrected weight of impurity in sample $(\mu \mathrm{g})$ : & & & \\
\hline & Weight of impurity in blank $(\mu \mathrm{g})$ : & & & \\
\hline & Minimum corrected weight of impurity in sample $(\mu \mathrm{g})$ : & & & \\
\hline & Maximum corrected weight of impurity in sample $(\mu \mathrm{g})$ : & & & \\
\hline \multirow{5}{*}{$\mathrm{Cr}$} & Measured concentration of impurity in sample $(\mu \mathrm{g} / \mathrm{ml})$ : & & & $\mathrm{Cr}$ \\
\hline & Uncorrected weight of impurity in sample $(\mu \mathrm{g})$ : & & & \\
\hline & Weight of impurity in blank $(\mu \mathrm{g})$ : & & & \\
\hline & Minimum corrected weight of impurity in sample $(\mu \mathrm{g})$ : & & & \\
\hline & Maximum corrected weight of impurity in sample $(\mu \mathrm{g})$ : & & & \\
\hline \multirow{5}{*}{ Mn } & Measured concentration of impurity in sample $(\mu \mathrm{g} / \mathrm{ml})$ : & & & Mn \\
\hline & Uncorrected weight of impurity in sample $(\mu \mathrm{g}):$ & & & \\
\hline & Weight of impurity in blank $(\mu \mathrm{g})$ : & & & \\
\hline & Minimum corrected weight of impurity in sample $(\mu \mathrm{g}):$ & & & \\
\hline & Maximum corrected weight of impurity in sample $(\mu g)$ : & & & \\
\hline \multirow{5}{*}{ Co } & Measured concentration of impurity in sample $(\mu \mathrm{g} / \mathrm{ml})$ : & & & Co \\
\hline & Uncorrected weight of impurity in sample $(\mu \mathrm{g})$ : & & & \\
\hline & Weight of impurity in blank $(\mu g)$ : & & & \\
\hline & Minimum corrected weight of impurity in sample $(\mu \mathrm{g})$ : & & & \\
\hline & Maximum corrected weight of impurity in sample $(\mu g)$ : & & & \\
\hline \multirow{5}{*}{$\mathrm{Ni}$} & Measured concentration of impurity in sample $(\mu \mathrm{g} / \mathrm{ml})$ : & & & $\mathbf{N i}$ \\
\hline & Uncorrected weight of impurity in sample $(\mu \mathrm{g})$ : & & & \\
\hline & Weight of impurity in blank $(\mu \mathrm{g})$ : & & & \\
\hline & Minimum corrected weight of impurity in sample $(\mu \mathrm{g})$ : & & & \\
\hline & Maximum corrected weight of impurity in sample $(\mu g)$ : & & & \\
\hline \multirow{5}{*}{$\mathrm{Ca}$} & Measured concentration of impurity in sample $(\mu \mathrm{g} / \mathrm{ml})$ : & & & $\mathbf{C a}$ \\
\hline & Uncorrected weight of impurity in sample $(\mu \mathrm{g})$ : & & & \\
\hline & Weight of impurity in blank $(\mu \mathrm{g})$ : & & & \\
\hline & Minimum corrected weight of impurity in sample $(\mu \mathrm{g})$ : & & & \\
\hline & Maximum corrected weight of impurity in sample $(\mu \mathrm{g}):$ & & & \\
\hline \multirow{5}{*}{ Al } & Measured concentration of impurity in sample $(\mu \mathrm{g} / \mathrm{ml})$ : & & & Al \\
\hline & Uncorrected weight of impurity in sample $(\mu \mathrm{g})$ : & & & \\
\hline & Weight of impurity in blank $(\mu \mathrm{g})$ : & & & \\
\hline & Minimum corrected weight of impurity in sample $(\mu \mathrm{g})$ : & & & \\
\hline & Maximum corrected weight of impurity in sample $(\mu \mathrm{g})$ : & & & \\
\hline \multirow{5}{*}{ Ti } & Measured concentration of impurity in sample $(\mu \mathrm{g} / \mathrm{ml})$ : & & & $\mathbf{T i}$ \\
\hline & Uncorrected weight of impurity in sample $(\mu \mathrm{g})$ : & & & \\
\hline & Weight of impurity in blank $(\mu \mathrm{g})$ : & & & \\
\hline & Minimum corrected weight of impurity in sample $(\mu \mathrm{g})$ : & & & \\
\hline & Maximum corrected weight of impurity in sample $(\mu \mathrm{g})$ : & & & \\
\hline \multirow{5}{*}{$\mathbf{v}$} & Measured concentration of impurity in sample $(\mu \mathrm{g} / \mathrm{ml})$ : & & & $\mathbf{V}$ \\
\hline & Uncorrected weight of impurity in sample $(\mu \mathrm{g})$ : & & & \\
\hline & Weight of impurity in blank $(\mu \mathrm{g})$ : & & & \\
\hline & Minimum corrected weight of impurity in sample $(\mu \mathrm{g}):$ & & & \\
\hline & Maximum corrected weight of impurity in sample $(\mu \mathrm{g}):$ & & & \\
\hline
\end{tabular}

\section{Comments}

Leached in Vessel \#30 (previously used for 14154D-Group 2 Clutch 8).

FCM checked the recorded data against the official Results of Analysis for RMAL18909 on 3/21/2019.

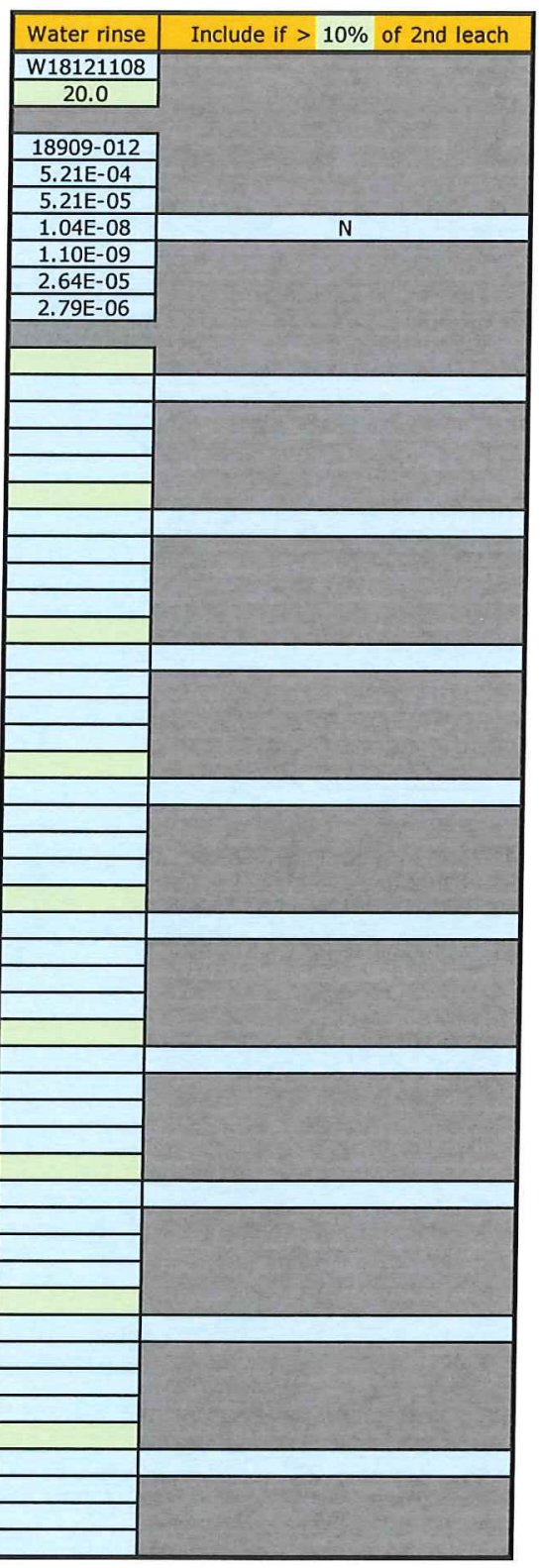

\section{Fued c. Montgrney}

$4-18-2019$

$\longrightarrow$ Date 